\title{
ENHANCING PRONUNCIATION TEACHING IN THE TERTIARY \\ EFL CLASSROOM: A VIETNAMESE CASE STUDY
}

By

NGUYEN TAN LOC

A thesis submitted to Victoria University of Wellington

in fulfilment of the requirements for the degree of Doctor of Philosophy in Applied Linguistics

Victoria University of Wellington

2019 



\section{STATEMENT OF AUTHORSHIP}

I, Nguyen Tan Loc, hereby certify that this thesis entitled

\section{ENHANCING PRONUNCIATION TEACHING IN THE TERTIARY EFL}

\section{CLASSROOM: A VIETNAMESE CASE STUDY}

submitted in fulfilment of the requirements for the degree of Doctor of Philosophy in Applied Linguistics issued by Victoria University of Wellington is my own work under the supervision of Associate Professor Jonathan Newton.

This thesis has not been submitted for the award of any degree or diploma in any other institution. 


\section{ACKNOWLEDGEMENTS}

With affection and appreciation, I would like to acknowledge my indebtedness to those whose contributions served as great assistance during my $\mathrm{PhD}$ journey at Victoria University of Wellington (VUW). This thesis would have been far from completion without valuable support from the people whom I thank below.

First and foremost, I would like to express my thankfulness to my thesis supervisors, Associate Professor Jonathan Newton and Dr. Sasha Calhoun, for their thoughtful guidance, useful advice, and insightful feedback. I especially owe in-depth gratitude to my primary supervisor, Associate Professor Jonathan Newton, for his enthusiasm, critical evaluative comments in proof-reading and careful line-by-line corrections on my writing. Without his guidance and assistance, this thesis would not have been accomplished.

I am especially indebted to Vietnam International Education Development (VIED) and VUW for granting me a doctoral scholarship to pursue this study. I wish to express my sincere thanks to the President of the university back home in Vietnam for his support during my data collection, and the Vietnamese EFL teachers and students who participated in my research for their trust, efforts and generous time. I would like to sincerely thank the Faculty of Humanities and Social Sciences at VUW for providing me with grants to go back to Vietnam for data collection and later to present at the international Pronunciation in Second Language Learning and Teaching (PSLLT) conference held in the United States of America in 2017 and 2018.

I am grateful to many staff members at the School of Linguistics and Applied Language Studies (LALS), VUW for creating a supportive and friendly academic environment, which had great value in facilitating my research project. Specifically, I wish to thank Associate Professor John Macalister, the former Head of School of LALS, for his advice and support before I was able to commence my PhD journey. Special thanks go to Bernie Hambleton and Janet Attrill for their administrative assistance, Sonia Millett for allowing me to observe her English Proficiency Programme classes, and Tony Quin for assistance with resources and Endnote references.

I am also thankful to my former office mate, Dr. Nguyen Chi Duc, for his help from the very beginning of my PhD journey at VUW and my supervisor's $\mathrm{PhD}$ group for their research stories and useful advice on my rehearsals of various oral presentations. I am in debt to Dr. David 
Semp, Dr. Shelley Dawson, and Dr. Emily Greenbank for proofreading some chapters in this thesis. My thanks go to Mr. Vo Hoang Thi for double-checking the accuracy of my translations of interview and catch-up extracts reported in this thesis. I would also love to thank all the authors and researchers whose books, book chapters, and journal articles have served as very helpful references for this thesis.

Last but not least, I thank my Mom and Dad for encouraging and supporting me to pursue this $\mathrm{PhD}$ study. I dedicate this work to them for their good care and endless love during this time and always. 


\begin{abstract}
Recent years have seen increasing research interest in the teaching of pronunciation in English as a second/foreign language classes (Thomson \& Derwing, 2014), with particular strands of this research focused on understanding how pronunciation is represented in instructional materials and actual teaching practices in a range of settings and in teacher cognition (e.g., Couper, 2017; Derwing, Diepenbroek, \& Foote, 2012; Foote, Trofimovich, Collins, \& Urzúa, 2016). The study reported in this dissertation extends this research by investigating pronunciation teaching in a context where it has hitherto been under-researched, namely tertiary EFL in Vietnam.
\end{abstract}

The research involved two phases. Phase 1 was an introductory situation analysis which investigated pronunciation teaching practices of six Vietnamese tertiary EFL teachers teaching six intact classes at a Vietnamese university. First, the representation of pronunciation features in prescribed textbooks and supplementary materials of the EFL programme were analysed. Six ninety-minute lessons (one from each of the teachers) were then observed, and the teachers and 24 students across the six groups interviewed. The teacher interviews included both stimulated recall and general questions probing their beliefs about pronunciation teaching. Students were interviewed in focus groups (four each) regarding their teachers' pronunciation teaching and their own pronunciation needs. The focus of Phase 1 was on how the teachers taught pronunciation, the factors shaping their pedagogical choices, and the students' beliefs about their teachers' pronunciation teaching and their instructional needs. The findings revealed that pronunciation was largely absent from course books and curriculum documents and that the teachers' beliefs were in contrast with what they actually did in class. The teachers reported that they would follow deliberate steps if they taught pronunciation explicitly such as listening discrimination followed by explaining places of articulation and then practice. However, in the observed lessons, they only corrected their students' pronunciation errors through recasts and/or prompts, with little if any explicit or pre-planned pronunciation teaching. In the interviews, the teachers confirmed that they never used any other techniques and that this was typically the only way they taught pronunciation in class.

The teachers' pronunciation teaching was textbook-driven and was shaped by contextual factors including the curriculum and the learners. Decision making by all the teachers reflected a general commitment to strictly follow the mandated curriculum, with little evidence of 
pronunciation being taught explicitly. All the teachers reported a lack of initial training and professional learning in pronunciation pedagogy. In addition, there was a mismatch between the teachers' and students' preferences and beliefs about pronunciation teaching. Whereas the teachers believed error correction through recasts and/or prompts was effective, the students did not, and expressed a strong need for more explicit, communicative teaching of pronunciation. This pronunciation instructional need and the teachers' lack of initial training and PL in pronunciation pedagogy motivated the Phase 2 study.

Phase 2 was an intervention study conducted with the same teachers teaching different classes. At the beginning of Phase 2, the teachers attended a teacher professional learning (TPL) workshop in which they were introduced to a pedagogic framework for teaching English pronunciation communicatively proposed by Celce-Murcia, Brinton, \& Goodwin (2010). The teachers then planned communicative pronunciation teaching (CPT) lessons using this framework, and were subsequently observed implementing these lessons in their classes. Both the workshop and subsequent classes of this phase were audio-video recorded. A total of seven lesson plans and 24 classroom observations were made across the six teachers (four observations each). Right after the classroom observations, the teachers were interviewed to obtain their views of the TPL workshop and their implementation of the CPT lessons. Twentyfour students across the six groups were interviewed to reflect on their experience with the CPT lessons.

Observational data showed that the teachers understood and were able to translate what they learned about CPT from the workshop into actual classroom practice as reflected in their lesson planning and subsequent teaching. The lesson plans designed by the teachers closely followed the principles of the communicative framework. Interview data showed that the CPT model was favoured by both teacher and student participants. On the basis of the teachers' implementation of the CPT lessons, both the teachers and students were confident that CPT has the advantages for promoting learners' pronunciation knowledge, fostering their phonological ability, and developing their oral communication skills. They also reported that CPT can arouse learners' interest and engagement in classroom learning.

Taken as a whole, this research highlights the need for pronunciation to be given a more explicit place in teaching and learning in tertiary EFL programmes in Vietnam, and for teachers to be better equipped for teaching pronunciation. Findings from interviews with teachers and learners in the study suggest that they would be receptive to such changes. 


\section{TABLE OF CONTENTS}

STATEMENT OF AUTHORSHIP

ACKNOWLEDGEMENTS

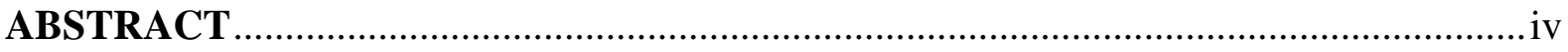

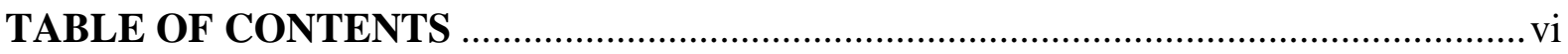

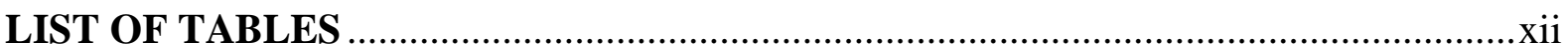

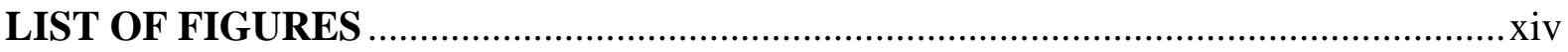

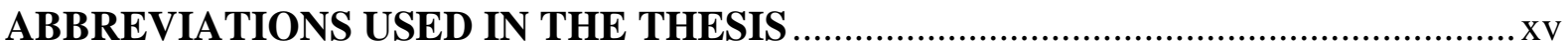

TRANSCRIPTION SYMBOLS USED IN THE THESIS .........................................

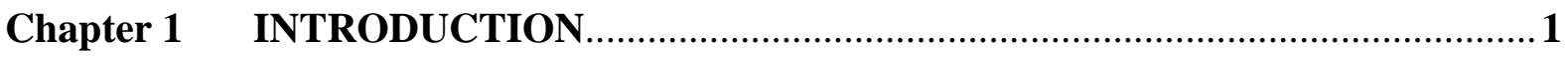

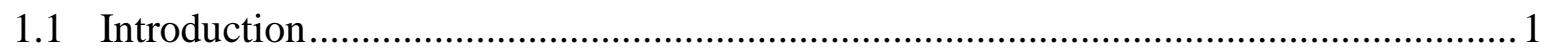

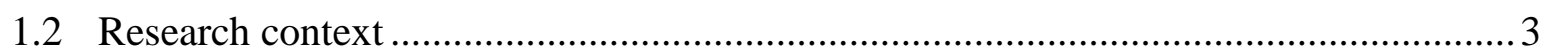

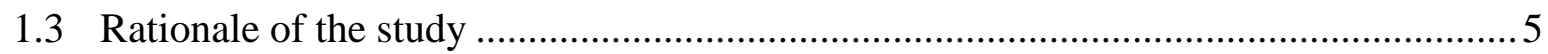

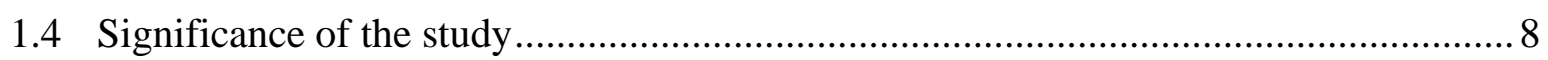

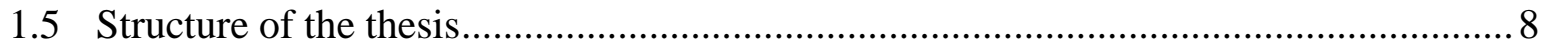

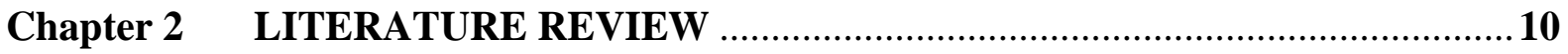

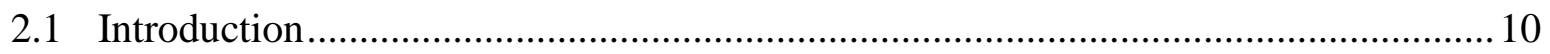

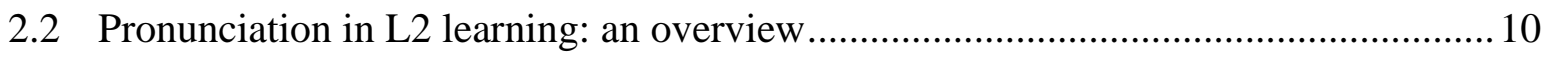

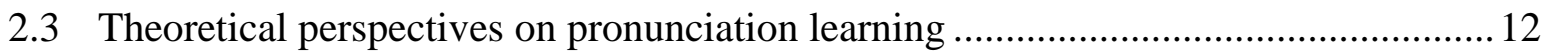

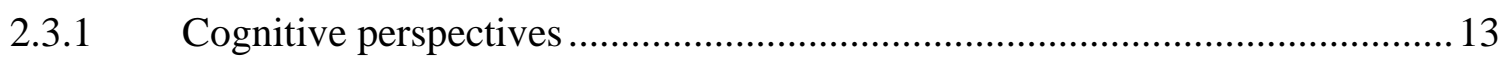

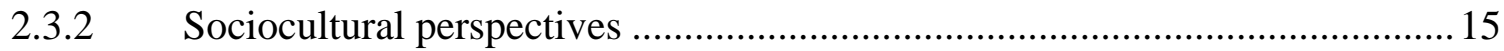

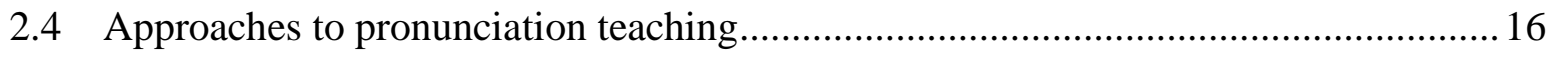

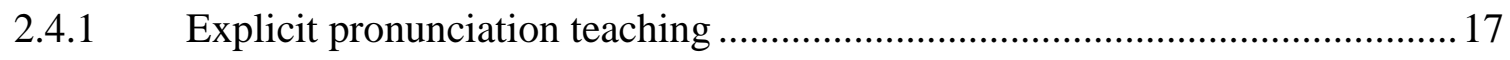

2.4.2 Corrective feedback in pronunciation teaching ........................................... 19

2.4.3 Communicative pronunciation teaching (CPT) .........................................22

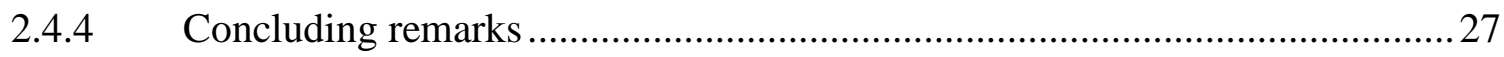

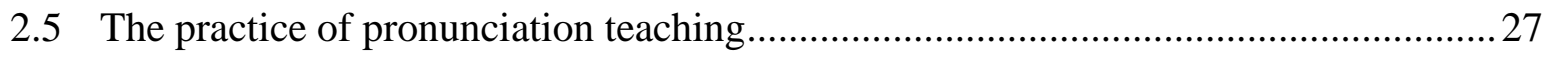




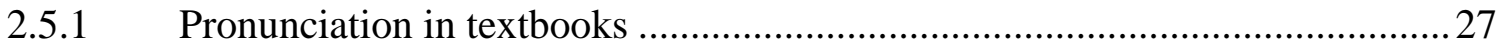

2.5.2 Research on pronunciation teaching practices .........................................29

2.5.3 Teacher cognition in pronunciation teaching .............................................. 31

2.6 Teacher professional learning (TPL) in pronunciation teaching ….........................39

2.6.1 The role of TPL in pronunciation teaching ................................................. 39

2.6.2 Research on TPL in pronunciation teaching .............................................. 40

2.6.3 Research on TPL in the Vietnamese EFL context ........................................ 41

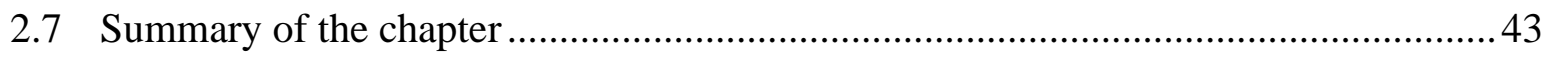

Chapter 3 RESEARCH DESIGN AND METHODOLOGY …................................45

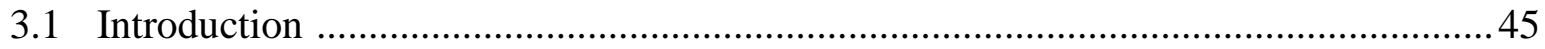

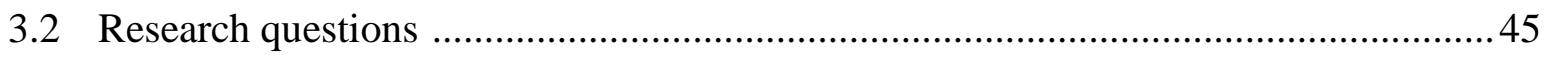

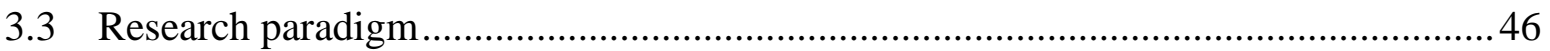

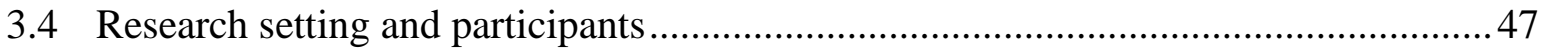

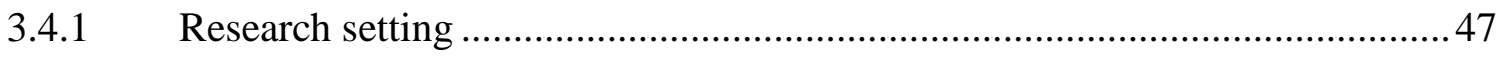

3.4.1.1 Teachers and students …............................................................. 48

3.4.1.2 Curriculum and course books ...................................................... 48

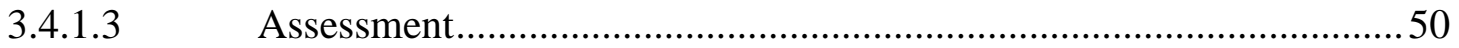

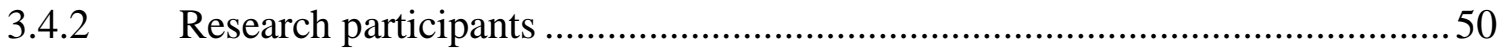

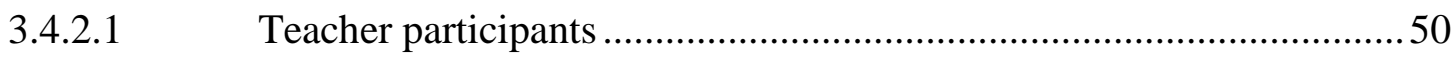

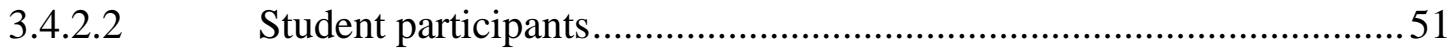

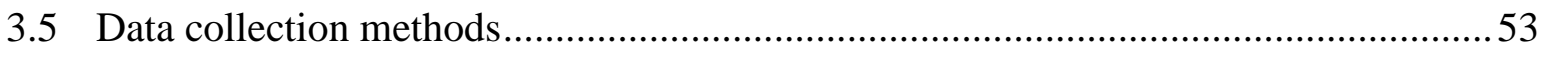

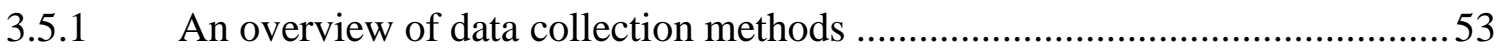

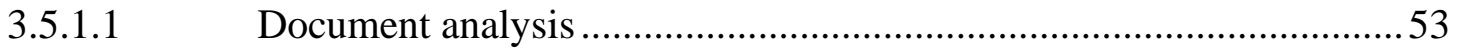

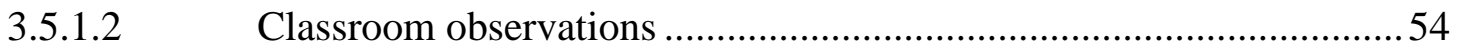

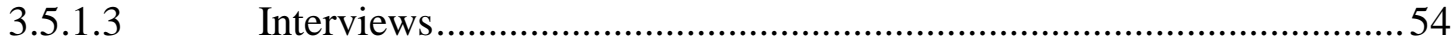

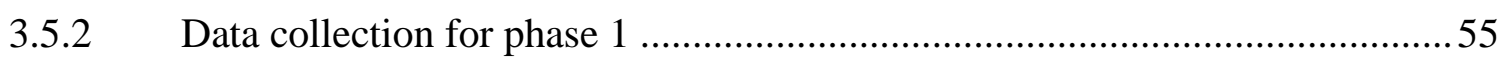

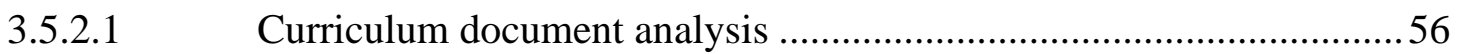

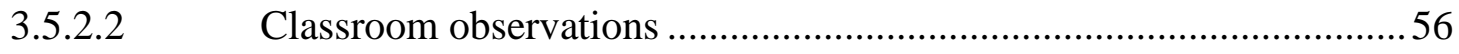

3.5.2.3 Teacher SR and in-depth interviews ............................................. 57 
3.5.3 Data collection for phase 2 ....................................................................59

3.5.3.1 Teacher professional learning and lesson planning ………..................59

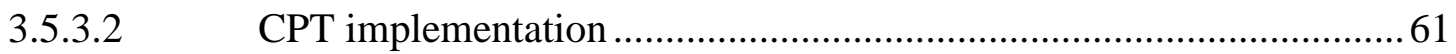

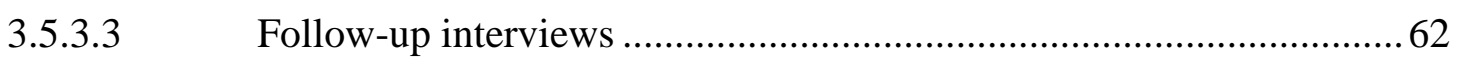

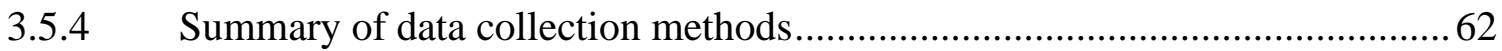

3.6 Data collection procedures.................................................................................6

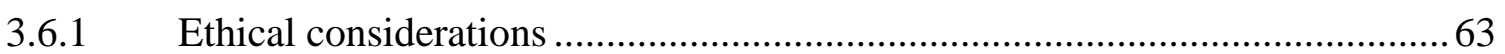

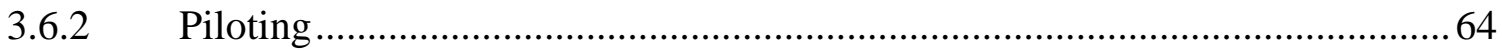

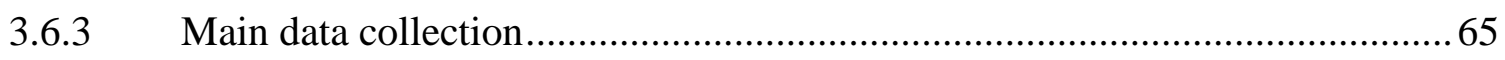

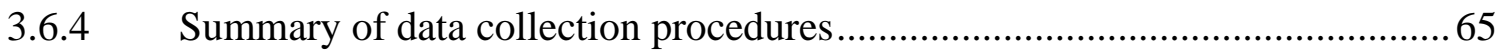

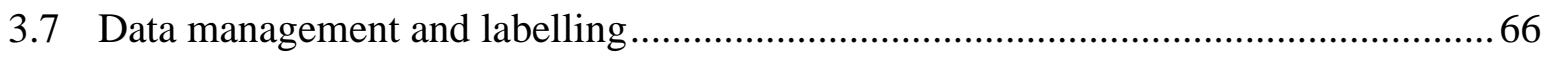

3.7.1 Labelling classroom observations.................................................................6 66

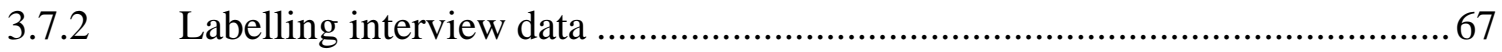

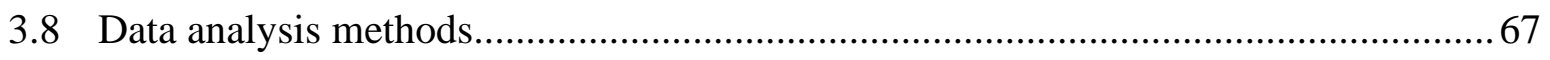

3.8.1 Analysing curriculum documents .................................................................... 67

3.8.2 Analysing classroom observations..................................................................6 68

3.8.3 Analysing CPT lesson plans …………………………………………….... 70

3.8.4 Analysing interview data .........................................................................

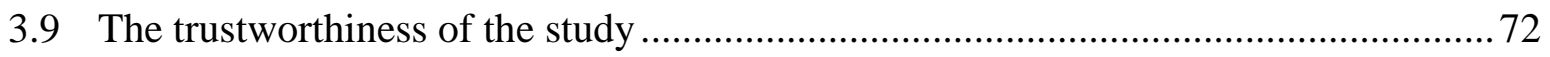

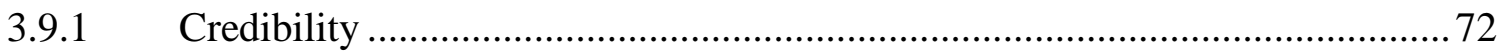

3.9.2 Dependability and confirmability ................................................................ 73

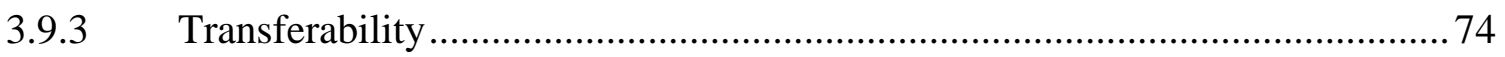

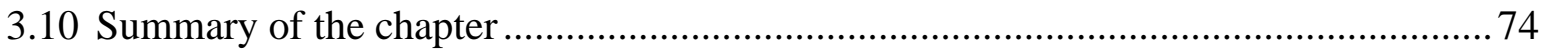

\section{Chapter 4 THE PHASE 1 STUDY: PRONUNCIATION TEACHING AND TEACHER COGNITION .....................................................................}

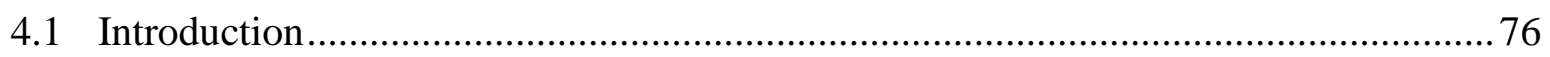

4.2 Pronunciation representation in the EFL programme of the university ........................76

4.3 Teachers' stated beliefs and pronunciation teaching practices ....................................82 
4.3.1 Teachers' self-reported pronunciation teaching practices ............................. 83

4.3.2 Teachers' observed pronunciation teaching practices ..................................... 84

4.3.3 Factors shaping teachers' pronunciation teaching decisions ..........................89

4.4 Teachers' perceptions of their own PTC, PL needs, and EFL teacher training in

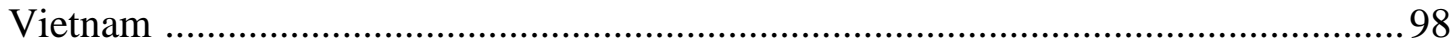

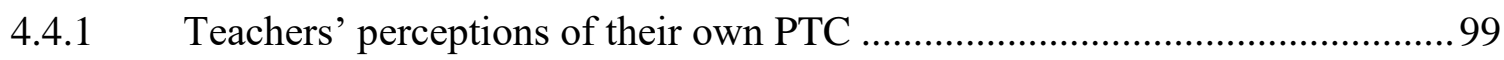

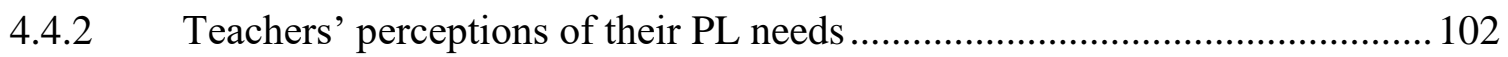

4.4.3 Teachers' beliefs about EFL teacher training in Vietnam ............................ 105

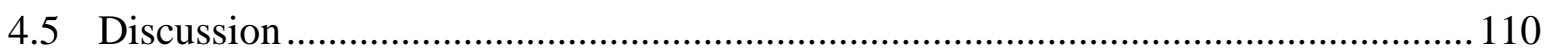

4.5.1 Pronunciation representation in the EFL programme ................................... 110

4.5.2 Teachers' beliefs and pronunciation teaching practices ............................... 111

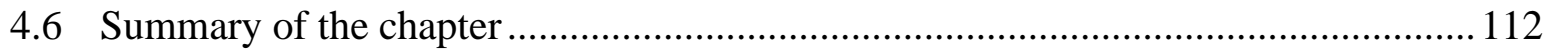

Chapter 5 THE PHASE 1 STUDY: VIETNAMESE EFL LEARNERS'

PRONUNCIATION NEEDS...................................................... 114

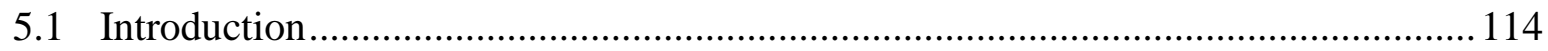

5.2 Students' perceptions of their teachers' pronunciation teaching .............................. 114

5.2.1 Students' reports of their teachers' pronunciation teaching ......................... 115

5.2.2 Students' beliefs about their teachers' pronunciation teaching efficacy ........ 117

5.3 Vietnamese EFL learners' pronunciation needs .................................................. 119

5.3.1 Teachers' perceptions of Vietnamese EFL learners' pronunciation needs.... 119

5.3.2 Students' perceptions of their own pronunciation needs ............................... 124

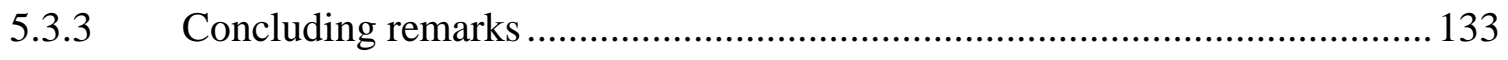

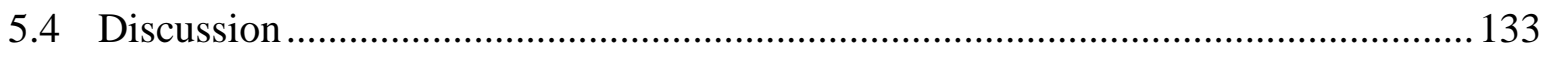

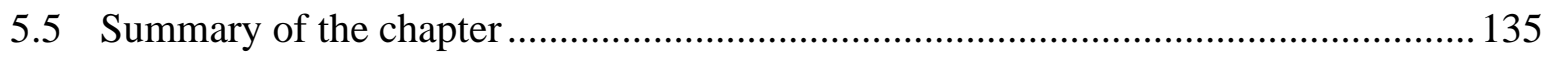

Chapter 6 THE PHASE 2 STUDY: TEACHER PROFESSIONAL LEARNING TO ENHANCE PRONUNCIATION TEACHING …................................136

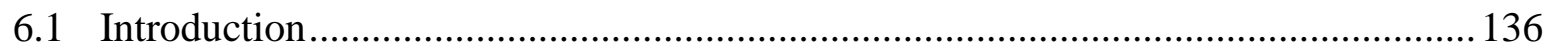

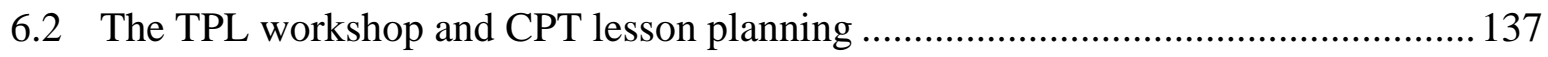

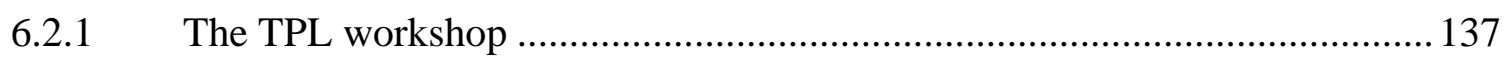




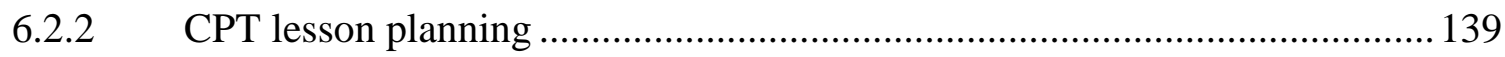

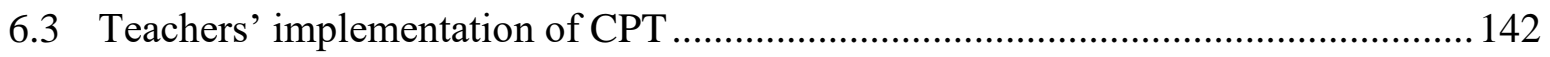

6.3.1 Teacher Nguyen's lessons: /i:/ vs. /I/ and /u:/ vs. /ð/................................... 144

6.3.2 Teacher Phuong's lessons: sentence stress and intonation ............................ 149

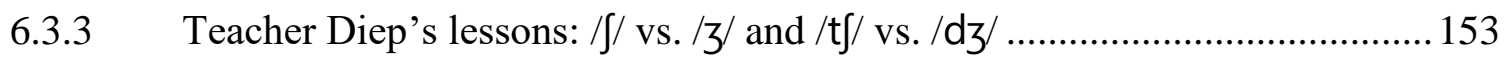

6.3.4 Teacher Quynh's lesson: final sounds and linking .................................... 157

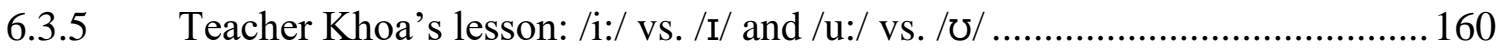

6.3.6 Teacher Na's lessons: sentence stress and intonation.................................. 163

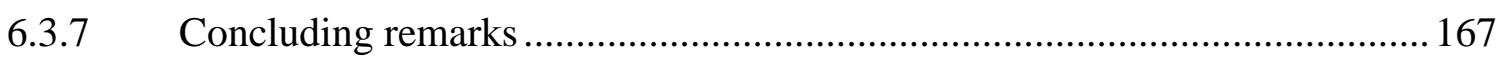

6.4 Teachers' perceptions of the workshop and TPL for Vietnamese EFL teachers....... 168

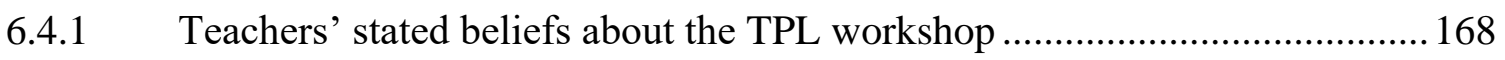

6.4.2 Teachers' perceptions of TPL for VTE teachers .......................................... 173

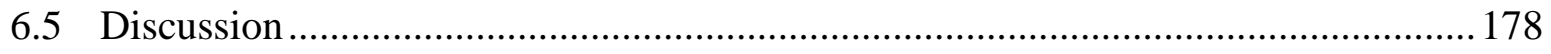

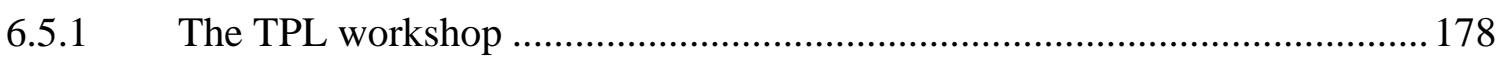

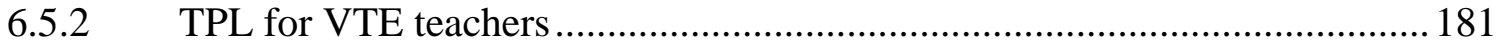

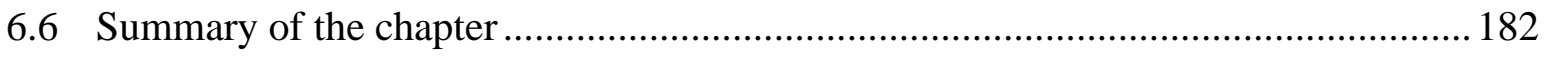

\section{Chapter 7 THE PHASE 2 STUDY: COMMUNICATIVE PRONUNCIATION}

TEACHING AND PERCEIVED STUDENT LEARNING ....................184

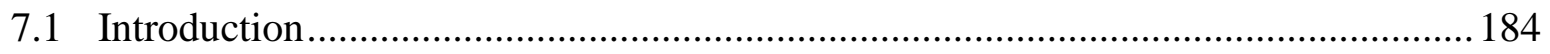

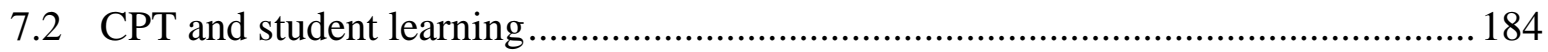

7.2.1 Teachers' beliefs about the value of CPT to student learning ........................ 184

7.2.2 Students' beliefs about the value of CPT to their learning ............................. 191

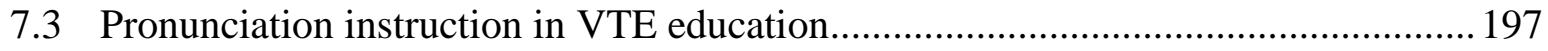

7.3.1 Teachers' beliefs about pronunciation instruction in the VTE classroom ...... 197

7.3.2 Students' beliefs about pronunciation instruction in the VTE classroom......205

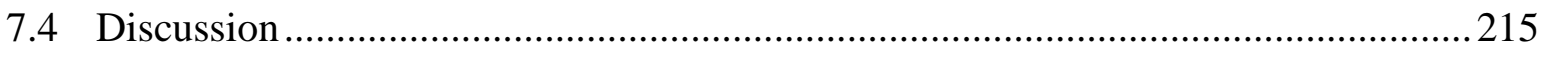

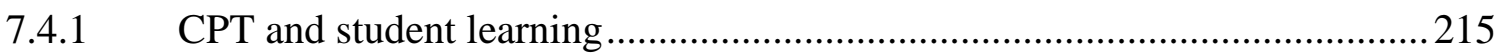

7.4.2 Pronunciation instruction in VTE education........................................... 217

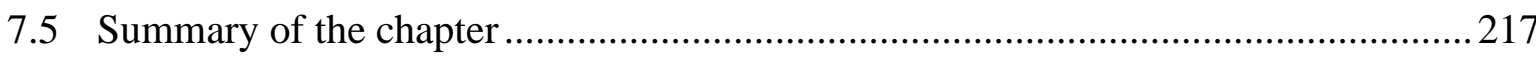




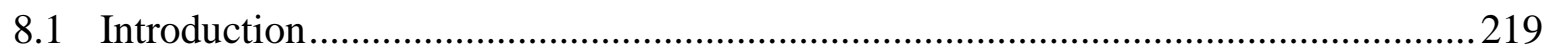

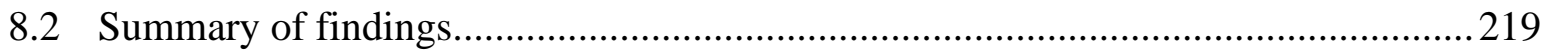

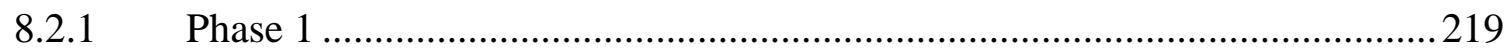

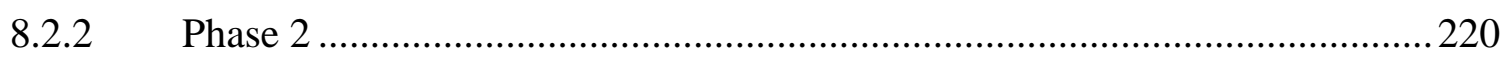

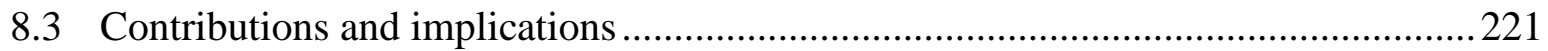

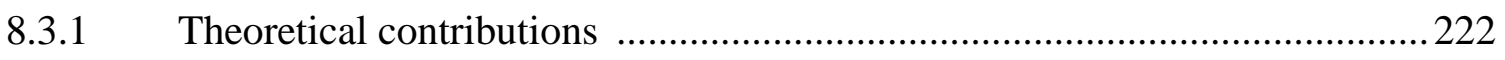

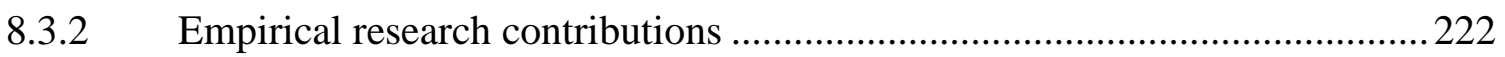

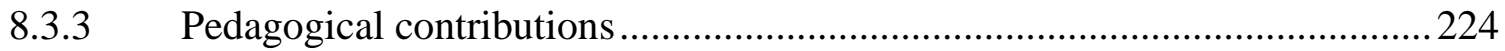

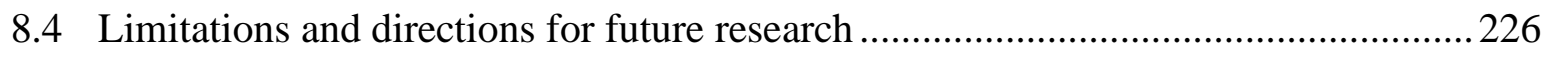

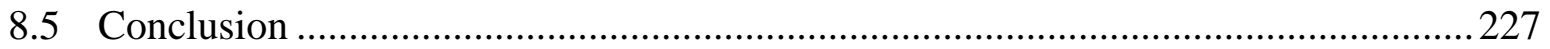

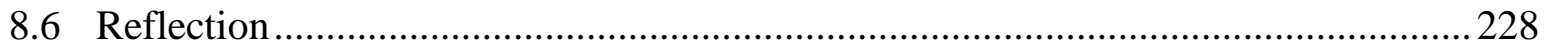

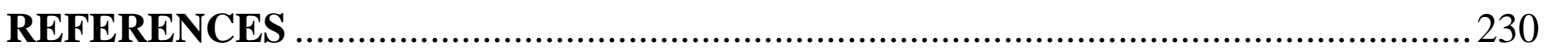

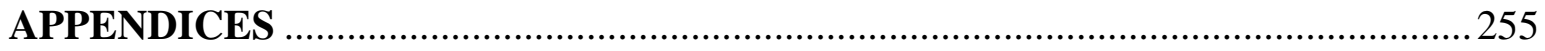




\section{LIST OF TABLES}

Table 2.1 The communicative framework for teaching English pronunciation ............ 24

Table 3.1 The theoretically-suggested teaching schedule for one module ..................... 49

Table $3.2 \quad$ Teacher Participant Profiles ....................................................................... 51

Table $3.3 \quad$ Student Participant Profiles................................................................................... 52

Table $3.4 \quad$ Phase 1 classroom observation scheme ...........................................................57

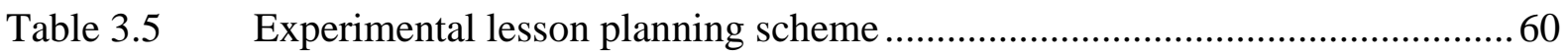

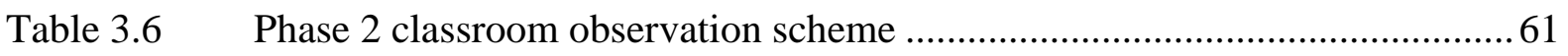

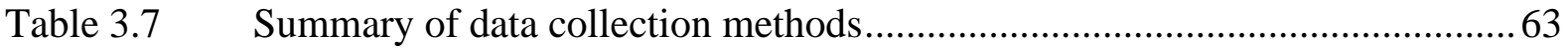

Table 3.8 Research-based principles in pronunciation teaching ....................................68

Table 3.9 Coding teachers' pronunciation teaching episodes........................................ 69

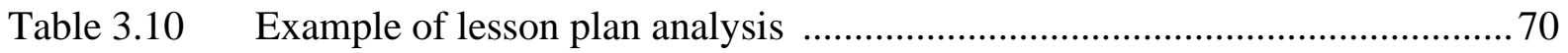

Table 4.1 Pronunciation representation in the course books ......................................... 77

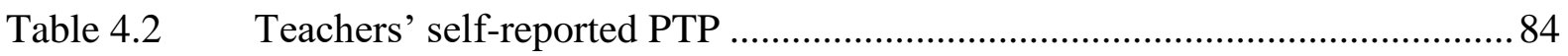

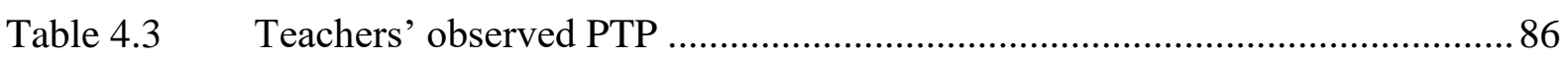

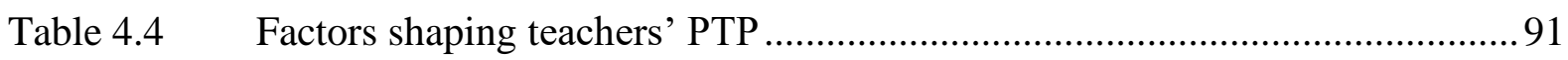

Table 4.5 Pronunciation features teachers were more confident teaching.................... 100

Table 4.6 Teachers' initial training and PL experience .............................................. 103

Table 4.7 Teachers' beliefs about EFL teacher training in Vietnam ............................ 106

Table 5.1 Students' reports of their teachers' pronunciation teaching .......................... 115

Table 5.2 Teachers' beliefs about the role of pronunciation in EFL learning ................ 120

Table 5.3 Teachers' reports of Vietnamese EFL learners' pronunciation errors ............ 124

Table 5.4 Students' perceptions of the role of pronunciation in English learning......... 125

Table 5.5 Students' perceptions of their own pronunciation errors ................................ 132

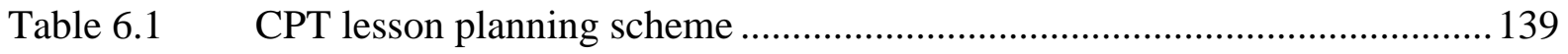

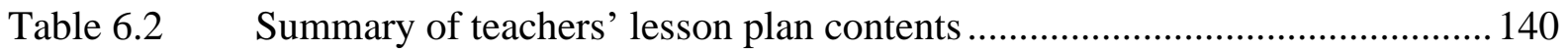

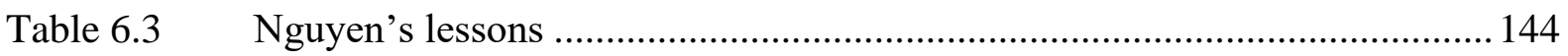

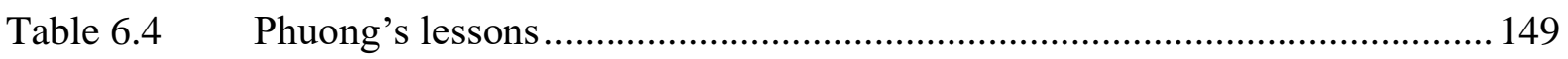

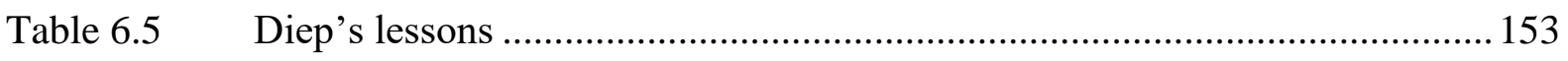

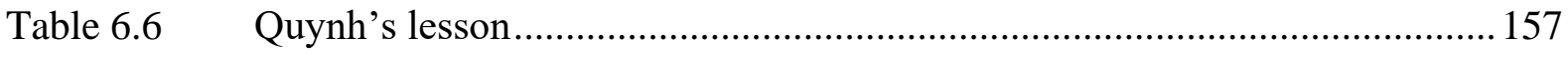

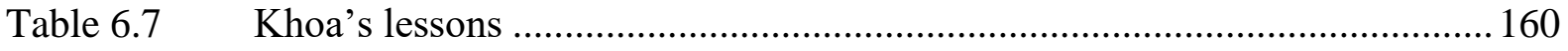

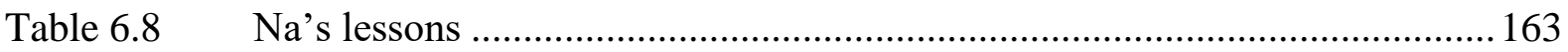


Table 6.9 Teachers' stated beliefs about the TPL workshop ….................................. 169

Table 6.10 Teachers' perceptions of TPL for VTE teachers .......................................... 174

Table 7.1 Teachers' stated beliefs about the value of CPT to student learning ............. 185

Table 7.2 Students' beliefs about the value of CPT to their learning ............................ 193

Table 7.3 Teachers' beliefs about pronunciation distribution at the tertiary level ........200

Table 7.4 Students' reasons for their preferred pronunciation teaching time ................209 


\section{LIST OF FIGURES}

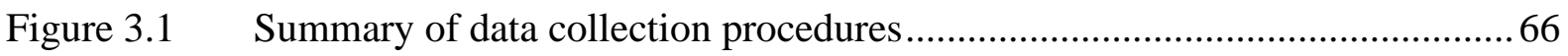

Figure 5.1 Students' beliefs about pronunciation in EFL learning ................................ 126

Figure 5.2 Phase 1 students' beliefs about their preferred pronunciation teaching

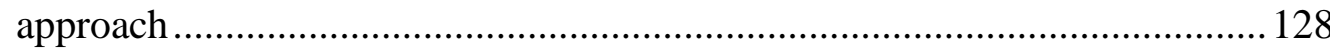

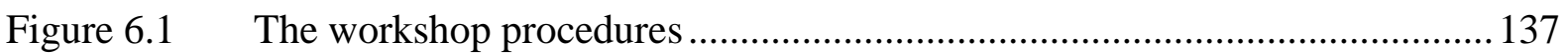

Figure 6.2 Communicative activity 1, Lesson focus of /i:/ and /I/ ............................. 148

Figure 6.3 Controlled practice activity 1, Lesson focus of intonation ........................... 152

Figure 6.4 Controlled practice activity 1 , Lesson focus of $/ \mathrm{t} \int /$ and $/ \mathrm{d} z / \ldots \ldots \ldots \ldots \ldots \ldots \ldots . . . . . . . . . . .155$

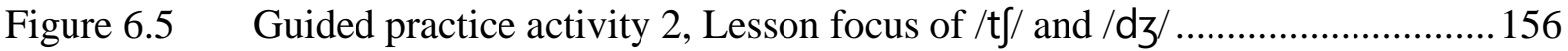

Figure 6.6 Controlled practice activity 1, Lesson focus of final sounds and linking ....... 158

Figure 6.7 Controlled practice activity 2, Lesson focus of /i:/ and /I/.......................... 161

Figure 7.1 Students' beliefs about pronunciation in tertiary EFL programmes ..............206

Figure 7.2 Phase 2 students' beliefs about their preferred pronunciation teaching approach 


\section{ABBREVIATIONS USED IN THE THESIS}

CF corrective feedback

CLT Communicative Language Teaching

CPT communicative pronunciation teaching

EFL English as a foreign language

ELT English Language Teaching

ESL English as a second language

FG focus group

L1 first language

L2 second language

LTC language teacher cognition

MOET Ministry of Education and Training

PL professional learning

PPP Presentation-Practice-Production

PTC pronunciation teaching competence

PTP pronunciation teaching practices

SAT Skill Acquisition Theory

SCT sociocultural theory

SFL School of Foreign Languages

SLA second language acquisition

SLM speech learning model

SLOs student learning outcomes

SR stimulated recall

TBLT task-based language teaching

TC teacher cognition

TPL teacher professional learning

VTE Vietnamese tertiary EFL 


\section{TRANSCRIPTION SYMBOLS USED IN THE THESIS}

$\begin{array}{ll}\text { Symbol } & \text { Meaning } \\ {[\text { ] }} & \text { the researcher's comments/explanations } \\ (\ldots) & \text { deleted texts } \\ \ldots & \text { pause } \\ \text { / } & \text { phonetic transcription } \\ \text { FGI } & \text { focus group interview } \\ \text { InI } & \text { in-depth interview } \\ \text { P1 } & \text { Phase 1 } \\ \text { P2 } & \text { Phase 2 } \\ \text { Q1 } & \text { question 1 } \\ \text { Q2 } & \text { question 2 } \\ \text { S } & \text { student } \\ \text { S1 } & \text { student 1 } \\ \text { S2 } & \text { student 2 } \\ \text { Ss } & \text { several students } \\ \text { SRI } & \text { stimulated recall interview }\end{array}$




\section{Chapter 1}

\section{INTRODUCTION}

\subsection{Introduction}

Pronunciation, according to Foote and Trofimovich (2018, p. 85), "permeates all spheres of human life, lying at the core of oral language expression and embodying the way in which the speaker and the hearer work together to produce and understand each other's utterances". In this respect, a number of scholars have argued that pronunciation is a particularly salient component of communicative competence which assures mutual understandings in oral communication (Derwing \& Munro, 2015; T. Jones, 2018; Rogerson-Revell, 2011). Although not every non-native speaker has difficulty making themselves properly understood, Derwing and Munro (2015), for example, have illustrated many situations in which pronunciation problems lead to misunderstandings and/or breakdowns in daily conversational exchanges. In this view, if a given utterance encompasses mispronunciations, then misinterpretations and potential discomfort devaluing the speaker's efforts in oral communication are more likely to emerge.

In second language (L2) learning, Celce-Murcia, Brinton, and Goodwin (2010) and Thomson and Derwing (2014) have pointed out that any L2 learner who has pronunciation problems is less likely to be properly understood in oral communication no matter how excellent their grammar and vocabulary is. In this sense, I would argue that a good command of pronunciation provides grounds for L2 learners' subsequent development of oral skills. In particular, pronunciation helps enhance the learner's ability to decode spoken English more efficiently (Adams-Goertel, 2013; Seyedabadi, Fatemi, \& Pishghadam, 2015), and research has shown that pronunciation instruction improves listening skills (Ahangari, Rahbar, \& Entezari Maleki, 2015; Kissling, 2018). As such, it has widely been accepted that pronunciation is too important to be ignored in English as a second or foreign language (ESL/EFL) classrooms (Celce-Murcia et al., 2010; Darcy, Ewert, \& Lidster, 2011; Derwing \& Munro, 2013, 2015; Gilakjani, 2012a). In a similar vein, Nation and Newton (2009) assert that it is important that "attention is given to pronunciation in the course so that learners can quickly develop a stable pronunciation, and become familiar with the patterns and rules that work within the second language" (p.76). 
However, pronunciation has been found to be overlooked by many ESL/EFL instructors and/or neglected in a number of language curricula offered by different institutions worldwide including Asian countries such as China (M. Wei, 2006), Taiwan (Lin, 1995), Thailand (Y. Wei \& Zhou, 2002), and Malaysia (Rajadurai, 2001). Vietnam may not be an exception. In my experience, a majority of Vietnamese EFL learners, after spending at least seven years learning English at secondary schools, enter university with an inadequate knowledge of pronunciation and poor L2 communicative competence. Such discouraging outcomes are possibly due in part to how English has been taught for decades at secondary schools in Vietnam. Teachers in these settings might assume that only with a good command of grammar can learners communicate effectively in English. Yet, they might not be aware that pronunciation is one of the most salient contributors attributed to the learner's communicative success. Unfortunately, the situation in higher education is not that much brighter since many Vietnamese tertiary EFL (VTE) learners struggle with English pronunciation and oral communication despite considerable time and effort spent on English learning. This is likely a consequence of a common belief amongst many secondary, and even tertiary EFL teachers that mastering grammar rules should be the main focus of instruction.

Research into teacher cognition has become a well-established field and been acknowledged as valuable in language teaching (Borg, 2006). Teacher cognition, "usually used interchangeably with beliefs" (Crookes, 2015, p. 486), is defined as "the unobservable cognitive dimension of teaching - what teachers know, believe, and think" (Borg, 2003, p. 81). It is an umbrella term that includes different cognitions that teachers may have about language and language teaching (Burri, Baker, \& Chen, 2017). As Macalister (2012) argues, "the knowledge and beliefs that teachers hold are an important determiner of what happens in the classroom" (p.99). In a similar vein, Borg also stressed in a conversation with Birello (2012) that teachers' subject-matter knowledge determines their teaching quality and has a strong influence on how they teach in the classroom. According to Borg (2015) and Johnson (2006), the beliefs teachers hold about language teaching have a powerful impact on the pedagogical choices they make in class. That is, what language instructors think and believe plays a key role in shaping classroom processes. Furthermore, information about language teacher cognition is of great use for curriculum designers if they take into account teachers' capacity to implement a language curriculum (Macalister, 2012; Nation \& Macalister, 2010). To this end, Barnard and Nguyen (2010) claim that only when teachers' beliefs about a pedagogical issue are taken into consideration can the aims of an intended curriculum be 
more fully realized. In this sense, I would argue that understanding ESL/EFL teachers' cognitions about pronunciation teaching and learning is an essential starting point for helping teachers develop their pronunciation teaching practices. This understanding also provides guidance and support for ESL/EFL teacher training and teacher professional learning (TPL) in relation to pronunciation pedagogy. Yet, there is limited research on teacher cognition regarding pronunciation instruction, and none of which I am aware addressed teachers' cognitions in this area of EFL education in Vietnam, the context of the current research.

\subsection{Research context}

Within the context of foreign language education in Vietnam, EFL teaching now far outstrips the teaching of all other foreign languages such as Chinese, French, or Russian. English is a compulsory subject from secondary to tertiary education and, more recently, for primary school pupils. When Vietnam embarked on its Đổi mói (Renovation) period in 1986, EFL teaching and learning started to grow throughout the country. English is now used in a wide range of fields such as economy, education, healthcare, politics, and foreign relations, a process that accelerated when the Vietnamese Government applied the open-door policy and the country officially joined the World Trade Organisation (WTO) in 2007. As a result, EFL teaching grew rapidly within the Vietnamese education system and still continues to expand.

However, from my experience as an L2 learner, from discussions with my students, and from research in the Vietnamese context (Dang, Nguyen, \& Le, 2013; H. T. Nguyen, Fehring, \& Warren, 2015), Vietnamese EFL teachers place greater emphasis on teaching language knowledge (e.g. vocabulary and grammar rules) than teaching language skills (e.g. oral communication skills). Such an emphasis on linguistic form in teachers' classroom practices reflects a strong exam-orientation; i.e. teachers mainly focus on teaching vocabulary and grammar rules to help students pass exams. Since oral communication skills are not tested in these exams, pronunciation as part of oral communication skills receive limited attention from Vietnamese EFL teachers.

How EFL teachers are trained in Vietnam also has an impact on their subsequent teaching after graduation. Although Vietnamese universities which offer teacher training are largely autonomous in designing their own programmes, their training programmes typically follow three common components: (1) foundation knowledge (e.g. educational psychology and Ho Chi Minh ideology); (2) subject-matter knowledge (e.g. English skills such as listening, 
speaking, reading and writing, and English linguistics such as phonetics and phonology, semantics, and morphosyntax, etc.); and (3) professional knowledge (ELT methodology and a practicum at a high school before graduation). The whole teacher training programme consists of 210 credits (fifteen 45-minute periods per credit), but professional knowledge only accounts for about $18 \%$ of the training time. In addition, Vietnamese teacher trainers are "strongly theory-oriented" (Hamano, 2008, p. 406) since training is usually in lecture format in which student teachers are taught theories about language learning instead of being guided on how to implement these in actual classroom practice (Hamano, 2008). This suggests that student teachers receive limited guidance on how to teach different language skills effectively, including pronunciation.

Considering English as one of the key components in strategies for Vietnam's globalisation and socio-economic development, educational leaders have, in recent years, attached a lot of importance to innovations in EFL teaching methodology in an attempt to provide the country with a well-qualified workforce who are proficient English users. In the era of global integration, English is viewed as an effective tool and indispensable prerequisite for those who work in multi-national environments. Upholding this perspective, the Vietnamese Government's Resolution 14/2005/NQ-CP on “Renovations on Vietnam's Higher Education in the period of 2006-2020" promulgated by the Prime Minister in November 2005 highlights the importance of English in higher education in Vietnam today. According to the Vietnam Ministry of Education and Training (MOET), one of the most important goals in the Vietnamese EFL context is that learners are able to competently use English for oral communication. To fulfil this, it is necessary that state-of-the-art approaches to English Language Teaching (ELT) be adopted so as to provide learners with more opportunities to use the target language for oral interaction. However, Vietnamese EFL learners have been (and are still) described as passive recipients of knowledge because they rarely have an opportunity for spontaneous interactions in classroom learning (H. T. Le, 2013; Luu, 2011; B. Tomlinson \& Bao, 2004). Particularly, V. C. Le (2001) found that in the Vietnamese EFL classroom, the teacher acts as the provider of knowledge and experience of the target language while learners sit silently to listen and can only make their voices heard when the teacher calls them to speak up.

In response to the call for innovative EFL teaching methodology in Vietnam, The National Foreign Languages Project 2008-2020 (currently extended to 2025) was initiated. The project 
aims to assist tertiary graduates to become proficient English users who are able to work in an integrative, multi-lingual and multi-cultural context (Prime Minister, 2008). To achieve this aim, several PL programmes have been carried out for tertiary EFL teachers to promote their knowledge and teaching skills about general ELT methodology, material development, testing, or the use of technology in EFL classrooms (Vietnam National University, 2016). Up to now, a particular course has run to support teachers to better teach speaking skills, yet no other courses have been designed to specifically enhance teachers' knowledge and pedagogy in teaching other language skills, including pronunciation (Vietnam National University, 2016).

As far as I am aware, no published research has examined how VTE teachers teach pronunciation in their language classes and how their beliefs inform their classroom actions. According to Foote, Trofimovich, Collins, and Urzúa (2016), understandings of teachers' current pronunciation teaching practices "assist language practitioners in their efforts to develop pedagogical materials for practicing instructors and to improve training programmes for pre-service teachers" (p.182). Thus, more empirical evidence on teachers' pronunciation teaching practices and related matters in Vietnam is necessary. Moreover, what has been missing until recently is empirical research findings that pinpoint the effects of TPL in equipping L2 instructors to teach pronunciation more effectively. There is therefore good reason to examine the impact of TPL on teachers' knowledge gains and pronunciation teaching skills. Finally, given the lack of research evidence about a specific effective teaching method (Dlaska \& Krekeler, 2013; Munro \& Derwing, 2011), it is necessary to investigate the effects of the CPT model on student learning outcomes (SLOs) specifically from both teacher and student perspectives.

\subsection{Rationale of the study}

A number of contextual and personal factors motivated this research project. First, by surveying the literature, I found that many studies on pronunciation teaching practices have been conducted in western English-speaking countries including America (Darcy et al., 2011), Australia (Burns, 2006; Macdonald, 2002; Yates, 2001), Canada (Breitkreutz, Derwing, \& Rossiter, 2001; Foote, Holtby, \& Derwing, 2011; Foote et al., 2016), Finland (Tergujeff, 2012), Ireland (D. Murphy, 2011), New Zealand (Couper, 2017), and the UK (Burgess \& Spencer, 2000). In contrast, much less research has been conducted in the EFL context of Asian countries. The research that does exist is somewhat scattered across time 
and space: for example, in China (Bai \& Yuan, 2019), Malaysia (Wahid \& Sulong, 2013), Taiwan (Chiu, 2008), and Thailand (Y. Wei \& Zhou, 2002). However, within the Vietnamese EFL context, no published research of which I am aware has investigated the teaching of English pronunciation, particularly in tertiary EFL education.

Second, my personal experience and observations also prompted this study. According to Dalton-Puffer, Kaltenböck, and Smit (1997), pronunciation teaching and learning is likely more important in tertiary settings. Nevertheless, working as a tertiary EFL teacher with particular interest in pronunciation teaching for over ten years, I have realized that English pronunciation teaching is often overlooked in VTE classrooms. From my observations, many instructors typically teach what is prescribed in the curriculum and since pronunciation learning is largely neglected there, they tend to ignore pronunciation teaching. While teachers are expected to teach pronunciation as it is prescribed in the syllabus, there is little empirical evidence about how pronunciation instruction is implemented in the classroom. Anecdotal evidence and my experience suggested that teachers tend to sporadically correct pronunciation errors that are most salient amongst learners. This is perhaps because they lack awareness of the value of explicit pronunciation instruction to fostering learners' oral communicative competence, or they lack guidance in how to teach pronunciation efficiently.

Third, in my own experience, the top-down approach of TPL with its emphasis on trainingthe-trainer (Day \& Townsend, 2009; Tsotetsi \& Mahlomaholo, 2015; Vazir \& Meher, 2010) is most popularly used within the Vietnamese education system. In this context, teachers do not have the right to make decisions on what to learn because it is predetermined by MOET, institution leaders, and/or stakeholders alike. In many cases, teachers can only study what they are assigned rather than what they actually need for their own professional growth. As a requirement, teachers have to be responsible for successfully completing the TPL programme in which they are involved; otherwise, they may face criticism and even penalty by their institutions. Research has shown that TPL which is responsive to teachers' learning needs is more likely to be successful mainly because practitioners find the activity meaningful and relevant to their own classroom contexts (Avalos, 2011; Mokhele \& Jita, 2010; Tsotetsi \& Mahlomaholo, 2013; Wayne, Yoon, Zhu, Cronen, \& Garet, 2008). However, given the bureaucratic constraints in the Vietnamese education system, TPL designed in consideration of teachers' actual needs seems to be scattered as illustrated in the following example. 
As part of The National Foreign Languages Project 2008-2020 mentioned above, several TPL programmes have been designed for tertiary EFL teachers at the national level. I participated in one of them: a six-week TPL course focusing on the use of technology in English classes. This course was carried out in 2014 for EFL teachers teaching at various universities and colleges in the south of Vietnam. At my institution, six teachers (myself included) were chosen to attend this course by our head of school without asking if we really needed it. All we had to do was to take it as one of our responsibilities at work. Yet, from our unofficial discussions, we all found that the course was of little value to our own teaching context. What we did really need was a TPL course that could provide us with state-of-the-art teaching theory and/or practice of teaching a particular language skill. A course such as this helps teachers become up to date on recent global trends of language teaching and refine their teaching skill, which in turns can enhance the quality of teachers' classroom practices and improves SLOs.

In my opinion, the above-mentioned factors have led to a number of issues regarding pronunciation teaching and learning within the VTE context. One potential detrimental issue is that VTE teachers and students are rarely able to make their voices heard in EFL curriculum design. Another problem lies with TPL designers who fail to take into account teachers' actual learning needs in constructing TPL programmes. The lack of TPL opportunities in pronunciation pedagogy may have led to teachers lacking guidance in how to effectively deliver pronunciation instruction in their classes. Research is therefore needed to investigate and address these issues if pronunciation teaching is to be enhanced and implemented more effectively in this context. Furthermore, research into the impact of TPL in pronunciation teaching on teachers' knowledge gains, pronunciation teaching skills, and SLOs is limited. For this reason, my study aims to examine the teaching of English pronunciation within the VTE context in two phases. Specifically, Phase 1 of the research investigates how pronunciation is taught in the English programme at a Vietnamese university and VTE teachers' beliefs about it. Based on the Phase 1 findings, in Phase 2, a TPL workshop on communicative pronunciation teaching (CPT) was designed and delivered to the teachers, followed by lesson planning and tracking of classroom processes. It then investigates the teachers' stated beliefs about the impact of the TPL workshop on their knowledge gains and pronunciation teaching skills. Phase 2 also looks into the effects of the CPT model on student learning from both teaching and learning perspectives. 


\subsection{Significance of the study}

This research project is of significance in several ways. First, the study has personal value to me as a practitioner dealing with pronunciation teaching as part of my daily work. I had been an EFL teacher with particular interest in pronunciation teaching and a teacher trainer for over ten years in Vietnam prior to taking PhD study leave. Thus, conducting this research helps widen my knowledge so I can be a more successful instructor as well as a teacher trainer. Second, given the current importance of English teaching and learning in the VTE context, the findings of this study can be used to make informed education renovations in relation to pronunciation teaching and learning in this EFL context. Specifically, the findings provide richer understandings about teachers' cognitions and pronunciation teaching practices, and important insights into students' perceptions about teachers' pronunciation teaching practices and their own pronunciation instructional needs. These insights and understandings are applicable to the work of millions of EFL teachers and students in all universities and colleges throughout the country. In addition, the findings can inform EFL curriculum design, selection of instructional materials, TPL design, and future EFL teacher training in Vietnam regarding pronunciation and pronunciation pedagogy. It is hoped that these findings will also be useful in other similar EFL contexts beyond Vietnam. More importantly, this research is expected to add to the current international literature on the value of focused instruction for pronunciation, and on language teacher education.

\subsection{Structure of the thesis}

The thesis includes eight chapters. Chapter 1 has introduced the thesis, including a general picture of the research context and the significance of the study. The rationale and research questions are presented in this introduction chapter as well.

Chapter 2 reviews the literature relevant to the focuses of the current study. Particularly, the chapter reviews research on three main aspects of pronunciation instruction, namely approaches to pronunciation teaching, the practice of pronunciation teaching, and TPL in pronunciation pedagogy. The chapter identifies the research gaps that motivate each phase of the study.

Chapter 3 presents research design and the methodology employed for this research project. It starts with a presentation of research questions, followed by the research paradigm that underpins the study and a detailed account of the research setting and participants. It then 
discusses the methods and procedures of data collection. Next, it deals with data management and coding methods, followed by a discussion of how the data were analysed. Finally, the chapter describes how the trustworthiness of the study was achieved.

Chapters 4 to 7 report on and discuss the findings of the two phases of the study. Specifically, Chapter 4 provides comprehensive information concerning the teachers' cognitions and pronunciation teaching practices; Chapter 5 presents findings regarding the students' perspectives of the efficacy of their teachers' pronunciation teaching; it also reports on the teachers' and students' stated beliefs about Vietnamese EFL learners' pronunciation needs. Chapter 6 reports on and discusses findings about the teachers' implementation of CPT lessons, and their articulated beliefs about the impact of the workshop and TPL for VTE teachers regarding pronunciation teaching. The teachers' and students' perceptions of the effects of the CPT model on student learning and of pronunciation instruction at the tertiary level in Vietnam are reported and discussed in Chapter 7.

Chapter 8 summarises the main findings of the thesis and discusses its implications. It then points out the limitations of the current study and proposes future research directions followed by a conclusion. The chapter ends with my personal reflection.

In the following chapter, Chapter 2, I will review the literature related to the focuses of the present research. 


\section{Chapter 2}

\section{LITERATURE REVIEW}

\subsection{Introduction}

The past few decades have witnessed a growing interest in pronunciation research, and even more recently, this research has extended to explore teacher cognition and professional learning (PL) in pronunciation teaching. This chapter begins with an overview of L2 pronunciation learning including its constructs and definitions of terms, and a discussion about L2 pronunciation goals. Next, it examines the theoretical perspectives that underpin pronunciation learning. Finally, the chapter reviews and discusses research on three aspects of pronunciation instruction particularly relevant to the focus of the present study. These are: (1) approaches to pronunciation teaching, (2) the practice of pronunciation teaching, and (3) TPL in pronunciation teaching. As I argue, limited research on these topics in the Vietnamese EFL context provided the impetus for the current research project.

\subsection{Pronunciation in L2 learning: an overview}

Broadly speaking, we can distinguish narrow and broad views of pronunciation. A narrow view sees pronunciation as the productions of individual consonant and vowel sounds in the phonological inventory of a language (H. D. Brown, 1987). In contrast, a broad view sees pronunciation as "an essential component of communicative competence" (Morley, 1991, p. 488) which involves all aspects of the oral production of segmentals (e.g., consonants and vowels) and suprasegmentals (i.e. prosody) including stress, rhythm, and intonation (Derwing \& Munro, 2015; Setter \& Jenkins, 2005). This broader view on pronunciation has led to the notion that intelligibility or comprehensibility is a more appropriately achievable goal of L2 pronunciation instruction than accent reduction. Munro and Derwing (1999, p. 289) define intelligibility as "the extent to which a speaker's message is actually understood by a listener", whereas comprehensibility is referred to as "the amount of work that listeners need to do in understanding a speaker" (Levis, 2018, p. 17). In other words, intelligibility refers to the extent to which an utterance is understandable to the listener and comprehensibility as the listener's perception of how easy an utterance is to understand (Munro, 2010). Although intelligibility and comprehensibility measure two different things 
(Levis, 2018), they are "closely tied to communicative success" (Munro, 2010, p.9). Another dimension of speech understanding is accentedness, which is defined as the "degree of difference between a speaker's productions and those of the interlocutor" (Derwing, 2018, p. $321)$.

Research has shown that native speakers can deprecate and/or ignore an L2 speaker if their speech is accented (Derwing, Rossiter, \& Munro, 2002; Munro, 2003). Recent studies such as Derwing and Munro (2009) and Dragojevic and Giles (2016) have also demonstrated that foreign-accented speakers are usually evaluated more negatively than those who speak with a native-like accent. For this reason, many L2 learners may become highly motivated in trying to achieve native-like pronunciation. Derwing (2003), for instance, found that 95\% of ESL immigrants in Canada who participated in the study reported that they would like to speak English like a native speaker. Similarly, most student participants (31/38) in Dao's (2018) study said they would like to achieve native-like pronunciation. However, Munro and Derwing (2011) and Scovel (2000) have pointed out that it is difficult for L2 adult learners to obtain a native-like accent. In reality, the possibility, if any, is limited to very few individuals who are exceedingly motivated (Celce-Murcia et al., 2010; Cunningham, 2009; Moyer, 2004) and/or show special aptitude in language learning (Abrahamsson \& Hyltenstam, 2008; Baker Smemoe \& Haslam, 2013).

Not surprisingly, then, a foreign accent is inevitable among L2 adult learners (Abrahamsson \& Hyltenstam, 2009; Counselman, 2015; Derwing \& Munro, 2015; Moyer, 2013). Yet, it does not follow that a foreign accent impedes L2 learners' oral communicative success. Research has shown that speech with a strong accent can be intelligible (Flege, Takagi, \& Mann, 1995; Munro \& Derwing, 1995a, 1995b; Munro, Flege, \& MacKay, 1996). An utterance rated as 'heavily accented', for example, might still be accurately interpreted by the listener (Munro \& Derwing, 1995a; Munro, Derwing, \& Morton, 2006). In this sense, the notion of intelligibility, "the most fundamental characteristic of successful oral communication" (Derwing \& Munro, 2015, p.1), has become the principle objective in pronunciation teaching and learning. As Field (2005, p. 400) argues, native-like pronunciation is "unrealistic, time-consuming, and potentially inhibitory [...] and might not necessarily represent the learners' wishes". Thus, it is more important and practical for instructors to help L2 learners achieve intelligibility rather than native-like pronunciation, a 
position that has widely been accepted in the field by Jenkins (2000), Couper (2003), Cunningham (2009), Munro and Derwing (2011), and Moyer (2013), amongst others.

As Derwing and Munro (2005, p. 384) have stressed:

[...] most learners who strive for nativeness are likely to become disheartened. Though all learners should be encouraged to reach their full potential, which may well exceed the minimum required for basic intelligibility, it may do more harm than good for teachers to lead learners to believe that they will eventually achieve native pronunciation or to encourage them to expend time and energy working toward a goal that they are unlikely to achieve.

Therefore, the clear implication for pronunciation instruction within the L2 classroom is that learners need support to improve their speech intelligibility or comprehensibility rather than encouragement to spend time and effort on accent elimination. This reorientation of pronunciation teaching away from accent reduction and towards intelligibility fits in well with the principle of Communicative Language Teaching (CLT), which is discussed in section 2.4 .3 below.

The question, then, is what type of instruction helps learners achieve intelligibility? One response has been a call for a greater instructional focus on suprasegmentals in keeping with research findings that learners who receive such instruction outperform those whose instruction focuses primarily on segmentals (e.g., Derwing \& Rossiter, 2003). However, as Levis (2005) points out, there is not much empirical evidence which shows that instruction on suprasegmentals is an optimal way to help learners achieve intelligibility. Current scholarship in the field concurs that both segmental and suprasegmental features are important for instruction focused on intelligibility and/or comprehensibility, and so both deserve to be focused within the language classroom (Celce-Murcia et al. 2010; Derwing \& Munro, 2015).

\subsection{Theoretical perspectives on pronunciation learning}

While there has been an increasing body of research on pronunciation, Thomson and Derwing (2014) point out that not many researchers follow a theoretical framework to frame their studies as they "tend to ask what the consequences of instruction are, but not why" (p.334-335, original italics). This is partly because "well-established theories of SLA have rarely been extended to pronunciation" (Foote \& Trofimovich, 2018, p.75). This section 
examines the theoretical foundations for pronunciation learning from both a cognitive and sociocultural perspective.

\subsubsection{Cognitive perspectives}

This section discuses key cognitive theories and hypotheses that underlie pronunciation learning. These include pronunciation learning as a cognitive skill, Skill Acquisition Theory (SAT), and the Input-Interaction-Output Hypotheses.

\section{Pronunciation learning as a cognitive skill and the Skill Acquisition Theory}

From a cognitive perspective, L2 pronunciation acquisition is explained through a process that relies on learners' cognitive abilities to establish sound categories, as seen in the Speech Learning Model (SLM) developed by Flege (1995). SLM assumes that if learners acquire a distinction between particular sounds in L1 and L2 at perceptual level, then their production of these sounds appears more accurate over time (Derwing \& Munro, 2015). As a cognitive skill, pronunciation learning involves learners forming new phonological concepts of segmental and suprasegmental features such as phonemes, syllables, stress, rhythm and intonation (Couper, 2018). Perceptual training through 'critical listening' exercises is one way that has been proposed to facilitate this concept formation (Fraser, 2010). Critical listening involves helping learners to focus on "the contrast between a correct (or appropriate) pronunciation versus an incorrect (or inappropriate) pronunciation within a particular communicative act" (Fraser, 2009, p. 301). There has been empirical research evidence that supports the value of critical listening in helping learners form new phonological concepts (Couper, 2006, 2013; Fraser, 2009). In addition, in discussing a cognitive linguistic framework to L2 pronunciation teaching, Couper (2018) argued that socially constructed metalanguage between teachers and learners enhances the process of pronunciation learning. Couper's research has shown that the use of socially constructed metalanguage accompanied by critical listening helped boost learners' pronunciation improvement (Couper, 2011, 2012, 2014).

As Fraser (2006) holds, pronunciation learning as a cognitive skill requires a large amount of practice through meaningful social interaction. This assumption aligns with SAT which emphasizes the importance of practice for skill learning (DeKeyser, 2015). According to DeKeyser (2007) and Segalowitz (2010), SAT supports a teaching model that moves from providing explicit knowledge (declarative knowledge) to gradually fine-tuning through practice (procedural knowledge) and finally to fluent communicative performance 
(automatization). The primary limitation of this teaching model is that the effects of instruction are tied to whether and how declarative knowledge is taught and whether and how this knowledge is subsequently proceduralized and automatized (DeKeyser, 2015). Pronunciation learning outcomes might therefore be incomplete since learners may not receive adequate comprehensible input or they may not involve in sufficient practice (Foote \& Trofimovich, 2018).

\section{Input-Interaction-Output Hypotheses and pronunciation learning}

According to Gass (1997), there are three main components that formulate the process of language learning: input, interaction and output. V. L. Nguyen (2011) maintains that these three components serve as a platform for developing pedagogical principles that facilitate optimal conditions for language learning. Krashen's (1985) Input Hypothesis proposes that language can automatically be acquired through learners' exposure to comprehensible input. Accordingly, input elaborations and/or modifications play an important role in facilitating learners' comprehension of the language input they receive (Ellis, Tanaka, \& Yamazaki, 1994; Oh, 2001). However, Long's (1996) Interaction Hypothesis argues that comprehensible input alone is not sufficient for language learning and that there is a need to engage learners in social interaction.

The Interaction Hypothesis proposes that language learning "take[s] place when communication is interactively co-constructed during conversational interaction involving L2 learners" (Foote \& Trofimovich, 2018, p. 80). According to Long (1996), interaction creates opportunities for negotiation for meaning, which is considered to be facilitative to language development. When engaging in interaction, learners use conversation adjustments such as clarification requests or confirmation and comprehension checks to repair communication breakdowns and in so doing, draw attention to learnable features in the input or to gaps in their language output. Together with negotiation for meaning, Long also suggested that such conversation adjustments provide learners with the opportunity to receive corrective feedback $(\mathrm{CF})$ on their non-target-like performance which can take many forms such as clarification requests or recasts (see section 2.4.2 below for further discussion of CF types). Thus, the Interaction Hypothesis highlights the role of feedback in interaction as inducing learners to notice the gap in their interlanguage and make intentional modifications in their output (Ellis \& Shintani, 2014; Schmidt, 2001). 
Such output modifications are supported by Swain's (1985) Output Hypothesis which posits that having to express meaning in language production pushes learners to test their knowledge about the language and provides opportunities for them to notice problems in using the language, and in doing so, to produce language forms that may "lie at the edge of their linguistic ability" (Ellis \& Shintani, 2014, p. 208). Research shows that negotiation for meaning focused on pronunciation errors and leading to output modifications is not uncommon in task-based interaction between language learners (Lasito \& Storch, 2013; McDonough \& Sunitham, 2009; Newton, 2013) and between the teacher and learners (Hawkes, 2012; Saito, Trofimovich, \& Isaacs, 2016). Empirical evidence also shows that interactional adjustments such as CF are beneficial to L2 learners' pronunciation improvement when pronunciation is part of their focus in oral communication (Saito, 2015; Saito \& Wu, 2014; Storch \& Aldosari, 2013). However, given that L2 learners' pronunciation accuracy might level out despite their daily engagement in social interaction (Derwing \& Munro, 2013), scholars have argued that, to continue to improve their pronunciation, they will typically need ongoing explicit phonetic instruction associated with extensive focused practice (Celce-Murcia et al., 2010; Derwing, Munro, Foote, Waugh, \& Fleming, 2014).

\subsubsection{Sociocultural perspectives}

This section discusses a complementary view on pronunciation learning based on a sociocultural perspective, and taking into account the social dimensions of learning. SCT views consciousness as a consequence of social activity and language as a tool of thought emerging from social interaction (Ellis, 2003; Lantolf, 2001). Accordingly, SCT emphasizes the role of learners as active agents in social interaction who bring their own motivations, identities, goals, approaches and learning needs, all of which influence the trajectory of language learning (Littlewood, 2013). In this respect, Foote and Trofimovich (2018, p.84) hold that "depending on learners' cognitive abilities, the frequency and type of interactions they engage in, and their identity orientation, age or L1, some learners might be more successful than others". In a similar vein, Lantolf, Thorne, and Poehner (2015) argue that learning outcomes will vary among L2 learners depending on the context of learning and use. For instance, in relation to pronunciation learning, Foote and Trofimovich (2018) point out that learners who identify strongly with an L2 community may become more motivated and successful to standardize their pronunciation than those who do not. 
SCT sees language learning as a mediated process located in a specific sociocultural environment (Lantolf \& Thorne, 2006) where interaction serves as a site of learning. Interaction with teachers provides opportunities for learners to co-construct knowledge and develop their cognitive and linguistic skills (Aljaafreh \& Lantolf, 1994; Swain, 2000). For their part, teachers scaffold instruction to assist learners to accomplish what they cannot without assistance, as expressed in the concept of the Zone of Proximal Development (ZPD). In L2 learning, ZPD is defined as the developmental difference between what an individual learner can achieve by themselves and what they can through assistance and collaboration with a more proficient interlocutor (Foote \& Trofimovich, 2018; Ohta, 1995). Considering language learning as a mediated process in social interaction, SCT also highlights the role of language production. Swain's (2006) “languaging” and Gibbon's (2006) teacher-learner talk both refer to the process of language learning through constructing meaning interactionally within social contexts. As Foote \& Trofimovich (2018) argue, SCT "has the potential to make unique contributions to our understanding of pronunciation learning” (p.82).

In summary, SCT accounts for the social nature of language learning in a way that Lantolf (2011) argues is complementary to cognitive approaches, such that SCT and cognitive approaches together can establish an over-arching theoretical base for language learning. In L2 pronunciation acquisition, SCT complements the cognitive approaches by accounting for "the social nature of learning and the social construction of meaning" (Couper, 2018, p.467).

\subsection{Approaches to pronunciation teaching}

Although many L2 learners recognize the value of pronunciation in oral communication and see it as a priority (Derwing \& Munro, 2005; Seyedabadi et al., 2015), for many of them, pronunciation appears to be difficult compared to all other aspects of language learning (Fraser, 2010). To address this need, numerous scholars have called for more attention to pronunciation instruction within the ESL/EFL classroom (Celce-Murcia et al., 2010; Counselman, 2015; Derwing, 2008; Derwing \& Munro, 2015). This section first presents the case for explicit pronunciation teaching. Then, it reviews and discusses research on approaches to pronunciation instruction which are relevant to the focus of the current study including CF and CPT. 


\subsubsection{Explicit pronunciation teaching}

According to Derwing (2018), many ESL/EFL instructors tend to avoid explicit pronunciation teaching in their language classes. One particular reason for this is that instructors do not have or perceive themselves to have the necessary knowledge and expertise to teach pronunciation (Breitkreutz et al., 2001; Darcy et al., 2011; Foote et al., 2011; Fraser, 2000; Yates, 2001). Another reason for the lack of explicit pronunciation teaching within the language classroom is that many instructors still remain sceptical about the efficacy of pronunciation instruction (Celce-Murcia et al., 2010). This may partly be because early studies, as cited in Pennington and Richards (1986), showed that pronunciation teaching was either ineffective (Madden, 1983; Suter, 1976) or useless and detrimental (S. Krashen, 1982).

However, research has provided compelling evidence that formal explicit instruction does improve L2 learners' pronunciation. For instance, in a study involving 15 post-intermediate students from a New Zealand university, Couper (2003) found positive changes in the learners' pronunciation after a 16-week learning course in which intensive pronunciation instruction was provided. Based on the students' errors arising from a diagnostic test, a pronunciation sub-syllabus of 18 units covering both segmentals and prosody was designed and taught by the researcher (about two hours per week including time in the language laboratory). The teaching of each session followed four steps: Description and Analysis Controlled and Semi-controlled Practice - Listening discrimination and Repetition - Selfrecordings and Self-correction. Though the learners' pronunciation showed improvement, the study faced problems of comparability since there was no control group. To accommodate this lack, Couper (2006) conducted another classroom-based study with a control group of 50 high-intermediate learners. This pronunciation course included 12 sessions (30 minutes each) specifically focusing on epenthesis (addition of a sound) and absence (inappropriate omission of a consonant). As reported in this study, after two weeks of training there was a considerable drop in errors by the learners of the experimental group but not the control group. The errors dropped from $19.9 \%$ in the pre-test to $5.5 \%$ in the immediate post-test and to $7.5 \%$ in the delayed post-test. The findings again confirm the progressive changes in the learners' phonological competence.

In a more recent study, Peltola, Lintunen, and Tamminen (2014) investigated the effects of explicit pronunciation instruction on Finnish tertiary EFL learners' production of English 
vowels. This study involved 11 participants who received intensive instruction over 42 hours on the features of ten English vowels (i.e. how tense and lax vowels differ from each other in duration), along with production training activities. After the course, the students' recordings of the target vowels in individual words were analysed. The findings showed that the students' production of the target vowels approached a native level, which suggests that the learners benefited from the explicit teaching of pronunciation. However, focused instruction implemented in the study was only on ten English vowels and mainly involved practice of monosyllabic words in the form of minimal pair drills. In addition, analysis of the participants' production of the vowel sounds was based on isolated words rather than sentences or spontaneous speech. As Rogerson-Revell (2011) holds, many L2 learners are able to reproduce the target pronunciation features in isolation but when it comes to a situation which requires spontaneous speech, they may still make pronunciation errors.

In the Asian EFL contexts, Saito (2007) examined how explicit instruction improves Japanese EFL students' pronunciation. The study involved six advanced adult learners: four received one hour of explicit phonetic instruction on the vowel/æ/ but the other two did not. The instruction was further supported by visual feedback using Praat software which allowed for self-monitoring of the learners' production and encouraged self-practice. Pre-test and post-test results showed significant improvement in the pronunciation of the experimental group but not the control group. The study was carried out on a small experimental design scale in which the focus of instruction was on just one vowel and lasted one hour only. In addition, the participants' speech samples were collected only from readings of single words rather than larger level of sentences or conversational contexts. However, the study demonstrated an immediate positive impact of explicit instruction on the learners' pronunciation.

Most recently, Pardede (2018) investigated the effectiveness of explicit pronunciation instruction on Indonesian EFL learners' pronunciation. The participants were 21 English majors at an Indonesian university. Although the study had a subset of data collected from two questionnaires that investigated the students' perceptions of pronunciation and their experience of the treatment, the main data were from a pre-test and three post-tests. First, a pre-test was carried out to identify pronunciation problems commonly facing the student participants. Based on this result, explicit pronunciation instruction was designed and portioned in three cycles: one focused on consonants, one on consonant clusters and stress, 
and the other on pausing, linking, prominence, and intonation. Instruction for the three cycles was delivered within five months (30 to 40 minutes per week). In the first cycle, instruction was implemented in five steps: explaining sound productions - practice individually practice in groups - recording and correcting self-productions - reproducing. Instruction delivered in cycles 2 and 3 followed a four-step procedure: listening - listening and imitating - recording and correcting self-productions - reproducing. At the end of each cycle, a posttest was conducted to assess the students' pronunciation using a 4-point grading scale (poor fair - good - very good). The findings showed that the students' pronunciation improved significantly from the pre-test $($ mean $=54.4)$ to the third post-test $($ mean $=77.3)$. Although instruction was delivered within a five-month period addressing both segmental and suprasegmental features, the focus was mainly based on listening and imitation. In addition, it is unclear about what type of the participants' speech samples (words, sentences, or spontaneous speech?) was collected and how each student's performance was scored. However, the study overall demonstrated that explicit instruction improved Indonesian EFL learners' pronunciation. Other empirical research has also highlighted the positive effects of formal instruction on learners' production of both segmental and prosodic features (e.g., Adams-Goertel, 2013; Lord, 2008; Ramírez Verdugo, 2006; Saito, 2011, 2012b).

In brief, research on the efficacy of deliberate pronunciation teaching shows that L2 learners "benefit from being explicitly taught phonological form to help them notice the differences between their own productions and those of proficient speakers in the L2 community" (Derwing \& Munro, 2005, p. 388). Clearly, many L2 learners need opportunities to improve their pronunciation, and explicit pronunciation instruction is often necessary to achieve this (Derwing, Munro, \& Thomson, 2008; Thomson \& Derwing, 2014). As such, researchers and practitioners have advocated giving pronunciation teaching more attention (Couper, 2006; Foote et al., 2011; Gilakjani, 2012a; Isaacs, 2009). However, research has shown a continuing lack of such attention in many contexts.

\subsubsection{Corrective feedback in pronunciation teaching}

One approach to pronunciation teaching that many teachers appear to fall back on is giving $\mathrm{CF}$ in response to individual learner's pronunciation errors (see, for example, Foote et al., 2011; Foote et al., 2016; Wahid \& Sulong, 2013, etc.). CF is defined as teachers responding to learners' erroneous utterances by pointing out the error, providing the correct language form, explaining the error using metalinguistic information, or a combination of all (Ellis, 
Loewen, \& Erlam, 2006). Lyster and Ranta (1997) identified six types of CF: explicit correction, recast, clarification request, metalinguistic feedback, elicitation, and repetition. In their interpretation of this classification, Lyster, Saito and Sato (2013) suggested that CF can be implicit or explicit and that it may take the form of recasts or prompts. Recasts may range from implicit reformulations to confirm meaning to more explicit correction where the teacher corrects an erroneous utterance and explains the errors. Prompts may involve the teacher making clarification requests to confirm meaning, drawing learners' attention to the error in an utterance and eliciting correction, and explicitly "using direct questions or metalinguistic cues to elicit the correction" (Couper, 2019, p.42).

In a similar vein, Varnosfadrani and Basturkmen (2009) suggest that implicit CF takes "the form of recast - the correct reformulation of the learners' erroneous utterances" whereas explicit CF involves "metalinguistic explanation of the erroneous structure" (p.83). Whether explicit or implicit, research suggests that $\mathrm{CF}$ plays a valuable role in $\mathrm{L} 2$ learning $(\mathrm{S}$. Li, 2010; Lyster, Saito, \& Sato, 2013; Sheen, 2010), including pronunciation improvement (J. Lee, Jang, \& Plonsky, 2015). In particular, empirical evidence has shown that explicit CF is more likely to lead to learner uptake of the targeted form than implicit CF (Dlaska \& Krekeler, 2013; Ellis et al., 2006; Varnosfadrani \& Basturkmen, 2009). In a similar vein, McGregor and Reed (2018) have argued that explicit CF is more effective in fostering L2 learners' pronunciation than implicit CF.

A number of recent quasi-experimental studies have investigated the effectiveness of $\mathrm{CF}$ on L2 learners' pronunciation. Research by Saito and Lyster (2012), for example, compared the effects of L2 pronunciation instruction with and without CF on learners' pronunciation development. The study involved 65 adult intermediate Japanese ESL learners in Montreal, Canada, divided into three groups: one control and two experimental. Each group received four hours of meaning-based pronunciation instruction integrated in argumentative skills lessons taught by two ESL teachers. The pronunciation focus for the control group was vowels, and for the two experimental groups was the English / $/ \mathrm{I} /$. The two experimental groups worked on the same activities practicing the target pronunciation features. However, one group received form-focused instruction only (the FFI-only group) whereas the other received FFI and CF (the FFI+CF group). The instructors gave CF to learners' mispronunciation or unclear pronunciation of / $\mathrm{x} /$ by recasting only one word in which an error occurred with falling intonation and without adding any additional meaning. The 
findings showed that learners of the FFI-only group did not show any significant change in their performance whereas those of the FFI+CF significantly improved their pronunciation of /.I/. In addition, the FFI+CF group outperformed the control group on similar task items including both reading and picture descriptions. The findings show how FFI involving CF can improve L2 learners' pronunciation in both controlled and spontaneous speech.

In a study involving 169 intermediate adult learners of German living in a German-speaking environment, Dlaska and Krekeler (2013) divided the participants into two different groups: one ( $n=85)$ received implicit feedback interventions (the listening-only group) and the other ( $n=84)$ received explicit individual CF (ICF) from the instructor (the ICF group). Learners of the listening-only group listened to a recording of their own recorded utterance and model speech following the procedures: (1) reading/recording, (2) listening to the recording twice, (3) listening to the teacher reading the text twice, (4) reading/recording the same text again. In contrast, learners of the ICF group, in addition to listening activities, also received explicit ICF from the teacher which encouraged them to modify their own output. The instructor explained learners' pronunciation problems using metalinguistic cues and gave examples. The procedures were partly similar to that of the listening-only group. However, giving ICF was an interactive process in which the learners were asked to produce the target features following four steps: (1) reading/recording, (2) listening to the recording twice and receiving explicit ICF, (3) listening to the teacher reading the text twice and receiving explicit ICF, (4) reading/recording the same text again. The findings showed that the immediate positive effect on comprehensibility of the ICF group was greater than that of the listening-only group. Thus, Dlaska and Krekeler conclude that ICF is more effective in improving learners' comprehensibility than listening only interventions. They also suggest that the inclusion of ICF significantly increased the effectiveness of pronunciation instruction. Though the study showed improvement in the learners' pronunciation, the analysis focus was on the participants' reading aloud rather than spontaneous speech.

In sum, these studies consistently suggest that CF facilitates pronunciation learning. However, Foote et al. (2016) have asserted that the feedback teachers give is less likely to be beneficial to student learning if they rely heavily on CF without explicit instruction that first helps students understand a target feature. Furthermore, not all learners perceive $\mathrm{CF}$ to be effective in improving their pronunciation. This highlights an issue which has not been 
widely researched, namely learners' beliefs and attitudes towards CF in pronunciation teaching. The current study addresses this issue.

\subsubsection{Communicative pronunciation teaching (CPT)}

CPT was advocated as a consequence of perceived limitations of CLT for pronunciation instruction, and was formalised and developed through a communicative framework proposed by Celce-Murcia et al. (2010). CLT emerged in the late 1970s and still remains predominant in language teaching world-wide. Underlying CLT is the assumption that "the learners' communicative competence develops automatically through their active participation in meaningful communicative tasks" (Dörnyei, 2009, p. 34). According to Foote and Trofimovich (2018) and J. Murphy and Baker (2015), such a focus on language learning for communicative purposes has led to many teachers attempting to make their pronunciation instruction fit into a CLT-oriented methodology. However, CLT prioritises meaning over form and is built on the assumption that L2 learners' pronunciation naturally improves through exposure to and communicative practice of the target language. Consequently, it marginalises explicit attention to pronunciation instruction within the language classroom (Adams-Goertel, 2013; Derwing \& Munro, 2005; Jenkins, 2004; Levis \& Sonsaat, 2018). For this reason, Adams-Goertel (2013) argues that CLT is not an optimal choice for pronunciation instruction.

CLT, in its weak form foregrounds the role of controlled practice as in the PresentationPractice-Production (PPP) sequence which involves three steps. In the first step, the teacher presents the target forms, and then in the second step, learners practice these forms in a controlled way. In the final step, learners are provided with the opportunity to use these targeted forms in communicative practice. Central to PPP are accuracy-based techniques with decontextualized drills that facilitate learners' language development mainly at the sentence level (Harmer, 2011). PPP has been critiqued for treating language development as a linear process, which, as Lewis (1993, p. 90) argues, reflects "neither the nature of language nor the nature of learning". Willis (1996) has also argued that since learners are required to rely on the language forms introduced in the presentation stage of the lesson, they are more likely to focus on form rather than meaning in the production phase.

In pronunciation learning, reliance on repetition and cue-response drills in the PPP model means that learners' attention is drawn to the forms of the targeted phonological features after 
which they have the opportunity to practice those forms through mechanical drills and then to use these forms in their production. Therefore, the PPP sequence contradicts the communicative orientation posited to be so central to pronunciation learning (Avery \& Ehrlich, 2013; Hismanoglu \& Hismanoglu, 2010; Levis \& Grant, 2003).

Task-based language teaching (TBLT), which can be seen as a strong version of CLT (Ellis, 2003), addresses these problems by promoting language development through learners' use of language for communicative purposes and especially through meaning-focused interaction (Ellis, 2003; Ellis \& Shintani, 2014; Long, 2015). However, given the form-focused orientation of pronunciation learning, it is unlikely that learners' attention will shift dramatically away from communication to language forms (Foote $\&$ Trofimovich, 2018). Thus, TBLT may not be a good fit for pronunciation instruction.

If we accept the claim that learners are likely to need explicit phonetic explanation about problematic phonological features followed by extensive form-focused practice in order to be able to use these features in meaningful communicative performance (Celce-Murcia et al., 2010; Foote \& Trofimovich, 2018), pronunciation instruction does not fit in well with either a weak form of CLT as instantiated in PPP, or in TBLT which prioritises meaning over form. As an alternative, scholars such as Gatbonton and Segalowitz (2005) and Trofimovich and Gatbonton (2006) have advocated an instructional process of CPT in which the instructor provides learners with explicit phonetic instruction followed by meaningful practice that enables them to use the target pronunciation features in social interaction. Celce-Murcia et al. (2010) have also argued that the pronunciation needs of L2 learners can effectively be addressed through a variety of pedagogical techniques, many of which involve learners in communicative practice. As Foote and Trofimovich (2018) hold, "language learning is hypothesised to take place when communication is interactively co-constructed during conversational interaction involving L2 learners" (p.80). Thus, CPT focuses on genuine communication rather than isolated practice of individual phonological features (Avery \& Ehrlich, 2013; Hismanoglu \& Hismanoglu, 2010; Levis \& Grant, 2003) and so allows L2 learners to practice the targeted phonological features in communication situations which immerse them in language use and in which they can get feedback on their production. In particular, CPT is compatible with the teaching of suprasegmental features such as stress and intonation given that it is the communicative context that helps the listener understand and interpret a given utterance (Foote et al., 2011). 
In order to formalise CPT, Celce-Murcia et al. (2010) proposed a framework for teaching pronunciation communicatively. In this communicative framework, a pronunciation lesson is typically divided into five stages moving from analysis and consciousness raising to listening discrimination and finally production. The framework is presented in Table 2.1 below.

Table 2.1 The communicative framework for teaching English pronunciation

(as based on Celce-Murcia et al., 2010, p.45)

\begin{tabular}{|c|c|}
\hline Stages & Descriptions/Features \\
\hline $\begin{array}{l}\text { 1. Description } \\
\text { and analysis }\end{array}$ & $\begin{array}{l}\text { Presents and explains how the feature is produced and when it occurs within } \\
\text { spoken discourse through oral and written illustrations. }\end{array}$ \\
\hline $\begin{array}{l}\text { 2. Listening } \\
\text { discrimination }\end{array}$ & $\begin{array}{l}\text { Provides focused listening practice accompanied by feedback on learners' } \\
\text { ability to correctly discriminate the feature. }\end{array}$ \\
\hline $\begin{array}{l}\text { 3. Controlled } \\
\text { practice }\end{array}$ & $\begin{array}{l}\text { Raises learner consciousness via oral reading of minimal-pair sentences, short } \\
\text { dialogues, etc., with special attention to the highlighted feature. }\end{array}$ \\
\hline $\begin{array}{l}\text { 4. Guided } \\
\text { practice }\end{array}$ & $\begin{array}{l}\text { Enables learners to monitor for the specified feature through structured } \\
\text { communication exercises, such as information-gap activities or cued dialogues. }\end{array}$ \\
\hline $\begin{array}{l}\text { 5. Communicative } \\
\text { practice }\end{array}$ & $\begin{array}{l}\text { Gives learners an opportunity and requires them to attend to both form and } \\
\text { meaning of their speech in forms of less structured, fluency-building activities } \\
\text { such as role play or problem solving. }\end{array}$ \\
\hline
\end{tabular}

As seen from Table 2.1, Stage 1 (description and analysis) is for the instructor to present and explain theory relevant to the highlighted pronunciation feature(s) followed by listening tasks in Stage 2 (listening discrimination) which help learners notice and concentrate on the difference between the targeted forms. In Stage 3 (controlled practice) and Stage 4 (guided practice), learners are provided with a variety of tasks that enable them to be attentive to and monitor their reproduction of the target feature(s) in a controlled and then semi-controlled way. While learners only need to focus on form in Stage 3, they are slightly oriented towards meaning in Stage 4. Finally, Stage 5 allows learners to practice the target feature(s) in free social interaction which requires them to attend to both form and meaning simultaneously.

Given that L2 learners typically need to spend a lot of time and effort on practicing a new phonological feature before they can automatize it in oral production (Celce-Murcia et al., 2010; Foote et al., 2011), the authors acknowledge that the framework needs to be applied across several lessons rather than a single one. According to Celce-Murcia et al. (2010), the most significant contribution of this framework is giving learners a chance to extend their practice of a newly-acquired phonological unit from the controlled phase of repetition to a 
higher level of more creative/communicative exchanges. In a similar vein, researchers and practitioners have advocated that pronunciation teaching needs to meet the learner's communicative needs (Gilakjani, 2012a; Hismanoglu, 2006; Hismanoglu \& Hismanoglu, 2010). To date, there has been no research of which I am aware that has investigated the implementation and effectiveness of this CPT model. However, several recent studies have examined the effects of explicit instruction incorporating communicative activities on L2 learners' pronunciation. Three such studies will now be reviewed.

Saito's (2011) research investigated the effectiveness of a combination of explicit instruction and communicative activities on ESL learners' pronunciation. The study involved 20 Japanese students at an American university. The participants were divided into two groups: the experimental group received four hours of explicit phonetic instruction but the control group did not. During the four hours of instruction for the experimental group, different communicative activities were used for students' practice. Pre- and post-test results revealed that the experimental group improved their pronunciation significantly in both the sentencereading task and the picture description task while the control group did not. From his findings, Saito argued for the use of communicative practice activities to enhance L2 learners' pronunciation.

Saito (2012b) subsequently re-examined the effects of explicit instruction incorporating communicative activities on L2 learners' pronunciation improvement. The study involved 49 Japanese EFL learners divided into two experimental groups and one control group. While the control group did not receive any pronunciation instruction, the two experimental groups attended four meaning-oriented pronunciation lessons with a variety of communicative activities including argumentative critique, debate tasks, and public speaking used for practice. The instruction for both experimental groups was form-focused but one of the groups additionally received explicit phonetic instruction. The findings showed that students of the control group did not improve their pronunciation but those in the experimental groups did. Saito also found that students who only received form-focused instruction demonstrated moderate improvement with medium effects in their pronunciation but those who received additional explicit phonetic instruction exhibited significant improvement with large effects. The study suggested the advantages of communicative practice activities in fostering L2 learners' pronunciation. 
Gordon, Darcy, and Ewert (2013) investigated the effects of explicit phonetic instruction on L2 learners' comprehensibility within a communicative methodology. Thirty intermediate ESL students of an intensive English programme at an American university participated in the study. The learners were divided into one control and two experimental groups. The experimental groups received a total of 225 minutes of explicit instruction during three weeks with one group focusing on four vowels /i:, I, æ, $\varepsilon /$ and the other on suprasegmental features of stress, rhythm, linking, and reductions. Each pronunciation lesson for the experimental groups followed a Presentation-Practice-Production sequence. The instructors first analysed and explicitly explained the target feature, then engaged students in discrimination and recognition tasks through minimal pair drills and passage reading, and finally provided communicative activities for production including pair/group discussions, role-plays, and information-gap activities. The control group did not receive explicit pronunciation instruction but for practice they listened to and repeated the words, phrases, and sentences taken from the materials used for the experimental groups; they also engaged in the same communicative activities for production as the experimental groups. The only difference at the production stage was that the instructors of the two experimental groups raised learner awareness of communication problems caused by mispronunciations of the target features whereas the instructor of the control group directed learners' attention to meaning and fluency.

The findings showed that only learners who received explicit suprasegmental instruction significantly improved their comprehensibility. The researchers argued that it might be because the focus on only four vowels in the segmental group did not fully engage the attention capacity of learners in other global aspects in speech perception. They therefore suggested that explicit suprasegmental instruction may facilitate comprehensibility more effectively. The study provided support for the role of explicit pronunciation instruction within a communicative methodology in improving L2 learners' comprehensibility but had some limitations. First, the results were not based on the learners' spontaneous speech. Instead, the participants recorded sentences through a delayed-sentence repetition task which may have allowed for a higher level of consciousness in controlling their production. Second, generalisability is limited given that only speech samples of 12 out of 30 students were collected for analysis and that the students had a high level of English proficiency (level 6 out of the seven institutional levels, with an average TOEFL score of around 500). Finally, 
the study did not examine the instructors' and learners' beliefs and attitudes towards their teaching and learning experiences of the instruction implemented in class.

Overall, these studies demonstrate the value of explicit instruction incorporating communicative activities in fostering L2 learners' pronunciation. However, no studies have investigated the effectiveness of the communicative framework proposed by Celce-Murcia et al. (2010) in classroom practice. Therefore, the effects of this CPT model on student learning still remains unexplored. Although Celce-Murcia et al. argued for the significant contribution of their framework on a theoretical level, evidence is needed to bridge the gap between theory and practice. Accordingly, in Phase 2 of the current study, I have adopted this communicative framework as an approach to pronunciation teaching and learning in the VTE classroom.

\subsubsection{Concluding remarks}

To conclude, research has highlighted the effectiveness of explicit pronunciation teaching on the intelligibility and accuracy of L2 learners' pronunciation. In particular, this body of research demonstrates that CF plays an important role in facilitating L2 learners' pronunciation learning. Research has suggested that explicit instruction incorporating communicative activities is effective for pronunciation learning. I will now turn to the practice of pronunciation teaching as it is represented in textbooks as well as in classroom practices and teachers' cognitions.

\subsection{The practice of pronunciation teaching}

The studies reviewed to this point have largely been quasi-experimental in nature, involving research into the introduction of pronunciation teaching approaches and innovations. Another less prominent but rapidly growing strand of pronunciation research seeks to describe and understand pronunciation teaching as it occurs in intact classrooms under normal instructional conditions. This section reviews research into the practice of pronunciation teaching in three domains: textbooks, classroom practices, and teachers' cognitions.

\subsubsection{Pronunciation in textbooks}

Textbooks are considered to be the mainstay of a language programme (Chapelle, 2009; Darcy et al., 2011; Sobkowiak, 2012). They provide not only the scaffold for teachers to plan 
their classroom activities (Macalister, 2016; B. Tomlinson, 2001) but also necessary guidance for learners to follow (İnal, 2006; Vettorel \& Lopriore, 2013). In pronunciation teaching, as Tergujeff (2010) and Derwing et al. (2012) argue, textbooks are important in that they partly guide the instructor's classroom practice and determine if learners receive useful pronunciation practice activities.

However, analyses of textbook content by Tergujeff (2010) and Derwing et al. (2012) have revealed striking discrepancies across a number of ESL/EFL textbook series. According to Derwing and Munro (2015, p. 79), many textbooks include a little or no pronunciation content. For example, Tergujeff (2010) analysed EFL course books used in Finnish schools including textbooks, exercise books and teacher's guides. She calculated pronunciation instruction in these course books based on whether the task: (1) required oral production of English, (2) involved the International Phonetic Alphabet (IPA), or (3) related to pronunciation and oral production. The findings showed that pronunciation in these texts mainly involved traditional mechanical drills of phonetic training and reading aloud and mainly focused on segmental features, primarily through phonetic training (33\%), followed by reading aloud (29\%), and listen and repeat (18\%). Activities designed for classroom practice were mostly in the form of tongue twisters and minimal pairs drills. The findings demonstrated that explicit instruction on suprasegmental features was entirely absent from EFL textbooks used in Finnish schools.

Derwing et al. (2012) examined how pronunciation was addressed across 12 general-skills textbook series and teacher' guides used in the ESL context of Canada and found that pronunciation was given a minor role compared to other language skills. They calculated pronunciation content by half-page counts of 48 student books and six teacher guides. Overall, they found that pronunciation accounted for between $0.4 \%$ and $15.1 \%$ of textbook content. Analysis of teachers' manuals for six of these series showed that only four provided instructors with guidance on pronunciation teaching, and typically only in the form of background information on pronunciation features and advice to remind learners to monitor their L2 pronunciation. Similarly, J. Murphy (1991) found that listening and speaking activities accounted for a much higher proportion in commercially available ESL/EFL textbooks than explicit pronunciation activities. Collectively, these studies provide insights into how poorly ESL/EFL textbooks address pronunciation. 
Pronunciation teaching is equally under-represented in teacher guides as Derwing and Munro (2005) concluded in their examination of general ESL/EFL teacher textbooks. They further argued that this lack of attention to pronunciation teaching has led to limited knowledge in the teaching profession about how to appropriately implement pronunciation instruction within the L2 classroom. They also pinpointed a lack of a direct link between research findings and specific ways to address particular pronunciation problems in publications for instructors. In other words, a growing body of research evidence on L2 pronunciation instruction has been poorly represented in teacher-oriented publications. For such a problem to be addressed, Derwing and Munro (2005) propose a scenario in which "applied linguists take responsibility for interpreting technical research for pedagogical specialists and incorporating pertinent findings into teacher training materials and student texts" (p.382).

In summary, research suggests that pronunciation instruction as found in instructional materials is under-represented compared to other language skills and that, where it is present, there is an imbalance in focus of instruction between segmental and suprasegmental features. The findings indicate that pronunciation is given limited attention in professional texts for teachers. There is a need to make better use of research findings to help teachers address pronunciation in the language classroom. No published research of which I am aware has looked into the position of pronunciation in EFL textbooks used in Asian countries including Vietnam. Thus, the current study is the first to examine how pronunciation is represented in EFL textbooks at a Vietnamese university. Research such as this is important in that it can provide useful information for textbook writers and/or curriculum designers in selecting instructional materials for language programmes in this EFL context and beyond.

\subsubsection{Research on pronunciation teaching practices}

While studies have documented limited attention to pronunciation instruction in many ESL/EFL textbook series, a growing body of research has sought to describe and understand the ways and extent to which teachers in specific contexts address pronunciation in intact classrooms. According to Derwing (2018) and Gilbert (2010), pronunciation teaching continues to be neglected in classroom practice of many language teachers. In a similar vein, Derwing (2010) points out that pronunciation seems to receive the least attention of all the language skills within a language programme although many L2 learners recognize the value of pronunciation in oral communication and see it as a priority (Derwing \& Munro, 2005; Fraser, 2010; Seyedabadi et al., 2015). This section reviews studies that addressed the 
question of how teachers in both ESL and EFL contexts teach pronunciation in their classes before concluding with an evaluation of the main findings.

Through a comprehensive survey of 67 ESL programmes, Breitkreutz et al. (2001) provided a snapshot of pronunciation instruction practices in Canada. A questionnaire including items of rating scales, multiple-choice, and close and open-ended questions was administered to 174 teachers and programme coordinators in three English-speaking provinces of the country. The study revealed a common perception that pronunciation instruction is important in ESL classes at all levels. In answer to open-ended questions, most of the teacher participants recognized the need for integrating pronunciation instruction into communication classes but claimed they lacked knowledge about how to do this. A quarter of the participants felt insufficiently trained in pronunciation teaching and thus called for more training opportunities so that they can teach pronunciation more effectively.

Ten years later, Foote et al. (2011) carried out another study to survey the teaching of pronunciation in ESL classes across Canada. The survey was delivered to 201 participants who responded to 45 survey items including multiple-choice questions, yes/no questions, checklists, Likert scales, and open-ended questions. From their survey findings, Foote et al. claimed that there had been little substantial change in pronunciation instruction in Canada over the ten years since Breitkreutz et al.'s study. Again, most teachers reported regularly integrating pronunciation into their general ESL classes, but a majority said that this usually consisted of correcting their students' pronunciation errors. In addition, whereas the teachers in the earlier study reported covering both segmental and suprasegmental features in class, the findings revealed a slightly greater focus on individual sounds among the teachers. In terms of classroom instruction, Foote et al. recommended that teachers more consistently integrate pronunciation into their general ESL classes so as to help students overcome their pronunciation problems. They also suggested that teachers give explicit feedback on students' errors of both segmentals and suprasegmentals.

More recently, Foote et al.'s (2016) classroom-based study investigated pronunciation teaching practices in communicative L2 classes. Data was collected from 40 hours of videotaped lessons from three experienced teachers recorded four times at 100-hour increments during a 400-hour programme. The findings revealed that "most pronunciation teaching episodes were not incorporated into lesson plans but instead involved various kinds of corrective feedback in response to individual student errors" (p.181). 
Similarly, D. Murphy (2011) found that 33 out of the 36 teacher participants in four different private schools in the Dublin area of Ireland reported using listen-and-repeat activities or giving CF when learners read aloud rather than spending class time teaching pronunciation explicitly.

Within the EFL context of Asian countries, only a few studies have been conducted on this topic. One such study by Wahid and Sulong (2013) investigated how EFL teachers at a Malaysian university taught pronunciation in class through a survey questionnaire, classroom observations, and semi-structured interviews. In terms of classroom practices, the observational data showed a strong tendency for the teachers to avoid explicit pronunciation teaching. Instead, the teachers mainly corrected their students' pronunciation errors of individual sounds through repetition. In Taiwan, Chiu (2008) found that $50 \%$ of the teacher participants based their pronunciation instruction on giving CF in response to learners' pronunciation errors of segmentals; $50 \%$ gave explicit explanations of phonics, syllables and word stress. The findings showed incongruence between the teachers' stated beliefs and their actual classroom practice. Although all the teachers reported addressing both segmentals and suprasegmentals, the observations showed that most of them focused on individual sounds with only one teacher dealing with prosodic features.

Taken together, these research findings suggest that teachers do address pronunciation in their classes but tend to limit their instruction to correcting learners' pronunciation errors of segmental features or modelling pronunciation through listen-and-repeat activities. The studies reviewed above provide insights into how teachers teach pronunciation in their ESL/EFL classes and what they teach. The question of why teachers teach pronunciation the way they do and what beliefs they hold about their classroom actions is equally important and is addressed in the following section.

\subsubsection{Teacher cognition in pronunciation teaching}

Understanding language teaching requires understandings of not only what teachers actually do in their language classes but also why they do what; i.e. the interplay between teachers' cognitions and their classroom events (Baker, 2014). Observing how teachers construct teaching procedures and make pedagogical choices provides evidence of their actual classroom practices but the beliefs teachers hold about these practices are not directly observable (Borg, 2015; Borg \& Al-Busaidi, 2012). Given that teaching is a "complex 
cognitively-driven process" (J. C. Richards, 2008, p. 167), it is important to gain in-depth understandings about teachers' mental constructs underlying their classroom actions (Borg, 2015). In this regard, research into teacher cognition about pronunciation teaching provides insights into teachers' stated beliefs about the pronunciation pedagogical choices they make in class. This information is important because it can assist practitioners to revise language curricula, improve teacher training programmes, and promote TPL in relation to pronunciation teaching. This section discusses the influence of language teacher cognition (LTC) on teachers' decision-making in class and reviews studies on teacher cognition (TC) in pronunciation teaching.

According to Borg (2015), the study of LTC emerged in the early 1990s and has become a well-established field of research activity worldwide within the past three decades. He defined LTC as language teachers' thoughts, knowledge and beliefs, which is often personally tacit and resistant to change (Borg, 2011, 2015). In Crookes' (2015) definition, LTC "refers to aspects of (language) teacher thinking [...] usually used interchangeably with beliefs" (p.486). Although the study of LTC in the context of L2 teaching and learning is still an emerging area of enquiry (Borg, 2015; Kubanyiova \& Feryok, 2015), this type of research benefits both language teaching and learning and language teacher education in different ways (Borg, 2011, 2015; Johnson, 2006). First, research into LTC provides in-depth understandings about how teachers' beliefs are constructed and how these shape their classroom events (Borg, 2015; Crookes, 2015; J. C. Richards, 2008). Second, the findings of this work, according to Kubanyiova and Feryok (2015), help bridge the gaps between the teachers' mental lives, their actual classroom practices, and their students' language learning experiences. Third, LTC research provides insights into the pivotal role teachers and their beliefs play in carrying out educational reforms (Basturkmen, 2012; Borg, 2015).

Given the influential role LTC has on teachers' pedagogical choices, I would argue that the cognitions of teachers can have a strong impact on how they deliver pronunciation instruction within their language classrooms. Thus, research into what teachers think, know and believe can provide insights into decision-making with respect to pronunciation teaching (McGregor \& Reed, 2018; Wahid \& Sulong, 2013). These insights can, in turn, assist language practitioners to make informed educational changes in relation to pronunciation instruction. Given the powerful impact of teachers' cognition on their pedagogical decisionmaking and its intricate relationship with classroom practice, the current study adopted a 
social ontology to understand teacher cognition in a contemporary context of EFL education in Vietnam. According to Burns, Freeman, and Edwards (2015), a social ontology emphasises the link between teachers' cognition and their learning, thus seeing teachers' "thinking and beliefs as both shifting and contextualised with teachers developing [teaching expertise] across professional careers, and within instructional contexts" (p.590). In addition, teachers' cognition is not as stable as "the realm of reality inside teachers' heads" (L. Li, 2013, p. 176) but rather influenced by wider affective factors, both personal and contextual in the setting in which teachers operate (Burns et al., 2015). Adopting the social ontology to understand teachers' cognition, the current study sought to provide insights into some of the unobservable affective factors in the pronunciation teaching practices of EFL teachers at a Vietnamese university. Specifically, the study examined not only what the teachers thought and believed but also the students' perceptions of their experience of their teachers' pronunciation teaching and their own pronunciation instructional needs. It also looked at the extent to which the syllabus and teaching materials address pronunciation, and the teachers' access to education and continuing education. By taking into account these different dimensions of the context of instruction, the study adopted a social ontology as the overarching theoretical framework to extend understandings about teacher cognition in pronunciation teaching to the context of tertiary EFL in Vietnam.

Although there has been limited research into TC in pronunciation teaching in both ESL and EFL contexts, recent studies such as Baker (2011, 2014), and Couper (2017) have begun to address this gap. This line of research mostly focuses on teachers' beliefs about the pronunciation features they usually teach, the techniques they often use, teachers' confidence and focus in pronunciation teaching, and their initial training and PL needs. These studies are now reviewed in turn.

Baker's (2011) study investigated teachers' beliefs and practices of pronunciation teaching in the American ESL context. The research involved five experienced ESL teachers teaching an intensive English programme at an American university. Data were collected through classroom observations and individual interviews with the teachers. The findings show that learning experience, initial training and teaching experience strongly affected not only the teachers' knowledge of pronunciation and pronunciation pedagogy but also their confidence level in teaching pronunciation. Reflecting on prior experience as a second language learner, the teachers reported to mainly engage in repetition activities as the main focus on L2 
pronunciation instruction in class. Regarding initial pronunciation training, the teachers reported receiving some training in the articulation of individual sounds and specific techniques for teaching prosodic features, with one teacher only having training in how to teach listening and speaking skills when they took a graduate course. From classroom observations, Baker found that the teachers' actual classroom practice was textbook-driven and frequently centred on repetition drills, which reflected their previous experience in L2 learning. The interview data showed that the knowledge the teachers received from their graduate course and their collaboration with colleagues had the strongest influence on their pronunciation teaching practices and confidence levels in teaching English pronunciation. All but one of the teachers reported being confident in teaching pronunciation as a result of their knowledge gains from the graduate course. Baker concludes that L2 pronunciation instruction warrants greater attention in TESOL training because any programme including even only one course in pronunciation pedagogy may have a significant impact on both teachers' knowledge and confidence in pronunciation teaching.

In another study, Baker (2014) explored knowledge of pronunciation-oriented techniques of five ESL teachers in a North American intensive English programme. Data was collected through semi-structured interviews, classroom observations, stimulated recall interviews with the teachers, and questionnaires with students. The findings showed that controlled techniques formed the foundation of the teachers' knowledge base of techniques and dominated across all the classes and that the teachers' knowledge and use of guided techniques seemed limited. Findings revealed that the teachers believed listening perception to be essential for improving learners' comprehensibility and kinesthetic/tactile practice integral to pronunciation improvement. The teachers who were textbook-driven perceived pronunciation instruction to be rather boring. Baker argues that to better facilitate L2 learner's comprehensible pronunciation, teachers need to understand how to effectively deliver explanations, practice and constructive feedback on pronunciation.

More recently, Couper (2017) examined how ESL teachers in New Zealand perceived pronunciation teaching. Data obtained from semi-structured interviews with 19 teachers teaching ESL adult learners of all proficiency levels addressed different issues in pronunciation teaching. Couper categorised these issues into four main themes but only reported and discussed findings about (1) training, knowledge, and confidence; (2) pronunciation goals, teaching focus, and identity; and (3) mixed-L1 classes. He found that 
the teachers lacked initial training and confidence in pronunciation teaching. The teachers reported developing confidence and expertise in teaching pronunciation through their own reflective practice. They indicated a preference for more PL opportunities. The findings showed several gaps in the teachers' knowledge of both phonetics and phonology including the articulation of phonemes, stress and intonation, and in knowing how to teach pronunciation, what to teach and how much or how often. Specifically, the teachers' stated beliefs revealed that intelligible pronunciation and effective communication was the main goal in their teaching. The teachers believed that it is necessary to teach suprasegmentals but reported lacking knowledge and confidence and consequently most often focused on segmentals. Regarding mixed-L1 classes, some teachers stated that this makes pronunciation instruction too hard to deal with but others thought it is beneficial for cross-cultural understandings and peer correction. Couper concluded that the teachers' knowledge gaps naturally led to their lack of confidence in teaching pronunciation and this led them to stay away from it. He suggested the utility of available research-based evidence for various stakeholders such as instructors, teacher educators, curriculum designers, and textbook writers.

Burri, Chen, and Baker (2017) explored the identity construction and cognition development of 15 student teachers (five native and ten non-native English speakers) in a postgraduate course on pronunciation pedagogy at an Australian university. Data were collected through two sets of questionnaires, focus group interviews, observations of a three-hour lecture, and semi-structured interviews with seven of the participants. Analysis of the focus group and interview data revealed that imagination of self and others substantially influenced the participants' cognition development and identity construction. Over the course, the nonnative participants imagined themselves as legitimate and competent pronunciation instructors due to their strong awareness of English pronunciation, leading to a higher level of confidence in teaching pronunciation. In contrast, the native participants became unconfident in teaching pronunciation and reported a challenge in imagining and positioning themselves as effective pronunciation instructors. The observational and the interview data also showed that the participants' personal engagement and investment in the course and course contents in the form of reading professional literature, status as classroom teacher, and value attributed to assessment tasks influenced their identity construction, which in turn facilitated their cognition development. Such engagement and investment enhanced not only the participants' knowledge of English pronunciation but also their understandings about pronunciation 
pedagogy including L2 pronunciation goals, models, and teaching techniques. For example, at the beginning, most participants reported segmentals to be the main focus for classroom instruction, but at the end of the course they believed that suprasegmentals are an important component in pronunciation pedagogy. Overall, the findings demonstrated that identity construction had a substantial influence on the development of the participants' cognitions, and that these two constructs were interwoven in a complex and reciprocal relationship that fostered the participants' learning to teach pronunciation.

In another study, Burri, Baker and Chen (2017) compared the cognition development between five experienced and ten inexperienced teachers during a postgraduate course on pronunciation pedagogy at an Australian university. Data were collected through questionnaires, focus group meetings, semi-structured interviews, classroom observations and an assessment task. The findings showed that there was little substantial development in the student teachers' cognition about pronunciation pedagogy and that the participants reported finding it difficult to integrate pronunciation into L2 classes. Prior to the course, all but one of the inexperienced teachers reported drills and repetition/imitation as their previous L2 pronunciation learning experience, and all the experienced teachers reported these types of controlled techniques to be most frequently used in their pronunciation teaching practice. At the end of the course, the student teachers' cognition about pronunciation instruction did not substantially develop because they still chose the same controlled activities in the assessment task as in the questionnaire. However, data from the assessment task, semi-structured interviews, and focus group meetings showed that the participants' cognition developed in how to teach English pronunciation more effectively. For example, the teachers perceived kinesthetic/tactile pronunciation teaching to be new to them, yet they developed an understanding of these teaching techniques over the course. Additionally, the teachers' beliefs about pronunciation pedagogy changed as a consequence of the training course during which they had an opportunity to observe real-life ESL pronunciation teaching. At the beginning of the course, the teachers did not see much value of the training, but they later perceived that using kinesthetic/tactile pronunciation teaching techniques improved pronunciation teaching, engaged learners in classroom tasks, and created an enjoyable learning environment.

The findings indicated that beliefs and knowledge about pronunciation pedagogy of experienced teachers developed more than that of inexperienced teachers. At the end of the 
semester, while some of the former reported being more confident and more aware of the impact of contextual factors on pronunciation instruction, most of the latter seemed to lack the confidence in teaching pronunciation. Focus group, observation and semi-structured interview data also showed that the intensity of the course and the complexity/ambiguity of English phonology posed difficulty to all the participants and so constrained the development of their cognition about pronunciation pedagogy. From their findings, Burri, Baker, and Chen argued that preparing teachers to teach pronunciation is a necessary and valuable component of L2 teacher education. They suggested that L2 teacher educators be well aware of the influential impact of the intensity/depth of content and complexity/ambiguity of English phonology on student teachers' cognition growth. One possible way to provide further support in postgraduate courses on pronunciation pedagogy as they recommended is to group experienced and inexperienced teachers during lectures. In this way, teachers can share classroom experiences and collaboratively reflect on implications of the knowledge they receive during the course, which makes inexperienced teachers' learning to teach pronunciation more meaningful and effective. The study provides insights into how experienced and inexperienced teachers' cognitions about L2 pronunciation teaching grew during a postgraduate course in pronunciation pedagogy.

In the Asian EFL context, a study by Wahid and Sulong (2013) was discussed earlier in section 2.4.2 on how Malaysian tertiary EFL teachers teach pronunciation. This study also involved an investigation into the teachers' stated beliefs about their pronunciation teaching practices and so warrants further discussion. In this research, a survey was distributed to 27 EFL teachers at a Malaysian university to investigate if the teachers taught pronunciation, what they taught, how often they taught, and which activities they used. The survey was followed by classroom observations of three teachers and semi-structured interviews with seven teachers. The findings showed a mismatch between the teachers' stated beliefs and their actual classroom practices of pronunciation teaching. The teachers reported that they taught pronunciation on a regular and sustained basis and that prosodic features were critical to speech intelligibility and so important to student learning. Nevertheless, Wahid and Sulong found that the teachers' pronunciation teaching was minimal and restricted to error correction of segmental features only.

Most recently, Bai and Yuan (2019) investigated beliefs and pronunciation teaching practices of seven primary and nine secondary teachers in Hong Kong. Data were collected from all the 
teachers' written reflections on their beliefs and practices of pronunciation teaching and semistructured interviews with four teachers. The findings showed that all the teachers recognized the value of pronunciation teaching to students' oral communication competence. According to the teachers, teaching pronunciation not only helps increase students' confidence and willingness to communicate, but it also facilitates other aspects of language learning. Some teachers stressed the importance of teaching suprasegmental features such as rhythm and intonation and thus called for more explicit pronunciation teaching within the language classroom in Hong Kong. However, most of the teachers reported a low level of confidence in teaching pronunciation due largely to their lack of initial training and PL in pronunciation pedagogy. Since the teachers did not perceive themselves as effective pronunciation instructors as native English teachers, they tended to avoid teaching it. In addition, the teachers reported the Native English Teacher Scheme applied in Hong Kong schools to be a factor shaping their pronunciation teaching. As the teachers said, pronunciation and oral communication skills in general are normally designated to native-speaker instructors whereas the local teachers are assigned to teach reading, writing, grammar and vocabulary to help students prepare for examinations. The teachers also reflected that time constraints and the accent preference by students' parents, school principals, and stakeholders alike restricted their pronunciation teaching. As such, most of the teachers reported frequently using the International Phonetic Alphabet (IPA) as a useful tool for students' practice. They believed that this teaching technique helps Hong Kong students become independent learners as they can rely on dictionaries for pronunciation learning. Yet, two teachers stated that using the IPA may make pronunciation learning more difficult for Hong Kong students who usually rely on the local teacher's pronunciation as a model. For this reason, they reported using interactive tasks for students' practice such as songs, stories, and tongue twisters. Since no observational data were collected, the study lacked robust evidence of how the teachers actually taught pronunciation in their English classes. This information is important given that the beliefs teachers hold do not usually correspond with their actual classroom practices (Basturkmen, 2012; Borg, 2015). Research has suggested that there is often a mismatch between what teachers say and what they actually do in the classroom (Phipps \& Borg, 2007, 2009). However, the study provides useful insights into the teachers' stated beliefs and reported practices of pronunciation teaching in Asia, a context in which limited pronunciation research has been conducted. 
What has been revealed in these studies into TC in pronunciation teaching is that TC shapes the way teachers deliver pronunciation instruction. Since teachers are active decision-makers, their knowledge, thoughts and beliefs have a powerful influence on the pedagogical choices they make in class (Borg, 2009, 2015a; Richards, 2008). Given that many teachers lacked confidence in teaching pronunciation and knowledge of pronunciation pedagogy, they restricted their classroom practices to particular types of teaching techniques. These findings suggest that more PL opportunities in pronunciation pedagogy be made available for teachers in order to build their confidence, knowledge, and skills in the expectation that this growth will, in turn, be reflected in improved delivery of pronunciation instruction.

\subsection{Teacher professional learning in pronunciation teaching}

Teacher professional learning (TPL) is a job-embedded learning opportunity (Muijs et al., 2014; Murtaza, 2010; Timperley, Wilson, Barrar, \& Fung, 2008) in which teachers transform the professional knowledge and skills they have received into actual classroom practice (Barnes \& Verwey, 2008; Shangase, 2013; Timperley, 2011; Tsotetsi \& Mahlomaholo, 2015). According to Diefes-Dux (2014), Steyn (2011) and Timperley (2011), the ultimate goal of TPL is to enhance teachers' classroom practice and improve SLOs. In this sense, TPL in pronunciation teaching can be operationalised as any type of PL that helps teachers enhance pedagogical knowledge and refine their pronunciation teaching skills so as to promote students' pronunciation learning. This section firstly discusses the role of TPL in pronunciation pedagogy. It then reviews studies on TPL in pronunciation teaching and particularly research on TPL in the Vietnamese EFL context, which identifies the research gaps that motivate Phase 2 of the current study.

\subsubsection{The role of TPL in pronunciation pedagogy}

Recent research has shown that many ESL/EFL teachers are insufficiently trained in pronunciation pedagogy and thus feel unconfident in teaching pronunciation (Couper, 2017; Foote et al., 2011; Henderson et al., 2012; Saito \& van Poeteren, 2012). A noticeable drawback amongst teacher education programmes is that not many of them provide courses on pronunciation pedagogy (Baker, 2014; Henderson et al., 2012). Given this lack, Darcy et al. (2011) and McGregor and Reed (2018) have pointed out that many ESL/EFL teachers are usually left without clear guidance for systematically integrating pronunciation into classroom instruction. According to Derwing and Munro (2005), L2 teachers are ill-prepared 
for teaching pronunciation, and this leads to a number of undesirable consequences. These include learners simply not receiving any instruction, or experiencing pedagogical misdirection, or teachers making ineffective pedagogical choices in class. They also claim that teachers who lack PL opportunities in pronunciation pedagogy "may develop some teaching strategies that actually have little or no value or that may be counterproductive" (ibid., p.390).

Therefore, PL that boosts ESL/EFL teachers' pronunciation pedagogical knowledge, refines their pronunciation teaching skills, and assists them to translate it into classroom practice is of paramount importance. Research has shown that even instructors who are more confident in their teaching ability have expressed a strong desire for more PL opportunities in pronunciation pedagogy (Burns, 2006). In particular, Baker (2014) holds that once L2 teachers start teaching, PL activities such as mentoring are advantageous for their professional growth. To this end, researchers and practitioners have suggested that more PL opportunities be provided for L2 instructors to help them feel comfortable teaching pronunciation (Celce-Murcia et al., 2010; Derwing \& Munro, 2015; Foote et al., 2011; J. Murphy, 2014). However, such opportunities are typically relatively scattered. Sections 2.5.2 and 2.5.3 below review research on TPL in pronunciation teaching and TPL within the Vietnamese EFL context respectively.

\subsubsection{Research on TPL in pronunciation teaching}

Given the strong need for more PL opportunities in pronunciation pedagogy expressed by many instructors, it is important to see how PL activities are translated into classroom practice and how they facilitate students' pronunciation learning. While an extensive body of research has argued for the impact of TPL on pronunciation instruction, limited research has been carried out to examine the effects of such TPL on teachers' instructional practice and student learning.

Early research by McCutchen et al. (2002) examined the effects of a TPL course on teachers' knowledge, classroom practice, and SLOs. The study involved 44 teachers (20 in the control group and 24 in the experimental) and 779 students from 40 schools in the metropolitan area in the western United States. Teachers in the experimental group attended a two-week course about phonology, phonological awareness, and its role in reading instruction but those in the control group did not. Data were collected through classroom observations together with pre- 
tests and post-tests of teachers' knowledge of English phonology, orthography, and their role in literacy instruction. The student participants' pre-test and post-test scores were analysed. The researchers found that teachers of the experimental group did deepen their phonological knowledge after the TPL course, and so they spent significantly more time on activities directed toward phonological awareness and explicit comprehension instruction than the control group teachers. They found that explicit phonetic instruction delivered by these teachers resulted in students' measurable growth in phonological awareness, orthographic fluency, listening comprehension, vocabulary, and reading comprehension as indicated by their pre- and post-test scores.

In another study, Burns (2006) investigated issues related to teachers' pronunciation teaching practices and their PL needs in pronunciation instruction. In the first phase of the study, 200 surveys were delivered nationally to all teachers working for the Australian Adult Migrant English Programme in all eight states and territories of Australia; 143 teachers from six states responded. Burns found that the teachers expressed a strong need for PL opportunities in pronunciation teaching. Thus, in the second phase of the project, she offered a national online PL course accompanied by three fact sheets presenting literature reviews and pronunciation teaching resources through the website of the National Centre for English Language Teaching and Research. Also, a national reference group frequently had meetings with the teachers to facilitate further input into their context-specific PL needs. From the participants' reports and their own classroom video-recordings, a TPL package that focused on pronunciation teaching was prepared for teachers including a video and a handbook. The TPL package aimed to provide teachers with knowledge and strategies about pronunciation teaching and was carried out through presentations, observations, and discussions followed by classroom-based investigations and reflections. The Phase 2 findings were expected to show how researchers could properly address teachers' PL needs in pronunciation teaching across a nationwide teaching system in such a way that it yields realistic positive impacts on teacher learning, classroom practice, and SLOs. However, the findings were not reported and so there is no evidence of whether or not this TPL package resulted in positive changes in the teachers' knowledge gains, instructional practice and SLOs as expected.

\subsubsection{Research on TPL in the Vietnamese EFL context}

Within the EFL context of Vietnam, a few studies on TPL have been carried out. For example, H. T. M. Nguyen (2011) conducted a qualitative study to investigate EFL teachers' 
and school leaders' experiences and perceptions about EFL teaching policies at primary schools, including TPL policies. The participants were from two schools: one public and one private. Data were collected through classroom observations followed by four focus group interviews with EFL teachers (three to five teachers each) and individual interviews with the principal at the public school and the EFL advisor at the private school. In terms of TPL, H.T.M. Nguyen found that all the teachers lacked initial training in teaching English to primary school students and so they expressed a strong need for PL opportunities. Only two public school teachers had a chance to attend a workshop but they reported not having time to be present on a regular basis and were not highly motivated since they found it irrelevant to their own teaching context. The other teachers said there were few PL opportunities and they had no access to their peers' classroom for observation purposes. In contrast, PL activities were more frequent at the private school. H.T.M. Nguyen's findings show that all the teachers reported having PL opportunities at the school level in the form of classroom observations and practice sharing, workshops, conferences, and even short courses overseas. Nevertheless, they reported no incentives offered by the government. From her findings, H.T.M. Nguyen advocated that high-quality PL programmes should be made available to assist Vietnamese primary EFL teachers to maintain and develop their language proficiency level and enhance their teaching skills. The study provides insights into teachers' experiences and beliefs about PL activities within the context of primary EFL education.

In higher education settings, H. T. M. Nguyen (2008) surveyed VTE teachers' thoughts and beliefs about the issues of mentoring. The survey included 45 Likert-scale items and was delivered to 31 EFL teachers who had less than 3 years of teaching experience. The data were analysed quantitatively. H.T.M. Nguyen found that all the teachers valued the importance of mentoring, rating it as either 'important' or 'very important' in their professional growth. Overall, the respondents reported that mentoring helped improve their professional knowledge and foster their confidence in teaching. H.T.M. Nguyen also found that the teachers' mentoring was self-initiated and many had not engaged in any mentoring programme before. Most of the respondents valued their mentor's professional competence, interpersonal skills, and teaching experience but indicated that they were not satisfied with their mentors in terms of feedback giving, collaboration, teaching strategies modelling, and time management. H.T.M. Nguyen concluded that these findings are important for future design and implementation of mentoring programmes for beginning EFL teachers at tertiary level in Vietnam. She recommended that mentors need proper training prior to taking on the 
role of a mentor. The study provides empirical research evidence for educational leaders and stakeholders alike in their efforts to enhance TPL programmes for tertiary EFL teachers. Other studies have also highlighted the effectiveness of TPL in promoting Vietnamese EFL teachers' professional growth such as the Critical Friends Group technique for beginning teachers (Vo \& Nguyen, 2009) or peer mentoring for pre-service teachers' instructional practicum practice (H. T. M. Nguyen \& Baldauf Jr, 2010).

In summary, the findings have shown that Vietnamese EFL teachers believe TPL is helpful for their professional growth. The studies provide insights into how TPL is implemented in different Vietnamese EFL settings, which lay the foundation for future TPL design and implementation in this context. However, none of the research has investigated how TPL in pronunciation pedagogy promotes Vietnamese EFL teachers' knowledge gains and instructional practice, especially within the context of higher education where pronunciation teaching and learning is likely more important (Dalton-Puffer et al., 1997). Furthermore, no research has examined how TPL in the form of workshops affects teacher learning, classroom practice, and SLOs. Little is known about the effects of a TPL workshop on CPT on teachers' knowledge gains, pronunciation teaching skills, and student learning. These gaps are addressed in Phase 2 of the current study.

\subsection{Summary of the chapter}

The chapter has reviewed research on key issues in L2 pronunciation teaching and learning including pronunciation goals, approaches to pronunciation teaching, and the practice of pronunciation teaching as represented in textbooks, classroom practices, and teacher cognition. This research is valuable but several gaps deserve mention.

First, studies that have reported on pronunciation teaching practices in intact classrooms have mainly been conducted in ESL contexts. Little research has documented the current status of pronunciation teaching in the EFL context of Asian countries, including Vietnam. Second, no prior research has looked into pronunciation presentation in EFL curricula in Asian countries, thus providing a limited picture of how pronunciation is represented in EFL textbooks used in these educational settings. Third, limited research has investigated L2 learners' perceptions of their own pronunciation needs. Finally, research into TC in pronunciation teaching is rare. So far, limited research has analysed why teachers teach pronunciation the way they do and what factors influence their pronunciation teaching practices. Accordingly, 
there is clearly a need to address these gaps since curriculum analysis and understandings about teachers' classroom practice are likely to reveal important elements of teacher thinking that need to be taken into account in designing a language curriculum. This research is expected to provide important information that assists language practitioners to make informed educational changes in relation to pronunciation teaching and learning. Phase 1 of the current research addresses these research gaps via an investigation into the teaching of English pronunciation in the context of Vietnamese tertiary education. It investigates how pronunciation is represented in the EFL programme of a Vietnamese university, how six EFL teachers teach pronunciation, and teacher thinking underpinning their pedagogical choices. In doing so, it responds to the call for more pronunciation research with a classroom focus (Derwing \& Munro, 2015; Foote et al., 2016). Phase 1 of the study also explores how students perceive their teachers' pronunciation teaching efficacy and their own pronunciation instructional needs, an equally important strand of research that provides insights into learner thinking about pronunciation instruction.

The chapter has also reviewed and discussed research on TPL in pronunciation teaching. It has identified the gaps that further motivate Phase 2 of the current research. First, research into TPL in pronunciation teaching is rare. Given the lack of inquiry into how TPL benefits instructors' pronunciation pedagogy, there is an urgent need to investigate the impact of TPL in pronunciation teaching on L2 teachers' knowledge gains, pronunciation teaching skills, and students' pronunciation learning. Second, many studies have looked into the impact of TPL on teacher learning, classroom practice, and SLOs from teachers' perspectives but have left the students' perspectives unexplored. To address these gaps, Phase 2 of the current research examines the impact of a TPL workshop on CPT on teacher uptake, including the teachers' knowledge gains and pronunciation teaching skills. It also looks into the effects of the CPT model on student learning from both the teachers' and students' viewpoints. It further documents the teachers' and students' stated beliefs about EFL pronunciation instruction at the tertiary level in Vietnam.

The next chapter presents the research design and methodology employed for this research project. The findings of Phase 1 will be reported and discussed in Chapters 4 and 5, and Phase 2 in Chapters 6 and 7. 


\section{Chapter 3}

\section{RESEARCH DESIGN AND METHODOLOGY}

\subsection{Introduction}

This chapter presents the research design and methodology of the study. First, the chapter presents research questions in section 3.2. It then introduces the research paradigm that underpins the study in section 3.3, followed by a description of the research setting and participants in section 3.4. The methods used to collect data for each of the two phases of the study are reported in section 3.5 , followed by section 3.6 which presents data collection procedures. Section 3.7 describes data management and coding. Sections 3.8 and 3.9 present how data were analysed and how the trustworthiness of the study was achieved respectively. The chapter ends with a summary in section 3.10.

\subsection{Research questions}

The overall objective of the current study was to investigate VTE teachers' pronunciation teaching and the beliefs they held in carrying out their classroom practices. It also looked at how students perceived the effectiveness of their teachers' pronunciation instruction. The study involved classroom observations of six teachers teaching six different classes in each of the two phases during which data was collected. Phase 1 was the observational phase that provided baseline data and laid grounds for the intervention phase which involved TPL followed by lesson planning and tracking of subsequent classroom processes. It then investigated the effects of the CPT model on student learning from both teacher and learner perspectives. Phase 2 of the study also examined the teachers' and students' stated beliefs about pronunciation instruction within the VTE context. The study aimed to answer the following research questions (RQs):

Phase 1:

RQ1. How was pronunciation represented in the EFL programme at a Vietnamese university?

RQ2. How did the teachers teach pronunciation in their EFL classes, and what reasons did they give for their teaching decisions? 
RQ3. How did the teachers perceive their pronunciation teaching competence, PL needs, and EFL teacher training in Vietnam regarding pronunciation teaching?

RQ4. What pronunciation instruction did the students report experiencing, and how did they perceive the efficacy of their teachers' pronunciation teaching practices as observed in intact classes?

RQ5. How did the teachers and students perceive Vietnamese EFL learners' pronunciation needs?

\section{Phase 2:}

RQ6. How did the teachers implement CPT in their EFL classes?

RQ7. How did the teachers perceive the impact of the TPL workshop on their knowledge gains and pronunciation teaching skill?

RQ8. What did the teachers think and believe about PL for VTE teachers regarding pronunciation teaching?

RQ9. How did the teachers and students perceive the effects of the CPT model on student learning?

RQ10. What did the teachers and students think and believe about pronunciation instruction at the tertiary level in Vietnam?

\subsection{Research paradigm}

In order to gain an in-depth understanding of the teachers' beliefs that underpinned their decision making in teaching pronunciation within their real-life teaching situations (Berg, 2009; Stake, 2006), I employed a case study approach to examine a contemporary phenomenon within its real-life context (Yin, 2014). Observations of how the teachers take actions in their language classrooms can reveal how congruent their beliefs and actual pronunciation teaching practices are. Since meaning is constructed and shared through social interactions (Burr, 2003; Elder-Vass, 2012), the current study was placed within a constructivist perspective (Charmaz, 2006; Creswell \& Miller, 2000; Patton, 2002). That is, the study portrayed the teachers' articulated beliefs relating to their pronunciation teaching practices through constructions and interpretations of meaning from the teachers' descriptions and explanations of their own teaching contexts (P. A. Brown, 2008; Myers, 1997). 
The study adopted a qualitative multiple case-study research methodology that could yield valued and trustworthy knowledge through descriptions of "how a phenomenon occurs in the circumstances of several exemplars" (Stake, 2005, pp. 458-459). Moreover, this methodology helped assure that the study's validity was constructed through triangulation of multiple data sources and that an in-depth understanding of the phenomenon examined in its real-life contexts was secured (Casey \& Houghton, 2010; Denzin \& Lincoln, 2008; Lauer, 2006). This is critical because triangulation enables researchers to obtain answers to a studied phenomenon from multiple perspectives (Casey \& Murphy, 2009; Patton, 2002). In addition, analysis in a multiple case-study allows for drawing not only within-case but also cross-case conclusions. Each case in the case-specific analysis is treated as a comprehensive unit whereas abstractions across the cases are constructed from the cross-case analysis (Winegardner, 2007).

Despite the convenience in collecting data at the university where I had been teaching for 12 years, I insisted on exercising 'bracketing' (L. Richards \& Morse, 2007; Schostak, 2006; Williams \& Morrow, 2009) in my approach to data collection and later on to data analysis. In other words, I took "the role of researcher as stranger, and thus see the familiar as strange" (Holliday, 2007, p. 68). During my data collection and analysis, I looked for information that answered the questions of 'what', 'how' and 'why' so as to learn from and make sense of the data (L. Richards \& Morse, 2007).

\subsection{Research setting and participants}

This section portrays the research setting where the study was carried out and describes in detail the research participants who took part in the data collection process.

\subsubsection{Research setting}

The study was conducted within a tertiary EFL programme at a public university in Ho Chi Minh city, Vietnam, where I had been working as a full-time lecturer for 12 years prior to taking $\mathrm{PhD}$ study leave. The university ranks among the top tertiary institutions in Vietnam in terms of the entry requirements as well as the rates of students receiving job offers at both domestic companies and multinationals after graduation. There are 15 training faculties at the university, and the English language teaching and learning is administered by the School of Foreign Languages (SFL). This section describes the teachers and students operating in this EFL programme, the curriculum and course books, and assessment. 


\subsubsection{Teachers and students}

At the time of data collection, SFL had classes for English majors and general English classes for students majoring in finance, banking, business administration, accounting, auditing, business law, and international trade, etc. (hereafter referred to as non-English majors used interchangeably with English non-majored students). There were 45 EFL teachers working at SFL, 40 of whom were full-time. The teachers were all considered well-qualified and experienced. All held an MA degree either in TESOL, Applied Linguistics, or Education and had at least five years of teaching experience at the tertiary level.

As the university's statistical records showed, approximately 16,000 full-time students from different parts of Vietnam, from cities to rural areas, aged from 18 to 25 , were enrolled at the university at the time of the study. Of these, about 80 were studying French, 80 were English majors, and the others were non-English majors. All had been exposed to the English language for at least seven years at secondary levels, from Grade 6 to Grade 12. English nonmajored students' (the focus of the current study) proficiency level ranged from elementary to pre-intermediate. The English programme offered General Business English and focused on the four major language skills, namely listening, speaking, reading and writing including grammar and vocabulary as integrated sections.

\subsubsection{Curriculum and course books}

As stated in the curriculum objectives, English as a mandatory subject is supposed to equip the university's non-English majors with sufficient language knowledge and skills to confidently enter the labour market after graduation. The students are expected to build up their English competence and confidence for oral interaction with others, including both native and non-native speakers of English. The programme included 192 forty-five-minute periods portioned equally in four semesters, hereafter referred to as modules $1,2,3$, and 4 (48 periods each). Module 1 was carried out in the second semester of the students' first year and module 2 in the first semester of their second year. After that, students were grouped into different majors and started to work on modules 3 and 4 in semesters 1 and 2 of their third year. Usually, each module was completed within 12 weeks and there was one class meeting every week which lasted for four successive periods with a fifteen-minute break in between. The mid-term test was normally carried out in week 7 of the official teaching schedule. 
Each module covered two sources of materials: the main textbooks - Market Leader Elementary Business English (Cotton, Falvey, \& Kent, 2006) and Pre-intermediate Market Leader (Cotton, Falvey, \& Kent, 2012) - and the supplementary materials (entitled Practice Books 1, 2, 3, and 4) compiled by SFL based on the corresponding themes in the Market Leader series. Eight out of the 12 units in each level of the main textbooks were officially assigned to be carried out during class meetings within the four modules (four units each) and the supplementary materials were respectively implemented in each module. Each Practice Book comprised six units four of which were selected for in-class teaching corresponding to those in the Market Leader textbooks. In general, the eight units in each module were subdivided into four study packages each of which was supposed to be covered within 12 periods. These 12 periods were assigned so that there were two periods each for listening, speaking, reading, writing, vocabulary, and grammar. Table 3.1 outlines a notional teaching schedule for each module based on these instructional materials.

Table 3.1 The theoretically-suggested teaching schedule for one module

\begin{tabular}{|c|c|c|c|}
\hline \multicolumn{2}{|c|}{$\begin{array}{l}\text { Teaching materials and } \\
\text { time distribution }\end{array}$} & $\begin{array}{l}\text { Main textbooks } \\
\text { (Market Leader) }\end{array}$ & $\begin{array}{c}\text { Supplementary materials } \\
\text { (Practice Book) }\end{array}$ \\
\hline \multirow{3}{*}{ Unit 1} & Week 1 & Vocabulary and Grammar & Listening and Speaking \\
\hline & Week 2 & Listening and Speaking & Reading \\
\hline & Week 3 & Reading and Writing & Writing \\
\hline \multirow{4}{*}{ Unit 2} & Week 4 & Vocabulary and Grammar & Listening and Speaking \\
\hline & Week 5 & Listening and Speaking & Reading \\
\hline & Week 6 & Reading and Writing & Writing \\
\hline & Week 7 & Mid-term test & \\
\hline \multirow{3}{*}{ Unit 3} & Week 8 & Vocabulary and Grammar & Listening and Speaking \\
\hline & Week 9 & Listening and Speaking & Reading \\
\hline & Week 10 & Reading and Writing & Writing \\
\hline \multirow{3}{*}{ Unit 4} & Week 11 & Vocabulary and Grammar & Listening and Speaking \\
\hline & Week 12 & Listening and Speaking & Reading \\
\hline & Week 13 & Reading and Writing & Writing \\
\hline
\end{tabular}

In implementing the curriculum, teachers were free to choose either to follow the order of language input in the course books or to begin the unit with any language skill they wanted. 
Moreover, they reserved the right to decide on what needed to be covered in class and what could be assigned for homework and/or self-study. This follows that the teachers might presumably be able to adapt materials from other resources for in-class teaching and learning as long as they stayed on schedule in completing all the prescribed tasks.

\subsubsection{Assessment}

As mentioned above, the English programme for non-English majors at the university was divided into four modules and the students' final result in each module was made up of a mid-term score (30\%) and an end-of-term score (70\%). The mid-term score may be determined through either an oral or a written test depending on each individual teacher's preference. Meanwhile, the end-of-term score arose from a written exam paper generally taken on the same day by all students of the same course. Typically, teachers who preferred to conduct the mid-term test orally asked their students to choose a topic and talk about it for several minutes. The teacher in charge as an examiner scored the students' performance. Yet, no common regulations covered the mid-term test and no criteria for assessing students' performance were specified. The final written exam paper tested the students' knowledge of vocabulary, grammar, reading, listening, and writing. Pronunciation plays no role in either assessment.

\subsubsection{Research participants}

Since this research adopted a case study methodology, convenience sampling was employed to select participants who were available and willing to participate (Creswell, 2005). Prior to data collection, I sought approval from the President of the university by email while I was still in New Zealand. I invited EFL teachers and students of the university to participate in this research project on a voluntary basis after they had been informed of the nature and purpose of my study and signed a consent form.

\subsubsection{Teacher participants}

Recruiting teacher participants was done while I was in New Zealand. I sent an invitation email to all the 40 full-time teachers of SFL including an information sheet which explained to them the purpose and nature of my research. Fifteen of the teachers replied, and seven voluntarily agreed to participate in this research project. Prior to the main study, I came to see the seven teachers in person to have them sign the consent form. However, one teacher took his sick leave before the second phase of the study began, so all the data he provided was 
discarded. The teacher participants, one male and five females, aged from 29 to 52; all had an MA degree in TESOL or Applied Linguistics. As presented in Table 3.2 below, the teachers can be grouped into 'more experienced' (having from 20 to 23 years of teaching experience) and 'less experienced' (having from six to seven years of teaching experience). The teachers have been given the pseudonyms Quynh, Phuong, Nguyen, Diep, Khoa, and Na for the purpose of this thesis.

Table 3.2 Teacher Participant Profiles

\begin{tabular}{|c|c|c|c|c|c|}
\hline $\begin{array}{l}\text { Teacher \& } \\
\text { Gender }\end{array}$ & Age & Highest degree & $\begin{array}{l}\text { Year } \\
\text { granted }\end{array}$ & Highest degree granted by & Experience \\
\hline Quynh (F) & 47 & MA in TESOL & 2000 & $\begin{array}{l}\text { Hanoi University of Foreign } \\
\text { Languages, Vietnam }\end{array}$ & 23 years \\
\hline Phuong (F) & 52 & MA in TESOL & 2001 & $\begin{array}{l}\text { University of Social Sciences } \\
\text { and Humanities, Vietnam }\end{array}$ & 20 years \\
\hline Nguyen (M) & 48 & MA in TESOL & 2001 & $\begin{array}{l}\text { University of Canberra, } \\
\text { Australia }\end{array}$ & 22 years \\
\hline Diep (F) & 29 & $\begin{array}{l}\text { MA in Applied } \\
\text { Linguistics }\end{array}$ & 2011 & Curtin University, Australia & 6 years \\
\hline Khoa (F) & 29 & $\begin{array}{l}\text { MA in Applied } \\
\text { Linguistics }\end{array}$ & 2011 & Curtin University, Australia & 7 years \\
\hline $\mathrm{Na}(\mathrm{F})$ & 29 & $\begin{array}{l}\text { MA in Applied } \\
\text { Linguistics }\end{array}$ & 2011 & Curtin University, Australia & 7 years \\
\hline
\end{tabular}

Note: $\mathrm{M}=$ male; $\mathrm{F}=$ female

\subsubsection{Student participants}

Although the university had classes for English majors and non-majors, this study only involved the latter for two reasons. First, at the time of data collection, there were only two classes of English majors as the first intake of the university who had just completed their first year. They were therefore not the intended participants of the current research. Second, non-English majors are the majority at the university and in wider Vietnam.

In order to recruit student participants for Phase 1, I delivered the information sheets to all the classes and explained to them the nature and purpose of my research in detail. Then I asked for four volunteers from each class and invited them to sign a consent form. On a voluntary 
basis, seven groups (four students each) from the seven classes agreed to participate in the study. However, as mentioned above, one teacher took his sick leave right before the second phase of the study, thus all the data his students provided were discarded as well.

Consequently, only the data provided by the other six groups of student participants were used. Recruiting student participants for Phase 2 was conducted in the same manner. Each student in each focus group was given a numeration as S1 to S4. Table 3.3 describes the student participants' demographic properties in each phase of the study.

Table 3.3 Student Participant Profiles

\begin{tabular}{|c|c|c|c|c|c|c|}
\hline Phase & ID & Gender & Year of study & Place of residence & YoB & ToLE \\
\hline \multirow{6}{*}{1} & FG1 & $2 \mathrm{M}, 2 \mathrm{~F}$ & $1^{\text {st }}$ year: $n=4$ & Ho Chi Minh city: & From & From \\
\hline & FG2 & $3 \mathrm{M}, 1 \mathrm{~F}$ & $2^{\text {nd }}$ year: $n=4$ & $\mathrm{n}=4$ & 1993 & 7 \\
\hline & FG3 & $2 \mathrm{M}, 2 \mathrm{~F}$ & $3^{\text {rd }}$ year: $n=8$ & Other provinces: & to & to \\
\hline & FG4 & $2 \mathrm{M}, 2 \mathrm{~F}$ & $4^{\text {th }}$ year: $n=8$ & $\mathrm{n}=20$ & 1997 & 14 \\
\hline & FG5 & $2 \mathrm{M}, 2 \mathrm{~F}$ & Total: $\mathrm{n}=24$ & & & years \\
\hline & FG6 & $1 \mathrm{M}, 3 \mathrm{~F}$ & & & & \\
\hline \multirow{6}{*}{2} & FG1 & $0 \mathrm{M}, 4 \mathrm{~F}$ & $1^{\text {st }}$ year: $n=20$ & Ho Chi Minh city: & From & From \\
\hline & FG2 & $2 \mathrm{M}, 2 \mathrm{~F}$ & $3^{\text {rd }}$ year: $n=4$ & $\mathrm{n}=3$ & 1994 & 8 \\
\hline & FG3 & $1 \mathrm{M}, 3 \mathrm{~F}$ & Total: $\mathrm{n}=24$ & \multirow{4}{*}{$\begin{array}{l}\text { Other provinces: } \\
\mathrm{n}=21\end{array}$} & to & to \\
\hline & FG4 & $2 \mathrm{M}, 2 \mathrm{~F}$ & & & 1997 & \multirow{3}{*}{$\begin{array}{l}15 \\
\text { years }\end{array}$} \\
\hline & FG5 & $3 \mathrm{M}, 1 \mathrm{~F}$ & & & & \\
\hline & FG6 & $0 \mathrm{M}, 4 \mathrm{~F}$ & & & & \\
\hline
\end{tabular}

Note: $\quad \mathrm{ID}=$ identification $; \mathrm{FG}=$ focus group; $\mathrm{M}=$ male $; \mathrm{F}=$ female $; \mathrm{n}=$ number of students; ToLE $=$ time of learning English; $\mathrm{YoB}=$ year of birth .

As seen from Table 3.3, Phase 1 involved 12 male and 12 female students: four first-year, four second-year, eight third-year and eight fourth-year. Of these, only four student participants were from Ho Chi Minh city, the biggest city in Vietnam, whereas the majority were from rural provinces in the central coast and south of Vietnam. The students' ages ranged from 19 to 23, and they had been studying English from seven to 14 years. In Phase 2, four third-year and 20 second-year students participated in the research; they had received from eight to 15 years of EFL instruction. The students were aged from 19 to 22 and the numbers of male and female participants were eight and 16 respectively. Like Phase 1 , the 
second phase of the study involved 21 student participants from rural provinces and a minority of three from Ho Chi Minh city. By the time the participants took part in the research, the first-year students had finished 48 periods of English lessons, the second-year 96, and the third- and fourth-year students 192 periods.

\subsection{Data collection methods}

This section first provides an overview of data collection methods used for the current study. It then presents in detail how the data for each phase of the study were collected. The section ends with a summary of data collection methods.

\subsubsection{Overview of data collection methods}

In order to obtain answers to the research questions mentioned in section 3.2 above, care was taken to ensure a match between research questions, data sources and data collection methods in research design (L. Richards, 2015). In this study, data were collected through curriculum document analysis, classroom observations, and interviews with teacher and student participants.

\subsubsection{Document analysis}

For the sake of convergence and corroboration in the data, qualitative researchers often use multiple data sources amongst which the use of document analysis serves as a means of triangulation (Bowen, 2009). Furthermore, using document analysis as a method of data collection helps shed light on the phenomenon being examined (Nieuwenhuis, 2016). In this study, a curriculum document analysis was conducted to portray the context in which the participants operated, and later on to verify the study findings. Specifically, the main textbooks, supplementary materials, teacher books and the syllabus of each module of the entire programme were all analysed. This analysis of curriculum documents addressed two main concerns: (1) pronunciation features included in the curriculum and (2) the approach proposed to these features by the curriculum. The analysis provided a detailed account of how pronunciation was represented in the English programme at the university, which laid the foundations for subsequent classroom observations and interviews, and later the intervention carried out in Phase 2 of the study. In Phase 2, the lesson plans designed by the teachers were collected for analysis to check the teachers' understanding of and then translating the professional knowledge they received into practice. 


\subsubsection{Classroom observations}

In order to obtain 'live' accounts from 'live' settings (Cohen, Manion, \& Morrison, 2007), classroom observations were a useful technique for recording what is actually happening in a natural setting (Yin, 2014). In this study, I conducted non-participant classroom observations; i.e. I took on the role of an observer instead of that of a participant (Marshall \& Rossman, 2011). I observed each teacher's teaching while their classes were video-taped. The videoed lessons in Phase 1 provided a reliable and practical context for me to derive the teachers' rationales for their pronunciation teaching practices in stimulated recall (SR) interviews. This is critical because the teachers might unavoidably re-construct their descriptions of the observed lessons if they exclusively relied on memory (Breen, Hird, Milton, Oliver, \& Thwaite, 2001). In addition, these video-recordings, together with field notes and instructional materials such as handouts and PowerPoint slides, were used as stimuli in subsequent SR interviews. In Phase 2, video-recordings of the experimental classes were archived for analysis and later multiple reviews where necessary.

\subsubsection{Interviews}

Interviewing was employed as the main method of data collection in both phases of the study given that interviews reflect the conversational and dialogical nature of understanding and promote insights into participants' lived experience and the meaning conceived by that experience (Seidman, 2013). According to Gass and Mackey (2000) and Creswell (2009), interviewing enables researchers to investigate phenomena that are not directly observable. Furthermore, interviewing allows researchers to obtain an in-depth understanding of the interviewees' thoughts and beliefs (Yin, 2014). All the interviews were conducted in Vietnamese for the sake of ease and comfort for the teachers and students as well as to maximise understandings between the researcher and the participants. They were audio recorded with a Sony digital voice recorder.

A potential weakness of interviewing is that interviewees might articulate post-hoc rationales that are not true to their own circumstances (Borg, 2006). To address this concern, I employed 'member-checking' as a means to ensure the credibility of the interview data (Houghton, Casey, Shaw, \& Murphy, 2013; Stake, 2006). In other words, I transcribed each teacher's interview in full and sent it back to them. Here, I asked the teachers to read the transcription of their own interviews to confirm, clarify and elaborate on what they had said 
before. This session allowed the teachers to go deeper into issues that emerged in the earlier interviews.

Semi-structured interviews, a frequently-used format in cognition research (Borg, 2012), were used with both teacher and student participants. This format "offers sufficient flexibility to approach different respondents differently while still covering the same areas of data collection" (Noor, 2008, p. 1603) and "facilitates a strong element of discovery" (Gillham, 2005, p. 72). Additionally, semi-structured interviewing allows the interviewer to reorder and/or reword the questions, to answer participants' questions, or to offer clarifications where necessary (Berg, 2009).

The format of focus group (FG) interviews was used with student participants in both phases of the study. This approach creates relaxation among the interviewees and thus they were able to feel more comfortable speaking their mind within a group (King \& Horrocks, 2010). Furthermore, the FG interview format, according to Marshall and Rossman (2011), yields opportunities for expansion and/or clarification and enables the researcher to utilize "the collective experience of group brainstorming" (Dörnyei, 2007, p. 144).

\subsubsection{Data collection for phase 1}

Following Ellis (2012), I have decided to entitle Phase 1 'descriptive research' given that it portrayed the teachers' pronunciation teaching practices in intact classes, the factors shaping their classroom actions, and the implications for language teaching and learning. As Ellis (2012, p. 42) has argued, descriptive research such as this provides rich stories from a specific teaching and learning setting from the insider's (i.e. the participant's) perspective. It involves no intervention but explores the studied phenomenon as it is. Ellis claims that this approach strengthens the trustworthiness of the data as well.

Phase 1 investigated the teachers' pronunciation teaching practices and the factors that shaped these. It then looked at how the students perceived their teachers' pronunciation instruction. The Phase 1 study also examined Vietnamese EFL learners' pronunciation needs from both the teachers' and students' perspectives. Data were obtained from three sources: (1) curriculum document analysis; (2) classroom observations (which were audio-video recorded accompanied by field notes and instructional materials); and (3) SR and in-depth interviews with the teachers and FG interviews with the students. 


\subsubsection{Curriculum document analysis}

In order to obtain an in-depth understanding of how pronunciation was represented in the English programme of the university, the analysis of curriculum documents addressed two main questions:

(1) What pronunciation features were included in the curriculum? And

(2) How did the curriculum propose that these features be taught?

I analysed all 16 units in a two-level textbook series, i.e. Market Leader Elementary and Preintermediate, officially assigned for teaching within this four-module programme. Sixteen respective lessons from the supplementary materials - the Practice Book series - were also analysed. Typically, each unit in the Market Leader series comprises seven sections: (1) Starting up (expressions and discussion), (2) Vocabulary, (3) Reading, (4) Listening, (5) Language review (grammar), (6) Skills (listening and speaking), and (7) Case study (discussion and writing). The Practice Book series were designed with a focus on the four language skills: Listening, Speaking, Reading and Writing. In addition, I analysed the 16 corresponding units in the teacher guides of the Market Leader series and the syllabus of each module. This analysis provided information about pronunciation representation in the programme which laid grounds for subsequent classroom observations and interviews. For example, classroom observations would focus on whether the teachers taught pronunciation, if prescribed in the syllabus, and how they went about teaching it in their class, etc.

\subsubsection{Classroom observations}

Observations in this first phase were carried out in intact classrooms and were supplemented by audio-video recordings, field notes and instructional materials. The precise focus (i.e. pronunciation teaching) was not specified so as to ensure that the teachers would not teach towards the data. I observed each teacher teaching one unit including two consecutive 45minute periods using one of the textbooks and took field notes while their classes were videotaped with a Sony HDR-PJ670. The classroom observation scheme is presented in Table 3.4. As Table 3.4 shows, a total of six classroom observations (90-100 minutes each) were made in Phase 1 of the study, producing a total of around 9-10 hours of observation data. Of these, four of the teachers taught Module 2 and two Module 3. Five teachers used the Market Leader series and one used Practice Book 2. One week after each classroom observation, each of the teachers were invited for individual SR and in-depth interviews. 
Table $3.4 \quad$ Phase 1 classroom observation scheme

\begin{tabular}{lcll}
\hline Teacher & Module & Textbook used & Lesson (90-100 minutes each) \\
\hline Quynh & 2 & Market Leader (Elementary) & Unit 8: Markets \\
\hline Phuong & 3 & Market Leader (Pre-intermediate) & Unit 1: Careers \\
\hline Nguyen & 2 & Market Leader (Elementary) & Unit 9: Companies \\
\hline Diep & 3 & Market Leader (Pre-intermediate) & Unit 1: Careers \\
\hline Khoa & 2 & Practice Book 2 & Unit 8: Markets \\
\hline $\mathrm{Na}$ & 2 & Market Leader (Elementary) & Unit 9: Companies \\
\hline
\end{tabular}

\subsubsection{Teacher $S R$ and in-depth interviews}

The SR interview procedures with the teachers were adapted from Borg's (1998) procedures. Prior to the interviews, I analysed the observational data of each teacher's lesson for key instructional categories - classroom events that generated questions about the rationales for the teachers' approach to pronunciation teaching and the factors shaping their classroom activities. For example, the use of a particular pronunciation teaching activity, explanation of a phonological feature, or a reaction to a student's pronunciation error were all considered as key categories as they prompted amendments of the prepared-in-advance questions through which I could gain insights into the factors behind the teachers' classroom actions.

The purpose of SR interviews was for the teachers to recall and explain. The priority was to seek the teachers' descriptions and interpretations of their own classroom actions rather than relying on the researcher's observation and interpretation (Borg, 1998). Thus, the investigation of this first phase entirely relied on how the teachers described what they did in particular lessons and explained why they did what. During the interview, the researcher mentioned the points he had noted during observations to seek the teachers' interpretations of what had happened and asked for their commentary and elucidation. Teacher SR interviews were carried out individually; each lasted in about 30 minutes and was audio recorded. Prior to the interview, each of the teachers watched two selected excerpts of their own videoed lesson in which pronunciation was a focus to recall what they were thinking at the time, including the reasons for the pedagogic choices they made in the selected excerpts (see 3.8 for how the study data were analysed). Given that teachers Khoa and $\mathrm{Na}$ used an additional pronunciation teaching technique different from other teachers, they were shown a third excerpt of their recorded lesson. After the teachers finished watching their lesson excerpts, I 
asked them: (1) if they used any other techniques to teach pronunciation in class, (2) if it was their most frequent approach to pronunciation teaching, and (3) what was the pronunciation goal they wanted their students to attain. Then, I prompted the teachers to comment on and explain their pronunciation teaching practices by asking several questions pertaining to why certain pedagogic choices were made. This encouraged the teachers to articulate and elaborate on the rationales for their classroom actions.

In the in-depth interview section, the questions the teachers were asked discussed the frequency of their teaching pronunciation explicitly, the teaching procedures they followed, the total time they used for each teaching session, and the resources from which their teaching activities came. Moreover, the teacher participants were encouraged to elaborate on their own pronunciation teaching competence (PTC), PL needs, and EFL teacher training in Vietnam regarding pronunciation teaching. Finally, the teachers were asked to discuss Vietnamese EFL learners' pronunciation needs. The interviews were then transcribed in full and sent back to the teachers for confirmation, clarification, and/or modification.

Cohen et al. (2007) have argued that interview data might not be valid due largely to the interviewer's seeking support for the concepts perceived beforehand, an issue closely related to confirmation bias. However, during each interview session, I listened to the teachers and avoided making judgemental or evaluative comments on what each teacher said. Instead, I responded neutrally to the teachers' answers using expressions like 'I see', 'uh-huh', or 'okay'. I also encouraged the teachers to elaborate on their answers by asking 'Could you clarify that, please?', 'You mean...?', 'Why's that?', 'What does it mean?' or 'What else?', etc. This way, I gave the teachers an opportunity to reflect and provide further input (Mackey \& Gass, 2016) and thus they were able to provide meaning that was true to themselves in their own contexts.

\subsubsection{Student FG interviews}

To set a baseline for Phase 2, I conducted FG interviews with the student participants. Each interview lasted for approximately 25 minutes and was audio recorded. The FG interviews of Phase 1 sought to obtain the learners' collective views and a snapshot of their experience and beliefs regarding their teachers' pronunciation teaching. the students' perceptions about the importance of pronunciation in EFL learning and their pronunciation instructional needs were also investigated. Through an in-depth, semi-structured interview, the students were encouraged to freely discuss the meaning of what they thought and believed about the 
teaching and learning of pronunciation in general and the actual practices they had so far experienced in particular. During the interviews, I sought to identify individual perspectives and so took the role of a moderator who facilitated discussions amongst the students within a group while minimising my own input (Bryman, 2008).

\subsubsection{Data collection for phase 2}

The second phase of the study involved TPL as a means to enhance the teachers' pronunciation teaching. It then tracked the understandings and classroom implementation of the teacher participants subsequent to the workshop. After the experimental teaching, the effects of the CPT model on student learning were investigated from both teaching and learning perspectives. The teachers' and students' stated beliefs about pronunciation instruction at the tertiary level in Vietnam were also examined.

The design of the intervention phase emerged from the triangulation of all the data collected in Phase 1 and from the principles for good practice derived from the literature review, specifically from Celce-Murcia et al. (2010). The targeted pronunciation features for the intervention were established by drawing on the data from Phase 1, especially from the outcomes of the interviews with both teachers and students, and those documented in the literature. Phase 2 began with a TPL workshop on CPT, followed by lesson planning and teaching in the following semester. For the tracking of subsequent classroom processes, nonparticipant observations and audio-video recordings were obtained. To examine the impact of the workshop on the teachers' knowledge gains, pronunciation teaching skills, and the effects of CPT on student learning, I invited the teachers for individual in-depth interviews and four students from each class for FG interviews after all the experimental classes were finished.

\subsubsection{Teacher professional learning and lesson planning}

The teachers were invited to attend a three-hour workshop held in the language laboratory of the university. During this session, I shared with the teachers the preliminary findings of Phase 1, from both classroom observations and interviews. They then explored Celce-Murcia et al.'s (2010) communicative framework for teaching English pronunciation (hereafter referred to as the framework) through my demonstration of a sample pronunciation lesson that involved different types of pronunciation activities (see Appendix 9.1 in the CD attached). The framework is presented in Table 2.1 in section 2.3.3 of the previous chapter. The idea of this TPL workshop was inspired from Timperley et al. (2008), who argue that 
when teachers take more responsibility and realize a positive impact of their new professional knowledge and practice on learners, they will feel more effective as teachers and that "heightened responsibility is developed most effectively when teachers observe that their new teaching practices are having positive impacts on their students" (p.9).

Following the exploration and discussion of the framework, the teachers were given a set of pronunciation features and associated materials to use in their experimental classes: one by Celce-Murcia et al. (2010) and another by Lane (2013). The teachers used these textbooks as resource materials and reserved the right to flexibly choose and/or adapt teaching activities for each experimental teaching session as long as they fit in the framework. In order to gauge the teachers' comprehension of how the framework works in practice, I put them in pairs when the workshop resumed after a tea break to plan a pronunciation lesson they intended to teach. Two teachers worked together to plan a 45-minute lesson in which pronunciation tasks/activities were developed applying the framework. They then shared and clarified their own lesson plans and we discussed them as a whole group. After the workshop, we discussed the portion of lesson planning each teacher would be in charge of during the semester break.

In order to minimise the teachers' burden in lesson planning, we discussed and finalised that each of the teachers would be in charge of planning one 45-minute CPT lesson and decisions on proportions with lesson planning were made. As mentioned above, one teacher took his sick leave prior to the semester break, the lesson plan he was in charge of was taken over voluntarily by one of the other six teachers. The lesson planning scheme is presented in Table 3.5 below.

Table 3.5 Experimental lesson planning scheme

\begin{tabular}{lcl}
\hline Teacher & Number of lesson plans & Focus of instruction \\
\hline Quynh & 1 & vowels /i:/ and /I/ \\
\hline Phuong & 1 & vowels /u:/ and / $/ \mathrm{J}$ \\
\hline Nguyen & 1 & consonants $/ \mathrm{J} /$ and $/ 3 /$ \\
\hline Diep & 2 & sentence stress; intonation \\
\hline Khoa & 1 & consonants $/ \mathrm{t} /$ and $/ \mathrm{d} 3 /$ \\
\hline $\mathrm{Na}$ & 1 & final sounds and linking
\end{tabular}


During the semester break, the teachers planned and then shared their experimental lessons with each other by email. One week before the new semester commenced, all the teacher participants and I had a meeting during which they took turns to clarify their own lesson plans. We then as a whole group discussed each lesson plan and no major changes were recorded. After the teachers took turns to clarify their own lesson plan(s), we discussed and agreed that the teachers would teach two lessons in two consecutive 45-minute periods on the same day, except the one that focused on final sounds and linking since it was planned as a single 45-minute lesson. Also, it was our consensus that the even weeks in the teachers' official teaching schedule (i.e. weeks $2,4,6$, and 8) were the dates on which the CPT lessons would be implemented.

\subsubsection{CPT implementation}

In the following semester, each teacher participant implemented the seven CPT lessons in one of their scheduled classes every two weeks as agreed and each session lasted for about 90 minutes. I observed their teaching and took field notes while audio-video recordings of these experimental classes were simultaneously made for the sake of later analysis and multiple reviews where necessary. In total, I made 24 classroom observations (four observations per teacher), leading to a total of about 35 hours of observation data. Table 3.6 outlines the classroom observation scheme for Phase 2 of the study.

Table 3.6 Phase 2 classroom observation scheme

\begin{tabular}{|c|c|}
\hline Week & Experimental teaching focus \\
\hline 1 & Classes were normally conducted as scheduled by SFL \\
\hline 2 & Lessons: vowels /i:/ vs. /I/ and /u:/ vs. /ひ/ \\
\hline 3 & Review meeting 1 (classes were normally conducted as scheduled by SFL) \\
\hline 4 & Lessons: sentence stress and intonation \\
\hline 5 & Review meeting 2 (classes were normally conducted as scheduled by $S F L$ ) \\
\hline 6 & Lessons: consonants /// vs. /z/ and /t $/ /$ vs. $/ \mathrm{d} z /$ \\
\hline 7 & Review meeting 3 (classes were normally conducted as scheduled by $S F L$ ) \\
\hline 8 & Lesson: final sounds and linking (classes were normally conducted as scheduled by SFL) \\
\hline 9 & Review meeting $4+$ follow-up interviews \\
\hline 10-12 & Classes were normally conducted as scheduled by SFL \\
\hline
\end{tabular}


In order to keep track of the intervention implementation, the week after each teaching session (weeks 3, 5, 7 and 9 in the teachers' official teaching schedule as shown in Table 3.6), all the teachers and I had an informal catch-up to review the lessons they had implemented. During these review meetings, we discussed any problems they had had with their teaching to make sure they were all on the right track. The CPT lesson implementation ended in week 8, and I invited the teachers for individual follow-up interviews and students for FG interviews in week 9.

\subsubsection{Follow-up interviews}

Each of the teachers' individual follow-up interviews lasted for about 30 minutes and was audio recorded. This in-depth, semi-structured interview for each of the teachers aimed to investigate their thoughts and beliefs about the impact of the TPL workshop on their knowledge gains and pronunciation teaching skills. The teachers' perceptions of the effects of the CPT model on student learning were also examined. Finally, the teachers were asked to discuss pronunciation instruction at the tertiary level in Vietnam. The interviews were then transcribed in full and sent back to the teachers for confirmation, clarification and/or modification.

According to Heary and Hennessy (2002) and Wong (2008), the ideal size for FG interviews falls between four to six participants per group since it is considered sufficiently large enough for the interviewer to facilitate discussion. In smaller groups, "discussion will resemble parallel interviews as opposed to a dynamic group interaction" (Heary \& Hennessy, 2002, p. 51) whereas larger groups may restrict the participants' opportunities and time in sharing their views (Halcomb, Gholizadeh, DiGiacomo, Phillips, \& Davidson, 2007; Wong, 2008). Thus, I sought to involve four students from each class on a voluntary basis for FG interviews one week after the CPT lesson implementation ended. Focus group interviews with the Phase 2 students sought to obtain their thoughts and beliefs about the CPT lessons they had experienced during the semester. They were also asked to talk about pronunciation instruction at the tertiary level in Vietnam. The interviews with learner groups lasted in about 25 minutes each and were audio recorded.

\subsubsection{Summary of data collection methods}

Apart from curriculum document and lesson plan analysis, the data collection methods used in the current study are summarised in Table 3.7 below. 
Table $3.7 \quad$ Summary of data collection methods

\begin{tabular}{|c|c|c|c|c|}
\hline Phase & Methods & Participants & Time per session & Number of sessions \\
\hline \multirow{4}{*}{1} & Classroom observations & 6 teachers & 90-100 minutes & 6 sessions, 1 per \\
\hline & & (6 classes) & & teacher per class \\
\hline & SR and in-depth interviews & 6 teachers & 30 minutes & 6 audio recordings \\
\hline & FG interviews & $\begin{array}{l}24 \text { students } \\
\text { (groups of } 4 \text { ) }\end{array}$ & 25 minutes & 6 audio recordings \\
\hline \multirow{4}{*}{2} & Classroom observations & 6 teachers & about 90 minutes & 24 sessions, 4 per \\
\hline & & (6 classes) & & teacher per class \\
\hline & In-depth interviews & 6 teachers & 30 minutes & 6 audio recordings \\
\hline & FG interviews & $\begin{array}{l}24 \text { students } \\
\text { (groups of } 4 \text { ) }\end{array}$ & 25 minutes & 6 audio recordings \\
\hline
\end{tabular}

\subsection{Data collection procedures}

This section outlines the procedural steps the researcher took during the data collection period, starting from ethical considerations to piloting and finally to main data collection.

\subsubsection{Ethical considerations}

This study involved teacher and student participants; thus, approval from the Human Ethics Committee (HEC), Victoria University of Wellington (VUW) was needed. Ethics approval was obtained on April $22^{\text {nd }} 2016$ and data were collected within a period of six months, from June $6^{\text {th }}$ to November $28^{\text {th }}, 2016$. Before I commenced my data collection, I notified in detail all the people involved including the President of the university, the teachers, and students of the nature and purpose of my research through verbal explanations and a written information sheet. They all then signed a consent form. During the talks with the teachers and students, I always emphasised that data was collected for research purpose only. I also told the participants that their confidentiality and anonymity would always be preserved through pseudonyms during data encoding and analysis and that they reserved the right to withdraw from my research whenever they wanted but no later than the interviews got started. I had never been in any position of power in relation to the teacher participants and they treated me as a normal colleague, who was then doing research and needed their support. For more 
information about ethics approval, information sheets, and consent forms, see Appendices 56 in the $\mathrm{CD}$ attached.

\subsubsection{Piloting}

Piloting of research instruments was conducted at both VUW and the university in Vietnam where data were collected. Piloting instruments with participants whose characteristics are similar to the intended participants for the main study enables the researcher to assess the feasibility and/or acceptability of the observation and interview protocols (Kim, 2011). This allowed me to revise the instruments so as to ensure they would work in practice. The piloting procedures and revisions are detailed below.

The research instruments were first piloted in New Zealand before data collection. Classroom observations were conducted in four classes of the English Proficiency Programme at the School of Linguistics and Applied Language Studies (LALS). From these four observations, I found that the teachers usually raised the students' awareness of their pronunciation errors and had them correct those errors through repetition. If many students in the class seemed to make the same error, then the teachers gave model pronunciations and had the whole class repeat.

The interview process was trialled in New Zealand with one Vietnamese and one Thai tertiary EFL teacher; they were both PhD candidates at LALS. From these piloted interviews, I learned that I needed to create subtopics in interviews with teacher participants and the interview questions should be grouped as guiding questions for each subtopic. This way, I could guide each teacher to answer the questions in more detail and so would gain a more insightful interview. As such, I made changes to the interview question set and a new version was created. When I was back to Vietnam, I piloted this new version again with another VTE teacher prior to the main study and this new version of the interview question set worked more efficiently.

Next, I piloted the interview questions with a small group of tertiary EFL learners in Vietnam. The piloting with students helped me gain an idea of what to ask and how to ask questions in as natural a manner as possible. The students were encouraged to comfortably engage in discussions and were able to speak their mind freely. From this piloting, only a minor change, i.e. the order of the questions in the set, was made: question 1 in the old set was asked later in the amended version. 
I trialled the model pronunciation lesson with a different teacher (not a participant in the main study) teaching a different class. Before he started, I had a briefing with him about the purpose of the piloting. First, I gave him a hard copy of the communicative framework and the model pronunciation lesson plan, i.e. the one I prepared for demonstrations during the TPL workshop. Then, I explained the framework carefully to him and we had a discussion about the lesson plan. Finally, I gave him the necessary materials for the experimental class which he carried out the following week. On the day of the piloting, I observed the procedures he followed in teaching the pronunciation lesson and took unstructured field notes. This piloted observation showed that the lesson ran well and the students were actively involved in most classroom activities. The only problem was that the period of 45 minutes was not long enough for all the prepared activities to be carried out. To this end, during demonstrations at the TPL workshop, I frequently told the teacher participants that they reserved the right to flexibly choose and/or adapt activities available in the materials or design their own activities as long as they fit within the timeframe of their classes.

Finally, the Phase 2 interview process was trialled with this teacher and four students from his class. As a result of this piloting, the numbers of the questions in the set were reordered; i.e. items 3 and 4 in the student interview question set. For more details about the questions asked during the interviews in each phase of the study, see Appendices $1-4$.

\subsubsection{Main data collection}

The main data collection began on June $6^{\text {th }}, 2016$ and ended on November $28^{\text {th }}, 2016$. Due to the teachers' concurrent teaching time in the summer term, I observed three teachers (one teaching module 2 and the others teaching module 3 ) in the second week of their teaching schedule. In the following week, classroom observations of Phase 1 were completed with the other three teachers who were all teaching module 2. One week after the observations, interviews with the teachers and student groups were conducted. In Phase 2, classroom observations were made in the even weeks of the autumn term as presented above and interview sessions were carried out one week after the observations had been done.

\subsubsection{Summary of data collection procedures}

The procedures for data collection are summarised in Figure 3.1 below. 
Figure $3.1 \quad$ Summary of data collection procedure

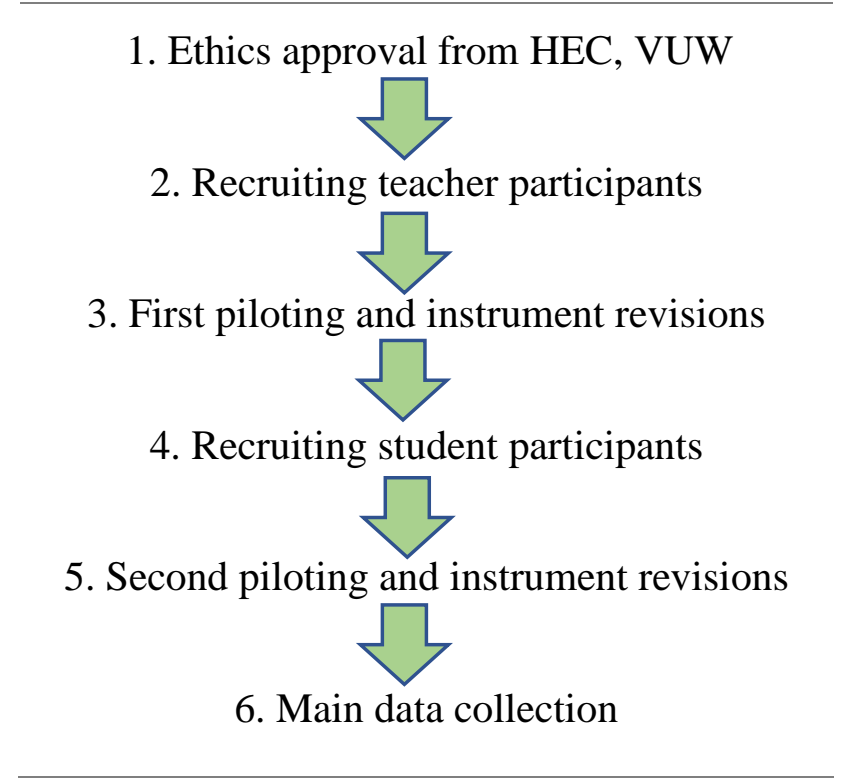

\subsection{Data management and labelling}

All the data collected from the teachers and students in forms of interviews and classroom observations were recorded. With the interview question sets for each of the two phases of the study, the researcher filed their hard copies in two different paper folders while digital audio and video files were organized into electronic folders. All the consent forms signed by the teacher and student participants were stored in a separate hard copy folder. The research participants' confidentiality was carefully managed through pseudonyms and only the researcher and his primary supervisor had access to all the files.

\subsubsection{Labelling classroom observations}

Thirty classroom observations (six in Phase 1 and 24 in Phase 2) were conducted.

Pseudonyms were used for the six teacher participants; they were identified as Quynh, Phuong, Nguyen, Diep, Khoa, and Na. The observations were coded according to the phase when the observation was made, the order the observation was recorded in the particular class where it was conducted, and the name of the teacher carrying out the lesson. An example of the coding is "P2, Observation 1, Quynh". The information quoted came from classroom observation numbered one in the second phase of the study, conducted by Teacher Quynh. 


\subsubsection{Labelling interview data}

The interviews were audio recorded and then transcribed in full. Numbers were assigned to the student participants during data transcription; the four students in each group were named S1 to S4. The teacher interviews were coded according to the name of the phase in which the interview was carried out, the number of the questions which were listed in the interview, and the teacher's name. A sample code is "P1, Teacher SRI, Q2, Na". In other words, the information quoted came from the SR interview conducted in Phase 1 with Teacher Na who responded to question 2. Another sample code for teacher interviews in Phase 2 is " $P 2$, Teacher InI, Q1, Khoa”. The information quoted came from the in-depth interview with Teacher Khoa in Phase 2, who answered question 1 in the interview question list. Interview data with the student participants were coded in a similar way. A sample code for student focus group interviews is "P1, FGI1, Q4, S3". This was the interview with FG1 in Phase 1 of the study. The person who answered thee interview was student number 3 responding to question 4 in the interview.

\subsection{Data analysis methods}

I adopted a qualitative content analysis approach which involves an iterative, cyclical and inductive process (Duff, 2008) for this study. In other words, the data were inductively analysed through an iterative process of examining and re-examining the multiple data sources. Themes and categories were then derived from each teacher/focus group profile and all the teacher/focus group profiles, and these themes and categories were compared and contrasted amongst the teachers/focus groups. The analysis concerning each type of data is detailed below.

\subsubsection{Analysing curriculum documents}

Analysis of curriculum documents provided information about which pronunciation features were represented in the main textbooks and supplementary materials and which approach to pronunciation teaching was taken (the findings are reported in section 4.2 of the following chapter). To guide the analysis, I adapted a set of ten research-based principles in pronunciation teaching (Table 3.8). These principles were identified and synthesised by Beven (2012, pp. 7-10). According to Beven, the 'what' factors prioritise the linguistic features in pronunciation teaching and learning while the development of an EFL programme 
is guided by the 'how' factors. However, since no pronunciation instruction was mentioned in the teaching materials for the classroom, these principles were redundant.

Table 3.8 Research-based principles in pronunciation teaching

\begin{tabular}{|c|c|}
\hline Factors & Principles \\
\hline \multirow{2}{*}{$\begin{array}{l}\text { The what - } \\
\text { linguistic } \\
\text { factors }\end{array}$} & 1. Both segmental and suprasegmental features should be included. \\
\hline & $\begin{array}{l}\text { 2. Priority should be given to pronunciation features that improve intelligibility } \\
\text { rather than nativeness. }\end{array}$ \\
\hline \multirow{8}{*}{$\begin{array}{l}\text { The how - } \\
\text { pedagogic } \\
\text { factors }\end{array}$} & 3. L2 input, output and opportunities for interaction should be incorporated. \\
\hline & $\begin{array}{l}\text { 4. Learner awareness of pronunciation features should be raised for production } \\
\text { improvement. }\end{array}$ \\
\hline & $\begin{array}{l}\text { 5. Both native speaker and non-native speaker input should be included, and } \\
\text { learner awareness of English as an International Language should be raised. }\end{array}$ \\
\hline & $\begin{array}{l}\text { 6. Form-focused explicit learning should be used to support meaning-focused } \\
\text { implicit learning. }\end{array}$ \\
\hline & $\begin{array}{l}\text { 7. The learnability of pronunciation features should be taken into account and } \\
\text { personalized for the learners. }\end{array}$ \\
\hline & $\begin{array}{l}\text { 8. Other language aspects such as vocabulary should be integrated with } \\
\text { pronunciation. }\end{array}$ \\
\hline & $\begin{array}{l}\text { 9. Raise learner awareness of physical factors such as movement of vocal tract } \\
\text { or relaxation techniques. }\end{array}$ \\
\hline & $\begin{array}{l}\text { 10. Raise learner awareness of sociocultural, psychological, and other affective } \\
\text { factors such as learner identity and social context. }\end{array}$ \\
\hline
\end{tabular}

\subsubsection{Analysing classroom observations}

Because the Phase 1 study aimed to investigate the teachers' pronunciation teaching practices, analysis of classroom observations of Phase 1 focused on parts of the lessons that involved pronunciation instruction. This analysis involved describing exactly what each individual teacher did in their classes regarding pronunciation teaching by visiting and revisiting the multiple data sources and noted the frequency of certain practices to find patterns for each teacher and for all the teachers. Specifically, the analysis focused on key teaching categories such as the teachers' use of a particular pronunciation teaching activity, explanation of a phonological feature, or a reaction to a student's pronunciation error. 
For the purpose of coding the teachers' pronunciation teaching episodes, I adopted the fourcategory scheme in previous study by Foote et al. (2016) to identify and code parts of each lesson where pronunciation instruction was present. These included: (1) Planning: preplanned versus reactive; (2) Target: segmental versus suprasegmental; (3) Specific form (sound contrast); and (4) Impact: involving individual students versus the whole class. However, examining and re-examining the Phase 1 classroom observations, I found that the main approach to pronunciation teaching across all the six teachers was giving $\mathrm{CF}$ in response to individual students' pronunciation errors. Accordingly, based on previous classroom-based research by Saito (2011), all instances of the teachers giving CF to students' pronunciation errors were further coded as recasts, prompts, or transcribing words followed by repetition as defined in Table 3.9 below.

Table 3.9 Coding teachers' pronunciation teaching episodes

\begin{tabular}{|c|c|}
\hline Classroom action & Description \\
\hline 1. Recasting & Teachers gave model pronunciation and asked students to listen and repeat \\
\hline 2. Prompting & Teachers raised students' awareness of errors and encouraged self-correction \\
\hline $\begin{array}{l}\text { 3. Transcribing } \\
\text { words + repetition }\end{array}$ & $\begin{array}{l}\text { Teachers provided transcriptions of the words that students pronounced } \\
\text { incorrectly and asked them to listen and repeat }\end{array}$ \\
\hline
\end{tabular}

Apart from coding the teachers' pronunciation teaching episodes, I also calculated the time they spent on each pronunciation teaching episode. This time calculation was counted to a second, from the moment the teachers started addressing pronunciation to the point they finished the episode. After that, I totalled the time the teachers spent teaching pronunciation in each stage of their lesson (presentation, practice, and production), and then added them up to see how much time each teacher spent on pronunciation teaching over a period of 90-100 minutes. Another Vietnamese EFL teacher was trained to code a sample of pronunciation teaching episodes from one of the lessons which was randomly selected by him. A comparison of coding by the two coders showed an agreement percentage of over $98 \%$. Observed practices were afterwards reflected on and explained by the teachers in SR interviews. Here, teacher cognitions were interpreted to explore how the teachers' beliefs related to their teaching practices with reference to the stated principles of pronunciation teaching. 


\subsubsection{Analysing CPT lesson plans}

Analysis of the seven CPT lesson plans designed by the teachers in Phase 2 was carried out in reference to the principles outlined in the communicative framework. Upon reading and rereading the lesson plans, I summarised the contents of each lesson plan by devising a table with three columns. Column 1 was for the five stages of the lesson (from description and analysis to communicative practice) accompanied by the aims and objectives of each stage; column 2 was for the activities each individual teacher designed, and column 3 for evaluative comments. The aim of column 3 was for me and another trained evaluator to decide on the adherence of the activities designed in each practice stage of the framework (from listening discrimination to communicative practice). Depending on the nature of each activity, the evaluative comment in column 3 was noted as 'strongly adherent', 'adherent', 'somewhat adherent', or 'not adherent at all'. This way, I was able to see if the activities the teachers designed adhered to the aims and objectives stated in each stage of the framework. This provided insights into the teachers' understanding and translating what they learned from the TPL workshop into practice.

The Vietnamese EFL teacher who helped me with piloting the model pronunciation lesson was trained to evaluate the teachers' experimental lesson plans. Specifically, I showed him a hard copy of the five stages of the communicative framework and re-explained to him the aims and objectives of each stage. During my briefing with him, I related each practice stage (from listening discrimination to communicative practice) to the activities in the model lesson he used in the piloting. After that, I gave him the table I devised and hard copies of the seven lesson plans. A comparison of evaluation by the two evaluators showed an agreement percentage of about $95 \%$. All the disagreements were resolved through a follow-up discussion between the two evaluators, and the final agreement rate was over $98 \%$. Table 3.10 shows an example of how the lesson plan on sentence stress was evaluated.

Table 3.10 Example of lesson plan analysis

\begin{tabular}{lll}
\hline Lesson stages and objectives & Activities & Evaluative comments \\
\hline Description and analysis & 1. Present sentence stress rules & Strongly adherent \\
$\begin{array}{l}\text { Presents and explains the feature production } \\
\text { with oral and written illustrations }\end{array}$ & 2. Explain rules and give oral & Strongly adherent \\
\hline Listening discrimination & illustrations & \\
\hline & 1. Listening: stressed words & Strongly adherent
\end{tabular}




\begin{tabular}{|c|c|c|}
\hline $\begin{array}{l}\text { Helps learners correctly discriminate the } \\
\text { feature via focused listening practice }\end{array}$ & $\begin{array}{l}\text { 2. Questions and responses: } \\
\text { matching and practice }\end{array}$ & Strongly adherent \\
\hline $\begin{array}{l}\text { Controlled practice } \\
\text { Raises learner consciousness via oral } \\
\text { reading of minimal-pair sentences, short } \\
\text { dialogues, etc. }\end{array}$ & $\begin{array}{l}\text { 1. Listening: stressed words in } \\
\text { a conversation } \\
\text { 2. Conversation practice }\end{array}$ & Somewhat adherent \\
\hline $\begin{array}{l}\text { Guided practice } \\
\text { Learners monitor for the feature via } \\
\text { structured communication exercises, such as } \\
\text { information-gap activities or cued dialogues }\end{array}$ & $\begin{array}{l}\text { 1. Game: Correction } \\
\text { 2. Follow-up game: factual } \\
\text { statements }\end{array}$ & $\begin{array}{l}\text { Adherent } \\
\text { Strongly adherent }\end{array}$ \\
\hline $\begin{array}{l}\text { Communicative practice } \\
\text { Learners attend to both form and meaning } \\
\text { through fluency-building activities such as } \\
\text { role play or problem solving }\end{array}$ & $\begin{array}{l}\text { 1. Conversation discussion } \\
\text { 2. Speaking: Neighbours }\end{array}$ & $\begin{array}{l}\text { Adherent } \\
\text { Strongly adherent }\end{array}$ \\
\hline
\end{tabular}

\subsubsection{Analysing interview data}

Analysis of the interview data was implemented applying an iterative process as well. In order to make sense of the interview data, I inductively looked for themes and categories in each of the interviews (L. Richards, 2015; L. Richards \& Morse, 2007). This was a process of sifting, combing or searching through the following five steps recommended by Nunan and Bailey (2009, pp. 416-424):

(1) Read the interview data multiple times to find a pattern. Finding a pattern involves searching for repeated themes or key words, parallel or connected comments and/or metaphoric use of language that carries a salient message.

(2) Write down overall initial feelings.

(3) Decide on the themes that emerged as the data unfolded from the beginning to the end.

(4) Highlight the emerging themes and read each thematic data set separately and repeatedly.

(5) Follow each of the themes throughout the data and draw some conclusions.

In order to minimise research subjectivity and bias, hard copies of handwritten codes were kept handy at all times for each teacher/focus group, allowing for navigation and crosschecking claims (L. Richards, 2015). In addition, the teachers'/students' own words were 
used as one of the sources of validation. The semi-structured interview format also enabled me to compare and contrast the themes that surfaced amongst the teachers/focus groups.

Analysis of the teacher follow-up interviews and student FG interviews in Phase 2 was carried out in the same manner as described above. The data from the teacher follow-up interviews was coded looking for categories specifically related to the teachers' beliefs about the TPL workshop, their teaching practice, and student learning; and how these interacted. These themes and categories were analysed and compared and contrasted to examine the teachers' thoughts and beliefs about the impact of the workshop on their knowledge gains, pronunciation teaching skills, and student learning. Simultaneously, I compared and contrasted the themes and categories generated from the student FG interviews with those derived in Phase 1 to explore the students' perceptions about the effects of the CPT model they had so far experienced. Finally, I cross-checked the findings of these two data sources to evaluate the overall uptake and efficacy of the TPL workshop.

In reporting the study findings, extracts from catch-ups with the teachers and from interviews with both the teachers and students were translated into English with good care taken to retain the accuracy and subtlety in translations (Marshall \& Rossman, 2011). The researcher tried to maintain the closest meaning to the original in his translations which were then double-checked for accuracy by another Vietnamese EFL teacher.

\subsection{The trustworthiness of the study}

All researchers endeavour to establish their studies as credible and trustworthy irrespective of what research paradigms they employ. This section discusses my endeavours to achieve trustworthiness through ways to enhance the credibility, dependability, confirmability and transferability in this qualitative research project.

\subsubsection{Credibility}

Credibility refers to the truth of the data (Cope, 2014). Given the qualitative data collected in the forms of classroom observations and interviews, the current study might be criticized for subjectivity and bias in analysis (Bryman, 2008). In order to address this, the study adopted a “thick, rich description" (Creswell \& Miller, 2000, p. 129) of the research participants and their context to achieve credibility. As Creswell and Miller (2000) have argued, this procedure "transports" readers into the context and enables them "to make decisions about 
the applicability of the findings to other settings or similar contexts" (p.129). Credibility was enhanced through the following principles which were adopted in data collection and analysis:

(1) The researcher's 'bracketing' in data collection and analysis to separate himself from the participants' stories (also see section 3.3).

(2) Rich, vivid quotes from the participants: the teachers' and students' own words were used in reporting findings rather than the researcher's interpretations.

(3) Emerging patterns of the teachers' thoughts and beliefs about the observed practices were cross-checked and then these were re-crosschecked with the themes from the student data.

(4) Finding themes of the teachers' thoughts and beliefs about the impact of the TPL workshop on their knowledge gains, pronunciation teaching skill, and student learning were compared and contrasted.

(5) Emerging patterns of the students' perceptions about their teachers' pronunciation teaching in Phase 1 were compared and contrasted with those in Phase 2.

(6) Triangulation of the data from different participants and sources (documents, observations, and interviews).

\subsubsection{Dependability and confirmability}

Dependability relates to the notion of constancy or stability of the data (Polit \& Beck, 2012; Rolfe, 2006) while confirmability refers to how neutral and accurate the data are (Polit \& Beck, 2012; Tobin \& Begley, 2004). However, according to Houghton et al. (2013, p. 13), confirmability "is closely linked to dependability - the processes for establishing both are similar". To this end, the following measures were taken into account so as to assure the dependability and confirmability of the current research:

(1) A research design that took into account the compatibility between research questions and data sources.

(2) Multiple case studies that involved six teachers teaching six different classes in each of the two phases of the study.

(3) A semi-structured interview protocol that allowed the data among the participants and finding patterns to be cross-checked. 
(4) Interview clarification/modification with the teachers to confirm accuracy in what the teachers had said and to collect additional evidence.

(5) A repeated data-driven process in which the data guided the analysis.

(6) Direct quotes from the participants' responses depicting each emerging theme.

(7) Visiting and re-visiting the emerging themes and categories.

(8) Triangulation of data sources that helped examine the teachers' pronunciation teaching practices as well as the overall uptake and efficacy of the TPL workshop.

\subsubsection{Transferability}

Transferability is referred to as the extent to which research findings can be transferred to similar educational settings (Houghton et al., 2013; Polit \& Beck, 2012). In order to achieve the transferability of the study, I provided a thick, rich description of the research context in which the participants operated. I discussed findings in reference to empirical studies existing in the literature and provided direct quotes from the participants that allowed readers to consider their own interpretations of the findings. And last but not least, I described to details the research methods so that readers in similar contexts can make informed decisions about the applicability of the current research findings to specific educational settings.

\subsection{Summary of the chapter}

The overall objective of the current study was to investigate the teachers' pronunciation teaching practices and the beliefs they held about pronunciation teaching. It then looked at how the students perceived their teachers' pronunciation instruction. Phase 1 aimed to describe what pronunciation instruction the teachers actually carried out in their EFL classes and how the students perceived the value of the instruction their teachers gave. This phase of the study adopted a descriptive research paradigm that aligned with its purposes. Multiple data sources were collected and analysed including textbooks and supplementary materials, classroom observations accompanied by audio-video recordings, field notes and instructional materials, teacher SR and in-depth interviews, and student FG interviews.

Phase 2 started with a TPL workshop followed by experimental lesson planning and tracking of subsequent classroom processes and perceived learning outcomes. The objective of the second phase was to investigate the teachers' thoughts and beliefs about the impact of the TPL workshop on their knowledge gains and pronunciation teaching skills, and student 
learning. It then examined the effects of the CPT model on student learning from both teacher and student perspectives. It also looked into the teachers' and students' beliefs about pronunciation instruction at the tertiary level in Vietnam. Data from the teacher and student interviews were analysed qualitatively using a theme-based approach and cross-checked to identify patterns in the teachers' and students' thoughts and beliefs. The trustworthiness of the study was taken into account through careful steps to enhance the credibility, dependability and confirmability, and transferability of the study findings. The following two chapters will present and discuss the Phase 1 findings. Chapter 4 reports on and discusses the findings regarding the teachers' cognitions and pronunciation teaching practices. Chapter 5 presents and discusses the findings about Vietnamese EFL learners' pronunciation needs from both the teachers' and students' perspectives. 


\section{Chapter 4}

\section{THE PHASE 1 STUDY: PRONUNCIATION TEACHING AND TEACHER COGNITION}

\subsection{Introduction}

Phase 1 of the study investigated the teaching of pronunciation in EFL classes at a

Vietnamese university. It began by examining the representation of pronunciation features in the prescribed textbooks and supplementary materials of an EFL programme. This curriculum document analysis served as the foundation for the subsequent stages of the research process, involving classroom observations followed by stimulated recall (SR) and in-depth interviews with teachers and focus group interviews with students. This chapter reports on the findings that answer the following three research questions (RQs):

RQ1. How was pronunciation represented in the EFL programme at a Vietnamese university?

RQ2. How did the teachers teach pronunciation in their EFL classes, and what reasons did they give for their teaching decisions?

RQ3. How did the teachers perceive their pronunciation teaching competence, $\mathrm{PL}$ needs, and EFL teacher training in Vietnam regarding pronunciation teaching?

\subsection{Pronunciation representation in the EFL programme}

Phase 1 of the study began with an analysis of pronunciation content in all curriculum documents of this EFL programme. Within the VTE context, universities are largely autonomous in the way they design language programmes for their own institution; thus, the appropriate level to begin the analysis was with the university curriculum, including the main textbooks, supplementary materials, teacher books, and the syllabus of each module.

Analysis of all the four syllabi showed that pronunciation teaching was not mentioned in their aims and objectives, and in lesson content prescribed for each module. Analysis of the main textbooks, the Market Leader series, showed that there were typically seven sessions in each unit: (1) Starting up, (2) Vocabulary, (3) Reading, (4) Listening, (5) Language review, (6) 
Skills, and (7) Case study. Each unit in the supplementary materials, the Practice Book series, contained four lessons corresponding to the four language skills, namely Listening, Speaking, Reading and Writing.

At the beginning of each unit in the Market Leader series (the 'Staring up' section), learners were provided with several words and expressions related to the unit topic followed by discussions about the topic. In the second section, learners learned new words and phrases they later used to do the tasks in the unit. The Reading section provided learners with article(s) extracted or adapted from the Financial Times and other newspapers. In this section, learners developed their reading skills and learn new business vocabulary; they were also provided with discussions about the article(s). In the Listening section, learners developed their skills of listening for information and note-taking through recordings of interviews with businesspeople. The Language review section focused on key grammar items that helped learners become more accurate in their language use. In the Skills section, learners were provided opportunities to develop their listening and speaking skills through different listening and communication tasks. The Case study section covered business topics that allowed learners to practise their speaking skills. Learners were also provided a writing task in this final section. In the Practice Book series, the Listening section was designed with listening tasks adapted from TOEIC (Test of English for International Communication) materials. The Speaking and Reading tasks were compiled based on the corresponding topics in each unit of the Market Leader series. The Writing tasks in Practice Books 1 and 2 focused on grammar and sentence structures, and those in Practice Books 3 and 4 on paragraph writing. The data are summarised in Table 4.1 below.

Table 4.1 Pronunciation representation in the course books

\begin{tabular}{lll}
\hline Module 1 & Market Leader (Elementary) & Practice Book 1 \\
\hline Unit 2: & - Starting up: work expressions & - Listening: Identifying \\
Work and & - Vocabulary 1: Days, months, dates & people \\
Leisure & - Reading: Describing your routine & - Speaking: Talking about \\
& - Language focus 1: Present simple & work and leisure \\
& - Vocabulary 2: Leisure activities & - Reading: Partnerships \\
& - Language focus 2: Adverbs/expressions of frequency & - Writing: Simple \\
& - Skills: Talking about work and leisure & sentences \\
& - Case study: & \\
& + Discussion: Independent Film Company & \\
& + Writing: working conditions & \\
\hline
\end{tabular}




\begin{tabular}{|c|c|c|}
\hline $\begin{array}{l}\text { Unit 3: } \\
\text { Problems }\end{array}$ & $\begin{array}{l}\text { - Starting up: problem expressions } \\
\text { - Vocabulary: Adjectives } \\
\text { - Reading: Dealing with problems at work } \\
\text { - Language focus 1: Present simple } \\
\text { - Language focus 2: have got } \\
\text { - Skills: Telephoning - solving problems } \\
\text { - Case study: } \\
\text { + Discussion: Sunrise Holidays } \\
\text { + Writing: messages }\end{array}$ & $\begin{array}{l}\text { - Listening: Identifying } \\
\text { opinions } \\
\text { - Speaking: Telephoning } \\
\text { - solving problems } \\
\text { - Reading: Corporations } \\
\text { - Writing: Compound } \\
\text { sentences }\end{array}$ \\
\hline $\begin{array}{l}\text { Unit 4: } \\
\text { Travel }\end{array}$ & $\begin{array}{l}\text { - Starting up: travel expressions } \\
\text { - Vocabulary: Travel details } \\
\text { - Listening: Listening for information } \\
\text { - Language focus 1: can / can't } \\
\text { - Reading: Business hotels } \\
\text { - Language focus 2: there is / there are } \\
\text { - Skills: Making bookings \& checking arrangements } \\
\text { - Case study: } \\
\text { + Discussion: Pacific Hotel } \\
\text { + Writing: faxes }\end{array}$ & $\begin{array}{l}\text { - Listening: Identifying } \\
\text { choices } \\
\text { - Speaking: Making } \\
\text { bookings and checking } \\
\text { arrangements } \\
\text { - Reading: What does an } \\
\text { executive do? } \\
\text { - Writing: Complex } \\
\text { sentences }\end{array}$ \\
\hline $\begin{array}{l}\text { Unit 6: } \\
\text { Sales }\end{array}$ & $\begin{array}{l}\text { - Starting up: product expressions } \\
\text { - Vocabulary 1: Buying and selling } \\
\text { - Reading: Thirsty for success? } \\
\text { - Language focus 1: Past simple } \\
\text { - Vocabulary 2: Buying and selling } \\
\text { - Listening: Selling } \\
\text { - Language focus 2: Past time references } \\
\text { - Skills: Presenting a product } \\
\text { - Case study: } \\
\text { + Discussion: Link-up Ltd } \\
\text { + Writing: emails }\end{array}$ & $\begin{array}{l}\text { - Listening: Identifying } \\
\text { reasons } \\
\text { - Speaking: Presenting a } \\
\text { product } \\
\text { - Reading: Retailing } \\
\text { - Writing: Revision and } \\
\text { sentence building }\end{array}$ \\
\hline Module 2 & Market Leader (Elementary) & Practice Book 2 \\
\hline $\begin{array}{l}\text { Unit 8: } \\
\text { Markets }\end{array}$ & $\begin{array}{l}\text { - Starting up: percentage expressions } \\
\text { - Vocabulary: Types of markets } \\
\text { - Reading: The car market in China } \\
\text { - Language focus 1: Comparatives and superlatives } \\
\text { - Listening: Doing business in Russia } \\
\text { - Language focus 2: much / a lot, a little / a bit } \\
\text { - Skills: Participating in discussions }\end{array}$ & $\begin{array}{l}\text { - Listening: TOEIC test } \\
\text { part } 2 \\
\text { - Speaking: Participating } \\
\text { in discussions } \\
\text { - Reading: Corporate } \\
\text { Finance } \\
\text { - Writing: Relative } \\
\text { clauses }\end{array}$ \\
\hline
\end{tabular}




\begin{tabular}{|c|c|c|}
\hline & $\begin{array}{l}\text { - Case study: } \\
\text { + Discussion: Cara Cosmetics } \\
\text { + Writing: product descriptions }\end{array}$ & \\
\hline $\begin{array}{l}\text { Unit 9: } \\
\text { Companies }\end{array}$ & $\begin{array}{l}\text { - Starting up: company quiz } \\
\text { - Listening: The Mini range } \\
\text { - Language focus 1: Present continuous } \\
\text { - Vocabulary: Describing companies } \\
\text { - Reading: LVMH } \\
\text { - Language focus 2: Present simple or present continuous } \\
\text { - Skills: Starting a presentation } \\
\text { - Case study: } \\
\text { + Discussion: You and your company } \\
\text { + Writing: company profiles }\end{array}$ & $\begin{array}{l}\text { - Listening: TOEIC test } \\
\text { part } 2 \\
\text { - Speaking: Starting a } \\
\text { presentation } \\
\text { - Reading: Banks and } \\
\text { businesses } \\
\text { - Writing: Conditionals }\end{array}$ \\
\hline $\begin{array}{l}\text { Unit 11: } \\
\text { Cultures }\end{array}$ & $\begin{array}{l}\text { - Starting up: tips for visiting a different country } \\
\text { - Vocabulary: Company cultures } \\
\text { - Listening: Cultural mistakes } \\
\text { - Language focus 1: should / shouldn't } \\
\text { - Reading: Fast food in Japan } \\
\text { - Language focus 2: could / would } \\
\text { - Skills: Identifying problems and agreeing action } \\
\text { - Case study: } \\
\text { + Discussion: A change of culture } \\
\text { + Writing: action minutes }\end{array}$ & $\begin{array}{l}\text { - Listening: TOEIC test } \\
\text { part } 2 \\
\text { - Speaking: Identifying } \\
\text { problems and agreeing } \\
\text { action } \\
\text { - Reading: International } \\
\text { business } \\
\text { - Writing: Conditionals } \\
\text { (continued) }\end{array}$ \\
\hline $\begin{array}{l}\text { Unit 12: } \\
\text { Jobs }\end{array}$ & $\begin{array}{l}\text { - Starting up: job vocabulary and expressions } \\
\text { - Vocabulary: Skills and abilities } \\
\text { - Language focus 1: Present perfect } \\
\text { - Reading: A curriculum vitae } \\
\text { - Listening: Interviewing for a job } \\
\text { - Language focus 2: Past simple and present perfect } \\
\text { - Skills: Interview skills } \\
\text { - Case study: } \\
\text { + Discussion: High Profile Inc. } \\
\text { + Writing: letters }\end{array}$ & $\begin{array}{l}\text { - Listening: TOEIC test } \\
\text { part } 2 \\
\text { - Speaking: Interview } \\
\text { skills } \\
\text { - Reading: Money matters } \\
\text { - Writing: Revision }\end{array}$ \\
\hline Module 3 & Market Leader (Pre-intermediate) & Practice Book 3 \\
\hline $\begin{array}{l}\text { Unit 1: } \\
\text { Careers }\end{array}$ & $\begin{array}{l}\text { - Starting up: career expressions } \\
\text { - Vocabulary: Career moves } \\
\text { - Reading: Be aware of your online image } \\
\text { - Listening: Changing jobs }\end{array}$ & $\begin{array}{l}\text { - Listening: TOEIC test } \\
\text { part } 3 \\
\text { - Speaking: Telephoning } \\
\text { - making contact }\end{array}$ \\
\hline
\end{tabular}




\begin{tabular}{|c|c|c|}
\hline & $\begin{array}{l}\text { - Language review: Modals: ability, requests and offers } \\
\text { - Skills: Telephoning - making contact } \\
\text { - Case study: } \\
\text { + Discussion: Youjuice } \\
\text { + Writing: emails }\end{array}$ & $\begin{array}{l}\text { - Reading: Training on the } \\
\text { job } \\
\text { - Writing: Paragraph } \\
\text { writing - jobs }\end{array}$ \\
\hline $\begin{array}{l}\text { Unit 2: } \\
\text { Companies }\end{array}$ & $\begin{array}{l}\text { - Starting up: company expressions } \\
\text { - Vocabulary: Describing companies } \\
\text { - Listening: A successful company } \\
\text { - Reading: Two different organisations } \\
\text { - Language review: Present simple and present continuous } \\
\text { - Skills: Presenting your company } \\
\text { - Case study: } \\
\text { + Discussion: Dino Conti Ice Cream } \\
\text { + Writing: proposals }\end{array}$ & $\begin{array}{l}\text { - Listening: TOEIC test } \\
\text { part } 3 \\
\text { - Speaking: Presenting } \\
\text { your company } \\
\text { - Reading: Computer } \\
\text { company success } \\
\text { - Writing: Paragraph } \\
\text { writing - companies }\end{array}$ \\
\hline $\begin{array}{l}\text { Unit 3: } \\
\text { Selling }\end{array}$ & $\begin{array}{l}\text { - Starting up: shopping expressions } \\
\text { - Vocabulary: Making sales } \\
\text { - Listening: Selling on TV } \\
\text { - Reading: Sales skills } \\
\text { - Language review: } \text { must, need to, have to, should } \\
\text { - Skills: Negotiating - reaching agreement } \\
\text { - Case study: } \\
\text { + Discussion: A partnership agreement } \\
\text { + Writing: letters }\end{array}$ & $\begin{array}{l}\text { - Listening: TOEIC test } \\
\text { part } 3 \\
\text { - Speaking: Negotiating - } \\
\text { reaching agreement } \\
\text { - Reading: Film deals } \\
\text { online } \\
\text { - Writing: Paragraph } \\
\text { writing - shopping }\end{array}$ \\
\hline $\begin{array}{l}\text { Unit 4: } \\
\text { Great } \\
\text { ideas }\end{array}$ & $\begin{array}{l}\text { - Starting up: discussions about ideas } \\
\text { - Vocabulary: verb and noun combinations } \\
\text { - Listening: Great business ideas } \\
\text { - Reading: Three great ideas } \\
\text { - Language review: Past simple and past continuous } \\
\text { - Skills: Successful meetings } \\
\text { - Case study: } \\
\text { + Discussion: The new attraction } \\
\text { + Writing: reports }\end{array}$ & $\begin{array}{l}\text { - Listening: TOEIC test } \\
\text { part } 3 \\
\text { - Speaking: Successful } \\
\text { meetings } \\
\text { - Reading: Ideas from } \\
\text { consumers } \\
\text { - Writing: Paragraph } \\
\text { writing - new ideas at the } \\
\text { work place }\end{array}$ \\
\hline Module 4 & Market Leader (Pre-intermediate) & Practice Book 4 \\
\hline $\begin{array}{l}\text { Unit 7: } \\
\text { New } \\
\text { Business }\end{array}$ & $\begin{array}{l}\text { - Starting up: business expressions } \\
\text { - Vocabulary: Economic terms } \\
\text { - Listening: New business } \\
\text { - Reading: New business ideas } \\
\text { - Language review: Time clauses }\end{array}$ & $\begin{array}{l}\text { - Listening: TOEIC test } \\
\text { part } 3 \\
\text { - Speaking: Telephoning } \\
\text { - exchanging information } \\
\text { - Reading: Luxury brands }\end{array}$ \\
\hline
\end{tabular}




\begin{tabular}{|c|c|c|}
\hline & $\begin{array}{l}\text { - Skills: Dealing with numbers } \\
\text { - Case study: } \\
\text { + Discussion: Taka Shimizu Cycles } \\
\text { + Writing: emails }\end{array}$ & $\begin{array}{l}\text { - Writing: Paragraph } \\
\text { writing - the last time you } \\
\text { shopped }\end{array}$ \\
\hline $\begin{array}{l}\text { Unit 8: } \\
\text { Marketing }\end{array}$ & $\begin{array}{l}\text { - Starting up: marketing expressions } \\
\text { - Vocabulary: Word partnerships } \\
\text { - Listening: Marketing pharmaceuticals } \\
\text { - Reading: Adidas and the Chinese market } \\
\text { - Language review: Yes/No and Wh- questions } \\
\text { - Skills: Telephoning - exchanging information } \\
\text { - Case study: } \\
\text { + Discussion: Wincote International } \\
\text { + Writing: emails }\end{array}$ & $\begin{array}{l}\text { - Listening: TOEIC test } \\
\text { part } 3 \\
\text { - Speaking: Interrupting } \\
\text { and clarifying } \\
\text { - Reading: Expansion } \\
\text { plans } \\
\text { - Writing: Paragraph } \\
\text { writing - business plan } \\
\text { revisions }\end{array}$ \\
\hline $\begin{array}{l}\text { Unit 9: } \\
\text { Planning }\end{array}$ & $\begin{array}{l}\text { - Starting up: ways of planning } \\
\text { - Vocabulary: Making plans } \\
\text { - Listening: How important is planning? } \\
\text { - Reading: To plan or not to plan } \\
\text { - Language review: Talking about future plans } \\
\text { - Skills: Meetings: interpreting and clarifying } \\
\text { - Case study: } \\
\text { + Discussion: European Press and Media Corporation } \\
\text { + Writing: letters }\end{array}$ & $\begin{array}{l}\text { - Listening: TOEIC test } \\
\text { part } 3 \\
\text { - Speaking: Socializing } \\
\text { and entertaining } \\
\text { - Reading: Staff freedom } \\
\text { - Writing: Paragraph } \\
\text { writing - a good manager }\end{array}$ \\
\hline $\begin{array}{l}\text { Unit 10: } \\
\text { Managing } \\
\text { people }\end{array}$ & $\begin{array}{l}\text { - Starting up: qualities of a good manager } \\
\text { - Vocabulary: Verbs and prepositions } \\
\text { - Listening: Managing people } \\
\text { - Reading: Management and motivation } \\
\text { - Language review: Reported speech } \\
\text { - Skills: Socializing and entertaining } \\
\text { - Case study: } \\
\text { + Discussion: Ashley Cooper - Search Agency } \\
\text { + Writing: reports }\end{array}$ & $\begin{array}{l}\text { - Listening: TOEIC test } \\
\text { part } 3 \\
\text { - Speaking: Dealing with } \\
\text { conflict } \\
\text { - Reading: Better } \\
\text { leadership } \\
\text { - Writing: Paragraph } \\
\text { writing - your own ways } \\
\text { to deal with conflicts }\end{array}$ \\
\hline
\end{tabular}

As displayed in Table 4.1, no pronunciation features were represented either in the main textbooks or in the supplementary materials. Instead, the course books emphasised teaching new vocabulary and revising grammar and structures essential for business negotiations. A unit-by-unit analysis of the two teacher guides shows that only Unit 6 of the Market Leader Elementary used for Module 1 suggested teaching the pronunciation of the "-ed" verb 
endings if learners needed to work on this feature. Yet, there was no further mention of pronunciation teaching elsewhere in any of the programme documents. The analysis had initially intended to use the ten research-based principles for pronunciation teaching described in section 3.8.1. However, since no pronunciation instruction was mentioned in the teaching materials for the classroom, these principles were redundant.

In terms of assessment, a minor role was given to pronunciation because all the students of the university took a mandatory written exam paper at the end of each semester. Some teachers might opt for a speaking test for the mid-term test. This test, however, was optional, and the teacher in charge scored students' performance with no criteria clearly specified for the assessment. As such, pronunciation played no explicit role in assessment at the university (also see 3.4.1.3).

To conclude, pronunciation instruction was largely absent from the EFL programme as reflected in the main textbooks, supplementary materials, and syllabus documents. This finding confirms previous research which showed that many textbook series used in the North American ESL context often excluded pronunciation entirely and, when it was present, was given a minor role (Breitkreutz et al., 2001; Derwing et al., 2012; Foote et al., 2011). I now turn to examine the teachers' pronunciation teaching practices and stated beliefs in implementing this EFL curriculum.

\subsection{Teachers' beliefs and pronunciation teaching practices}

This section reports on the findings that answer RQ2, i.e. how the teachers taught pronunciation in their EFL classes, and what reasons they gave for their pronunciation teaching decisions. Data from classroom observations and SR and in-depth interviews were analysed. Classroom observations looked into if, when, what, and how the teachers taught pronunciation in their EFL classes, and how much time they spent on pronunciation instruction. The first part of in-depth interviews centred on the teachers' self-reported pronunciation teaching practices (PTP), their thoughts and beliefs about their own PTC, PL needs, and EFL teacher training in Vietnam in relation to pronunciation pedagogy. The second part asked the teachers to discuss Vietnamese EFL learners' pronunciation needs, which will be reported in Chapter 5. The SR interview data primarily focused on the teachers' understandings of their observed PTP and the rationales for their classroom actions. In the SR interview sessions, each of the teachers was first shown video-recordings of two short 
excerpts from their observed class. Given that teachers Khoa and $\mathrm{Na}$ used an additional pronunciation teaching activity different from other teachers, they were shown a third excerpt from their recorded lesson. When the teachers finished watching their lesson excerpts, they were asked (1) if they used any different techniques to teach pronunciation in class other than those in the video-recordings of their lesson, (2) if it was their most frequent approach to pronunciation teaching, and (3) what pronunciation goal they wanted their students to attain. After that, the teachers were encouraged to elaborate on the rationales for the pronunciation pedagogic choices they made in class. The following sections provide a detailed account of the teachers' PTP, both reported in the in-depth interviews and observed in intact classes, and their stated beliefs about their classroom practices.

\subsubsection{Teachers' self-reported pronunciation teaching practices}

The teachers' reports of their PTP were obtained from the in-depth interviews. The interviews sought to gain information on how often the teachers taught pronunciation explicitly in their EFL classes, how much time they typically spent on pronunciation teaching, what teaching procedures they followed, and what materials they used. The data are presented in Table 4.2.

First, as Table 4.2 shows, two of the teacher participants reported that they sometimes taught pronunciation explicitly; three seldom taught it and one never taught it. Five teachers elaborated by saying that they only taught pronunciation explicitly when it was a common error amongst students and when class time allowed. Second, as seen in column 3, the teachers reported that on the infrequent occasion that they explicitly taught pronunciation, they typically spent between ten and twenty minutes in an average ninety-minute lesson, with one teacher spending no time on pronunciation teaching. Third, in terms of pronunciation teaching procedures, all five teachers commonly reported following three steps in their teaching: (1) Listening discrimination - (2) Explanation of places of articulation - (3) Listen and repeat. However, three of the teachers extended their teaching procedures to the Practice stage. Activities used for learners' practice at this stage varied: two teachers conducted minimal pair practice and one employed passage reading with a focus on the words containing the target sound(s). Fourth, as shown in the last column, pronunciation teaching activities that the five teachers carried out in their classes came from a variety of resources. Four of the teachers used pronunciation textbooks such as Tree or Three or Ship or Sheep; and one teacher used activities for pronunciation practice in general ESL/EFL texts such as Tactics for Listening and Vocabulary Games and Activities. 
Table 4.2 Teachers's self-reported PTP

\begin{tabular}{|c|c|c|c|c|}
\hline Teacher & Frequency & Time spent & Procedures & Materials used \\
\hline Quynh & Sometimes & $\begin{array}{l}\text { about } 15 \\
\text { minutes }\end{array}$ & $\begin{array}{l}\text { - Listening discrimination } \\
\text { - Explanation of places of articulation } \\
\text { - Listen and repeat } \\
\text { - Practice (passage reading aloud) }\end{array}$ & $\begin{array}{l}\text { Pronunciation in } \\
\text { Use }\end{array}$ \\
\hline Phuong & Seldom & $\begin{array}{l}15-20 \\
\text { minutes }\end{array}$ & $\begin{array}{l}\text { - Listening discrimination } \\
\text { - Explanation of places of articulation } \\
\text { - Listen and repeat }\end{array}$ & Ship or Sheep \\
\hline Nguyen & Never & N/A & N/A & N/A \\
\hline Diep & Seldom & $\begin{array}{l}\text { about } 10 \\
\text { minutes }\end{array}$ & $\begin{array}{l}\text { - Listening discrimination } \\
\text { - Explanation of places of articulation } \\
\text { - Listen and repeat }\end{array}$ & $\begin{array}{l}\text { - Tree or Three } \\
\text { - Sounds English }\end{array}$ \\
\hline Khoa & Seldom & $\begin{array}{l}\text { about } 20 \\
\text { minutes }\end{array}$ & $\begin{array}{l}\text { - Listening discrimination } \\
\text { - Explanation of places of articulation } \\
\text { - Listen and repeat } \\
\text { - Practice (minimal pair drills) }\end{array}$ & $\begin{array}{l}\text { - Ship or Sheep } \\
\text { - Elements of } \\
\text { Pronunciation }\end{array}$ \\
\hline $\mathrm{Na}$ & Sometimes & $\begin{array}{l}10-15 \\
\text { minutes }\end{array}$ & $\begin{array}{l}\text { - Listening discrimination } \\
\text { - Explanation of places of articulation } \\
\text { - Listen and repeat } \\
\text { - Practice (minimal pair drills) }\end{array}$ & $\begin{array}{l}\text { - Tactics for } \\
\text { Listening } \\
\text { - Vocabulary Games } \\
\text { and Activities }\end{array}$ \\
\hline
\end{tabular}

Note: N/A = not applicable

In brief, the teachers reported that when class time allowed and when it was a common pronunciation error amongst students, they spent between ten and 20 minutes out of a 90minute teaching session on explicit pronunciation instruction. Although their pronunciation teaching was on an infrequent basis, the teacher reported following deliberate teaching steps such as explicitly explaining places of articulation accompanied by listen-and-repeat activities and practice using minimal pairs or passage reading. They reported using activities from different pronunciation or ESL/EFL textbooks which were commercially available. I will now turn to investigate how they actually taught pronunciation in their English classes.

\subsubsection{Teachers' observed pronunciation teaching practices}

The observational data was comprised of two parts. The first part paints a general picture of the lesson structure and how the lessons progressed. The second part reports on the analysis 
of specific instances of pronunciation teaching which were carried out by each of the teachers in intact classes. Video-recordings of each teacher teaching two consecutive 45-minute periods supplemented by unstructured field notes and instructional materials were analysed. The analysis of this data included identifying and categorising all classroom events that involved pronunciation instruction such as the teachers' use of a particular pronunciation teaching activity, explanation of a phonological feature, or reaction to a student's pronunciation error.

In terms of lesson structure, the observational data show that the teachers, despite each having a distinctive teaching approach, shared common ways of conducting their lessons. They typically followed the sequence of sections provided in the course books (see Table 4.1 above). During each ninety-minute period, the teachers sequentially covered at least two or three sections in the unit. These language inputs/skills generally included vocabulary, listening, speaking, reading and grammar, but not writing (for the textbook units under observation, see Appendix 7 in the $\mathrm{CD}$ attached). In their teaching of each language input/skill, the teachers followed a presentation-practice-production sequence. Yet, for pronunciation, the teachers used a reactive rather than a proactive approach compared to other language skills such as grammar, listening, speaking, or reading. That means they responded to individual students' pronunciation errors, mostly of individual sounds, upon performance rather than working to a pre-determined formal syllabus.

As far as pronunciation teaching is concerned, the observational data (Table 4.3) show that the six teachers' pronunciation teaching was restricted to the following three types of activities: (1) giving recasts (showing model pronunciations); (2) giving prompts (encouraging self-correction through metalinguistic clues); and (3) transcribing words incorrectly pronounced by students followed by repetition. In this data set, students were generally asked to repeat after the teachers those words with which they made pronunciation errors, which is referred to as recasts (Saito, 2011). In other cases, the teachers raised students' awareness of their pronunciation errors and encouraged them to self-correct. This practice is normally referred to as prompting whereby teachers give learners an opportunity to correct themselves through requesting clarification, repeating the learners' errors with intonation, or giving metalinguistic clues (Lyster, 2007; Saito, 2011). As the observational data show, the activities the teachers used to address pronunciation represented a reactive focus-on-form approach (Basturkmen, Loewen, \& Ellis, 2004; Ellis, Basturkmen, \& Loewen, 
2002). In other words, they responded to individual students' pronunciation errors through $\mathrm{CF}$ in the form of recasts and/or prompts. In other instances where students made pronunciation errors in some words, the teachers noted the words down on the board, transcribed the words, and asked students to listen and repeat. The teachers' observed PTP are summarised in Table 4.3 below.

Table 4.3 Teachers' observed PTP

\begin{tabular}{|c|c|c|c|c|c|}
\hline \multirow[b]{2}{*}{ Teacher } & \multicolumn{3}{|c|}{ Pronunciation teaching practices } & \multirow{2}{*}{$\begin{array}{l}\text { Time spent on } \\
\text { pronunciation in } \\
\text { each stage }\end{array}$} & \multirow{2}{*}{$\begin{array}{l}\text { Total } \\
\text { time } \\
\text { used }\end{array}$} \\
\hline & Recasts & Prompts & $\begin{array}{l}\text { Transcribing words } \\
\text { followed by repetition }\end{array}$ & & \\
\hline \multirow{3}{*}{ Quynh } & \multirow{3}{*}{$\checkmark$} & \multirow{3}{*}{$\checkmark$} & \multirow{3}{*}{--} & Pres.: $42 \mathrm{~s}$ & $6 m$ \\
\hline & & & & Prac.: $2 \mathrm{~m} \mathrm{41s}$ & $11 \mathrm{~s}$ \\
\hline & & & & Prod.: $2 \mathrm{~m} 48 \mathrm{~s}$ & \\
\hline \multirow{3}{*}{ Phuong } & \multirow{3}{*}{$\checkmark$} & \multirow{3}{*}{$\checkmark$} & \multirow{3}{*}{--} & Pres.: $1 \mathrm{~m} 6 \mathrm{~s}$ & $4 \mathrm{~m}$ \\
\hline & & & & Prac.: $1 \mathrm{~m} 26 \mathrm{~s}$ & $27 \mathrm{~s}$ \\
\hline & & & & Prod.: $1 \mathrm{~m} 55 \mathrm{~s}$ & \\
\hline \multirow{3}{*}{ Nguyen } & \multirow{3}{*}{$\checkmark$} & \multirow{3}{*}{$\checkmark$} & \multirow{3}{*}{--} & Pres.: 18s & $1 \mathrm{~m}$ \\
\hline & & & & Prac.: $34 \mathrm{~s}$ & $46 s$ \\
\hline & & & & Prod.: 54s & \\
\hline \multirow{3}{*}{ Diep } & \multirow{3}{*}{$\checkmark$} & \multirow{3}{*}{$\checkmark$} & \multirow{3}{*}{--} & Pres.: $34 \mathrm{~s}$ & $4 \mathrm{~m}$ \\
\hline & & & & Prac.: $2 \mathrm{~m} \mathrm{15s}$ & $45 \mathrm{~s}$ \\
\hline & & & & Prod.: $1 \mathrm{~m} \mathrm{56s}$ & \\
\hline \multirow{3}{*}{ Khoa } & \multirow{3}{*}{$\checkmark$} & \multirow{3}{*}{$\checkmark$} & \multirow{3}{*}{$\checkmark$} & Pres.: $3 \mathrm{~m} \mathrm{54s}$ & $6 \mathrm{~m}$ \\
\hline & & & & Prac.: $1 \mathrm{~m} \mathrm{25s}$ & $52 \mathrm{~s}$ \\
\hline & & & & Prod.: $1 \mathrm{~m} \mathrm{33s}$ & \\
\hline \multirow{3}{*}{$\mathrm{Na}$} & \multirow{3}{*}{$\checkmark$} & \multirow{3}{*}{$\checkmark$} & \multirow{3}{*}{$\checkmark$} & Pres.: $2 \mathrm{~m} \mathrm{12s}$ & $5 \mathrm{~m}$ \\
\hline & & & & Prac.: $1 \mathrm{~m} 31 \mathrm{~s}$ & $35 \mathrm{~s}$ \\
\hline & & & & Prod.: $1 \mathrm{~m} 52 \mathrm{~s}$ & \\
\hline
\end{tabular}

Note: 1 . The tick $(\checkmark)$ indicates that the teachers took this action and the dash (--) that they did not.

2. Pres. $=$ Presentation; Prac. $=$ Practice; Prod. $=$ Production; $\mathrm{m}=$ minutes $; \mathrm{s}=$ seconds.

As can be seen from Table 4.3, recasts and prompts were used by all the six teachers while transcribing words followed by repetition was less frequent, being carried out by only two of the teachers. The total time the teachers spent on pronunciation teaching during these observed lessons ranged from just under two minutes to almost seven minutes. All but one of the teachers spent between four and seven minutes in a ninety-minute period addressing 
pronunciation. These teaching activities were carried out at each of the Presentation, Practice and Production stages of the lesson. However, the teachers' pronunciation teaching was more frequent in the Practice and Production stages where student errors were more likely. Overall, the observational data reveal a strong tendency for the teachers to instantiate pronunciation teaching as correcting their students' pronunciation errors through giving model pronunciations or through raising learner awareness of errors and encouraging selfcorrection. The following pronunciation teaching episodes illustrate this.

Episode 1: (Note: $\mathrm{T}=$ teacher; $\mathrm{S}=$ student; $\mathrm{Ss}=$ students $)$

T: Okay. Now, which four adjectives do we use to describe this car?

S1: It's stylist and powerful. [pronounced as /powefol/ with no lexical stress]

T: Say 'powerful'. [emphasized lexical stress and vowel production]

S1: Powerful.

T: That's right. What else? You, please.

S2: Big and fast. [pronounced as /fes/]

T: $\quad$ Say 'fast'. [emphasized vowel production and final sound]

S2: Fast.

T: That's good. Can anyone think of other adjectives?

Episode 2:

$\mathrm{T}$ : When you make your presentation, if you pronounce incorrectly, then you won't get good scores. Beside content, you must pronounce intelligibly for people to understand. Remember? Say these words again for me, please. How do you say this? [pointing to the first word in the list]

Ss: Male. [pronounced briefly as /meo/]

T: No. Look at the vowel and the final sound. Say...?

Ss: male.

T: Good. This word? [pointing to the second word in the list] 
Ss: image. [pronounced as /imei/]

$\mathrm{T}: \quad$ not 'mei' but...?

Ss: image. [pronounced vowel correctly but dropped the final sound].

T: Yes. What about the final consonant?

Ss: image.

T: That's right. Now, say 'image'

Ss: image.

As demonstrated in these and other episodes, the teachers' approach to pronunciation teaching almost exclusively consisted of correcting students' errors of segmental features through recasts and/or prompts. This was true for all the teachers in all the observed lessons. In none of the classes did the teachers take a proactive approach to pronunciation teaching. That is, no pre-determined teaching activities for any pronunciation features were found in any of the teachers' EFL classes.

The finding that, for these teachers, the most frequent approach to pronunciation teaching was to give $\mathrm{CF}$ through recasts and/or prompts confirms the students' reports of the pronunciation instruction they most recently experienced in class (see Chapter 5). This finding also aligns with previous studies. D. Murphy (2011), for instance, has found that Irish teachers in four different private sector EFL schools in the Dublin area used listen-and-repeat activities or gave $\mathrm{CF}$ when learners read aloud rather than spending class time teaching pronunciation explicitly. Similar findings were found in the EFL contexts of Finland (Tergujeff, 2012) and Brazil (Buss, 2013). Foote et al.'s (2011) survey of ESL programmes across Canada showed that most of the instructors reported correcting learner pronunciation errors in their approach to pronunciation teaching. In a subsequent study, Foote et al. (2016) again found that rather than incorporating pronunciation teaching into lesson plans, teachers mostly gave $\mathrm{CF}$ in response to individual student errors. Pronunciation instruction conducted through error corrections accompanied by listen-and-repeat activities is contrary to one of the principles of pronunciation teaching which emphasises that the focus of instruction should be on genuine communication rather than isolated practice of individual phonological features (Celce-Murcia et al., 2010; Isaacs, 2009; Levis \& Grant, 2003). Additionally, Avery and 
Ehrlich (2013) have argued that pronunciation should always be incorporated in every aspect of language teaching and fostered in all classes.

In summary, the data show that there was a strong tendency for the teachers to keep the explicit teaching of pronunciation in their EFL classes to a minimum. This finding is consistent with previous research findings at a Malaysian university which found that the teachers avoided teaching pronunciation explicitly in their EFL classes (Wahid \& Sulong, 2013). It also confirms many previous studies which show that many EFL/ESL instructors are not inclined to teach pronunciation in their language classes (Breitkreutz et al., 2001; Darcy et al., 2011; Foote et al., 2011; Macdonald, 2002). The following section gives more details about the teachers' beliefs pertaining to the factors that shaped their classroom actions.

\subsubsection{Factors shaping teachers' pronunciation teaching decisions}

Data from SR interviews with the teachers were used to identify the rationales they gave for their PTP. At the beginning of the SR session, the six teachers were asked if they used any other techniques to teach pronunciation in class, if the way they taught pronunciation in the observed lessons was their most frequent approach to pronunciation teaching, and what pronunciation goal they wanted their students to attain. In response, all the teachers confirmed that correcting students' pronunciation errors through recasts and/or prompts was the only way they addressed pronunciation in their English classes. This confirmation contradicts what the teachers reported on their pronunciation teaching practices, as presented in Table 4.2 of section 4.3.1 above. This indicates that there is a mismatch between the teachers' stated beliefs and their actual classroom practices.

In terms of pronunciation goals, all the teachers reported that the underlying goal behind their teaching practices was "phát âm đúng và rõ ràng để đạt được mục đích giao tiếp chứ không thể như người bản xứ" ("intelligible pronunciation for successful oral communication rather than a native-like accent"), as illustrated in the following extracts:

(1) "My number-one priority in teaching pronunciation is to help my students achieve intelligible pronunciation for successful communication. In English learning, I think the ability to pronounce like a native speaker depends on different factors one of which is the learner's aptitude. But our students have been exposed to English for over seven years, so I think it's very hard for them to acquire a native-like accent now." (P1, Teacher SRI, Q1, Diep) 
"My goal is to help my students achieve intelligible pronunciation for successful communication rather than native-like pronunciation. If people could understand what they say in English, then I would be more than happy. Nativeness is something illusive for our students at this stage to acquire as they have aged." (P1, Teacher SRI, Q1, Na)

As shown in these and other extracts, the teachers all described intelligible pronunciation as a realistic and achievable goal for their students in EFL learning. This perspective resonates with an earlier claim about realistic pronunciation goals for adult EFL/ESL learners (Derwing \& Munro, 2015; Munro, 2010a). The six teachers all acknowledged that it would be impossible for their students as adult learners to achieve native-like pronunciation, a viewpoint supported by numerous scholars about ultimate attainment in L2 pronunciation (Abrahamsson \& Hyltenstam, 2009; Adams-Goertel, 2013; Cunningham, 2009; Moyer, 2013). This indicates that the teachers, in their descriptions of the pronunciation goal they wanted their students to achieve, attached special importance to intelligible pronunciation as a realistic and attainable goal for their students to become successful communicators in oral interaction.

The teachers' view of a native-like accent as an impossible goal for their students as young adult learners to attain in EFL learning corresponds with many previous studies. Derwing and Munro (2005), for example, have pointed out that L2 learners might become disheartened if they aim for native pronunciation which is unlikely to be achieved. This is because in reality, the ability to achieve native-like pronunciation is limited to very few highly motivated individuals (Celce-Murcia et al., 2010; Cunningham, 2009; Moyer, 2013). Empirically, Abrahamsson and Hyltenstam (2009) have found that none of the adult learner participants in their study exhibited linguistic native-likeness when their performance was scrutinized in detail by native-speaker listeners.

The teachers were then asked if their approach to pronunciation teaching as observed in intact classes was effective and which factors influenced their PTP. In response, all the teachers stated that correcting students' pronunciation errors through recasts and/or prompts was effective, and identified two main factors that influenced their classroom actions: curriculum factors and learner factors. As the data in Table 4.4 show, the curriculum factors are made up of time constraints and course books, and the learner factors comprise students' errors, awareness, proficiency level, and age. Of these, time constraints, students' errors and students' awareness were reported by all six teachers, while course books, students' 
proficiency level and student's age were less frequent, being mentioned by three, two and one teacher respectively. Table 4.4 presents an analysis of the frequency of these factors.

Table 4.4 Factors shaping teachers' PTP

\begin{tabular}{llll}
\hline \multicolumn{1}{c}{ Factors shaping teachers' PTP } & Frequency & Mentioned by \\
\hline \multirow{2}{*}{ Curriculum } & 1. Time constraints & $\mathrm{n}=6$ & All six teachers \\
\cline { 2 - 4 } & 2. Course books & $\mathrm{n}=3$ & Quynh, Phuong, Diep \\
\hline \multirow{2}{*}{ Learner } & 3. Errors & $\mathrm{n}=6$ & All six teachers \\
\cline { 2 - 4 } & 4. Awareness & $\mathrm{n}=6$ & All six teachers \\
\cline { 2 - 4 } 5. Proficiency level & $\mathrm{n}=2$ & Phuong, Khoa \\
\cline { 2 - 4 } & 6. Age & $\mathrm{n}=1$ & $\mathrm{Na}$ \\
\hline
\end{tabular}

Note: $\mathrm{n}=$ number of teachers

The first curriculum factor was time constraints. All the teachers, in response to being asked to talk about their preferred pronunciation teaching activities, mentioned time constraints exacerbated by an overload of language knowledge prescribed in the curriculum and the large number of students in their classes. The following extracts are representative:

(3) “(...) The first factor is that there's too much to teach in each lesson. There has been an overload of knowledge that needs transferring and so we don't have time for pronunciation teaching. Time is too limited while classes are too crowded. We only have four periods per class meeting in 12 weeks whereas what we must cover is enormous." (P1, Teacher SRI, Q4, Phuong)

(4) “(...) The number of students and time allotted in the curriculum are the two main factors that influence my pronunciation teaching. Whatever we do, we have to comply with the obligations in implementing the curriculum. Giving students more opportunities to practice pronunciation is good but the timeframe doesn't allow it. If I try to teach pronunciation explicitly, then I won't be able to finish what I'm required to do by the programme." (P1, Teacher SRI, Q4, Na)

These and other extracts show that the teachers all stated that they were heavily overloaded with the amount of work they were expected to get through in each module in limited class time. Thus, they saw teaching pronunciation as not feasible because it would put them behind schedule. This belief finds support from Gilbert (2008) who has pointed out that limited teaching time prevents teachers from addressing pronunciation appropriately in class. In 
addition, two of the teachers believed that only when each student in the class was given an opportunity to perform and get teacher feedback did the explicit teaching of pronunciation benefit learners. However, in their own teaching situations, the teachers did not have time and so were not able to provide this opportunity for their students as a large group. As Teacher Nguyen commented, "teaching pronunciation explicitly within a class of 40 to 50 students is a waste of time because it is not possible that all students in the class have enough time for practice, performance and getting feedback from the teacher" (P1, Teacher SRI, Q2, Nguyen, translated from Vietnamese).

The finding that time constraints restricted the time the teachers could spend on pronunciation teaching resonates with previous research. Wahid and Sulong's (2013) study, for instance, showed that teachers reported time constraints to be one of the key factors that played an influential role in shaping their practices of pronunciation teaching within their EFL classes. This finding is also consistent with Bai and Yuan's (2019) research which showed that time constraints restricted the teachers' pronunciation teaching. In an empirical study in the EFL context of Hong Kong, I. Lee, Mak, and Burns (2016) found that the limited time within a prescribed curriculum influenced the teachers' capacity in using an alternative teaching approach in their writing classes. In addition, Wang (2011) found that teachers, instead of taking learner outcomes into consideration, opted to follow the mandated curriculum as they were pressed on time to complete the schedule of the textbook prescribed in the curriculum which had been already overloaded. Thus, it can be argued that within the context of VTE, teaching time should be allotted more appropriately including a proportionate part for pronunciation so that teachers would not be under time pressure in implementing the curriculum.

The second curriculum factor was textbooks. According to three of the teachers, if the teaching materials they were using included pronunciation instruction, then they would teach it. This is because the teachers were required to finish all the units prescribed in each module within an allotted timeframe. They said:

(5) "Another factor is course books. Neither the main textbooks nor the supplementary materials we're using comprise any section for pronunciation instruction. If we had this section [pronunciation] in teaching materials, we would be able to teach it without the need to adapt materials from other sources while still managing to cover the required programme.” (P1, Teacher SRI, Q4, Quynh) 
(6) "Second, course books also have influence on my practice of pronunciation teaching. The main textbooks and the Practice Books only focus on the four main language skills: listening, speaking, reading, and writing. So, it's really difficult to supplement the lesson with pronunciation materials from outside the textbooks." (P1, Teacher SRI, Q4, Phuong)

(7) "Course books are another factor. The course books being used at my university exclude pronunciation. Meanwhile, teachers are required to stay on schedule in [their] teaching regarding the timeframe and what must be covered in class has been too enormous already. So, I think it's hard to adapt pronunciation materials from outside the textbooks even though sometimes I want to teach pronunciation explicitly." (P1, Teacher SRI, Q4, Diep)

These comments show that the teachers found using pronunciation materials in their EFL classes unviable because they had to stay on schedule in implementing the prescribed textbooks in which pronunciation was not represented. According to the teachers, if they tried to adapt pronunciation teaching materials from outside the prescribed textbooks, then they would certainly fall behind schedule. As the teachers were required to follow the course books closely, the absence of pronunciation instruction in those teaching materials restricted their pronunciation teaching. This suggests that the teachers' classroom practice was textbook-driven. This finding echoes previous research in which Baker (2014) found that the way teachers taught pronunciation in class was guided by the prescribed textbooks.

Breitkreutz et al. (2001), Couper (2017), Derwing et al. (2012), Foote et al. (2011), and others have similarly noted the strong influence of the textbooks on the instructors' classroom actions.

The teachers' PTP was also influenced by learner factors, the first of which was the students' pronunciation errors. All the teachers reasoned that the reactive, unplanned pronunciation teaching activities they conducted were useful for correcting common errors amongst students as a whole group and so they could save time in class. For instance:

(8) “Another factor is students' pronunciation errors. As I've just said, we don't have enough time to transfer all the content knowledge prescribed in the curriculum, and so correcting students' errors (...) is the quickest and most effective way. Moreover, these [pronunciation] errors are common amongst Vietnamese learners." (P1, Teacher SRI, Q4, Quynh) 
(9)

“Correcting students' pronunciation errors not only works for those students but it also makes all other students aware of such errors and so they can correct themselves. This way could help me save time for other tasks." (P1, Teacher SRI, Q4, Nguyen)

"I think when I correct my students' pronunciation errors, I can make the whole class aware of these errors and they'll be more conscious when encountering words containing these sounds in the future." (P1, Teacher SRI, Q4, Na)

In sum, the primary concern of the teachers was how to support their students with some kind of pronunciation instruction while staying on schedule in implementing the curriculum. To this end, the teachers believed that correcting the students' errors as a whole group was the most efficient way to address pronunciation in their classes. The value that these teachers put on error correction is in agreement with a general claim that CF yields improvement in language learning (I. Lee, 2011; Lyster et al., 2013; Sheen, 2010). In pronunciation learning, research suggests that CF facilitates L2 learners' pronunciation improvement (Dlaska \& Krekeler, 2013; J. Lee et al., 2015; Saito \& Lyster, 2012).

However, this common belief stated by the teachers contradicts the students' expectations because all the 24 students interviewed for this phase of the study found such an approach to pronunciation teaching unbeneficial to their English learning (see section 5.2 of Chapter 5). What the students said they needed was a pronunciation teaching approach that facilitates their involvement in communicative activities. Thus, they wanted teachers to spend class time teaching pronunciation communicatively so that their pronunciation in particular and their listening and speaking skills in general could be improved. According to C. Tomlinson and Imbeau (2010), effective teachers not only teach content but also offer learners a legitimate opportunity to develop as much as they can. In line with this view, Gömleksiz (2010) has argued that in order to develop learners' positive attitudes towards English learning, teachers should consider learner needs before classroom actions are to be taken. In this sense, it can be argued that the need for pronunciation teaching approach demonstrated by Vietnamese EFL learners should be taken into account if their involvement in classroom events is to be maximised and their attitudes towards English learning are to be positively changed.

The second learner factor was awareness. According to Derwing and Munro (2015) and McGregor and Reed (2018), one of the most important initial steps to L2 pronunciation improvement is to make learners well aware of their pronunciation problems. In the current study, all the teachers perceived that raising learner awareness of their pronunciation errors 
and encouraging the students to correct themselves is beneficial to self-regulated learning. In talking about the underlying grounds for raising learner awareness and encouraging selfcorrection, the teachers articulated definite beliefs about their expectations of how students would respond to their own pronunciation errors, as illustrated in the following extracts:

"If my students pronounce a certain word incorrectly, I'll encourage them to look it up in the dictionary and correct their pronunciation by themselves. So, raising the students' awareness of their own pronunciation errors for self-correction helps establish a habit of self-regulated learning and so they won't rely heavily on the teacher, such that they only study what the teacher prescribes.” (P1, Teacher SRI, Q4, Khoa)

(12) 'Raising the students' awareness of their own pronunciation errors for self-correction promotes students' independence in self-regulated learning. I usually provide transcriptions of sounds on the board and show my students how to articulate them so they by themselves can correctly pronounce a new word containing those sounds when they look it up in the dictionary." (P1, Teacher SRI, Q4, Na)

As seen from these and other extracts, the teachers articulated beliefs that raising awareness could promote the students' independence in self-regulated learning. Vitanova and Miller (2002) have argued that self-regulation is critical for learners to become independent and competent in language learning, and the teachers in the present study were all well aware of such value in terms of pronunciation practice. There has also been evidence that selfregulated learning is one of the key factors that contributes to the development of L2 learners' pronunciation (He, 2011; Sardegna, 2012). The perception that raising awareness can help improve learners' pronunciation is supported by a number of scholars and researchers such as Beven (2012), Ducate and Lomicka (2009), Kennedy, Blanchet, and Trofimovich (2014), and Ramírez Verdugo (2006). In this EFL context, the teachers believed that in the pursuit of better pronunciation, if their students are more aware of and independent in correcting their own pronunciation errors, then practice will be more effective and their pronunciation will be improved. This belief aligns with research which shows that selfcorrection is beneficial to learners' improvement in language learning because it promotes their reflection and encourages them to take heightened responsibility for their own progress (Todd, 2001; Yang, 2010).

Teacher Quynh also stated that another benefit of raising learner awareness was bringing about positive changes in students' attitudes towards pronunciation practice. She said: 
“Also, from my own experience and observations, I realise that today many students tend to aim at fluency rather than pronunciation accuracy in their speaking. They think they only need to be fluent so that other people can understand what they say, so they don't pay attention to pronunciation practice. But they aren't aware that many pronunciation errors in their speaking make their conversation unsuccessful. I think this can be solved by teachers raising learner awareness for error detection and self-correction. And when they're aware of this, there'll be positive changes in their attitudes towards pronunciation practice." (P1, Teacher SRI, Q4, Quynh)

This comment shows that since students tended to treat fluency as more important than pronunciation accuracy in oral interactions, they unconsciously ignored pronunciation practice. However, this tendency is in contrast with an argument that pronunciation plays a vital role in building L2 learners' fluency (Adams-Goertel, 2013). According to Thomson and Derwing (2014), any L2 learner who is fluent with advanced knowledge of vocabulary and grammar can still make pronunciation errors leading to misunderstandings and/or communication breakdowns. Therefore, raising learners' awareness of their own pronunciation difficulties provides important grounds for improving their pronunciation (Derwing \& Munro, 2015). In the light of these arguments, Quynh believed that if teachers make students aware that pronunciation errors result in communication breakdowns and/or misunderstandings, then their attitudes towards pronunciation will be changed positively and they will pay more attention to practice. This finds support in Khamkhien (2010) who maintains that raising learner awareness of the importance of pronunciation in oral interactions helps avoid communication breakdowns and/or misunderstandings. Research has shown that learner attitudes play an important role in SLA as they affect learner motivation (Al-Tamimi \& Shuib, 2009; Csizér, Kormos, \& Sarkadi, 2010) and have a strong influence on learners' efforts and persistence in language learning (Gilakjani, 2011; Kormos \& Csizér, 2008; Kormos, Kiddle, \& Csizér, 2011). Karahan (2007) maintains that "positive language attitudes let learners have a positive orientation towards learning English" (p.84). In this sense, it can be argued that if learners have a positive view on their improved pronunciation, then they will make a greater effort to learn and practice.

The third learner factor that shaped the teachers' PTP was proficiency level. Two of the teachers (Phuong and Khoa) stated that their choice of particular pronunciation teaching activities was informed by their sense of what activities were best suited to students' proficiency. They said: 
“Another factor is students' proficiency level. Most students at my university are not very good at English, so I think the best way is to correct their pronunciation errors as I usually do in class. For me, this way is more or less beneficial to the students' learning English. They'll be more conscious in practicing pronunciation, and so will be more autonomous in learning the language. With higher-level students, perhaps I'll teach pronunciation explicitly rather than only correcting errors through repetition because it certainly arouses the students' interest in learning pronunciation and makes the classroom atmosphere more welcoming. But this will be done at a basic level because we don't have time." (P1, Teacher SRI, Q4, Phuong)

“Students' proficiency levels also have a big influence on my pronunciation teaching practices. Most students at my university are not very good at English, so I think it's useful to correct their pronunciation errors or raise their awareness for error detection and self-correction through repetition. But for higher-level students, this teaching approach will make them bored and demotivated because they'll feel as if they were child learners. For higher-level students, the explicit teaching of pronunciation will work but I think listen-and-repeat activities should be skipped." (P1, Teacher SRI, Q4, Khoa)

As can be seen from the two extracts, Phuong and Khoa reported that their low proficiency students benefit from CF such as recasts and/or prompts as the way they usually addressed pronunciation in class. According to the teachers, correcting errors through recasts and/or prompts best suited lower-level learners whereas explicit pronunciation teaching promoted higher-level learners' motivation. This beliefs finds support in R. Jones (1997) who argued that learners may respond differently, both emotionally and cognitively, to different teaching approaches and task types. In this EFL context, Phuong and Khoa believed that if their students were better at English, then teaching pronunciation explicitly and systematically would be effective. Yet, given the time constraints in the programme, they said that instruction would have to be at a basic level and listen-and-repeat activities should be skipped.

Finally, Teacher $\mathrm{Na}$ also identified age as a learner factor that shaped her pronunciation teaching practice. As she commented, "Our students are adult learners. Their pronunciation has fossilized so it's very difficult to be changed for the better. This is why I only correct students' errors instead of spending class time teaching [pronunciation] explicitly." (P1, Teacher SRI, Q2, Na, translated from Vietnamese). Framing her students as young adult learners whose pronunciation has fossilised, $\mathrm{Na}$ believed that the explicit teaching of 
pronunciation was not likely to be effective. However, this view is in conflict with previous research findings. Although a native-like accent is unlikely to be achieved amongst adult ESL/EFL learners (Abrahamsson \& Hyltenstam, 2009; Cunningham, 2009; Moyer, 2004, 2013), research has showed that explicit pronunciation instruction can yield positive change in adult learners' speech (Couper, 2006, 2011; Lord, 2005, 2008; Saito, 2011, 2012b; Saito \& Lyster, 2012). Thus, Beven (2012) argued that it is important to consider how mouth movements are exercised physically and fixed over time rather than seeing learner age as a barrier in teaching pronunciation. Birdsong and Molis (2001) have also found that age is not a reliable contributor to the development of L2 learners' pronunciation.

In summary, the teachers' comments indicated that intelligible pronunciation rather than nativeness is a realistic and attainable goal for their students as young adult learners. In terms of classroom practice, the study has showed that the teachers used a restricted range of pronunciation teaching activities in their EFL classes. In particular, they provided CF in response to the students' pronunciation errors of segmental features through recasts and/or prompts. Underlying these choices made by the teachers was a commitment to stay on schedule in implementing the top-down curriculum while being able to give learners some kind of pronunciation instruction. The teachers' pronunciation teaching was also guided by learner factors such as errors, awareness, proficiency level, and age. The following section reports on the teachers' perceptions of their PTC, their PL needs as related to pronunciation pedagogy, and EFL teacher training in Vietnam in relation to pronunciation teaching.

\subsection{Teachers' perceptions of their PTC, PL needs, and EFL teacher training in Vietnam}

Answers to RQ3 of how the teachers perceive their PTC, PL priorities, and EFL teacher training in Vietnam regarding pronunciation teaching were obtained from the in-depth interview data. First, the teachers were asked to rate their own confidence level in teaching pronunciation and were encouraged to explain their rating. Next, they were asked which pronunciation features they felt more comfortable teaching and so more frequently focused on. After that, the teachers were prompted with questions that elicited their thoughts and beliefs about their PL needs in pronunciation pedagogy with reference to their initial training and previous PL experience. Finally, they were asked to discuss EFL teacher training in Vietnam in relation to pronunciation teaching. 


\subsubsection{Teachers' perceptions of their own PTC}

First, the teachers were asked to judge their confidence levels in teaching pronunciation on a rating scale of 1-5 (where $1=$ completely unconfident and $5=$ completely confident) in describing their confidence in teaching pronunciation. Then, the pronunciation features which the teachers felt more confident teaching were discussed. The data show that five of the teachers reported being confident (level 3) in teaching pronunciation while only one teacher cited not very confident (level 2) as her choice.

Teacher Diep, who claimed to be not very confident in teaching pronunciation, explained that it was because she had not so far received any formal training in pronunciation teaching approaches during her undergraduate and post-graduate education. This is why she reported that she seldom taught pronunciation in her EFL classes. She commented:

(16) "I think level 2, not very confident. This is why I seldom teach pronunciation in class. The reason is that I wasn't taught how to teach pronunciation when doing my BA and MA.” (P1, Teacher InI, Q2, Diep)

The finding about Teacher Diep lacking training and confidence in teaching pronunciation is consistent with previous research. For instance, in Bai and Yuan's (2019) study, the teachers reported not having the expertise to teach pronunciation and thus avoiding it in their English classes. Similarly, Couper (2017) found that the teachers in the ESL context of New Zealand did not receive adequate training in pronunciation pedagogy and so felt unconfident in teaching pronunciation. Other studies have also shown that the main reason for many ESL/EFL teachers' shortage of confidence in teaching pronunciation was their lack of training and PL opportunities in pronunciation pedagogy (Foote et al., 2011; Henderson et al., 2012; Saito \& van Poeteren, 2012)

However, the other five teachers reported being confident in teaching pronunciation, as illustrated in the following extracts:

(17) 'I think level 3-confident is my choice. The reason is that I'm confident of my pronunciation skill and my teaching ability.” (P1, Teacher InI, Q2, Nguyen)

“Number 3-confident because I'm confident of my pronunciation skill and my ability in transferring knowledge to my students." (P1, Teacher InI, Q2, Khoa) 
The actual words used by the teachers in these and three other extracts reveal that they held a positive view on their own PTC. The teachers reasoned that they were confident in their own pronunciation skills and their teaching ability. This finding is inconsistent with previous research as mentioned above. It is also in conflict with earlier studies in the ESL contexts of Britain and Australia which showed that many teachers did not feel comfortable teaching pronunciation (Burgess \& Spencer, 2000; Burns, 2006; Macdonald, 2002; Yates, 2001). It is likely that non-native speaker (NNS) teachers of English like those in the current study differ from native speaker (NS) teachers in that NNS teachers usually take their own pronunciation proficiency and teaching skills into account when talking about their confidence level in teaching pronunciation. NNS teachers believe that if they are good at pronunciation and if they are skilled teachers, then they feel more confident teaching it. In contrast, NS teachers in previous studies might have considered many other aspects such as their knowledge of pronunciation and teaching approaches, initial training, and PL experience in pronunciation pedagogy.

Although most of the participating teachers stated that they were confident in teaching pronunciation, they all reported being more comfortable teaching segmentals than suprasegmental features and so more frequently focused on individual sounds. Only one of the teachers said that he also felt more comfortable teaching linking. The data in Table 4.5 summarise the reasons the teachers gave for their pronunciation instruction focus.

Table 4.5 Pronunciation features teachers were more confident teaching

\begin{tabular}{lll}
\hline Teacher & Focused features & Reasons \\
\hline Quynh & vowels and consonants & easier to teach with visualisations \\
\hline Phuong & sounds & more important than suprasegmentals \\
\hline Nguyen & sounds and linking & more important so take priority \\
\hline Diep & vowels and consonants & more important so take priority \\
\hline Khoa & vowels and consonants & more important than suprasegmentals; \\
& & easier to teach with visualisations \\
\hline $\mathrm{Na}$ & sounds & easier to teach with visualisations \\
\hline
\end{tabular}

As Table 4.5 shows, three of the teachers reported that they found it easier to teach individual sounds than suprasegmental features such as stress and intonation; three claimed that 
segmentals were more important than suprasegmentals and so priority should be given to the former rather than the latter, with Teacher Khoa mentioning both reasons. On the one hand, Quynh, Khoa, and Na reasoned that it was easier for them to teach segmental than suprasegmental features using visual aids for illustrations, as evident in the following comments:

"If to teach pronunciation explicitly, I think both are important as they're both necessary for learners' listening and speaking skills. But I feel more confident and so usually focus on vowels and consonants because I can give students visual illustrations of articulators and easily explain to them places of articulation.” (P1, Teacher InI, Q3, Quynh)

(20) "I think vowels and consonants are more important [than suprasegmental features], so that's why I often teach these. Moreover, when teaching vowels and consonants, I can use pictures to illustrate my explanations of different places of articulation and students will find it easier to understand. Intonation is quite abstract and it's hard to help students get the hang of it." (P1, Teacher InI, Q3, Khoa)

"I feel more confident in teaching sounds because I think students find it easier to understand how to use different articulators such as lips, teeth and tongue using pictures. Intonation is quite complex and it's not easy for students to understand teachers' explanations because we can't use visual aids." (P1, Teacher InI, Q3, Na)

As seen from these extracts, the teachers held a strong belief that intonation was 'complex' and 'abstract', so students were unlikely to make sense of teachers explaining the features. They reasoned that students would comprehend the teaching of a segmental accompanied by visual aids more easily than that of a prosodic feature which they believed to be more abstract and could not be illustrated by any visualisation. However, previous studies have revealed that the teaching of intonation is viable and effective with speech visualisation technology (Gorjian, Hayati, \& Pourkhoni, 2013; Rude, 2012; Tanner \& Landon, 2009). It is feasible that the teachers of the current study had never taken into account the use of technology in pronunciation teaching, and so they were not aware of the value of such teaching tools within the language classroom.

On the other hand, Phuong, Nguyen, Diep, and Khoa elaborated by saying that vowels and consonants took priority over suprasegmental features. However, this belief finds no support from the literature. Research has shown that for the sake of L2 learners' pronunciation improvement, there should be a balance between segmental and suprasegmental features in 
pronunciation teaching (Celce-Murcia et al., 2010; Derwing \& Munro, 2015; Fraser, 2000; Lane \& Brown, 2010). In particular, Saito (2012a) has argued that in order to adequately address learner pronunciation needs, classroom instruction should cover a wide selection of various target features including both segmentals and suprasegmentals rather than focus only on one of the two. More importantly, pronunciation scholars have also suggested that suprasegmental features such as stress and intonation should always be integrated in classroom learning of pronunciation given the communicative values they convey in oral interaction (Caspers, 2010; Field, 2005; Hahn, 2004; Kang, Rubin, \& Pickering, 2010).

In sum, the teachers' comments revealed that their confidence levels in teaching pronunciation were quite high. In addition, they felt more comfortable teaching segmentals than suprasegmentals and so more frequently focused on these features. This finding confirms many previous studies. Foote et al.'s (2011) survey, for example, showed that Canadian ESL teachers' pronunciation teaching centred greater on segmentals than suprasegmental features although ten years ago the teachers in Breitkreutz et al.'s study (2001) reported focusing on both. Similarly, Tergujeff's (2012) study demonstrated that Finnish EFL teachers emphasised segmental features such as sibilants and affricates which were typically difficult for Finnish learners and entirely neglected to teach suprasegmentals in their language classes. Foote et al. (2016) also found that most pronunciation teaching episodes by ESL teachers across Canada targeted individual sounds but not suprasegmental features. Within the EFL contexts of Asian countries, Wahid and Sulong (2013) discovered that segmentals were given more emphasis than suprasegmental features in classroom experience of EFL teachers at a Malaysian university.

\subsubsection{Teachers' perceptions of their PL needs}

The teachers' PL needs were examined through questions asking them to talk about their initial training and PL experience in pronunciation pedagogy, a communicative framework for teaching English pronunciation (hereafter referred to as the framework), and their needs for a PL course about the communicative teaching of pronunciation. First, the teachers were asked to recall if they had had any training experience or PL opportunities in pronunciation pedagogy. The data are summarised in Table 4.6. 
Table 4.6 Teachers' initial training and PL experience

\begin{tabular}{lllll}
\hline Teacher & Types of learning & Quantity & Time of learning & Level \\
\hline Quynh & N/A & N/A & N/A & N/A \\
\hline Phuong & N/A & N/A & N/A & N/A \\
\hline Nguyen & N/A & N/A & N/A & N/A \\
\hline Diep & Auditing & 1 & 12 weeks & Undergraduate \\
\hline Khoa & Lectures & 2 & 3 hours each & Undergraduate \\
\hline Na & Lectures & 2 & 3 hours each & Undergraduate \\
\hline
\end{tabular}

Note: N/A = not applicable

As presented in Table 4.6, half of the teacher participants did not receive any formal training in teaching English pronunciation while the other half did. However, none of the teachers had been involved in PL of any type subsequent to beginning their career as EFL teachers. Of the three teachers who had experience in learning how to teach pronunciation, two attended two lectures about pronunciation teaching theory as part of an ELT methodology course, each of which was three hours. The other teacher engaged in a twelve-week course of auditing where she observed how her lecturers taught pronunciation in EFL classes. The teachers' learning experience was gained in their undergraduate programmes. However, none of the teachers had been involved in PL of any type at the post-graduate level and from then on. This indicates that the teachers lacked PL opportunities in pronunciation teaching during both their pre-service and in-service education. The lack of initial training and PL experience during their undergraduate and post-graduate education might be a possible explanation for why the teachers felt more comfortable teaching segmentals than suprasegmental features in their EFL classes.

The finding that the teachers had had little initial training and lacked PL opportunities in pronunciation teaching confirms previous studies which have also concluded that ESL/EFL teachers lack professional training in pronunciation pedagogy. Derwing (2010), for instance, has pointed out that the number of TESL programmes in Canada offering a full course in pronunciation teaching is limited. Thus, she advocates that "there is a definite need for more courses for ESL teachers" (ibid., p. 27). In a similar vein, Couper (2017) found, within the New Zealand ESL context, that most of the participating teachers lacked initial training and PL experience in how to teach pronunciation. A number of scholars have advocated that 
ESL/EFL teachers need more training opportunities so that they can feel completely comfortable teaching pronunciation in their language classes (Baker, 2011; Burns, 2006; Derwing \& Munro, 2015; Foote et al., 2011; D. Murphy, 2011).

In response to being asked about the framework for teaching English pronunciation communicatively, four of the teachers reported that they had not ever heard about it. Teachers Nguyen and Na said they had heard about the framework before but had no idea about what it is and how it works in reality. Interestingly, all the teacher participants expressed interest in studying this framework, expecting that it could help enhance their pronunciation teaching within the Vietnamese EFL classroom. The following extracts are representative:

(22) "To tell the truth, I've never heard about this and so really want to know what it is and how it works. Then, I can apply it in my teaching." (P1, Teacher InI, Q5, Quynh)

"I've heard about it somewhere but didn't take the trouble to figure it out. So, I really want to study it more deeply because this is actually very necessary. If teachers are good at pronunciation skills and knowledgeable about pronunciation teaching theory, then it'll be much more useful as they can promote student learning more efficiently." (P1, Teacher InI, Q5, Nguyen)

(24) "Actually, I have no idea about this teaching approach. Of course, I'm really keen to understand how it works in practice and hopefully I can apply this framework in my teaching practice." (P1, Teacher InI, Q5, Khoa)

Given the limited initial training and a lack of PL opportunities in pronunciation pedagogy, all six teachers, when asked about their needs for a PL course about CPT, showed a high demand for it. According to the teachers, a PL course such as this would be valuable because it would not only help enhance their teaching career but also benefit their students' English learning. The following comments illustrate this collective belief:

(25) "Yes, absolutely. I hope that this course can promote my pronunciation teaching competence. After the course, I expect that I'll be able to teach pronunciation more efficiently and so can help improve students' pronunciation in particular and their oral communication skill in general." (P1, Teacher InI, Q6, Quynh)

"Yes, of course and I have two expectations. First, I hope to widen my knowledge of English pronunciation and teaching theory. But my highest expectation is that this course can foster my pronunciation teaching competence. (...) I think a professional learning 
course specialising in communicative pronunciation teaching is very necessary because teachers can apply the knowledge in their teaching jobs." (P1, Teacher InI, Q6, Phuong)

"Yes. I expect to update state-of-the-art theories about how to teach pronunciation communicatively. Hopefully this course can promote my pronunciation teaching competence so that I'll be able to teach pronunciation more effectively and help students improve their pronunciation skills." (P1, Teacher InI, Q6, Nguyen)

Arising from these and other extracts, the teachers' expectations about a PL course specialising in teaching pronunciation communicatively were that it could help widen their knowledge about English pronunciation and promote their PTC. The teachers all believed that if their PTC was strengthened, then they would be able to teach pronunciation more effectively which would consequently enhance their students' learning; i.e. improve learners' pronunciation skills. Teacher Na also expected that such PL could foster her confidence in teaching pronunciation. She said:

(28) “Yes. If I have a chance for a learning course like this, then I'll certainly go for it. My expectation is that this course can promote my pronunciation teaching competence and so I'll feel completely confident teaching pronunciation to my students." (P1, Teacher InI, Q6, Na)

In sum, although all the teachers had limited initial training in teaching pronunciation and lacked PL opportunities to refine their pronunciation teaching skills, most of the teachers reported being confident in teaching pronunciation. Yet, they all reported feeling more comfortable teaching segmentals than suprasegmental features. They believed that individual sounds are more important than suprasegmental features and so should take priority for instruction in the classroom. Given the teachers' lack of pronunciation pedagogical knowledge during their initial training process, I asked them to discuss EFL teacher training in Vietnam in relation to pronunciation instruction, which will now be reported on.

\subsubsection{Teachers' beliefs about EFL teacher training in Vietnam}

When asked what should be improved in EFL teacher training in Vietnam, particularly in relation to pronunciation teaching, the teachers identified two stages of the training process that need to be updated: pre-training and while-training. The stage of while-training was 
discussed by all the teachers while the pre-training stage was mentioned by only four of the teachers. For each stage of the training process, the teachers suggested that more attention needs to be paid to candidate selection (pre-training), and language skills and pronunciation of candidates (while-training). They further discussed different focuses for each of the criteria as shown in column 3 of Table 4.7 below.

Table 4.7 Teachers' beliefs about EFL teacher training in Vietnam

\begin{tabular}{llll}
\hline Training stages & Criteria & Focuses & Mentioned by \\
\hline \multirow{2}{*}{ 1. Pre-training } & candidate selection & entry requirements & Phuong, Diep, Khoa, Na \\
\hline \multirow{2}{*}{ 2. While-training } & language skills in & testing and assessment & All six teachers \\
\cline { 2 - 4 } & general & student exchange & Phuong, Khoa \\
\cline { 2 - 4 } & pronunciation in & proficiency and pedagogy & All six teachers \\
\cline { 2 - 4 } & particular & native-speaker teachers & Quynh, Nguyen \\
\hline
\end{tabular}

As seen in column 3 of Table 4.7, Phuong, Diep, Khoa, and Na discussed criteria for selecting candidates prior to the training process. They reported that the criteria for selecting candidates for EFL teacher training programmes in Vietnam needs to be modified. According to the teachers, if good candidates are expected, then entry requirements have to be raised in selecting the best candidates for the programme. That is, in order to have high quality student teachers whose major is English Language Teaching (hereafter referred to as ELT students), only candidates of a high level of English proficiency can be accepted. The teachers' comments reveal a belief that the entry requirement of English proficiency partly guarantees the quality of teachers after graduation. For example, Na said:

(29) "First, I think universities offering EFL teacher training programme need to pay more attention to intakes. We don't need to train so many [ELT students]. We only train a few but they must be of high quality. So, I think they should only accept students who have achieved a high level of English proficiency. The higher the quality of intakes, the better the outcomes." (P2, Teacher InI, Q7, Na)

More importantly, all the teachers reported that EFL teacher training programmes in Vietnam need to raise the importance of ELT students' general language skills and pronunciation during the while-training stage. First, as all the teachers commented, ELT students' general language skills should be emphasised through stricter regulations for testing and assessment as illustrated in the following comments: 
"Then during the while-training stage, ELT students need to be 'taken good care of" throughout their four years at university to make sure we have 'good products'. Their language skills must be 'controlled' strictly. There should be stricter regulations for testing and assessing ELT students' language abilithe(...) so that their future students' learning can be assured and promoted." (P2, Teacher InI, Q7, Phuong)

"During the while-training stage, universities need to have strict regulations for testing and evaluating ELT students' language ability to make sure that they graduate being qualified for teaching. The stricter the regulations are, the harder ELT students will try to study." (P2, Teacher InI, Q7, Diep)

The teachers' primary concern is how to have a better control of ELT students' English proficiency during the training process. The teachers' responses show a strong belief about the positive impact of strict regulations in testing and evaluating ELT students' language proficiency. In other words, they believed that the higher the requirements for a pass and above in testing and assessment are, the more ELT students will endeavour in order to achieve their expected scores. As implied in the teachers' comments, the ultimate goal of such regulations is to assure the learning quality of ELT students' future learners. In addition, Phuong and Khoa suggested another possible way to enhance ELT students' language skills through student exchange programmes between Vietnam and institutions in English-speaking countries. As these teachers explained, such programmes would not only help Vietnamese ELT students develop language skills but they can also gain socio-cultural knowledge, which is helpful for their teaching career after graduation. These teachers were well aware that such programmes can be costly but worth investing in. For instance, Khoa said:

“Another way to help develop ELT students' language ability is to cooperate with institutions in English-speaking countries. Student exchange programmes are an opportunity for ELT students not only to improve their English skills in an Englishspeaking country but they can also learn about the cultures and social life there. This is also necessary and useful for their teaching after graduation." (P2, Teacher InI, Q7, Khoa)

Second, in terms of pronunciation skills and pronunciation pedagogy, the teachers all stated that EFL teacher training programmes in Vietnam need to include three separate courses: (1) pronunciation training; (2) phonetics and phonology; and (3) pronunciation pedagogy. All the teachers elaborated by saying that Vietnamese EFL teachers need to be good at pronunciation 
as well as pronunciation pedagogy if they want to teach the language well. According to the teachers, these three courses in the while-training process are closely related and together can help ELT students deal with pronunciation instruction more effectively after graduation. The following extracts are representative:

"For pronunciation skills in particular, I think EFL teacher training programmes in Vietnam should have three separate courses including pronunciation training, phonetics and phonology, and pronunciation pedagogy. Also, more time needs to be allocated to these courses. The pronunciation training course is for ELT students to learn and practice their pronunciation skills. Phonetics and phonology provides them with more specialised knowledge useful for their teaching pronunciation later. Meanwhile, the pronunciation pedagogy course is very important in providing ELT students with knowledge about pronunciation teaching methodology which they can apply in their future classes. These courses better assist ELT students to teach the language in general and pronunciation in particular. Also, testing and assessment criteria need to be strict to ensure the outcome quality.” (P2, Teacher InI, Q7, Quynh)

“(...) At the same time, [universities] need to design a separate pronunciation course in EFL teacher training programme. ELT students need to learn and practice a lot because pronunciation requires time to be bettered. For this to be done, credits for this course must be increased and divided into several semesters. Besides, requirements in testing and assessment must also be strict to avoid ELT students being lazy in the training process. More time is also needed for pronunciation pedagogy in the teaching methodology course so ELT students can learn more about pronunciation teaching methodology and they can also have more opportunities for teaching practice. In addition, the course of phonetics and phonology also needs to be emphasised. This is the theoretical basis ELT students should master in order to know how to teach [pronunciation] after graduation." (P2, Teacher InI, Q7, Na)

As the teachers explained, the pronunciation training course requires ELT students to learn and practice their own pronunciation skills. While the course of phonetics and phonology is for ELT students to master theoretical knowledge that lays the foundation for their later pronunciation teaching, the pronunciation pedagogy course provides ELT students with knowledge and skills about pronunciation teaching methodology. In addition, credits for these courses need to be increased so that ELT students can have more time and opportunities to be exposed to all the necessary knowledge and practice. All the teachers stressed that testing and assessment criteria need to be strict so as to ensure the outcomes of each course. 
They believed that if ELT students wish to pass the exit tests of these courses, then they have to work hard to satisfy all the requirements in testing and assessment.

Another solution to ELT students' pronunciation skills as proposed by teachers Quynh and Nguyen is to have pronunciation taught by native-speaker teachers. From their personal perspectives, Quynh and Nguyen saw that studying with native-speaker teachers allows ELT students to be exposed to the pronunciation of the target language in real-life contexts. Accordingly, they can have more opportunities to practice and refine their own pronunciation skills through exposure to nativeness. For example, Nguyen said:

"For the pronunciation training course, if possible, I think universities should invite native-speaker teachers to teach pronunciation to ELT students. This provides them with more exposure to native pronunciation in real-life situations. It's also an opportunity for them to learn, practice, and refine their pronunciation skills with native speakers and so they'll be more confident in teaching after graduation." (P2, Teacher InI, Q7, Nguyen)

Overall, the teachers' discussion about EFL teacher training in Vietnam revealed their common belief that sweeping changes are necessary so that ELT students are well-prepared for working effectively with their learners after graduation. Given that the quality of teachers has great influence on SLOs, the teachers believed that teacher-training programmes in Vietnam needs to improve policies and requirements of ELT students' knowledge and skills in relation to pronunciation and pronunciation pedagogy. According to the teachers, this is a possible way to better equip teachers for teaching pronunciation more effectively upon graduation. Samson and Collins (2012) have argued that checkpoints before becoming a teacher such as passing exams or successfully completing required coursework or practicum is an opportunity to ensure teachers are well-prepared to work with students effectively. Likewise, in this EFL context, the teachers believed that ELT students should undergo several checkpoints during the training process if they are to foster their future learners' pronunciation learning. In other words, ELT students' competence in pronunciation skills, pronunciation knowledge, and pronunciation pedagogy needs to be warranted during the training process for effective pronunciation teaching after graduation. The study's findings suggest that EFL teacher-training programme designers need to give serious attention to ELT students outcomes, particularly pronunciation skills and pronunciation pedagogy, if Vietnamese EFL learners' pronunciation learning is to be promoted. 


\subsection{Discussion}

This section discusses in detail the main trends in this Phase 1 data of the study regarding how pronunciation was represented in the EFL programme at a Vietnamese university. Issues related to the teachers' beliefs and pronunciation teaching practices are also discussed.

\subsubsection{Pronunciation representation in the EFL programme}

The finding that pronunciation was not represented either in the course books or in any other curriculum documents raises the question of why pronunciation teaching was so notably absent in this EFL programme. The following explanations about teacher cognition and learner needs might be a possible answer to this question.

First, a number of scholars have pinpointed the value of teacher cognition in language curriculum design. Nation and Macalister (2010), for example, note that information about teacher cognition is of great use for curriculum designers if they take the instructors' capacity in implementing a language curriculum into account upon designing a language curriculum. According to Macalister (2012), "the knowledge and beliefs that teachers hold are an important determiner of what happens in the classroom" (p.99). In addition, Barnard and Nguyen (2010) have argued that only when teachers' beliefs about a pedagogical issue are taken into consideration can the aims of an intended curriculum be more fully realized. This study has found that all the teacher participants valued the important role of pronunciation in English learning, seeing it as a necessary skill their students need to build and foster (see Chapter 5). Unfortunately, teachers' beliefs might have been left out of consideration in designing this EFL programme.

Second, Carreira and Kagan (2011) have argued that teachers' instruction is guided by an understanding of learner language learning needs. In particular, Derwing (2008) has advocated that learner pronunciation needs should be adequately addressed in designing a language curriculum. In the present study, all the students demonstrated an understanding of the importance of pronunciation, and saw it as indispensable to their English learning. Believing that good pronunciation helps improve their listening and speaking skills, all the students expressed a strong need for pronunciation classes (see Chapter 5). However, administrators and curriculum designers of this EFL programme might not have taken such understandings into account when designing the curriculum. They might have assumed that pronunciation had been prescribed at secondary schools for seven years despite a lack of 
empirical evidence that pronunciation was taught at secondary schools in Vietnam. Therefore, it is suggested that pronunciation teaching should always be represented in the curriculum and classroom experience of EFL teachers at the tertiary level if Vietnamese EFL learners' pronunciation needs are to be adequately addressed.

\subsubsection{Teachers' beliefs and pronunciation teaching practices}

Taken together, findings from the classroom observation data showed a strong tendency for the teachers to keep explicit pronunciation teaching to a minimum in their EFL classes. Giving CF through recasts and prompts in response to individual students' errors was the most popular pronunciation teaching practice within the VTE classroom. The teachers' beliefs revealed that factors concerning the curriculum and students restricted their opportunities to address pronunciation explicitly in class.

The finding about the teachers' beliefs and their actual practices of pronunciation teaching is similar to findings from Phipps and Borg's (2007) research. In this study, Phipps and Borg found that the teachers' practices of grammar teaching were contradictory to their articulated beliefs. It also conforms to Phipps and Borg's (2009) argument that the teachers' stated beliefs about language learning were in contrast with their practices observed in intact classrooms. In the current study, most of the teachers stated that they were confident in teaching English pronunciation even though they reported limited initial training and a lack of PL experience in pronunciation teaching. Moreover, all the teachers reported that they would follow deliberate steps if they taught pronunciation explicitly such as listening discrimination followed by explaining places of articulation and then practice. However, in the observed lessons, they only corrected students' pronunciation errors through recasts and/or prompts, with little if any explicit or pre-planned pronunciation teaching. In the interviews, they confirmed that this was typically the only way they taught pronunciation in class. What led the teachers to teach pronunciation in the ways contrary to their articulated beliefs was the nature of the curriculum, time constraints, and learner factors such as errors, awareness, proficiency level, and age. These findings suggest that for the sake of promoting VTE learners' communicative competence, programme administrators need to pay serious attention to teacher beliefs and gain in-depth understandings of learner needs in designing the English language curriculum. 
Last but not least, this phase of the study has also found that the teachers had limited initial training in teaching pronunciation. They therefore called for more emphasis on ELT students' pronunciation skills and pronunciation pedagogy in EFL teacher training in Vietnam. This can, according to the teachers, better assist student teachers to teach pronunciation more effectively upon graduation. In addition, the teachers reported a lack of PL experience in pronunciation pedagogy during and since their pre-service education and so expressed a strong need for more PL opportunities to help them refine their pronunciation teaching skills. Accordingly, it may be necessary that PL programmes regarding pronunciation teaching be made available for Vietnamese EFL teachers if their PTC and confidence are to be strengthened. In return, learners will benefit from such professionally-promoted teaching practice.

\subsection{Summary of the chapter}

This chapter has described some preliminary findings concerning teachers' beliefs and pronunciation teaching practices. In the current study, the teachers reported teaching pronunciation explicitly on an infrequent basis following deliberate steps from listening discrimination to explaining places of articulation and finally practice. Nevertheless, classroom observations showed that they tended to correct their students' pronunciation errors of individual sounds through recasts and/or prompts. Evidence indicated that giving $\mathrm{CF}$ was most frequently used by all the teachers to address pronunciation in class. Underlying the teachers' pedagogical choices was a commitment to stay on schedule in implementing the mandated curriculum, and a number of contextual factors such as textbooks, class size, students' pronunciation errors, awareness, and English proficiency. The findings indicate that the teachers were confident in teaching pronunciation but felt more comfortable and so more frequently focused on segmentals than suprasegmental features. According to the teachers, priority needs to be given to consonants and vowels and they found it easier to teach these through visual illustrations.

The study has also found that the teachers lacked knowledge of pronunciation pedagogy and PL opportunities to enhance their pronunciation teaching skills. The teachers perceived a PL course in teaching pronunciation communicatively as useful for their teaching jobs and recognised the opportunity to refine their pronunciation teaching skills and foster their PTC. They perceived the communicative framework for teaching English pronunciation as a good way to enhance their pronunciation pedagogy, which in turn better facilitates students' 
pronunciation learning. The teachers' lack of initial training and PL opportunities in pronunciation pedagogy together with the findings about VTE learners' pronunciation instructional needs reported in Chapter 5 provided the underpinnings and motivation for the intervention carried out in the Phase 2 study. In this phase, the teachers attended a TPL workshop during which they studied the communicative framework for teaching pronunciation and subsequently applied it to lesson planning and implementation in real classroom practice.

The next chapter reports on and discusses findings about Vietnamese EFL learners' pronunciation needs from both the teachers' and students' perspectives. 


\section{Chapter 5}

\section{THE PHASE 1 STUDY: VIETNAMESE EFL LEARNERS' PRONUNCIATION NEEDS}

\subsection{Introduction ${ }^{1}$}

This chapter reports on Vietnamese EFL learners' pronunciation needs from the perspectives of both teachers and students so as to address the following research questions (RQs):

RQ4. What pronunciation instruction did the students report experiencing, and how did they perceive the efficacy of their teachers' pronunciation teaching practices as observed in intact classes?

RQ5. How did the teachers and students perceive Vietnamese EFL learners' pronunciation needs?

The chapter first presents the findings in two sections. The first section deals with the students' reports of any pronunciation instruction they previously experienced, followed by their stated beliefs about their teachers' pronunciation teaching practices as observed in intact classrooms. The second section focuses on the teachers' and students' perceptions of Vietnamese EFL learners' pronunciation needs. The findings are drawn from in-depth interviews with the six case study teachers and 24 students across the six groups. The chapter continues with a discussion of main trends in the data and concludes with a summary.

\subsection{Students' perceptions of their teachers' pronunciation teaching}

Answers to RQ4 were obtained from six FG interviews with 24 student participants (four students each). In the first part of the interview, the students were asked to recall any pronunciation instruction they most recently experienced. This part of the interview sought to gain information on what pronunciation teaching activities their teachers previously carried

\footnotetext{
${ }^{1}$ Part of this chapter has been reported in the following article:

Nguyen, L. T., Newton, J. (2019). Corrective feedback in pronunciation teaching: A Vietnamese perspective. In J. Levis, C. Nagle, \& E. Todey (Eds.), Proceedings of the $10^{\text {th }}$ Pronunciation in Second Language Learning and Teaching Conference, ISSN 2380-9566, Ames, IA, September 2018 (pp. 201-212). Ames, IA: Iowa State University.
} 
out in class, and when and how they taught pronunciation. In the second part of the interview, each student group was shown two selected excerpts of their teachers' recorded lessons in which pronunciation was a focus. These two excerpts were the same as the one I used for stimuli in the teachers' stimulated recalled interviews. In particular, students in FG5 and FG6 who were taught by teachers Khoa and Na respectively were shown a third excerpt in which their teachers provided word transcriptions followed by repetition. This part of the interview aimed to examine the students' stated beliefs about the efficacy of the teachers' observed pronunciation teaching practices as reported in Chapter 4. This section reports in turn the findings of each of these two parts of the students' FGI.

\subsubsection{Students' reports of their teachers' pronunciation teaching}

Because the students in each focus group were from different classes taught by different teachers in the past term, their recollections of teachers' pronunciation teaching varied. Moreover, some students in one focus group reported more than one pronunciation teaching activity their teacher carried out in the previous semester. For this reason, the pronunciation teaching activities the students reported were categorised thematically as presented by the data in Table 5.1 below. Overall, five types of pronunciation teaching activities were recalled and identified by the 24 student participants across the six groups: (1) correcting segmental errors through repetition; (2) correcting word stress; (3) transcribing words followed by repetition; (4) correcting final sounds and linking; and (5) explaining places of articulation followed by repetition.

Table 5.1 Students' reports of their teachers' pronunciation teaching

\begin{tabular}{lccccccc}
\hline $\begin{array}{l}\text { Teachers' pronunciation teaching } \\
\text { activities }\end{array}$ & $\begin{array}{c}\text { FG1 } \\
(\mathrm{n}=4)\end{array}$ & $\begin{array}{c}\text { FG2 } \\
(\mathrm{n}=4)\end{array}$ & $\begin{array}{c}\text { FG3 } \\
(\mathrm{n}=4)\end{array}$ & $\begin{array}{c}\text { FG4 } \\
(\mathrm{n}=4)\end{array}$ & $\begin{array}{c}\text { FG5 } \\
(\mathrm{n}=4)\end{array}$ & $\begin{array}{c}\text { FG6 } \\
(\mathrm{n}=4)\end{array}$ & $\begin{array}{c}\text { Total } \\
(\mathrm{n}=24)\end{array}$ \\
\hline $\begin{array}{l}\text { 1. Correcting segmental errors } \\
\text { through repetition }\end{array}$ & 4 & 2 & 4 & 2 & 4 & 4 & 20 \\
\hline $\begin{array}{l}\text { 2. Correcting word stress } \\
\text { 3. Transcribing words + repetition }\end{array}$ & 0 & 3 & 0 & 4 & 0 & 0 & 7 \\
\hline $\begin{array}{l}\text { 4. Correcting final sounds \& linking } \\
\text { 5. Explaining places of articulation } \\
\text { followed by repetition }\end{array}$ & 0 & 0 & 1 & 0 & 1 & 1 & 3 \\
\hline
\end{tabular}

Note: $\mathrm{n}=$ number of students 
Of the five teaching activities shown in Table 5.1, teachers correcting students' pronunciation errors of individual sounds by having students listen and repeat was the most common teaching activity, as recalled by 20 out of the 24 student participants. Only eight of the students reported that their teachers corrected word stress, and seven students said their teachers transcribed words and asked them to listen and repeat. Teachers correcting final sounds and linking was reported by four students, and teachers explaining places of articulation followed by repetition were cited by three of the students. Although students in FG5 and FG6 were later shown an additional excerpt with word transcriptions followed by repetition, they did not report this teaching practice when asked to recall their pronunciation learning experience. It is likely that the students were not well aware of this teaching practice or they may have relied on their previous classes taught by other teachers rather than on the current classes taught by Khoa and Na.

As the students further explained, their teachers only taught pronunciation when they saw students make pronunciation errors in their speaking. The following extracts illustrate this:

(36) "I remember my teacher mostly asked us to listen and repeat after her. Normally, when we made pronunciation errors in our speaking, she wrote the words down on the board. Then she asked us how to read those words. When we got it wrong, she smiled, then read the words and asked us to repeat after her. That's it." (P1, FGI1, Q1, S1)

“As I recall, my teacher seldom taught pronunciation. Usually, he corrected our errors when we got it wrong. With the words we made pronunciation errors when speaking, he usually transcribed them on the board. Then he read [the words] and asked the whole class to repeat after him.” (P1, FGI4, Q1, S3)

"I remember my teacher corrected the way we stressed in words. When we spoke with some words that we stressed wrong, she pointed out where the mistakes were and asked us to listen and repeat after her. But usually, she only corrected the words we spoke with pronunciation errors through repetition. Normally, she gave model pronunciations and then asked us to repeat after her. She didn't even transcribe the words." (P1, FGI6, Q1, S1)

Typically, the students' reports showed a strong tendency for teachers to correct pronunciation errors of segmental features through repetition, with little explicit phonetic instruction. According to the students, what their teachers most frequently did in class was that they showed model pronunciations of the words in which students made pronunciation 
errors and asked them to listen and repeat. As the students recalled, some teachers also emphasised word stress or final sounds and linking. However, this emphasis was in the form of error correction through repetition at word level. The actual words the students used in their responses showed that their teachers did not deliberately spend class time on explicit pronunciation teaching, but they instead responded to individual students' pronunciation errors through listen-and-repeat activities. This aligns with the findings from the observational data of the teacher participants' pronunciation teaching practices reported in Chapter 4. I will now turn to examine how the students perceived the efficacy of their teachers' pronunciation teaching as shown by the observational data.

\subsubsection{Students' beliefs about their teachers' pronunciation teaching efficacy}

After each student group finished watching the two pronunciation teaching episodes, I explained in detail to the students the nature of the teaching practices they have seen in the excerpts; i.e. CF through recasts and/or prompts. I further explained to the students in FG5 and FG6 the way their teachers transcribed the words in which they made pronunciation errors and asked them to listen and repeat. Then, each student in each group was encouraged to give their individual opinions about how effective they thought their teachers' pronunciation teaching was.

In response, all the 24 student participants gave a negative response when asked to talk about the effectiveness of their teachers' approach to pronunciation teaching. Eight out of the 24 student participants across the six groups believed that teachers correcting students' pronunciation errors through recasts and/or prompts was not very effective, and a majority of 16 students perceived it as not effective at all (for the quantification of the students' responses, see Appendix 12.1 in the $\mathrm{CD}$ attached). According to eight of the students, teaching pronunciation by correcting errors through recasts and/or prompts, with or without word transcriptions, was not very effective. The following extracts are evidence:

(39) "I think this approach to pronunciation teaching is not very effective. It's okay but just like 'a drop in the ocean'. So, I think there should be classes for pronunciation like other skills so that we can have a clearer understanding about pronunciation and have opportunities for practice and so the effects will be long lasting." (P1, FGI1, Q2, S4)

(40) 'I think it's effective but not much. The effect doesn't last long because we don't have a chance for practice but only repeat after the teacher. Because we aren't taught 
pronunciation explicitly and systematically, we don't know how to pronounce a new word we encounter even when we look it up in the dictionary." (P1, FGI3, Q2, S2)

"I think this way of teaching doesn't help me much. In my opinion, the sole purpose of the teacher's transcribing words is to have the transcriptions on the board. What we only do is to listen and repeat after the teacher like a machine. Later on, we'll forget all about it because we aren't taught pronunciation theory and don't have opportunities for communication practice either." (P1, FGI5, Q2, S3)

As seen from these and five other extracts, the students saw that their teachers' approach to pronunciation teaching was just a temporary solution and felt that this did not do much to promote learning. They implied that what they really needed was something that could bring about long-term improvements in their pronunciation skills. Also implied in the students' comments were their expectations of the explicit teaching of pronunciation and opportunities for oral practice, such that pronunciation should be treated as the other four language skills of listening, speaking, reading, and writing.

Two thirds of the students $(16 / 24)$ believed that their teachers' pronunciation teaching had no effect at all on their learning. A majority of the students perceived that imitating through repetition was too mechanical and difficult for them to remember, and thus not at all useful for their pronunciation skills. As these students held, their pronunciation was not improved through such a teaching approach. The following comments represent this collective view:

(42) 'I think it's completely ineffective. The teacher correcting our errors through repetition is too mechanical. I think pronunciation requires time but I realise that not only the teacher teaching this semester but also those in previous terms don't care about it and so they don't spend time teaching pronunciation explicitly and systematically in class." (P1, FGI2, Q2, S3)

(43) “Completely ineffective. My teacher's teaching approach made no impression on me. This way of imitating is too mechanical and too difficult to remember and so my pronunciation skills don't improve." (P1, FGI4, Q2, S4)

(44) “I think it's not effective at all. The teacher correcting our errors through repetition looks just like the way we teach a parrot how to speak. Even when she transcribed words on the board, we can only read [pronounce] the words that she has taught. When encountering a new word, we don't know how to say it correctly." (P1, FGI6, Q2, S1) 
In sum, the students held a negative view on the efficacy of their teachers' pronunciation teaching, which they found too mechanical and thus not beneficial to their pronunciation skills. This collective view is inconsistent with their teachers who all believed that correcting students' pronunciation errors through recasts and/or prompts was effective (see also section 4.3.3 in Chapter 4). Although repetition can enhance L2 learners' pronunciation (Saito \& Lyster, 2012; Trofimovich \& Gatbonton, 2006), it is "no longer a satisfactory tool for either the educator or the learner" (Adams-Goertel, 2013, p. 121) given that repetition and drills are not compatible at discourse level whereby learners engage in communicative practice (Isaacs, 2009). In the current study, what the students said they expected was that teachers give more attention to their pronunciation skills by spending more time teaching pronunciation explicitly in class. This is because the students believed that only when teachers did this, could they have a better understanding of English pronunciation and more opportunities for practice. They saw this as leading to an improvement in their pronunciation skills.

The question, then, is how the students would like to be taught pronunciation in class. This issue is addressed in the following section which presents findings about Vietnamese EFL learners' pronunciation needs as perceived by both the teacher and student participants.

\subsection{Vietnamese EFL learners' pronunciation needs}

This section reports on the findings that answer RQ5 about Vietnamese EFL learners' pronunciation needs from both the teachers' and students' perspectives. Data were drawn from the last part of teachers' in-depth interviews and the third part of the students' FGI.

\subsubsection{Teachers' perceptions of Vietnamese EFL learners' pronunciation needs}

In order to examine Vietnamese EFL learners' pronunciation needs from the teaching perspective, I first asked the teachers to answer how important pronunciation is in English learning based on a rating scale of 1-5 (where $1=$ not important at all and $5=$ most important of all language skills). The interview data show that the teachers all cited 'very important' as their choice. This indicates that all the teachers highly valued the importance of pronunciation in EFL learning. To some extent, this finding is in conflict with Elliot's (1995) claim that "teachers tend to view pronunciation as the least useful of the basic language skills" (p.531). In the current study, all the teachers believed it is important that pronunciation skills be built and fostered in EFL learning as they were well aware that pronunciation is one of the most essential features for successful oral communication. 
The teachers were then asked to elaborate on the underlying rationale for their choice. The data presented in Table 5.2 show that five different reasons were given. Of these, the first two reasons, i.e. improving listening and speaking skills and promoting learners' confidence, were reported by six and four of the teachers respectively. The third one, good pronunciation enhances learners' motivation in language learning, was cited by two of the teachers, while the last two reasons were given by only one of the teachers.

Table 5.2 Teachers' beliefs about the role of pronunciation in EFL learning

\begin{tabular}{lll}
\hline The role of pronunciation in EFL learning & Frequency & Mentioned by \\
\hline 1. Improve listening and speaking skills & $\mathrm{n}=6$ & All six teachers \\
\hline 2. Promote students' confidence & $\mathrm{n}=4$ & Quynh, Phuong, Nguyen, Khoa \\
\hline 3. Enhance students' motivation & $\mathrm{n}=2$ & Quynh, Phuong \\
\hline 4. Create a good impression on interlocutors & $\mathrm{n}=1$ & Diep \\
\hline 5. Improve the listening test score & $\mathrm{n}=1$ & Khoa \\
\hline
\end{tabular}

Note: $\mathrm{n}=$ number of teachers

As seen from Table 5.2, all the teachers believed that good pronunciation results in improved listening and speaking skills. This may partly be because pronunciation, listening, and speaking are interdependent (Adams-Goertel, 2013; Seyedabadi et al., 2015). Four of the teachers, Quynh, Phuong, Nguyen, and Khoa, further reasoned that if students face pronunciation problems that impede their listener's proper interpretations of an intended message in oral communication, they may become disheartened. This aligns with an argument that L2 learners who have pronunciation problems may lose confidence and willingness to speak (Gilakjani, 2012b; Zielinski, 2012). However, these teachers believed when students realise that their interlocutors understand what they say due to their improvement in pronunciation, they will become more confident in using English for oral interaction. Quynh and Phuong added that such an outcome will be accompanied by the students' increased motivation in learning the language and so they will more frequently use English for oral practice. Accordingly, their listening and speaking skills will improve. The following comments are representative:

(45) “Pronunciation is one of the most important skills that helps improve language learners' listening and speaking skills. When students fail in oral communication due to their pronunciation errors, they'll certainly be disheartened and so will be demotivated in 
learning the language. However, if they have more chances for pronunciation learning and practising and realise that other people such as teachers and their peers understand what they say, they will feel more confident in speaking English. Accordingly, their motivation in English learning will be promoted." (P1, Teacher InI, Q8, Quynh)

(46) “Clearly, pronunciation is a must because it helps develop learners' language skills, especially listening and speaking. Pronunciation is extremely important in foreign language learning. If interlocutors understand what students want to say, then they'll be happier and more motivated in learning the language. Gradually, they'll be more confident in speaking English.” (P1, Teacher InI, Q8, Phuong)

Given that "poor pronunciation degrades good language skills and condemns learners to less than their deserved social, academic and work advancement" (Varasarin, 2007, p. 45), Teacher Diep also believed that a good command of pronunciation could create a good impression on interlocutors in oral communication. She said that if speakers' pronunciation skills are good, then they are considered as proficient English users by the listener. She said:

$$
\begin{aligned}
& \text { "Pronunciation is a very important skill. First, it helps improve listening and } \\
& \text { speaking skills. Second, many pronunciation features such as sentence stress, } \\
& \text { intonation or linking play an essential role in oral communication. These features not } \\
& \text { only help speakers succeed in exchanging information but also give a good } \\
& \text { impression on interlocutors. They'll consider the speaker as being proficient in using } \\
& \text { English." (P1, Teacher InI, Q8, Diep) }
\end{aligned}
$$

Teacher Khoa took listening test scores into consideration as another reason to support her evaluation of the importance of pronunciation. She believed that if learners are good at pronunciation and vocabulary, they will not only be successful in oral interactions but also do a better job in listening tests. This is partly because, according to Underhill (2012), pronunciation is tested all the time in listening comprehension. Khoa added:

(48) "Pronunciation is a very important skill in English learning because it helps improve learners' listening and speaking skills. So, I usually raise my students' awareness of this and encourage them to practice [pronunciation]. When teachers and other students in class understand what they say, they'll feel more confident in speaking English. Listening test scores can be improved too if students are good at pronunciation and vocabulary." (P1, Teacher InI, Q8, Khoa) 
In brief, the study has found that all the participating teachers valued the important role pronunciation plays in their students' English learning. This finding finds support in the current literature in which a number of scholars have argued that pronunciation should never be ignored in ESL/EFL learning. Nation and Newton (2009), for example, assert that it is of great importance that "attention is given to pronunciation in the course so that learners can quickly develop a stable pronunciation, and become familiar with the patterns and rules that work within the second language" (p.76). Given the indispensability of pronunciation in oral communication, Celce-Murcia et al. (2010) and Rogerson-Revell (2011) have claimed that without correct pronunciation, oral interactions are more likely to be unsuccessful. In a similar vein, Derwing and Munro (2015) have illustrated a number of cases in which pronunciation errors lead to breakdowns in daily conversational exchanges.

Although all the teachers saw the clear importance of pronunciation in English learning, central to their pronunciation teaching as observed in this EFL context were giving $\mathrm{CF}$ through recasts and/or prompts in response to individual students' pronunciation errors upon performance. This finding provided the impetus to examine the teachers' thoughts and beliefs about the communicative teaching of English pronunciation. Thus, the teachers were then encouraged to talk about the communicative practice stage in pronunciation teaching procedures. In response, all the teachers agreed that pronunciation instruction including communicative practice activities is more beneficial to student learning than isolated practice of pronunciation features alone. The following extracts illustrate this perspective:

(49) "Of course, it would be better if we include communicative practice activities in teaching pronunciation. This is also what our students expect because they can apply what they have learned in real communication practice." (P1, Teacher InI, Q9, Phuong)

(50) "The aim of teaching pronunciation is certainly to improve learners' communication skills and this is what they need. So, we can give students more opportunities for practice by creating different communication situations so that they can apply what they have learned." (P1, Teacher InI, Q9, Diep)

(51) "I think it would be much better if we teach pronunciation explicitly including the communicative practice stage. Today, students are more demanding. They need theory and practice at the same time. They expect to get involved in real communication situations." (P1, Teacher InI, Q9, Na) 
As seen from these and three other extracts, the teachers all stated that the stage of communicative practice is what their students expect because they can apply what they have learned in real-life communication situations. However, the classroom observations indicated that the teachers' main pronunciation teaching role was to give $\mathrm{CF}$ in response to their students' pronunciation errors through recasts and/or prompts with or without word transcriptions. Carreira and Kagan (2011) state that "it is critical for instructors to understand their students individually as well as collectively and apply this knowledge to differentiating instruction by learner needs" (p.62). In the present study, the teachers demonstrated their understanding of the students' instructional needs, yet such knowledge was not at all applied by the teachers in taking their classroom actions. They were well aware that their students expected communicative practice activities, but within their own teaching situations, the teachers were unable to provide such activities for students' practice. As the teachers said, given the time constraints in the mandated curriculum, what they could only do was correcting their students' pronunciation errors through recasts and/or prompts. From the teachers' perspectives, this approach to pronunciation teaching was effective in this EFL context. Yet, this “traditional approach" (Baker, 2014, p. 153) suggests the ongoing influence of repetition drills in which instructors act as the model of the target language and in which practice occurs mechanically. As a result, students were not given the opportunity to take the initiative in pronunciation learning, and consequently, as reported in section 5.2.2 above, did not find their teachers' instruction beneficial to their pronunciation skills.

Finally, Vietnamese EFL learners' pronunciation needs were examined through the teachers' teaching experience. That is, they were asked to identify which pronunciation errors Vietnamese EFL learners commonly make. The data (Table 5.3) show that five types of errors were reported by the teachers, including both segmental and suprasegmental features: (1) consonants that do not exist in Vietnamese; (2) final sounds and linking; (3) intonation; (4) long and short vowels; and (5) sentence stress. Of the five error types, as Table 5.3 shows, the most common errors were consonants that do not exist in Vietnamese, final sounds and linking, and intonation as being reported by all the six teachers. Problems related to long and short vowels and sentence stress were less frequent, being mentioned by three of the teachers. 
Table 5.3 Teachers' reports of Vietnamese EFL learners' pronunciation errors

\begin{tabular}{lll}
\hline Common errors & Frequency & Mentioned by \\
\hline 1. Consonants not existing in L1 & $\mathrm{n}=6$ & All six teachers \\
\hline 2. Final sounds and linking & $\mathrm{n}=6$ & All six teachers \\
\hline 3. Intonation & $\mathrm{n}=6$ & All six teachers \\
\hline 4. Long and short vowels & $\mathrm{n}=3$ & Quynh, Diep, Khoa \\
\hline 5. Sentence stress & $\mathrm{n}=3$ & Phuong, Nguyen, Khoa \\
\hline
\end{tabular}

Note: $\mathrm{n}=$ number of teachers

The finding about pronunciation problems faced by Vietnamese EFL learners is consistent with those reported in Smith and Swan (2001), Lane and Brown (2010), and Avery and Ehrlich (2013). As documented in the current literature, Vietnamese EFL learners commonly have a wide range of pronunciation problems including those reported by the teachers of the current study. I will now turn to examine the students' perceptions of their own pronunciation instructional needs.

\subsubsection{Students' perceptions of their own pronunciation needs}

This section reports on Vietnamese EFL learners' pronunciation needs from the learning perspective. The data was derived through questions that sought to investigate the students' stated beliefs about how important pronunciation is in English learning, if they needed pronunciation instruction, how they would like to be taught pronunciation in class, and what pronunciation problems they commonly have. The rationales for the teaching approach the students preferred teachers to take in class were further discussed.

First, the students were asked to discuss the importance of pronunciation in English learning by choosing an item on a rating scale of 1-5 (where $1=$ not important at all and $5=$ most important of all language skills). The data show that more than half of the student participants across the six groups (15/24) believed that pronunciation is very important, and nearly one third (7/24) stated that it is the most important skill. Only two of the students rated pronunciation as being an important skill in English learning. The data are summarised in Table 5.4 below. 
Table 5.4 Students' perceptions of the role of pronunciation in English learning

\begin{tabular}{lccccccc}
\hline $\begin{array}{l}\text { Pronunciation in English } \\
\text { learning }\end{array}$ & $\begin{array}{c}\text { FG1 } \\
(\mathrm{n}=4)\end{array}$ & $\begin{array}{c}\text { FG2 } \\
(\mathrm{n}=4)\end{array}$ & $\begin{array}{c}\text { FG3 } \\
(\mathrm{n}=4)\end{array}$ & $\begin{array}{c}\text { FG4 } \\
(\mathrm{n}=4)\end{array}$ & $\begin{array}{c}\text { FG5 } \\
(\mathrm{n}=4)\end{array}$ & $\begin{array}{c}\text { FG6 } \\
(\mathrm{n}=4)\end{array}$ & $\begin{array}{c}\text { Total } \\
(\mathrm{n}=24)\end{array}$ \\
\hline Most important & 1 & 2 & 1 & 3 & 0 & 0 & 7 \\
\hline Very important & 3 & 2 & 2 & 1 & 3 & 4 & 15 \\
\hline Important & 0 & 0 & 1 & 0 & 1 & 0 & 2 \\
\hline
\end{tabular}

Note: $\mathrm{n}=$ number of students

Like the teachers, all the students highly valued the importance of pronunciation in English learning. They further explained that pronunciation lays the foundation for other language skills, especially communication skills, to be developed. According to the students, given that pronunciation promotes understandings between interlocutors, it contributes to their communicative success in oral interaction. The following extracts are representative:

(52) 'I think it's extremely important, the most important. It's the basis for listening and speaking skills. Good pronunciation makes it easier for messages to get through in oral communication with foreigners." (P1, FGI2, Q3, S2)

(53) "Pronunciation is a very important skill. In my opinion, it lays the foundation for other language skills to develop, especially listening and speaking. I think good pronunciation helps the speaker and the listener understand each other more easily. Only when we understand what the speaker is talking about can we respond properly." (P1, FGI6, Q3, S4)

This finding is consistent with the findings in Kang's (2010) and Simon and Taverniers' (2011) studies in which a majority of the student participants agreed that pronunciation is an important feature in oral communication. Interestingly, one of the students who stated that pronunciation is the most important skill showed her acknowledgement of the communicative value of English intonation. This student believed that if learners are good at pronunciation, then they will be aware of how intonation functions in oral communication. She said:

"Pronunciation is the most important skill. I think it's the basis of other language skills, especially listening and speaking, because good pronunciation promotes mutual understandings between the speaker and the listener. Only when we understand the problem a speaker is talking about can we solve it. Besides, English has intonation. 
When we're good at pronunciation, we'll 'appreciate the beauty' of intonation and so we'll try our best to practice." (P1, FGI4, Q3, S3)

Elaborating on the underlying rationales for their ratings of the importance of pronunciation, the students stated that good pronunciation: (1) improves listening and speaking skills; (2) promotes their confidence in oral communication; and (3) improves test scores (for the quantification of the students' responses, see Appendix 12.2 in the CD attached). This resonates with the teachers' beliefs about the role pronunciation plays in EFL learning (also see section 5.3.1). Figure 5.1 displays the students' beliefs about what role pronunciation plays in English learning.

Figure 5.1 Students' beliefs about pronunciation in EFL learning

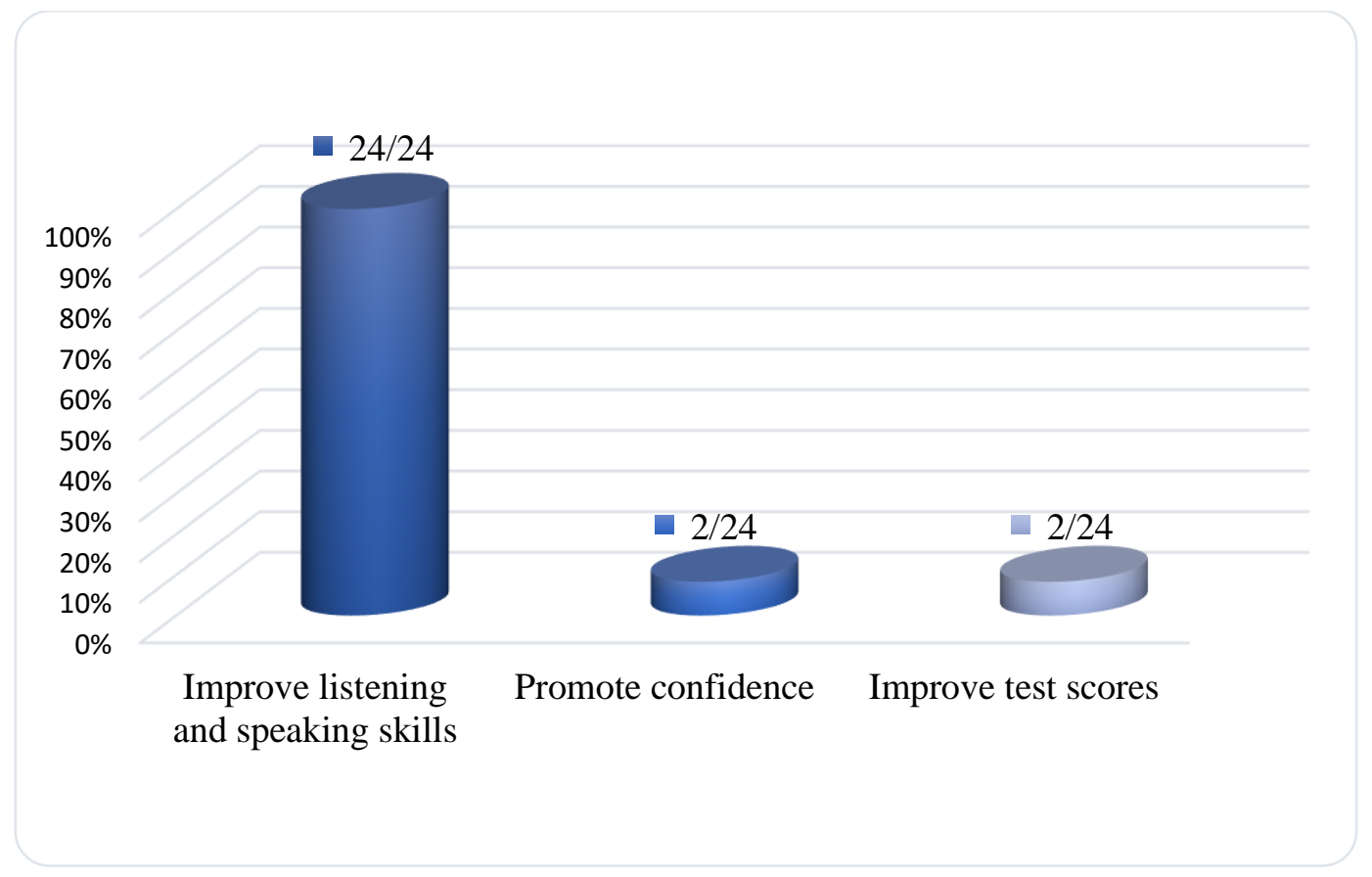

As shown in Figure 5.1, all the students believed that good pronunciation improves their listening and speaking skills. Overall, this collective view amongst the student participants reveals that if they are good at pronunciation, then their listening and speaking skills will be boosted. This is partially true because, according to Adams-Goertel (2013), Baker (2014), and Celce-Murcia et al. (2010), listening comprehension and pronunciation are interconnected in oral interaction. In the current study, the students believed that good pronunciation promotes mutual understandings between the speaker and the listener, increasing the likelihood of successful oral communication. Consequently, they believed that 
the more students are involved in oral conversations, the better their listening and speaking skills will be. The following comments illustrate this collective view:

"I think pronunciation is very important. Good pronunciation helps improve listening and speaking skills. When I spoke English with native speakers, they seemed not to understand what I was saying although I'm sure I used correct grammar structures." (P1, FGI1, Q3, S1)

"I think pronunciation is an important skill because it helps me speak better, making oral interactions successful. It also improves my listening skills.” (P1, FGI3, Q3, S3)

"Important, I think. It improves my listening and speaking skills. Good pronunciation skills make it easier for me to communicate with foreigners. It serves the communicative purposes in daily life." (P1, FGI5, Q3, S2)

Two of the students believed that good pronunciation enhances their confidence in oral interaction. This finding lends support to Gilakjani (2012b) and Zielinski (2012), who argue that good pronunciation gives rise to L2 learners' confidence and willingness to communicate. It is also consistent with the finding in Kang's (2010) survey, which involved 115 ESL learners in New Zealand and 123 in North America. In this study, Kang found that up to $93 \%$ of the participants reported that if their pronunciation is good, they will feel more confident in using English for oral communication. In the present study, the students believed that a good command of pronunciation helps them easily understand their interlocutors and make themselves precisely understood in oral communication. As a consequence, the students will become more confident in speaking English and simultaneously can score better in tests. They said:

(58) "Pronunciation is very important. It helps improve my listening and speaking skills. Good pronunciation also makes me speak better and more confidently. So, foreigners can understand what I say more easily." (P1, FGI1, Q3, S3)

“I think it's very important. It improves listening and speaking skills. It's better if my pronunciation is good because I can understand what other people say and vice versa. Also, I can improve my scores in tests." (P1, FGI2, Q3, S4)

(60) “I think it's very important. It improves my listening and speaking skills. Other people can understand us only when we pronounce correctly. If we pronounce some words incorrectly, the listener may interpret our message in a wrong way. Moreover, good 
pronunciation also makes me feel more confident and helps me score better in tests." (P1, FGI5, Q3, S1)

In response to being asked if they wanted to attend pronunciation classes, and how they would like teachers to teach it, all the students across the six groups stated that they would like to attend pronunciation classes. In addition, all of them showed a strong need for teachers to teach pronunciation communicatively. Although the term 'CPT' was not explicitly used by the students, their responses revealed that they would like teachers to teach pronunciation communicatively so as to help them improve not only pronunciation but also listening and speaking skills. Elaborating on the teaching approach they preferred teachers to take in class, the students believed that CPT is much better than an approach grounded in listen-and-repeat activities. According to the students, when pronunciation is taught communicatively, it could: (1) improve learner listening and speaking skills; (2) reduce classroom tension and increase learner motivation; (3) speed up learner comprehension of teacher instruction; and (4) promote interactions through error corrections (for the quantification of the students' responses, see Appendix 12.3 in the $\mathrm{CD}$ attached). Figure 5.2 provides a visual representation of the students' stated beliefs about how they would like teachers to teach pronunciation.

Figure 5.2 Phase 1 students' beliefs about their preferred pronunciation teaching approach

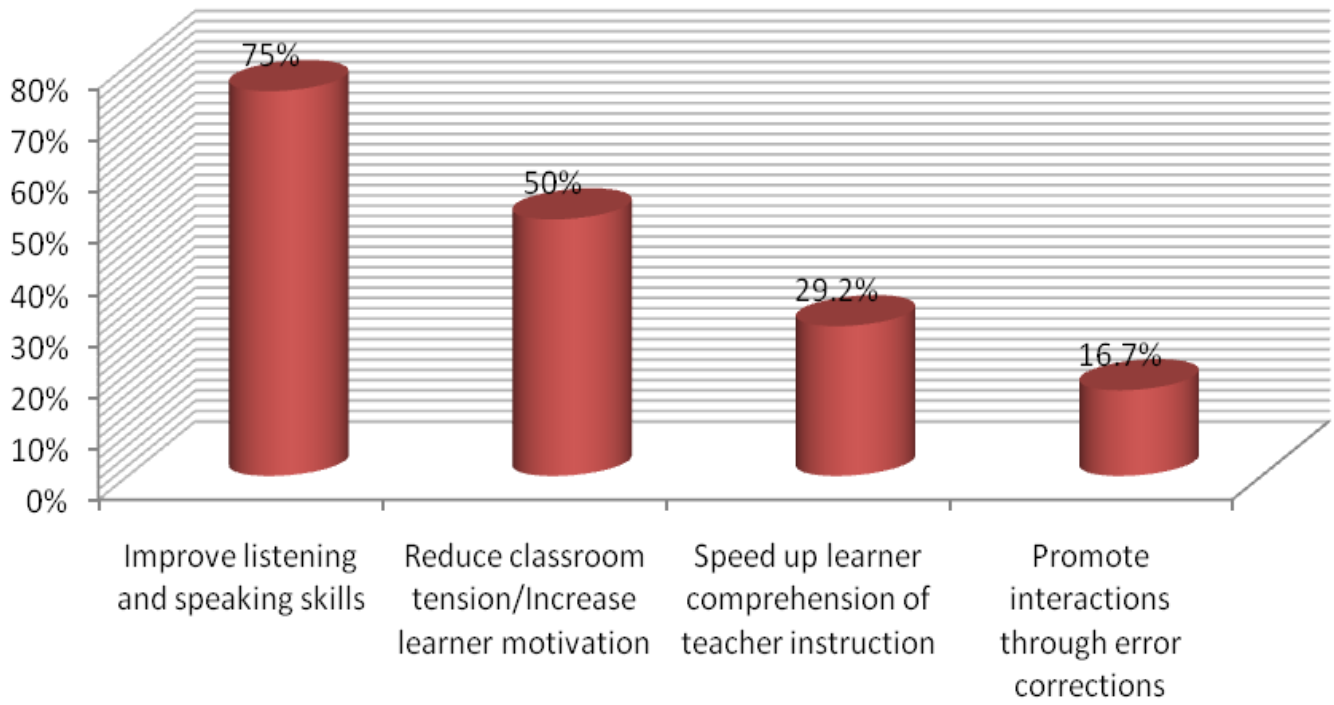

First, Figure 5.2 shows that $75 \%$ of the student participants (18/24) believed that teaching pronunciation communicatively helps improve their listening and speaking skills.

Interestingly, this view aligns with the teachers' beliefs that students expected communicative practice activities in pronunciation instruction, as reported in section 5.3.1 above. According 
to the students, it is more practical for teachers to teach pronunciation communicatively within the EFL classroom. The students believed that teachers teaching pronunciation this way will provide learners with more opportunities to apply what they have been taught in real-life communication situations. Accordingly, their listening and speaking skills would be reinforced. The following extracts are representative:

(61) 'Yes. I'd like to attend pronunciation classes but teachers should teach it communicatively. This approach is more practical because we can apply what we've learned in communication. And when we have more opportunities for practice, our listening and speaking skills will improve." (P1, FGI2, Q4, S1)

(62) 'Yes. I'd love it and I'd prefer teachers to teach pronunciation communicatively because it's practical and more interesting. Learning through listen-and-repeat activities is very boring, and we'll forget everything after repeating. If teachers teach [pronunciation] communicatively, we can improve not only my pronunciation but also listening and speaking skills. Then, it'll be better when I communicate with others outside the class." (P1, FGI4, Q4, S3)

(63) “Yes. It's better to have pronunciation classes. For a teaching approach, I don't know how to say but I would prefer that teachers taught it in ways that can help me improve both pronunciation and communication skills. If we can practice what we've learned from the theory, then the outcomes will be much better. Our listening and speaking skills can be improved much more." (P1, FGI6, Q4, S2)

Second, half of the students (12/24) stated that teaching pronunciation communicatively helps reduce classroom tension and increase learner motivation. As these students stressed, this teaching approach is more interesting and makes the classroom atmosphere more welcoming. Thus, they believed that learners will be more motivated in attending class meetings. They said:

(64) "I think it would be good. I'd love to attend pronunciation classes. I hope teachers teach pronunciation communicatively because students will have more opportunities for practice in communicative situations. Also, the classroom atmosphere will be more interesting, making students more motivated to come to class." (P1, FGI2, Q4, S4)

(65) "Yes. I love it. There should be that part [pronunciation] in English learning to help learners master pronunciation and improve their communication skills, so they'll be more confident in speaking English. I'd prefer teachers to teach [pronunciation] 
communicatively because it's practical and makes me more interested in learning. Learning through listen-and-repeat activities is boring, so the outcomes won't be that great." (P1, FGI4, Q4, S1)

(66) "I think pronunciation is an integral part in English learning. And I would prefer teachers to teach it communicatively. Learning through listen-and-repeat activities is very boring and mechanical. If teachers teach [pronunciation] communicatively, then it'll help us develop our listening and speaking skills because we have more opportunities for communication practice. It also makes students more motivated and active and so their 'brains' will work harder. They can learn more.” (P1, FGI6, Q4, S4)

As shown in these and other extracts, the students attached special importance to the classroom atmosphere in characterising their preferred approach to pronunciation teaching. For the students, it is the welcoming classroom atmosphere that makes them come to class. They believed that if they find their class meetings interesting, they will be more motivated and active, and thus will benefit more from the teacher's instruction. According to the students, since this approach makes them more hard-working, they will become more productive learners.

Third, seven of the students stressed that CPT helps speed up learner comprehension of teacher instruction. These students perceived that when pronunciation is taught communicatively, learners will find it easier to understand teacher instruction. They therefore believed that knowledge would be absorbed faster and the outcomes would be better, as illustrated in the following comments:

(67) "Yes. The reason is that I want to improve my communication skills. When I communicate with foreigners, I can understand them easily and they can understand what I say in return. I'd prefer that pronunciation was taught communicatively because it makes me more interested in learning. The lessons will be more comprehensible and I can absorb the knowledge transferred by my teacher faster. So, the results will be much better." (P1, FGI3, Q4, S1)

(68) "I think pronunciation needs to be integrated in our English programme so that our pronunciation and communication skills can be improved. It's better for pronunciation to be taught communicatively because it's more practical. We can understand teachers' instruction faster and more easily, so the results will be better." (P1, FGI5, Q4, S1) 
Finally, teaching pronunciation communicatively is also seen to promote interactions between the teacher and students and amongst students themselves through error corrections, as articulated by four of the students. They commented:

"Yes. I want to improve my pronunciation and communication skills. It's better if teachers teach [pronunciation] communicatively, giving us more opportunities to improve listening and speaking skills. Then I think students will have more chances for interactions and we can help each other correct our pronunciation errors too." (P1, FGI1, Q4, S4)

(70) "I think pronunciation needs to be included in our English programme and it should be taught effectively. Learning through listen-and-repeat activities is very boring, mechanical, and not practical. Teaching [pronunciation] communicatively can help improve our listening and speaking skills a lot more. Also, there'll be more interactions between teachers and students through teacher correction of students' errors. We can also help each other correct ourselves. This helps students become more confident and so the results will be better." (P1, FGI5, Q4, S2)

As these and two other extracts show, the students believed that pronunciation practice including communicative activities encourages interaction amongst learners and between the teacher and learners. In addition, the students were aware that, in communicating in English, they will generally face pronunciation problems. Here, interactions amongst pair/group members will be facilitated through peer correction, and thus these errors could be addressed. This belief finds support in the work of Derwing and Munro (2015) who claim that peer correction helps raise learner awareness of their own pronunciation errors and thus should be encouraged in classroom learning. Moreover, the students believed that their teacher as a facilitator will give $\mathrm{CF}$ upon their rehearsals and/or performance. They suggested that the more they were involved in oral interactions, the more corrections could be made, and thus the learning outcomes would be better.

Vietnamese EFL learners' pronunciation needs were investigated through the students' perceptions of pronunciation problems they commonly have in oral communication as well. The last question in the interview asked each student in each group to recall what pronunciation errors they usually make in speaking English. According to the students, they have problems with both segmental and suprasegmental features, including intonation, 
linking, final sounds, sentence stress, consonants not existing in Vietnamese, and long and short vowels. The data are presented in Table 5.5.

Table 5.5 Students' perceptions of their own pronunciation errors

\begin{tabular}{|c|c|c|c|c|c|c|c|}
\hline $\begin{array}{l}\text { Students' perceived } \\
\text { pronunciation problems }\end{array}$ & $\begin{array}{c}\text { FG1 } \\
(\mathrm{n}=4)\end{array}$ & $\begin{array}{c}\text { FG2 } \\
(\mathrm{n}=4)\end{array}$ & $\begin{array}{c}\text { FG3 } \\
(n=4)\end{array}$ & $\begin{array}{c}\text { FG4 } \\
(n=4)\end{array}$ & $\begin{array}{c}\text { FG5 } \\
(\mathrm{n}=4)\end{array}$ & $\begin{array}{c}\text { FG6 } \\
(\mathrm{n}=4)\end{array}$ & $\begin{array}{l}\text { Total } \\
(\mathrm{n}=24)\end{array}$ \\
\hline 1. Intonation & 4 & 3 & 4 & 4 & 3 & 3 & 21 \\
\hline 2. Linking & 3 & 2 & 3 & 4 & 3 & 3 & 18 \\
\hline 3. Final sounds & 3 & 2 & 4 & 2 & 3 & 4 & 16 \\
\hline 4. Sentence stress & 2 & 3 & 2 & 2 & 3 & 3 & 15 \\
\hline 5. Consonants not existing in L1 & 2 & 1 & 2 & 2 & 2 & 2 & 11 \\
\hline 6. Long and short vowels & 1 & 1 & 0 & 1 & 1 & 1 & 5 \\
\hline
\end{tabular}

Note: $\mathrm{n}=$ number of students

As Table 5.5 shows, the majority of the students across the six groups (21/24) reported that the pronunciation errors they most commonly make in speaking English are related to intonation, followed by linking (18/24), dropping final sounds (16/24), and sentence stress (15/24). Whereas all the teachers reported that one of the most common errors amongst Vietnamese EFL learners is related to consonants not existing in Vietnamese, less than $50 \%$ of the students $(11 / 24)$ thought that they had problems pronouncing such consonants. Problems regarding long and short vowels are the least frequent, being mentioned by only five of the students across the six groups. Jenkins (2002) in discussing the pronunciation targets for speakers of English as an international language proposed that pitch movement (i.e. intonation) is not essential for speakers who have limited interaction with native speakers and may even be unteachable. However, the current study shows that both the teacher and student participants perceived intonation to be a problematic feature for Vietnamese learners of English. They both considered intonation as important for learners' spoken English competence, with one student particularly articulating her belief about the value of intonation in oral communication as reported above.

In sum, pronunciation problems reported by the student participants are consistent with those in the teachers' reports which have also been well documented in the literature (also see section 5.3.1 above). These pronunciation errors can be classified into four categories: (1) long and short vowels; (2) consonants not existing in Vietnamese; (3) final sounds and 
linking; and (4) sentence stress and intonation. This classification laid grounds for the design and implementation of the experimental teaching in Phase 2 of the study as described in Chapter 3 and later reported in Chapter 6.

\subsubsection{Concluding remarks}

Taken as a whole, both the teachers and students who participated in the present study perceived that pronunciation is an important feature in EFL learning and that good pronunciation skills are essential for successful oral interaction. Since the students expressed a strong need for pronunciation instruction as an integral part in English learning, it can be argued that VTE teachers should always incorporate pronunciation within their language classroom. More importantly, the findings suggest that teachers extend learner practice of a phonological feature from the stage of repetition to a higher level of more creative/communicative exchanges so as to meet the students' instructional needs. The students believed that CPT would foster their listening and speaking skills, make the classroom atmosphere more interesting, create more interactions within the classroom, and enhance learner motivation.

\subsection{Discussion}

The findings show that the Vietnamese learners in this study faced several pronunciation problems including both segmental and suprasegmental features as reported by both the teacher and student participants. Also, both groups held strong beliefs about the important role pronunciation plays in EFL learning. As Levis (2005) holds, the importance of pronunciation teaching has often been in an ideological position or based on intuition rather than on empirical evidence from research. In this sense, the study has taken the first step to examine teachers' and students' stated beliefs about the important role pronunciation plays in a particular setting of EFL education in Asia. The belief the teachers and students hold about the importance of pronunciation in English learning finds support in Celce-Murcia et al. (2010), T. Jones (2018), and Rogerson-Revell (2011), who maintain that without intelligible pronunciation, oral communication is less likely to be successful. Both the teacher and student participants reported that pronunciation is an essential part in English learning, and thus needs to be taught explicitly and systematically.

Nation and Macalister (2010) have pointed out that in order to meet students' learning needs in designing a language curriculum, it is important to address three domains: (1) necessities 
(what students need to know to be successful in using the target language), (2) lacks (what students were not taught or did not practice in their previous learning), and (3) wants (what and how students would like to learn). In the current study, the teachers and students believed that a good command of pronunciation can help develop learners' listening and speaking skills, foster their confidence and willingness to communicate, and improve test scores. However, they reported that Vietnamese secondary EFL teachers mainly focused on teaching vocabulary and grammar in class and tended to ignore pronunciation. To this end, both the teachers and students stated that pronunciation instruction needs to be included and carried out explicitly and systematically in tertiary EFL programmes in Vietnam. Thus, it may be necessary that teachers place more emphasis on pronunciation teaching in their EFL classes if Vietnamese EFL learners' pronunciation, and listening and speaking skills in general, are to be more efficiently fostered. By doing this, the necessities and the lacks would be accommodated. A number of researchers and practitioners have called for more focused pronunciation in ESL/EFL classes (Couper, 2006; Derwing \& Munro, 2014; Isaacs, 2009). In a similar vein, Derwing (2008) has advocated that learner pronunciation needs should be adequately addressed in designing a language curriculum. Previous research has also shown that students expect more opportunities to learn and practice pronunciation in class (Derwing \& Rossiter, 2002; Foote et al., 2011; Pardede, 2018).

The study has also found that the students held a negative view on their teachers' pronunciation teaching (correcting errors through recasts and/or prompts), and expressed a strong need for a CPT approach. According to the students, if teachers teach pronunciation communicatively in class, they can improve not only pronunciation but also listening and speaking skills. The students believed that CPT makes the classroom atmosphere more relaxing and welcoming, promotes interaction in classroom learning and thus makes students more motivated to attend classes. The findings suggest that the focus of pronunciation instruction within this EFL context should be on genuine communication rather than isolated practice of individual phonological units so that learners can make use of those opportunities to practice their pronunciation in real-life communicative situations. Although repetition drills are believed to facilitate the acquisition of L2 pronunciation (Saito \& Lyster, 2012; Trofimovich \& Gatbonton, 2006), the students' favourable attitudes towards CPT are encouraging. Avery and Ehrlich (2013), Celce-Murcia et al. (2010), and Isaacs (2009) have argued that CPT allows L2 learners to use the targeted phonological features in communicative practice, which is more likely to improve their production. 
Spada and Lightbown (2008) hold that communicative activities "may be best for helping learners develop the kind of fluency and automaticity that are needed for communication outside the class" (p. 181). In this EFL context, the students have little need to use English for oral interaction outside the classroom, and examinations are not orally conducted. However, the value that the students put on CPT is consistent with the teachers' beliefs about learners' expectation of instructors' teaching approach, as reported in section 5.3.1. It is also consistent with the learners in an American ESL setting who reported that they needed more opportunities to practice those target phonological features in real-life communication situations (Vitanova \& Miller, 2002). In particular, pronunciation teaching implemented in cooperation with communicative activities has empirically been reported to foster L2 learners' pronunciation improvement (Gordon et al., 2013; Saito, 2011, 2012b). Since "learners have their own views about what they think is useful for them" (Nation \& Macalister, 2010, p. 29), it is necessary that the wants of learners' pronunciation instructional needs be addressed in this EFL context. In other words, the findings suggest that pronunciation instruction within the Vietnamese EFL classroom be delivered communicatively so as to maximise learners' practice outcomes through real-life communicative situations.

\subsection{Summary of the chapter}

This chapter has presented and discussed the findings about Vietnamese EFL learners' pronunciation instructional needs from both the teachers' and students' perspectives. As both groups perceived, pronunciation is an integral part in EFL learning given that good pronunciation skills facilitate mutual understandings in oral interaction. Since Vietnamese EFL learners face unique pronunciation problems, it is important that pronunciation instruction be represented in both the language curriculum and in teachers' classroom practice. More importantly, both the teachers and students believed that pronunciation instruction including communicative practice activities helps learners improve not only pronunciation but also listening and speaking skills. In brief, the study's findings can be useful for EFL curriculum designers in this educational context and elsewhere.

The next chapter, Chapter 6, reports on findings of the Phase 2 study regarding how the teachers enacted the intervention and how they perceived the impact of a TPL workshop on CPT on their knowledge gains and pronunciation teaching skills. 


\section{Chapter 6}

\section{THE PHASE 2 STUDY: TEACHER PROFESSIONAL LEARNING TO ENHANCE PRONUNCIATION TEACHING}

\subsection{Introduction}

We have seen from Phase 1 that the teachers in the current EFL context reported having limited initial training and a lack of PL in pronunciation pedagogy. They thus expressed a strong need for more opportunities to enhance their pronunciation teaching skills. The teachers valued the notion of CPT and the opportunity to study and apply this in classroom practice so as to facilitate student pronunciation learning (see Chapter 4). Phase 2 followed up on Phase 1 to specifically address the impact of TPL on the teachers' learning and pronunciation instructional practice. This second phase of the research commenced one month after the Phase 1 study completed. It began with a TPL workshop on CPT followed by lesson planning and tracking of classroom processes. It then investigated the teachers' stated beliefs about the impact of the workshop on their knowledge gains and pronunciation teaching skills. It examined the effects of the CPT model on student learning from both teaching and learning perspectives, which will be reported in Chapter 7 together with the teachers' and students' perceptions of pronunciation instruction at the tertiary level in Vietnam. The Phase 2 study also looked into the teachers' perceptions of TPL for VTE teachers in relation to pronunciation teaching. The chapter reports on and discusses the findings related to three research questions (RQ):

RQ6. How did the teachers implement CPT in their EFL classes?

RQ7. How did the teachers perceive the impact of the TPL workshop on their knowledge gains and pronunciation teaching skills?

RQ8. What did the teachers think and believe about TPL for VTE teachers regarding pronunciation teaching?

This chapter will first describe how the TPL workshop was carried out, and how the teachers planned CPT lessons. It then reports on the findings related to each of the research questions, discusses the main findings, and concludes with a summary. 


\subsection{The TPL workshop and CPT lesson planning}

Based on the preliminary findings of Phase 1, a TPL workshop was designed and delivered to the teacher participants. The main aim of the workshop was for the teachers to explore a framework for teaching English pronunciation communicatively (hereafter referred to as the framework) proposed by Celce-Murcia et al. (2010, also see section 2.3.3). Later, the teachers were asked to plan and deliver pronunciation instruction applying this framework in the following semester. The following sections outline how the TPL workshop was conducted, and how the teachers planned CPT lessons.

\subsubsection{The TPL workshop}

Given my experience in EFL teacher training in Vietnam prior to taking my $\mathrm{PhD}$ study leave, I implemented the workshop as I would in a teacher training class and adopted a learnercentred approach. During this 'class' I acted as an EFL teacher trainer and the teachers were viewed as active learners. The teachers explored the framework and how it works in practice through my modelling of a 45-minute pronunciation lesson and through group discussions after the lesson. The workshop procedures are summarised in Figure 6.1.

Figure 6.1 The workshop procedures

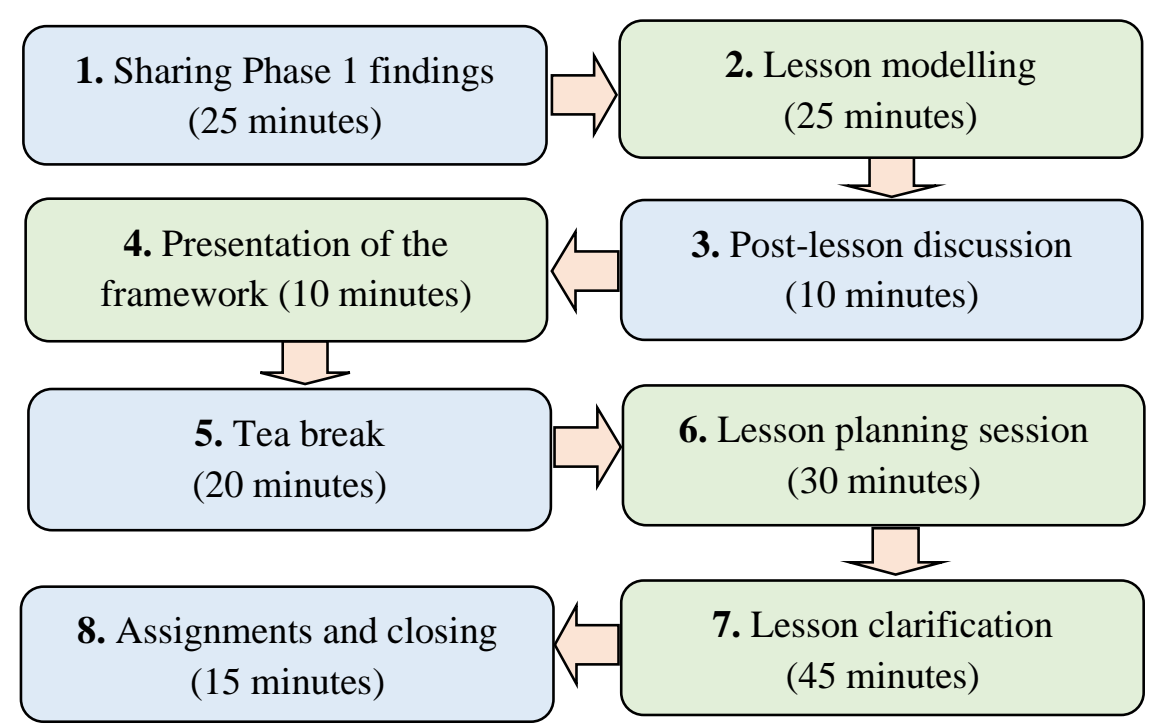

As Figure 6.1 shows, at the beginning of the workshop I shared with the teachers a brief summary of preliminary findings from Phase 1 in PowerPoint slides. This sharing took approximately 25 minutes and included the following:

(1) The teachers' self-reported and observed pronunciation teaching practices;

(2) Their rationales for their pronunciation teaching practices; 
(3) Students' beliefs about their teachers' pronunciation teaching;

(4) The teachers' and students' beliefs about pronunciation in English language teaching and learning;

(5) Pronunciation features which commonly cause problems to Vietnamese EFL learners;

(6) The teachers' reports of initial training and PL regarding pronunciation teaching.

After that, I modelled a pronunciation lesson teaching the sounds /s/ and / / following the five stages of the communicative framework: Description and analysis, Listening discrimination, Controlled practice, Guided practice, and Communicative practice. In this lesson, I acted as an instructor and asked the teachers to take the role of learners (for the lesson details, see Appendix 9.1 in the $\mathrm{CD}$ attached). The lesson was planned to last 45 minutes, yet it ended within around 25 minutes since these 'learners' are EFL teachers. Then, the teachers worked in pairs to review their understandings of the framework discussing the two following prompt questions:

(1) How many stages were there in my lesson and what were they?

(2) What were the main aims and objectives of each stage?

The teachers' discussions lasted around ten minutes and we then went through the answers together. Discussions showed that all the teachers were able to identify the five stages of the framework as well as the aims and objectives of each stage, which suggests that they had a full understanding of the nature of the framework and how it works in practice. After the discussion, I showed the teachers the framework through a PowerPoint presentation which took about ten minutes.

After a twenty-minute break, the workshop resumed and I gave each teacher the textbooks (as mentioned in section 3.5.3.1 of Chapter 3) to guide their lesson planning and subsequent teaching. The teachers then worked in pairs using the textbooks to plan a 45-minute lesson teaching any of the pronunciation features commonly causing problems to Vietnamese EFL learners which I had shared with them (also see section 5.3 of the previous chapter). Quynh worked with Diep, Phuong with Na, and Nguyen with Khoa; each pair spent about 30 minutes deciding on the activities for their lesson plan. The aim of this lesson planning session was to help the teachers apply the framework to their classroom practice.

After half an hour, each pair of the teachers took turns to clarify their own lesson plan while the others listened and then asked further questions about that lesson. Each pair had ten 
minutes to present their lesson plan followed by five minutes for questions and answers. This process of lesson clarification lasted for around 45 minutes. Overall, through these discussions, the teachers all demonstrated their understandings of the framework. The activities they selected all adhered to the aims and objectives of each stage of the framework.

About 15 minutes before the workshop ended, the teachers and I discussed and decided on the portion of lesson planning each teacher would be in charge of during the semester break. The aim was for each of the teachers to plan one 45-minute CPT lesson for the following semester. As reported in Chapter 3, one of the teacher participants took his sick leave before Phase 2 started, thus the lesson plan apportioned to him was voluntarily taken over by Teacher Diep. The pronunciation features targeted in these CPT lessons are those that cause common problems to Vietnamese EFL learners, as mentioned above. They emerged from the triangulation of the data from the literature, the teachers' reports, and the students' reports as presented in Chapter 5. The CPT lesson planning scheme is presented in Table 6.1 below.

Table 6.1 CPT lesson planning scheme

\begin{tabular}{lcl}
\hline Teacher & Number of lesson plans & Focus of instruction \\
\hline Quynh & 1 & vowels /i:/ and /I/ \\
\hline Phuong & 1 & vowels /u:/ and /ひ/ \\
\hline Nguyen & 1 & consonants /f/ and /3/ \\
\hline Diep & 2 & sentence stress; intonation \\
\hline Khoa & 1 & consonants /t $/$ / and /dz/ \\
\hline $\mathrm{Na}$ & 1 & final sounds and linking \\
\hline
\end{tabular}

When the teachers all finished planning their lesson(s), they shared their lesson plans with each other through email, which is, from my personal experience, a common practice in the Vietnamese EFL context at all levels. I will now turn to examine how the teachers designed the lesson(s) they were in charge of.

\subsubsection{CPT lesson planning}

One week before the following semester started, the teachers and I had a meeting during which each teacher took turns to present his/her own lesson plan(s), followed by further discussions about each lesson. Table 6.2 summarises the content of these lesson plans (for details of the seven lesson plans, see Appendix 9.2 in the $\mathrm{CD}$ attached). 
Table 6.2 Summary of teachers' lesson plan contents

\begin{tabular}{|c|c|c|c|c|c|}
\hline $\begin{array}{l}\text { Lesson plans } \\
\text { and stages }\end{array}$ & $\begin{array}{l}\text { 1. Description } \\
\text { and analysis }\end{array}$ & $\begin{array}{l}\text { 2. Listening } \\
\text { discrimination }\end{array}$ & $\begin{array}{l}\text { 3. Controlled } \\
\text { practice }\end{array}$ & $\begin{array}{l}\text { 4. Guided } \\
\text { practice }\end{array}$ & $\begin{array}{l}\text { 5. Communicative } \\
\text { practice }\end{array}$ \\
\hline $\begin{array}{l}\text { 1. Vowels } \\
\text { /i:/ and /I/ }\end{array}$ & $\begin{array}{l}\text { 1. Describing } \\
\text { articulations; } \\
\text { 2. Providing } \\
\text { spellings. }\end{array}$ & $\begin{array}{l}\text { 1. Listening: } \\
\text { minimal pairs; } \\
\text { 2. Bingo game. }\end{array}$ & $\begin{array}{l}\text { 1. Definition } \\
\text { game; } \\
\text { 2. Pair work } \\
\text { using flash } \\
\text { cards. }\end{array}$ & $\begin{array}{l}\text { 1. Information } \\
\text { gap; } \\
\text { 2. Conversation: } \\
\text { gap-fill and } \\
\text { practice. }\end{array}$ & $\begin{array}{l}\text { 1. Discussion: a } \\
\text { given situation; } \\
\text { 2. Speaking: } \\
\text { Missing about } \\
\text { hometown. }\end{array}$ \\
\hline $\begin{array}{l}\text { 2. Vowels } \\
\text { /u:/ and /v/ }\end{array}$ & $\begin{array}{l}\text { 1. Describing } \\
\text { articulations; } \\
\text { 2. Providing } \\
\text { spellings. }\end{array}$ & $\begin{array}{l}\text { 1. Listening: } \\
\text { minimal pairs; } \\
\text { 2. Word reading } \\
\text { and guessing. }\end{array}$ & $\begin{array}{l}\text { 1. Sentence } \\
\text { reading; } \\
\text { 2. Idiom } \\
\text { definitions: } \\
\text { matching and } \\
\text { practice. }\end{array}$ & $\begin{array}{l}\text { 1. Conversations: } \\
\text { gap-fill and } \\
\text { practice; } \\
\text { 2. Conversation: } \\
\text { building and } \\
\text { practice. }\end{array}$ & $\begin{array}{l}\text { 1. Discussion: } \\
\text { questions about } \\
\text { different } \\
\text { situations; } \\
\text { 2. Speaking: } \\
\text { becoming a } \\
\text { billionaire. }\end{array}$ \\
\hline $\begin{array}{l}3 . \\
\text { Consonants } \\
\text { / } / \text { and /3/ }\end{array}$ & $\begin{array}{l}\text { 1. Describing } \\
\text { articulations; } \\
\text { 2. Providing } \\
\text { spellings. }\end{array}$ & $\begin{array}{l}\text { 1. Listening: } \\
\text { word grouping; } \\
2 \text {. Word } \\
\text { reading. }\end{array}$ & $\begin{array}{l}\text { 1. Conversations: } \\
\text { gap-fill and } \\
\text { practice; } \\
\text { 2. Small talk: } \\
\text { daily routines. }\end{array}$ & $\begin{array}{l}\text { 1. Information } \\
\text { gap activity; } \\
\text { 2. Discussion: } \\
\text { vacation } \\
\text { descriptions. }\end{array}$ & $\begin{array}{l}\text { 1. Discussion: } \\
\text { vacations; } \\
\text { 2. Speaking: } \\
\text { Your last } \\
\text { vacation. }\end{array}$ \\
\hline $\begin{array}{l}4 . \\
\text { Consonants } \\
/ \mathrm{t} \int / \text { and /dz/ }\end{array}$ & $\begin{array}{l}\text { 1. Describing } \\
\text { articulations; } \\
\text { 2. Providing } \\
\text { spellings. }\end{array}$ & $\begin{array}{l}\text { 1. Listening: } \\
\text { minimal pairs; } \\
\text { 2. Word reading } \\
\text { and guessing. }\end{array}$ & $\begin{array}{l}\text { 1. Story } \\
\text { reading; } \\
2 . \text { Conversation } \\
\text { matching and } \\
\text { practice. }\end{array}$ & $\begin{array}{l}\text { 1. Information } \\
\text { gap activity; } \\
\text { 2. Picture } \\
\text { descriptions: } \\
\text { food in fridges. }\end{array}$ & $\begin{array}{l}\text { 1. Discussion: } \\
\text { describing jobs; } \\
\text { 2. Discussion: The } \\
\text { best and the worst } \\
\text { jobs. }\end{array}$ \\
\hline $\begin{array}{l}\text { 5. Sentence } \\
\text { stress }\end{array}$ & $\begin{array}{l}\text { 1. Presenting } \\
\text { sentence } \\
\text { stress rules; } \\
\text { 2. Explaining } \\
\text { rules and } \\
\text { giving oral } \\
\text { illustrations. }\end{array}$ & $\begin{array}{l}\text { 1. Listening: } \\
\text { stressed words; } \\
\text { 2. Questions } \\
\text { and responses: } \\
\text { matching and } \\
\text { practice. }\end{array}$ & $\begin{array}{l}\text { 1. Listening: } \\
\text { stressed words in } \\
\text { conversation; } \\
\text { 2. Conversation } \\
\text { practice. }\end{array}$ & $\begin{array}{l}\text { 1. Correction } \\
\text { Game; } \\
\text { 2. Follow-up } \\
\text { game: factual } \\
\text { statements. }\end{array}$ & $\begin{array}{l}\text { 1. Conversation: } \\
\text { listening and } \\
\text { question } \\
\text { discussion; } \\
\text { 2. Question } \\
\text { discussion: } \\
\text { neighbors. }\end{array}$ \\
\hline
\end{tabular}




\begin{tabular}{|c|c|c|c|c|c|}
\hline $\begin{array}{l}6 . \\
\text { Intonation }\end{array}$ & $\begin{array}{l}\text { 1. Presenting } \\
\text { intonation } \\
\text { rules; } \\
\text { 2. Explaining } \\
\text { rules and } \\
\text { giving oral } \\
\text { illustrations. }\end{array}$ & $\begin{array}{l}\text { 1. Conversation: } \\
\text { listen and draw } \\
\text { intonation lines; } \\
\text { 2. Lists: listen, } \\
\text { draw intonation } \\
\text { lines. }\end{array}$ & $\begin{array}{l}\text { 1. Conversation: } \\
\text { listen and practice } \\
\text { 2. Questions and } \\
\text { answers: } \\
\text { rearranging and } \\
\text { practice. }\end{array}$ & $\begin{array}{l}\text { 1. Conversation: } \\
\text { gap-fill and } \\
\text { practice; } \\
\text { 2. Conversation: } \\
\text { building and } \\
\text { practice. }\end{array}$ & $\begin{array}{l}\text { 1. Discussion: } \\
\text { read a paragraph, } \\
\text { complete the } \\
\text { table, and discuss } \\
\text { answers; } \\
\text { 2. Discussion: A } \\
\text { weekend picnic. }\end{array}$ \\
\hline $\begin{array}{l}\text { 7. Final } \\
\text { sounds and } \\
\text { linking }\end{array}$ & $\begin{array}{l}\text { 1. Presenting } \\
\text { linking rules; } \\
\text { 2. Explaining } \\
\text { rules and } \\
\text { giving oral } \\
\text { illustrations. }\end{array}$ & $\begin{array}{l}\text { 1. Listening: } \\
\text { minimal pairs; } \\
\text { 2. Word reading } \\
\text { and guessing. }\end{array}$ & $\begin{array}{l}\text { 1. Phrase } \\
\text { reading; } \\
\text { 2. Sentence } \\
\text { completion and } \\
\text { reading practice. }\end{array}$ & $\begin{array}{l}\text { 1. Conversation: } \\
\text { question-answer } \\
\text { matching and } \\
\text { practice; } \\
\text { 2. Conversation: } \\
\text { identify linking } \\
\text { and practice. }\end{array}$ & $\begin{array}{l}\text { 1. Discussion: to } \\
\text { cope or not to } \\
\text { cope with stress; } \\
\text { 2. Speaking: } \\
\text { situations that } \\
\text { reduce or increase } \\
\text { stress. }\end{array}$ \\
\hline
\end{tabular}

As Table 6.2 shows, each CPT lesson typically included five stages the first of which was for the instructors to present and explain relevant theory of the instruction focus such as places and manners of articulation or sentence stress rules. The other four stages were for student practice in which the teachers designed a variety of activities from word to discourse level. As can be seen from Table 6.2, two activities were designed for each practice stage in each lesson, resulting in a total of 56 practice activities across the seven lesson plans. Based on the exercise and page number indicated by the teachers in each lesson plan, I traced these activities and found that a majority of 41 activities were selected and adapted from Lane (2013) and 15 were reported being from other textbooks and online resources. As seen from Table 6.2, these 15 activities (in bold) were present from lesson plans 1 to 6, but not lesson plan 7.

Overall, the lesson plans created by the teachers closely followed the principles of the framework with activities adhering to the aims and objectives of each lesson stage. For the teachers' convenience, flexibility and creativity, I made it clear that the teachers reserved the right to retain, adapt or replace the activities in these shared lesson plans. The teachers and I agreed that they would carry out two lessons in two consecutive 45-minute periods on the same day, except the one that focused on final sounds and linking which would last 45 minutes. In other words, the teachers carried out these seven lessons within four teaching 
sessions: one for long and short vowels, one for sentence stress and intonation, one for troublesome consonants, and the other for final sounds and linking (see also 3.5.3.2 for the experimental teaching scheme). The following section reports on how the teachers implemented these CPT lessons in their English classes.

\subsection{Teachers' implementation of CPT}

In the following semester, the teacher participants implemented the seven CPT lessons in one of their scheduled classes. They all used English as the medium of instruction in their classes. During their experimental teaching, I video-taped their classes with a Sony HDR-PJ670, made non-participant observations, and took unstructured field notes. One week after each teaching session, all the teachers and I had an informal catch-up to review how their teaching went. In total, we had four group review meetings. In the first review meeting, the teachers all reported that their students actively participated in most classroom activities, especially those in the communicative practice stage. However, they felt that many students did not seem to very much enjoy the controlled practice activities. The following extract from the first catchup illustrates this:

Researcher: Thank you all for taking your time to come here today. Let's talk about your first experimental teaching session. How do you think your class went and which activities worked well? Respects to seniors, so please Teacher Phuong, you will talk first.

Phuong: [Laughed] Thank you. I saw students enjoyed most of my classroom activities, especially the communicative ones. Students engaged actively in practicing and especially liked speaking with their friends. But I felt many of them didn't like the controlled-practice activities very much.

Researcher: Uh huh. So, what do you think might be the problem?

Phuong: $\quad$ Uhm... Maybe because they found these activities boring. Usually students don't like mechanical tasks involving repetition. They prefer to practice speaking.

Researcher: I see. What about you, Teacher Nguyen?

Nguyen: Ifelt that too. I think another reason may be because my students are quite good at English, they found activities that only need repetition not very interesting. For students of a lower level, I think these activities would work.

Researcher: Uh huh. What do you think, Teacher Quynh? 
Quynh: $\quad$ Ifelt the same. Students were really interested in speaking activities but seemed unresponsive to listen-and-repeat activities.

( ...)

(Extracted discussion with the teachers in review meeting 1, translated from Vietnamese)

This part of the discussion shows the teachers' thoughts and beliefs about their students' attitudes towards activities used for the controlled-practice stage in their first teaching session. According to the teachers, it might be that students who were quite good at English found these mechanical drills 'dry' and 'boring' since they mainly involved repetition of sound contrasts that these students were probably well aware of. The teachers did not report any problem during the three later review meetings.

Although I had made it clear that the teachers reserved the right to retain, adapt or replace the activities in the lesson plans, classroom observations showed that they retained almost all the activities, apart from Teacher Nguyen replacing activity 2 in the controlled practice stage of lesson plan 1 and activity 1 in the controlled practice stage of lesson plan 2 . To shed light on this, prior to each teacher's follow-up interviews, I asked them to clarify their decisionmaking in implementing these CPT lessons. During each individual discussion, I asked the teachers to talk about why they decided to retain the activities in the lesson plans.

Collectively, the main reason for the teachers to retain all the activities in the lesson plans was that they were available and suitable for classroom use. According to the teachers, the activities adhered to the aims and objectives of each teaching stage of the framework, and were feasible in their classes and useful for student learning. For example, Teacher Diep said:

Because these activities are available in the lesson plans, so I think designing new ones is a waste of time, not necessary. For me, I just use what can be used in my class. But the important reason is that they match the objectives of each stage in the framework. Also, I see that the activities the teachers have designed are suitable and useful for students' practice. So, I just used them. (Individual lesson clarification with Diep, review meeting 4, translated from Vietnamese)

Given that the teachers shared their lesson plans with each other, followed the same teaching procedures, and retained almost all the activities designed in each lesson, reporting on each teacher implementing seven lessons will result in repetition. For this reason, I have decided to report on each teacher teaching one session (two lessons each) instead of four (seven lessons 
each). This will provide samples of all the teachers enacting the intervention. The report follows the sequence of the experimental teaching scheme outlined in section 3.5.3.2.

\subsubsection{Teacher Nguyen's lessons: /i:/ vs. /I/ and /u:/ vs. / $/$}

Based on the assigned schedule for each of the teachers, Nguyen was the first teacher to implement the first two CPT lessons: lesson 1 focused on /i:/ and /I/ and lesson 2 on /u:/ and /ひ/. These two lessons were planned by teachers Quynh and Phuong respectively and were implemented in week 2 of the teachers' official 12-week teaching schedule. As mentioned above, unlike other teachers, Nguyen replaced one activity in each of the two lesson plans. Table 6.3 summarises the five stages of the lessons and indicates the total time Nguyen spent on associated activities in each lesson.

Table 6.3 Nguyen's lessons

\begin{tabular}{|c|c|c|c|c|}
\hline Lesson stages & $\begin{array}{l}\text { Classroom activities } \\
\text { (/i:/ vs. /I/) }\end{array}$ & $\begin{array}{l}\text { Time used } \\
\text { (47 minutes) }\end{array}$ & $\begin{array}{c}\text { Classroom activities } \\
\text { (/u:/ vs. / } /)\end{array}$ & $\begin{array}{c}\text { Time used } \\
\text { (46 minutes) }\end{array}$ \\
\hline 1. Description & Describing articulations & 4 minutes & Describing articulations & 4 minutes \\
\hline and analysis & Providing spellings & 3 minutes & Providing spellings & 3 minutes \\
\hline 2. Listening & Listening task & 3 minutes & Listening task & 3 minutes \\
\hline discrimination & Bingo game & 3 minutes & $\begin{array}{l}\text { Word reading and } \\
\text { guessing }\end{array}$ & 4 minutes \\
\hline 3. Controlled & Definition game & 4 minutes & Rhyme reading & 4 minutes \\
\hline practice & Sentence reading & 3 minutes & Idiom matching task & 5 minutes \\
\hline $\begin{array}{l}\text { 4. Guided } \\
\text { practice }\end{array}$ & $\begin{array}{l}\text { Information gap activity } \\
\text { Conversation: gap-fill }\end{array}$ & $\begin{array}{l}5 \text { minutes } \\
7 \text { minutes }\end{array}$ & $\begin{array}{l}\text { Conversations: gap-fill } \\
\text { and practice }\end{array}$ & 6 minutes \\
\hline & and practice & & $\begin{array}{l}\text { Conversation: build up } \\
\text { and practice }\end{array}$ & 7 minutes \\
\hline $\begin{array}{l}\text { 5. Communicative } \\
\text { practice }\end{array}$ & $\begin{array}{l}\text { Question discussion } \\
\text { Speaking: hometown }\end{array}$ & $\begin{array}{l}9 \text { minutes } \\
6 \text { minutes }\end{array}$ & Question discussion & 10 minutes \\
\hline
\end{tabular}

Both lessons started with descriptions and explanations of articulation (Stage 1) in which Nguyen explained to students how the target sounds are produced and how they differ from each other in terms of vowel length. He used pictures to show how the lips are shaped differently in articulating each member of each sound pair. He himself demonstrated by 
producing the sounds and asked students to look at the shapes of his lips. Unlike other teachers who only resorted to the pictures in the lesson plans, Nguyen let students watch video clips in which native speakers instructed how to produce the vowels properly. I noticed at this stage that students observed and listened attentively to both Nguyen and the native speakers in the clips; some students tried imitating the pronunciation of the vowels in silence. Nguyen then wrote some words on the board and asked students to say them aloud. Here, he was checking if students could recognize which words had long /i:/ and which had short /I/. Finally, Nguyen provided spellings for the vowels and got students to listen and repeat the words chorally several times.

Nguyen moved on to Stage 2 - listening and descrimination - by having students do a listening task for both lessons. He first asked students to listen and repeat the words, then listen again and choose the words they heard. After giving feedback, Nguyen continued the listening discrimination stage with another activity for each of the lessons: a Bingo game for /i:/ and /I/ in lesson 1, and a word reading and guessing task for /u:/ and / $/ /$ in lesson 2. For the Bingo game, Nguyen first delivered the Bingo cards to students and explained the rules of the game in English. He then read the words while students listened and crossed out the words they heard. Before the game started, Nguyen told students that the first to say "Bingo!" would be given some candy as an award. This feature of competitiveness Nguyen added to the Bingo game was effective since students seemed excited and listened attentively to Nguyen reading the words. In the word reading and guessing activity in lesson 2, Nguyen had students work in pairs. Students took turns; one read the words while the other listened and guessed which word he/she heard by saying a or b together with the number of the word pair in the list. He then called some students to read the words aloud for the whole class to guess which word they heard.

For controlled practice of /i:/ and /I/ in Stage 3, Nguyen used activity 1 which was available in the lesson plan but replaced activity 2 with the one he selected. In activity $1-$ the Definition game, students worked in pairs and took turns to ask and answer questions about the meaning of the words in the list. Activity 2 in the lesson plan was replaced by a sentence reading task. Nguyen showed on PowerPoint slides five sentences with words containing either /i:/ or /I/ and delivered handouts to students. The handouts included the following sentences: 
1. On the weekend, the women went swimming in the deep river.

2. We found Miss Meese's mittens on the table after the meeting.

3. Steven Stivens reached for a dish of rich ice cream.

4. Sit in this seat and draw a picture of a sheep and a ship.

5. Does the criminal still steal political secrets?

The handouts showed that this activity was taken from Lane (2013, p. 9). To implement this activity, Nguyen had students listen to the recording and repeat the sentences, then asked them to work in pairs to read the sentences to a partner. Before students started, Nguyen reminded them to monitor each other's pronunciation. For activity 1 in the stage of controlled practice of lesson 2, Nguyen conducted a reading task but replaced the sentences designed by the planner with a rhyme in which /u:/ and / / appeared. This activity was selected from Lane (2013, p. 48) as well:

How much wood would a woodchuck chuck?

If a woodchuck could chuck wood?

Just as much as a woodchuck would

If a woodchuck could chuck wood.

To implement this rhyme practice, Nguyen first had students listen to the recording and repeat each line of the rhyme. Then he asked them to practice reading the rhyme to a partner in a couple of minutes. I noticed that students usually laughed after finishing each sentence in the rhyme and they gave comments on their peers' production. This indicates that this activity added fun to the classroom atmosphere making it more relaxing when students practiced. The second activity Nguyen used for lesson 2 controlled practice was a listening and speaking activity. Students were asked to listen and repeat eight idioms in which /u:/ and / $/$ occurred. After that, Nguyen had them discuss in pairs and match the idioms with definitions. He elicited answers by inviting students to write them on the board and gave feedback.

The main reason for Nguyen to carry out these two activities instead of the ones available in the lesson plans was their usefulness. Nguyen reported that the activities he selected could engage students more effectively than the original versions. According to Nguyen, the sentences he chose for lesson 1 had more words with the target sounds and thus were more useful for student practice than those in the original flash cards. In replacing the activity in lesson 2, Nguyen reasoned that the rhyme could create more fun for practice than the simple 
sentences in the lesson plan. Since the rhyme sounds like a tongue twister, students found it interesting and amusing during practice. Nguyen said:

Because these sentences are longer than those in the flash cards and so have more words containing long /i:/ and short/I/. So, I think it's more useful for students because they can practice more words containing the two vowels. For the rhyme, do you agree with me that students had a lot of fun when they practiced reading it? It sounds more like a tongue twister, so students found it amusing when reading. Clearly, those short sentences in the lesson plan Teacher Phuong designed can't do this for sure. (Individual lesson clarification with Nguyen, review meeting 4, translated from Vietnamese)

Lesson 1's guided practice (Stage 4) started with an information gap activity. Nguyen placed students in pairs and handed out flash cards to each student. Each flash card had six words available and six missing; all contained either /i:/ or /I/. Each student took turns to ask his/her partner for the missing words in his/her flash card. He proceeded by getting students to complete a conversation with the given words and practice the conversation in groups of three. In lesson 2, a gap-filling activity was firstly conducted. Nguyen gave students three short conversations with blanks and asked them to fill the blanks with the correct idioms. Then, he had students practice the conversations in pairs after giving feedback. The guided practice stage of lesson 2 ended with a speaking activity. Nguyen had students build up a conversation using the cues provided. He elicited answers from students before asking them to practice the conversation in pairs.

Both lessons ended with communicative activities in Stage 5. In lesson 1, Nguyen showed the whole class a picture of two students and a situation about them coming to a different part of their country for college. Students looked at the picture, read the situation, and discussed with a partner what the two students would miss about their hometown. To facilitate the students' discussion, Nguyen provided them with some words and phrases as hints. I noticed that students quickly turned to each other and started discussing and writing down their answers. After four minutes, Nguyen called on some students to answer. The first communicative activity Nguyen used in lesson 1 is presented in Figure 6.2 below. 
Figure 6.2 Communicative activity 1 , Lesson focus of /i:/ and /I/

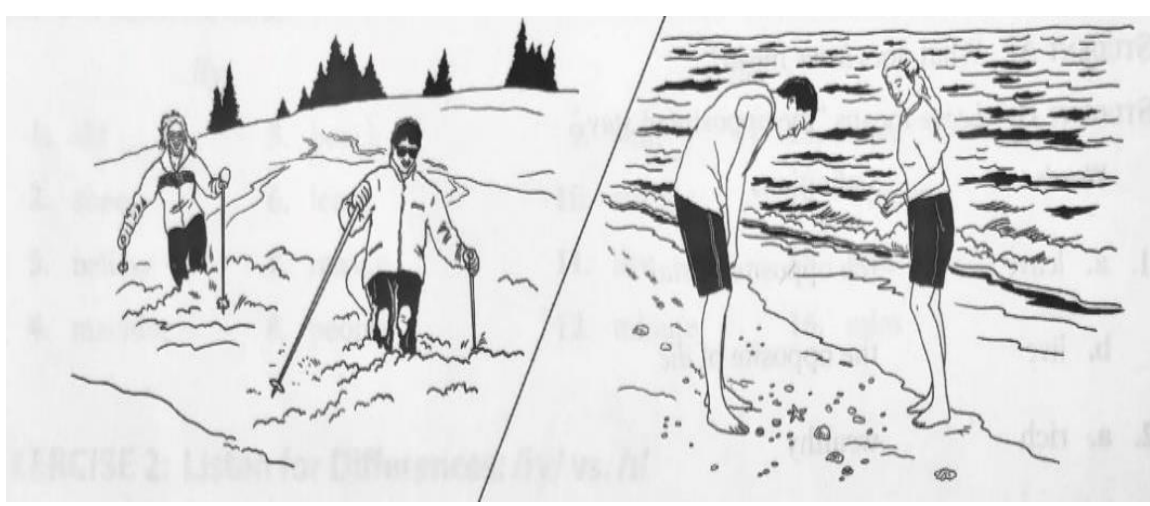

Steve Stimson is from Boulder, Colorado. He's leaving home to go to college in Miami, Florida. Silvia Seely is from Miami. She's decided to go to college in Boulder. They both love their hometowns, but they want to live in another part of the country for a while. They know they're going to miss their hometowns.

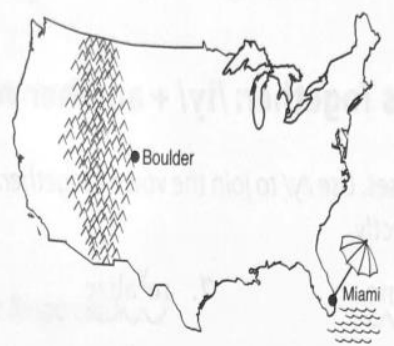

Lesson 1 ended with a similar scenario: students worked in pairs to talk in English about what they missed about their hometown when going to university. Students seemed really excited to share their feelings with friends about their hometown and only stopped talking when the teacher asked them to do so. In lesson 2, Nguyen first gave three different situations and had students discuss the questions in groups of three or four. Here, students were required to talk not only about the person in each situation but also about themselves using 'could', 'should', and 'would'. Unlike other teachers, Nguyen ended lesson 2 without conducting activity 2 as originally designed by the planner since he ran out of time. While students were still in discussion, the bell went off signalling break time.

In these two lessons, the students' initial problem was not being able to show contrast in producing each of the target sound pairs in terms of vowel length. However, I observed that after Nguyen explained, demonstrated, and had students listen and repeat several times, they were able to make the distinction. Later during these lessons, I noticed that students seemed to enjoy most of the activities in class. Overall, they actively participated in practice and were eager to talk afterwards, especially in activities that involved communication practice. In 
addition, the students seemed to be interested in games such as Bingo and the Definition game which stimulated their ability of recognising sounds. They were therefore more active and engaged in learning than usual.

\subsubsection{Teacher Phuong's lessons: sentence stress and intonation}

These lessons were both designed by Teacher Diep and were implemented in week 4 of the teachers' normal schedule. Lesson 1 focused on sentence stress and lesson 2 on intonation. Activities designed in the lesson plans were retained and carried out by all the teachers. Table 6.4 presents how Teacher Phuong constructed each of the two lessons and the total time she spent on each classroom activity.

Table 6.4 Phuong's lessons

\begin{tabular}{|c|c|c|c|c|}
\hline Lesson stages & $\begin{array}{l}\text { Classroom activities } \\
\text { (sentence stress) }\end{array}$ & $\begin{array}{c}\text { Time used } \\
\text { (44 minutes) }\end{array}$ & $\begin{array}{l}\text { Classroom activities } \\
\quad \text { (intonation) }\end{array}$ & $\begin{array}{l}\text { Time used } \\
\text { (48 minutes) }\end{array}$ \\
\hline 1. Description & Presenting rules & 2 minutes & Presenting rules & 2 minutes \\
\hline and analysis & $\begin{array}{l}\text { Explaining and giving } \\
\text { oral illustrations }\end{array}$ & 3 minutes & $\begin{array}{l}\text { Explaining and giving } \\
\text { oral illustrations }\end{array}$ & 4 minutes \\
\hline \multirow[t]{2}{*}{$\begin{array}{l}\text { 2. Listening } \\
\text { discrimination }\end{array}$} & $\begin{array}{l}\text { Listening task } \\
\text { Conversation practice }\end{array}$ & $\begin{array}{l}3 \text { minutes } \\
4 \text { minutes }\end{array}$ & $\begin{array}{l}\text { Listening task } \\
\text { (conversation) }\end{array}$ & 2 minutes \\
\hline & & & Listening task (lists) & 3 minutes \\
\hline $\begin{array}{l}\text { 3. Controlled } \\
\text { practice }\end{array}$ & $\begin{array}{l}\text { Conversation: read and } \\
\text { circle stressed words } \\
\text { Conversation practice }\end{array}$ & 5 minutes & $\begin{array}{l}\text { Conversation practice } \\
\text { One-word conversations: } \\
\text { matching and practice }\end{array}$ & $\begin{array}{l}5 \text { minutes } \\
6 \text { minutes }\end{array}$ \\
\hline \multirow[t]{2}{*}{$\begin{array}{l}\text { 4. Guided } \\
\text { practice }\end{array}$} & $\begin{array}{l}\text { "Correction" game } \\
\text { Follow-up game: facts }\end{array}$ & $\begin{array}{l}4 \text { minutes } \\
6 \text { minutes }\end{array}$ & $\begin{array}{l}\text { Conversation: gap-filling } \\
\text { and practice }\end{array}$ & 8 minutes \\
\hline & & & $\begin{array}{l}\text { Conversation: building } \\
\text { and practice }\end{array}$ & 7 minutes \\
\hline $\begin{array}{l}\text { 5. Communicative } \\
\text { practice }\end{array}$ & $\begin{array}{l}\text { Conversation discussion } \\
\text { Question discussion }\end{array}$ & $\begin{array}{l}7 \text { minutes } \\
5 \text { minutes }\end{array}$ & $\begin{array}{l}\text { Discussion: environment } \\
\text { Discussion: a weekend } \\
\text { picnic }\end{array}$ & $\begin{array}{l}5 \text { minutes } \\
6 \text { minutes }\end{array}$ \\
\hline
\end{tabular}

Lesson 1 started with the presentation of three basic rules of sentence stress: highlighting new information, contrasting or correcting information, and function words. Like other teachers, Phuong presented and explained the rules through examples, gave oral demonstrations, and 
had students listen and repeat several times. In the second stage of listening discrimination, Phuong first conducted a listening activity in which students listened to statements and circled the stressed word. She then called for answers, gave feedback, and let students listen again to check. In activity 2, Phuong asked students to match each of the statements in activity 1 to the correct questions. Following the note for this activity 2 in the lesson plan, Phuong asked students to explain their answers to each question in the feedback stage. She then had students practice the conversations in pairs. Phuong reminded students to monitor each other's sentence stress before they began practicing.

Phuong started the controlled practice stage with a reading and listening activity. She first provided a conversation on a handout to students. They were then asked to read the conversation and circle the stressed words. After eliciting answers from students, Phuong had them listen to the recording and check their answers. Since students got both right and wrong answers, Phuong, during the 'listen and check' process, paused at each speech chunk to reexplain the sentence stress rules to ensure students' understanding. She finally had students practice the conversation in pairs as the second activity for this stage. In this activity, Phuong asked students to monitor each other's sentence stress while practicing. After two minutes, Phuong called some students to read aloud and moved on to the guided practice stage.

In Stage 4, the first activity Phuong used for guided practice was a "Correction" game. Phuong had students work in pairs to correct their partner's statements about general facts. Students took turns to read statement by statement while the other listened and repeated the statement with corrected information. Before going on to activity 2, Phuong called some students to read aloud. Activity 2 was a follow-up game that replicated the "Correction" game in activity 1 but was implemented through group work. Phuong organised students in groups; each student wrote a statement about general facts they know about Vietnam or the world. This statement had to include wrong information so that when each student read the statement aloud, other members in the group could have the opportunity to practice the sentence stress rule of correcting information. I observed that students were actively involved in both activities of this stage. This may have been partly because these activities not only gave students a chance to practice applying the sentence stress rule of correcting information but also aroused their interest in general knowledge.

The lesson then continued with a listening and speaking activity for communicative practice (Stage 5). Phuong had students listen to a conversation between two speakers and then 
discuss three questions about the conversation in pairs. After about three minutes, she invited some students to answer the questions. The lesson ended with a similar scenario whereby students talked with a partner about their relationship with neighbours. After three minutes, Phuong called some students to speak before moving on to teaching intonation in lesson 2.

In lesson 2, Phuong first presented and explained the rules of rising and falling intonation at the end of a sentence and in lists. She used a number of sentences and lists with intonation lines to illustrate the rules. She got students to listen and repeat the sample sentences several times before conducting two listening activities in Stage 2 - listening discrimination. In activity 1 , Phuong had students listen to a conversation and draw rising or falling intonation lines; she let students listen to the recording once and then elicited answers. After that, Phuong conducted a similar listening activity in the same manner but with lists. In this activity, students were asked to listen to eight lists and draw a rising or falling intonation line over the last word in each list. Students were required to decide if the speaker had finished the list by writing yes or no in the blank. After giving feedback, Phuong let students listen to the recording again to check their answers and then moved on to the next stage of the lesson.

At the beginning of the controlled practice stage, Phuong provided a conversation with intonation lines above each speech chunk for students to practice (Figure 6.3). Students were first asked to read the conversation in silence, paying attention to the intonation lines. Then, Phuong had them listen to the recording once before practicing the conversation with a partner. Before students started, Phuong asked them to monitor each other's intonation. After three minutes, Phuong called some students to speak up before giving instructions for a second activity. In activity 2 , students were asked to arrange two sets of questions and answers to make conversations. The uniqueness of this activity was that all the questions and answers of the conversations were one-or-two worded. After eliciting answers from students, Phuong had them practice the conversations in pairs then called some students to speak up. Despite the mechanical feature of these controlled practice activities, I noticed that students practiced eagerly. I also noted that students still made mistakes with their intonation upon performance. For example, some students still spoke with a flat tone (at different points) instead of a rising or falling tone. Noticing this, Phuong raised awareness and encouraged the students to correct themselves. 
Figure 6.3 Controlled practice activity 1, Lesson focus of intonation

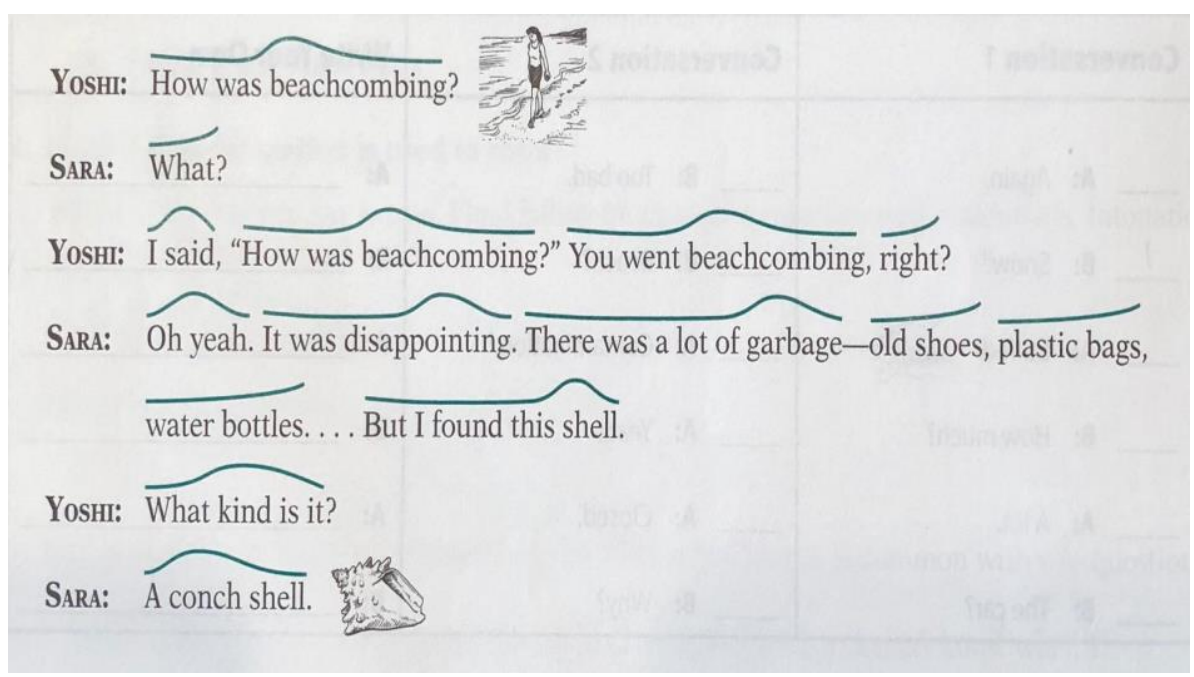

The guided practice stage started with a reading and listening activity. Phuong asked students to read a conversation and complete it with the words and phrases provided. After having students write their answers on the board, Phuong had them listen to the recording to check their answers. She then got students to practice the conversation in pairs; she also asked them to monitor each other's intonation. This stage of the lesson ended with another conversationpractice activity in which students worked in pairs to build up a conversation from the cues given. After two minutes, Phuong invited students to write the conversation on the board and gave feedback. She then had students practice the conversation with a partner. Before students started, Phuong gave instructions on where in the conversation to apply rising and falling intonation. It may have been partly because of Phuong's instructions that students who were invited to speak used the targeted intonation rules appropriately (both at the end of a sentence and in lists).

In the communicative practice stage, Phuong first divided students into groups of three or four. Students read a paragraph about how a town in New York tried to reduce its impact on the environment and wrote three specific things they could do to reduce electricity use, garbage, and water use. They then shared their answers within their groups. While students were discussing, Phuong went around the classroom and reminded them to speak with listing intonation. After inviting some students to speak, Phuong organised students in different groups to discuss a place for a weekend picnic as the last activity of the lesson. To put students at ease, Phuong encouraged them to use structures they had practiced in activity 1 of the guided practice stage in their discussion. Phuong finished the lesson by reminding students to do more practice of sentence stress and intonation at home. 
The students' problem was that they spoke English with a flat tone attaching equal stress to every single word in an utterance. For this reason, when they were taught sentence stress and intonation, I noticed that they listened to the teacher attentively and later on engaged actively in most classroom activities. Based on my observation notes and the teachers' reflection during the interviews, the students were, with a few exceptions, able to apply in practice what the teachers taught.

\subsubsection{Teacher Diep's lessons: / $/$ / vs. / $/$ and /t $\int /$ vs. /dz/}

These two lessons were planned by teachers Nguyen and Khoa respectively and were implemented in week 6 of the teachers' official teaching schedule. Lesson 1 focused on the consonants $/ \int /$ and $/ z /$ and lesson 2 on $/ \mathrm{t} / /$ and $/ \mathrm{d} z /$. Diep's teaching procedures, classroom activities, and time allocation are summarised in Table 6.5.

Table 6.5 Diep's lessons

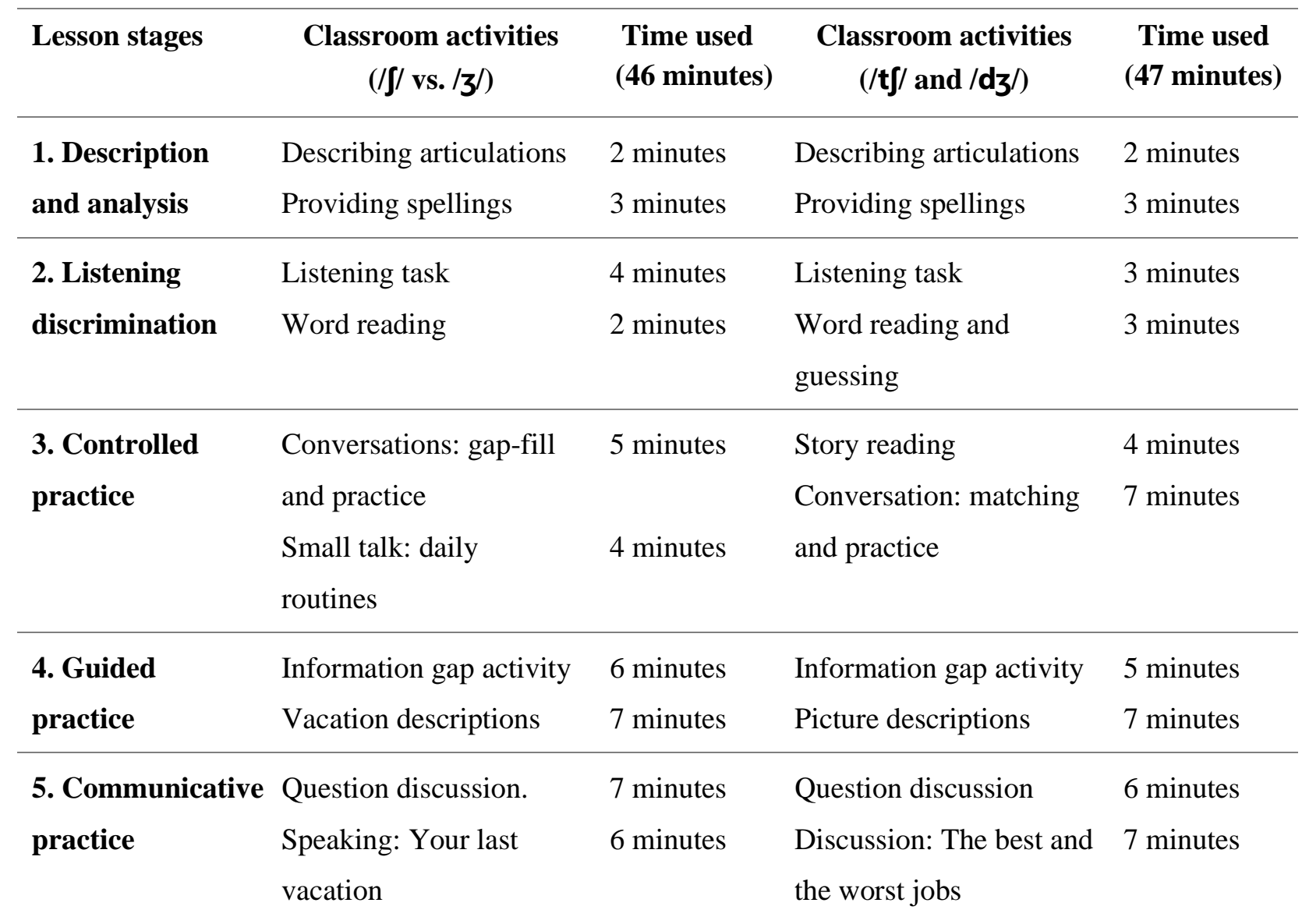

Diep started both lessons by describing and explaining the articulation of each of the target consonants. First, Diep used pictures to show how the sounds are produced and which 
articulators are involved. She explained to students that they would feel some vibration in the throat when voiced consonants are articulated. Diep demonstrated this by putting fingers on her Adam's apple while making the sounds. She then asked students to do the same, following her instructions. I noticed that students seemed excited at this tip for recognising sounds as they quickly followed the teacher's instruction. They put fingers on their throats and tried making the sounds. As Diep instructed, students tried out the voiceless consonants first and then the voiced ones. I saw some of them nodding their heads when feeling the vocal cords vibrating. Diep then presented spellings for the target consonants and had the whole class listen and repeat several times before moving to the second stage.

Both lessons then continuted with a listening task in the listening discrimination stage. In lesson 1, Diep provided a list of words containing either a /s/, / $/$, /z/, or $/ 3 /$ sound and asked students to listen to the recording and write the words into the correct column. After students wrote their answers on the board, Diep let them listen to the recording again to check. She then asked students to read the words to a partner as a second activity; she reminded students to monitor each other's pronunciation before students practiced. In lesson 2, Diep had students listen and repeat the words and then listen again and choose the words they heard. After eliciting answers, Diep continued with a word reading and guessing activity. Students took turns to read the words while the partner listened and guessed by saying a or $b$ together with the number of the word pair in the list. She then called some students to read the words aloud for the whole class to guess which word they heard.

In the controlled practice stage of lesson 1, Diep first conducted a gap-filling activity. She had students listen to the recording twice to complete the conversations. After students wrote their answers on the board, Diep let them listen to the recording again to check before they started practicing the conversations with a partner. She then called some students to speak and moved on to another activity whereby students talked about their daily routines. Prior to students' practice, Diep explained to students how 'usually' is pronounced by exaggerating the /3/ sound in the second syllable. Although this controlled practice activity only focused on the production of $/ 3$ / in 'usually', I noticed that students practiced really actively. This may partly be because of the common topic of daily routines with which students were familiar. In lesson 2, Diep carried out a story reading activity. A story with words containing /t $\mathrm{f} / \mathrm{and} / \mathrm{d} z /$ were delivered to students on handouts as shown in Figure 6.4 below. 
Figure 6.4 Controlled practice activity 1 , Lesson focus of $/ \mathrm{t} \int /$ and $/ \mathrm{d} z /$

\section{The Butchers}

A new shopping centre has three butcher's shops next to each other. The name of each butcher is Joe.

When the three butcher's shops open, the first butcher writes above his shop: "Joe's - the Largest butcher's Shop."

The second butcher writes abovehis shop: "Joe's - The Cheapest

Butcher's Shop."

The third butcher writes abovehis shop in large letters: "JOE'S

BUTCHER'S SHOP - MAIN ENTRANCE".

In this activity, Diep firstly had students listen to her reading the story once before they took turns to practice reading the story to a partner. She then called two students to read the story to the whole class and gave feedback on the students' production. This stage of lesson 2 ended with an activity in which Diep asked students to match the questions and responses containing $/ \mathrm{t} / \mathrm{and} / \mathrm{d} z /$. After eliciting answers from students and giving feedback, Diep had students practice the conversations in pairs.

In the guided practice stage, Diep first conducted an information gap activity for both lessons. She put students in pairs and delivered flash cards to each student. In lesson 1, each flash card had part of the information from a global survey on paid time off in 12 countries around the world. Students took turns to ask and answer about minimum paid vacation days and paid public holidays in each country in the cards. This activity allowed students to practice not only words with $/ \int /$ and $/ 3 /$ but also other concurrent sounds. In lesson 2, each flash card had eight words available and eight missing; all contained either $/ \mathrm{t} \int /$ or $/ \mathrm{d} z /$. Students took turns to ask for the missing words in their flash card.

The guided practice stage continued with a group discussion in lesson 1 and a picture description activity in lesson 2. In lesson 1, Diep showed a list of words and seven vacations. Students were asked to discuss these in groups of three or four, and to put the words that described each vacation on the correct lines. In lesson 2, Diep first organised students in pairs and showed two different pictures on a PowerPoint slide: one of a large fridge and the other of a small fridge with different food in them. She then asked students to look at the pictures and listen and repeat the words and phrases after her. Finally, Diep instructed students how to 
do the task by giving an example of a question-answer exchange. Students then took turns to ask about the food in the two fridges. After two minutes of practice, Diep called students to ask and answer. The picture description activity Diep used is shown in Figure 6.5.

Figure 6.5 Guided practice activity 2, Lesson focus of $/ \mathrm{t} / \mathrm{and} / \mathrm{d} 3 /$

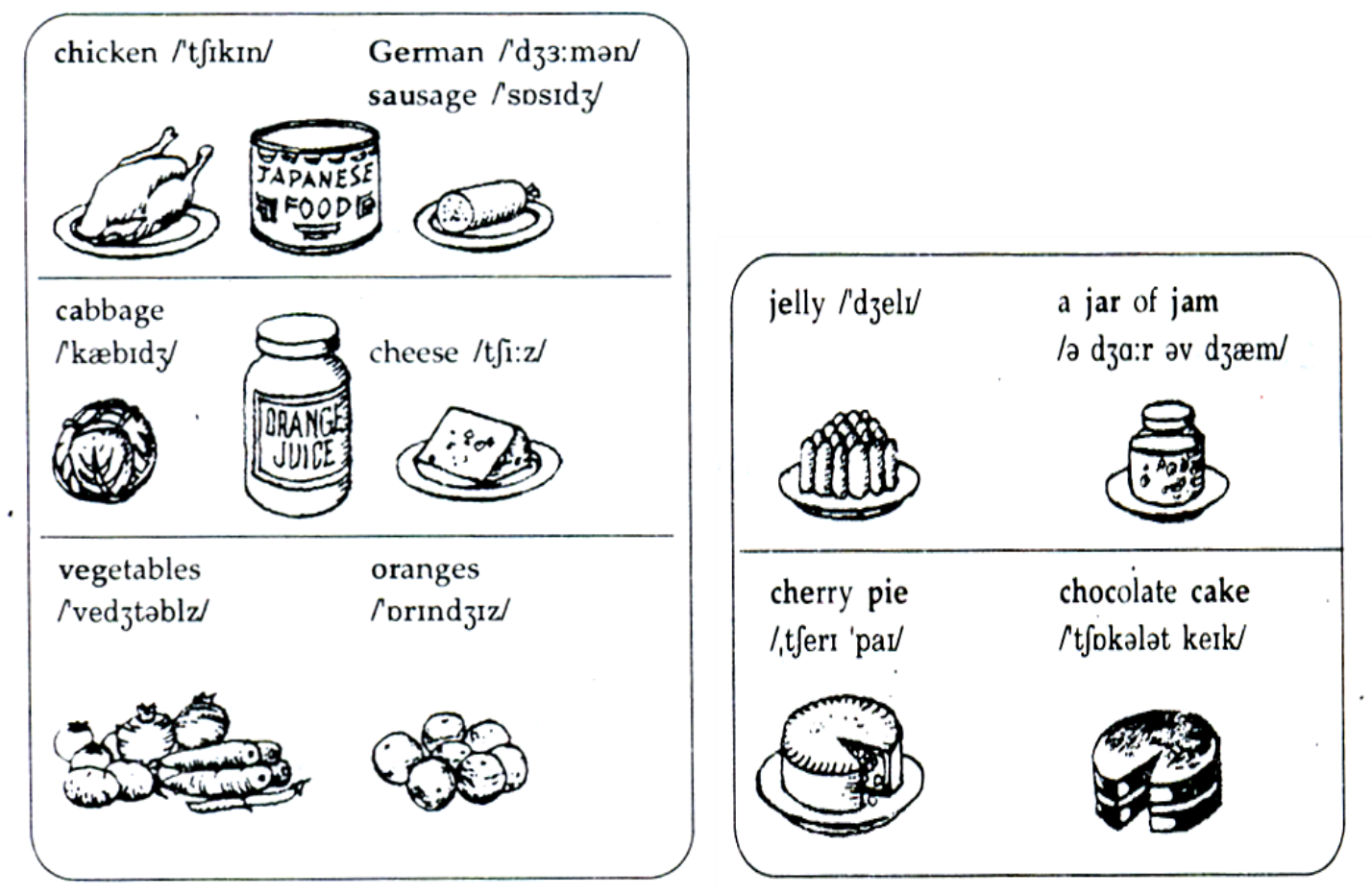

In the final stage of communicative practice, Diep first conducted a group discussion for both lessons. In lesson 1, Diep divided students into groups of three or four. Students were asked to discuss two questions about the seven vacations provided. In lesson 2, Diep showed a list of jobs followed by a list of characteristics; she organised students in groups of three or four and explained the task instructions. In this activity, students were asked to discuss and write the jobs on the correct lines below each characteristic. Lesson 1 ended with a speaking activity in which Diep had students talk with a partner about their last vacation. In lesson 2, students were given a list of jobs and asked to discuss the best and the worst in their small groups.

Overall, I observed that not many students had difficulty pronouncing / $/$ in lesson 1 and $/ \mathrm{t} \int /$ in lesson 2 properly but most of them struggled with $/ 3 /$ and $/ d z /$ at the beginning. It may partly be because of this that some students kept repeating the words with $/ 3 /$ or $/ \mathrm{d} z /$ several times before, during, and after practice although the teacher did not ask them to. I also 
noticed that students were actively involved in most classroom activities, especially those in the final stage of each lesson which gave them more meaningful communicative practice.

\subsubsection{Teacher Quynh's lesson: final sounds and linking}

This lesson was created by Teacher $\mathrm{Na}$ and was implemented in week 8 of the teachers' normal schedule. Table 6.6 summarises how Quynh structured her lesson and indicates how long each classroom activity lasted.

Table 6.6 Quynh's lesson

\begin{tabular}{|c|c|c|}
\hline Lesson stages & Classroom activities & $\begin{array}{l}\text { Time used } \\
\text { (61 minutes) }\end{array}$ \\
\hline 1. Description and & Raising students' awareness of releasing final sounds & 3 minutes \\
\hline \multirow[t]{2}{*}{ analysis } & Presenting common cases of linking sounds & 3 minutes \\
\hline & Explaining and giving oral illustrations & 5 minutes \\
\hline 2. Listening & Listening task & 3 minutes \\
\hline discrimination & Reading and guessing task & 4 minutes \\
\hline 3. Controlled & Phrase reading task & 4 minutes \\
\hline practice & Sentence completion and reading practice & 9 minutes \\
\hline \multirow[t]{2}{*}{ 4. Guided practice } & Conversation: matching and practice & 6 minutes \\
\hline & Conversation: linking identified and practice & 8 minutes \\
\hline 5. Communicative & Discussion: How to cope or not to cope with stress & 7 minutes \\
\hline practice & Speaking: Situations that reduce or increase stress & 9 minutes \\
\hline
\end{tabular}

Like other teachers, Quynh retained all the activities that had been designed for this lesson except the awareness raising at the beginning. To be specific, the lesson was planned to begin with the presentation of common cases of linking sounds but Quynh started it with an awareness raising activity. She firstly explained to students the importance of releasing final sounds in speaking English. Quynh told her students that dropping final sounds not only makes their speech unintelligible but also makes linking sounds between words impossible. Given the students' problem of dropping final sounds in speaking English, which is common amongst Vietnamese EFL learners, Quynh gave examples of minimal pairs in which this problem may cause misunderstandings such as car vs. card, fine vs. fire, and white vs. wife. Here, I observed that many students nodded their heads, signalling that they realised how important final sounds are in distinguishing word meaning and therefore indicating awareness 
of their pronunciation difficulties. After that, Quynh used sample phrases to present three cases of linking sounds: final consonant + vowel, final consonant + identical consonant, and final consonant + different consonant. She challenged students by asking them to read the phrases aloud without explanation. Since many students failed to link sounds, Quynh explained and got the whole class to listen and repeat the phrases several times.

In the stage of listening discrimination, a listening activity was firstly conducted. After having students listen to the recording and repeat the minimal word pairs, Quynh asked them to listen again and choose the words they heard. Quynh then had students work in pairs to do another listening discrimination activity. Students took turns to read the words while the other listened and guessed which word he/she heard by saying a or b accompanied by the number of the word pair in the list. Quynh finally called some students to read the words aloud and the whole class guessed which word they heard.

For controlled practice, students were first provided three lists of phrases corresponding to the three common cases of linking sounds presented in the first stage of the lesson. In this activity, Quynh had students listen to the recording and repeat the phrases. She then read the phrases one more time with exaggeration to raise students' awareness and re-explained how sounds are linked in each case. Finally, Quynh asked students to practice saying these phrases to a partner. Before students started, Quynh told them to monitor their partner's pronunciation. The lists are shown in Figure 6.6 below.

Figure 6.6 Controlled practice activity 1, Lesson focus of final sounds and linking

\begin{tabular}{|c|c|c|}
\hline $\begin{array}{c}\text { Consonant }+ \\
\text { Vowel }\end{array}$ & $\begin{array}{c}\text { Consonant + } \\
\text { Same Consonant }\end{array}$ & $\begin{array}{c}\text { Consonant }+ \\
\text { Different Consonant }\end{array}$ \\
\hline 1. correct answer & 6. red door & 11. junk' food \\
\hline 2. expert advice & 7. half & 12. walked' fast \\
\hline 3. finished early & 8. dark clouds & 13. health' club \\
\hline 4. piles of paper & 9. both thumbs & 14. change) clothes \\
\hline 5. picked it up & 10. deep p̧ool & 15. bird bath \\
\hline
\end{tabular}

This controlled practice stage then continued with a listening task in which Quynh had students listen to the recording twice and complete the sentences with the phrases they heard. She then asked students to write the phrases on the board; students got both right and wrong answers. After that, Quynh had students listen to the recording again; she paused at each 
answer to point out how sounds are linked in each phrase. At this point, I noticed that students listened attentively and seemed excited to find out how sounds are linked in spoken English. Quynh ended this controlled practice stage by having students read the sentences to a partner; she also reminded them to monitor each other's production.

The lesson proceeded with a matching exercise in the guided practice stage. Students were asked to match sentences and responses to make minimal conversations. After students wrote their answers on the board, Quynh gave feedback and got them to practice the conversations in pairs. She reminded students to monitor each other's production of linking. I noticed that when Quynh invited students to speak, some of them forgot to apply linking between words but realised it and self-corrected immediately. Yet, some students still did not realise their omission until Quynh raised their awareness and had them repeat the whole sentences in which they did not apply the linking rules.

In the communicative practice stage, Quynh implemented two speaking activities. In activity 1, she organised students in pairs to discuss how they cope or do not cope with stress. Students read eight statements, put a tick $(\checkmark)$ next to the ones that described themselves, and discussed their answers together afterwards. After five minutes, Quynh invited some students to answer. Again, I noticed at this stage that some students still forgot to link the final consonant of a word to the initial vowel of the following word in their speaking. Yet, they realised it promptly and corrected themselves without the teacher's assistance. Finally, Quynh conducted a group discussion as another communicative practice activity. She had students work in small groups to discuss and explain their ideas about which statements in activity 1 described situations that could reduce or increase stress. Quynh ended the lesson by encouraging students to do more self-practice on final sounds and linking at home.

The lesson was planned to last for 45 minutes; however, the total time the teachers actually spent implementing all the activities designed in the lesson plan ranged from 60 to 65 minutes. In retrospect, the lesson should have focused on only one pronunciation feature to allow students more time for practice and/or performance. In general, I observed that students enjoyed most classroom activities in this lesson. They actively engaged in speaking and group discussions. However, I noticed that some students, when invited to speak, did not remember to link sounds in their performance. The possible reason for this is that final sounds in the Vietnamese language are not articulated and there are no linking features as in 
English. Yet, it is encouraging to find that some students upon performance realised their problem and immediately corrected themselves.

\subsubsection{Teacher Khoa's lesson: /i:/ vs. /I/ and /u:/ vs. / $/$}

Unlike Teacher Nguyen, who replaced one activity in each lesson plan with the ones he selected, Khoa and other teachers retained all the activities designed by the planners. Even so, Teacher Khoa, in teaching these two lessons, still replicated to some extent what Nguyen did in his class. Table 6.7 summarises Khoa's classroom activities, teaching procedures, and time allocation for each lesson.

Table $6.7 \quad$ Khoa's lessons

\begin{tabular}{|c|c|c|c|c|}
\hline Lesson stages & $\begin{array}{l}\text { Classroom activities } \\
\text { (/i:/ vs. /I/) }\end{array}$ & $\begin{array}{l}\text { Time used } \\
\text { (43 minutes) }\end{array}$ & $\begin{array}{l}\text { Classroom activities } \\
\text { (/u:/ vs. /v/) }\end{array}$ & $\begin{array}{c}\text { Time used } \\
\text { (45 minutes) }\end{array}$ \\
\hline \multirow{2}{*}{$\begin{array}{l}\text { 1. Description } \\
\text { and analysis }\end{array}$} & Describing articulations & 2 minutes & Describing articulations & 2 minutes \\
\hline & Providing spellings & 3 minutes & Providing spellings & 3 minutes \\
\hline \multirow{2}{*}{$\begin{array}{l}\text { 2. Listening } \\
\text { discrimination }\end{array}$} & Listening task & 3 minutes & Listening task & 3 minutes \\
\hline & Bingo game & 3 minutes & Word reading + guessing & 3 minutes \\
\hline \multirow{2}{*}{$\begin{array}{l}\text { 3. Controlled } \\
\text { practice }\end{array}$} & Definition game & 5 minutes & Sentence reading & 4 minutes \\
\hline & $\begin{array}{l}\text { Sentence reading and } \\
\text { guessing }\end{array}$ & 3 minutes & Idiom matching task & 4 minutes \\
\hline \multirow[t]{2}{*}{$\begin{array}{l}\text { 4. Guided } \\
\text { practice }\end{array}$} & $\begin{array}{l}\text { Information gap activity } \\
\text { Conversation: gap-fill }\end{array}$ & $\begin{array}{l}5 \text { minutes } \\
6 \text { minutes }\end{array}$ & $\begin{array}{l}\text { Conversations: gap-fill } \\
\text { and practice }\end{array}$ & 5 minutes \\
\hline & and practice & & $\begin{array}{l}\text { Conversation: build up } \\
\text { and practice }\end{array}$ & 6 minutes \\
\hline \multirow{2}{*}{$\begin{array}{l}\text { 5. Communicative } \\
\text { practice }\end{array}$} & Question discussion & 7 minutes & Question discussion & 8 minutes \\
\hline & Speaking: hometown & 6 minutes & $\begin{array}{l}\text { Speaking: becoming a } \\
\text { billionaire }\end{array}$ & 7 minutes \\
\hline
\end{tabular}

Both lessons started with descriptions of articulation in which Khoa explained to students how the target sounds are produced and how they differ from each other in terms of vowel length. She used pictures to demonstrate how the lips are shaped when pronouncing each sound. Explaining the production of /i:/ and /I/, Khoa showed the different positions of the tongue. She then gave model pronunciations of the vowels and asked students to listen and 
repeat. After that, Khoa provided spellings for the vowels and got the whole class to listen and repeat several times before moving to practice.

The listening discrimination stage started with a listening task for both lessons. Khoa asked students to listen and repeat the words and then listen again and choose the words they heard. After eliciting answers, Khoa gave feedback by getting the whole class to listen again and check. This stage of each lesson continued with a second activity: a Bingo game for /i:/ and /I/ in lesson 1, and a word reading and guessing task for /u:/ and / $/$ / in lesson 2 . Instructions for the Bingo game were carefully delivered. Khoa first asked students to look at the Bingo card in the handout and read all the words. She explained to students that she was going to read the words on the Bingo card and students had to listen to her carefully to cross out the words they heard. Any student who had four words in a row or column crossed out would say "Bingo!". Khoa then started the game; she read and students listened to her and crossed the words out. The game ended after two minutes. For the word reading and guessing activity in lesson 2, Khoa placed students in pairs and instructed them on how to do the task. Students took turns to read the words while the other listened and guessed which word he/she heard by saying a or $b$ together with the number of the word pair in the list.

In the controlled practice stage of lesson 1, Khoa conducted a game called 'Definition'. In this activity, students worked in pairs and took turns to ask and answer questions about the meaning of the words in the list. After three minutes, Khoa invited some students to answer. The second activity Khoa carried out in lesson 1 was a sentence reading task. She first organised students in pairs as A and B and delivered the flash cards to each student. The flash cards used by Teacher Khoa and the other teachers (except Nguyen) are shown in Figure 6.7.

Figure 6.7 Controlled practice activity 2, Lesson focus of /i:/ and /I/

\begin{tabular}{l}
\hline Student A \\
\hline I. Read sentences 1-3 to your partner \\
1. It's been seen. \\
2. Hand me the pin, please. \\
3. Go on. Sick him! \\
II. Circle the word that your partner reads \\
4. I'd like to see that cheek / chick. \\
5. It's sipping / seeping. \\
6. Give him a lick / leek. \\
\hline
\end{tabular}

\section{Student B}

I. Circle the word that your partner reads

1. It's been $\sin /$ seen.

2. Hand me the pin / peen, please.

3. Come on. Sick / Seek him!

II. Read sentences 4-6 to your partner

4. I'd like to see that chick.

5. It's sipping.

6. Give him a lick. 
As shown in Figure 6.7, both flash cards had six sentences; students took turns to read the sentences as instructed on their flash card. In the first turn, student A read the first three sentences in his/her card while student B listened and circled the word he/she heard. In the second turn, student B read the last three sentences on his/her card while student A listened and circled the word he/she heard. Lesson 2 controlled practice started with a sentence reading activity. First, Khoa had students listen and repeat the sentences after her. Then, she asked them to work in pairs to read the sentences to a partner. After two minutes, she invited some students to read the sentences aloud. In activity 2, Khoa conducted a reading and speaking task. Students were asked to listen and repeat eight idioms in which /u:/ and / / occurred. Khoa then had them discuss in pairs to match the idioms with definitions. She finally called students to write their answers on the board and gave feedback.

The guided practice stage of lesson 1 was begun with an information gap activity. Khoa organised students in pairs; each student was given a flash card in which six words were available and six missing. All the words on both flash cards contained either /i:/ or /I/. Each student took turns to ask his/her partner for the missing words on his/her flash card. Khoa then continued by having students complete a conversation with the given words as a second activity. After giving feedback, she had students practice the conversation in groups of three. In lesson 2, a gap-fill activity was conducted first. Khoa asked students to complete three short conversations with the correct idioms in activity 2 of the controlled practice stage. Then, she called for answers and gave feedback before getting students to practice the conversations in pairs. Lesson 2 guided practice ended with a conversation-building activity. Students worked in pairs to make the conversation using the cues provided. After two minutes, Khoa invited students to write their answers on the board. She gave feedback and finally asked students to practice the conversation in pairs.

The communicative practice stage of each lesson was implemented with two activities each. In lesson 1, a situation-based speaking activity was firstly carried out. Khoa used a picture to show a situation of two students coming to different parts of their country for college. She then provided a list of words and phrases and explained the task instructions. Students worked in pairs to discuss and write down what the two students in the situation would miss about their hometown. After about four minutes, Khoa called some students to answer. Lesson 1 ended with a similar activity in which Khoa asked students to talk with a partner 
about what they missed about their hometown when going to university. Students seemed excited as they quickly turned to their friends and started talking.

In lesson 2, the first communicative practice activity Khoa conducted was a group discussion. She showed three different situations and had students discuss the questions in small groups. In this activity, students practiced the pronunciation of short/ひ/ in 'could', 'should', and 'would' to talk not only about the person in each situation but also about themselves. After five minutes, Khoa called some students to answer. The second communicative practice activity of lesson 2 was a speaking task. Khoa had students work in pairs to talk about what they could do and would do if they won a lottery ticket and became a billionaire. Again, students were eager to share their ideas and so they paired themselves and started the activity immediately when the teacher finished the instructions.

Like students in the other groups, this student group taught by Teacher Khoa had problems showing contrast in their production of long and short vowels in terms of vowel length. However, I observed that after the teacher's demonstrations and explanations followed by practice, students were able to show the distinction in their production through sound exaggerations. In other words, they tended to lengthen the words in which the targeted long vowels occurred, which made them yet sound unnatural in their speaking. The interesting point, though, is that students seemed to enjoy most classroom activities; they actively engaged in most tasks and were eager to talk.

\subsubsection{Teacher Na's lessons: sentence stress and intonation}

Because the teachers all retained the activities designed by the planner (Teacher Diep), descriptions of Teacher $\mathrm{Na}$ implementing these two lessons are similar to what Teacher Phuong did in her class as presented in 6.3.2 above. Na's teaching process and time allocation for each lesson are summarised in Table 6.8 below.

Table 6.8 Na's lessons

\begin{tabular}{lllll}
\hline Lesson stages & \multicolumn{1}{c}{$\begin{array}{c}\text { Classroom activities } \\
\text { (sentence stress) }\end{array}$} & $\begin{array}{c}\text { Time } \\
\mathbf{( 4 3} \text { minutes) }\end{array}$ & $\begin{array}{c}\text { Classroom activities } \\
\text { (intonation) }\end{array}$ & $\begin{array}{c}\text { Time used } \\
\mathbf{( 4 5} \text { minutes) }\end{array}$ \\
\hline $\begin{array}{l}\text { 1. Description } \\
\text { and analysis }\end{array}$ & $\begin{array}{l}\text { Presenting rules } \\
\text { Explaining and giving } \\
\text { oral illustrations }\end{array}$ & 2 minutes & Presenting rules & 2 minutes \\
& & & $\begin{array}{l}\text { Explaining and giving } \\
\text { oral illustrations }\end{array}$ & 4 minutes \\
\end{tabular}




\begin{tabular}{|c|c|c|c|c|}
\hline \multirow[t]{2}{*}{$\begin{array}{l}\text { 2. Listening } \\
\text { discrimination }\end{array}$} & \multirow[t]{2}{*}{$\begin{array}{l}\text { Listening task } \\
\text { Conversation practice }\end{array}$} & \multirow[t]{2}{*}{$\begin{array}{l}3 \text { minutes } \\
5 \text { minutes }\end{array}$} & $\begin{array}{l}\text { Listening task } \\
\text { (conversation) }\end{array}$ & 2 minutes \\
\hline & & & Listening task (lists) & 3 minutes \\
\hline \multirow{3}{*}{$\begin{array}{l}\text { 3. Controlled } \\
\text { practice }\end{array}$} & Conversation: read and & 4 minutes & Conversation practice & 5 minutes \\
\hline & circle stressed words & & One-word conversations: & 5 minutes \\
\hline & Conversation practice & 5 minutes & matching and practice. & \\
\hline \multirow{3}{*}{$\begin{array}{l}\text { 4. Guided } \\
\text { practice }\end{array}$} & "Correction" game & 4 minutes & Conversation: gap- & 7 minutes \\
\hline & Follow-up game: facts & 6 minutes & filling and practice & \\
\hline & & & $\begin{array}{l}\text { Conversation: building } \\
\text { and practice }\end{array}$ & 6 minutes \\
\hline \multirow{2}{*}{$\begin{array}{l}\text { 5. Communicative } \\
\text { practice }\end{array}$} & Conversation discussion & 6 minutes & Discussion: environment. & 5 minutes \\
\hline & Question discussion & 5 minutes & $\begin{array}{l}\text { Discussion: a weekend } \\
\text { picnic }\end{array}$ & 6 minutes \\
\hline
\end{tabular}

Lesson 1 started with Na presenting three basic rules of sentence stress. At this stage, she used sample sentences to present and explain the rules, gave oral demonstrations, and had students listen and repeat several times before moving to the second stage of the lesson. The first activity $\mathrm{Na}$ used in the listening discrimination stage was a listening task in which students listened to nine statements and circled the stressed word in each statement. She then elicited answers and gave feedback by letting students listen to the recording again to check. In activity 2, Na showed nine questions and asked students to match the statements in activity 1 to the correct questions. After getting students to write answers on the board, Na had them practice the conversations in pairs. Before students started, she reminded them to monitor each other's production of sentence stress.

The lesson then continued with a reading and listening activity in controlled practice stage. $\mathrm{Na}$ delivered handouts of a conversation to students and instructed them on what to do in this activity. She explained to students that they were to read the conversation and circle the stressed words in each speech chunk, and that they could discuss with a partner if they wanted. After two minutes, Na called for answers and had students listen to the recording to check. During this process, she paused at each speech chunk to re-explain the sentence stress rules. In activity $2, \mathrm{Na}$ had students practice the conversation in activity 1 with a partner. Before students started, she asked them to monitor each other's sentence stress during 
practice. Na finally invited some students to read the conversation aloud and moved on to guided practice.

The first guided practice activity Na carried out was a game called "Correction". The aim of this activity was for students to practice the sentence stress rule of correcting information. Students worked in pairs and took turns to read statements about general facts while the other listened and repeated each statement with corrected information. After two minutes, $\mathrm{Na}$ called some students to speak in pairs. Activity 2 was a follow-up game which was implemented in a similar manner as the "Correction" game in activity 1. Na first organised students in small groups and then gave task instructions. She explained to students that each of them was to write a statement about a general fact in Vietnam or the world that contained some wrong information. Then within their own groups, students took turns to read their statement aloud while other members listened and corrected the wrong information applying the sentence stress rule. While students were practicing, Na moved around the class to offer help where necessary. After three minutes, she called some students to read aloud their statements to the whole class. After each statement, Na paused and invited other students to correct it. The goal of this activity was successfully achieved since students were able to work on both form and meaning effectively. That is, they applied the sentence stress rule of correcting information properly in speaking and were able to correct the information in the spoken statements upon performance.

In the communicative practice stage, a listening and speaking activity was firstly implemented. Na first showed three questions on a PowerPoint slide and asked students to read the questions. She then had students listen to a conversation between two neighbours and answer question 1. After eliciting answers, $\mathrm{Na}$ let students listen to the recording again and discuss questions 2 and 3 with a partner. Na ended lesson 1 with a discussion in which students worked in small groups to discuss two questions about their relationship with neighbours. Finally, Na called some students to answer and moved on to teaching intonation in lesson 2.

At the beginning of lesson 2, Na presented the use of rising and falling intonation in two cases: end of a sentence and lists. She explained and illustrated these through sample sentences and lists with intonation lines. Then, she had students listen and repeat after her several times before moving to practice stages. The stage of listening discrimination was implemented with two listening activities. The first activity was for students to listen to a 
conversation and draw rising or falling intonation lines. Na let students listen to the recording once, elicited answers, and then had students listen again to check. A similar listening activity with lists was conducted in the same manner. In this activity, Na asked students to listen to eight lists and draw a rising or falling intonation line over the last word in each list. Students were required to decide if the speaker had finished the list by writing yes or no in the blank. $\mathrm{Na}$ then called for answers and let students listen to the recording again to check.

The lesson continued with a controlled practice activity in which $\mathrm{Na}$ had students listen to a conversation with intonation lines above each speech chunk and then practice it with a partner. Before students started, Na asked them to monitor each other's intonation during practice. After two minutes, Na invited some students to read the conversation aloud. In activity $2, \mathrm{Na}$ asked students to make conversations by rearranging two sets of questions and answers. After students wrote their answers on the board, Na gave feedback and had them practice the conversations in pairs. At this stage of the lesson, I noticed that certain students upon performance sometimes spoke with a flat tone instead of a rising or falling intonation and that Na subsequently corrected these students through recasts.

In the guided practice stage, $\mathrm{Na}$ first implemented a reading and listening activity in which students were asked to read a conversation and complete it with the words and phrases provided. After eliciting answers, $\mathrm{Na}$ had students listen to the conversation to check. She then asked students to practice the conversation with a friend and called some to read aloud after two minutes. In activity 2, Na got students to build up a conversation from the provided cues. When students were done, she asked them to write the conversation on the board, gave feedback, and had them practice the conversation in pairs. She reminded students of the use of rising and falling intonation at the end of sentences and in lists before they started. After two minutes, $\mathrm{Na}$ invited some students to answer.

The stage of communicative practice started with a reading and speaking activity. Na had students read a paragraph about how a town in New York tried to reduce its impact on the environment. After that, she asked students to write three specific things they could do to reduce electricity use, garbage, and water use. She then organised students in groups of three to discuss their answers. While students were discussing, Na went around the classroom and reminded them to apply listing intonation. She finally carried out a speaking activity in which students worked in pairs to discuss a place for a weekend picnic. Na encouraged students to base this on the conversation they practiced in activity 1 of the guided practice stage. She 
explained to students that they could use the structures in this conversation to build up their own.

Generally, I noticed at the beginning of the intonation lesson that many students across the six classes seemed a little shy and hesitant to apply the targeted intonation rules they had been taught in speaking practice. A reason for this might be that Vietnamese is different from English in that the former is a tone language whereas the latter is intonational (Avery \& Ehrlich, 2013). Thus, many Vietnamese EFL learners have trouble with intonation and are used to speaking English using flat intonation without any pitch change occurring in their utterances. However, after the teachers explained and demonstrated how intonation functions in spoken English, students became more interested in learning, engaged more actively in classroom tasks, and were eager to practice throughout the lesson. From my observations, students laughing during practice indicated that they had a lot of fun practicing intonation rules in speaking. As reflected on later in focus group interviews, 21/24 of the student participants reported that they were not taught pronunciation before and so did not know much about intonation. Therefore, for these students the teaching of intonation was 'something new'. Student 1 from focus group 3, for instance, said:

(...) I wasn't taught things like sentence stress and intonation. Although I've been learning English for nearly ten years, teachers didn't teach pronunciation before and so many of my friends and I knew nothing about it. So far, I've been speaking English with a flat tone and so sounded very weird. I found it very interesting when my teacher taught these [sentence stress and intonation] in this semester (...)" (Phase 2, FGI3 with student 1, question 2, translated from Vietnamese).

\subsubsection{Concluding remarks}

Taken together, classroom observations showed that the teachers were all able to fully translate what they learned from the workshop into their actual teaching practice. The five stages of the framework were clearly implemented in each lesson and the aims and objectives of each stage were fully achieved through a variety of classroom tasks. During these lessons, I observed that students quickly turned to each other to practice speaking, especially practice with conversations. Possibly, students were in part excited to engage in meaningful practice at a discourse level where communication is more likely to be developed. 
Phase 1 revealed that the teachers were poorly trained in pronunciation teaching given that they reported having limited initial training and a lack of PL opportunities that help foster their pronunciation teaching skills. However, the Phase 2 observational data show that after the TPL workshop all six teachers were better equipped to teach pronunciation communicatively. The following section reports on the teachers' stated beliefs about the impact of the TPL workshop on their knowledge gains and pronunciation teaching skills, and their perceptions of TPL for VTE teachers.

\subsection{Teachers' perceptions of the workshop and TPL for Vietnamese EFL teachers}

This section reports on the findings that answer RQ7 and RQ8 which examine the teachers' thoughts and beliefs about the impact of the TPL workshop on their knowledge gains and pronunciation teaching skills, and their perceptions of TPL opportunities for VTE teachers. The findings report on the teachers' in-depth interview data.

\subsubsection{Teachers' stated beliefs about the TPL workshop}

One week after the experimental teaching was completed, all the teachers were invited for individual in-depth interviews. The first part of the interviews was for each teacher to reflect on the impact of the workshop on their knowledge gains and pronunciation teaching skills. In the second part, the teachers were asked to discuss the effects of the CPT model on student learning and their beliefs about pronunciation instruction at the tertiary level in Vietnam, which will be reported in Chapter 7.

When asked to rate the usefulness of the workshop to their teaching job based on a rating scale of 1-5 (where $1=$ completely not useful and 5= extremely useful), all the teachers cited level 4 (very useful). Elaborating on the benefits of the workshop, the teachers all reported positive gains in terms of pronunciation knowledge, pronunciation pedagogy, and confidence in teaching pronunciation. Of these, all the teachers claimed that the workshop fostered their pronunciation knowledge and updated their pronunciation teaching methodology; four teachers said it helped boost their confidence in teaching pronunciation. The data are presented in Table 6.9. 
Table 6.9 Teachers' stated beliefs about the TPL workshop

\begin{tabular}{lcl}
\hline The workshop helped teachers & Frequency & Mentioned by \\
\hline 1. Foster pronunciation knowledge & $\mathrm{n}=6$ & All six teachers \\
\hline 2. Update pronunciation pedagogy & $\mathrm{n}=6$ & All six teachers \\
\hline 3. Boost confidence in teaching pronunciation & $\mathrm{n}=4$ & Quynh, Phuong, Diep, Khoa \\
\hline
\end{tabular}

Note: $\mathrm{n}=$ number of teachers

First, all the teachers stated that the workshop followed by experimental teaching was a good opportunity for them to review in detail the pronunciation knowledge they learnt years ago. According to the teachers, only when they teach pronunciation explicitly and systematically like this can they foster their knowledge about English pronunciation; otherwise, they will gradually forget it. The following extracts are representative:

(71) "I think the first point is I have fostered my knowledge about pronunciation. Clearly, if we don't apply previously learned knowledge in our teaching, it's certain that we'll gradually forget it. So, when I taught pronunciation communicatively in this semester, I had a chance to review pronunciation knowledge such as how English sounds are articulated, named and classified, etc. Understandings derived from this revision have helped me give clearer and precise explanations about places and manners of articulation of different sounds to my students." (P2, Teacher InI, Q2, Quynh)

(72) “As I told you in the previous interview session, I haven't taught pronunciation explicitly and systematically for a long time and so I think my professional knowledge has more or less faded. But when I did the experimental teaching, I had a chance to foster my pronunciation knowledge (...) For example, I know how a certain sound is produced but almost forgot what it's exactly called in English. Only when I planned experimental lessons did I recall how sounds are classified and named based on places and manners of articulation and I can explain this to my students in a clearer way. I think lesson planning helps teachers review their professional knowledge about what they are going to teach and this is the first benefit I received from the workshop and experimental teaching sessions.” (P2, Teacher InI, Q2, Nguyen)

These and other extracts show that the teachers all appreciated the opportunity to review and boost their pronunciation knowledge brought to them by the workshop and subsequent experimental teaching. As found in Phase 1, the most common approach to pronunciation teaching amongst the teachers was correcting students' pronunciation errors through recasts 
and/or prompts, and this restriction in the teachers' pronunciation teaching practices was shaped by different contextual factors including the curriculum and the student factors (see also section 4.3.3). The teachers' stated beliefs revealed that since they had not dealt with pronunciation instruction explicitly and systematically for a long time, their knowledge about pronunciation had diminished. However, the workshop followed by lesson planning and experimental teaching provided the teachers with an opportunity to revise and reinforce their pronunciation knowledge, which enabled them to explain places and manners of articulation of sounds to their students more clearly and precisely. In addition, the teachers stated that the workshop introduced to them a state-of-the-art approach to English pronunciation teaching; i.e. teaching pronunciation communicatively, as illustrated in the following comments:

"Another benefit is that the workshop has given me an in-depth understanding about the communicative framework for teaching pronunciation. As I told you in the previous interview session, I didn't know about this teaching approach. But thanks to the workshop, I now know exactly what it is and how it works. For me, this teaching strategy is completely new and it's what I really need because no one taught me how to teach pronunciation when I did my BA and MA.” (P2, Teacher InI, Q2, Diep)

"Another benefit is that after the workshop I have had a better understanding about the communicative framework for teaching pronunciation. I heard about this framework somewhere before but didn't have time to study it, to see if I can apply it in my teaching or not. Now I have a clear idea about how to apply this framework in my teaching pronunciation. I realised that this useful framework was proposed several years ago but failed to give it a careful examination. So far, my so-called pronunciation teaching has consisted of correcting students' pronunciation errors. From now on, I can apply this framework in my teaching pronunciation, so it will be better." (P2, Teacher InI, Q2, Na)

The actual words the teachers used in these and other extracts indicate that the workshop has brought to them 'something new' about pronunciation teaching. In the Phase 1 interviews, all the teachers reported that they had no idea about the framework and how it works in real practice (see also section 4.4.2). Not until the teachers attended the workshop were they able to study this framework in detail. According to the teachers, they can now apply this up-todate approach to teach pronunciation to their students. Teacher Diep further stated that the workshop has widened her knowledge about pronunciation textbook design. According to Diep, she previously did not know why activities in ESL/EFL pronunciation textbooks are designed in a certain sequence for classroom use. However, after the workshop it has become 
clear to her that pronunciation activities in textbooks are designed for specific aims and objectives. She said:

(75) "I also realised the principles of teaching pronunciation. Before, I saw in pronunciation textbooks that some activities are introduced before others but didn't know why they are designed that way. But when I got to know about the five steps of the framework, I understand that such design has its own purposes.” (P2, Teacher InI, Q2, Diep)

Second, the teachers reported finding the workshop very useful and they all believed that their approach to pronunciation teaching has been rejuvenated through the application of the framework. The following comments are evidence:

(76) “After the workshop, I realised that pronunciation teaching doesn't simply mean correcting students' pronunciation errors through listen-and-repeat activities but it's better to involve students in different communication situations (...) Now I have a more detailed picture of the communicative framework, how to apply it, and how to design teaching activities to fit each stage in the procedures. To tell you the truth, this workshop has given me 'a second wind' in teaching pronunciation. From now on, I may apply this approach to make my pronunciation teaching more interesting and more effective." (P2, Teacher InI, Q2, Phuong)

"In my opinion, this workshop is very useful for my pronunciation teaching. So far, I only correct students' pronunciation errors by asking them to listen and repeat after me. I've realised that teaching pronunciation through applying the communicative framework is much better. I now know the sequence of teaching steps. The principles of each stage help me design activities that meet the aims and objectives when I plan lessons. So, it makes my pronunciation teaching more vivid and so students become more interested. Actually, I always want to 'refresh myself' in teaching and this is actually a good way." (P2, Teacher InI, Q2, Khoa)

As shown in the teachers' comments, attending the workshop has changed their perspectives about pronunciation teaching. To be specific, all the teachers reported that after the workshop they realised that pronunciation teaching involving communicative activities is more beneficial to student learning than only error corrections through repetition. It was the workshop that showed them a way to refine their pronunciation teaching skill. This indicates that there has been a shift in the teachers' perceptions about pronunciation teaching from giving $\mathrm{CF}$ to integrating communicative practice to better assist student pronunciation 
learning. Interestingly, in Phase 1 of the study, all the teachers initially believed that correcting students' pronunciation errors through recasts and/or prompts was effective. However, after exploring and then applying the framework in practice, they all reported that their pronunciation teaching was more interesting and more effective than it used to be.

Finally, four of the teachers reported that they have become more confident in teaching pronunciation as a consequence of the workshop as illustrated in the following extracts:

(78) "I feel more confident. I told you before that I'm confident in teaching pronunciation, did I? At that time, it was simply because I was positive about my pronunciation skill and my teaching ability. But in fact, I only feel completely confident [in teaching pronunciation] after attending the workshop and doing the experimental teaching. Before, I only corrected some of my students' pronunciation errors to help them realise their problems in oral communication. But now I have the 'basis' to confidently diversify pronunciation activities in my class based on this theory [CPT] to help my students practice and improve their pronunciation.” (P2, Teacher InI, Q2, Quynh)

"Ah, there's one more thing. After attending the workshop, I felt more confident in teaching pronunciation. Before, I didn't teach pronunciation explicitly and systematically because I was not really sure about how to teach it well. I feel much better now and I'm sure that I can do it well from now on. I especially like the communicative practice stage of the framework because I've so far only corrected my students' pronunciation errors through repetition. But with this step, I now can give my students more communication situations to practice their pronunciation and at the same time develop their communication skills." (P2, Teacher InI, Q2, Diep)

These and two other extracts show that the teachers' confidence levels in teaching pronunciation have been strengthened as a result of the workshop. This indicates that the teachers' cognition has changed as a result of their perceived knowledge gains. To be specific, prior to the workshop, Quynh, Phuong, and Khoa in Phase 1 stated that they were confident in teaching pronunciation. Yet, after the workshop they realised that pronunciation teaching is far more than giving $\mathrm{CF}$ through repetition and so reported being more confident in how to teach pronunciation in a more productive way. They further noted that the workshop offered them a knowledge base to make their pronunciation teaching more interesting and diversified through the use of the framework. Teacher Diep reported in Phase 1 that she was not confident in teaching pronunciation because of her lack of initial training and PL in pronunciation pedagogy, but that the workshop has made her feel more confident 
in teaching pronunciation. According to Diep, the workshop provided her with knowledge of pronunciation pedagogy which she was not taught at both undergraduate and graduate levels.

In brief, the teachers' feedback in the interviews provided evidence to show that the TPL workshop on CPT was beneficial to their knowledge and classroom practice. In other words, the workshop had been an opportunity for the teachers to reinforce their pronunciation knowledge, widen their knowledge of pronunciation pedagogy and consequently strengthen their teaching practices. Most of the teachers reported that the workshop has boosted their confidence in teaching pronunciation. None reported any negative outcomes.

As a consequence of the teachers' experience with the TPL workshop and subsequent implementation of CPT in their EFL classes, I examined their thoughts and beliefs about TPL for VTE teachers in relation to pronunciation instruction, which will now be reported on in the following section.

\subsubsection{Teachers' perceptions of TPL for VTE teachers}

To examine the teachers' thoughts and beliefs about TPL for VTE teachers, I first asked them to talk about how TPL would assist them in their job. In response, the teachers all believed that TPL is advantageous to their teaching job and reported two benefits: refining teaching skills and avoiding tediousness in both teaching and learning. The former benefit was mentioned by all the teachers, and the latter by three of the teachers (Quynh, Diep, and Khoa).

As perceived by all the teachers, the overall benefit of TPL is improved SLOs. According to the teachers, TPL helps widen their knowledge, so they can adopt state-of-the-art teaching methodology and refine their teaching skills. It can be inferred from the teachers' responses that teaching potentially impacts students' learning either positively or negatively. As such, all the teachers believed that once their teaching skills are refined, they can apply them in real practice to better facilitate student learning and help them improve their achievement. The following extracts are representative:

(80) “Clearly, attending PL programmes helps teachers widen their professional knowledge, update new teaching methodology that helps them teach better and students can learn the language better.” (P2, Teacher InI, Q3, Nguyen) 
"I think PL programmes are very necessary because this is an opportunity for teachers to update new teaching theory to serve their teaching job. And of course, modern teaching methodology helps students learn the language better." (P2, Teacher InI, Q3, Khoa)

Three of the teachers further mentioned that TPL is an opportunity for teachers to learn new things that can animate both teaching and learning. For example, Quynh said:

$$
\begin{aligned}
& \text { "Second, if teachers keep doing the same thing every day, then both teachers and students } \\
& \text { will get bored. Routineness makes teachers lose their interest in teaching and students } \\
& \text { become demotivated in learning. So, it's much better if teachers update new teaching } \\
& \text { theory and skills to serve their daily teaching job." (P2, Teacher InI, Q3, Quynh) }
\end{aligned}
$$

As shown in this and two similar comments, the teachers' main concern is that the replication of certain teaching practices leads to tediousness for both teachers and students. To this end, the teachers believed that TPL can help them stay away from routineness in their daily job and so reduce boredom and monotony in teaching and learning for both teachers and students.

In talking about their expectations of TPL opportunities for VTE teachers in relation to pronunciation instruction, the teachers reported three types of TPL activities: (1) annual workshops; (2) short-term learning courses; and (3) doing a PhD. Annual workshops and short-term learning courses were expected by all the teachers; doing a $\mathrm{PhD}$ was reported by three of the teachers. The data are summarised in Table 6.10.

Table 6.10 Teachers' perceptions of TPL for VTE teachers

\begin{tabular}{lcl}
\hline PL opportunities & Frequency & Mentioned by \\
\hline 1. Annual workshops & $\mathrm{n}=6$ & All six teachers \\
\hline 2. Short-term learning courses & $\mathrm{n}=6$ & All six teachers \\
\hline 3. Doing PhDs & $\mathrm{n}=3$ & Quynh, Phuong, Nguyen \\
\hline
\end{tabular}

Note: $\mathrm{n}=$ number of teachers

First, all the teachers reported that attending an annual workshop is necessary, and they all emphasised that such workshops need to be facilitated by a native-speaker expert. As the teachers explained, this is an opportunity for teachers to both refine teaching skills and share classroom experiences. The following comments are evidence: 
"In my opinion, it's very good if we have workshops twice a year. But if that's not possible, then there should be at least a big annual workshop with native speaker experts as keynote speakers. This is not only for teachers to update new knowledge and teaching methodology but it's also an opportunity for teachers to share their teaching experience." (P2, Teacher InI, Q4, Quynh)

"First, I think workshops with native speaker experts as keynote speakers are very good because they can help teachers to widen their professional knowledge and to learn new teaching skills. This is also it's an opportunity for teachers to share their teaching experience and learn from each other." (P2, Teacher InI, Q4, Nguyen)

"I think the first thing our school should do is to have a workshop once a year for teachers to share their teaching experience and learn from each other. If we can invite native speaker experts to be keynote speakers, it'll be excellent because teachers can update on new knowledge and recent teaching trends in the world." (P2, Teacher InI, Q4, Khoa)

These and other extracts show that the teachers highly valued workshops as a means for their professional growth. As they said, attending workshops helps teachers learn not only from experts of the field but also from each other through experience and practice sharing. Conferences and/or workshops have been reported not to bring about sustained impact on classroom practice and students' achievement (Darling-Hammond, Wei, Andree, Richardson, \& Orphanos, 2009). In the current study, however, workshops were the first to be mentioned when the teachers talked about their PL needs. As explicitly stated in their comments, the teachers believed that workshops that nurture collaborative learning and practice sharing are beneficial to their professional growth. This belief finds support from one of the principles of effective TPL documented in the literature that collaboration best helps facilitate teacher learning (Desimone, 2009; Diefes-Dux, 2014; Wayne et al., 2008).

Interestingly, the teachers expected to attend workshops in which native-speaker experts are keynote speakers. It is likely that the teachers' expectation was influenced by the dichotomy between native and non-native speakers as trainers in TPL. Implied in the teachers' responses was a belief that native speakers, given their linguistic backgrounds, are better qualified than non-native speakers. However, Dewaele (2017) and Faez (2011) saw this native-/non-nativespeaker dichotomy as problematic and argued that neither native speakers nor non-native speakers are superior to the other and that "they are equal and can be complementary" 
(Dewaele, 2017, p. 240). In addition, Schmid (2011) has pointed out that native speakers may lose their L1 proficiency as a result of the attrition process and yet such loss does not affect their status as a native speaker. Thus, it is important to consider how the trainers construct and negotiate meanings in a given social context of training rather than "their self-affiliations, backgrounds, or countries of birth" (Faez, 2011, p. 234).

Second, all the teachers stated that short-term learning courses from three to six months in an English-speaking country are necessary for teachers to enhance their language skills and update on recent teaching trends around the world. They said:

(86) "Second, learning courses in English-speaking countries are very good and very necessary for teachers' professional growth. But these courses must be at least three months in length. Before, I attended a three-week course in the US and did learn something but not much because it was too short. But the three-month course in New Zealand was amazing. I studied in a modern education environment with advanced teaching methodology. I learnt a lot from the teaching staff there, from the knowledge they transferred in class to their teaching styles. I must say they were very professional." (P2, Teacher InI, Q4, Phuong)

“Short-term learning courses are also very important for teachers' professional growth. A majority of our teachers were trained in Vietnam, so if they can attend a three-or-sixmonth course in an English-speaking country such as England, America or Australia, then they can not only develop their professional ability but they can also improve their language skills." (P2, Teacher InI, Q4, Diep)

“Short-term learning courses are also necessary for both teachers' professional growth and language skills development. A majority of teachers studied English through their teachers and textbooks in Vietnam, so if we have more opportunities for our teachers to study in English-speaking countries for about three months, I think they can not only improve their professional knowledge but also develop their language skills. Then they'll teach better and can help students learn the language better." (P2, Teacher InI, Q4, Na)

As seen from these and other comments, the teachers believed that attending a TPL course in an English-speaking country not only promotes teachers' specialised knowledge but also helps refine their language skills. According to the teachers, this opportunity can help teachers update on knowledge and state-of-the-art teaching methodologies from both the course they attend and the teaching staff who are in charge of the course. Also implied in the 
teachers' comments is an expectation of improving English skills. According to the teachers, since many Vietnamese EFL instructors were trained domestically, if they have an opportunity to study in an environment where English is the official language, then exposure to the target language can help improve their English skills. However, the teachers stated that a learning course such as this should be at least three months in length if it is to bring about positive gains. The teachers believed that the longer teachers study in an English-speaking country, the better the outcomes are. This belief is consistent with a consensus in the literature that intensive TPL is more likely to have positive and long-lived effects on teacher change, instructional practice, and SLOs (Capps, Crawford, \& Constas, 2012; Desimone, 2009; Diefes-Dux, 2014; Opfer \& Pedder, 2011). As Phuong reflected on her own experience, what she learnt from a three-month course in New Zealand was more than that from a three-week course in the US.

Third, three of the teachers believed that doing a $\mathrm{PhD}$ in an English-speaking country is a good way for doing research and updating professional knowledge. According to the teachers, if a three-to-six-month course in a developed country where English is the official language is valuable to teacher learning, then spending several years doing research there would optimise teachers' professional knowledge and language skills. Then, teachers can share their knowledge gains with colleagues on return and help students study the language better. For example, as Quynh commented:

"I think another long-term strategy is sending teachers to English-speaking countries to do a PhD. The university should have annual plans to encourage and support teachers in this. As I've just said, teachers will benefit a lot from studying in developed countries where there are modern educational environments and advanced teaching methodology. If short-term courses can be so effective, then spending four to five years studying and doing research will bring about a lot more benefits. After finishing, they're back with new things that can better facilitate students' language learning. They can also share what they've learnt in foreign countries with teachers who are unable to do so." (P2, Teacher InI, Q4, Quynh)

In short, the teachers' stated beliefs indicate that TPL opportunities such as annual workshops and short courses are important and necessary for VTE teachers to update knowledge and refine their teaching skills, which in turn helps facilitate students' language learning. 


\subsection{Discussion}

This section presents detailed discussions of the impact of the TPL workshop on the teachers' knowledge gains and pronunciation teaching skills. It also discusses the most distinguishing features of PL for VTE teachers in relation to pronunciation instruction.

\subsubsection{The TPL workshop}

The shift from giving CF as the most frequent approach to CPT in the VTE classroom was facilitated and achieved through the application of the pedagogic framework introduced to the teachers in the workshop. Analysis of the data from Phase 2 showed that the TPL workshop was a success as measured in the teacher reports of their knowledge gains (both content and pedagogical knowledge), pronunciation teaching skills, and perceived improvement in student learning. The value of the workshop was further seen in the students' stated beliefs about how the CPT model enhances their pronunciation, listening and speaking skills. This section only discusses the impact of the workshop on the teachers' knowledge gains and pronunciation teaching skills. The teachers' and students' perceptions of the effects of the CPT model on student learning will be discussed in Chapter 7.

Positive changes in the teachers' knowledge were attributed to the TPL workshop. The teachers benefited from the workshop in terms of knowledge gains in pronunciation pedagogy, which they reported to be useful and applicable in their English teaching. In other words, the TPL workshop provided the teachers with an opportunity to refine their pronunciation teaching skills. While it was expected that after the workshop the teachers would improve their knowledge of pronunciation pedagogy, it was encouraging to discover that they reported having a chance to enhance their own knowledge of English pronunciation. As reflected in their reports, upon completion of the workshop the teachers gained an indepth understanding of how to teach pronunciation communicatively and become more confident in doing so. In addition, given that the teachers did not explicitly and systematically teach pronunciation prior to the intervention, they reported having more or less forgotten what they had learned about pronunciation theory during their initial training process. Yet, the teachers stated that applying the new pronunciation teaching approach helped them boost this limited knowledge of pronunciation. They therefore believed that planning experimental lessons allowed them to revise and enhance this knowledge to be well-prepared for their pronunciation classes. 
This finding of the Phase 2 study resonated with previous research. For example, in a qualitative study conducted in the context of Sri Lankan secondary schools, Ekanayake and Wishart (2015) found that after attending TPL workshops, the teacher participants developed their understanding of the potential of mobile phones in science teaching and learning, and were able to identify their own pedagogical needs of applying technology in their classroom. They discovered that the teachers highly valued the opportunity to share knowledge and teaching skills brought to them by the workshops they engaged in. Research by Borg and AlBusaidi (2012) also showed that participating teachers responded positively to the workshops they attended. That means the workshops enabled the teachers to create a sense of joint purpose and momentum in studying how to more effectively promote learner autonomy in their language classes.

These findings strengthen the claim about the success of the TPL workshop which was designed and implemented in relation with five research-based principles of effective TPL. First, the workshop was designed based on the teachers' actual learning needs. It was motivated by part of the Phase 1 data which revealed that the teachers had limited initial training in teaching pronunciation and lacked PL opportunities in pronunciation pedagogy. The workshop filled this knowledge gap and provided the teachers with an opportunity to refine their pronunciation teaching skills. According to Timperley et al. (2008, p. 12), teachers "have very diverse professional learning needs arising from the specific demands that their particular students place on their teaching skills". Thus, TPL which is responsive to teachers' learning needs is more likely to be successful since they find the activity meaningful and relevant to their own classroom contexts (Murray \& Zoul, 2015; Timperley et al., 2008; Wayne et al., 2008).

Second, the workshop was content-focused and job-embedded. In other words, the workshop focused on only one particular aspect of English language teaching - pronunciation instruction - which is considered as an integral part in this EFL programme by both teachers and students. Moreover, Phase 1 of the study found that explicit pronunciation instruction was largely absent from the curriculum and almost always neglected in class. In Phase 2, it was the workshop that helped the teachers bring explicit pronunciation instruction back to their classroom in such a way that they did not know prior to the intervention. As Desimone (2009) and Timperley et al. (2008) hold, TPL which is directly relevant to teachers' classroom realities is more likely to bring about positive gains in terms of teacher learning, 
instructional practice, and SLOs. This is because, according to Timperley (2011) and Van Driel and Berry (2012), teachers hold strong beliefs about what teaching methods are good and how best to promote their student learning.

Third, the workshop focused on the connection between teaching and SLOs. According to Muijs et al. (2014) and Timperley et al. (2008), the common reason for many teachers to engage in TPL activities is to widen their knowledge and hone teaching skills to ultimately improve their students' achievement. Timperley (2011) maintains that teachers' awareness of what needs to be changed and which changes are positive is important, thus they need to "understand the links between particular teaching activities, the ways different groups of students respond, and what their students actually learn" (Timperley et al., 2008, p. 8). In the current study, the stated aims of the EFL programme in which the teachers operated were to develop students' language skills and to help them gain confidence in using English for oral interaction. The teachers all acknowledged that pronunciation is essential in English learning and that students expected pronunciation instruction to help improve their listening and speaking skills. They were willing to make changes in their teaching to meet their students' learning needs and the workshop provided them an opportunity to do so. Additionally, the workshop helped the teachers understand the link between CPT and the development of students' oral communication. By the end of the workshop, the teachers all understood what the framework is and how it works in classroom reality.

Fourth, the workshop encouraged active, collaborative learning amongst the teacher participants and required them to take responsibility for translating the workshop content into actual lesson plans. Research has shown that teachers learn best when they learn collaboratively, sharing experiences and planning lessons (Darling-Hammond et al., 2009; Desimone, 2009; Diefes-Dux, 2014). In this study, the teachers participated in the workshop as a whole group and actively studied the communicative framework for teaching English pronunciation by themselves based on the model lesson I gave. They collaboratively engaged in discussions to figure out what the communicative framework is together with the aims and objectives of each stage of the framework. Later on, the teachers planned lessons together and took turns to clarify their own lesson plans. They cooperated in planning lessons for their subsequent teaching and shared lesson plans with each other, which allowed for collaborative learning amongst the teachers. As Muijs et al. (2014) have argued, TPL becomes effective 
when teachers work together "to investigate, challenge, and extend their current views" (p.249).

Finally, follow-up support was provided to help the teachers translate what they had learned into actual classroom practice. Timperley et al. (2008) have pointed out that TPL activities are less effective if no follow-up support is provided when teachers get back to their classroom. In the current study, the teacher participants were supplied with all necessary teaching materials, i.e. relevant pronunciation textbooks and CDs, for lesson planning and subsequent teaching. After the workshop, the teachers used the textbooks provided to plan and share lessons with each other. Prior to the experimental teaching, the teachers and I had a meeting during which they clarified and discussed these shared lesson plans. We also had a group discussion a week after each experimental teaching session to review the lessons taught in each. These review meetings allowed the teachers to talk about the lessons and to report any problems regarding the experimental teaching they had implemented (if there were any).

\subsubsection{TPL for VTE teachers}

Traditional TPL in the form of one-shot workshops has been criticised as being short-lived and not really effective in bringing about changes in teacher classroom instruction and SLOs. One particular reason is that workshops are traditionally implemented independently of teachers' instructional contexts and not accompanied by genuine follow-up support (Armour \& Makopoulou, 2012; Dichaba \& Mokhele, 2012; Murray \& Zoul, 2015). However, Guskey and Yoon (2009) have pointed out that workshops can be effective if they centre on the application of research-based instructional practices, promote teachers' active learning, and give participants opportunities to adapt the new instructional practice to their unique teaching situations. This argument aligns with Tate's (2009) claim that workshops subsequently accompanied by job-embedded activities or action research support teachers finding them relevant and authentic, which in turn promotes teachers' PL process. Thus, workshops, if implemented well, can be beneficial to teacher learning. As Guskey and Yoon (2009) have concluded, "workshops are not the poster child of ineffective practice that they are often made out to be" (p.496).

It has been found that the TPL workshop in Phase 2 of the study was successful in promoting the teachers' content and pedagogical knowledge and refining their pronunciation teaching skills, which in turn facilitated students' pronunciation learning. It was carried out in 
consideration of the teachers' actual needs, classroom realities, and the connection between teaching and student learning. The workshop encouraged active, collaborative learning amongst the participants, and follow-up support was provided to help the teachers translate what they had learned into actual classroom practice. More importantly, the teachers had an opportunity to learn a new approach to pronunciation teaching. During the workshop, they explored the communicative framework for teaching English pronunciation by themselves through the demonstration of a model lesson and actively discussed what they were studying. The teachers then made, shared, and discussed their own lesson plans prior to actual classroom instruction. They shared their experiences of applying the new teaching skill within the group during the process of translating theory into practice. This suggests that workshops such as this are feasible at the tertiary level in Vietnam.

The Phase 2 study also found that the teachers, apart from workshops, favoured short-term courses and doing a PhD in English-speaking countries. They believed that TPL such as these can help promote teachers' professional knowledge, refine teaching skills, and enhance teachers' English proficiency, especially pronunciation skills. From the teachers' perspectives, such short-term courses should be three months at least if they are to be beneficial to teacher learning. This finding lends support to a claim that TPL is a long-term process in which positive changes require extra work and time to emerge (Guskey, 2002; Papastamatis, Panitsidou, Giavrimis, \& Papanis, 2009; Villegas-Reimers, 2003). It is also consistent with a consensus in the literature that the more intensive PL teachers have, the more long-lasting the effects are on their instructional practice and student learning (Capps et al., 2012; Desimone, 2009; Diefes-Dux, 2014; Opfer \& Pedder, 2011). Although such courses may require a lot of effort, time and money, it is worth doing so if SLOs are to be prioritised and ensured. Given the expectation of the society and the labour market, this type of TPL is not only suitable but also beneficial to VTE teachers who help facilitate students' English learning.

\subsection{Summary of the chapter}

This chapter has presented the findings and discussion about how the teachers implemented CPT in class, the teachers' articulated beliefs about the impact of the TPL workshop on their knowledge gains and pronunciation teaching skills, and their perceptions of TPL opportunities for VTE teachers. The findings included evidence from CPT lesson plans, classroom observations, and in-depth interviews with the six case study teachers. The 
findings showed that the teachers' knowledge of pronunciation and pronunciation pedagogy increased as a consequence of the TPL workshop. The teachers believed that the workshop helped them update on state-of-the-art pronunciation pedagogy, which they found useful for their English teaching. They developed an in-depth understanding of how to teach pronunciation communicatively resulting in a refinement of their pronunciation teaching skills. Some teachers reported becoming more confident in teaching pronunciation; they have been able to design pronunciation lessons applying the communicative framework. They perceived the CPT model as an innovation that made their pronunciation teaching more effective in facilitating students' pronunciation learning. To this end, the teachers all reported workshops to be the first type of PL necessary for their professional growth. They mentioned short-term courses and doing PhDs as effective PL programmes for VTE teachers.

In brief, the Phase 2 study's findings suggested that workshops designed according to research-based principles of effective TPL can be beneficial to promote teachers' PTC. The study has provided evidence for the feasibility of TPL workshops as an effective tool to promote pronunciation teaching within an Asian context, particularly in enhancing the teachers' pedagogical knowledge and refining their pronunciation teaching skills.

In the next chapter, I will present and discuss the findings regarding the teachers' and students' stated beliefs about the effects of the CPT model on student learning, and how they perceived pronunciation instruction at the tertiary level in Vietnam. 


\section{Chapter 7}

\section{THE PHASE 2 STUDY: COMMUNICATIVE PRONUNCIATION TEACHING AND PERCEIVED STUDENT LEARNING}

\subsection{Introduction}

Building on the findings about how the teachers planned and implemented the seven CPT lessons in their English classes as reported in Chapter 6, this chapter focuses on the effects of the CPT model on student learning from both teaching and learning perspectives. It also reports on the findings regarding the teachers' and students' perceptions of pronunciation instruction at the tertiary level in Vietnam. It addresses the following research questions (RQs):

RQ9. How did the teachers and students perceive the effects of CPT on student learning?

RQ10. What did the teachers and students think and believe about pronunciation instruction at the tertiary level in Vietnam?

I will first report on the findings related to each of the research questions and then discuss some main findings and conclude with a summary.

\subsection{CPT and student learning}

This section addresses RQ9 which investigates the teachers' and students' stated beliefs about the effects of the CPT model on student learning. The findings report on the teachers' indepth interview data and the students' FGI data. The interviews were carried out one week after the teacher participants finished implementing all the CPT lessons.

\subsubsection{Teachers' beliefs about the value of CPT to student learning}

Regarding the effects of the CPT model, all the teachers stated that it was very useful for student learning. The teachers elaborated by saying that CPT: (1) raised students' awareness, (2) provided pronunciation knowledge, (3) fostered students' confidence, and (4) aroused students' interest in classroom learning. Of these, the first three benefits were mentioned by 
all the teachers, while the last advantage was less frequent, being cited by only four of the teachers. The data are summarised in Table 7.1.

Table 7.1 Teachers' stated beliefs about the value of CPT to student learning

\begin{tabular}{lll}
\hline \multicolumn{1}{c}{ Benefits of CPT } & Frequency & Mentioned by \\
\hline 1. Raising students' awareness & $\mathrm{n}=6$ & All six teachers \\
\hline 2. Providing pronunciation knowledge & $\mathrm{n}=6$ & All six teachers \\
\hline 3. Fostering students' confidence & $\mathrm{n}=6$ & All six teachers \\
\hline 4. Arousing students' interest & $\mathrm{n}=4$ & Quynh, Nguyen, Diep, Khoa \\
\hline
\end{tabular}

Note: $\mathrm{n}=$ number of teachers

The first point all the teachers made in articulating the advantages of the CPT model is that students became more aware of how important pronunciation is in oral communication. In Phase 1, students of the university were observed to aim at fluency rather than pronunciation accuracy and tended to discount or even ignore pronunciation practice. However, through applying the framework, the teachers reported having succeeded in raising their students' awareness of the importance of pronunciation in their English learning as illustrated in the following extracts:

(90) "I think students have become more aware of how important pronunciation is to their listening and speaking skills. Before, as I told you, many students just aimed at fluency and ignored pronunciation practice. From those experimental classes, I'm sure they've been more aware that their pronunciation errors cause oral communication breakdowns. When I explained to them this matter, I believe they've realised that pronouncing correctly and clearly for others to understand is as important as speaking fluently." (P2, Teacher InI, Q5, Quynh)

(91) "Through the new teaching approach in this semester, I had time to analyse students' pronunciation problems, explain and illustrate how important pronunciation is in listening and speaking. I think students have realised that they have so far ignored this in English learning. From examples of communication misunderstandings due to pronunciation errors I showed in class, I'm sure students have become more attentive to pronunciation practice." (P2, Teacher InI, Q5, Nguyen)

(92) 'For me, the first rewarding thing is that I've raised students' awareness of the importance of pronunciation in English learning. During my experimental teaching in 
this semester, I analysed students' speaking to help them see how serious their pronunciation problems are in speaking English. Through my explanations, I think students have been more aware of how important pronunciation is and from now on they'll definitely pay more attention to practicing pronunciation." (P2, Teacher InI, Q5, Khoa)

These and other responses show that the teachers believed they had made their students more aware of the importance of pronunciation during their experimental teaching sessions. Unlike their common practice of pronunciation teaching as found in Phase 1, i.e. correcting students' errors through recasts and/or prompts, the teachers believed that the explicit, communicative teaching of pronunciation in this semester has contributed to raising learner awareness of pronunciation learning. Such a teaching approach, according to the teachers, has provided them with a showcase for pronunciation error analysis, and explanations and illustrations of common breakdowns in daily communication, which makes students more conscious of their own potential pronunciation problems. As further implied in their responses, the teachers believed that not until they clearly explain and show real-life situations in which mispronunciations impede interlocutors' proper interpretations of an intended message will students become more attentive to pronunciation practice. The experimental teaching has given the teachers a chance to do so.

The second benefit of the CPT model as reported by all the teachers was that students obtained some basic knowledge about English pronunciation. The teachers believed that students generally gained better understandings of some typical pronunciation features which were addressed in this semester, as evident in the following comments:

(93) "The second benefit is pronunciation knowledge. The experimental teaching sessions of sounds have provided students with basic knowledge about places of articulation, manners of articulation as well as characteristics of the target sounds. They were also more conscious of final sounds and linking in their speaking. When I taught them sentence stress and intonation, students understood them more deeply and clearly and basically could apply them in speaking English. Before, students didn't learn about these and so they didn't know how to use rising and falling intonation in their speaking or they didn't know which word to stress in a sentence." (P2, Teacher InI, Q5, Phuong)

(94) "Basically, students have understood more clearly about places and manners of articulation of the target sounds, sentence stress, intonation and especially linking. They've known how and when to raise and lower their voice in speaking and which word 
needs to be stressed in sentences. What pleased me the most was that students were more conscious of final consonants and linking although they still sometimes forgot to apply linking but I think this requires them to do more practice." (P2, Teacher InI, Q5, Diep)

(95) "Second, students have had a more specific understanding about places of articulation, manners of articulation and the essence of those sounds I taught them. Students have also basically understood more clearly about sentence stress and intonation and could apply this in communication. Especially, students were more aware of linking sounds in their speaking. Before, they usually dropped the final consonant in their speaking and didn't link it with vowel that follows." (P2, Teacher InI, Q5, Na)

According to the teachers, through CPT they were able to provide their students with basic knowledge about certain pronunciation features including places and manners of articulation of sounds, linking, sentence stress and intonation. In comparison to error correction through repetition, the teachers believed that students understood what they were taught and were basically able to apply this in their speaking. The teachers specifically emphasised the effects of teaching linking, sentence stress and intonation explicitly. In Phase 1 of the study, intonation and linking were reported as two of the most severe pronunciation problems commonly facing Vietnamese EFL learners (see also section 5.3), yet the teachers all stated that students, after being explicitly taught these features, benefited a lot from classroom learning and were able to translate theory into communication practice.

The third point all the teachers mentioned when talking about the effectiveness of CPT is that students' confidence in using English for oral communication can be enhanced. All the teachers reasoned that teaching pronunciation using the framework offers students more opportunities for communicative practice which simultaneously helps improve their listening and speaking skills. The following extracts are evidence:

(96) "When I gave students communication situations for practice, I felt they were really eager to talk. They worked harder and engaged more actively in classroom activities. So, I think the results will be much better if we teach [pronunciation] during the whole semester. Then I'm sure that students' pronunciation in particular and listening and speaking skills in general will be remarkably improved and so they'll be more confident in speaking English." (P2, Teacher InI, Q5, Phuong)

(97) "The last stage in the framework provides students with communicative practice in reallife situations. I like this because it involves students more actively in classroom 
activities. Students practice not only pronunciation but also listening and speaking. I'm sure if we have more classes like these, students' pronunciation, listening and speaking skills will improve. So, students will be more confident in using English for oral communication. Some students asked me the other day for the book title so that they can go to the bookstore to buy one for their self-study.” (P2, Teacher InI, Q5, Diep)

"I saw that students were actively involved in most classroom activities, especially those communication tasks at the end of the lesson. In my opinion, if we teach [pronunciation] communicatively like this, then students' pronunciation skill will definitely be improved. And this helps develop their listening and speaking skills as well. Gradually, they'll be more active and confident in speaking English. But the outcomes didn't come up to my expectation because the experimental teaching was too limited. If we teach more, then I'm sure it'll be much better." (P2, Teacher InI, Q5, Na)

The actual words the teachers used in these and other extracts show their positive beliefs about SLOs facilitated by the new pronunciation teaching approach. According to the teachers, CPT can definitely improve students' pronunciation and help develop their listening and speaking skills. The teachers reported seeing students actively engaged in most classroom events and believed that students' pronunciation, listening and speaking skills improved through different communicative practice activities. And once these skills improve, students' confidence in using English for oral interaction will be enhanced. Overall, all the teachers believed that if there were to be more pronunciation classes taught communicatively like these, pronunciation learning outcomes would be markedly improved.

Finally, four of the teachers reported that the explicit CPT they implemented during the semester can also arouse students' interest in classroom learning. As these teachers saw it, CPT had made their classes more interesting and so more welcoming to students as illustrated in the following comments by Nguyen and Diep.

(99) "Clearly, when I taught students theory about places and manners of articulation of the target sounds and explained to them about special features of these sounds, they found it very interesting and realised that they didn't know about these before. They engaged actively in communication situations in class and this made the classroom atmosphere more lively." (P2, Teacher InI, Q5, Nguyen)

(100) "Through this teaching approach, I realised that students were more interested and more actively involved in classroom activities. They like speaking very much and so practiced 
more eagerly, which made the classroom atmosphere more interesting and lively." (P2, Teacher InI, Q5, Diep)

As shown in these and two other comments, the new pronunciation teaching approach boosted the classroom atmosphere, as evidenced in students' greater interest in learning and more active involvement in most classroom activities, especially the oral communication tasks. From their own observations, these teachers saw that the more that enthusiastically students participated in classroom events, the more welcoming and lively the atmosphere became. They reported that what made students energetically engage in classroom learning was those communication tasks that offered them an opportunity for speaking practice.

As further stated by Quynh and Khoa, students' positive attitudes towards the communicative teaching of English pronunciation and their engagement in most classroom activities in turn increased the teachers' motivation in teaching pronunciation. They said:

(101) "Teaching and learning is a reciprocal process, I believe. Whether students are interested in learning partly depends on the way teachers teach. Similarly, students' attitudes towards learning in class greatly affect teachers' teaching. The students' eagerness in learning and practicing pronunciation itself has given me an incentive for teaching pronunciation. Now I feel I more like teaching pronunciation." (P2, Teacher InI, Q5, Quynh)

(102) "Although the teaching time was limited, students have had a chance to learn and practice pronunciation in class and they can also do more self-practice from home. This depends on the teaching approach teachers choose. If students find it interesting, then they'll study harder and more eagerly. When seeing students actively involved in most classroom activities, I felt very happy and so have more motivation in helping them practice to improve their pronunciation." (P2, Teacher InI, Q5, Khoa)

According to Quynh and Khoa, teaching and learning is reciprocally related. They believed that how teaching is constructed determines students' level of interest and engagement in classroom learning, and students' enthusiasm for participating in classroom activities, in turn, motivates them in their teaching job. As such, Quynh and Khoa reported that students' positive attitudes towards the new teaching strategy have energised them in teaching pronunciation. 
When asked if they had any difficulty teaching pronunciation applying the framework, Diep and Khoa reported no difficulty but four other teachers mentioned time constraints as a barrier. The following comments are representative:

(103) "If talking about difficulty, then I think the only problem is time. In reality, our class time is too limited, so teachers find it difficult to do whatever they want although they know what's good for students. When doing the experimental teaching, some sections in the textbook had to be assigned as students' homework. Apart from pronunciation, students have to learn many other things. Thus, if we actually want to teach pronunciation to students communicatively, then I think teaching time for the English subject needs to be increased so that we can help students practice pronunciation in communication situations." (P2, Teacher InI, Q6, Phuong)

(104) "Difficulty? Uhm... maybe time constraints. As you see, time allotted to the English subject is too limited. Before students studied [English] for six semesters and each semester was 60 periods. Now it's been shortened to only four semesters and each semester is only 45 periods. This, as I told you, has made the curriculum overloaded and it's hard for teachers to teach as much as they want because they don't have enough time. So, I think if we want to apply this approach in teaching pronunciation, then the first and foremost important thing is to increase the number of periods for the English subject. Otherwise, teachers can only help students correct their pronunciation errors as we usually do.” (P2, Teacher InI, Q6, Nguyen)

The main concern amongst the teachers in applying the framework in real practice is the time distribution in this English programme. According to the teachers, the credits assigned to the English subject at the university are limited whereas there is too much to be covered in the mandated curriculum (see also section 4.3.3). As the teachers said, there has been a marked decrease in the total number of class meetings for English and this has overloaded teachers with what they are assigned to teach in class. The teachers believed that if pronunciation is to be taught communicatively using the new teaching strategy, then class time for the English subject needs to be extended.

The finding that the teachers found teaching time as a constraint in applying the new approach to pronunciation teaching within their own teaching situations echoes previous research in the Asian EFL/ESL context. In their study, I. Lee et al. (2016) investigated how two EFL teachers at a secondary school in Hong Kong translated the innovative feedback principles they received from a six-hour TPL workshop into their writing classroom. The 
findings show that the two teachers were unable to fully translate the feedback strategies they learnt into their own classroom practice due largely to the limited time in the prescribed curriculum. In the current study, even though the teachers were all able to fully transform what they have learnt from the workshop on CPT into their classroom practice, many of them still identified teaching time in the prescribed curriculum as a constraint.

In sum, the study has found that the teachers held a strongly positive view on the positive effects of the CPT model on student learning, such that it has the potential to help improve students' pronunciation in particular, and listening and speaking skills in general. The teachers believed that through this teaching approach they can make students more aware of the importance of pronunciation in English learning, transfer basic pronunciation knowledge to students, and foster their confidence in using English for oral interactions through a variety of communicative practice activities. Most of the teachers believed that the new approach to pronunciation teaching can arouse students' interest in learning and practicing English pronunciation, given that students are explicitly taught pronunciation features and simultaneously encouraged to practice these in different communication situations. I will now turn to examine the students' stated beliefs about how effective CPT is in facilitating their pronunciation learning.

\subsubsection{Students' beliefs about the value of CPT to their learning}

At the beginning of the interviews, the students were encouraged to talk about their learning experience with the CPT lessons their teachers implemented in class. Acknowledging that students might be influenced by their peers' answers, I made it clear before the interviews commenced that they did not need to agree or disagree with their friends in a group but instead that they should simply speak their minds.

The findings show that all the students reported really enjoying the way pronunciation was taught during that semester, as seen in the following representative comments:

(105) "I really enjoyed it. This way of teaching is more interesting than the old one, listen-andrepeat, and of course more effective. It makes classroom atmosphere more lively and students work harder. I felt more interested in learning pronunciation this semester." (P2, FGI1, Q1, S4) 
(106) "I liked it a lot. I find it more interesting than teachers simply ask us to listen and repeat as they usually do. This teaching approach makes me feel more interested in learning pronunciation than before." (P2, FGI3, Q1, S3)

(107) "Oh, I really liked it. Classroom atmosphere is more lively than teachers having us listen and repeat like a machine. I saw my friends were more actively involved in activities. This way of teaching helps me understand more clearly about pronunciation, so I really like it.” (P2, FGI5, Q1, S2)

What emerged strongly from the students' talking about their experience of CPT was a strong feeling of favouring this approach to pronunciation teaching. Such actual words used by the students as 'enjoyed', 'liked', 'interesting', 'effective', 'lively', and 'actively', etc. in these and other extracts convey the students' positive attitudes towards being taught pronunciation communicatively. Recalling how their teachers usually taught pronunciation in class, i.e. correcting errors through repetition, the students reported that they found CPT to be superior. Interestingly, 5/24 students explicitly expressed their expectation of more pronunciation classes like these. They said:

(108) "I see this way of teaching is very interesting. The atmosphere was lively and students engaged actively in activities in class. I liked it a lot but it was too short, only four classes. I think it'll be better for our pronunciation skills if there are more classes like these." (P2, FGI2, Q1, S3)

(109) “I liked it very much. After those pronunciation classes in this semester, I've become more interested in learning pronunciation. This way of teaching is more useful than to listen and repeat after the teacher when I make pronunciation errors. But why was it so short, teacher? I think it'll be more helpful for us if teachers spend more time teaching pronunciation this way." (P2, FGI6, Q1, S2)

Although the students found CPT enjoyable, they were not really satisfied with the limited time available in that semester. As they said, it would be more beneficial to their pronunciation learning if more time was spent on teaching pronunciation communicatively as they have experienced. To some extent, this finding resonates with previous studies which showed that students had a strong desire for more pronunciation instruction. For example, the student participants in Pardede's (2018) study reported that they highly valued the pronunciation instruction delivered to them, and $90 \%$ of these expressed a strong need for more opportunities to improve their pronunciation. Similarly, $90 \%$ of the students 
participating in Derwing and Rossiter's (2002) research said that they would attend pronunciation classes if there were any available.

Underlying the students' favourable attitudes towards the CPT model are the benefits they believed to have gained from these CPT lessons. According to the students, from these pronunciation classes, they had: (1) opportunities to improve listening and speaking skills; (2) a better understanding of the target pronunciation features; (3) a sense of achievement in pronunciation and communication skills; and (4) opportunities to identify and correct their own pronunciation errors. The data in Table 7.2 show the students' beliefs about the advantages of CPT as they experienced in this second phase of the study.

Table 7.2 Students' beliefs about the value of CPT to their learning

\begin{tabular}{lccccccc}
\hline Perceived benefits of CPT & $\begin{array}{c}\text { FG1 } \\
(\mathrm{n}=4)\end{array}$ & $\begin{array}{c}\text { FG2 } \\
(\mathrm{n}=4)\end{array}$ & $\begin{array}{c}\text { FG3 } \\
(\mathrm{n}=4)\end{array}$ & $\begin{array}{c}\text { FG4 } \\
(\mathrm{n}=4)\end{array}$ & $\begin{array}{c}\text { FG5 } \\
(\mathrm{n}=4)\end{array}$ & $\begin{array}{c}\text { FG6 } \\
(\mathrm{n}=4)\end{array}$ & $\begin{array}{c}\text { Total } \\
(\mathrm{n}=24)\end{array}$ \\
\hline $\begin{array}{l}\text { 1. Opportunities to improve } \\
\text { listening and speaking skills }\end{array}$ & 4 & 4 & 4 & 4 & 4 & 4 & 24 \\
\hline $\begin{array}{l}\text { 2. Better understandings of the } \\
\text { target pronunciation features }\end{array}$ & 4 & 4 & 3 & 3 & 4 & 3 & 21 \\
\hline $\begin{array}{l}\text { 3. Sense of better pronunciation } \\
\text { and communication skills }\end{array}$ & 4 & 4 & 3 & 3 & 3 & 3 & 20 \\
\hline $\begin{array}{l}\text { 4. Opportunities to identify and } \\
\text { correct errors established since }\end{array}$ & 1 & 0 & 0 & 1 & 1 & 0 & 3 \\
secondary schools & & & & & & & \\
\hline
\end{tabular}

Note: $\mathrm{n}=$ number of students

First, all the students (24/24) reported that CPT has provided them with opportunities to improve their listening and speaking skills. This is, according to the students, due largely to the communication situations brought to them by their teachers, as evident in the following comments:

(110) "Through these pronunciation classes, we had an opportunity to improve listening and speaking skills, although not much. With communication situations my teacher gave in class, we could practice not only pronunciation but also listening and speaking." (P2, FGI2, Q2, S3) 
(111) "I think the first benefit is that we had a chance to improve listening and speaking skills beside pronunciation. I prefer this way of teaching to the old one that teachers only corrected errors through repetition. Teaching [pronunciation] this way, my teacher created communication situations for us to practice the target sounds. I find it very interesting." (P2, FGI4, Q2, S2)

(112) “Although my teacher taught pronunciation, she taught it towards communication. So, I think we also had a chance to improve listening and speaking skills through communication situations she gave us to practice in class. This is very good because listening and speaking skills are very important for our future job." (P2, FGI6, Q2, S4)

Throughout their comments, the students recognised CPT as an opportunity for them to improve their listening and speaking skills. It can be inferred from the students' responses that they highly appreciated the communication situations their teachers gave for oral practice in class. According to the students, they can practice, through these communicative activities, not only pronunciation but also listening and speaking skills, which are really important for their future jobs as stated by student 4 from FG6 above. This finding is consistent with the teachers' beliefs about how CPT helps improve learners' listening and speaking skills as reported in the above section.

Second, a majority of the students (21/24) stated that CPT helped them obtain a better understanding of pronunciation. As the students said, not until their teachers taught pronunciation communicatively did they come to know, although basically, about the articulation mechanism of sounds, sentence stress, or intonation, etc. The following extracts are representative:

(113) "After these classes, I've known where to put my tongue when pronouncing and how to pronounce those sounds properly. Also, my teacher taught us where to stress in sentences, how to raise and lower my voice in speaking and I've also been more aware of linking between words. I didn't know about these before." (P2, FGI1, Q2, S1)

(114) "In my opinion, this way of teaching helped me understand more clearly about pronunciation. My teacher helped us know the differences between sounds, showed us where to put lips, teeth, and tongue when reading [producing] different sounds (...) By now, I've learnt about sentence stress, how to speak with rising and falling intonation, and been more aware of reading final sounds and linking between two words. No one taught me these before." (P2, FGI3, Q2, S3) 
(115) 'I've learnt basically about pronunciation theory through my teacher's classes. I've learnt how to pronounce sounds, what parts to use, and how to put my lips and tongue, etc. When my teacher showed us the difference between this and that sound or taught us how to stress in sentences, I found it very interesting because I didn't know about these before. My teacher also taught us how to speak with rising and falling intonation that helped us speak more naturally." (P2, FGI5, Q2, S2)

As seen from these and other extracts, the students had a positive view on the pronunciation knowledge they believed to have acquired from their teachers' new teaching approach. Although some terminological terms, i.e. places and manners of articulation, were not explicitly used, the students' explanations about their knowledge gains show that they believed they have had a better understanding about the pronunciation features targeted in those classes. As the students elaborated, those pronunciation classes helped them better understand how the target sounds are produced (i.e. manners of articulation), which articulators should be involved and where to place them (i.e. places of articulation), and how to apply sentence stress and rising and falling intonation in speaking. They reported that they have become more aware of producing final sounds and applying linking to make their speech flow smoothly. They said they were not taught about these before.

Third, 20/24 of the student participants reported that those experimental teaching sessions gave them a sense of improved pronunciation and oral communication skills. It became clear from the students' responses that CPT helped them feel more positive about their improvement in pronunciation, listening and speaking skills, as illustrated in the following extracts.

(116) "I feel that my pronunciation and communication skills are improving. This is what I feel but I'm not sure how they are in reality because there were only four classes. But if we're taught more classes, then I'm sure my pronunciation and listening and speaking skills will be better." (P2, FGI2, Q2, S2)

(117) “Before, I was really pessimistic about my English proficiency, especially listening and speaking skills because they hadn't improved after several years learning [English]. During these years, I mostly learnt grammar. But when my teacher taught us pronunciation by having us practice in communication situations like this semester, Ifeel more optimistic that my pronunciation and listening and speaking skills are improving. I think if teachers use this way to teach pronunciation more and more, the result will be much better." (P2, FGI4, Q2, S3) 
(118) "I saw that learning pronunciation this way helps students progress not only in pronunciation but also in communication skills. When I understand what people say and they also get what I mean, the communication is more likely to be successful. In fact, because there were only four classes, effectiveness is not that much as expected. But if teachers teach more, then I'm sure our improvement will be much better." (P2, FGI6, Q2, S2)

These and other extracts show the students' strong belief about the effectiveness of CPT in its capacity to enhance their pronunciation and oral communication skills in general. They believed that achievement will be more obvious if there are more such classes focusing on $\mathrm{CPT}$ as they experienced in the semester. Interestingly, six of these students further stated that improvement in pronunciation, listening and speaking skills consequently lifts their confidence in using English for oral interaction and fosters their motivation in learning the language. The students reasoned that a good command of pronunciation, listening and speaking skills helps assure mutual understandings in oral communication. They therefore will be more confident in making themselves properly understood in speaking English. They said:

(119) "And one more important thing in my opinion is that when pronunciation and listening and speaking skills have improved, I can understand correctly what people say in English and in turn they understand me. This naturally makes me feel more confident in communication and so more motivated in learning English." (P2, FGI1, Q2, S4)

(120) "In my opinion, being good at pronunciation and listening and speaking skills have improved, I'll know what people mean more easily and they also understand what I'm expressing. At that time, I'll feel more confident in communication and of course my motivation in learning English will increase." (P2, FGI6, Q2, S4)

Finally, three of the students mentioned that their teachers' new pronunciation teaching approach has given them an opportunity to identify and correct pronunciation errors which have been established since secondary schools. According to the students, the teachers' feedback on their practice or performance of the target pronunciation features through communicative activities helped them realise and improve their pronunciation problems. For example, student 2 from the first focus group said:

(121) "Moreover, this way of teaching also helps me realise my pronunciation errors. When we practiced communicating or when we spoke up, my teacher pointed out where our 
pronunciation problems were and helped us correct them. I remember we had to read [pronounce words] by ourselves at secondary schools. No one taught us, so we made a lot of mistakes and gradually these have become a habit [of pronouncing incorrectly]." (P2, FGI1, Q2, S2)

Overall, the students' positive attitudes towards CPT were in line with the teachers' beliefs about the benefits of this new teaching approach to student learning, which they described as effective in helping learners understand the target features, having the advantages for improving their pronunciation, listening and speaking skills, and fostering their interest and motivation in English learning. As reported in Chapter 5, the Phase 1 student participants held a negative view on the efficacy of teachers correcting their pronunciation errors through recasts and/or prompts. They found this approach to pronunciation teaching too mechanical and not beneficial to their pronunciation skills. Thus, they expressed a strong need for pronunciation to be taught communicatively since they believed it could improve not only their pronunciation but also oral communication skills. This belief confirmed the Phase 2 students' belief about how CPT could help enhance their pronunciation, listening and speaking skills. The Phase 1 students also described their preferred pronunciation teaching approach as motivating learners and promoting interaction in classroom learning. This is consistent with what the Phase 2 students said about their experience in learning pronunciation through the CPT model. As such, it can be concluded that the teaching practice described by the Phase 1 students aligns with the CPT model the Phase 2 students experienced. These findings suggest that CPT can meet students' needs in pronunciation learning (also see Chapter 5). I will now turn to examine how the teachers and students perceived pronunciation instruction at the tertiary level in Vietnam.

\subsection{Pronunciation instruction in VTE education}

The following sections present answers to RQ10 regarding the teachers' and students' beliefs and perspectives about pronunciation teaching within the VTE context. The findings were obtained from the teachers' in-depth interviews and the second part of students' FGI data.

\subsubsection{Teachers' beliefs about pronunciation instruction in the VTE classroom}

Following the teachers' discussions about Vietnamese EFL learners' pronunciation instructional needs as examined in Phase 1 of the study (see also Chapter 5), this Phase 2 further investigated the teachers' perceptions about pronunciation instruction within the VTE 
context. This included if pronunciation needed to be taught at the tertiary level, how much time should be allotted, which features to cover, and which approach to be taken. The teachers were also asked to elaborate on the underlying rationales for their responses to each of these issues. In response to the question of whether or not pronunciation should be taught in tertiary EFL classes, all the teachers again reported that pronunciation teaching needs to be implemented explicitly and systematically. Underlying the need for pronunciation instruction at the tertiary level as stated by all the teachers is the observation that a majority of Vietnamese EFL learners enter university with poor pronunciation, listening and speaking skills. The explicit teaching and learning of pronunciation at this level is therefore a possible way to make up for this lack. According to the teachers, this can firstly raise learner awareness of the importance of pronunciation in English learning, and secondly help improve students' pronunciation, listening and speaking skills, which are essential for their future jobs.

Discussing why they believed pronunciation instruction at university level in Vietnam is necessary, all the teachers stated that apart from the importance of pronunciation in oral communication, for most VTE learners, their pronunciation in particular and listening and speaking skills in general are poor and so need to be improved. The main reason, according to the teachers, is that pronunciation, listening and speaking skills were overlooked at secondary levels, as illustrated in the following comments:

(122) "In my opinion, pronunciation should be taught immediately when students start to learn English at secondary levels. If secondary teachers teach pronunciation explicitly and systematically and students practice [pronunciation] during their seven years learning English at secondary schools, then it's not a burden for tertiary teachers any more. But the fact is that pronunciation in particular and listening and speaking skills in general were neglected at lower levels, so students need to learn these skills again at tertiary level. I think this is really important because we need to move forward but can't ignore it. So, pronunciation must be included in university English programmes and certain credits must be assigned to it." (P2, Teacher InI, Q7, Phuong)

(123) "In my opinion, it would be better if pronunciation was taught properly at lower levels and communication skills were taken good care of immediately when students started learning English. But the fact is that secondary teachers only focused on grammar and vocabulary for the sake of students passing the secondary school graduation and university entrance exams. As a result, they entered universities with poor listening and 
speaking skills, especially pronunciation. So, I think this [pronunciation instruction at the tertiary level] is very important if we want students to use English for oral communication effectively. And so, certain credits must be assigned to pronunciation in university English programmes." (P2, Teacher InI, Q7, Nguyen)

(124) “Pronunciation is a very important skill because it's really necessary for students to develop listening and speaking skills but it was not appreciated right after students started learning English from Grade 6. At tertiary level, it's easy to see that most students are weak at communication skills, especially pronunciation, and the main reason, in my opinion, is that students were not taught and corrected at secondary levels. Now at tertiary level they need support to improve their pronunciation in particular and listening and speaking skills in general. So, pronunciation should be officially included in university English programmes." (P2, Teacher InI, Q7, Na)

The teachers' beliefs about the necessity of pronunciation instruction at tertiary level are drawn from their own observations that a majority of Vietnamese EFL learners enter university with poor listening, speaking and pronunciation skills. One of the contextual factors resulting in such discouraging outcomes as reported by all the teachers is the common practice of English teaching at secondary schools in Vietnam. In English learning, according to the teachers, it is much better if pronunciation is properly addressed as soon as students start learning the language at secondary schools; i.e. from Grade 6. Unfortunately, they reported that pronunciation is usually overlooked at lower levels. This resonates with a previous study in which Tergujeff (2013) found systematic EFL pronunciation teaching at Finnish high schools to be rare. Teacher Nguyen specifically explained that EFL teachers at Vietnamese secondary schools only focus on grammar and vocabulary since students need these to pass the national secondary school graduation exam and later on the university entrance exam. The teachers therefore believed that it is important for pronunciation to be included and addressed properly at tertiary level if students are to use English for oral interaction more effectively.

Regarding how much time should be allotted to pronunciation teaching at tertiary level, all the teachers stated that the ideal timeframe is from one to two 45-minute periods per week. However, in response to the question pertaining to focus of instruction, the teachers expressed different beliefs about which pronunciation features need to be covered in class. Specifically, three teachers reported that instruction needs to cover all features. In contrast, the other three teachers said that instruction does not necessarily need to focus on all features 
but only those that cause common pronunciation problems amongst Vietnamese EFL learners (see also section 5.3). The data are summarised in Table 7.3 below.

Table 7.3 Teachers' beliefs about pronunciation distribution at the tertiary level

\begin{tabular}{lccc}
\hline \multirow{2}{*}{ Teacher } & Time frame for & \multicolumn{2}{c}{ Targeted features for classroom instruction } \\
\cline { 3 - 4 } & instruction (per week) & Particular features & All features \\
\hline Quynh & $1-2$ periods & $\checkmark$ & x \\
\hline Phuong & $1-2$ periods & $\checkmark$ & x \\
\hline Nguyen & $1-2$ periods & x & $\checkmark$ \\
\hline Diep & $1-2$ periods & x & x \\
\hline Khoa & $1-2$ periods & $\checkmark$ & x \\
\hline $\mathrm{Na}$ & $1-2$ periods & $\checkmark$ & \\
\hline
\end{tabular}

Note: $\quad 1$. The tick ( $\checkmark$ ) indicates a yes and the cross (x) means a no;

2. Particular features refer to those that cause common pronunciation problems to Vietnamese EFL learners (see also section 5.3).

Elaborating on the reason for the timeframe they suggested, all the teachers stated that university students are adult learners, so they need to be independent in learning. The teachers also believed that too much pronunciation instruction can be boring. They explained:

(125) "I think one or two periods per week is enough. In my opinion, if we focus too much on pronunciation, I'm afraid students may get bored. Moreover, they're adults and so mature enough to know what they have to do if they want to be good at English. At university level, they must be more conscious of self-study, not only study what teachers teach in class." (P2, Teacher InI, Q8, Quynh)

(126) "In my opinion, one to two periods per week would be okay. This is just enough, not too much that can make students bored. Teachers present theory and basically instruct students to practice in class. Basing on this, students then can practice more at home. Also, being good at pronunciation requires a long time to practice, not only a couple of days, so students' self-study is also very important." (P2, Teacher InI, Q8, Na)

As seen from these representative comments, the teachers again stressed the importance of self-study at the tertiary level (see also Chapter 4). All the teachers were well aware that pronunciation takes time to improve; thus, they stated that students need to do more self- 
practice based on the instruction given in class if they want to better their language skills in general and pronunciation in particular. In addition, they believed that a heavy focus on pronunciation may make students bored of such instruction.

As far as targeted pronunciation features are concerned, Quynh, Phuong, Khoa and Na stated that only particular features that cause common pronunciation problems to Vietnamese EFL learners should be assigned for classroom instruction. According to these teachers, it is important that tertiary students, unlike those at secondary schools, do self-study rather than heavily rely on what teachers teach in class. The extracts below are representative:

(127) “They're adult learners and must be responsible for their self-study. So, I think we only need to focus on features that commonly cause pronunciation problems to Vietnamese learners. At university level, students are mature and conscious enough to acquire these and if they want to be better, they can do more practice at home independently." (P2, Teacher InI, Q9, Phuong)

(128) “At university level, students can't only study what teachers teach in class as they used to do at secondary schools. If they want to be good, then they're obliged to do more selfstudy and self-practice at home. So, I think it's enough to focus on features that commonly cause pronunciation problems to Vietnamese learners only. Later on, they can base on what teachers have taught to do more self-study and self-practice without relying on teachers." (P2, Teacher InI, Q9, Khoa)

Again, these and two other comments show the teachers' strong beliefs in the importance of self-study in the context of Vietnamese higher education. According to the teachers, students at this level are mature enough, so need to be responsible for their own study. In other words, if students want to be more knowledgeable about the subject they are studying, then they are expected to be proactive in widening their knowledge based on what they have been instructed in the classroom rather than considering this as the only source of knowledge. To this end, focus of instruction should only be on those features that cause common problems amongst Vietnamese EFL learners (see section 5.3 of Chapter 5). The teachers further explained that since students are adult learners, they should take pronunciation instruction given in class as basic guidance, and from there they can independently do further practice.

In contrast, Nguyen and Diep believed that pronunciation instruction at the tertiary level should cover all features. Underlying this articulated belief is the observation that, according 
to the teachers, pronunciation was not properly addressed at secondary schools and that not all students in one class face the same pronunciation problems. They said:

(129) "About what to teach, I think we should teach all features from sounds to intonation, etc. The first reason is, as I've told you, students basically don't know anything about pronunciation as they weren't taught [pronunciation] at secondary schools. So, I think we should teach them basic knowledge about pronunciation and from there they can practice more if they want to be better. That's right that self-study is really important for tertiary students but without basic instruction, how can they practice by themselves? Second, if we cover only particular sounds from time to time, I'm sure our lessons will become repetitive and this will make students bored and lose all their interest in learning. And we also need to make our lessons diverse because not every student in one class has the same pronunciation problems. Some have difficulty with this sound but others with different sounds, for example." (P2, Teacher InI, Q9, Nguyen)

“(...) but we should teach all features to avoid repetition. For example, if we teach a certain sound from time to time, then students may think 'oh, that's all he/she can teach' and at that time they'll find it boring. So, I think teaching a variety of features makes a difference from lesson to lesson and so arouses students' interest [in learning]. I agree that Vietnamese learners share common pronunciation problems, but not all students in one class have the same problems. For example, student A can't produce this consonant properly but student B can do it. Conversely, student B has difficulty with this vowel but student A doesn't. Right? So, I think teaching all features is necessary. Of course, at university level self-study is very important but let's suppose students want to practice everything to improve their pronunciation but teachers only give instruction on some particular features, then how can they practice properly features that have not been taught? So, teaching all features will make every student aware of their own pronunciation problems and with teachers' basic guidance they can do more selfpractice at home." (P2, Teacher InI, Q9, Diep)

Again, Nguyen and Diep also stressed the importance of self-study at university level to students' learning progress. Yet, given a lack of pronunciation instruction at secondary schools, the teachers believed it is better to provide students with basic instruction on all pronunciation features based on which they can do further practice outside the classroom. As the teachers reported, without basic instruction provided in class students' further selfpractice is less likely to be boosted. Despite their shared belief with other teachers about common pronunciation problems amongst Vietnamese EFL learners, Nguyen and Diep 
explained that not every student in a particular class had the same pronunciation problems. Thus, they believed that pronunciation instruction covering all features not only adds something new to each lesson, but it also helps students identify their own pronunciation problems. Students can further practice those features they still have problems with based on the instruction teachers give in class. As Diep said, if target features covered in class are only those that commonly cause pronunciation problems to Vietnamese EFL learners, then it will lead to repetition which makes students bored with classroom instruction. This belief, to some extent, finds support from previous research in which Baker (2014) found that the teachers who were textbook-driven believed that pronunciation instruction can be boring. In Baker's study, the teachers' instruction was based on textbooks and since pronunciation activities, mostly drilling work, were designed to be implemented the same way, they found it tedious.

Regarding approaches to pronunciation teaching, all the teachers stated that CPT is a promising approach that should be taken in the VTE classroom. All the teachers then reasoned that this approach to pronunciation teaching will help develop learners' oral communication skills, which are essential for students after graduation, given that they are required to use English for oral communication at the work place. Reflecting on their recent experience with the CPT model, the teachers reported that if pronunciation is taught communicatively, then both students' pronunciation and their listening and speaking skills can be improved simultaneously through communication practice. The following comments are representative:

(131) "Of course, if we want to help students improve their pronunciation as well as listening and speaking skills, then I think teachers' teaching approach is extremely important. To make it doable, in my opinion, teaching pronunciation communicatively is the most suitable. Students can practice not only pronunciation but also listening and speaking skills through communication situations. These are very important for students when they start working after graduation. A majority of our students expect to work for foreign companies to get high salaries as well as other benefits. But, to achieve this goal they firstly have to practice these skills during the time studying English at university. This is why I suppose we have to teach pronunciation if students' desire is to be satisfied." (P2, Teacher InI, Q10, Phuong)

“Teaching pronunciation not only helps improve students' pronunciation but it also develops their listening and speaking skills if we teach it communicatively like this 
semester. Through different communication situations students can practice the target sounds and at the same time practice speaking. If we carry on like this, then I believe that students' pronunciation and listening and speaking skills will be remarkably improved. This is very important because students after graduation have to use English at their workplace but before that they will have to pass interviews in English. During an interview [in English], if the interviewer can't understand what they say, then the opportunity for them to be employed is rare." (P2, Teacher InI, Q10, Diep)

"As a job requirement after graduation, students need to be fluent in using English for oral interactions, so good pronunciation skill is a top priority. If during the interview process students' pronunciation, listening and speaking skills are rated as poor, then the opportunity for them to be recruited will be very low. Therefore, teaching pronunciation communicatively to help students improve their listening and speaking skills is very important. In class, students will practice not only pronunciation but also listening and speaking skills if teachers apply this teaching approach [CPT]." (P2, Teacher InI, Q10, Khoa)

These and other extracts show that the teachers held strong views that students need to be fluent in listening and speaking skills in order to communicate as effectively as possible at the workplace. In this regard, they expressed beliefs in the positive value of the CPT model in the VTE classroom. Specifically, all the teachers believed that teaching pronunciation to university students explicitly and communicatively not only improves their pronunciation, but it also helps develop their listening and speaking skills. The teachers held that this is essential since students are expected to meet the English proficiency requirement set by companies where English is widely used in the workplace. In other words, students need to be fluent communicators in English as judged by the interviewer if they want to be offered the job they apply for. As such, the teachers believed that helping university students improve their listening and speaking skills is important as it increases their opportunities for employment after graduation, and CPT is one of the ways for teachers to do so.

In addition, three of the teachers (Quynh, Nguyen and Diep) further mentioned that CPT will help raise learner awareness of how important pronunciation is in English learning. For example, Quynh said:

(134) “Also, I've noticed that most university students' pronunciation is very poor. Moreover, they're also weak at listening and speaking skills. Of course, there are also many students who are good at English, but this is only about fluency. They still make 
pronunciation errors in speaking but aren't aware that they need to practice to improve [pronunciation]. They're completely wrong when assuming that in communication their messages only need to get through and that's enough. This really is what makes them ignore pronunciation practice. So, I think English programmes at Vietnamese universities can't exclude this part [pronunciation instruction] but need to have certain credits for it. When teaching pronunciation communicatively, we can make students more aware of how pronunciation enhances their listening and speaking skills. So, they'll realise that pronunciation learning is as important as other language skills." (P2, Teacher InI, Q10, Quynh)

This and two other comments show the teachers' beliefs about how to positively change students' lukewarm attitudes towards pronunciation practice. From the teachers' observations, many Vietnamese tertiary students tend to disregard pronunciation in English learning and so they are not attentive to practicing this language skill. According to these teachers, however, if pronunciation is properly addressed at tertiary level, then solutions to this problem can be obvious. The teachers believed that the explicit teaching of pronunciation can make students well aware that this skill is as equally important as the others in EFL learning. Thus, they will know how important pronunciation is in oral interactions and so will pay more attention to learning and practicing this language aspect.

In sum, despite their different perspectives of what to teach, the teachers shared common beliefs about the role of pronunciation in English learning and how much time to spend on pronunciation instruction within the context of VTE education. That is, the teachers believed it is essential that pronunciation be given a more explicit role in the curriculum and be taught communicatively. I will now turn to examine the students' stated beliefs about pronunciation teaching at the tertiary level in Vietnam.

\subsubsection{Students' beliefs about pronunciation instruction in the VTE classroom}

This section reports on the findings regarding the Phase 2 students' stated beliefs about pronunciation instruction at the tertiary level in Vietnam which were examined in the second part of their FGI. In this interview session, the students were asked to talk about how important pronunciation is in EFL programmes for English non-majors in Vietnam, followed by prompting questions that elicited the reasons beyond their articulated beliefs, how much instruction they expect, and how they would like to be taught pronunciation in class. 
Discussing the importance of pronunciation in English programmes for non-majored students at Vietnamese universities, the student participants were asked to choose an option on a fivepoint rating scale (where $1=$ not important at all and $5=$ most important of all language skills). Collectively, a majority of the students across the six groups selected 'very important' (16/24), followed by 'important' (6/24). Only two students cited 'most important' (for the quantification of the students' responses, see Appendix 12.4 in the CD attached). They also stated that pronunciation needs to be taught explicitly and systematically at universities. The finding that the students were all well aware of the important role of pronunciation is consistent with those from Phase 1 of the study. In other words, all the student participants of both phases of the study (48/48) believed that pronunciation is a fundamental component in English learning. To comment on their beliefs about including pronunciation in non-majored English programmes at Vietnamese universities, the students reasoned that good pronunciation helps: (1) develop listening and speaking skills; (2) foster their confidence in speaking English; and (3) facilitate vocabulary learning. The data are visualised in Figure 7.1.

Figure 7.1 Students' beliefs about pronunciation in tertiary EFL programmes

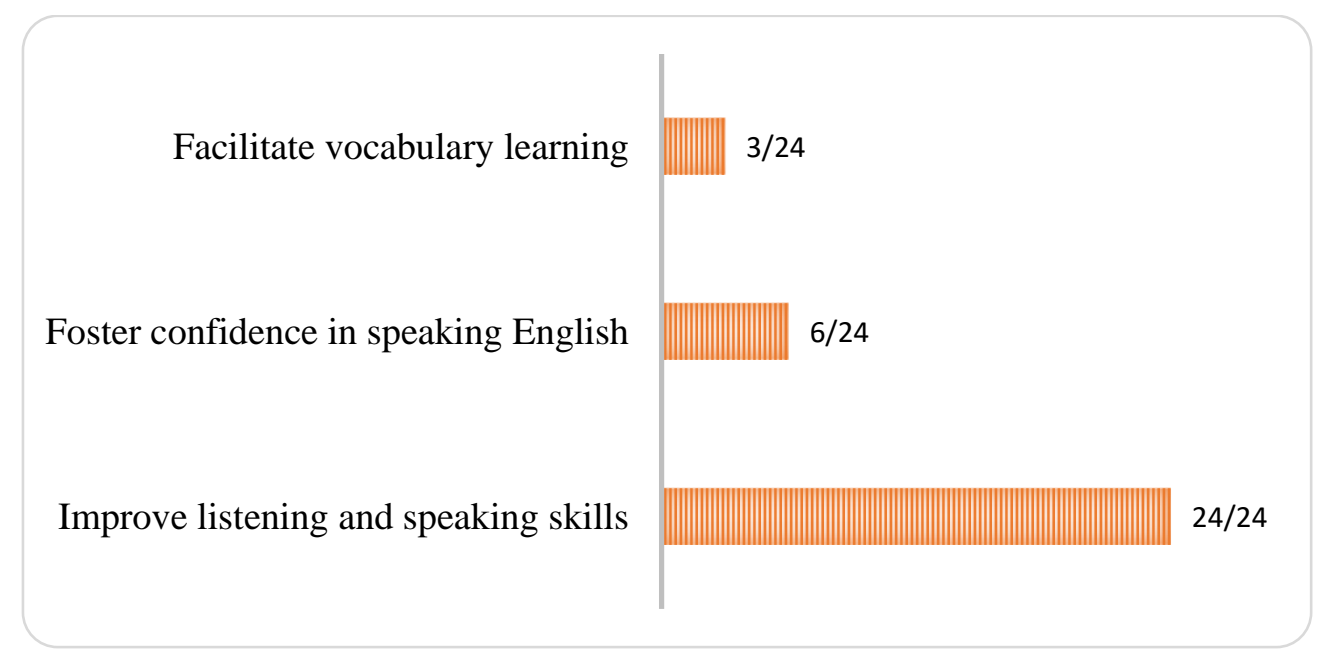

First, Figure 7.1 shows that all the students $(n=24)$ believed good pronunciation helps develop their listening and speaking skills given that it assures mutual understandings between the interlocutors. Ten of the students further elaborated that when their listening and speaking skills improve, they will consequently have more opportunities to get a job offer at foreign companies after graduation. The following extracts are evidence:

(135) “In my opinion, pronunciation must be taught immediately when we started learning English (...) Unfortunately, secondary teachers in Vietnam almost disregarded it, so I think reteaching pronunciation at university is very important. If university teachers 
teach pronunciation explicitly and systematically like this semester, then we'll have more chances to develop listening and speaking skills. This is very necessary because if we're good at pronunciation, listening, and speaking skills, the opportunity to be employed by foreign companies is very high." (P2, FGI2, Q3, S2)

(136) “I think it's very important and needs to be taught officially like other language skills. If teachers teach pronunciation like this semester, we'll have more chances to improve listening and speaking skills. After graduation, we'll have more job opportunities at foreign companies because they usually require applicants to be fluent in listening and speaking. And if we want to be good at listening and speaking, then we have to practice pronunciation more." (P2, FGI4, Q3, S4)

(137) “I think it's very important. For university students, learning English doesn't simply mean test scores but it's also a tool for us to apply for jobs after graduation. Secondary teachers didn't teach pronunciation, so it's better for us if we're taught [pronunciation] from the beginning. Teaching pronunciation explicitly and systematically provides us with basic knowledge and more chances to practice listening and speaking skills. This is really necessary because after graduation we all expect to be employed by foreign companies where we have to use English for daily communication. So, I think if we're good at pronunciation, listening and speaking skills, the opportunity to get a job is higher." (P2, FGI6, Q3, S4)

Like the Phase 1 students, all the students of this phase held strong beliefs about the fundamental role pronunciation plays in successful oral interaction. While both groups reported that good pronunciation enhances listening and speaking skills, the Phase 2 student group further stressed the potential of being fluent in listening and speaking for future work. To some extent, this resonates with Newton's (2018) claim that pronunciation, with a close relation to speaking, is essential for work and study. In the current study, the students reported that given their expectation of being recruited after graduation by foreign companies where English is the main medium of communication, being good at pronunciation, listening and speaking skills is essential. Without this, as the students reasoned, the opportunity to be offered a job at a prestigious company can be limited.

Second, 6/24 of the students stated that their confidence level in using English for oral interaction will increase if they are good at pronunciation. For example, they said:

(138) “According to my own feelings, many Vietnamese students' pronunciation is poor, so they're too shy to speak English. Usually, they're afraid that people will laugh at them 
when they pronounce inctheectly (...) So, I think if we're good at pronunciation, we'll be more confident in communicating in English." (P2, FGI3, Q3, S1)

(139) “Although we've been studying English for more than seven years, secondary teachers almost taught vocabulary and grammar. This is why when we enter university, many of us can't speak English. I see that many students are scared of speaking English because they're afraid their pronouncing incorrectly makes people laugh at them. So, I think if teachers help us improve pronunciation, then we'll be gradually more confident in speaking English." (P2, FGI5, Q3, S4)

These and other comments show the students' positive attitudes towards good pronunciation. As the students clarified, fear of being laughed at because of pronunciation errors in their speech makes them unwilling to communicate in English. This finding is consistent with Zielinski's (2012) research which showed that $23 \%$ of the participants reported that "bad experiences where someone laughed at their pronunciation had seriously affected their confidence to speak" (p.24). Yet, the students of the current study believed that if their pronunciation improves and people can understand what they say, then they will be more confident in using English for oral interaction. This finding echoes the finding in Phase 1 of the study that good pronunciation increases learners' confidence in oral communication. It aligns with Zielinski and Yates' (2014) argument that helping L2 learners improve their intelligible pronunciation can enhance their confidence in speaking English. The findings find support from a claim that the purpose of teaching pronunciation is for learners to develop oral communication that "serves the learner's individual needs, and allows a positive image of himself as a speaker of a foreign language" (Adams-Goertel, 2013, p. 123).

Finally, three of the students mentioned that a good command of pronunciation makes vocabulary learning more effective. According to Trofimovich and Gatbonton (2006), learning a lexical item involves learning both its meaning and phonological regularities. In a similar vein, Cakir (2012) has argued that it is disadvantageous to learn new words without learning their pronunciations. Thus, it can be interpreted from the students' responses that being good at pronunciation helps them memorise new words more easily. For example, student 2 from FG1 said:

(140) "Moreover, it [being good at pronunciation] also helps me in learning vocabulary a lot. If I'm good at pronunciation, it's easier for me to learn new words by heart and remember them longer." (P2, FGI1, Q3, S2) 
In summary, the students recognised the importance of pronunciation in English learning and saw this as an essential aspect that facilitates their oral interaction. They all stated that pronunciation is a must in tertiary EFL curriculum. The subsequent interview questions asked the students to talk about their expectations of time allocation and approach to pronunciation teaching at the tertiary level in Vietnam.

In response to the total time to be allocated to pronunciation teaching, two thirds of the students (16/24) across the six groups reported that one to two 45-minute periods on a weekly basis would be enough; one third (8/24) said they wanted as much pronunciation teaching as they can. This finding is in part consistent with the teachers' perspectives that one to two periods per week is appropriate for pronunciation instruction. The students who said they needed one to two periods per week identified three different reasons for this timeframe: (1) self-practice is important; (2) they are non-English majors; and (3) too much instruction is boring. Meanwhile, the eight students who called for as much pronunciation instruction as possible elaborated on the nature of crowded classes. The data is presented in Table 7.4.

Table 7.4 Students' reasons for their preferred pronunciation teaching time

\begin{tabular}{lccccccc}
\hline Reasons & $\begin{array}{c}\text { FG1 } \\
(\mathrm{n}=4)\end{array}$ & $\begin{array}{c}\text { FG2 } \\
(\mathrm{n}=4)\end{array}$ & $\begin{array}{c}\text { FG3 } \\
(\mathrm{n}=4)\end{array}$ & $\begin{array}{c}\text { FG4 } \\
(\mathrm{n}=4)\end{array}$ & $\begin{array}{c}\text { FG5 } \\
(\mathrm{n}=4)\end{array}$ & $\begin{array}{c}\text { FG6 } \\
(\mathrm{n}=4)\end{array}$ & $\begin{array}{c}\text { Total } \\
(\mathrm{n}=24)\end{array}$ \\
\hline 1. Self-practice & 2 & 2 & 2 & 3 & 2 & 2 & 13 \\
\hline 2. Non-English majors & 1 & 2 & 1 & 0 & 0 & 2 & 6 \\
\hline 3. Too much focus is boring & 0 & 1 & 1 & 1 & 0 & 1 & 4 \\
\hline 4. Crowded classes & 2 & 1 & 1 & 1 & 3 & 0 & 8 \\
\hline
\end{tabular}

Note: $\mathrm{n}=$ number of students

First, Table 7.4 shows that more than half of the students (13/24) reported one to two 45minute periods to be adequate for teachers to provide basic theory and practice instruction in class and students need to do further practice at home. The following extracts are representative:

(141) “(...) At university level, teachers only need to teach basic knowledge and instruct students to practice in class. Then, students have to do further practice at home if they want to be better. Self-study at university is very important, so I think one to two periods per week is enough." (P2, FGI2, Q4, S3) 
(142) "I think teachers only need to spend one or two periods per week teaching basic theory and instructing us to practice in class. Then, students have to do further practice because at university level students are required to self-study rather than only studying what teachers teach in class." (P2, FGI3, Q4, S4)

Clearly, the students were well aware of self-study as one of the requirements at university level. Implied in the students' responses is a concern that fully relying on teachers' in-class instruction is not helpful to their learning. Therefore, the students believed that further selfpractice based on the instruction their teachers give in class is essential if they wish to better their pronunciation. This is consistent with teachers' stated beliefs about the importance of self-study at the tertiary level in Vietnam as presented in section 7.3.1 above. It is also consistent with Timperley et al.'s (2008) argument that self-regulated learning is important for all learners. A number of other researchers such as Little (2007), T. C. L. Nguyen (2009), and Schunk and Zimmerman (2008) have noted the influential role of self-regulated learning in learners' language development.

Second, six of the students stated that since they are English non-majors, one to two periods per week would work for them. According to the students, unlike English majors who need in-depth understandings of pronunciation theory, teaching basic knowledge followed by practice works for English non-majors like them. This serves as a basis for further practice outside the classroom. Again, these students stressed the role of self-study as an important part of their pronunciation learning process as illustrated in the following comment:

(143) “In my opinion, teachers only need to provide basic pronunciation theory. We're not English majors so don't need to understand it as deeply as English majors. Then, teachers instruct us to practice in class as a foundation for us to further practthe at home (...)" (P2, FGI6, Q4, S1)

Third, four students said that too much focus on pronunciation teaching can be boring. Like the teachers, these students believed that it might not be a good idea when too much time is allocated to pronunciation in class. As evident in the students' comments, too much pronunciation instruction can be tedious and stress the learners, which consequently might not be able to provoke their interest in learning pronunciation. For example, student 1 from the third focus group said: 
(144) "I think one or two periods per week is enough, teacher. Sometimes, too much teaching [of pronunciation] can be boring and students will feel stressed out in learning. Maybe, it's counter-productive." (P2, FGI3, Q4, S1)

From a different perspective, the eight students who reported they needed as much pronunciation instruction as possible reasoned that given crowded classes it is better for teachers to spend more time on pronunciation teaching to provide them with more communication practice. What emerged strongly from these students' responses was their expectation of more opportunities for practicing listening and speaking skills and subsequently for teachers to correct their pronunciation errors. For this to be feasible, according to the students, more time should be allocated to pronunciation teaching as illustrated in the following comments:

(145) 'I don't know how many is enough but the more, the better, teacher. If there are more periods for pronunciation, we'll have more chances to practice listening and speaking. Classes are crowded, so if there's only one or two periods, it's unlikely that everyone in class has a chance to speak up and so teachers can't help correct pronunciation of each student." (P2, FGI1, Q4, S2)

(146) "I want as many as possible (...) When I studied at an English centre, a teacher told me that good pronunciation requires a long time for practice. So, if we're taught more, we'll have more chances to practice pronunciation and also develop communication skills. Also, classes are crowded, usually 40 to 50 students, so if there's more time for teaching pronunciation, teachers can help correct our pronunciation." (P2, FGI4, Q4, S3)

Although the students differed in their needs of instruction time, they all, in talking about how they would like teachers to teach pronunciation in class, stated that they preferred CPT as they had recently experienced. From their recent learning experience, the students reasoned that CPT: (1) provides more opportunities for oral interaction in class; (2) arouses students' interest in classroom learning; and (3) provides basic pronunciation theory (for the quantification of the students' responses, see Appendix 12.5 in the CD attached). Figure 7.2 provides a visual representation of the students' beliefs about their preferred pronunciation teaching approach. 
Figure 7.2 Phase 2 students' beliefs about their preferred pronunciation teaching approach

Understanding basic pronunciation theory

Arousing students' interest in classroom learning

Opportunities for oral interactions

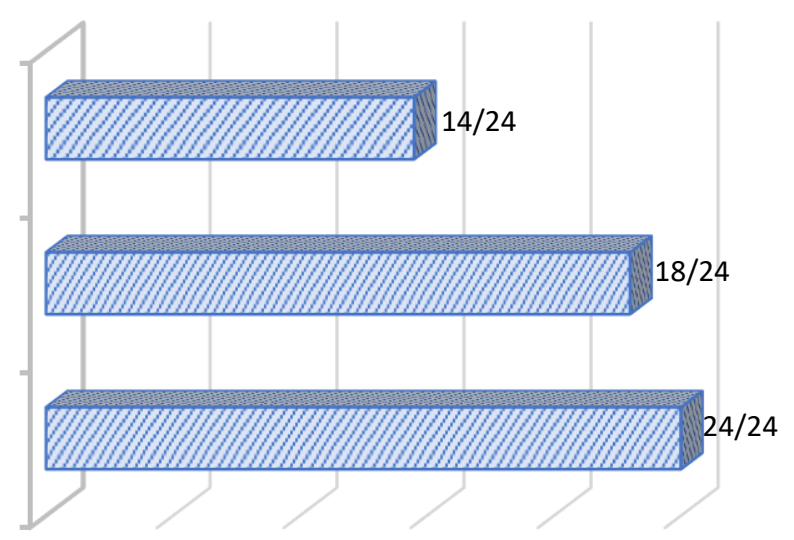

Figure 7.2 shows that all the students (24/24) believed a communicative approach to pronunciation teaching provides learners with more oral communication practice. The students also referred to error corrections through repetition as a reference in talking about the superiority of the communicative approach as evident in the following extracts:

(147) "If comparing with my previous teachers, I realise that the way my teacher taught pronunciation in this semester is much more effective. Before, teachers only sometimes corrected errors by having us listen and repeat when we pronounced incorrectly. This semester, we had more chances to practice what my teacher taught right away in communication situations. I saw this very interesting because it can help foster our listening and speaking a lot." (P2, FGI1, Q5, S1)

(148) "I suggest pronunciation to be included in the English programme of our university and teachers teach it communicatively. When we're taught [pronunciation] communicatively, we'll be given more chances for communication practice. The communication situations my teacher gave in class this semester were very useful because they were closely associated with daily life. So, I think teaching [pronunciation] communicatively is more effective than simply having us listen and repeat." (P2, FGI3, Q5, S3)

(149) "I suggest pronunciation to be included and taught like this semester. I expect that teachers provide us with more chances for communication practice in specific situations. I don't know how to say but I see that teaching [pronunciation] communicatively as my teacher did in this semester is more effective than teachers only correcting errors by getting us to listen and repeat." (P2, FGI5, Q5, S1) 
These and similar comments indicate that the students all considered CPT as an effective approach. Referring to how their teachers used to teach pronunciation in class, i.e. correcting errors through repetition, the students were well aware that teaching pronunciation communicatively provides them with more practice though different communication situations. For this reason, they expected pronunciation to be taught communicatively so they can have more opportunities to practice listening and speaking skills. Because the opportunity for communication output, according to Ellis (2005), is attributed to proficiency development in L2 learning, learners need opportunities to practice the new target features in more spontaneous interaction (Nation \& Newton, 2009).

Second, a majority of the students (18/24) said that CPT arouses students' interest in classroom learning. The key reason for the students' preference of CPT is the classroom atmosphere and how the new teaching approach benefits their learning. The following comments are representative:

(150) “(...) Moreover, this way of teaching makes the classroom atmosphere more relaxing. Uhm ... when we feel the practical applicability of these communication situations, we'll be more interested in learning. So, I prefer this way of teaching because it's more effective." (P2, FGI1, Q5, S4)

(151) “(...) I see that the way my teacher taught pronunciation in this semester is more interesting and more helpful than teachers infrequently correcting errors in previous semesters. This way of teaching allows us to practice the target sounds in communication situations, so I feel that our learning is more meaningful." (P2, FGI2, Q5, S3)

(152) “(...) If teachers teach [pronunciation] communicatively like this semester, I'm sure students will be more interested in learning pronunciation. Classroom activities are diversified, so we'll be more excited and enjoy learning more. And once students feel they like learning pronunciation, I think they'll spend more time on practice." (P2, FGI6, Q5, S4)

Given the range of communication activities provided in the experimental CPT lessons, the students believed that CPT can make the classroom atmosphere more relaxing and more welcoming and so learners become more interested in learning and practicing pronunciation. Interestingly, this finding is consistent with Phase 1 of the study in which half of the students stated that teaching pronunciation communicatively helps reduce classroom tension and makes students more motivated in their English learning. It can be interpreted from the 
students' responses that the classroom atmosphere has particular influence on learners' motivation in classroom learning. Thus, the more interesting and welcoming pronunciation classes are, the more devoted they become to pronunciation learning.

Third, 14/24 of the students stated that CPT helps learners basically understand pronunciation principles. They said:

(153) 'In my opinion, if teachers teach pronunciation communicatively like this semester, we'll get to know more about pronunciation theory. For example, teachers explain how to pronounce a sound or tell us when to use rising or falling intonation in speaking. This is very necessary because we need to know the basis so that we can do self-practice properly." (P2, FGI2, Q5, S2)

(154) “(...) Before, teachers only transcribed words on the board and asked us to listen and repeat. And that's it. This way of teaching is old-fashioned, boring and not as effective as the communicative teaching my teacher used in this semester. Teaching [pronunciation] communicatively allows us, although basically, to know more about pronunciation theory. For example, my teacher showed us how a sound is pronounced and how to recognise its spellings. She also taught us sentence stress and intonation. These are the basis for our further practice at home." (P2, FGI4, Q5, S1)

(155) “(...) I see teaching [pronunciation] communicatively as my teacher did in this semester is very effective, so I prefer this approach. We're provided with basic knowledge about pronunciation theory, and my teacher's explanations were very clear and easy to understand. She had both sounds and pictures for illustrations. We don't need to understand [pronunciation theory] as deeply as English majors but need to know basically so that we can do more self-practice at home." (P2, FGI6, Q5, S3)

Although the students reported they do not need in-depth understandings of pronunciation theory, they believed that it is important for them to know the basic principles as a foundation for further practice outside the classroom. Implied in the students' comments is the idea that without basic instruction provided in class, it is less likely for them to be successful in selfpractice. Therefore, the students saw that CPT can provide them with such basic theory they need to guide their self-practice more systematically.

In brief, the students were all well aware of the importance of pronunciation in their English learning and potential benefits that CPT offers them and thus expected pronunciation to be taught communicatively in class. The students' preference of CPT is consistent with the 
teachers' beliefs about learners' expectations as presented in Chapter 5. This finding also aligns with the Phase 1 students' articulated beliefs about how they would like teachers to teach pronunciation in class (see also section 5.3 of Chapter 5).

Taken together, the teachers and students all reported pronunciation to be an essential component in tertiary EFL programmes in Vietnam. More importantly, the teachers' and students' articulated beliefs suggest that pronunciation should be taught communicatively so as to help students develop their pronunciation in particular, and listening and speaking skills in general. For this to be viable, according to the teachers, the amount of teaching time for English has to be increased. This is also consistent with the students' expectation of more time to be allocated to the English subject at the university. The following section discusses the main findings regarding the teachers' and students' stated beliefs about the effects of CPT on student learning as well as pronunciation instruction within the VTE context.

\subsection{Discussion}

This section presents a detailed discussion of the effects of the CPT model on students' perceived learning outcomes from the perspectives of both teachers and students. It also discusses the teachers' and students' stated beliefs about pronunciation instruction in tertiary EFL programmes in Vietnam.

\subsubsection{CPT and student learning}

The teachers reported that applying CPT in classroom practice enabled them to make their students more aware of the importance of pronunciation in English learning, to transfer basic pronunciation knowledge to students, and to foster their confidence in using English for oral interactions. More importantly, the teachers believed that their implementation of CPT has the advantages for facilitating students' pronunciation learning in ways which were not evident prior to the intervention. This resonates with the students' stated beliefs about the effectiveness of CPT they experienced. The teachers' and students' articulated beliefs suggest that, through a variety of communication activities, CPT has the potential to help improve learners' pronunciation in particular and listening and speaking skills in general. These findings strengthen the claim about the success of the TPL workshop which was constructed and implemented in relation with the five research-based principles of effective PL as discussed in the previous chapter. 
The value the teachers and students put on CPT aligns with a general claim that communicative activities foster L2 learners' pronunciation improvement (Celce-Murcia et al., 2010; Isaacs, 2009; Saito, 2011; Saito \& Lyster, 2012). Rogerson-Revell (2011) has argued that L2 learners who can reproduce targeted pronunciation features properly in isolation may still make errors in the larger context of oral interaction; thus, meaningful communication tasks such as problem-solving or rule-deducing activities can promote learners' phonological development. In grammar teaching, Lyster (2007) suggested that instruction would be more effective if implemented in communicative contexts which enable learners to translate what they have learned in class into oral interactions. The same applies in pronunciation teaching. In classroom-based studies, for example, Saito $(2011 ; 2012 b)$ found that explicit pronunciation instruction in cooperation with communication tasks improved Japanese EFL learners' comprehensibility, given that communicative practice activities provided to the learners helped enhance not only accuracy but also fluency and automaticity of their pronunciation. Gordon et al. (2013) have found that explicit pronunciation instruction incorporating communicative activities helps improve L2 learners' comprehensibility. In the current study, both the teacher and student participants responded positively to CPT, which supports the idea that this teaching model is viable within the Vietnamese tertiary EFL classroom.

The teachers also believed that CPT aroused students' interest in learning and practicing English pronunciation because they were explicitly taught pronunciation features and simultaneously encouraged to practice these features in different communication situations. Similarly, the students described the CPT model they experienced as interesting and welcoming, which they believed to facilitate interaction in classroom learning. Consistent with the teachers' reports during the first catch-up and the students' reflection in FG interviews, I observed that the students actively participated in most classroom activities, enthusiastically practiced when asked and were eager to speak up. Interestingly, the students were reported to more readily interact with their peers in discussions when given communication tasks. It was encouraging that the students were more interested in communicative practice activities than some controlled practice activities which mainly involved repetition. 


\subsubsection{Pronunciation instruction in VTE education}

The study has found that both the teacher and student participants highly valued the role of pronunciation in English learning and recommended pronunciation to be included in tertiary EFL curriculum in Vietnam. On the one hand, the teachers believed that it is better to address pronunciation immediately when students start learning English at secondary schools. This belief finds support in Cakir (2012), Counselman (2015), and Gilakjani (2012b) who claim that pronunciation should be taught at the beginning of the L2 learning process. This will help L2 learners "quickly develop a stable pronunciation, and become familiar with the patterns and rules that work within the second language" (Nation \& Newton, 2009, p. 76). However, both the teachers and students reported that Vietnamese secondary EFL teachers mainly focused on teaching grammar and vocabulary and entirely ignored pronunciation in class. Thus, they believed that it is necessary to reteach pronunciation when students enter universities as a possible way to make up for what students lacked from secondary education.

On the other hand, all the student participants expressed a strong need for CPT which they believed can enhance not only their pronunciation but also listening and speaking skills. This finding is consistent with previous research in which the learner participants in an American ESL setting reported that they needed more opportunities to practice those target phonological features in real-life communication situations (Vitanova \& Miller, 2002) Although Nation and Newton (2009) have argued that form-focused instruction leads to positive changes in learners' pronunciation, "repetitive practice [...] is widely viewed as being incompatible with communicative principles" (Isaacs, 2009, p. 1). In addition, given that speech perception and speech production are inter-related and that the listener is an important interlocutor in oral communication, it is essential to tie pronunciation instruction to communicative activities so that students can practice the target features in communication situations (Adams-Goertel, 2013). Given all the benefits of CPT experienced and perceived by the student participants, it is important that explicit pronunciation instruction in the VTE classroom be carried out with a variety of communication tasks so as to provide learners with opportunities to develop pronunciation through listening and speaking practice.

\subsection{Summary of the chapter}

This chapter has reported findings concerning the effects of CPT on student learning in a particular EFL setting of Vietnamese tertiary education from both teacher and learner perspectives. The teachers believed that CPT can improve not only students' pronunciation 
but also listening and speaking skills due largely to the communicative activities CPT brings to students. They reported that CPT can transfer basic pronunciation knowledge to students, make them more aware of how important pronunciation is in English learning, and foster their confidence in using English for oral communication. Most of the teachers believed that CPT can arouse students' interest in classroom learning given that they are provided explicit instruction and simultaneously encouraged to use these targeted features through communicative practice.

The students perceived pronunciation as an important skill in their English learning. They believed that a good command of pronunciation can help them develop their listening and speaking skills, foster their confidence in using English for oral communication, and better facilitate their learning vocabulary. The students perceived CPT they experienced to be beneficial to their pronunciation, listening and speaking skills, which they believed to be important and useful for their future work. They recognised and highly valued the opportunities for communicative practice their teachers provided in class. They perceived CPT as superior and more effective than error correction through repetition. They therefore would like pronunciation to be included in tertiary EFL programmes and be taught communicatively.

Taken together, the findings suggested that CPT can be useful for learners' pronunciation improvement and development of listening and speaking skills. The study has provided evidence for the feasibility of CPT as an effective tool to enhance pronunciation learning within a particular tertiary EFL setting of Asian countries. On the basis of these findings, I would argue that CPT has the potentials to drive learners' practice outcomes through real-life communication situations brought to them by the instructors.

The next chapter summarises the findings of the two phases of the research, suggests implications for EFL pronunciation teaching and learning as well as TPL in pronunciation teaching in Vietnam, and addresses limitations of the study and future research areas. 


\section{Chapter 8}

\section{SUMMARY, IMPLICATIONS AND CONCLUSION}

\subsection{Introduction}

The study investigated pronunciation teaching in EFL classes at a Vietnamese university, a context in which little research has been conducted. The study draws on both teacher and student views of their experience of pronunciation teaching and learning. It is a two-phase study, with the second phase building on the first one. The study provides an in-depth account of TPL in the area of pronunciation pedagogy, and detailed accounts of teachers putting PL into practice. This chapter summarises the main findings of the current research, highlights the main contributions, and suggests implications for education policy makers, curriculum designers, and EFL pronunciation teaching and learning. Also, the limitations and suggestions for further research will be addressed along with a personal reflection.

\subsection{Summary of findings}

This section summarises the main findings of each of the two research phases that make up the thesis.

\subsubsection{Phase 1}

Phase 1 investigated (1) how pronunciation was represented in the EFL programme at a Vietnamese university; (2) the teachers' cognition and pronunciation teaching practices; (3) the teachers' perceptions of their own PTC and PL needs; and (4) Vietnamese EFL learners' pronunciation needs. Six Vietnamese EFL teachers were observed teaching two consecutive 45-minute textbook lessons in six intact classes, leading to a total of 540 minutes of classroom observations being made. After the observations, each of the six teachers were invited for individual stimulated recall and in-depth interviews (30 minutes each). Twentyfour students across the six groups (four students each) participated in focus group interviews, each of which lasted for about 25 minutes.

The findings showed that pronunciation was almost completely neglected in teaching materials and curriculum documents. In terms of classroom practice, the most frequent pronunciation teaching approach taken by all the teachers was giving $\mathrm{CF}$ through recasts 
and/or prompts in response to individual student's pronunciation errors of segmental features, the most common of which were vowels, consonants, final sounds, and word stress.

According to the teachers, these pedagogical choices were guided by curriculum factors such as time constraints and textbooks, and a number of student factors including errors, awareness, proficiency, and age. The teachers' comments indicated that the mandated curriculum imposed a heavy teaching load, teaching time was limited, classes were crowded, and students often had low English proficiency. The findings also revealed a mismatch between the teachers' stated beliefs and their actual classroom practice. The teachers reported that if they taught pronunciation explicitly, they would follow deliberate steps such as listening discrimination followed by explaining places of articulation and then practice. However, in the observed lessons, they only corrected students' pronunciation errors through recasts and/or prompts, with little if any explicit or pre-planned pronunciation teaching. In the interviews, they confirmed that they did not ever use any other technique, and that this was typically the only way they taught pronunciation in class.

All of the teachers reported a lack of initial training and PL in pronunciation pedagogy. Additionally, both the teacher and student participants believed that pronunciation plays an important role in English learning. Both groups reported four types of pronunciation errors (long and short vowels; consonants not existing in Vietnamese; final sounds and linking; and sentence stress and intonation) commonly facing Vietnamese learners of English. However, there was an incongruence between the teachers' and students' preferences and beliefs about pronunciation teaching. While the teachers believed error correction through recasts and/or prompts was effective, the students did not, and expressed a strong need for more explicit and communicative teaching of pronunciation which they believed could help improve not only their pronunciation but also their listening and speaking skills. This pronunciation instructional need and the teachers' lack of initial training and PL in pronunciation pedagogy motivated Phase 2 of the study.

\subsubsection{Phase 2}

Phase 2 was an intervention study that examined the impact of a TPL workshop on CPT on the teachers' knowledge gains and pronunciation teaching skills. It investigated teacher and student perceptions of the effects of the CPT model on student learning from both teaching and learning perspectives. Data were collected from three hours of workshop participation, over 30 hours of classroom observations across the six teachers, six 30-minute in-depth 
interviews with the teachers, and six 25-minute focus group interviews with students (six groups). During the workshop, the teachers were first introduced to a communicative framework for teaching English pronunciation followed by a lesson planning session in pairs and then lesson discussion as a whole group. Later, each of the teachers was asked to plan one CPT lesson (with one teacher responsible for two). They then shared their lessons with each other during the break between the two semesters. In the following semester, the teachers each implemented the seven CPT lessons across four teaching sessions.

The observational data showed that the teachers understood and were able to translate what they learned about the CPT model from the TPL workshop into actual classroom practice as manifested in their lesson planning and subsequent successful implementation of CPT lessons in their English classes. The lesson plans designed by the teachers closely followed the principles of the communicative framework with activities all adhering to the aims and objectives of each stage in the framework. The interview data showed that the teachers all reported benefiting from the workshop in terms of knowledge gains (both content and pedagogical knowledge) and pronunciation teaching skills. They stated that the workshop was an opportunity for them to update their understanding of how to teach pronunciation communicatively, which was reflected in their lesson plans during the workshop and in subsequent CPT lesson planning and implementation during the following semester. Some teachers said they became more confident in teaching pronunciation. This suggests the potential for a sustainable impact from the intervention beyond the experimental teaching sessions. The interview data also revealed that the CPT model was favoured by both the teacher and student participants. They believed that CPT has the potential to promote learners' pronunciation knowledge, foster their phonological ability, and develop their oral communication skills. The teachers and students also said that CPT can arouse learners' interest and engagement in classroom learning. Thus, the students expressed a strong need for more explicit, communicative pronunciation instruction in the VTE classroom.

\subsection{Contributions and implications}

Based on the study findings, this section presents the main contributions with implications for education policy makers, curriculum designers, and pronunciation teaching and learning within the Vietnamese EFL context and beyond. 


\subsubsection{Theoretical contributions}

The findings of the current study suggest that it is important to view pronunciation instruction through both a cognitive and sociocultural lens. A cognitive perspective enables an understanding of how learners' attention can be drawn to the form of targeted pronunciation features during the processes of establishing declarative knowledge (e.g., description and analysis) and subsequently proceduralizing this knowledge (e.g., listening discrimination and controlled practice). In addition, a sociocultural perspective provides insights into how pronunciation learning is co-constructed in classroom interaction between teachers and learners, and between learners during interaction in the automatization stage (e.g., guided and communicative practice) of the CPT approach. Alignment, which is a tendency for speakers to replicate each other's language such as words, phrases and pronunciation patterns, is a key component of the learning process (Trofimovich, 2016). As Foote and Trofimovich (2018) argue:

L2 pronunciation learning can be conceptualized as a complex task requiring learners to align or realign their pronunciation patterns $[\ldots]$ to their interlocutors, be they teachers or fellow non-native speakers. Depending on learners' cognitive abilities, the frequency and type of interactions they engage in, and their identity orientation, age or L1, some learners might be more successful than others" (p.84).

In the current study, this point is illustrated in the reflective accounts of students and teachers which provide a rich socially-situated perspective on pronunciation instruction. The adoption of these two perspectives provided more in-depth understandings about the process of pronunciation teaching implemented within the communicative framework and how this process could facilitate pronunciation learning.

\subsubsection{Empirical research contributions}

The Phase 1 study was an exploratory investigation involving thick description of the pronunciation teaching practices and cognitions of EFL teachers at a Vietnamese university. This study extends our understanding of pronunciation teaching in an EFL context where little such research has been conducted to date. The Phase 2 study also addressed a gap in the research literature, namely on how professional development, in this case in the form of insitu workshops, can assist pronunciation teaching. A third contribution of the study was the inclusion of learners' voices about their pronunciation learning experience. The study 
findings have implications for education policy makers, curriculum designers, and teacher trainers in Vietnam and elsewhere.

First, understanding teachers' current pronunciation teaching practices and their stated beliefs helps education policy makers build new policies on foreign language education, teacher training, and TPL. The study has found that all the teacher participants had limited initial training in teaching pronunciation. According to Baker and Murphy (2011) and J. Murphy (2014), content knowledge (knowledge about phonetics and phonology) together with pedagogical knowledge (knowledge about pronunciation pedagogy) constitute the knowledge base for pronunciation teaching. As such, if pronunciation teaching is to be improved, clearly teacher training programmes in Vietnam will need to provide more systematic coverage of this topic. It may also be necessary that teacher trainers provide useful guidance for preservice teachers so they can easily integrate pronunciation instruction into L2 lessons. In addition, the teachers reported lacking PL in pronunciation pedagogy and so expressed a strong need for more learning opportunities to develop their pronunciation pedagogy through, for example, workshops on pronunciation teaching, short courses, or PhD study in Englishspeaking countries. Therefore, it is important that education policy makers be well aware of teachers' PL needs on which new policies on TPL design and implementation can be developed.

Second, one of the goals of foreign language education policy at the tertiary level in Vietnam as stated by MOET is for Vietnamese EFL learners to function effectively and confidently in oral communication. This suggests that the learners need to develop communicative competence to a level that they can make themselves properly understood in conversational exchanges. Given that pronunciation is an essential component of communicative competence (Derwing \& Munro, 2015; T. Jones, 2018; Rogerson-Revell, 2011), education policy makers need to consider integrating pronunciation instruction into the education policy so that students can have opportunities to practice pronunciation and achieve the goal of becoming effective communicators in English. Such a policy will provide clear guidance for curriculum designers in planning their own institutional language programme.

Third, the teacher and student participants in the current study highly valued the important role that pronunciation plays in English learning. Both groups believed that a good command of pronunciation not only improves learners' listening and speaking skills but also fosters their confidence in using English for oral interaction. Moreover, both the teachers and 
students reported that pronunciation was usually neglected in classroom practice of Vietnamese secondary EFL teachers. To this end, they both stated that pronunciation needs to be taught explicitly and systematically in the tertiary EFL classroom. However, the study finding shows that pronunciation was not mentioned in curriculum documents nor played any explicit role in assessment in the EFL programme. Given that teachers in the Vietnamese context are required to teach to the curriculum, this gap means that pronunciation instruction is invariably neglected in classroom practice, as my findings confirm. Clearly, if this neglect is to be addressed, the starting point is to include pronunciation in curriculum planning. For example, in designing their language programmes, curriculum designers may need to select instructional materials that include pronunciation instruction. In addition, since the goal of language education is for learners to use the target language effectively in oral communication, if pronunciation is a component of the language curriculum, then students will have more opportunities to improve their pronunciation in particular and oral communication in general. This issue is compounded by assessment practices at the university. Research has suggested that many Vietnamese EFL teachers tend to teach towards the final exam (H. T. Nguyen et al., 2015). In the context of the current study, the end-ofterm exam which accounts for $70 \%$ of the students' final result mainly tested the students' knowledge of vocabulary, grammar, reading, listening and writing. The remaining $30 \%$ was from the mid-term exam which might be in the form of a written or a speaking test depending on each individual teacher's preference. Yet, even when teachers opted for a speaking test for the mid-term exam, there were no specified criteria for assessing the students' oral performance. Thus, if learners' pronunciation is treated as an integral part of language testing, then it will encourage teachers to set up the goals for their lessons.

\subsubsection{Pedagogical contributions}

On the basis of the study findings, a number of pedagogical contributions and implications may be drawn. These implications may also be relevant to other similar Asian EFL settings. First, the study findings show that the teachers had all adopted a reactive focus-on-form approach to pronunciation teaching in their English classes. As observed in intact classes and later confirmed by the teachers, they most frequently corrected individual students' pronunciation errors of segmental features through recasts and/or prompts. While reactive $\mathrm{CF}$ has been shown to be an effective instructional approach for teaching pronunciation (Dlaska \& Krekeler, 2013; Saito \& Lyster, 2012), these findings show how restricted the teachers' 
pronunciation teaching practices were. Although the teachers believed in the efficacy of their pronunciation teaching, such an approach was not at all favoured by the students. Contrary to the teachers, the student participants reported that having their pronunciation errors corrected through recasts and/or prompts does not help improve their pronunciation. They said they would like teachers to spend more time teaching pronunciation explicitly in class. These findings provide encouragement for teachers to rethink the commonly-held belief about the effectiveness of sporadically correcting learners' pronunciation errors through recasts and/or prompts, as research has shown that the systematic, explicit instruction of pronunciation improves L2 learners' pronunciation at all levels (Derwing, 2018; Derwing \& Munro, 2015; Thomson \& Derwing, 2014; Zielinski \& Yates, 2014).

Second, the findings showed that the students highly valued the importance of pronunciation instruction within the VTE classroom. As the teachers and students reported, pronunciation is neglected in Vietnamese secondary schools where the focus is on grammar and vocabulary, and on passing the graduation exam by the end of Grade 12 and the subsequent university entrance exam. The lack of pronunciation instruction at secondary schools, according to the teachers, led to most students entering university with inadequate knowledge of English pronunciation and poor communicative competence. As such, explicit pronunciation teaching may need to be addressed in the classroom practice of Vietnamese EFL teachers at all levels so that students can establish competence with pronunciation fundamentals in their early years of EFL learning and continue to build on these foundations through their education.

Third, positive responses from the teachers and students to their experience of the CPT model suggest that such an approach to pronunciation teaching holds considerable promise in this tertiary EFL context. As inferred from the teachers' and students' stated beliefs, CPT has the advantages for improving learners' pronunciation alongside more general communication skills given that they not only focus on the form of the targeted features but also have opportunities to practice pronunciation in more creative, meaningful conversations. Both groups also reported that CPT engages students more actively in learning by creating an interesting and relaxing classroom atmosphere, which increases their confidence in using English for oral interaction. The students' engagement in classroom activities and willingness to speak, as observed in experimental classes and later reported by the teachers, provides evidence that CPT is viable within the VTE classroom. V. C. Le (2001, pp. 35-36) described EFL classes in Vietnam as "a cultural island" in which teachers are dominant entities who 
transfer knowledge and learners are passive recipients of that knowledge. Yet, this study's findings provide encouragement for Vietnamese EFL teachers to differentiate their decisionmaking in teaching pronunciation and involve students in a more active, meaningful learning environment. This suggests that CPT not only simply provides pronunciation instruction but it is actually pushing teachers to teach pronunciation more communicatively. And it is this change that both teachers and students are enjoying.

It is worth noting that, in addition to communicative practice activities, the CPT model involves a large amount of explicit phonetic instruction in the Description and analysis and Listening discrimination stages, and controlled and semi-controlled activities during the Controlled and Guided practice stages. It is the combination of all three components that is seen to be a key characteristic of this model. Furthermore, alongside with controlled, guided and communicative practice, the role of the teacher's feedback on learners' performance is also highlighted in this model (Celce-Murcia et al., 2010). Research by Saito and Lyster (2012) showed that form-focused practice alone was insufficient for promoting L2 learners' pronunciation improvement and that $\mathrm{CF}$ during communicative practice led to positive changes in learners' pronunciation. Thus, in implementing this CPT model, it is important that teachers scaffold instruction to provide learning opportunities for their students. In other words, teachers may need to consider explaining and re-explaining targeted pronunciation features explicitly throughout the teaching process until students are able to transform this knowledge into practice and finally automatize it in meaningful, fluency-building communication tasks.

\subsection{Limitations and directions for future research}

The study has a number of limitations that merit further research. First, the research was conducted at a particular university in Vietnam which is likely different from other universities in terms of curriculum design, teacher expertise, and student motivation to learn due to the degree of institutional autonomy permitted in Vietnam. For this reason, a larger sample of EFL teacher participants from different universities in Vietnam could be recruited to take part in future research so as to provide a firmer basis for generalising from research findings. A questionnaire that investigates teachers' stated beliefs about pronunciation teaching techniques and/or PL in pronunciation pedagogy offers one option for collecting a larger data set. 
Second, there is a need for further research into pronunciation teaching practices in this EFL context to extend the findings of the current study. For example, future classroom-based studies could investigate VTE teachers' pronunciation teaching practices through intensive observational data sets collected in similar settings with learners of different English proficiency, ranging from elementary to advanced level. Such studies will provide grounds for a closer link between teachers' actual pronunciation teaching practices and the construct and treatment of pronunciation instruction in curriculum documents to be developed.

Third, the current study did not track or transcribe learners' performance in the CPT lessons (beyond the observation data) or measure students' learning outcomes from CPT including a control group in the research. Although the students said they favoured the CPT approach and reported that it helped them improve not only pronunciation but also listening and speaking skills, it is unclear whether the students' pronunciation actually improved as a consequence of CPT lessons. Thus, future studies should be conducted to address this limitation. Other studies could be done to compare the uptake between learners who receive CF through recasts and/or prompts and those who receive explicit CPT. Future research could investigate the efficacy of explicit pronunciation instruction on learners' production of both segmental and suprasegmental features in this EFL context, especially targeted research on specific features causing common pronunciation problems for Vietnamese EFL learners.

Finally, the current study only provided TPL in the form of a three-hour workshop and observed its impact on the teachers' classroom practice over a period of eight weeks (approximately two months). Longitudinal research is needed to provide deeper insights into how teachers' pronunciation teaching changes or is sustained over a longer period. For example, it would be interesting to see how teachers translate the professional knowledge they receive into their actual instructional practice over a period of one year. Such a longitudinal study may consider examining teacher uptake over time, which may help education policy makers work out a better way to promote TPL that assists teachers to better teach pronunciation in their language classes.

\subsection{Conclusion}

Despite the limitations mentioned above, the current study has original contributions which lie in its central focus on pronunciation instruction in an EFL context where it has not hitherto been examined. The research provided insights into not only current pronunciation teaching 
practices in VTE classrooms but also teacher and student thinking. It has shed light on the positive impact of TPL in pronunciation pedagogy on teacher uptake in terms of knowledge gains and pronunciation teaching skill. The study has provided the first evidence, of which I am aware, of teacher and student perceptions of the affordances offered by CPT.

Overall, the study has provided insights into the teaching of English pronunciation at a Vietnamese university. These insights are likely to resonate with the experience of teachers and learners across tertiary EFL education in Vietnam. The importance of pronunciation teaching and learning is not emphasised in the curriculum at this university where pronunciation instruction was almost completely neglected. The teachers' pronunciation teaching practices were greatly influenced by contextual factors including the curriculum and the learners. Most of the teachers reported being confident in teaching pronunciation but feeling more comfortable teaching segmental features. They all treated intelligibility as a realistic, attainable pronunciation goal for their students. Both the teachers and students believed that pronunciation is an essential component of communicative competence and thus needs to be taught properly in class. The study also showed the positive response of teachers and learners to CPT. If Vietnamese EFL learners are to function more effectively in oral communication, it may be necessary for teachers to put more emphasis on communicative pronunciation instruction that can foster the learners' phonological ability and improve their pronunciation within the context of communicative skill development.

Given the inseparable relationship between content knowledge and pedagogical knowledge in pronunciation instruction and the importance of initial training and PL in pronunciation pedagogy, if Vietnamese EFL teachers are to teach pronunciation more efficiently in class, then it may be essential that pronunciation and pronunciation pedagogy be covered in teacher training and TPL programmes in Vietnam. Since TPL is a long-term process in which positive changes require extra work and time to emerge (Guskey, 2002; Papastamatis et al., 2009; Villegas-Reimers, 2003), TPL programmes in Vietnam may need to offer teachers multiple contact hours of learning activities so as to achieve more notable gains on teacher uptake and SLOs.

\subsection{Reflection}

I conclude with my personal reflection on conducting this research project. As stated in the introduction chapter, the current study has personal value to me as an EFL instructor, a 
teacher trainer and now as a pronunciation researcher. Conducting this research project has helped me see the interdependence between research and pedagogy. The implications of this research, as discussed earlier, will be most directly relevant to me when I return to the classroom as an EFL instructor as well as a teacher trainer. According to Derwing and Munro (2015) and J. Murphy and Baker (2015), successful practice is usually based on teachers' experiences in the classroom rather than on empirical research findings. However, this research has inspired me to address the need to bring research data into real L2 classrooms so as to bridge the gap between research and practice in the teaching of English pronunciation. It has inspired me to bring research findings to EFL teacher training programmes with a hope that pronunciation and pronunciation pedagogy is given a more substantial role in equipping teachers to deliver more effective communicative pronunciation instruction.

I would like to close the thesis with an argument that there needs to be a process of brick-bybrick rebuilding of a professional space for pronunciation instruction within the L2 classroom (Levis \& LeVelle, 2010), and that this process needs to assure that:

“our foundations (L2 pronunciation research, teachers' reflections on their experiences) are sound and that the architects (researchers, material developers, classroom teachers, course developers) design a structure that provides a constructive and stimulating living environment for as many teachers and language learners as possible” (Brinton, 2018, p. 457). 


\section{REFERENCES}

Abrahamsson, N., \& Hyltenstam, K. (2008). The robustness of aptitude effects in near-native second language acquisition. Studies in Second Language Acquisition, 30(4), 481509.

Abrahamsson, N., \& Hyltenstam, K. (2009). Age of onset and nativelikeness in a second language: Listener perception versus linguistic scrutiny. Language learning, 59(2), 249-306.

Adams-Goertel, R. (2013). Prosodic elements to improve pronunciation in English language learners: A short report. Applied Research on English Language, 2(2), 117-128.

Ahangari, S., Rahbar, S., \& Entezari Maleki, S. (2015). Pronunciation or listening enhancement: Two birds with one stone. International Journal of Language and Applied Linguistics, 1(2), 13-19.

Al-Tamimi, A., \& Shuib, M. (2009). Motivation and attitudes towards learning English: A study of petroleum engineering undergraduates at Hadhramout University of Sciences and Technology. GEMA: Online Journal of Language Studies, 9(2), 29-55.

Aljaafreh, A., \& Lantolf, J. P. (1994). Negative feedback as regulation and second language learning in the zone of proximal development. The Modern Language Journal, 78(4), 465-483.

Armour, K. M., \& Makopoulou, K. (2012). Great expectations: Teacher learning in a national professional development programme. Teaching and teacher education, 28(3), 336346.

Avalos, B. (2011). Teacher professional development in Teaching and Teacher Education over ten years. Teaching and teacher education, 27(1), 10-20.

Avery, P., \& Ehrlich, S. (2013). Teaching American English Pronunciation. Oxford: Oxford University Press.

Bai, B., \& Yuan, R. (2019). EFL teachers' beliefs and practices about pronunciation teaching. ELT Journal, 73(2), 134-143. doi:10.1093/elt/ccy040

Baker, A. (2011). ESL teachers and pronunciation pedagogy: Exploring the development of teachers' cognitions and classroom practices. Paper presented at the The Second Pronunciation in Second Language Learning and Teaching Conference, Ames, Iowa, IA. 
Baker, A. (2014). Exploring teachers' knowledge of second language pronunciation techniques: Teacher cognitions, observed classroom practices, and student perceptions. Tesol Quarterly, 48(1), 136-163.

Baker, A., \& Murphy, J. (2011). Knowledge base of pronunciation teaching: Staking out the territory. TESL Canada Journal, 28(2), 29 - 50.

Baker Smemoe, W., \& Haslam, N. (2013). The effect of language learning aptitude, strategy use and learning context on L2 pronunciation learning. Applied Linguistics, 34(4), 435-456.

Barnard, R., \& Nguyen, G. (2010). Task-based language teaching (TBLT): A Vietnamese case study using narrative frames to elicit teacher's beliefs. Language Education in Asia, 1(1), 77-86.

Barnes, H., \& Verwey, H. (2008). Teacher Education Review. South Africa: University of Pretoria.

Basturkmen, H. (2012). Review of research into the correspondence between language teachers' stated beliefs and practices. System, 40(2), 282-295.

Basturkmen, H., Loewen, S., \& Ellis, R. (2004). Teachers' stated beliefs about incidental focus on form and their classroom practices. Applied Linguistics, 25(2), 243-272.

Berg, B. L. (2009). Qualitative research methods for the social sciences (7 ed.). Boston, MA: Allyn \& Bacon

Beven, L. (2012). A Review of ESOL Publications Using Research-based Principles of Pronunciation Pedagogy. (MA Unpublished Research Project), Victoria University of Wellington,

Birdsong, D., \& Molis, M. (2001). On the evidence for maturational constraints in secondlanguage acquisition. Journal of Memory and language, 44(2), 235-249.

Birello, M. (2012). Teacher cognition and language teacher education: Beliefs and practice. A conversation with Simon Borg. Bellaterra Journal of Teaching \& Learning Language \& Literature, 5(2), 88-94.

Borg, S. (1998). Teachers' pedagogical systems and grammar teaching: A qualitative study. Tesol Quarterly, 32(1), 9-38.

Borg, S. (2003). Teacher cognition in language teaching: A review of research on what language teachers think, know, believe, and do. Language Teaching, 36(2), 81-109.

Borg, S. (2006). Teacher cognition and language education: Research and practice: London, England: Continuum. 
Borg, S. (2011). The impact of in-service teacher education on language teachers' beliefs. System, 39(3), 370-380.

Borg, S. (2012). Current approaches to language teacher cognition research: A methodological analysis. In R. Barnard \& A. Burns (Eds.), Researching language teacher cognition and practice: International case study (pp. 11-29). Bristol: Multilingual Matters.

Borg, S. (2015). Teacher cognition and language education: Research and practice. London: Bloomsbury Publishing Plc.

Borg, S., \& Al-Busaidi, S. (2012). Teachers' beliefs and practices regarding learner autonomy. ELT Journal, 66(3), 283-292.

Bowen, G. A. (2009). Document analysis as a qualitative research method. Qualitative research journal, 9(2), 27-40.

Breen, M. P., Hird, B., Milton, M., Oliver, R., \& Thwaite, A. (2001). Making sense of language teaching: Teachers' principles and classroom practices. Applied Linguistics, $22(4), 470-501$.

Breitkreutz, J., Derwing, T. M., \& Rossiter, M. J. (2001). Pronunciation teaching practices in Canada. TESL Canada Journal, 19(1), 51-61.

Brinton, D. (2018). Innovations in pronunciation teaching. In O. Kang, R. I. Thomson, \& J. Murphy (Eds.), The Routledge Handbook of Comtemporary English Pronunciation (pp. 449-461). New York: Routledge.

Brown, H. D. (1987). Principles of language learning and teaching (2nd ed.). New York: Pearson Education.

Brown, P. A. (2008). A review of the literature on case study research. Canadian Journal for New Scholars in Education, 1(1), 1-13.

Bryman, A. (2008). Social research methods (3rd ed.). Oxford: Oxford university press.

Burgess, J., \& Spencer, S. (2000). Phonology and pronunciation in integrated language teaching and teacher education. System, 28(2), 191-215.

Burns, A. (2006). Integrating research and professional development on pronunciation teaching in a national adult ESL program. TESL Reporter, 39(2), 34-41.

Burns, A., Freeman, D., \& Edwards, E. (2015). Theorizing and studying the languageteaching mind: Mapping research on language teacher cognition. The Modern Language Journal, 99(3), 585-601.

Burr, V. (2003). Social constructionism (2nd ed.). Great Britain: Routledge. 
Burri, M., Baker, A., \& Chen, H. (2017). I feel like having a nervous breakdown. Journal of Second Language Pronunciation, 3(1), 109-135. doi:doi 10.1075/jslp.3.1.05bur

Burri, M., Chen, H., \& Baker, A. (2017). Joint development of teacher cognition and identity through learning to teach L2 pronunciation. The Modern Language Journal, 101(1), 128-142.

Buss, L. (2013). Pronunciation from the perspective of pre-service EFL teachers: An analysis of internship reports. Paper presented at the Proceedings of the 4th pronunciation in second language learning and teaching conference, Iowa State University, USA.

Cakir, I. (2012). Promoting correct pronunciation through supported audio materials for EFL learners. Energy Education Science and Technology Part B: Social and Educational Studies, 4(3), 1801-1812.

Capps, D. K., Crawford, B. A., \& Constas, M. A. (2012). A review of empirical literature on inquiry professional development: Alignment with best practices and a critique of the findings. Journal of science teacher education, 23(3), 291-318.

Carreira, M., \& Kagan, O. (2011). The results of the National Heritage Language Survey: Implications for teaching, curriculum design, and professional development. Foreign Language Annals, 44(1), 40-64.

Casey, D., \& Houghton, C. (2010). Clarifying case study research: examples from practice. Nurse researcher, 17(3), 41-51.

Casey, D., \& Murphy, K. (2009). Issues in using methodological triangulation in research. Nurse researcher, 16(4), 40-55.

Caspers, J. (2010). The influence of erroneous stress position and segmental errors on intelligibility, comprehensibility and foreign accent in Dutch as a second language. Linguistics in the Netherlands, 27(1), 17-29.

Celce-Murcia, M., Brinton, D. M., \& Goodwin, J. M. (2010). Teaching Pronunciation: A Course Book and Reference Guide. Cambridge: Cambridge University Press.

Chapelle, C. A. (2009). A hidden curriculum in language textbooks: Are beginning learners of French at US universities taught about Canada? The Modern Language Journal, 93(2), 139-152.

Charmaz, K. (2006). Constructing grounded theory: A practical guide through qualitative analysis. London: Sage.

Chiu, H.-H. W. (2008). Practical understandings: Teachers' beliefs and practices in pronunciation teaching. (MA Unpublished), The University of Texas at Arlington, 
Cohen, L., Manion, L., \& Morrison, K. (2007). Research methods in education (6th ed.). New York: Routledge.

Cope, D. G. (2014). Methods and meanings: credibility and trustworthiness of qualitative research. Oncology Nursing Forum, 41(1), 89-91.

Cotton, D., Falvey, D., \& Kent, S. (2006). Market Leader Coursebook - Elementary Business English. Edinburgh: Pearson Education Limited.

Cotton, D., Falvey, D., \& Kent, S. (2012). Pre-intermediate Market Leader - Business English Coursebook (3rd ed.). Edinburgh: Pearson Education Limited.

Counselman, D. (2015). Directing attention to pronunciation in the second language classroom. Hispania, 98(1), 31-46.

Couper, G. (2003). The value of an explicit pronunciation syllabus in ESOL teaching. Prospect, 18(3), 53-70.

Couper, G. (2006). The short and long-term effects of pronunciation instruction. Prospect, 21(1), 46-66.

Couper, G. (2011). What makes pronunciation teaching work? Testing for the effect of two variables: Socially constructed metalanguage and critical listening. Language Awareness, 20(3), 159-182.

Couper, G. (2012). Teaching word stress: Learning from learners' perceptions. TESOL in Context, S3(Special edition), 1-15.

Couper, G. (2013). Talking about pronunciation: Socially constructing metalanguage. English Australia Journal, 29(1), 3-18.

Couper, G. (2014). Teaching concepts of pronunciation: syllables, stress and drunk snails. Speak Out, 50, 46 - 50.

Couper, G. (2017). Teacher Cognition of Pronunciation Teaching: Teachers' Concerns and Issues. Tesol Quarterly, 51(4), 820-843.

Couper, G. (2018). Applying a cognitive linguistic framework to L2 pronunciation teaching. In O. Kang, R. I. Thomson, \& J. Murphy (Eds.), The Routledge Handbook of Contemporary English pronunciation (pp. 462-477). London and New York: Routledge.

Creswell, J. W. (2005). Educational research: Planning, conducting, and evaluating quantitative: Prentice Hall.

Creswell, J. W. (2009). Research design: Qualitative, quantitative, and mixed methods approaches (3rd ed.). Los Angeles: Sage. 
Creswell, J. W., \& Miller, D. L. (2000). Determining validity in qualitative inquiry. Theory into practice, 39(3), 124-130.

Crookes, G. V. (2015). Redrawing the boundaries on theory, research, and practice concerning language teachers' philosophies and language teacher cognition: Toward a critical perspective. The Modern Language Journal, 99(3), 485-499.

Csizér, K., Kormos, J., \& Sarkadi, A. (2010). The dynamics of language learning attitudes and motivation: Lessons from an interview study of dyslexic language learners. The Modern Language Journal, 94(3), 470-487.

Cunningham, U. (2009). Models and Targets for the Pronunciation of English in Vietnam and Sweden. Research in Language, 7, 113-128.

Dalton-Puffer, C., Kaltenböck, G., \& Smit, U. (1997). Learner attitudes and L2 pronunciation in Austria. World Englishes, 16(1), 115-128.

Dang, T. K. A., Nguyen, H. T. M., \& Le, T. T. T. (2013). The impacts of globalisation on EFL teacher education through English as a medium of instruction: An example from Vietnam. Current Issues in Language Planning, 14(1), 52-72.

Dao, D. (2018). Learners' perspectives on English pronunciation teaching and learning: A preliminary study in the Vietnamese context. Paper presented at the Proceedings of the 9th Pronunciation in Second Language Learning and Teaching conference, University of Utah, September, 2017.

Darcy, I., Ewert, D., \& Lidster, R. (2011). Bringing Pronunciation Instruction Back into the Classroom: An ESL Teachers' "Pronunciation toolbox". Paper presented at the 3rd Pronunciation in Second Language Learning and Teaching Conference, Ams, IA, USA.

Darling-Hammond, L., Wei, R. C., Andree, A., Richardson, N., \& Orphanos, S. (2009). Professional learning in the learning profession. Retrieved from Washington, DC: National Staff Development Council:

Day, C., \& Townsend, A. (2009). Practitioner action research: Building and sustaining success through networked learning communities. In E. N. Susan \& S. Bridget (Eds.), The SAGE Handbook of Educational Action Research (pp. 178-189). London: Sage.

DeKeyser, R. (2007). Introduction: Situating the concept of practice. In R. DeKeyser (Ed.), Practice in a second language: Perspectives from applied linguistics and cognitive psychology (pp. 1-20). New York, NY: Cambridge. 
DeKeyser, R. (2015). Skill acquisition theory. In B. VanPatten \& J. Williams (Eds.), Theories in second language acquisition: An introduction (2nd ed., pp. 94-112). New York, NY: Routledge.

Denzin, N. K., \& Lincoln, Y. S. (2008). Collecting and interpreting qualitative materials (3rd ed.). Thousand Oaks: Sage.

Derwing, T. M. (2003). What do ESL students say about their accents? Canadian Modern Language Review, 59(4), 547-567.

Derwing, T. M. (2008). Curriculum issues in teaching pronunciation to second language learners. In G. H. J. Edwards \& L. M. Zampini (Eds.), Phonology and second language acquisition (Vol. 36, pp. 347-369). Amsterdam: John Benjamins Publishing Company.

Derwing, T. M. (2010). Utopian goals for pronunciation teaching. Paper presented at the The 1st pronunciation in second language learning and teaching conference, Iowa State University, September 17-19, 2009.

Derwing, T. M. (2018). The efficacy of pronunciation instruction. In O. Kang, R. I. Thomson, \& J. Murphy (Eds.), The Routledge Handbook of Contemporary English Pronunciation (pp. 320-334). London and New York: Routledge.

Derwing, T. M., Diepenbroek, L. G., \& Foote, J. A. (2012). How Well do General-Skills ESL Textbooks Address Pronunciation? TESL Canada Journal, 30(1), 22-44.

Derwing, T. M., \& Munro, M. J. (2005). Second language accent and pronunciation teaching: A research-based approach. Tesol Quarterly, 39(3), 379-397.

Derwing, T. M., \& Munro, M. J. (2009). Comprehensibility as a factor in listener interaction preferences: Implications for the workplace. Canadian Modern Language Review, 66(2), 181-202.

Derwing, T. M., \& Munro, M. J. (2013). The Development of L2 Oral Language Skills in Two L1 Groups: A 7-Year Study. Language learning, 63(2), 163-185.

Derwing, T. M., \& Munro, M. J. (2014). Once you have been speaking a second language for years, it's too late to change your pronunciation. Michigan ELT, 1(Pronunciation Myths: Applying Second Language Research to Classroom Teaching), 34-55.

Derwing, T. M., \& Munro, M. J. (2015). Pronunciation Fundamentals: Evidence-based perspectives for L2 teaching and research (Vol. 42). Amsterdam/Philadelphia: John Benjamins Publishing Company. 
Derwing, T. M., Munro, M. J., Foote, J. A., Waugh, E., \& Fleming, J. (2014). Opening the window on comprehensible pronunciation after 19 years: A workplace training study. Language learning, 64(3), 526-548.

Derwing, T. M., Munro, M. J., \& Thomson, R. I. (2008). A longitudinal study of ESL learners' fluency and comprehensibility development. Applied Linguistics, 29(3), 359380.

Derwing, T. M., \& Rossiter, M. J. (2002). ESL learners' perceptions of their pronunciation needs and strategies. System, 30(2), 155-166.

Derwing, T. M., \& Rossiter, M. J. (2003). The Effects of Pronunciation Instruction on the Accuracy, Fluency, and Complexity of L2 Accented Speech. Applied Language Learning, 13(1), 1-17.

Derwing, T. M., Rossiter, M. J., \& Munro, M. J. (2002). Teaching native speakers to listen to foreign-accented speech. Journal of Multilingual and Multicultural Development, 23(4), 245-259.

Desimone, L. M. (2009). Improving impact studies of teachers' professional development: Toward better conceptualizations and measures. Educational researcher, 38(3), 181199.

Dewaele, J.-M. (2017). Why the dichotomy 'L1 versus LX user' is better than 'native versus non-native speaker'. Applied Linguistics, 39(2), 236-240.

Dichaba, M. M., \& Mokhele, M. L. (2012). Does the cascade model work for teacher training? Analysis of teachers' experiences. International Journal of Educational Sciences, 4(3), 249-254.

Diefes-Dux, H. A. (2014). In-Service Teacher Professional Development in Engineering Education. In Ş. Purzer, J. Strobel, \& M. E. Cardella (Eds.), Engineering in precollege settings: synthesizing research, policy, and practices (pp. 233-257): Purdue University Press.

Dlaska, A., \& Krekeler, C. (2013). The short-term effects of individual corrective feedback on L2 pronunciation. System, 41(1), 25-37.

Dörnyei, Z. (2007). Research methods in applied linguistics: Quantitative, qualitative, and mixed methodologies. Oxford: Oxford University Press.

Dörnyei, Z. (2009). The 2010s. Communicative Language Teaching in the 21st Century: The “Principled Communicative Approach". Perspectives, 36(2), 33-43. 
Dragojevic, M., \& Giles, H. (2016). I don't like you because you're hard to understand: The role of processing fluency in the language attitudes process. Human Communication Research, 42(3), 396-420.

Ducate, L., \& Lomicka, L. (2009). Podcasting: An effective tool for honing language students' pronunciation? Language Learning \& Technology, 13(3), 66.

Duff, P. (2008). Case study research in applied linguistics. New York: Routledge.

Ekanayake, S. Y., \& Wishart, J. (2015). Integrating mobile phones into teaching and learning: A case study of teacher training through professional development workshops. British Journal of Educational Technology, 46(1), 173-189.

Elder-Vass, D. (2012). The reality of social construction. New York: Cambridge University Press.

Elliott, A. R. (1995). Foreign language phonology: Field independence, attitude, and the success of formal instruction in Spanish pronunciation. The Modern Language Journal, 79(4), 530-542.

Ellis, R. (2003). Task-based language learning and teaching. Oxford: Oxford University Press.

Ellis, R. (2005). Principles of instructed language learning. System, 33(2), 209-224.

Ellis, R. (2012). Language teaching research and language pedagogy. Oxford: John Wiley \& Sons.

Ellis, R., Basturkmen, H., \& Loewen, S. (2002). Doing focus-on-form. System, 30(4), 419432.

Ellis, R., Loewen, S., \& Erlam, R. (2006). Implicit and explicit corrective feedback and the acquisition of L2 grammar. Studies in Second Language Acquisition, 28(2), 339.

Ellis, R., \& Shintani, N. (2014). Exploring language pedagogy through second language acquisition research. Great Britain: Routledge.

Ellis, R., Tanaka, Y., \& Yamazaki, A. (1994). Classroom interaction, comprehension, and the acquisition of L2 word meanings. Language learning, 44(3), 449-491.

Faez, F. (2011). Reconceptualizing the native/nonnative speaker dichotomy. Journal of Language, Identity \& Education, 10(4), 231-249.

Field, J. (2005). Intelligibility and the listener: The role of lexical stress. Tesol Quarterly, 39(3), 399-423.

Flege, J. E. (1995). Second language speech learning: Theory, findings, and problems. In W. Strange (Ed.), Speech perception and linguistic experience: Issues in cross-language research (Vol. 92, pp. 233-277). Baltimore York Press. 
Flege, J. E., Takagi, N., \& Mann, V. (1995). Japanese adults can learn to produce English/I/and/l/accurately. Language and speech, 38(1), 25-55.

Foote, J. A., Holtby, A. K., \& Derwing, T. M. (2011). Survey of the teaching of pronunciation in adult ESL programs in Canada, 2010. TESL Canada Journal, 29(1), $1-22$.

Foote, J. A., \& Trofimovich, P. (2018). Second Language Pronunciation Learning: An overview of theoretical perspectives. In O. Kang, R. I. Thomson, \& J. Murphy (Eds.), The Routledge Handbook of Contemporary English Pronunciation (pp. 75-90). London and New York: Routledeg.

Foote, J. A., Trofimovich, P., Collins, L., \& Urzúa, F. S. (2016). Pronunciation teaching practices in communicative second language classes. The Language Learning Journal, 44(2), 181-196.

Fraser, H. (2000). Coordinating improvements in pronunciation teaching for adult learners of English as a second language: DETYA (ANTA Innovative project).

Fraser, H. (2006). Helping teachers help students with pronunciation: A cognitive approach. Prospect, 21(1), 80-96.

Fraser, H. (2009). Pronunciation as categorization: The role of contrast in teaching English/r/and/l. In A. Mahboob \& C. Lipovsky (Eds.), Studies in applied linguistics and language learning (pp. 289-306). Newcastle upon Tyne: Cambridge Scholars Publishing.

Fraser, H. (2010). Cognitive theory as a tool for teaching second language pronunciation. In S. De Knop, F. Boers, \& A. De Rycker (Eds.), Fostering language teaching efficiency through cognitive linguistics (pp. 357-379). Berlin: Mouton de Gruyter.

Gass, S. M. (1997). Input, interaction, and the second language learner. Mahwah, NJ: Erlbaum.

Gass, S. M., \& Mackey, A. (2000). Stimulated recall methodology in second language research: Routledge.

Gatbonton, E., \& Segalowitz, N. (2005). Rethinking communicative language teaching: A focus on access to fluency. Canadian Modern Language Review, 61(3), 325-353.

Gibbons, P. (2006). Bridging discourses in the ESL classroom: Students, teachers and researchers. London, New York: Continuum.

Gilakjani, A. P. (2011). A study on the situation of pronunciation instruction in ESL/EFL classrooms. Journal of Studies in Education, 1(1). 
Gilakjani, A. P. (2012a). The significance of pronunciation in English language teaching. English language teaching, 5(4), 96-107.

Gilakjani, A. P. (2012b). A study of factors affecting EFL learners' English pronunciation learning and the strategies for instruction. International Journal of Humanities and Social Science, 2(3), 119-128.

Gilbert, J. (2008). Teaching pronunciation: Using the prosody pyramid. New York: Cambridge University Press.

Gilbert, J. B. (2010). Pronunciation as orphan: What can be done. TESOL SPLIS, 7(2), 1-5.

Gillham, B. (2005). Research Interviewing: The range of techniques: A practical guide. Great Britain: McGraw-Hill Education (UK).

Gömleksiz, M. N. (2010). An evaluation of students' attitudes toward English language learning in terms of several variables. Procedia-Social and Behavioral Sciences, 9, 913-918.

Gordon, J., Darcy, I., \& Ewert, D. (2013). Pronunciation teaching and learning: Effects of explicit phonetic instruction in the L2 classroom. Paper presented at the Proceedings of the 4th pronunciation in second language learning and teaching conference, Ames, IA.

Gorjian, B., Hayati, A., \& Pourkhoni, P. (2013). Using Praat software in teaching prosodic features to EFL learners. Procedia-Social and Behavioral Sciences, 84, 34-40.

Guskey, T. R. (2002). Professional development and teacher change. Teachers and Teaching, 8(3), 381-391.

Guskey, T. R., \& Yoon, K. S. (2009). What works in professional development? Phi Delta Kappan, 90(7), 495-500.

Hahn, L. D. (2004). Primary stress and intelligibility: Research to motivate the teaching of suprasegmentals. Tesol Quarterly, 38(2), 201-223.

Halcomb, E. J., Gholizadeh, L., DiGiacomo, M., Phillips, J., \& Davidson, P. M. (2007). Literature review: considerations in undertaking focus group research with culturally and linguistically diverse groups. Journal of clinical nursing, 16(6), 1000-1011.

Hamano, T. (2008). Educational reform and teacher education in Vietnam. Journal of education for teaching, 34(4), 397-410.

Harmer, J. (2011). The practice of English language teaching. China: Pearson Education Limited.

Hawkes, M. L. (2012). Using task repetition to direct learner attention and focus on form. ELT Journal, 66(3), 327-336. 
He, L. (2011). Metacognition in EFL pronunciation learning among Chinese tertiary learners. Applied Language Learning, 21(1\&2), 1-27.

Heary, C. M., \& Hennessy, E. (2002). The use of focus group interviews in pediatric health care research. Journal of pediatric psychology, 27(1), 47-57.

Henderson, A., Frost, D., Tergujeff, E., Kautzsch, A., Murphy, D., Kirkova-Naskova, A., . . . Curnick, L. (2012). The English pronunciation teaching in Europe survey: Selected results. Research in Language, 10(1), 5-27.

Hismanoglu, M. (2006). Current perspectives on pronunciation learning and teaching. Journal of Language and Linguistic Studies, 2(1).

Hismanoglu, M., \& Hismanoglu, S. (2010). Language teachers' preferences of pronunciation teaching techniques: traditional or modern? Procedia-Social and Behavioral Sciences, 2(2), 983-989.

Holliday, A. (2007). Doing and writing qualitative research. London: Sage.

Houghton, C., Casey, D., Shaw, D., \& Murphy, K. (2013). Rigour in qualitative case-study research. Nurse researcher, 20(4), 12-17.

İnal, B. (2006). Coursebook selection process and some of the most important criteria to be taken into consideration in foreign language teaching. Cankaya University Journal of Arts and Sciences, 1(5), 19-29.

Isaacs, T. (2009). Integrating form and meaning in L2 pronunciation instruction. TESL Canada Journal, 27(1), 1-12.

Jenkins, J. (2000). The phonology of English as an international language. Oxford: Oxford University Press.

Jenkins, J. (2002). A sociolinguistically based, empirically researched pronunciation syllabus for English as an international language. Applied Linguistics, 23(1), 83-103.

Jenkins, J. (2004). Research in Teaching Pronunciation and Intonation Annual Review of Applied Linguistics, 24, 109-125.

Johnson, K. E. (2006). The sociocultural turn and its challenges for second language teacher education. Tesol Quarterly, 40(1), 235-257.

Jones, R. (1997). Beyond "listen and repeat": Pronunciation teaching materials and theories of second language acquisition. System, 25(1), 103-112.

Jones, T. (2018). Pronunciation with other areas of language. In O. Kang, R. I. Thomson, \& J. Murphy (Eds.), The Routledge Handbook of Contemporary English Pronunciation (pp. 370-384). London and New York: Routledge. 
Kang, O. (2010). ESL learners' attitudes toward pronunciation instruction and varieties of English. Paper presented at the Proceedings of the 1st Pronunciation in Second Language Learning and Teaching Conference., Ames, IA: Iowa State University.

Kang, O., Rubin, D., \& Pickering, L. (2010). Suprasegmental measures of accentedness and judgments of language learner proficiency in oral English. The Modern Language Journal, 94(4), 554-566.

Karahan, F. (2007). Language attitudes of Turkish students towards the English language and its use in Turkish context. Journal of arts and sciences, 1(7), 73-87.

Kennedy, S., Blanchet, J., \& Trofimovich, P. (2014). Learner pronunciation, awareness, and instruction in French as a second language. Foreign Language Annals, 47(1), 79-96.

Khamkhien, A. (2010). Teaching English speaking and English speaking tests in the Thai context: A reflection from Thai perspective. English language teaching, 3(1), 184.

Kim, Y. (2011). The pilot study in qualitative inquiry identifying issues and learning lessons for culturally competent research. Qualitative Social Work, 10(2), 190-206.

King, N., \& Horrocks, C. (2010). Interviews in qualitative research. Los Angeles: Sage. Kissling, E. M. (2018). Pronunciation Instruction Can Improve L2 Learners' Bottom-Up Processing for Listening. The Modern Language Journal, 102(4), 653-675.

Kormos, J., \& Csizér, K. (2008). Age-related differences in the motivation of learning English as a foreign language: Attitudes, selves, and motivated learning behavior. Language learning, 58(2), 327-355.

Kormos, J., Kiddle, T., \& Csizér, K. (2011). Goals, attitudes, and self-related beliefs in second-language-learning motivation: An interactive model of language learning motivation. Applied Linguistics, 32(5), 495-516.

Krashen, S. (1982). Principles and practice in second language acquisition: Oxford Pergamon.

Krashen, S. D. (1985). The input hypothesis: Issues and implications. London: Longman. Kubanyiova, M., \& Feryok, A. (2015). Language teacher cognition in applied linguistics research: Revisiting the territory, redrawing the boundaries, reclaiming the relevance. The Modern Language Journal, 99(3), 435-449.

Lane, L. (2013). Focus on Pronunciation 2 (3rd ed.). New York: Pearson Education.

Lane, L., \& Brown, H. D. (2010). Tips for teaching pronunciation: A practical approach. New York: Pearson Longman.

Lantolf, J. P. (2001). Introducing sociocultural theory. In J. P. Lantolf (Ed.), Sociocultural theory and second language learning (pp. 1-26). Oxford: Oxford University Press. 
Lantolf, J. P. (2011). Integrating sociocultural theory and cognitive linguistics in the second language classroom. In E. Hinkel (Ed.), Handbook of research in second language teaching and learning (Vol. 2, pp. 303-318). Hoboken, NJ: Routledge.

Lantolf, J. P., \& Thorne, S. L. (2006). Introduction. In J. P. Lantolf \& S. L. Thorne (Eds.), Sociocultural Theory and the Genesis of Second Language Development. Oxford: Oxford University Press.

Lantolf, J. P., Thorne, S. L., \& Poehner, M. E. (2015). Sociocultural theory and second language development. In B. van Patten \& J. Williams (Eds.), Theories in second language acquisition: An introduction (pp. 207-226). New York: Routledge.

Lasito, \& Storch, N. (2013). Comparing pair and small group interactions on oral tasks. RELC Journal, 44(3), 361-375.

Lauer, P. A. (2006). An Education Research Primer: How to Understand, Evaluate and Use It. San Francisco: Jossey-Bass.

Le, H. T. (2013). ELT in Vietnam general and tertiary education from second language education perspectives. VNU Journal of Foreign Studies, 29(1), 65-71.

Le, V. C. (2001). Language and Vietnamese Pedagogical Contexts. Paper presented at the Language and Development: Partnership and Interaction, Vietnam.

Lee, I. (2011). Feedback revolution: what gets in the way? ELT Journal, 65(1), 1-12.

Lee, I., Mak, P., \& Burns, A. (2016). EFL teachers' attempts at feedback innovation in the writing classroom. Language teaching research, 20(2), 248-269.

Lee, J., Jang, J., \& Plonsky, L. (2015). The effectiveness of second language pronunciation instruction: A meta-analysis. Applied Linguistics, 36(3), 345-366.

Levis, J. M. (2005). Changing contexts and shifting paradigms in pronunciation teaching. Tesol Quarterly, 39(3), 369-377.

Levis, J. M. (2018). Intelligibility, oral communication, and the teaching of pronunciation. New York, NY: Cambridge University Press.

Levis, J. M., \& Grant, L. (2003). Integrating pronunciation into ESL/EFL classrooms. Tesol Journal, 12(2), 13-19.

Levis, J. M., \& LeVelle, K. (2010). Rebuilding a professional space for pronunciation. Paper presented at the Proceedings of the 1st Pronunciation in Second Language Learning and Teaching Conference, Ames, IA.

Levis, J. M., \& Sonsaat, S. (2018). Pronunciation teaching in the early CLT era. In O. Kang, R. I. Thomson, \& J. M. Murphy (Eds.), The Routledge Handbook of Contemporary English Pronunciation (pp. 267-283). London and New York: Routledge. 
Lewis, M. (1993). The lexical approach (Vol. 1). Hove: Language teaching publications

Li, L. (2013). The complexity of language teachers' beliefs and practice: One EFL teacher's theories. The Language Learning Journal, 41(2), 175-191.

Li, S. (2010). The effectiveness of corrective feedback in SLA: A meta-analysis. Language learning, 60(2), 309-365.

Lin, H.-P. (1995). Teaching Pronunciation in the Learner-Centered Classroom. Paper presented at the Proceedings of the TEFL Conference (May 20, 1995), Taichung, Taiwan.

Little, D. (2007). Language learner autonomy: Some fundamental considerations revisited. International Journal of Innovation in Language Learning and Teaching, 1(1), 14-29.

Littlewood, W. (2013). Developing a context-sensitive pedagogy for communication-oriented language teaching. ENGLISH TEACHING, 68(3), 3-25.

Long, M. (1996). The role of the linguistic environment in second language acquisition. In W. C. Ritchie \& T. K. Bhatia (Eds.), Handbook of second language acquisition (pp. 413-468). New York: Academic.

Long, M. (2015). Second language acquisition and task-based language teaching. West Sussex: John Wiley \& Sons.

Lord, G. (2005). (How) can we teach foreign language pronunciation? On the effects of a Spanish phonetics course. Hispania, 88, 557-567.

Lord, G. (2008). Podcasting communities and second language pronunciation. Foreign Language Annals, 41(2), 364-379.

Luu, T. T. (2011). Matching and Stretching Learners' Learning Styles. Journal of Language Teaching \& Research, 2(2), 285-294.

Lyster, R. (2007). Learning and teaching languages through content: A counterbalanced approach (Vol. 18). Amsterdam: John Benjamins Publishing.

Lyster, R., Saito, K., \& Sato, M. (2013). Oral corrective feedback in second language classrooms. Language Teaching, 46(1), 1-40.

Macalister, J. (2012). Pre-service teacher cognition and vocabulary teaching. RELC Journal, 43(1), 99-111.

Macalister, J. (2016). Applying Language Learning Principles to Coursebooks. In W. A. Renandya \& H. P. Widodo (Eds.), English Language Teaching Today (pp. 41-51): Springer.

Macdonald, S. (2002). Pronunciation-views and practices of reluctant teachers. Prospect, 17(3), 3-18. 
Mackey, A., \& Gass, S. M. (2016). Second language research: Methodology and design (2nd ed.). New York: Routledge.

Madden, E. H. (1983). The Effect of Training on Pronunciation. ORTESOL journal, 4, 69-80. Marshall, C., \& Rossman, G. B. (2011). Designing qualitative research (5th ed.). Thousand Oaks: Sage.

McCutchen, D., Abbott, R. D., Green, L. B., Beretvas, S. N., Cox, S., Potter, N. S., . . Gray, A. L. (2002). Beginning literacy: Links among teacher knowledge, teacher practice, and student learning. Journal of learning disabilities, 35(1), 69-86.

McDonough, K., \& Sunitham, W. (2009). Collaborative dialogue between Thai EFL learners during self-access computer activities. Tesol Quarterly, 43(2), 231-254.

McGregor, A., \& Reed, M. (2018). Integrating Pronunciation into the English Language Curriculum: A Framework for Teachers. CATESOL Journal, 30(1), 69-94.

Mokhele, M. L., \& Jita, L. C. (2010). South African teachers' perspectives on continuing professional development: a case study of the Mpumalanga Secondary Science Initiative. Procedia-Social and Behavioral Sciences, 9, 1762-1766.

Morley, J. (1991). The pronunciation component in teaching English to speakers of other languages. Tesol Quarterly, 481-520.

Moyer, A. (2004). Age, accent, and experience in second language acquisition: an integrated approach to critical period inquiry (Vol. 7). New York: Multilingual Matters.

Moyer, A. (2013). Foreign accent: The phenomenon of non-native speech. New York: Cambridge University Press.

Muijs, D., Kyriakides, L., van der Werf, G., Creemers, B., Timperley, H., \& Earl, L. (2014). State of the art-teacher effectiveness and professional learning. School Effectiveness and School Improvement, 25(2), 231-256.

Munro, M. J. (2003). A Primer on Accent Discrimination in the Canadian Context. TESL Canada Journal, 20(2), 38-51.

Munro, M. J. (2010). Intelligibility: Buzzword or buzzworthy? Paper presented at the The 2nd Pronunciation in Second Language Learning and Teaching Conference, Ames, IA: Iowa State University.

Munro, M. J., \& Derwing, T. M. (1995a). Foreign accent, comprehensibility, and intelligibility in the speech of second language learners. Language learning, 45(1), 73-97. 
Munro, M. J., \& Derwing, T. M. (1995b). Processing time, accent, and comprehensibility in the perception of native and foreign-accented speech. Language and speech, 38(3), 289-306.

Munro, M. J., \& Derwing, T. M. (1999). Foreign accent, comprehensibility, and intelligibility in the speech of second language learners. Language learning, 49(1), 285-310.

Munro, M. J., \& Derwing, T. M. (2011). The foundations of accent and intelligibility in pronunciation research. Language Teaching, 44(3), 316-327.

Munro, M. J., Derwing, T. M., \& Morton, S. L. (2006). The mutual intelligibility of L2 speech. Studies in Second Language Acquisition, 28(01), 111-131.

Munro, M. J., Flege, J. E., \& MacKay, I. R. (1996). The effects of age of second language learning on the production of English vowels. Applied Psycholinguistics, 17(03), 313334.

Murphy, D. (2011). An investigation of English pronunciation teaching in Ireland. English Today, 27(4), 10-18.

Murphy, J. (1991). Oral communication in TESOL: Integrating speaking, listening, and pronunciation. Tesol Quarterly, 25(1), 51-75.

Murphy, J. (2014). Teacher training programs provide adequate preparation in how to teach pronunciation. In L. Grant (Ed.), Pronunciation Myths: Applying Second Language Research to Classroom Teaching (pp. 188-224). United States of America: University of Michigan Press.

Murphy, J., \& Baker, A. (2015). History of ESL pronunciation teaching. In M. Reed \& J. M. Levis (Eds.), The handbook of English pronunciation (pp. 36-65). United Kingdom: Wiley-Blackwell.

Murray, T. C., \& Zoul, J. (2015). Leading professional learning: Tools to connect and empower teachers. Thousand Oaks, CA: Corwin.

Murtaza, K. F. (2010). Teachers' Professional Development Through Whole School Improvement Program (Wsip). International Journal of Business and Social Science, 1(2).

Myers, M. D. (1997). Qualitative research in information systems. Management Information Systems Quarterly, 21(2), 241-242.

Nation, I. S. P., \& Macalister, J. (2010). Language curriculum design: Routledge.

Nation, I. S. P., \& Newton, J. (2009). Teaching ESL/EFL listening and speaking. New York and London: Routledge. 
Newton, J. (2013). Incidental vocabulary learning in classroom communication tasks. Language teaching research, 17(2), 164-187.

Newton, J. (2018). Pronunciation and Speaking. In O. Kang, R. I. Thomson, \& J. Murphy (Eds.), The Routledge Handbook of Contemporary English Pronunciation (pp. 337351). London and New York: Routledeg.

Nguyen, H. T., Fehring, H., \& Warren, W. (2015). EFL Teaching and Learning at a Vietnamese University: What Do Teachers Say? English language teaching, 8(1), 3143.

Nguyen, H. T. M. (2008). Mentoring beginning EFL teachers at tertiary level in Vietnam. The Asian EFL Journal Quarterly March 2008, 10(1), 111-132.

Nguyen, H. T. M. (2011). Primary English language education policy in Vietnam: Insights from implementation. Current Issues in Language Planning, 12(2), 225-249.

Nguyen, H. T. M., \& Baldauf Jr, R. B. (2010). Effective peer mentoring for EFL pre-service teachers' instructional practicum practice. The Asian EFL Journal Quarterly Special Issue on English Language Teacher Education and Development, 12(3), 40-61.

Nguyen, T. C. L. (2009). Learner autonomy and EFL learning at the tertiary level in Vietnam. (PhD), Victoria University of Wellington, New Zealand.

Nguyen, V. L. (2011). Dynamic conceptions of input, output and interaction: Vietnamese EFL lecturers learning second language acquisition theory. (PhD Unpublished), University of Waikato, New Zealand,

Nieuwenhuis, J. (2016). Qualitative research designs and data gathering techniques. In K. Maree (Ed.), First steps in research (2nd ed., pp. 70-92). Pretoria: Van Schaik Publishers.

Noor, K. B. M. (2008). Case study: A strategic research methodology. American journal of applied sciences, 5(11), 1602-1604.

Nunan, D., \& Bailey, K. M. (2009). Exploring second language classroom research: A comprehensive guide. MA: Heinle, Cengage Learning.

Oh, S. Y. (2001). Two types of input modification and EFL reading comprehension: Simplification versus elaboration. Tesol Quarterly, 35(1), 69-96.

Ohta, A. S. (1995). Applying sociocultural theory to an analysis of learner discourse: Learner-learner collaborative interaction in the zone of proximal development. Issues in applied linguistics, 6(2), 93-121.

Opfer, V. D., \& Pedder, D. (2011). Conceptualizing teacher professional learning. Review of educational research, 81(3), 376-407. 
Papastamatis, A., Panitsidou, E. A., Giavrimis, P., \& Papanis, E. (2009). Facilitating teachers' and educators' effective professional development. Review of European studies, 1(2), 83 .

Pardede, P. (2018). Improving EFL Students' English Pronunciation by Using the Explicit Teaching Approach. JET (Journal of English Teaching), 4(3), 143-155.

Patton, M. Q. (2002). Two decades of developments in qualitative inquiry: A personal, experiential perspective. Qualitative Social Work, 1(3), 261-283.

Peltola, M. S., Lintunen, P., \& Tamminen, H. (2014). Advanced English learners benefit from explicit pronunciation teaching: an experiment with vowel duration and quality. AFinLA-e: Soveltavan kielitieteen tutkimuksia, 2014(6), 86-98.

Pennington, M. C., \& Richards, J. C. (1986). Pronunciation revisited. Tesol Quarterly, 20(2), 207-225.

Phipps, S., \& Borg, S. (2007). Exploring the relationship between teachers' beliefs and their classroom practice. Teacher Trainer, 21(3), 17 - 19.

Phipps, S., \& Borg, S. (2009). Exploring tensions between teachers' grammar teaching beliefs and practices. System, 37(3), 380-390.

Polit, D. F., \& Beck, C. T. (2012). Nursing research: Generating and assessing evidence for nursing practice. Philadelphia, PA: Lippincott Williams \& Wilkins.

Prime Minister, V. (2008). Về việc phê duyệt Đề án "Dạy và học ngoại ngũ trong hệ thống giáo dục quốc dân giai đoạn 2008 - 2020". (1400/QD-TTg). The Government of Vietnam.

Rajadurai, J. (2001). An investigation of the effectiveness of teaching pronunciation to Malaysian TESL students. Paper presented at the Forum.

Ramírez Verdugo, D. (2006). A study of intonation awareness and learning in non-native speakers of English. Language Awareness, 15(3), 141-159.

Richards, J. C. (2008). Second language teacher education today. RELC Journal, 39(2), 158177.

Richards, L. (2015). Handling qualitative data: A practical guide (3rd ed.). London: Sage.

Richards, L., \& Morse, J. M. (2007). Read me first for a user's guide to qualitative methods (2nd ed.). Thousand Oaks: Sage.

Rogerson-Revell, P. (2011). English phonology and pronunciation teaching. London and New York: Continuum International Publishing Group.

Rolfe, G. (2006). Validity, trustworthiness and rigour: quality and the idea of qualitative research. Journal of advanced nursing, 53(3), 304-310. 
Rude, M. (2012). Native-like Duration Ratio of Stressed vs. Unstressed Syllables through Visualizing Prosody. Paper presented at the Proceedings of Speech Prosody 2012 6th International Conference, Shanghai.

Saito, K. (2007). The influence of explicit phonetic instruction on pronunciation in EFL settings: The case of English vowels and Japanese learners of English. Linguistics Journal, 2(3), 16-40.

Saito, K. (2011). Examining the role of explicit phonetic instruction in native-like and comprehensible pronunciation development: An instructed SLA approach to L2 phonology. Language Awareness, 20(1), 45-59.

Saito, K. (2012a). Effects of instruction on L2 pronunciation development: A synthesis of 15 quasi-experimental intervention studies. Tesol Quarterly, 46(4), 842-854.

Saito, K. (2012b). Reexamining effects of form-focused instruction on L2 pronunciation development: The role of explicit phonetic information. Studies in Second Language Acquisition, 35(1), 1-29. doi:10.1017/S0272263112000666

Saito, K. (2015). Communicative focus on second language phonetic form: Teaching Japanese learners to perceive and produce English/I/without explicit instruction. Applied Psycholinguistics, 36(2), 377-409.

Saito, K., \& Lyster, R. (2012). Effects of form-focused instruction and corrective feedback on L2 pronunciation development of/.t/by Japanese learners of English. Language learning, 62(2), 595-633.

Saito, K., Trofimovich, P., \& Isaacs, T. (2016). Second language speech production: Investigating linguistic correlates of comprehensibility and accentedness for learners at different ability levels. Applied Psycholinguistics, 37(2), 217-240.

Saito, K., \& van Poeteren, K. (2012). Pronunciation-specific adjustment strategies for intelligibility in L2 teacher talk: Results and implications of a questionnaire study. Language Awareness, 21(4), 369-385.

Saito, K., \& Wu, X. (2014). Communicative focus on form and second language suprasegmental learning: Teaching Cantonese learners to perceive Mandarin tones. Studies in Second Language Acquisition, 36(4), 647-680.

Samson, J. F., \& Collins, B. A. (2012). Preparing All Teachers to Meet the Needs of English Language Learners: Applying Research to Policy and Practice for Teacher Effectiveness. Retrieved from Washington DC: Center for American Progress:

Sardegna, V. G. (2012). Learner differences in strategy use, self-efficacy beliefs, and pronunciation improvement. Paper presented at the Social factors in pronunciation 
acquisition. Proceedings of the 3rd Pronunciation in Second Language Learning and Teaching Conference, Ames, IA.

Schmid, M. (2011). First Language Attrition. Cambridge: Cambridge University Press.

Schmidt, R. (2001). Attention. In P. Robinson (Ed.), Cognition and second language instruction. Cambridge: Cambridge University Press.

Schostak, J. (2006). Interviewing and representation in qualitative research. Berkshire: Open University Press.

Schunk, D. H., \& Zimmerman, B. J. (2008). Motivation and self-regulated learning: Theory, research, and applications. New York and London: Routledge.

Scovel, T. (2000). A critical review of the critical period research. Annual Review of Applied Linguistics, 20, 213-223.

Segalowitz, N. (2010). Cognitive bases of second language fluency. London: Routledge.

Seidman, I. (2013). Interviewing as qualitative research: A guide for researchers in education and the social sciences (4th ed.). New York: Teachers college press.

Setter, J., \& Jenkins, J. (2005). State-of-the-art review article. Language Teaching, 38(1), 117.

Seyedabadi, S., Fatemi, A. H., \& Pishghadam, R. (2015). Towards better teaching of pronunciation: review of literature in the Area. Mediterranean Journal of Social Sciences, 6(4), 76 - 81.

Shangase, B. B. (2013). Strategies for the implementation of further education and training learner attainment improvement plan. (Unpublished MA thesis), University of the Free State, Bloemfontein.

Sheen, Y. (2010). Introduction: The role of oral and written corrective feedback in SLA. Studies in Second Language Acquisition, 32, 169-179.

Simon, E., \& Taverniers, M. (2011). Advanced EFL learners' beliefs about language learning and teaching: a comparison between grammar, pronunciation, and vocabulary. English Studies, 92(8), 896-922.

Smith, B., \& Swan, M. (2001). Learner English: A teacher's guide to interference and other problems: Ernst Klett Sprachen.

Sobkowiak, W. (2012). This is tom=/ZYZYS'tom/pronunciation in beginners' EFL textbooks then and now. Research in Language, 10(1), 111-122.

Spada, N., \& Lightbown, P. M. (2008). Form-Focused Instruction: Isolated or Integrated? Tesol Quarterly, 42(2), 181-207. 
Stake, R. E. (2005). Qualitative case studies. In The Sage handbook of qualitative research (3rd ed.): Thousand Oaks: SAGE.

Stake, R. E. (2006). Multiple case study analysis. New York: Guilford Press.

Steyn, T. (2011). Implementing continuing professional teacher development: policy and practice. Acta Academica, 43(1), 211-233.

Storch, N., \& Aldosari, A. (2013). Pairing learners in pair work activity. Language teaching research, 17(1), 31-48.

Suter, R. W. (1976). Predictors of Pronunciation Accuracy in Second Language Learning1. Language learning, 26(2), 233-253.

Swain, M. (1985). Communicative competence: Some roles of comprehensible input and comprehensible output in its development. In S. M. Gass \& C. G. Madden (Eds.), Input in second language acquisition (pp. 235-253). Rowley, MA: Newbury House.

Swain, M. (2000). The output hypothesis and beyond: Mediating acquisition through collaborative dialogue. In J. P. Lantolf (Ed.), Sociocultural theory and second language learning (Vol. 97, pp. 97-114). Oxford: Oxford University Press.

Swain, M. (2006). Languaging, agency and collaboration in advanced second language proficiency. In H. Byrnes (Ed.), Advanced language learning: The contribution of Halliday and Vygostky (pp. 95-108). London Continuum.

Tanner, M. W., \& Landon, M. M. (2009). The effects of computer-assisted pronunciation readings on ESL learners' use of pausing, stress, intonation, and overall comprehensibility. Language Learning \& Technology, 13(3), 51-65.

Tate, M. L. (2009). Workshops: Extend learning beyond your presentation with these brainfriendly strategies. Journal of Staff Development, 30(1), 44-46.

Tergujeff, E. (2010). Pronunciation teaching materials in Finnish EFL textbooks. Paper presented at the English pronunciation: issues and practices (EPIP): Proceedings of the first international conference 2009, Université de Savoie, Chambéry, France.

Tergujeff, E. (2012). English pronunciation teaching: Four case studies from Finland. Journal of Language Teaching and Research, 3(4), 599-607.

Tergujeff, E. (2013). English pronunciation teaching in Finland. (PhD), University of Jyväskylä,

Thomson, R. I., \& Derwing, T. M. (2014). The effectiveness of L2 pronunciation instruction: A narrative review. Applied Linguistics, 36(3), 326-344. 
Timperley, H. (2011). A background paper to inform the development of a national professional development framework for teachers and school leaders. Australian Institute for Teaching and School Leadership (AITSL), 2011(April), 1-26.

Timperley, H., Wilson, A., Barrar, H., \& Fung, I. (2008). Teacher professional learning and development: Best Evidence Synthesis Iteration [BES]. Retrieved from Wellington, New Zealand:

Tobin, G. A., \& Begley, C. M. (2004). Methodological rigour within a qualitative framework. Journal of advanced nursing, 48(4), 388-396.

Todd, R. W. (2001). Induction from self-selected concordances and self-correction. System, 29(1), 91-102.

Tomlinson, B. (2001). Materials development. In D. Nunan \& R. Carter (Eds.), The Cambridge guide to teaching English to speakers of other languages (pp. 66-71). Cambridge: Cambridge University Press.

Tomlinson, B., \& Bao, D. (2004). The contributions of Vietnamese learners of English to ELT methodology. Language teaching research, 8(2), 199-222.

Tomlinson, C., \& Imbeau, M. (2010). Leading and managing a differentiated classroom. United States of America: ASCD.

Trofimovich, P. (2016). Interactive alignment: A teaching-friendly view of second language pronunciation learning. Language Teaching, 49(3), 411-422.

Trofimovich, P., \& Gatbonton, E. (2006). Repetition and focus on form in processing L2 Spanish words: Implications for pronunciation instruction. The Modern Language Journal, 90(4), 519-535.

Tsotetsi, C. T., \& Mahlomaholo, S. M. (2013). Teacher professional development programmes: what is missing? Journal of Educational Studies, 12(1), 89-102.

Tsotetsi, C. T., \& Mahlomaholo, S. M. (2015). Exploring Strategies to Strengthen Continuing Professional Development of Teachers in Rural South Africa. Journal of Higher Education in Africa/Revue de l'enseignement supèrieur en Afrique, 13(1-2), 45-73.

Underhill, A. (2012). Make pronunciation physical, visible, audible. Paper presented at the Macmilan Online Conference, Macmilan, http://www.macmillanenglish.com/onlineconference/2012.

Van Driel, J. H., \& Berry, A. (2012). Teacher professional development focusing on pedagogical content knowledge. Educational researcher, 41(1), 26-28. 
Varasarin, P. (2007). An action research study of pronunciation training, language learning strategies and speaking confidence. (PhD Unpublished), Victoria University, Thailand.

Varnosfadrani, A. D., \& Basturkmen, H. (2009). The effectiveness of implicit and explicit error correction on learners' performance. System, 37(1), 82-98.

Vazir, N., \& Meher, R. (2010). Mentoring in teacher education: Building nurturing contexts and teaching communities for rural primary school teachers in Sindh, Pakistan. Journal of educational research, 13(1), 123.

Vettorel, P., \& Lopriore, L. (2013). Is there ELF in ELT coursebooks? Studies in Second Language Learning and Teaching, 3(4), 483-504.

Vietnam National University, U. (2016, November 17th 2017). Chương trình bồi dưỡng giáo viên. Retrieved from http://daotaoboiduong.ulis.vnu.edu.vn/category/boi-duong-giaovien/chuong-trinh-boi-duong-boi-duong-giao-vien/

Villegas-Reimers, E. (2003). Teacher professional development: an international review of the literature (9280312286). Retrieved from Paris:

Vitanova, G., \& Miller, A. (2002). Reflective practice in pronunciation learning. The Internet TESL Journal, 8(1).

Vo, L. T., \& Nguyen, H. T. M. (2009). Critical friends group for EFL teacher professional development. ELT Journal, 64(2), 205-213.

Wahid, R., \& Sulong, S. (2013). The Gap between Research and Practice in the Teaching of English Pronunciation: Insights from Teachers' Beliefs and Practices. World Applied Sciences Journal, 21(Special Issue of Studies in Language Teaching and Learning), 133-142.

Wang, D. (2011). The dilemma of time: Student-centered teaching in the rural classroom in China. Teaching and teacher education, 27(1), 157-164.

Wayne, A. J., Yoon, K. S., Zhu, P., Cronen, S., \& Garet, M. S. (2008). Experimenting with teacher professional development: Motives and methods. Educational researcher, 37(8), 469-479.

Wei, M. (2006). A Literature Review on Strategies for Teaching Pronunciation. Online Submission.

Wei, Y., \& Zhou, Y. (2002). Insights into English Pronunciation Problems of Thai Students. Paper presented at the Proceedings of the Annual Meeting of the Quadruple Helix (8th, April 6, 2002). 
Williams, E. N., \& Morrow, S. L. (2009). Achieving trustworthiness in qualitative research: A pan-paradigmatic perspective. Psychotherapy research, 19(4-5), 576-582. doi:10.1080/10503300802702113

Willis, J. (1996). A framework for task-based learning (Vol. 60). Harlow: Longman Winegardner, K. E. (2007). The case study method of scholarly research. The Graduate School of America, 1-23.

Wong, L. P. (2008). Focus group discussion: a tool for health and medical research. Singapore Med J, 49(3), 256-261.

Yang, Y.-F. (2010). Students' reflection on online self-correction and peer review to improve writing. Computers \& Education, 55(3), 1202-1210.

Yates, L. (2001). Teaching pronunciation in the AMEP: Current practice and professional development. AMEP Research Centre.

Yin, R. K. (2014). Case study research: Design and methods (5th ed.). London and Singapore: Sage publications.

Zielinski, B. (2012). The social impact of pronunciation difficulties: Confidence and willingness to speak. Paper presented at the Proceedings of the 3rd pronunciation in second language learning and teaching conference, Ames, IA

Zielinski, B., \& Yates, L. (2014). Myth 2: Pronunciation instruction is not appropriate for beginning-level learners. In L. Grant (Ed.), Pronunciation Myths: Applying Second Language Research to Classroom Teaching (pp. 56-79). Ann Arbor: University of Michigan Press. 


\section{APPENDICES}

Appendix 1

Appendix 1.1

\section{PHASE 1 TEACHER INTERVIEWS}

PHASE 1 GUIDING QUESTIONS FOR TEACHER INTERVIEWS

(English version)

\section{In-depth Interview}

1. How often do you teach pronunciation explicitly in your class? Always, often, sometimes, seldom, or never?

- Within a 90-minute period, how much time do you usually spend teaching pronunciation explicitly?

- What teaching steps do you usually follow when teaching pronunciation explicitly? Please, elaborate on each step.

- What materials do you usually use for pronunciation activities?

2. On a rating scale of $1-5$ (where $1=$ completely unconfident, $2=$ not very confident, $3=$ confident, $4=$ very confident, and 5= completely confident), where do you think your confidence level is and why?

3. Between sounds (including vowels and consonants) and suprasegmental features such as sentence stress or intonation, which features do you feel more confident teaching and why?

4. Let's talk about your initial training and professional learning experience in pronunciation pedagogy.

- What types of training or professional learning in pronunciation teaching have you received?

- How many times/sessions have you attended? Who organised?

- How long was each session?

- When did you get it? During undergraduate education, post graduate, or on the job?

- In your opinion, how useful was it to your teaching job?

5. Have you ever heard about the communicative framework for teaching English pronunciation?

- What do you know about it?

- Would you like to study this framework? Why or why not?

6. Would you like to participate in a professional learning course about teaching pronunciation communicatively? If yes, what are your expectations of this professional learning course? Please elaborate on each of your expectations. 
7. Let's talk about EFL teacher training in Vietnam.

- What do you think needs to be changed or improved so that teachers can teach pronunciation more effectively after graduation?

- Please elaborate on your suggestions and the reason for each suggestion?

8. On a rating scale of $1-5$ (where $1=$ completely unimportant, $2=$ not very important, $3=$ important, $4=$ very important, and 5= most important of all language skills), how important do you think pronunciation is in English learning and why?

9. What do you think about including communicative practice activities in your teaching pronunciation and why?

10. From your teaching experience, what pronunciation problems commonly face Vietnamese learners of English? Please give examples.

\section{Stimulated Recall Interview}

Let's watch two/three excerpts of your recorded lesson on the day of ......

Now, please answer my questions:

1. What's your goal in pronunciation teaching? Do you want your students to attain a native-like accent or intelligible pronunciation for communicative purposes? Why?

2. Did you ever use any other technique to teach pronunciation in class apart from the ones in the excerpts you have just seen? Please elaborate on each technique you have used.

3. Is the way you teach pronunciation in these excerpts the approach you most frequently take in class?

4. Do you think your teaching pronunciation this way is effective? What factors influence your pronunciation teaching practice? 


\section{BẢNG CÂU HỎI PHỎNG VẤN GIÁO VIÊN GIAI ĐOẠN 1}

\section{Phỏng vấn chuyên sâu}

1. Thầy/Cô có thường xuyên dạy phát âm một cách bài bản trong lớp không? Luôn luôn, thường xuyên, thỉnh thoảng, hiếm khi, hay không bao giờ?

- Trong một buổi học 90 phút, Thầy/Cô thường dành bao nhiêu thời gian để dạy phát âm một cách bài bản?

- Khi dạy phát âm một cách bài bản, Thầy/Cô thực hiện các bước dạy như thế nào? Xin hãy trình bày rõ từng bước.

- Thầy/Cô thường lấy các hoạt động phát âm từ những nguồn tài liệu nào?

2. Trên thang đo từ 1 đến 5,1 là hoàn toàn không tự tin, 2 là không tự tin lắm, 3 tự tin, 4 rất tự tin, và 5 là hoàn toàn tự tin, Thầy/Cô tự đánh giá độ tự tin khi dạy phát âm của bản thân mình ở mức nào? Vì sao?

3. Giữa âm (bao gồm nguyên âm lẫn phụ âm) và các yếu tố siêu đoạn tính như nhấn câu hoặc ngữ điệu thì Thầy/Cô cảm thấy tự tin để dạy yếu tố nào hơn? Vì sao?

4. Hãy nói về trải nghiệm của quý Thầy/Cô trong quá trình đào tạo cũng như việc bồi dưỡng giáo viên về vấn đề giảng dạy môn phát âm.

- Thầy/Cô đã từng tham gia khóa đào tạo hay bồi dưỡng chuyên môn nào về vấn đề dạy phát âm chưa?

- Thầy/Cô đã tham gia bao nhiêu lần/bao nhiêu khóa? Ai đứng ra tổ chức?

- Mỗi khóa như vậy kéo dài trong bao lâu?

- Thầy/Cô tham dự các khóa như vậy khi nào? Trong quá trình học đại học, sau đại học, hay trong quá trình công tác?

- Theo Thầy/Cô thì các khóa đào tạo hay bồi dưỡng như vậy giúp ích cho việc giảng dạy của Thầy/Cô như thế nào?

5. Thầy/Cô đã từng nghe qua về cái communicative framework dành cho việc dạy phát âm tiếng Anh chưa?

- Xin hãy cho biết Thầy/Cô biết gì về nó?

- Quý Thầy/Cô có muốn tìm hiểu về cái framework này không? Vì sao? 
6. Thầy/Cô có muốn tham gia một khóa bồi dưỡng giáo viên về dạy phát âm theo định hướng giao tiếp không? Nếu có thì mong đợi của Thầy/Cô đối với khóa bồi dưỡng này là gì? Xin hãy trình bày rõ từng nguyện vọng.

7. Hãy nói về chương trình đào tạo giáo viên tiếng Anh tại Việt Nam.

- Để giúp giáo viên dạy phát âm hiệu quả hơn sau khi tốt nghiệp ra trường thì theo Thầy/Cô chương trình đào tạo cần thay đổi hay cải tiến những gì?

- Xin hãy trình bày rõ từng đề xuất và cho biết lí do vì sao Thầy/Cô lại đề xuất như vậy.

8. Trên thang đo từ 1 đến 5,1 là hoàn toàn không quan trọng, 2 là không quan trọng lắm, 3 quan trọng, 4 rất quan trọng, và 5 là quan trọng nhất trong tất cả các kĩ năng ngôn ngữ, Thầy/Cô đánh giá tầm quan trọng của phát âm trong việc học tiếng Anh ở mức độ nào? Vì sao?

9. Thầy/Cô nghĩ thế nào nếu mình đưa các hoạt động giao tiếp vào việc dạy phát âm cho sinh viên? Vì sao Thầy/Cô lại nghĩ như vậy?

10. Từ kinh nghiệm giảng dạy của bản thân, Thầy/Cô thấy học viên người Việt thường mắc những lỗi phát âm nào? Xin hãy cho ví dụ minh họa.

\section{Phỏng vấn gọii nhớ}

Hãy xem lại hai/ba đoạn trích trong bài giảng của quý Thầy/Cô được ghi hình ngày ...... Bây giờ xin Thầy/Cô vui lòng trả lời những câu hỏi sau đây:

1. Mục tiêu của Thầy/Cô khi dạy phát âm cho sinh viên là gì? Thầy/Cô hướng sinh viên đến khả năng phát âm như người bản xứ hay phát âm đúng và rõ để đạt được mục đích giao tiếp? Vì sao?

2. Ngoài cách dạy như trong các đoạn trích thì Thầy/Cô có còn dùng những cách dạy phát âm nào khác không? Xin hãy trình bày rõ từng cách mà Thầy/Cô đã sử dụng.

3. Cách Thầy/Cô dạy phát âm trong các đoạn trích vừa rồi có phải là phương pháp Thầy/Cô thường sử dụng nhất để dạy phát âm trong lớp không?

4. Cách Thầy/Cô dạy phát âm như thế này có hiệu quả không? Yếu tố nào ảnh hưởng đến việc dạy phát âm của quý Thầy/Cô? Xin trình bày rõ từng yếu tố. 


\section{Appendix $2 \quad$ PHASE 1 STUDENT INTERVIEWS \\ Appendix 2.1 PHASE 1 GUIDING QUESTIONS FOR STUDENT INTERVIEWS \\ (English version)}

1. Let's reflect on your most recent experience with pronunciation teaching in class.

- What did your teacher teach and how did he/she teach it?

- Did your teacher usually teach pronunciation in class and when did they teach it?

2. Let's watch these two/three excerpts of the recorded lesson on the day of ...... (The researcher gave detailed explanations about recasts and prompts to students prior to asking questions)

- How effective do you think this approach to pronunciation teaching is to your learning?

- Why do you think so?

3. On a rating scale of $1-5$ (where $1=$ completely unimportant, $2=$ not very important, $3=$ important, $4=$ very important, and 5= most important of all language skills), how important do you think pronunciation is in English learning? Can you elaborate your choice?

4. Would you like to be taught pronunciation like other language skills? Why?

- How would you like to be taught pronunciation in class and why?

5. From your English learning experience, what pronunciation problems do you usually have? Please elaborate on each of the problems you have. 
(Vietnamese version)

\section{BẢNG CÂU HỎI PHỎNG VẤN SINH VIÊN GIAI ĐOẠN 1}

1. Hãy suy ngẫm về trải nghiệm gần đây nhất của các em khi giáo viên dạy phát âm trên lớp.

- Thầy cô của các em đã dạy những gì và dạy như thế nào?

- Thầy cô của các em có hay dạy phát âm trên lớp không và thường thì khi nào thầy cô các em dạy phát âm?

2. Hãy xem lại hai/ba đoạn trích từ bài học được ghi hình ngày ...... (Nghiên cứu sinh giải thích chi tiết về recasts và prompts cho sinh viên trước khi hỏi)

- Theo nhận định của các em, phương pháp dạy phát âm như thế này có hiệu quả như thế nào đối với việc học của các em?

- Vì sao các em nghĩ như vậy?

3. Trên thang đo từ 1 đến 5,1 là hoàn toàn không quan trọng, 2 là không quan trọng lắm, 3 quan trọng, 4 rất quan trọng, và 5 là quan trọng nhất trong tất cả các kĩ năng ngôn ngữ, các em đánh giá tầm quan trọng của phát âm trong việc học tiếng Anh ở mức độ nào? Vì sao?

4. Các em có muốn được học phát âm giống như các kĩ năng ngôn ngữ khác không? Vì sao?

- Các em mong muốn thầy cô dạy phát âm theo phương pháp như thế nào và vì sao?

5. Từ trải nghiệm của bản thân trong quá trình học tiếng Anh, các em nhận thấy mình thường mắc những lỗi phát âm nào? Các em hãy trình bày rõ từng lỗi mà mình hay mắc phải. 


\section{Appendix 3}

Appendix 3.1
PHASE 2 TEACHER INTERVIEWS

PHASE 2 GUIDING QUESTIONS FOR TEACHER INTERVIEWS

(English version)

1. Let's reflect on the workshop about communicative pronunciation teaching you attended in the summer term. On a rating scale of 1-5 (where $1=$ completely not useful, $2=$ not very useful, $3=$ useful, $4=$ very useful, and 5= extremely useful), to what extent did you find the workshop useful to your teaching job?

2. What benefits do you think you have gained from the workshop? Please elaborate on each benefit.

3. In your opinion, what benefits does teacher professional learning bring to teachers? Please elaborate on each benefit.

4. What types of teacher professional learning do you think would best enhance teachers' English teaching in general and pronunciation teaching in particular? Please elaborate on each type of learning you recommend.

5. Let's reflect on the pronunciation lessons you implemented during this semester.

- Are they useful to your students' pronunciation learning?

- Please elaborate on each of the benefits you think the communicative pronunciation teaching model brings to your students' learning.

6. Did you have any difficulties teaching pronunciation applying the communicative framework? What are they?

7. Let's talk about pronunciation instruction at the tertiary level in Vietnam. Do you think pronunciation needs to be included in non-majored English programmes at Vietnamese universities? Why do you think so?

8. If pronunciation is prescribed in English programmes for non-majored students at Vietnamese universities, how many periods per week do you think should be assigned to pronunciation instruction and why?

9. When pronunciation is included in English programmes, what pronunciation features do you think should be taught, all features or only features that particularly cause common problems to Vietnamese learners? Please elaborate on your choice?

10. Which approach do you think can best facilitate students' pronunciation learning? And why do you think so? 


\section{BẢNG CÂU HỎI PHỎNG VẤN GIÁO VIÊN GIAI ĐOẠN 2}

1. Hãy suy ngẫm lại buổi workshop về dạy phát âm theo định hướng giao tiếp mà Thầy/Cô đã tham dự ở học kì hè. Thầy/Cô đánh giá độ hữu ích của buổi workshop đối với công việc giảng dạy của mình ở mức nào dựa trên thang đo từ 1 đến 5,1 là hoàn toàn không hữu ích, 2 không hữu ích lắm, 3 hữu ích, 4 rất hữu ích, và 5 là cực kì hữu ích?

2. Từ buổi workshop đó thì Thầy/Cô nghĩ bản thân mình đã gặt hái được những lợi ích gì? Xin hãy trình bày rõ từng lợi ích.

3. Theo nhận định của quý Thầy/Cô, các khóa bồi dưỡng chuyên môn sẽ mang đến cho giáo viên những lợi ích như thế nào? Xin hãy trình bày rõ từng lợi ích.

4. Thầy/Cô thấy hoạt động bồi dưỡng chuyên môn nào hiệu quả nhất đối với việc nâng cao năng lực dạy tiếng Anh cho giáo viên nói chung và năng lực dạy phát âm nói riêng? Xin hãy trình bày rõ từng hoạt động.

5. Hãy suy ngẫm lại các buổi dạy phát âm mà Thầy/Cô đã thực hiện ở học kì này.

- Theo Thầy/Cô, các buổi học này có hữu ích đối với việc học phát âm của sinh viên không?

- Xin hãy trình bày rõ từng lợi ích việc dạy phát âm theo định hướng giao tiếp đã mang đến cho các em?

6. Thầy/Cô có gặp khó khăn gì trong việc triển khai dạy phát âm theo định hướng giao tiếp ở học kì này không? Những khó khăn đó là gì?

7. Theo ý kiến của Thầy/Cô, có nên đưa môn phát âm vào dạy chính thức trong chương trình tiếng Anh không chuyên tại các trường đại học ở Việt Nam không? Vì sao?

8. Nếu môn phát âm được đưa vào dạy chính thức trong chương trình tiếng Anh không chuyên tại các trường đại học ở Việt Nam thì theo Thầy/Cô nên dành bao nhiêu tiết mỗi tuần cho kĩ năng này? Vì sao?

9. Khi môn phát âm được đưa vào dạy chính thức thì theo Thầy/Cô mình nên dạy những yếu tố nào? Tất cả các yếu tố hay chỉ cần dạy những yếu tố mà học viên người Việt hay mắc lỗi? Xin hãy trình bày rõ lí do cho sự lựa chọn của Thầy/Cô. 
10. Theo nhận định của Thầy/Cô, phương pháp giảng dạy nào có thể mang lại hiệu quả cao nhất đối với việc học phát âm của sinh viên? Vì sao? 


\section{Appendix $4 \quad$ PHASE 2 STUDENT INTERVIEWS \\ Appendix 4.1 PHASE 2 GUIDING QUESTIONS FOR STUDENT INTERVIEWS \\ (English version)}

1. Did you like the way your teacher taught pronunciation during this semester? If yes, how much did you like it and why?

2. Let's reflect on your pronunciation learning experience this semester.

- What benefits do you think these pronunciation classes have brought to you?

- Please elaborate on each benefit.

3. On a rating scale of $1-5$ (where $1=$ completely unimportant, $2=$ not very important, $3=$ important, $4=$ very important, and 5= most important of all language skills), how important do you think pronunciation is in English programmes for non-majored students at Vietnamese universities? Can you elaborate your choice?

4. If pronunciation instruction is prescribed in English programmes for non-majored students at Vietnamese universities, how many periods per week do you think should be assigned to this skill and why?

5. How would you like to be taught pronunciation in class? Why do you expect that? 
(Vietnamese version)

\section{BẢNG CÂU HỎI PHỎNG VẦN SINH VIÊN GIAI ĐOẠN 2}

1. Các em có thích cách thầy cô của các em dạy phát âm ở học kì này không? Nếu có thì các em thích đến mức nào và vì sao?

2. Hãy suy ngẫm về trải nghiệm học phát âm của các em ở học kì này.

- Theo các em thì những buổi học phát âm mà thầy cô dạy ở học kì này mang lại những lợi ích gì đối với việc học tiếng Anh của các em?

- Xin các em hãy trình bày rõ những lợi ích đó.

3. Trên thang đo từ 1 đến 5,1 là hoàn toàn không quan trọng, 2 là không quan trọng lắm, 3 quan trọng, 4 rất quan trọng, và 5 là quan trọng nhất trong tất cả các kĩ năng ngôn ngũ̃, các em đánh giá tầm quan trọng của môn phát âm trong chương trình tiếng Anh không chuyên tại các trường đại học tại Việt Nam ở mức độ nào? Vì sao?

4. Nếu môn phát âm được đưa vào dạy chính thức trong chương trình tiếng Anh không chuyên tại các trường đại học ở Việt Nam thì theo các em nên dành bao nhiêu tiết mỗi tuần cho kĩ năng này? Vì sao?

5. Các em mong muốn được thầy cô dạy phát âm theo phương pháp như thế nào? Vì sao các em lại có mong muốn như vậy? 
Appendices 5 - 12 are enclosed in the CD attached to this thesis.

Appendix $5 \quad$ Ethics Approval

Appendix $6 \quad$ Ethics

Appendix 6.1 Information sheets and consent forms for university participant

Appendix 6.2 Information sheets and consent forms for teacher participants

Appendix 6.3 Information sheets and consent forms for student participants (Phase 1)

Appendix 6.4 Information sheets and consent forms for student participants (Phase 2)

Appendix $7 \quad$ The textbook units under observation (Phase 1)

Appendix $8 \quad$ Extracts from Phase 1 interviews

Appendix $9 \quad$ Lesson plans

Appendix 9.1 Lesson plan used for the workshop demonstration

Appendix 9.2 Lesson plans designed and implemented by the teacher participants

Appendix $10 \quad$ Extracted discussion from Phase 2 Review meeting 1 with teachers

Appendix $11 \quad$ Extracts from Phase 2 interviews

Appendix 12 Quantifications of students' responses

Appendix 12.1 Students' beliefs about their teachers' pronunciation teaching efficacy

Appendix 12.2 Students' beliefs about pronunciation in EFL learning

Appendix 12.3 Students' beliefs about the pronunciation teaching approach they preferred (Phase 1)

Appendix 12.4 Students' beliefs about pronunciation in tertiary EFL programmes

Appendix 12.5 Students' beliefs about the pronunciation teaching approach they preferred (Phase 2) 


\section{Appendix $5 \quad$ Ethics approval}

TE WHARE WĀNANGA O TE ŨPOKO O TE IKA A MĀUI

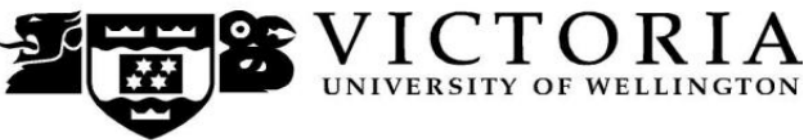

MEMORANDUM

Phone 0-4-463 5480

Email_susan.corbett@vuw.ac.nz

\begin{tabular}{l|l}
\hline TO & Tan Loc Nguyen \\
\hline COPY TO & \\
\hline FROM & AProf Susan Corbett, Convener, Human Ethics Committee \\
\hline DATE & 22 April 2016 \\
\hline PAGES & 1 \\
\hline
\end{tabular}

\begin{tabular}{l|l}
\hline SUBJECT & $\begin{array}{l}\text { Ethics Approval: } 22722 \\
\text { Pronunciation Instruction Practices: A case study of Vietnamese } \\
\text { tertiary EFL teachers }\end{array}$ \\
\hline
\end{tabular}

Thank you for your application for ethical approval, which has now been considered by the Standing Committee of the Human Ethics Committee.

Your application has been approved from the above date and this approval continues until 31 July 2018. If your data collection is not completed by this date you should apply to the Human Ethics Committee for an extension to this approval.

Best wishes with the research.

Kind regards

Susan Corbett

Convener, Victoria University Human Ethics Committee 
Appendix 6

Appendix 6.1
Ethics

Information sheet and consent form for university participant

TE WHARE WÃNANGA OTE ÔPOKO O TE IKAA MÃUI

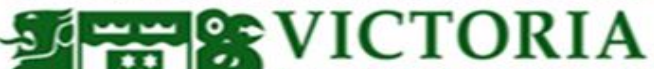

Ea UNIVERSITY OF WELLINGTON

INFORMATION FOR THE PRESIDENT OF THE UNIVERSITY

Date: .../.../2016

Dear Rector of University X

I am Nguyen Tan Loc, currently a PhD student at the School of Linguistics and Applied Language Studies (LALS), Victoria University of Wellington (VUW), New Zealand. I am undertaking research which leads to a PhD thesis at LALS, VUW. The study investigates the teaching of English pronunciation in the Vietnamese tertiary EFL context, which will hold enormous values for EFL teaching and learning at tertiary level in Vietnam. The research will also be practically beneficial for Vietnamese EFL teachers and learners, curriculum designers, and teacher educators. In your particular concern, this study will provide insights into teacher cognition regarding pronunciation teaching practices the information of which can be of great use for program development.

The Victoria University Human Ethics Committee has granted ethics approval for this study. I, therefore, would like to invite your university to participate in this research project. With your agreement, I will, on a voluntary basis, recruit six lecturers of English and 12 groups of four learners to participate in the study. Data will be collected within two successive semesters, from June to November 2016. The research project will be conducted within two phases the steps of which are as follows.

Phase 1: In the summer term, I will observe and video-record each teacher participant teaching one unit including two 45-minute lessons and take field notes. After observations, I will carry out individual stimulated recall interviews with each teacher to investigate the rationales for their teaching practices and the factors shaping their classroom activities. Simultaneously, I will invite four students from each class for focus group interviews which seek to gain their collective views and a snapshot of their experience and beliefs regarding pronunciation teaching/learning. The interview sessions are supposed to take place in about 40 minutes each. After that, the teacher participants will attend a three-hour workshop held in 
the language laboratory of your university. During this session, I will share with the teachers the results of phase 1 . They will then explore a framework for teaching pronunciation communicatively, accompanied by a sample lesson and demonstrations of different types of pronunciation activities. After the workshop, a set of pronunciation features and associated materials will be given to the teachers to plan communicative pronunciation lessons in their classes. All interviews and discussions during the workshop will be recorded.

Phase 2: In the autumn term, the teacher participants will implement those pronunciation lessons in their classes. I will observe and video-tape each teacher's four teaching sessions (90 minutes each) and will have discussions with them after each session at the teacher lounge of your university. Each discussion will be about 30 minutes and the teachers will share their teaching procedures and any problems they have. These discussed points will be used to make sure they are all on the right track in their experimental teaching. When the course is finished, I will invite the teachers for follow-up interviews to investigate what they think and believe about the impact of the workshop on their teaching and student learning. Also, I will invite four students from each class for focus group interviews regarding their experience and beliefs about the pronunciation lessons they have experienced during the semester. Observations and interviews will be conducted at any arranged time and place that best suit the teachers and students.

The data the participants of your university supply will be kept confidential and will not be identified in any way in the research (including the real names of youruniversity, teachers and students). Pseudonyms will be used, instead. Access to data will be in restriction to the researcher and his supervisors. The data will be used as part of the written report of the researcher's $\mathrm{PhD}$ thesis and it is intended that they will be presented at academic journals or conferences or at the oral examination as a requirement of a $\mathrm{PhD}$ at Victoria University of Wellington. A copy of the researcher's PhD thesis will be deposited at the Library of Victoria University of Wellington, New Zealand. Since the teachers and students of your university participate in this research on a voluntary basis, they may withdraw from this study any time during data collection without stating reasons.

If you have any query or concern about the research procedure, please contact The Victoria University Human Ethics Committee, Associate Professor Susan Corbett at susan.corbett@vuw.ac.nz, phone +64-4-463-5480. Also, should you need to be further informed about this research, please contact me or my supervisors through the following contact details: 
Researcher:

Loc Tan Nguyen

tanloc.nguyen@vuw.ac.nz

PhD student, Room 206, 22KP, Kelburn Parade,

Wellington 6140, New Zealand; or

Phone: +84906874362
Supervisors:

Dr. Jonathan Newton

Jonathan.Newton@vuw.ac.nz

Dr. Sasha Calhoun

Sasha.Calhoun@vuw.ac.nz

School of Linguistics and Applied Language Studies,

Victoria University of Wellington, New Zealand, PO

Box 600, Wellington 6140, New Zealand.

Thank you very much for your cooperation in advance.

Yours sincerely,

Nguyen Tan Loc 


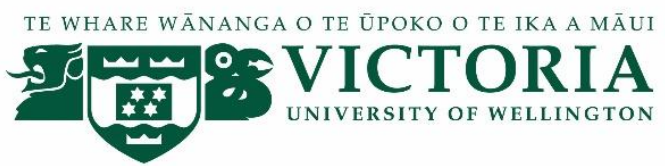

\section{UNIVERSITY CONSENT TO PARTICIPATE IN RESEARCH}

\section{Research title: Pronunciation teaching in the Vietnamese tertiary EFL classroom: An intervention-based case study}

Researcher: Loc Tan Nguyen, School of Linguistics and Applied Language Studies

(LALS), Victoria University of Wellington (VUW), New Zealand

(loctan.nguyen@vuw.ac.nz).

Supervisors: Associate Professor Jonathan Newton (Jonathan.newton@vuw.ac.nz) and

Dr. Sasha Calhoun (Sasha.calhoun@vuw.ac.nz).

1. I have read the information sheet for this research project.

2. I have had an opportunity to ask questions.

3. I understand that my university may withdraw from this study any time during data collection without stating reasons. If my university withdraws from this study, all data supplied will be destroyed.

4. I understand that the data that the teacher participants from my university provide will be kept confidential and access to it will be strictly granted to the investigator and the supervisors.

5. I understand that the real names of my university and the teachers will not be used and identified in any way in the research. Pseudonyms will be used.

6. I understand that the data collected from the participant teachers will be used for the investigator's doctoral thesis, for his conference papers and/or publications in scholarly journals, and I consent for it to be used in that manner.

7. I allow this research to take place at my university.

Signed:

President's name:

Date: 


\section{Appendix 6.2 Information sheet and consent form for teacher participants}

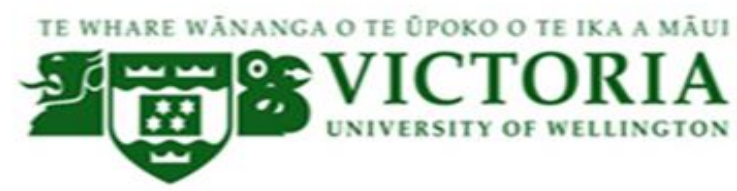

\section{INFORMATION FOR TEACHER PARTICIPANTS IN RESEARCH}

Date: .../.../2016

Dear colleagues

I am Nguyen Tan Loc, currently a PhD student at School of Linguistics and Applied Language Studies (LALS), Victoria University of Wellington (VUW), New Zealand. I am undertaking research which leads to a PhD thesis at LALS, VUW. The study investigates the teaching of English pronunciation in the Vietnamese Tertiary EFL context, which will hold enormous values for EFL teaching and learning at tertiary level in Vietnam. The research will also be practically beneficial for Vietnamese EFL teachers and learners, curriculum designers, and teacher educators.

The Victoria University Human Ethics Committee has granted ethics approval for this study and the Rector of your university has allowed this research to take place at your university. I, therefore, would like to invite you to participate in this research project. With your agreement, I will collect data within two successive semesters, from June to November 2016. Data collection will be conducted within two phases the steps of which are as follows.

Phase 1: In the summer term, I will observe and video-tape you teaching one unit including two 45-minute lessons. Observations will be conducted at any arranged time that best suits you. After observations, I will have an individual stimulated recall interview with you at the teacher lounge or library, which is supposed to take place in about 40 minutes. After that, I will invite you to attend a three-hour workshop held in the language laboratory of your university. During this session, I will share with you the results of phase 1. You will then explore a framework for teaching pronunciation communicatively, accompanied by a sample lesson and demonstrations of different types of pronunciation activities. After the workshop, I will give you a set of pronunciation features and associated materials to plan communicative pronunciation teaching lessons during the semester break. All interviews and discussions during the workshop will be recorded. 
Phase 2: In the autumn term, you will implement these pronunciation lessons in one of your classes. I will observe and video-tape your classes and after each teaching session we will all have a discussion about your teaching at the teacher lounge of your university. Each discussion will be about 30 minutes and you will share your teaching procedures and any problems you have. These discussed points will be used to make sure you are all on the right track in your experimental teaching. When the course is finished, I will invite you for a follow-up interview. Interviews will be conducted at any arranged time and place that best suit you.

The data you supply will be kept confidential and will not be identified in any way in the research. The real name of your university, your real name and your students' will not be used. Pseudonyms will be employed, instead. Access to data will be in restriction to the researcher and his supervisors. The data will be used as part of the written report of the researcher's $\mathrm{PhD}$ thesis and it is intended that they will be presented at academic journals or conferences or at the oral examination as a requirement of a $\mathrm{PhD}$ at Victoria University of Wellington. A copy of the researcher's PhD thesis will be deposited at the Library of Victoria University of Wellington, New Zealand. Since you participate in this research on a voluntary basis, you may withdraw from this study any time during data collection without stating reasons. However, to make sure that your withdrawal has no impact on data analysis, please inform me of your withdrawal three weeks in advance through email, phone or text messages. If you have any query or concern about the research procedure, please contact The Victoria University Human Ethics Committee, Associate Professor Susan Corbett at susan.corbett@vuw.ac.nz, phone + 64-4-463-5480. Also, should you need to be further informed about this research, please contact me or my supervisors through the following contact details:

\section{Researcher:}

Loc Tan Nguyen

tanloc.nguyen@vuw.ac.nz

PhD student, Room 206, 22KP, Kelburn Parade,

Wellington 6140, New Zealand; or

Phone: +84906874362

\section{Supervisors:}

Dr. Jonathan Newton

Jonathan.Newton@vuw.ac.nz

Dr. Sasha Calhoun

Sasha.Calhoun@vuw.ac.nz

School of Linguistics and Applied Language Studies, Victoria University of Wellington, New Zealand, PO Box 600, Wellington 6140, New Zealand. 
Thank you very much for your cooperation.

Yours sincerely,

Nguyen Tan Loc 


\section{TEACHER CONSENT TO PARTICIPATE IN RESEARCH}

\section{Research title: Pronunciation teaching in the Vietnamese tertiary EFL classroom: An intervention-based case study}

Researcher: Loc Tan Nguyen, School of Linguistics and Applied Language Studies

(LALS), Victoria University of Wellington (VUW), New Zealand

(loctan.nguyen@vuw.ac.nz).

Supervisors: Associate Professor Jonathan Newton (Jonathan.newton@vuw.ac.nz) and

Dr. Sasha Calhoun (Sasha.calhoun@ vuw.ac.nz).

1. I have read the information sheet for this research project.

2. I have had an opportunity to ask questions.

3. I understand that my participation is voluntary.

4. I understand that I may withdraw myself (or any information I have provided) from this project during the data gathering without having to give reasons or without penalty of any sort.

5. I understand that any data I provide will be confidential and pseudonyms will be used.

6. The data collected from my participation will be used for a doctoral thesis, for conference papers and/or publications in scholarly journals, and I consent for it to be used in that manner.

Signed:

Teacher's name:

Date:

If you would like to receive a copy of a written summary of the study at the end of the research, please tick here $\square$ and provide your e-mail address to which this summary can be sent: 


\section{Appendix 6.3 Information sheet and consent form for student participants}

(Phase 1)

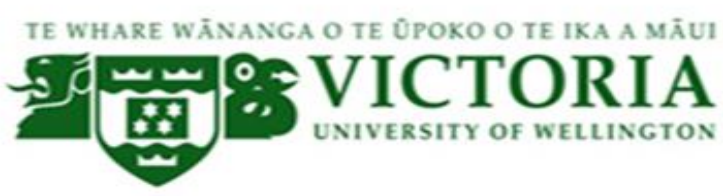

\section{INFORMATION FOR STUDENT PARTICIPANTS IN RESEARCH (PHASE 1)}

Date: .../.../2016

Dear students

I am Nguyen Tan Loc, currently a PhD student at School of Linguistics and Applied Language Studies (LALS), Victoria University of Wellington (VUW), New Zealand. I am undertaking research which leads to a PhD thesis at LALS, VUW. The study explores the teaching of English pronunciation in the Vietnamese tertiary EFL context, which will hold enormous values for EFL teaching and learning at tertiary level in Vietnam. The research will also be practically beneficial for Vietnamese EFL teachers and learners, curriculum designers, and teacher educators. In your particular concern, this study will provide insights into pedagogical decisions that can be made to improve your English learning.

The Victoria University Human Ethics Committee has granted ethics approval for this study. Your Rector has allowed this research to take place at your university and your English lecturer has agreed on my observations and video-recordings of your class. I, therefore, would like to invite you to participate in this research project. With your agreement, I will observe two 45-minute periods of your class in this summer semester. The observed classes will be audio and video recorded by means of a digital camera. After class observations, four students will be invited, on a voluntary basis, to participate in a focus group interview at any arranged time and place that best suit you. The focus group interview is supposed to last in about 40 minutes and will be audio recorded.

The data you supply will be kept confidential and your real name will not be used or identified in any way in the research. Pseudonyms will be used instead. Access to data will be in restriction to the researcher and his supervisors. The data will be used as part of the written report of the researcher's $\mathrm{PhD}$ thesis and it is intended that they will be presented at academic journals or conferences or at the oral examination as a requirement of a $\mathrm{PhD}$ at Victoria 
University of Wellington. A copy of the researcher's $\mathrm{PhD}$ thesis will be deposited at the Library of Victoria University of Wellington. Since you participate in this research on a voluntary basis, you may withdraw from this study any time during data collection without stating reasons. However, to make sure that your withdrawal has no impact on data analysis, please inform me of your withdrawal at least one week prior to focus group interviews through email, phone or text messages because you can only withdraw up until the start of focus group interviews.

If you have any query or concern about the research procedure, please contact The Victoria University Human Ethics Committee, Associate Professor Susan Corbett at susan.corbett@vuw.ac.nz, phone +64-4-463-5480. Also, should you need to be further informed about this research, please contact me or my supervisors through the following contact details:

Researcher:

Loc Tan Nguyen

tanloc.nguyen@vuw.ac.nz

PhD student, Room 206, 22KP, Kelburn Parade,

Wellington 6140, New Zealand; or

Phone: +84906874362

\section{Supervisors:}

Dr. Jonathan Newton

Jonathan.Newton@vuw.ac.nz

Dr. Sasha Calhoun

Sasha.Calhoun@vuw.ac.nz

School of Linguistics and Applied Language Studies, Victoria University of Wellington, New Zealand, PO Box 600, Wellington 6140, New Zealand.

Thank you very much for your cooperation.

Yours sincerely,

Nguyen Tan Loc 


\section{STUDENT CONSENT TO PARTICIPATE IN RESEARCH (PHASE 1)}

\section{Research title: Pronunciation teaching in the Vietnamese tertiary EFL classroom: An intervention-based case study}

Researcher: Loc Tan Nguyen, School of Linguistics and Applied Language Studies

(LALS), Victoria University of Wellington (VUW), New Zealand

(loctan.nguyen@vuw.ac.nz).

Supervisors: Associate Professor Jonathan Newton (Jonathan.newton@vuw.ac.nz) and Dr. Sasha Calhoun (Sasha.calhoun@vuw.ac.nz).

1. I have read the information sheet for this research project.

2. I have had an opportunity to ask questions.

3. I understand that my participation is voluntary and will not impact on my grades for the course.

4. I understand that I may withdraw myself (or any information I have provided) from this project during the data gathering without having to give reasons or without penalty of any sort.

5. I understand that any data I provide will be confidential and pseudonyms will be used.

6. The data collected from my participation will be used for a doctoral thesis, for conference papers and/or publications in scholarly journals, and I consent for it to be used in that manner.

Signed:

Student's name:

Date:

If you would like to receive a copy of a written summary of the study at the end of the research, please tick here $\square$ and provide your e-mail address to which this summary can be sent: 


\section{Appendix 6.4 Information sheet and consent form for student participants}

(Phase 2)

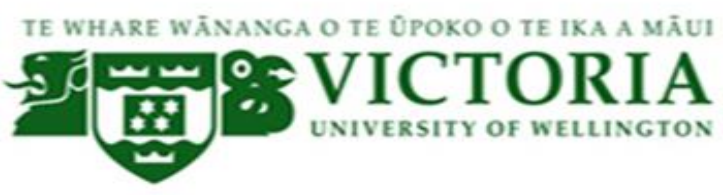

\section{INFORMATION FOR STUDENT PARTICIPANTS IN RESEARCH (PHASE 2)}

Date: .../.../2016

Dear students

I am Nguyen Tan Loc, currently a PhD student at School of Linguistics and Applied Language Studies (LALS), Victoria University of Wellington (VUW), New Zealand. I am undertaking research which leads to a $\mathrm{PhD}$ thesis at LALS, VUW. The study explores the teaching of English pronunciation in Vietnamese Tertiary EFL context, which will hold enormous values for EFL teaching and learning at tertiary level in Vietnam. The research will also be practically beneficial for Vietnamese EFL teachers and learners, curriculum designers, and teacher educators. In your particular concern, this study will provide insights into pedagogical decisions that can be made to improve your English learning.

The Victoria University Human Ethics Committee has granted ethics approval for this study. Your Rector has allowed this research to take place at your university and your English lecturer has agreed on my observations and video-recordings of your class and therefore I now would like to invite you to participate in this research project. With your agreement, I will observe your class every two weeks across this autumn semester (four times in total). The observed classes will be audio and video recorded by means of a digital camera. When the semester ends, four volunteer students will be invited, on a voluntary basis, to participate in a focus group interview at any arranged time and place that best suit you. The focus group interview is supposed to last in about 40 minutes and will be audio recorded.

The data you supply will be kept confidential and your real name will not be used or identified in any way in the research. Pseudonyms will be used instead. Access to data will be in restriction to the researcher and his supervisors. The data will be used as part of the written report of the researcher's $\mathrm{PhD}$ thesis and it is intended that they will be presented at academic 
journals or conferences or at the oral examination as a requirement of a $\mathrm{PhD}$ at Victoria University of Wellington. A copy of the researcher's $\mathrm{PhD}$ thesis will be deposited at the Library of Victoria University of Wellington. Since you participate in this research on a voluntary basis, you may withdraw from this study any time during data collection without stating reasons. However, to make sure that your withdrawal has no impact on data analysis, please inform me of your withdrawal at least one week prior to focus group interviews through email, phone or text messages because you can only withdraw up until the start of focus group interviews.

If you have any query or concern about the research procedure, please contact The Victoria University Human Ethics Committee, Associate Professor Susan Corbett at susan.corbett@vuw.ac.nz, phone + 64-4-463-5480. Also, should you need to be further informed about this research, please contact me or my supervisors through the following contact details:

Researcher:

Loc Tan Nguyen

tanloc.nguyen@vuw.ac.nz

PhD student, Room 206, 22KP, Kelburn Parade,

Wellington 6140, New Zealand; or

Phone: +84906874362
Supervisors:

Dr. Jonathan Newton

Jonathan.Newton@vuw.ac.nz

Dr. Sasha Calhoun

Sasha.Calhoun@vuw.ac.nz

School of Linguistics and Applied Language Studies, Victoria University of Wellington, New Zealand, PO Box 600, Wellington 6140, New Zealand.

Thank you very much for your cooperation.

Yours sincerely,

Nguyen Tan Loc 


\section{STUDENT CONSENT TO PARTICIPATE IN RESEARCH (PHASE 2)}

\section{Research title: Pronunciation teaching in the Vietnamese tertiary EFL classroom: An intervention-based case study}

Researcher: Loc Tan Nguyen, School of Linguistics and Applied Language Studies

(LALS), Victoria University of Wellington (VUW), New Zealand

(loctan.nguyen@vuw.ac.nz).

Supervisors: Associate Professor Jonathan Newton (Jonathan.newton@vuw.ac.nz) and Dr. Sasha Calhoun (Sasha.calhoun@vuw.ac.nz).

1. I have read the information sheet for this research project.

2. I have had an opportunity to ask questions.

3. I understand that my participation is voluntary and will not impact on my grades for the course.

4. I understand that I may withdraw myself (or any information I have provided) from this project during the data gathering without having to give reasons or without penalty of any sort.

5. I understand that any data I provide will be confidential and pseudonyms will be used.

6. The data collected from my participation will be used for a doctoral thesis, for conference papers and/or publications in scholarly journals, and I consent for it to be used in that manner.

Signed:

Student's name:

Date:

If you would like to receive a copy of a written summary of the study at the end of the research, please tick here $\square$ and provide your e-mail address to which this summary can be sent: 


\section{Appendix $7 \quad$ Textbook units under observation (Phase 1)}

\section{Market Leader Elementary, Unit 8}

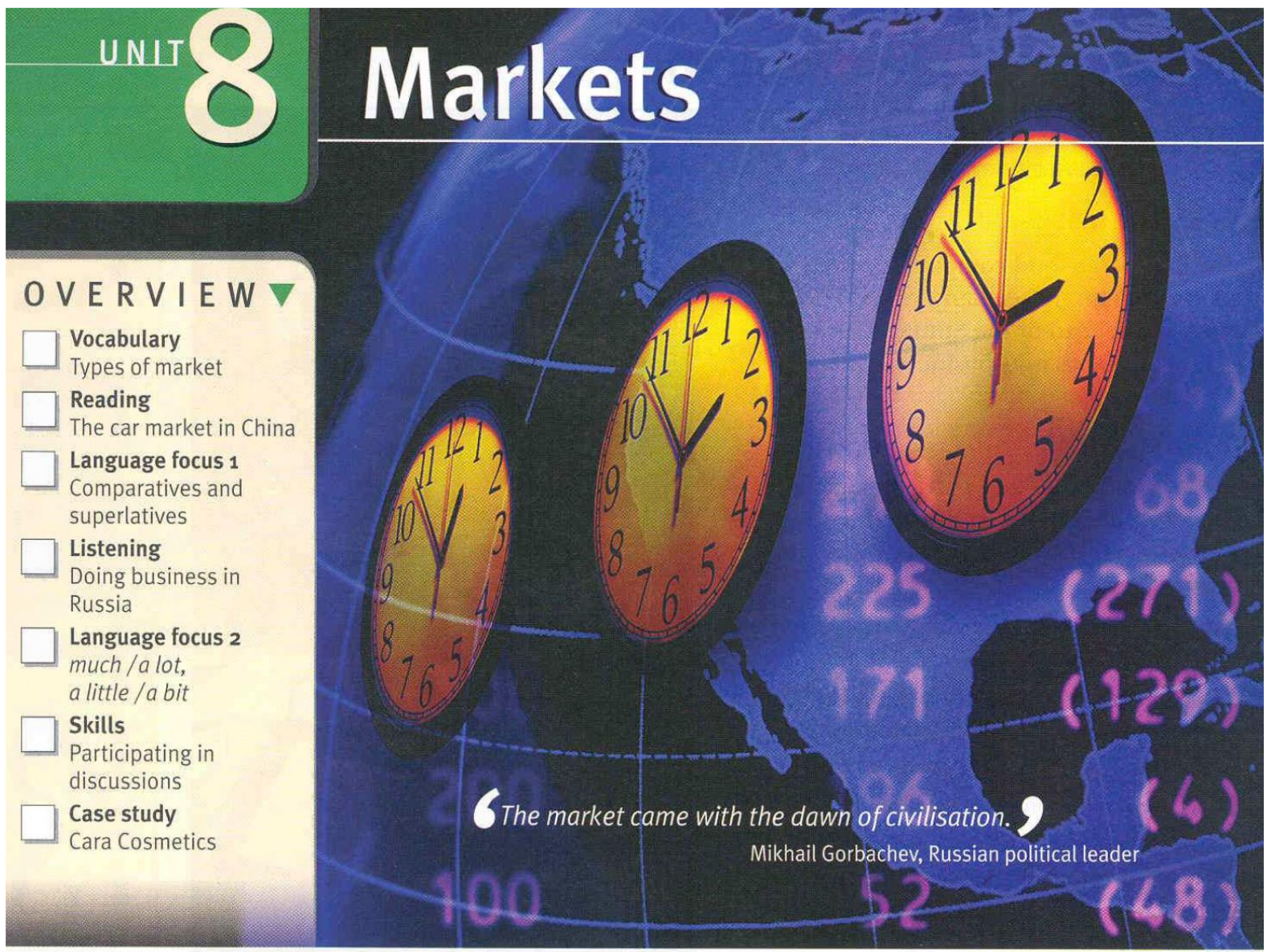

A Look at the pie chart and answer these questions.

1 What is the population of North America?

The population of North America is three hundred and ten million.

2 What percentage of the world's population lives in Europe?

B Now ask and answer other questions about the chart.

Population by region (in millions)

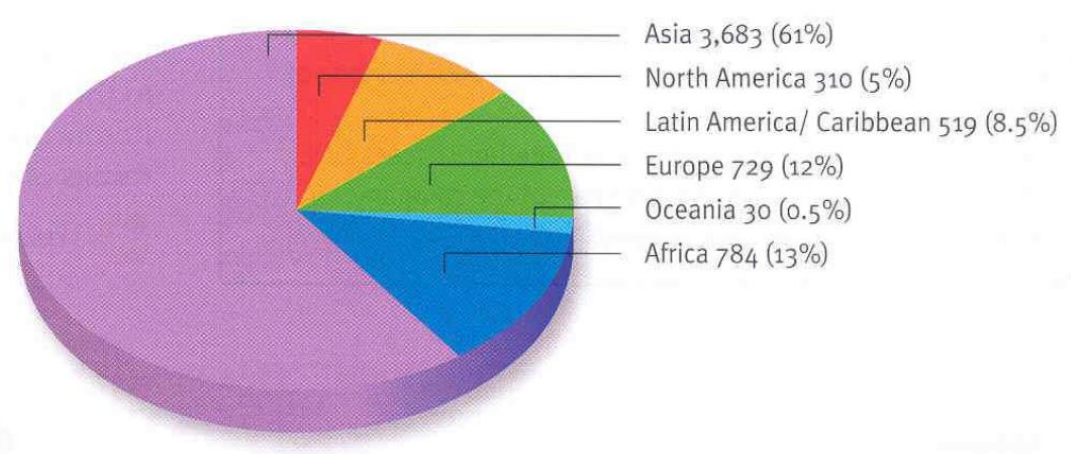




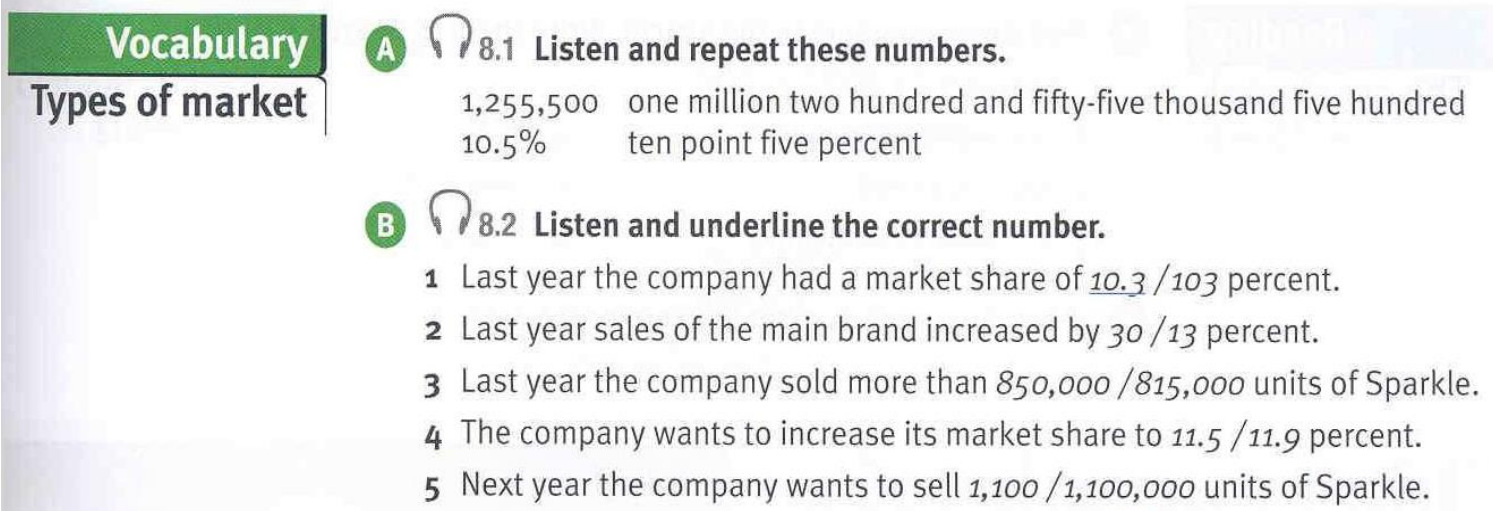

Vocabulary file page 159

C Match the beginnings of the sentences 1 to 5 with their endings a) to e).

1 Coca-Cola is a mass market product; it

2 Selling special interest holidays is a niche market; it

3 Rolex watches sell in a luxury market; they are

4 An export market

5 A home market a) is a small but often profitable market.

b) is outside the producer's country.

c) is in the producer's country.

d) high quality and expensive goods.

e) sells to large numbers of people.

D Now think of products which match the types of market in Exercise C.

Nike shoes sell in a mass market.

Ferrari sports cars are a luxury market product.

(E) Match the beginnings of the sentences 1 to 5 with their endings a) to e).
1 A new market
a) is large.
2 A growing market
b) allows companies to make money.
3 A profitable market
c) is good to enter.
4 A big market
d) is getting larger.
5 An attractive market
e) is at an early stage.

F Match the adjectives from Exercise $\mathrm{E}$ with their opposite meanings a) to e).

a) unattractive

b) unprofitable

c) mature

d) declining

e) small

G Now choose adjectives from Exercise $\mathrm{E}$ to describe the markets in your country for the following products.

laptop computers holidays abroad video phones self-help books bicycles beauty products

The market for laptop computers is a mature market.

Selling holidays abroad is a growing market. 


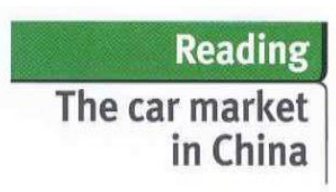

A Find these numbers in the article. Write them in figures.

1.3 billion / 1,300,000,000
1 one point three billion
4 sixty
2 four thousand
5 twelve thousand pounds
3 six hundred thousand
6 ninety thousand pounds

B What does each number in Exercise A refer to?

1.3 billion - the number of people in China

\section{China car sales rise}

By Oliver August in Beijing

Edward Zong, China's 20 Porsche salesman, is ready for the biggest boom in the car business since Henry

5 Ford. Only 1 percent of the 1.3 billion Chinese own a car, but sales are 50 percent more than a year ago.

As a result, the country is 10 now the biggest market for some car manufacturers, and you can read about the end of the 'bicycle age' in Chinese newspapers.

15 In Beijing alone, about 4,000 new cars arrive every week and 600,000 new drivers will get licences this year. This is a rise of 40 percent. Sales of 3 million vehicles this year will make China the fourth largest market in the world.

Some carmakers need 25 Chinese consumers. Volkswagen will sell more cars in China than in Germany this year, and Porsche hopes to double its sales to 60 cars 30 next year

When $\mathrm{Mr}$ Zong was young, children played ball games on Beijing's big roads. People didn't own private cars and only government drivers, such as Mr Zong's

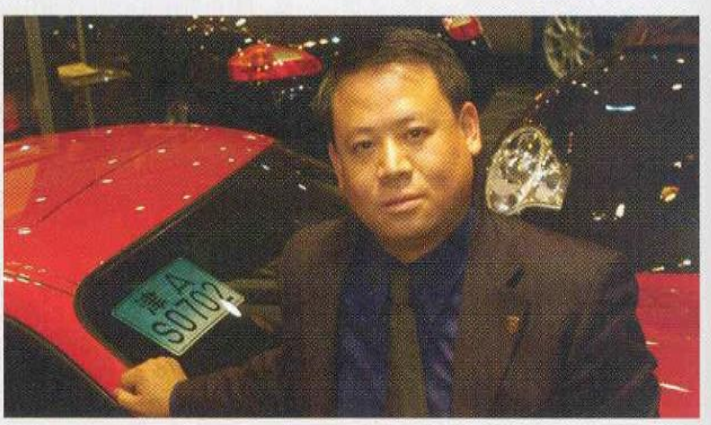

father, went faster than bicycles.

change single-lane roads into eight-lane highways.

This year, $\mathrm{Mr}$ Zong in car traffic for an hour on 50 purchased his first car, for his way to work every $£ 12.000$ - a Jeep Cherokee. morning. The millions of He wanted a Porsche, but bicycles cause great with a price of more than problems for other traffic. $£ 90,000$, this is a distant The government plans to 55 dream for him.

destroy many old areas and

From The Times

C Read the article carefully and complete these sentences.

1 Car sales in China are. .... a year ago.
a) the same as
b) higher than
c) lower than

2 China is a big market for ......
a) Ford
b) Volkswagen
c) Porsche

3 The number of ..... causes problems for other traffic.
a) cars
b) animals
c) bicycles

4 The government wants to make roads ......
a) wider
b) longer
c) cleaner

5 Mr Zong owns a ......
a) Jeep
b) Porsche
c) Ford

D Find words in the article which mean:

1 time of high sales (paragraph 1) boom

2 makers (paragraph 2)

3 people who buy (paragraph 4)

4 two times as many (paragraph 4)

5 to damage very badly (paragraph 6)

6 bought (paragraph 7)

E Find three words in the article which refer to each of the following:

1 people salesman,

2 business getting better 


\section{Language focus 1 \\ Comparatives and superlatives}

- We compare two people or things with comparative forms of adjectives. Only government drivers went faster than bicycles.

For Volkswagen the Chinese market is more profitable than the German market.

- We compare three or more people or things with superlative forms of adjectives.

The country is now the biggest market for some car manufacturers What is the most expensive make of car?

A Correct the mistakes in these sentences.

1 It is more harder to break into export markets than home markets. harder

2 China is a more big market than Japan.

3 Our market share is more low than it was last year.

4 The rate of inflation is more bad this month than it was last month.

5 This month's sales are more high than last month's.

6 The Asian market is more good than the European market for rice.

B Complete the conversations using the superlative form of the adjectives.

1 This is a good product. Yes, it's . the best. . . product on the market.

2 This is an expensive hotel. Yes, it's place in the city.

3 She is a very popular manager. Yes, she's ............ head of department in the company.

4 This is a cheap product. Yes, it's product in the catalogue.

5 This is a very competitive market. Yes, it's market in Asia.

6 This is a bad year. Yes, it's ............ year in the last ten years.

C Complete the article with the appropriate form of the words in brackets.

\section{Profile}

I opened a hairdressing salon last year. The . most important 1 (important) thing is to think about your target customers. My hairdressing salon is located in my parents' hotel. My customers are ${ }^{2}$ (old) and .$^{3}$ (rich) than my main competitor's. They like excellent service and a cup of coffee. My main competitor's customers are .$^{4}$ (young) than mine. She offers a ................... ${ }^{5}$ (cheap) service than I do. However, my salon is ${ }^{6}$ (comfortable) than hers. My ................. (exciting) customer is a famous model.

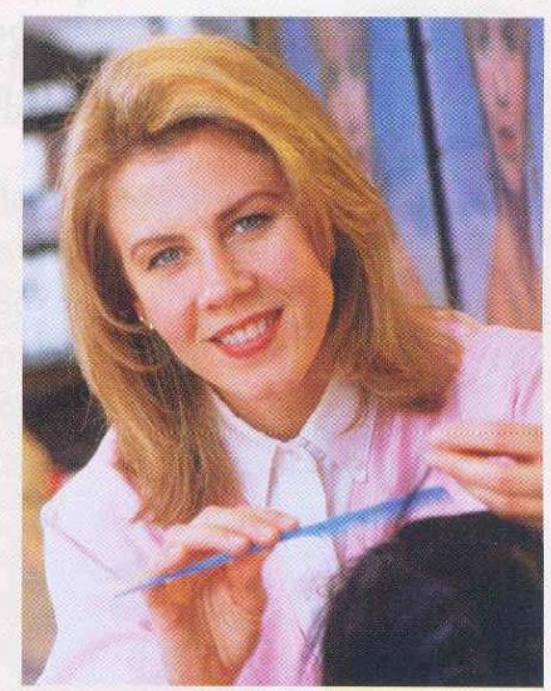




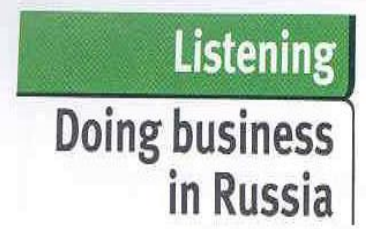

A 78.3 Listen to the first part of a presentation by Anna Nabirukhina about doing business in Russia. Then tick the correct answers.

1 a) Russians expect foreign visitors to take them to parties.

b) Russians do business with people who like parties.

c) Russians enjoy entertaining foreign people who visit them.

2 To do business with Russian companies, you need to have ...
a) a business arrangement.
b) a personal relationship.
c) a useful contact.

3 Who do you need in your team?
a) a friendly person
b) a service provider
c) a technical person

B 18.4 Listen to the second part of the presentation. Then answer these questions.

1 Who should you take on your first visit to a Russian company?
a) new people
b) team members
c) senior people

2 When Russians buy products from foreign companies, they offer ...
a) to pay as little as possible.
b) to pay a fair price.
c) to pay as much as possible.

C 8.5 Listen to the third part of the presentation. Then complete these extracts.

1 Russians value information. They think information is .... power......, so they do not tell you everything.

2 It's important to be patient. Russians take a long time to make a , and there's always a lot of to deal with.

3 You must watch Russians carefully and study their language. This is very important.

4 Remember that Russians are ............ people. Sometimes emotions are more than facts. 


\section{Language focus 2 \\ much / a lot, a little / a bit}

- We use much or a lot with comparative adjectives to talk about large differences. Much is more formal than a lot. Fruit snacks are much healthier than sugary snacks. New Zealand is a good market, but Australia is a lot more attractive.

- We use a little or a bit with comparative adjectives to talk about small differences. A little is more formal than a bit. The PDX100 is a little more expensive than the PDX200. This month's sales are a bit higher than last month's.

A Complete these sentences about the cars.

1 The white car is bigger than the black car.

2 The black car is . bigger than the red car.
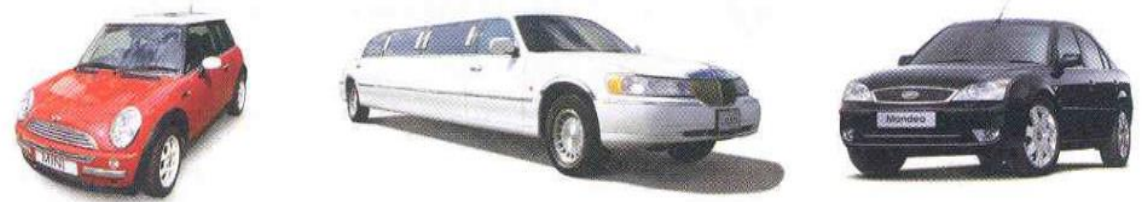

B Talk about sales in France and in Spain. Use the chart.

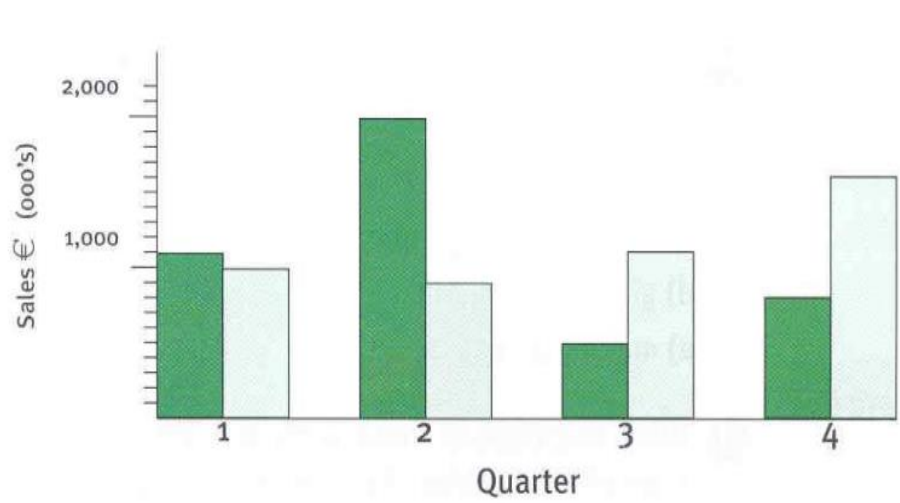

Sales in Fran Sales in Spai

In the first quarter, sales in France were a little higher than in Spain. In France, sales in the second quarter were much higher than in the first quarter.

C Compare these two pool tables using much, a lot, a little and much. The Classic pool table is a bit wider than the Trainer pool table.

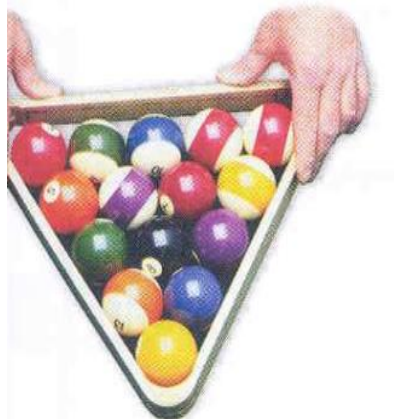

\section{Trainer pool table}

Width

Length

Height

Weight

Price
$93 \mathrm{~cm}$

$176 \mathrm{~cm}$

$78 \mathrm{~cm}$

$25 \mathrm{~kg}$

$€ 144$

\section{Classic pool table}

$95 \mathrm{~cm}$

$180 \mathrm{~cm}$

$80 \mathrm{~cm}$

$50 \mathrm{~kg}$

$€ 280$ 
A 78.6 Three marketing executives, Jacek, Paul and Anna, talk about a new morning snack called Krakel. Listen to their conversation and underline the correct answer.

1 Who does Jacek want to target with the new bar?
a) children
b) rich women
c) young workers

2 Jacek says more people these days
a) do not have breakfast.
b) have breakfast on the way to work.
c) eat breakfast at home.

3 Krakel contains
a) no sugar.
b) a bit of sugar.
c) a lot of sugar.

4 Krakel contains
a) no fruit.
b) a bit of fruit.
c) a lot of fruit.

B 78.6 Listen to the conversation again. Complete the extracts.

1 Sorry, Paul, I don't ....9gree .... with you.

2 । ........... we need to target young working people.

3 You're ............ There is a big market for morning snacks.

4 How do you ............. about this, Anna?

5 I really ............ the idea.

6 OK............. call a meeting and talk to the rest of the department.

C Look at the extracts in Exercise B. Decide whether the speaker is:
a) agreeing.
b) disagreeing.
c) asking for an opinion.
d) giving an opinion.
e) making a suggestion.

D Work in groups of three. Role play this situation. You are taking part in a marketing meeting. You are discussing the name and price of a new cereal bar and how to promote it.

Student A: turn to page 136.

Student B: turn to page 139.

Student C: turn to page 144 .

\section{Useful language}

Agreeing

You're right.

I really like the idea.

Disagreeing

(Sorry) I don't agree with you.

I'm afraid I don't agree.

Asking for an opinion

What do you think?

How do you feel about this?
Giving an opinion

I think ...

In my opinion ...

Making a suggestion

Let's ...

How about ... 


\section{Background}

Cara Cosmetics is an international company based in Italy. It sells body care products. Its target market is usually women who buy the products for the whole family. Cara Cosmetics is launching a new shampoo.

\section{Competitors' products}

$\begin{array}{llll}\text { Name } & \text { Price } & \text { Size } & \text { Outlets } \\ \text { HairGlow } & € 8 & 300 \mathrm{ml} & \text { supermarkets } \\ & € 4 & 100 \mathrm{ml} & \text { pharmacies } \\ \text { Shinesoft } & € 10 & 300 \mathrm{ml} & \text { supermarkets } \\ & € 7 & 200 \mathrm{ml} & \text { pharmacies } \\ & € 5 & 100 \mathrm{ml} & \text { hairdressers } \\ \text { Sheen } & € 14 & 250 \mathrm{ml} & \text { hairdressers } \\ & € 10 & 150 \mathrm{ml} & \text { hairdressers }\end{array}$

\section{The new shampoo}

The biggest competitor is HairGlow. Look at the options below for the new shampoo.

\section{Names \\ Finesse \\ Radiance \\ Silk}

\section{Selling prices (for $300 \mathrm{ml}$ ) Less than $€ 8$ \\ $€ 8$ \\ More than $€ 8$ \\ Bottle sizes \\ $300 \mathrm{ml}$ only \\ $300 \mathrm{ml}$ and $100 \mathrm{ml}$ \\ $500 \mathrm{ml}, 300 \mathrm{ml}$ and $200 \mathrm{ml}$}

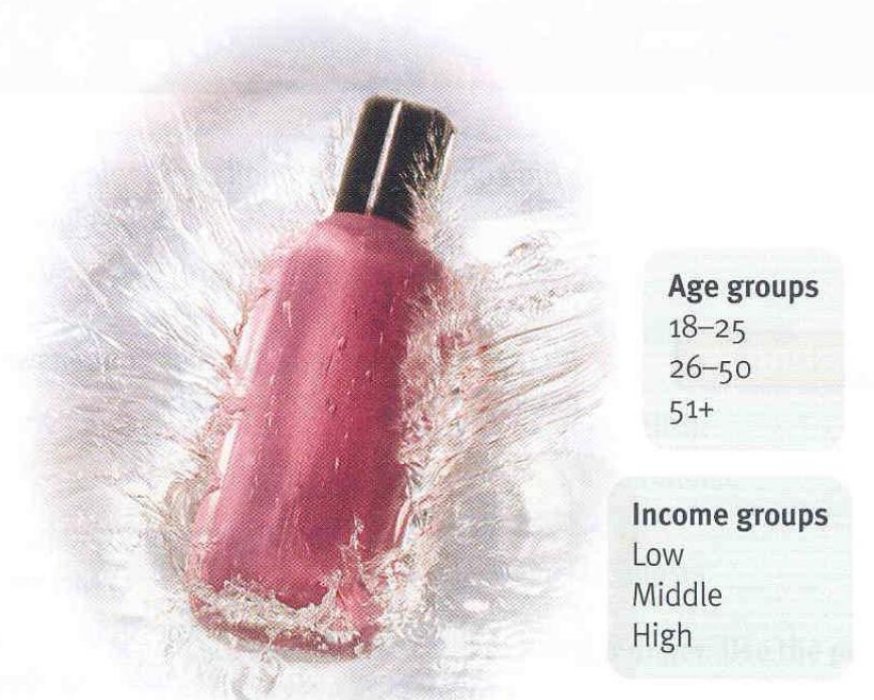

Main outlets

Supermarkets

Pharmacies

Hairdressers

\section{Task}

Work in small groups. Look at the information and discuss how Cara Cosmetics needs to launch its shampoo.

Decide on the name, price, age group, size, income group, target market and main outlet.

\section{Writing}

Write a short description of the new shampoo for Cara's catalogue.

- Writing file page 134 


\section{Market Leader Elementary, Unit 9}

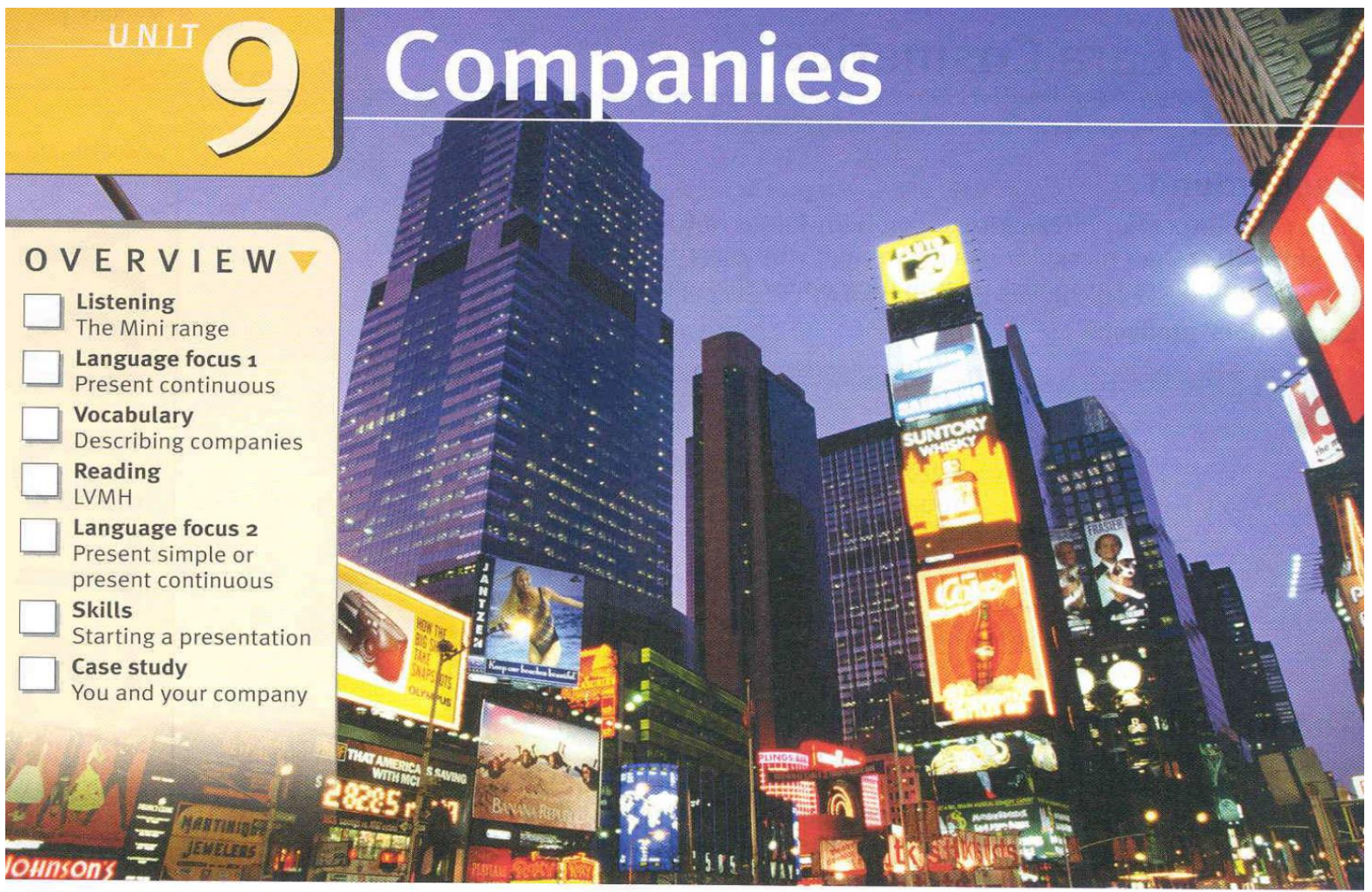

Big companies are small companies that succeeded.

Robert Townsend, American executive and author

Do the companies quiz. Discuss your answers with a partner. Then turn to page 137 to check your answers.

Which company:

1 began in 1865 as a forestry and power business?
a) Ericsson
b) Nokia
c) Motorola

2 produces the most successful toy in history?
a) Disney
b) Fisher-Price
c) Mattel

3 has its head office in San Francisco?
a) Levi-Strauss
b) Nike
c) Calvin Klein

4 buys more sugar than any other company in the world?
a) Nestlé
b) Coca-Cola
c) Suchard

5 employs more people than any other company?
a) Wal-Mart
b) Siemens
c) General Motors

6 has the largest factory in the world?
a) Boeing
b) Ford
c) Sony

7 was started by Ray A. Kroc in 1955 ?
a) Burger King
b) Kentucky Fried Chicken
c) McDonald's

What famous companies come from your country? What do they do or make? 


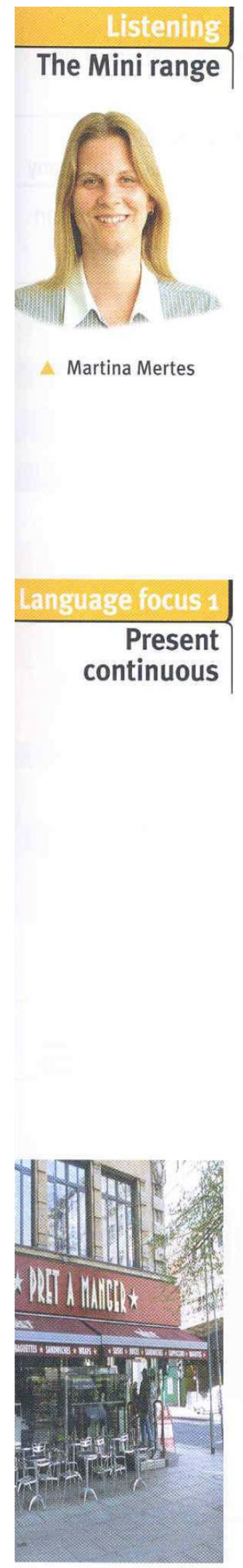

Martina Mertes is Corporate Communications Manager for the Mini range of cars at BMW. Tick the words you think you will hear in the interview.

model launch production factory university
demand exhibition

\section{Check the meanings of any words you don't know in a good dictionary.}

C 9.1 Listen to the interview. Then answer these questions.
1 Where is the factory? Oxford
2 How is business?
3 How many days a week is the factory working to meet demand?
4 What is the biggest market for Minis?
5 What is the newest market for Minis?
6 Where were the original Minis built?
7 Is BMW developing new models in Oxford?

- We use the present continuous to talk about temporary actions and situations that are happening now.

The factory is working seven days a week.

We are selling in 72 different countries.

What is Jackie doing? She is talking to a customer.

- The present continuous is formed with be and the -ing form of the main verb.

Complete these sentences with the present continuous form of the verbs in brackets.
1 BMW .... is sellling..... (sell) Minis in China now.
2 People (work) in the factory 51 weeks a year.
31 (call) about a problem.

4 Many Chinese people (learn) English.

5 She . (attend) a course on presentations.

$6 \mathrm{He}$ (not work) in the office today.

7 They..... (entertain) some foreign guests.

Complete the article about the food group Pret a Manger. Use the present continuous form of the words from the box.

increase export plan expand translate

The number of Pret a Manger (PaM) shops . is increasing $\ldots{ }^{1}$ not only in London, but also in other parts of the UK. At present PaM .... its overseas business, particularly in China. Currently it its advertising material into Chinese. PaM . 4 its winning formula to Hong Kong and Japan. PaM ${ }^{5}$ to open new shops in New York.

How is your business, institution or life changing? 

companies
These sentences describe two companies, Autotech and Green Fingers. Choose pairs of sentences which describe similar things and match them with the correct company.

\begin{tabular}{|c|c|}
\hline $\begin{array}{c}\text { AUTOTECH } \\
\text { A large car parts company }\end{array}$ & $\begin{array}{c}\text { GREEN FINGERS } \\
\text { A small garden products company }\end{array}$ \\
\hline John Smith started Autotech in 1960 & $\begin{array}{l}\text { George and James Hawkins began } \\
\text { Green Fingers in the 1920s. }\end{array}$ \\
\hline
\end{tabular}

1 John Smith started Autotech in 1960.

2 It has a workforce of 2,500.

3 Autotech exports to over 12 countries.

4 It manufactures car parts.

5 It introduces one or two new components each year.

6 It employs about 35 people.

7 Green Fingers sells some of its products abroad.

8 It makes garden products.

9 George and James Hawkins began Green Fingers in the 1920 .

10 Green Fingers supplies the gardening industry.

11 It launches twelve new products a year.

12 Autotech provides components for the car industry.

B Now underline the verbs which mean the same thing in each pair of sentences in the box in Exercise A.

John Smith started Autotech in 1960

George and James Hawkins began Green Fingers in the 1920 s.

Use verbs from Exercise A which you underlined to complete this company profile.

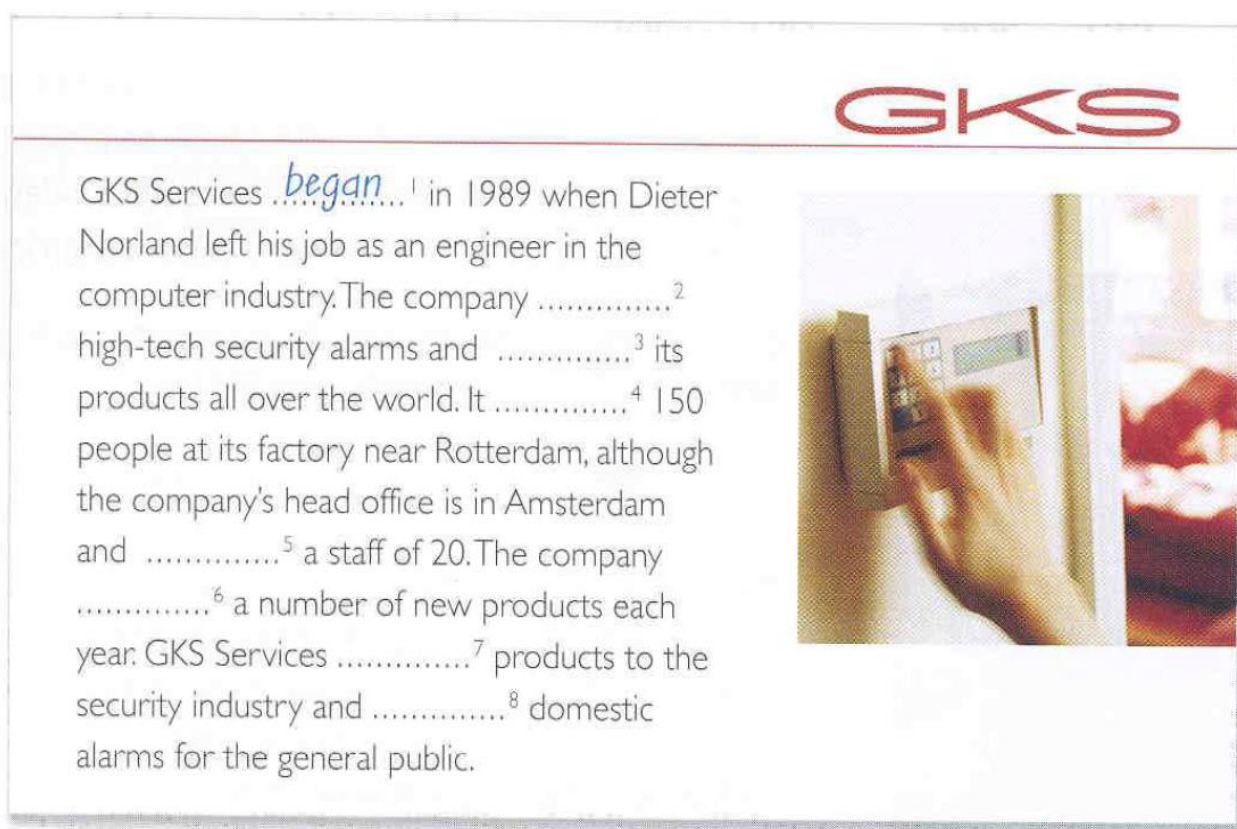




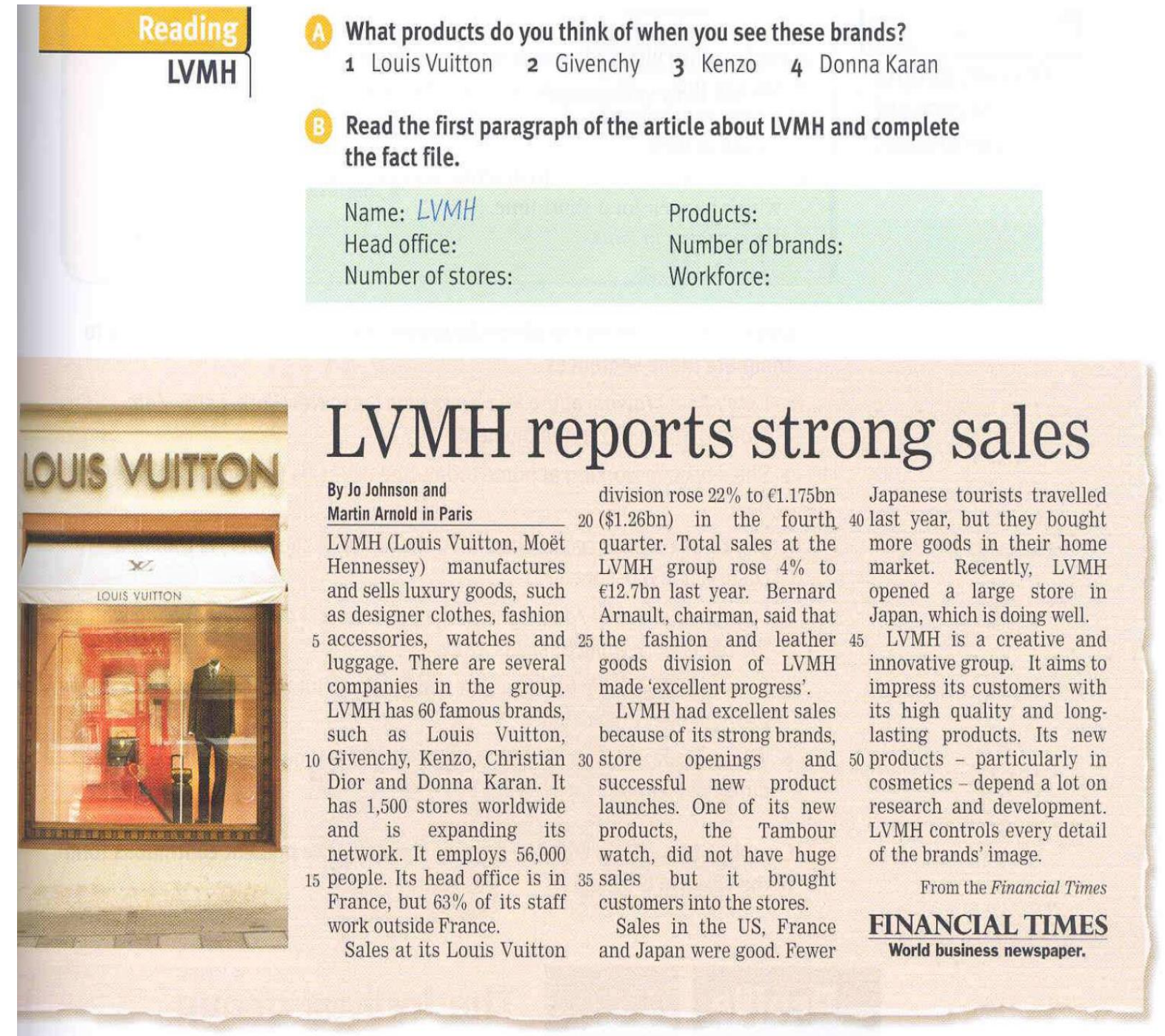

\section{Answer these questions.}

1 What percentage of LVMH's staff do not work in France?

2 What was the percentage increase in sales at the Louis Vuitton division in the fourth quarter?

3 Which of the following were reasons for the increase in LVMH's sales?
a) well-known products
c) better research
b) new stores
d) new products

4 How did the launch of the Tambour watch help LVMH?

5 In which markets did LVMH sell a lot of products?

D) Mark each statement true or false.

1 LVMH's main product is cosmetics. false

2 LVMH doesn't launch many new products.

3 Sales in Japan are poor.

4 LVMH's products are well made.

5 The image of its products is important to LVMH.

Why do you think LVMH is a successful company? What other successful companies do you know? Why are they successful? 


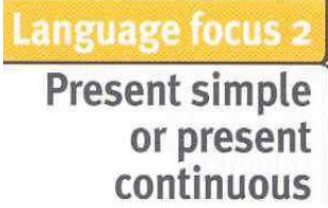

Language focus 2

or present continuous
Complete the rules with present simple or present continuous.

- We use the ............. to describe permanent situations, ones which won't change.

I work in Paris.

- We use the ............. to describe temporary situations, ones which happen for a short time.

I'm working in Paris.

page 126

Underline the present simple or the present continuous form of the verb to complete these sentences.

1 I stav/am staying at the Ritz every time I'm in New York. I stay / am staying at the Ritz at the moment.

2 She works/is working at home today. She works/is working at home every day.

3 She often calls / is calling Russia. At the moment she calls / is calling a customer in Moscow.

4 I don't usually deal /dealing with the paperwork. I deal /am dealing with all the paperwork while Susan is away.

5 It normally takes / is taking about two months. But this delivery takes / is taking longer than usual.

6 We normally use / are using a London firm. This time we use / are using a different company.

Complete this article with the present simple or the present continuous form of the verbs in brackets.

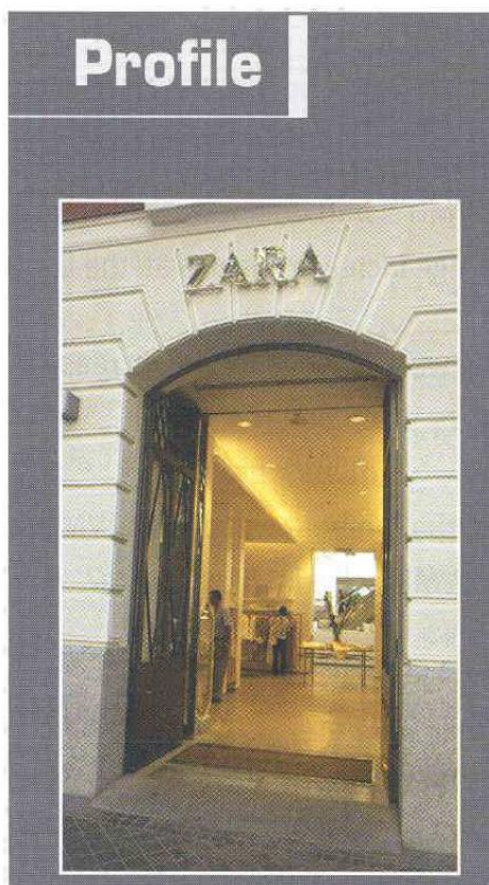

\section{The Inditex group}

The Inditex group ...Wns...... (own) six fashion chains including Zara. It $\ldots \ldots \ldots \ldots{ }^{2}$ (have) around 1,500 stores worldwide. It .................. ${ }^{3}$ (operate) in 44 countries. Inditex .................. ${ }^{4}$ (employ) 27,000 people and ................. ${ }^{5}$ (have) more than 200 fashion designers.

Currently the fashion designers ................... ${ }^{6}$ (work) on next year's designs. The Inditex group (do) very well at the moment, and it ................. ${ }^{8}$ (try) to become a global fashion leader.

Amancio Ortega, the founder of Inditex, also .$^{9}$ (invest) in property and hotels. Most of this year's investment .$^{10}$ (stay) in Spain. 
Work in pairs. Role play this situation. Student A works at the EBB Bank. Student B works at the Goldcrest Hotel. Take it in turns to show each other around your company. Say what happens in each area and what is happening now.

\section{Student A}

\section{EBB Bank}

\begin{tabular}{|l|l|l|}
\hline Area & What happens & What is happening now \\
\hline Main hall & serve customers & cashier / talk / to a customer \\
\hline Currency section & exchange foreign currency & customer / change / dollars into euros \\
\hline Loans Section & $\begin{array}{c}\text { assistant manager arranges } \\
\text { loans for customers }\end{array}$ & $\begin{array}{c}\text { assistant Manager / talk / to a customer } \\
\text { on the phone } \\
\text { manager's office }\end{array}$ manager works / meet / an important client \\
\hline Reception desk & $\begin{array}{l}\text { staff answer questions from } \\
\text { customers }\end{array}$ & $\begin{array}{l}\text { receptionist / listen / to a customer's } \\
\text { complaint }\end{array}$ \\
\hline
\end{tabular}

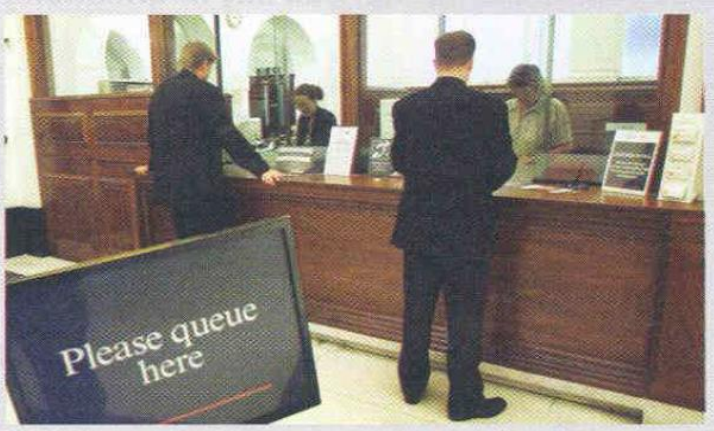

This is the main hall. We serve customers here. At the moment a cashier is talking to a customer.

\section{Student B}

\section{Goldcrest Hotel}

\begin{tabular}{|c|c|c|}
\hline Area & What happens & What is happening now \\
\hline Kitchen & prepare and cook meals & chefs / prepare / today's lunch \\
\hline Restaurant & $\begin{array}{l}\text { serve breakfast, lunch } \\
\text { and dinner }\end{array}$ & waiter / clear / the tables \\
\hline Reception & welcome guests, answer calls & receptionist / talk / to a guest \\
\hline Gift shop & sell souvenirs & sales assistant / help / a customer \\
\hline A bedroom & guests stay & maid / clean / the room \\
\hline
\end{tabular}

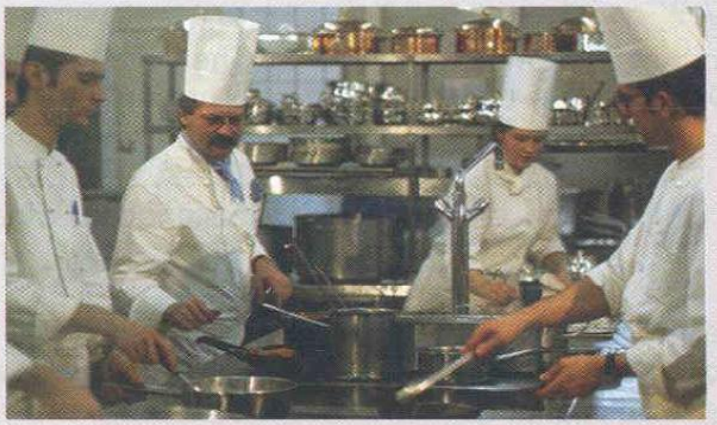

This is the kitchen. We prepare and cook meals here. At the moment the chefs are preparing today's lunch. 

presentation

P 9.2 Listen to the start of a presentation. Number items a) to e) in the order you hear them.

a) There are three parts to my presentation. Firstly,

b) By the end of my presentation you will understand clearly our future plans.

c) Good afternoon, everyone. My name's Ricardo Valdes.

d) I'd like to talk about our new marketing strategy.

e) Finally, the details of the costs ...

A 9.2 Listen again. Match the headings 1 to 4 to the items a) to e) in Exercise A.

1 Topic of the talk

2 Aim

3 Greeting the audience

4 Plan of the talk

Work in pairs. Prepare an introduction to a presentation. Then introduce the presentation to each other. Choose role $A$ or role $B$, and use the notes to introduce your presentation. Add any information you wish.

\section{Role A}

Topic The launch of your company's new product

Plan 1 The background to the launch

2 The features of the new product

3 The advertising and marketing plans

Aim To give a clear idea of the sales potential of the product

\section{Role B}

Topic Your company's new e-mail system

Plan 1 The background

2 Why the company needed to change the system

3 How to use it and to report faults

Aim To give a clear idea of how the new e-mail system improves communication in the company

\section{Useful language}

\section{Greeting}

Good morning / afternoon. I'm ... Hello, everyone. Nice to see you again.

\section{Topic}

My subject today is ...

I'd like to talk to you about ...

I'm going to talk about...

\section{Plan}

There are three parts to my presentation.

My presentation is in three sections.

Firstly, ...

Secondly, ... Finally, ...

\section{Aims}

By the end of my presentation, you will have a clear idea of ...

By the end of my talk, you will understand how / why... 


\section{Background}

You are beginning a training course on giving presentations. The trainer has provided a structure for an introduction. She asks you to introduce yourself and the company you work for. You are all from different parts of the world and different industries.

\section{Task}

1 Work in small groups. Choose role card A, B or C and read your company profile (page 138).

2 Prepare an introduction for a presentation about yourself and the company you work for. It should last approximately one minute.

3 Make your presentation to the other members of your group. Try to answer any questions they ask.

4 As a group, decide what you like about each presentation. Why was it interesting?
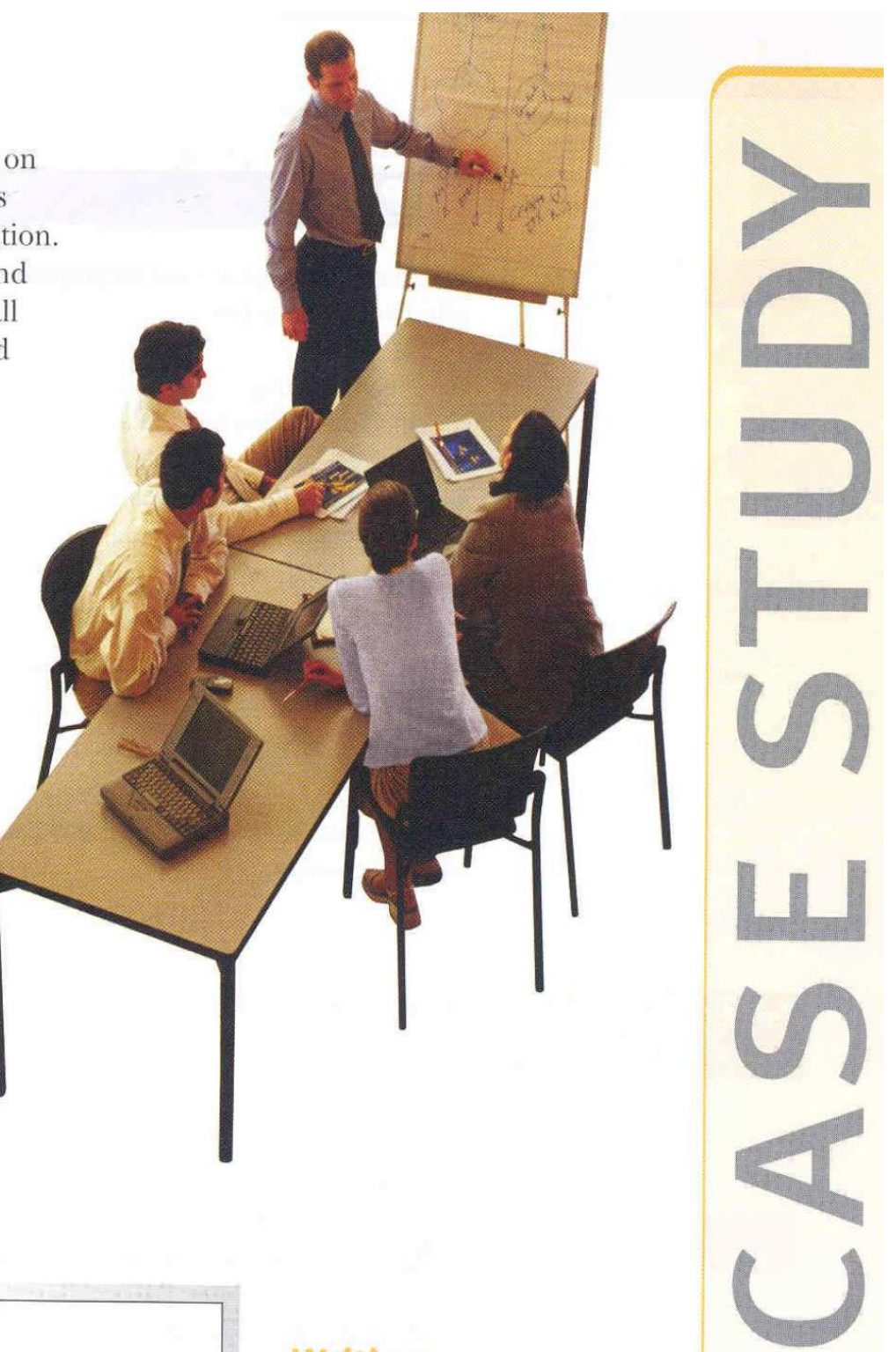

\section{Structure for introduction}

\section{A Greeting}

Your name

Your nationality

Your position

(B) Topic

Your company

C) Plan

Company products or services

Important figures: number of employees, turnover, profits

Your duties

\section{Writing}

You are a representative of your company. Write a short profile of the company. Include some of the information from the introduction to your presentation.

\section{Writing file page 134}




\section{Market Leader Pre-intermediate, Unit 1}

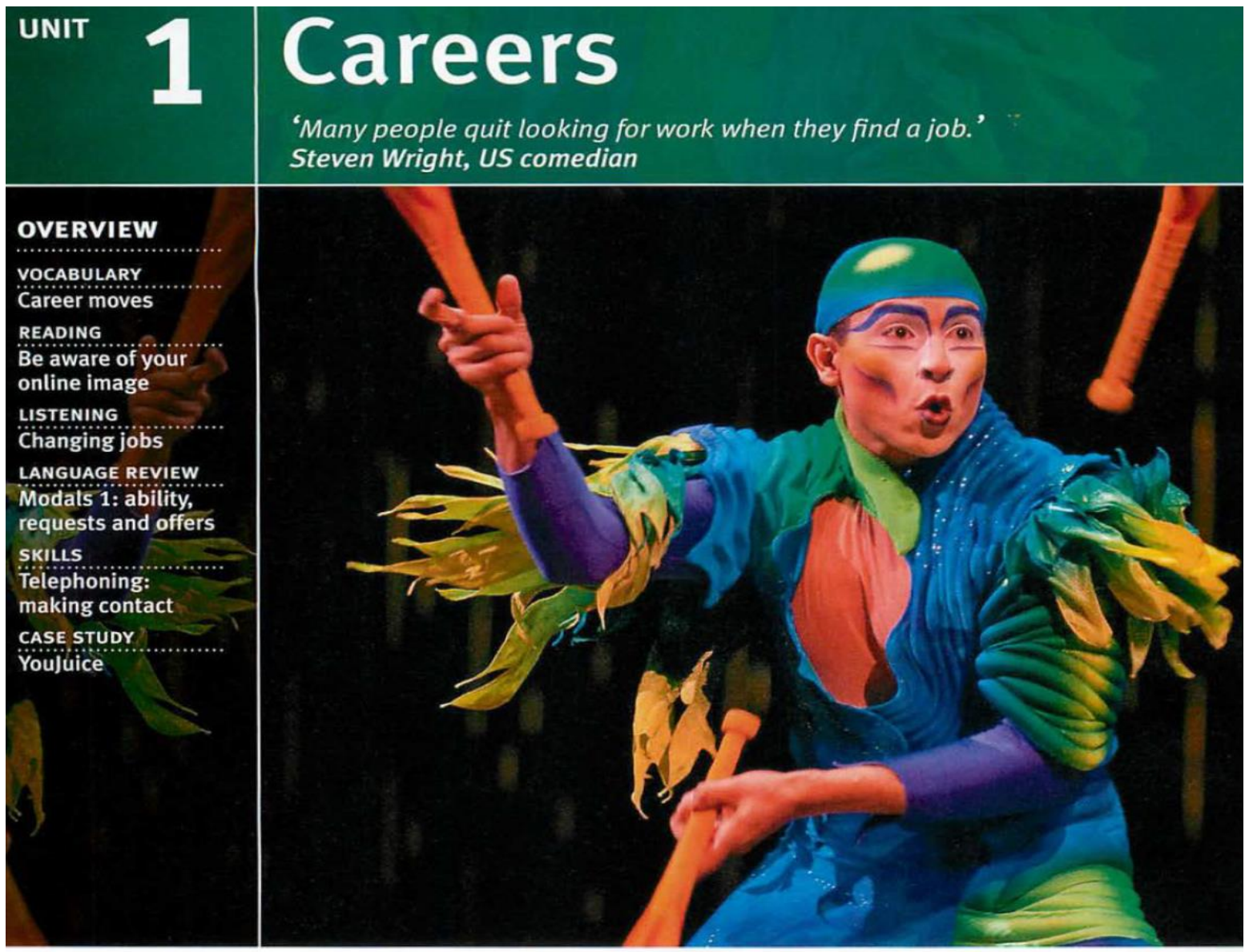

A Discuss these questions.

1 How ambitious are you?

2 Do you have a career plan? Where do you want to be in 10 years' time?

3 Which of the following would you prefer to do?
a) work for one company during your career
b) work for several different companies
c) work for yourself

B Look at these activities (1-7). In pairs, match each activity to its corresponding area of work $(\mathrm{a}-\mathrm{g})$. Which of these areas do you work in or would you like to work in? Why?
1 making/manufacturing things
a) Sales and Marketing
2 being in charge of people
b) Finance and running the organisation
c) Management
3 selling products or services
d) Human Resources (HR)
4 dealing with clients/consumers
e) Production
5 working with figures
6 dealing with employees and training
f) Research and Development (R\&D)
g) Customer Service

7 investigating and testing 
C What should you do to get ahead in your career? Choose the four most important tips from this list. Compare your ideas in a group and try to agree on a final choice.
1 Change companies of ten.
5 Be energetic and enthusiastic at all times.
2 Use charm with your superiors.
6 Be the last to leave work every day.
3 Attend all meetings.
7 Find an experienced person to give you help and advice.
4 Go to your company's social functions.
8 Study for extra qualifications in your free time.

\begin{tabular}{|c|} 
VOCABULARY \\
Career moves
\end{tabular}

These phrases (1-6) all include the word career. Match each of them to its correct meaning (a-f). Use a dictionary to help you.
1 career move
a) chances to start/improve your career
2 career break
b) ideas you have for your future career
3 career plan
c) an action you take to progress in your career
4 career opportunities
d) a period of time away from your job to, for example, look after your children
5 career path
6 career ladder
e) a series of levels or steps in your working life
f) the direction your working life takes

B (1)) $C D 1.1-1.3$ Listen to three people talking about their careers. Which person is at the beginning, in the middle and at the end of their career?

C (1)) CD1.1-1.3 Listen again. Which of the phrases with career in Exercise $A$ does each person use? Which of the experiences do you think are common?

D Complete the sentences below with the verbs in the box. Use a dictionary to help you.

climb decide trove make offer take

1 Employees in large multinationals have .. excellent career opportunities if they are willing to travel.

2 Some people ............ a career break to do something adventurous like sailing round the world or going trekking in India.

3 One way to ........... a career move is to join a small but rapidly growing company.

4 Certain companies ............. career opportunities to the long-term unemployed or to people without formal qualifications.

5 Ambitious people often ............ on a car eer plan while they are still at university.

6 In some industries, it can take a long time to ........... the career ladder.

E Look at these groups of words. Cross out the noun or noun phrase in each group which doesn't go with the verb in italics.
1 make a fortune / progress / a living / atraining course
4 do part-time work / a mistake / a nine-to-five job / your best progress / a promotion / a bonus
5 take fired $(\mathrm{AmE}) /$ the sack $(\mathrm{BrE})$
2 get
3 earn commission / a part-time
money / 40,000 per year ansion / an opportunity / time off / early retirement
6 work flexitime / anti-social hours / overtime / an office job 
F Complete each of these sentences with the appropriate form of a word partnership from Exercise $E$.

1 In banking, you can ............ with the big bonuses and retire at 35 .

2 When you ............., you can arrange your own schedule, so this is very convenient when you have children.

3 People who work in sales often have the opportunity to ........... on top of a basic salary.

4 Luke is ambitious and does not want to be a sales assistant all his life. In fact, he hopes to ............ and become Assistant Managervery soon.

5 Many students........... when they are at university because it fits in with their studies.

6 Goran is 59, but he does not want to ............ In fact, he is taking on more work!

\section{READING A Discuss these questions in pairs.}

Be aware of
your online
image

1 What social-networking sites do you a) know, and b) use?

2 Why do you use them?

B Scan the article below quickly and answer these questions.

1 What percentage of employers research candidates online?

2 Which social-networking sites are mentioned?

3 Who do Peter Cullen and Farhan Yasin work for?

\section{by Andy Bloxham}

Jobseekers have been warned that their Facebook profile could damage their employment prospects. after a study found that seven in 10 employers now research candidates online.

According to new figures released by Microsoft, checks on Facebook and Twitter are now as important in the job-selection 5 process as a $\mathrm{CV}$ or interview.

The survey, which questioned human-resource managers at the top 100 companies in the UK, the US, Germany and France, found that 70 per cent admitted to rejecting a candidate because of their online behaviour.

10 But HR bosses also said that a strong image online could actually help job hunters to land their dream job. Peter Cullen, of Microsoft, said: "Your online reputation is not something to be scared of. it's something to be proactively managed. These days, it 's essential that web users cultivate the kind of online 15 reputation that they would want an employer to see."

Facebook faux pas include drunken photographs, bad language and messages complaining about work.

Farhan Yasin, of online recruitment network Careerbuilder.co.uk, said: "Social net working is a great way to make connections with

20 job opportunities and promote your personal brand across the Internet. People really need to make sure they are using this resource to their advantage. by conveying a professional image."

But Mr Yasin cautioned job seekers to be aware of their online image even after landing the perfect job, after their own research

25 found that 28 per cent of employers had fired staff for content found on their social-networking profile. He added, "A huge number of employers have taken action against staff for writing negative comments about the company or another employee on

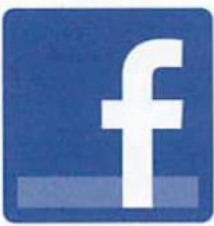

LIKE us on Facebook

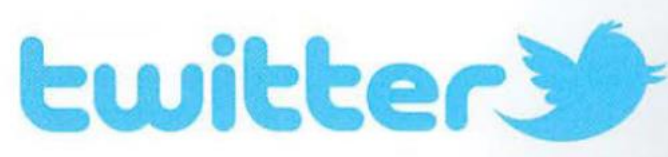

Linkedin. 
C Read the article again and choose the best headline (a, b or c).
a) Complaining about your job could lose you your job
b) Facebook profile 'could damage job prospects'
c) Ambition is key to a successful career

D According to the article, how can social-networking sites make or break your career?

E In pairs, write a short list of things you should not do on your socialnetworking pages. You can include your own ideas.

F Should staff be allowed to use social-networking sites during the working day? Discuss.

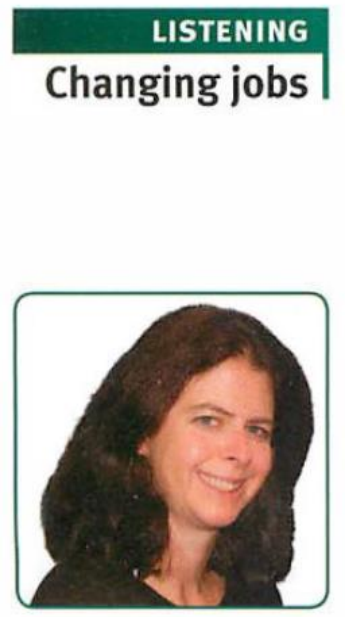

Melissa Foux
Watch the interview on the DVD-ROM.
A (1)) CD1.4 Melissa Foux is the Finance Director of CSC Media Limited, a television company. Listen to the first part of the interview and answer these questions.

1 How does she describe her current company?

2 What was her previous job?

3 Why is it easy to move from sector to sector in the finance world?

B (1) CD1.5 Listen to the second part and complete this extract.

When I was a student, although I was studying ............ I thought I would like to do something ........... ${ }^{2}$ afterwards, and I actually did a summer ........... ${ }^{3}$ with one of the big .${ }^{4}$ firms, which was an excellent way to get an ............ of what the job would be like. I started off as an auditor, and it was through that ............ ${ }^{6}$ that I got my first job.

C (1)) $C D 1.6$ Melissa is asked if she has had any good advice during her career. Listen to the third part and number these points in the order in which she mentions them.
a) maintain clarity
b) be able to see the key point and the key decision you have to make
c) do not overcomplicate things

D A) CD1.7 Listen to the final part and decide which was the interviewer's question (a, b or c).

a) What is the most interesting question you have been asked at interview?

b) What is the key difference between people who work in finance and those who work in research?

c) How would you advise people who are starting their careers?

E In groups, discuss these questions.

1 What do you hope to do in the future in your career?

2 Do you think there is an ideal career for you? What is it? Why?

3 What is the best advice you have been given during your career or your studies? 


\section{LANGUAGE REVIEW \\ Modals 1: \\ ability, requests \\ and offers}

Modal verbs are very common in English. Match these functions (a-c) to the examples (1-3).
a) making an offer
b) describing ability
c) making a request

1 Can you help me? Could you say that again, please?

2 Can I help you?

Would you like a cup of coffee?

3 I can speak Polish and Russian.

She could read and write before she was three.

Grammar reference page 141

A Rearrange the words to make questions from a job interview. Then decide whether each question is a) making a request, b) making an offer, or c) asking about ability.

1 get / you / can / / / a drink / ?

Can I getyou a drink? (b)

2 e-mail address / your / confirm / / / could / ?

$3 \mathrm{can} /$ you / spreadsheets / use / ?

4 speak / languages / any other / you / can / ?

5 about / tell / you / job / us / your present / more / could / ?

6 tell / your current salary / me / you / could / ?

7 would you / as soon as possible / your decision / let us know / ?

$8 \mathrm{start} /$ you / when / can / ?

9 like / tea / some more / you / would / ?

B Match the questions in Exercise A (1-9) to these interviewee's answers (a-i).

a) It's $€ 60,000$ a year.

b) Not very well, but I'm doing a course next week.

c) I can let you knownext week.

d) Thank you. A cup of tea, please.

e) The address is correct, but l've got a new mobile number.

f) I'd love some. Thank you.

g) Well, I'm currently supervising an HR project.

h) Yes, I can speak Korean and Japanese.

i) My notice period is two months.

C Work in pairs. Student A is an interviewer and Student B is an interviewee.

Student A: Follow the instructions below.

Student B: Answer the questions truthfully.

\section{Then switch roles.}

Student A

- Offer tea or coffee.

- Find out Student B's ability to:

1 speak any languages;

2 use Excel, PowerPoint or Publisher;

3 drive.

- Ask Student B:

1 to tell you about themselves;

2 for the best number to contact them on tomorrow;

3 to repeat the number;

4 if they would like to work abroad;

5 if there are any hours they wouldn't be able to work. 
A What kinds of phone calls do you make in English? What useful telephone

Telephoning: making contact

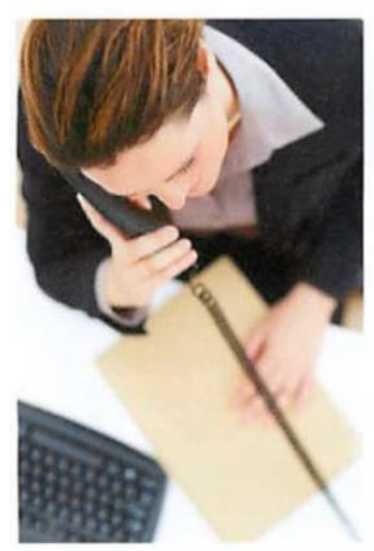
expressions do you know?

B (1)) CD1.8-1.10 Listen to three phone calls and answer these questions.

1 What is the purpose of each call?

2 Do the callers know each other?

C (1)) CD1.8 Listen to the first call again. Complete the expressions on the right so they have the same meaning as the ones on the left.
1 Can I talk to ...?
l'd like to speak to ...
2 Just a moment...
Thank you.
3 I'll connect you.
l'll
4 Am I speaking to Corina Molenaar?
Hello. Corina Molenaar?
5 Yes, it's me.
6 The reason I'm calling is ...
Yes, I'm..... your advert ...
7 Can I have your name and address?
your name and address, please?

D 1) CD1.9 Listen to the second call again and complete this extract.

A: Hello. Could I speak '. to Giovanna, please?

A: Yes, please. ${ }^{2}$ she's not here at the moment. Can I. .... be able to ${ }^{5}$ Johan from Intec. .6 you ${ }^{8}$ the training course on Saturday? She can her I won't if there's a problem. I'm ... 01914980051.

E 1 (1) CD1.10 Listen to the third call again. Choose the phrases the speakers use.

Matt: Hello, Matt speaking.

Karl: $\quad \mathrm{Hi}$, Matt. Karl here.

Matt: Oh, hello, Karl. How are things /you'?

Karl: $\quad$ Fine, thanks. Listen, just a quick word /question ${ }^{2}$.

Matt: Yeah, go ahead.

Karl: Do you think you could give me / let me have $e^{3}$ the other number for Workplace Solutions? I can't get through to them. Their phone's always busy /engaged ${ }^{4}$.

Matt: I've got it here /right in front of me $e^{5}$. It's 02097564237.

Karl: Sorry, I didn't hear $/$ catch $^{6}$ the last part. Did you say 4227 ?

Matt: No, it's 4237.

Karl: OK. Thanks. Bye.

Matt: No problem /Don't mention it'. Bye.

F Study the Useful language box below. Then role-play the phone calls. Student A: Turn to page 132. Student B: Turn to page 136.

\section{USEFUL LANGUAGE}

\section{MAKING CALLS}

Could I speak to Carmela Cantani, please? Yes, this is Erika Mueller from KMV. Is this the sales/finance/marketing department? I'm calling about ... Could you transfer me to the IT department, please? Could you tell him/her that I called? Could you ask him/her to call me back? Can I leave a message, please?

\section{RECEIVING CALLS}

Who's calling, please?

Could you tell me what it's about?

I'll put you through.

Can you hold?

He seems to be with someone right now. Can I get him to call you? I'm afraid there's no answer. Can I take a message?

I'm sorry, there's no answer. I can transfer you to his/her voice mail. 


\section{YOUJUICE \\ An international drinks company needs a dynamic new director to build its Latin American sales}

\section{Background}

Youjuice Inc., based in Monterrey, Mexico, sells ready-to-drink juices all over the world. It was originally a Mexican company, but it is now owned by a large US corporation. YouJuice is currently looking for a Sales and Marketing Director for its sales facilities in Brazil, Argentina and Colombia.

Recently, sales results have been poor. Overall, sales revenue was $35 \%$ below target. The reasons are:

- Sales staff are not highly motivated, and staff turnover is high.

- The Sales Managers say that the low sales are due to strong competition in this segment of the market.

- The previous director had no clear strategy for developing sales.

- Not enough market research has been done, and the customer database does not produce reliable results.
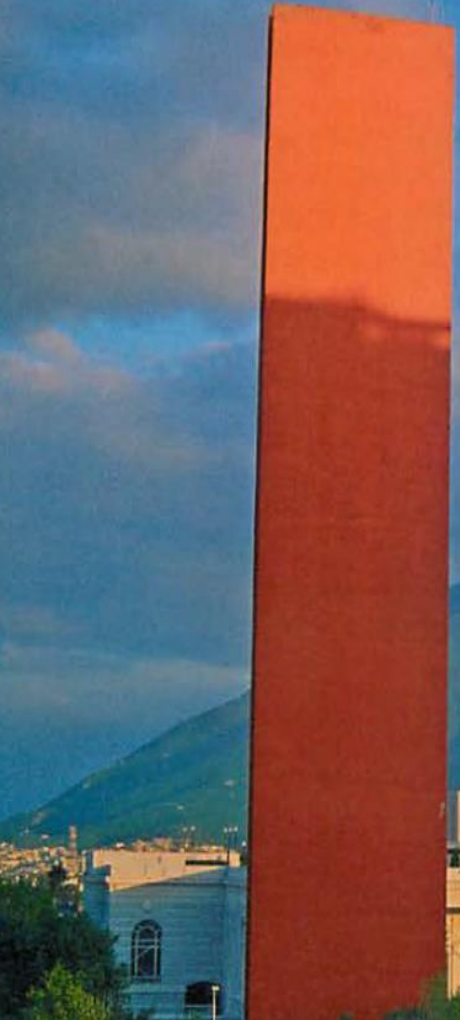

\section{A new appointment}

There are three candidates for the position of Sales and Marketing Director. They all work for Youjuice in either Mexico or one of the foreign subsidiaries. The new director will be based in São Paulo, Brazil. Here is an extract from the job description for the position.

The successful candidate will be responsible for: - increasing sales and developing marketing strategies

- coordinating the work of the sales teams so that they are more motivated and effective

- carrying out market research to improve customer numbers.

The successful candidate will be:

- a strong personal ity with leadership qualities

- energetic, dynamic, and enthusiastic.

He/She will have:

- a good academic background and relevant work experience

- organizational and interpersonal skills

- numeracy skills and analytical ability

- good linguistic ability.

The position will involve frequent travel in the three countries.
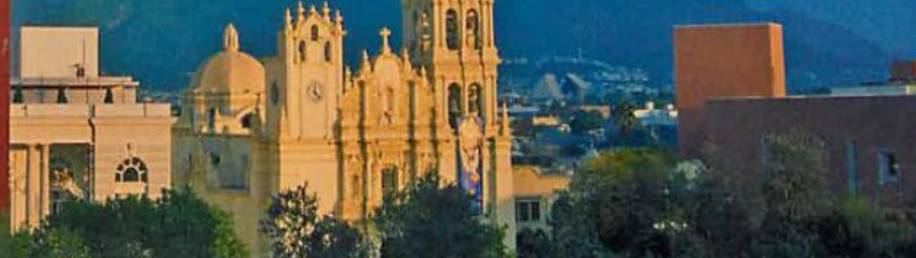


\section{Profiles of the candidates}

Read the essential information about each candidate. Then listen to the interview extracts.

(1)) CD1.11, 1.12 Juana Ramos

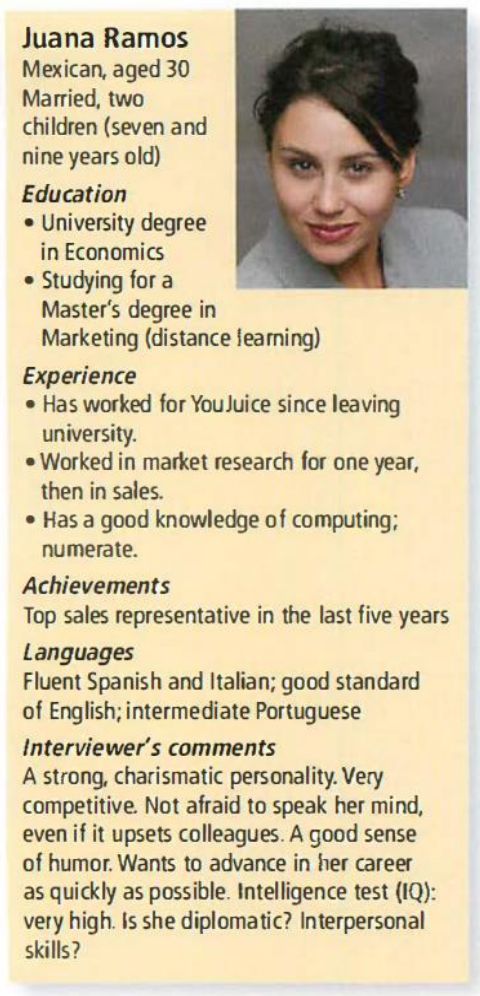

(1) CD1.13, 1.14 Chantal Lefevre

Chantal
Lefeure
Swiss, aged 41
Divorced, one child
(five years old)
Education
- University degree
in Business
Administration
- Diploma in Marketing
Experience
- 'Two years' market research, then over
15 years' sales and marketing in various
companies, including one year in Spain
and six years in Portugal.
- Joined You Juice three years ago as sales
representative in Switzerland. Very hard-
working. Has done an excellent job and
earned large bonuses each year.
Achievements
A good sales record in all her previous
positions
Languages
Fluent Portuguese; intermediate Spanish;
excellent English
Interviewer's comments
A quiet, modest person, but very eager to
progress in her career. Answered questions
directly and honestly. A sociable person.
She's chief organizer of her local tennis club.
Believes that the new director should involve
staff in all decisions. Intelligence test (IQ):
average. Leadership qualities? Decisive?

(b)) CD1.15, 1.16 Jeff Sanderson

Jeff Sanderson
American, aged 54
Single
Education
- University degree
in Sociology
- Master's in
Business
Administration
(MBA) from
Harvard Business School
Experience
Joined You Juice 20 years ago. Has always
worked in sales. In the last five years, Sales
Manager (France and Italy).
Achievements
Has increased sales by $8 \%$ in the five-year
period
Languages
Fluent English and Portuguese; Spanish:
good reading skills, needs to improve his
oral ability
Interviewer's comments
A serious person. Respected by his staff.
Has a strong sense of responsibility. 'I am
a company man.' Not very creative. Believes
new ideas should come from staff. Some
staff say he's a workaholic and difficult
to get to know. Very interested in South
American cultures. Intelligence test (IQ):
above average. Why does he really want
the job? Energetic enough?

Watch the case

study commentary

on the DVD-ROM.

1 Work in groups. You are members of the interviewing team. Discuss the strengths and weaknesses of each candidate. Decide who to select for the vacant position. Note down the reasons for your choice.

2 Meet as one group. Discuss your choices. Decide who should fill the vacant position.

\section{Writing}

Complete this e-mail from the head of the interviewing team to Claudia López, Regional Director of Youjuice. Write about at least three strengths of the candidate you have chosen. Explain how these strengths relate to the job description.

\begin{tabular}{rl|}
\cline { 2 - 2 } To: & Regional Director \\
From: & Head, interviewing team \\
Subject: & Appointment of Sales and Marketing Director (Brazil, Argentina, Colombia)
\end{tabular}

Dear Claudia

We recently interviewed three candidates for this position.

We have decided to appoint ...

I will briefly describe the candidate's strengths and explain the reasons for our decision.

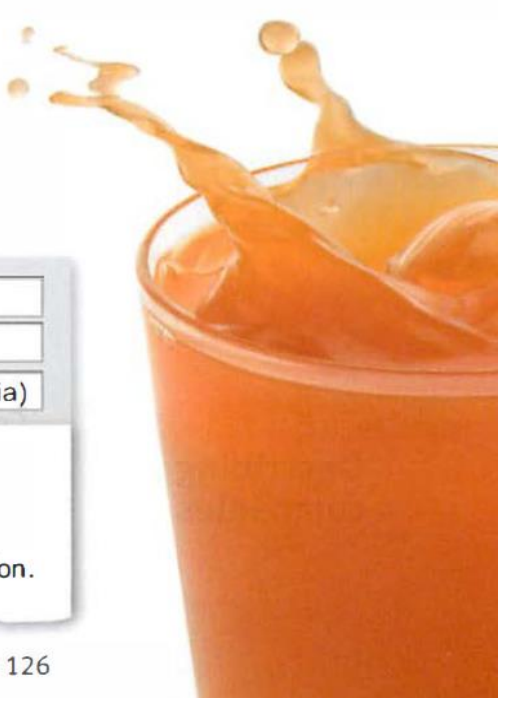




\section{Practice Book 2, Unit 8: Markets}

\section{Listening}

You will hear 10 questions. Some questions will begin with Wh-questions. Others will be yes/no questions or polite requests. The answer to a yes/no question is sometimes a statement without yes or no.

\section{Example}

Are you in charge of this project?

(A) No, they only charged us 100 dollars.

(B) No, Mrs. Ono is the supervisor.

(C) No, it's not very large.

The correct answer is (B). Choice (A) tries to confuse you by using charged in a different context. Choice (C) tries to confuse you with the similar sounding word large for charge.

These are some words you might hear in questions.

- Where

- How much

- When/what time

- What

- Which

- How many times

\section{Vocabulary}

Match the word with its definition. The first one has been done for you.

1. a pay phone

2. favorite

3. full

4. connection

5. biology

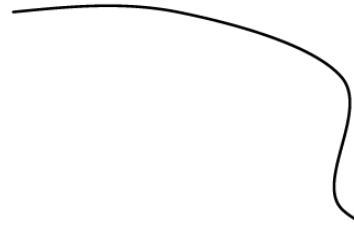

a. having had enough to eat and drink

b. best liked

c. connecting to the internet

d. study of plants and animals

e. coin-operated telephone

\section{Practice}

DIRECTIONS: Listen to the questions, which are followed by three responses. They will not be written out for you. Choose the best response to each question.
1. (A) (B) (C)
6. (A) (B) (C)
2. (A) (B) (C)
7. (A) (B) (C)
3. (A) (B) (C)
8. (A) (B) (C)
4. (A) (B) (C)
9. (A) (B) (C)
5. (A) (B) (C)
10. (A) (B) (C) 


\section{Speaking}

Participating in discussions

A. Write the sentences 1 to 8 under the correct heading.

\begin{tabular}{|l|l|l|l}
\hline Agreeing & Disagreeing & Asking for opinions & Making suggestions \\
\hline & I don't know about that. & & \\
& & & \\
& & & \\
& & & \\
\hline
\end{tabular}

1. I don't know about that.

2. What do you think?

3. How about increasing the budget?

4. I agree; the sales figures are very good.

5. I'm afraid I don't agree.

6. Let's launch the product in June.

7. You're right. I like that idea.

8. How do you feel about this, Karin?

B. Work in groups of four. Role play this situation. You are directors. Look at the list. Discuss which three benefits to offer key employees in your company.

\section{Benefits}

- A seven-day company conference in Fiji

- A bonus ( $10 \%$ of employees' salary)

- A new company car

- Free health insurance for employees' families

- Low cost holidays (company apartments in Italy)

- Corporate entertainment (free tickets to the opera, theatre and concerts)

- Financial help with housing costs

- Free private education for employees' children 


\section{Reading}

\section{Business reading 1}

Read the following passage and answer the questions that follow.

After two decades of growing student enrollments and economic prosperity, business schools in the United States have started to face harder times. Only Harvard's MBA School has shown a substantial increase in enrollment in recent years. Both Princeton and Stanford have seen 5 decreases in their enrollments. Since 1990, the number of people receiving Masters in Business Administration (MBA) degrees, has dropped about 3 percent to 75,000 , and the trend of lower enrollment rates is expected to continue.

There are two factors causing this decrease in students seeking an MBA degree. The first one is that many graduates of four-year colleges are finding that an MBA degree does not guarantee a plush job on Wall Street, or in other financial districts of major American cities. Many of the entry-level management jobs are going to students graduating 15 with Master of Arts degrees in English and the humanities as well as those holding MBA degrees. Students have asked the question, "Is an MBA degree really what I need to be best prepared for getting a good job?" The second major factor has been the cutting of American payrolls and the lower number of entry-level jobs being offered. Business needs are changing, and MBA schools are struggling to meet the new demands.

\section{Choose the best answer}

1. What is the main focus of this passage?
(A) jobs on Wall Street
(B) types of graduate degrees
(C) changes in enrollment for MBA schools
(D) how schools are changing to reflect the economy

2. The phrase "two decades" in line 1 refers to a period of
(A) 10 years
(B) 20 years
(C) 50 years
(D) 100 years

3. Which of the following business schools has NOT shown a decrease in enrollment?
(A) Princeton
(B) Harvard
(C) Stanford
(D) Yale

What does each of the following underlined words/phrases refer to?

4. "The first one is that many graduates of four-year colleges ...."( paragraph 2)

5. "... and the humanities as well as those holding MBA degrees." ( paragraph 2)

Which words in the passage mean the following?

6. to become less, or to make something become less

7. the qualification given to a student who has done this course

8. a person who has finished their school, college or university education

Fill in each blank with ONE suitable word from the passage. Put it in its correct form or tense if necessary.

9. This company many good opportunities for its hard-working workers to get promotion.

10. The lending interest have been pushed by commercial banks up to 20-22 percent per year. 


\section{Business reading 2}

\section{CORPORATE FINANCE}

Corporations need financing for the purchase of assets and the payment of expenses. The corporation can issue shares in exchange for money or property (sometimes referred to as equity funding). The holders of the shares together form the ownership of the company. Each share is represented by a stock certificate. This is negotiable, which means that it can be bought and sold. The value of a share is determined not only by the net assets divided by the total number of shares outstanding, but also by any particular rights it gives to shareholders. The greater the success of the company, the more value the shares usually have.

A corporation can also get capital funds by borrowing. This is called debt funding. When corporations borrow money, they give notes or bonds, which are also negotiable. However, interest has to be paid out whether the business is profitable or not.

Management must consider both the outflow and inflow of capital funds in running the corporation. The purchase of inventory and supplies, or payment of salaries, results in an outflow. The sale of goods and services results in an inflow. In the long run, the inflow must be greater than the outflow to result in a profit. In addition, a company must deduct its costs, expenses, losses on bad debts, interest on borrowed capital and other items in order to determine whether its financial management has been profitable. The amount of risk involved is an important factor in determining fund raising and whether a particular corporation is a good investment.

\section{Note- taking}

\section{Complete the following guided notes.}

1. The reasons for financing

2. The value of a share or certificate is usually determined by

3. Example of activities that produce an inflow of capital

4. Examples of activities that produce an outflow of capital

\section{Comprehension}

What does each of the underlined parts refer to?

5.“... but also by any particular rights it gives to shareholders...." (Paragraph 1)

6.“... they give notes or bonds, which are also negotiable." (Paragraph 2) 


\section{Writing}

\section{THE NON - DEFINING RELATIVE CLAUSE}

\section{THE NON DEFINING RELATIVE CLAUSE}

* Non defining relative clauses are placed after nouns which are definite already. They do not therefore describe the noun, but merely provide some additional information.

* The non defining relative clause is separated from the main clause by commas (,)

Compare:

The man who is the Managing Director of Travel Services visited the trade fair in Cairo. Mr. Benson, who is the Managing Director of Travel Services, visited the trade fair in Cairo.

The following is a table of subordinators used in non-defining relative clauses.

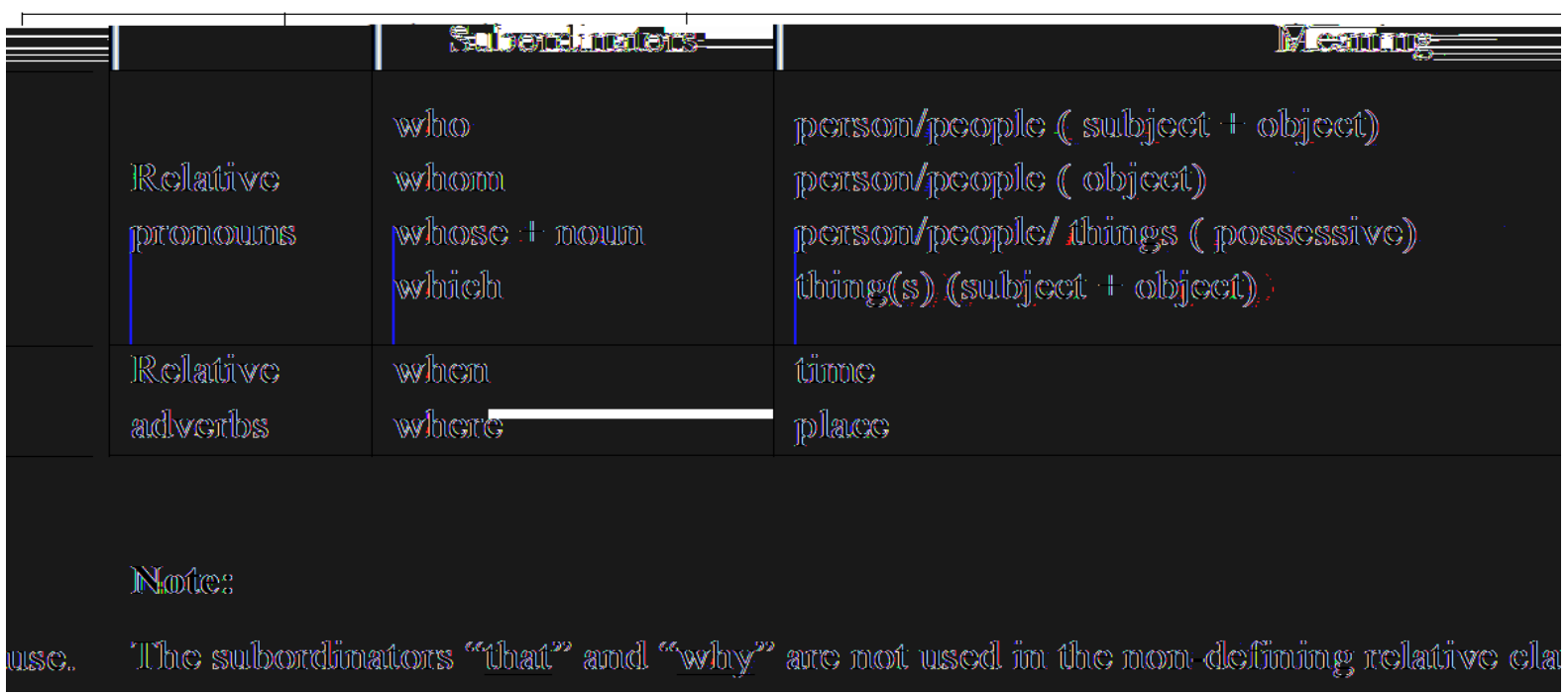


2. Combine two sentences in each pair to make a complex sentence containing a non-defining or defining relative clause. Put the relative clause immediately after the noun it describes. Add commas to the non-defining relative clause

1. The Managing Director of Gourmet LTD is Mr. Mann.

His expertise on financial investments is well-known.

2. It is important to sometimes see clients in a more relaxed atmosphere.

You can get to know your business partner better in a more relaxed atmosphere.

3. Mr. Sanchez has been the manager of General Union Bank PLC for five years.

Mr Blake met Mr. Sanchez at the convention in Paris.

4. The man is an engineer of Travel Services.

That man got an electric shock when fixing a duplicator.

5. Stockholders are not responsible for a company's debts.

Stockholders' financial liability is limited.

6. Paul Rime manages lmpex International.

Impex International employs 94 people in five offices.

7. Tet is the time.

All offices and businesses are closed at that time.

8. The factory finances its expansion by issuing more stock.

My brother is working in that factory. 
9. The anual conference of the Association of European Exporters adjourns at 11 o'clock. All participants will have coffee break at 11 o'clock.

10. Mr. Green is planning the tour.

His clients will be most interested in that tour.

11. The document is called a statement.

The document shows all your transactions.

12. The secretary is going to leave the firm.

Her salary has not been raised for two years. 


\section{Extract English translations}

(1) "My number-one priority in teaching pronunciation is to help my students achieve intelligible pronunciation for successful communication. In English learning, I think the ability of pronouncing like a native speaker depends on different factors, one of which is the learner's aptitude. But our students have been exposed to English for over seven years, so I think it's very hard for them to acquire a native-like accent now." (P1, Teacher SRI, Q1, Diep)

(2) "My goal is to help my students achieve intelligible pronunciation for successful communication rather than native-like pronunciation. If people could understand what they say in English, then I would be more than happy. Nativeness is something illusive for our students at this stage to acquire as they have aged." (P1, Teacher SRI, Q1, Na)

(3) “(...) The first factor is that there's too much to teach in each lesson. There has been an overload of knowledge that needs transferring and so we don't have time for pronunciation teaching. Time is too limited while classes are too crowded. We only have four periods per week in 12 weeks

\section{Original Vietnamese}

Uu tiên số 1 của em khi dạy phát âm là giúp sinh viên phát âm đúng và rõ để đạt được mục đích giao tiếp. Em nghĩ trong việc học tiếng Anh, cái khả năng phát âm theo giọng bản xứ tuỳ thuộc nhiều yếu tố và trong đó có yếu tố năng khiếu của từng sinh viên. Nhưng mà sinh viên trường mình đã học tiếng anh 7 năm rồi cho nên em nghĩ bây giờ cũng rất khó để hi vọng các em có thể luyện phát âm được như giọng bản ngữ.

Mục tiêu dạy phát âm của em là giúp sinh viên phát âm đúng và rõ để đạt được mục đích giao tiếp chứ không thể như người bản xứ. Các em nói tiếng Anh mà người khác nghe hiểu được là đã vui lắm rồi. Phát âm chuẩn như người bản xứ là quá xa vời đối với các em ở tuổi này. Các em lớn rồi nên rất khó.

(...) Yếu tố thứ nhất là có quá nhiều thứ cần phải dạy trong một buổi. Nó quá tải rồi nên không còn thời gian dành cho việc dạy phát âm nữa. Lớp thì đông mà thời gian lại hạn chế. Mỗi tuần mình dạy có 4 tiết trong vòng 12 tuần mà lượng 


\begin{tabular}{|c|c|c|}
\hline & $\begin{array}{l}\text { whereas what we must cover is enormous.” } \\
\text { (P1, Teacher SRI, Q4, Phuong) }\end{array}$ & $\begin{array}{l}\text { kiến thức cần truyền tải lại quá } \\
\text { nhiều. }\end{array}$ \\
\hline (4) & $\begin{array}{l}\text { “(...) The number of students and time } \\
\text { allotted in the curriculum are the two main } \\
\text { factors that influence my pronunciation } \\
\text { teaching. Whatever we do, we have to } \\
\text { comply with the obligations in } \\
\text { implementing the curriculum. Giving } \\
\text { students more opportunities to practice } \\
\text { pronunciation is good but the timeframe } \\
\text { doesn't allow it. If I try to teach } \\
\text { pronunciation explicitly, then I won't be } \\
\text { able to finish what I'm required to do by } \\
\text { the programme." (P1, Teacher SRI, Q4, } \\
\text { Na) }\end{array}$ & $\begin{array}{l}\text { (...) Thời gian khóa học và bản } \\
\text { thân sinh viên là hai yếu tố lớn nhất } \\
\text { ảnh hưởng đến thực tiễn giảng dạy } \\
\text { môn phát âm của em. Mình muốn } \\
\text { dạy như nào cũng buộc phải theo } \\
\text { quy định trong chương trình. Cho } \\
\text { sinh viên luyện phát âm cũng tốt } \\
\text { nhưng mà vấn đề là thời gian } \\
\text { không cho phép. Nếu cố dạy bài } \\
\text { bản và cho sinh viên luyện tập thì } \\
\text { không thể theo kịp chương trình. }\end{array}$ \\
\hline (5) & $\begin{array}{l}\text { "Another factor is course books. Neither the } \\
\text { main textbooks nor the supplementary } \\
\text { materials we're using comprise any section } \\
\text { for pronunciation instruction. If we had this } \\
\text { section [pronunciation] in teaching } \\
\text { materials, we would be able to teach } \\
\text { students [pronunciation] explicitly without } \\
\text { the need to adapt materials from other } \\
\text { sources while still managing to cover the } \\
\text { required programme." (P1, Teacher SRI, } \\
\text { Q4, Quynh) }\end{array}$ & $\begin{array}{l}\text { Giáo trình cũng là một yếu tố. Giáo } \\
\text { trình chính cũng như tài liệu bổ trợ } \\
\text { mà chúng tôi đang sử dụng cũng } \\
\text { không có phần dạy phát âm nào cả. } \\
\text { Nếu mà giáo trình có phần này thì } \\
\text { có thể dạy cho sinh viên mà không } \\
\text { cần lấy từ nguồn khác và như vậy } \\
\text { vẫn đảm bảo theo kịp chương trình } \\
\text { chung. }\end{array}$ \\
\hline (6) & $\begin{array}{l}\text { "Second, course books also have influence } \\
\text { on my practice of pronunciation teaching. } \\
\text { The main textbooks and the Practice Books } \\
\text { only focus on the four main language } \\
\text { skills: listening, speaking, reading, and } \\
\text { writing. So, it's really difficult to }\end{array}$ & $\begin{array}{l}\text { Thứ hai là giáo trình giảng dạy } \\
\text { cũng có tác động đến việc dạy phát } \\
\text { âm của cô. Trong giáo trình chính } \\
\text { cũng như Practice Book chỉ tập } \\
\text { trung } 4 \text { kĩ năng nghe nói đọc viết } \\
\text { nên cũng rất là khó để mà đưa }\end{array}$ \\
\hline
\end{tabular}


supplement the lesson with pronunciation

materials from outside the textbooks." ( $\mathrm{P} 1$,

Teacher SRI, Q4, Phuong)

(7) "Course books are another factor. The course books being used at my university exclude pronunciation. Meanwhile, teachers are required to stay on schedule in their teaching regarding the timeframe and what must be covered in class has been overloaded already. So, I think it's hard to adapt pronunciation materials from outside the textbooks even though sometimes I'm willing to teach pronunciation explicitly." (P1, Teacher SRI, Q4, Diep)

(8) “Another factor is students' pronunciation errors. As I've just said, we don't have enough time to transfer all the content knowledge prescribed in the curriculum, and so correcting students' errors (...) is the quickest and most effective way.

Moreover, these [pronunciation] errors are common amongst Vietnamese learners." (P1, Teacher SRI, Q4, Quynh)

(9) 'Correcting students' pronunciation errors not only works for those students but it also makes other students aware of such errors and so they can correct themselves. This way could help me save time for other tasks." (P1, Teacher SRI, Q4, Nguyen) thêm bài vở ở ngoài vào để dạy phát âm.

Một yếu tố khác nữa đó là giáo trình. Giáo trình đang sử dụng ở trường mình không có phần dạy phát âm. Trong khi đó giáo viên buộc phải dạy cho kịp chương trình vì lượng kiến thức thì quá tải. Vì vậy em nghĩ khó để đưa thêm tài liệu phát âm ở ngoài vào để dạy mặc dù đôi lúc em cũng muốn dạy phát âm cho bài bản.

Cái nữa là lỗi phát âm của sinh viên. Như tôi vừa mới nói thì do không có thời gian để dạy hết nội dung trong chương trình cho nên việc sửa lỗi cho sinh viên (...) là cách nhanh nhất và hiệu quả nhất. Hơn nữa, các lỗi mà các em mắc cũng là lỗi chung mà sinh viên người Việt hay gặp.

Việc sửa lỗi phát âm cho sinh viên để không chỉ tốt cho riêng bản than những sinh viên đó mà kể cả những sinh viên khác cũng chú ý và sửa được những lỗi sai đó. Cách này có thể tiết kiệm được thời gian để làm việc khác.

Em nghĩ khi em sửa lỗi phát âm cho sinh viên sẽ giúp cả lớp ý thức 
class aware of these errors and they'll be more conscious when encountering words containing these sounds in the future." (P1, Teacher SRI, Q4, Na)

(11) "If my students pronounce a certain word incorrectly, then I'll encourage them to look it up in the dictionary and correct their pronunciation by themselves. This helps establish a habit of self-regulated learning for students and so they won't rely heavily on the teacher, such that they only study what the teacher teaches." (P1, Teacher SRI, Q4, Khoa)

(12) 'Raising the students' awareness of their own pronunciation errors for selfcorrection promotes students' independence in self-regulated learning. I usually provide transcriptions of sounds on the board and show my students how to articulate them so they by themselves can correctly pronounce a new word containing those sounds when they look it up in the dictionary." (P1, Teacher SRI, Q4, Na)
“Also, from my own experience and observations, I realise that today many students tend to aim at fluency rather than accuracy in their speaking. They think they only need to be fluent so that other people can understand what they say, so they don't pay attention to pronunciation practice. But they aren't aware that many được các lỗi này và sẽ chú ý hơn sau này khi gặp lại những từ có các âm đó.

Nếu sinh viên phát âm sai một từ nào đó thì em sẽ khuyến khích các em tự dò từ điển và tự sửa, giúp các em hình thành thói quen tự giác trong việc học và không phụ thuộc hoàn toàn vào giáo viên, kiểu như giáo viên cho bao nhiêu học bấy nhiêu.

Việc giúp sinh viên tự nhận ra lỗi trong phát âm của mình để tự sửa sai sẽ giúp sinh viên độc lập hơn trong việc tự học ở nhà. Em thường viết phiên âm quốc tế lên bảng và hướng dẫn sinh viên phát âm để sinh viên có thể tự phát âm được các từ có chứa những âm này khi tra từ điển ở nhà.
Hơn nữa, theo kinh nghiệm và quan sát của riêng tôi thì tôi nhận thấy hiện nay có một xu hướng chung đối với nhiều sinh viên là các em không cần phát âm cho chuẩn mà chỉ cần nói trôi chảy một chút để người ta nghe hiểu là được rồi. Vì vậy mà các em không chú trọng vào việc luyện 
pronunciation errors in their speaking

make their conversations unsuccessful. I

think this can be solved by teachers raising

learner awareness for error detection and self-correction. And when they're aware of this, there'll be positive changes in their attitudes towards pronunciation practice." (P1, Teacher SRI, Q4, Quynh) phát âm lắm. Tuy nhiên, các em không hề nhận thức được là các lỗi phát âm các em mắc trong khi giao tiếp sẽ khiến các em không đạt được mục đích giao tiếp. Theo tôi thì cái này có thể thay đổi bằng cách giáo viên giúp sinh viên nâng cao ý thức trong việc phát hiện ra lỗi sai và tự sửa lỗi cho mình. Và khi mà các em đã hình thành được ý thức như vậy thì thái độ của các em đối với việc luyện phát âm sẽ tích cực hơn.

Một yếu tố nữa là trình độ của sinh viên. Ở trường mình thì chỉ có số ít sinh viên giỏi tiếng Anh còn đa phần là các em yếu. Vì vậy theo cô thì cách tốt nhất là sửa lỗi phát âm cho các em giống như cô hay làm trong lớp. Với cô thì cách này ít nhiều cũng có hiệu quả đối với việc học tiếng Anh của sinh viên. Các em sẽ chú ý hơn về việc luyện phát âm và do đó sẽ ý thức hơn trong việc tự học. Đối với sinh viên trình độ khá hơn thì có thể cô sẽ dạy phát âm một cách bài bản thay vì chỉ sửa lỗi bằng cách cho nghe và lặp lại vì chắc chắn sẽ khiến các em thích thú hơn trong việc học phát âm và không khí lớp học cũng dễ chịu hơn. Tuy nhiên, việc này cũng chỉ dừng lại ở mức hết sức căn bản chứ không thể 
đào sâu được vì mình không có thời gian.

(15) 'Students' proficiency levels also have a big Trình độ của sinh viên cũng ảnh influence on my pronunciation teaching hưởng lớn đối với việc dạy phát âm practices. Most students at my university are của em. Đa số sinh viên trường weak at English, so I think it's useful to mình tiếng Anh yếu cho nên em correct their pronunciation errors or raise their awareness for error detection and selfcorrection through repetition. But for higher-level students, this teaching approach will make them bored and demotivated because they'll feel as if they were child learners. For higher-level students, the explicit teaching of pronunciation will work but I think listenand-repeat activities should be skipped." (P1, Teacher SRI, Q4, Khoa) nghĩ việc sửa lỗi hoặc lưu ý các em lỗi sai và khuyến khích các em tự sửa lỗi cũng rất hữu ích. Tuy nhiên, đối với sinh viên khá hơn thì cách dạy như này theo em sẽ làm các em chán nản và mất hết động lực vì cảm giác học như kiểu của con nít. Cho nên theo em việc dạy phát âm một cách bài bản đối với sinh viên trình độ khá sẽ ok nhưng nên bỏ qua hoạt động listen-and-repeat.

(16) "I think level 2, not very confident. This is Em nghĩ chắc là level 2 - không tự why I seldom teach pronunciation in class. The reason is that I wasn't taught how to teach pronunciation when doing my BA and MA.” (P1, Teacher InI, Q2, Diep) tin lắm. Đây là lí do vì sao em hiếm khi dạy phát âm trong lớp. Do là hồi lúc em học đại học cũng như học Thạc sĩ đâu có môn này nên đâu có ai dạy em cách dạy phát âm đâu.

(17) "I think level 3-confident is my choice. The Anh nghĩ chắc là mức 3 reason is that I'm confident of my pronunciation skill and my teaching confident, là lựa chọn của anh. Lý ability.” (P1, Teacher InI, Q2, Nguyen) do là anh tự tin vào kĩ năng phát âm cũng như năng lực giảng dạy của mình.

(18) “Number 3-confident, because I'm Mức 3 - confident. Bởi vì em tự tin confident of my pronunciation skill and my vào kĩ năng phát âm cũng như khả ability in transferring knowledge to my năng truyền tải kiến thức đến sinh students." (P1, Teacher InI, Q2, Khoa) viên. 
(19) "If to teach pronunciation explicitly, I think both are important as they're both necessary for learners' listening and speaking skills. But I feel more confident and so usually focus on vowels and consonants because I can give students visual illustrations of articulators and easily explain to them places of articulation.” (P1, Teacher InI, Q3, Quynh)
Nếu mà để dạy phát âm cho bài bản thì theo tôi cả hai đều cần thiết đối với kĩ năng nghe nói của các em. Tuy nhiên, tôi cảm thấy tự tin hơn và thường tập trung dạy nguyên âm phụ âm. Lý do là tôi thấy dễ dạy hơn khi mà mình có thể giải thích cho sinh viên các cơ quan vị trí cấu âm bằng hình ảnh minh họa.

Em nghĩ nguyên âm phụ âm quan trọng hơn nên đó là lí do vì sao em thường dạy âm. Thêm nữa là khi dạy nguyên âm phụ âm mình có thể dung tranh ảnh khi giải thích các cơ quan vị trí cấu âm khác nhau và như vậy sinh viên sẽ dễ hiểu hơn. Ngữ điệu hơi trừu tượng và khó để giúp các em hiểu rõ. and it's hard to help students get the hang of it." (P1, Teacher InI, Q3, Khoa)

(21) "I feel more confident in teaching sounds because I think students find it easier to understand how to use different articulators such as lips, teeth and tongue using pictures. Intonation is quite complex and it's not easy for students to understand teachers' explanations because we can't use visual aids." (P1, Teacher InI, Q3, Na)

(22) "To tell the truth, I've never heard about this and so really want to know what it is and how it works. Then I can apply it in my teaching.” (P1, Teacher InI, Q5, Quynh)
Em cảm thấy tự tin hơn khi dạy âm vì theo em sinh viên dễ hiểu hơn khi mình dùng hình ảnh minh họa cách đặt môi răng lưỡi. Phần ngữ điệu hơi phức tạp mà mình lại không thể dùng tranh ảnh để minh họa giải thích cho sinh viên hiểu.

Nói thật, tôi cũng chưa bao giờ nghe qua cách dạy này vì vậy thật sự rất muốn tìm nhiểu về nó để 
xem nó như nào. Cũng có thể áp dụng được trong việc giảng dạy.

(23) 'I've heard about it somewhere but didn't take the trouble to figure it out. So, I really want to study it because this is actually very necessary. If teachers are good at pronunciation skills and knowledgeable about pronunciation teaching theory, then it'll be much more useful as they can promote student learning more efficiently." (P1, Teacher InI, Q5, Nguyen)

(24) "Actually, I have no idea about this teaching approach. Of course, I'm really keen to understand how it works in practice and hopefully I can apply this framework in my teaching practice." (P1, Teacher InI, Q5, Khoa)

(25) "Yes, absolutely. I hope that this course can promote my pronunciation teaching competence. After the course, I expect that I'll be able to teach pronunciation more efficiently and so can help improve students ' pronunciation in particular and their oral communication skill in general." (P1, Teacher InI, Q6, Quynh)
Anh có nghe qua đâu đó rồi nhưng không tìm hiểu. Do đó cũng rất muốn tìm hiểu kĩ xem bởi vì thật sự cái này cũng hết sức cần thiết. Nếu mà giáo viên giỏi kĩ năng phát âm và vững kiến thức về lý thuyết dạy thì sẽ hữu ích hơn nhiều vì sẽ giúp sinh viên học tiếng hiệu quả hơn.

Thực sự em cũng chưa biết về cách dạy này. Chắn chắn là em rất muốn tìm hiểu xem thực tế nó như nào và hi vọng em có thể ứng dụng cái framework này vào việc giảng dạy của em.

Đương nhiên là có rồi. Tôi hi vọng là khóa bồi dưỡng này có thể giúp tôi phát triển khả năng dạy phát âm của mình. Sau khóa bồi dưỡng thì tôi mong đợi là mình sẽ dạy phát âm hiệu quả hơn. Giúp sinh viên cải thiện được kĩ năng phát âm nói riêng và kĩ năng giao tiếp bằng lời nói tốt hơn.

Có, tất nhiên rồi. Và cô có hai cái mong đợi lớn. Thứ nhất là cô hi vọng mở rộng kiến thức về phát âm tiếng Anh cũng như là lý thuyết dạy kĩ năng này. Nhưng mà mong đợi lớn nhất của cô là khóa học này 
(...) I think a professional learning course specialising in communicative pronunciation teaching is very necessary because teachers can apply the knowledge in their teaching jobs." (P1, Teacher InI, Q6, Phuong)

(27) "Yes. I expect to update state-of-the-art theories about how to teach pronunciation communicatively. Hopefully this course can promote my pronunciation teaching competence so that I'll be able to teach pronunciation more effectively and help students improve their pronunciation skills." (P1, Teacher InI, Q6, Nguyen)

(28) "Yes. If I have a chance for a learning course like this, then I'll certainly go for it. My expectation is that this course can promote my pronunciation teaching competence and so I'll feel completely confident teaching pronunciation to my students." (P1, Teacher InI, Q6, Na)

(29) "First, I think universities offering EFL teacher training programmes need to pay more attention to intakes. We don't need to train so many [ELT students]. We only train a few but they must be of high quality. So, I think they should only accept students who have achieved a high level of English proficiency. The higher the quality of intakes, the better the outcomes are assured." (P2, Teacher InI, Q7, Na) có thể cải thiện năng lực dạy phát âm của cô. (...) Cô nghĩ khóa bồi dưỡng chuyên về dạy phát âm theo định hướng giao tiếp là hết sức cần thiết để giáo viên có thể áp dụng trong việc giảng dạy của mình.

Có. Anh mong đợi được cập nhật được lý thuyết hiện đại về việc dạy phát âm theo định hướng giao tiếp. Hi vọng khóa học này có thể giúp anh cải thiện năng lực dạy phát âm. Mình sẽ dạy phát âm hiệu quả hơn và do đó có thể giúp sinh viên cải thiện kĩ năng phát âm của các em.

Dạ có. Nếu có cơ hội chắc chắn em sẽ tham gia một khóa như này. Mong đợi của em là khóa bồi dưỡng có thể giúp em cải thiện năng lực dạy phát âm. Em sẽ hoàn toàn tự tin khi dạy phát âm cho sinh viên trên lớp.

Trước hết em nghĩ các trường đại học đào tạo giáo viên tiếng Anh cần phải chú ý hơn trong công tác tuyển sinh đầu vào. Đào tạo ít thôi nhưng phải có chất lượng cho nên theo em chỉ tuyển sinh viên thực sự giỏi tiếng Anh thôi. Chất lượng đầu vào càng cao thì chất lượng đầu ra mới được đảm bảo. 
(30) "Then during the while-training stage, ELT students need to be 'taken good care of' throughout their four years at university to make sure we have 'good products'. Their language skills must be 'controlled' strictly. There should be stricter regulations for testing and assessing ELT students' language ability (...) so that their future students' learning can be assured and promoted." (P2, Teacher InI, Q7, Phuong)

(31) "During the while-training stage, universities need to have strict regulations for testing and evaluating ELT students' language ability to make sure that they graduate being qualified for teaching. The stricter the regulations are, the harder ELT students will try to study." (P2, Teacher InI, Q7, Diep)

(32)

"Another way to help develop ELT students' language ability is to cooperate with institutions in English-speaking countries. Student exchange programmes are an opportunity for ELT students not only to improve their English skills in an English-speaking country but they can also learn about the cultures and social life there. This is also necessary and useful for their teaching after graduation." (P2, Teacher InI, Q7, Khoa)
Sau đó trong quá trình đào tạo thì giáo sinh cần phải được chăm sóc kĩ lưỡng trong suốt bốn năm học đại học để đảm bảo có sản phẩm tốt. Kĩ năng ngôn ngữ của các em phải được kiểm soát thật chặt. Cần có quy định kiểm tra đánh giá khắt khe hơn đối với năng lực tiếng của giáo $\sinh (\ldots)$ thì mới đảm bảo chất lượng học tiếng của học trò sau này.

Trong quá trình đào tạo, các trường đại học cần phải có quy định nghiêm ngặt về kiểm tra đánh giá năng lực ngôn ngữ của giáo sinh để đảm bảo sau khi các em tốt nghiệp ra trường đủ năng lực để giảng dạy. Quy chế càng nghiêm ngặt thì giáo sinh sẽ càng cố gắng học hành.

Một cách khác để giúp phát triển năng lực tiếng của giáo sinh là hợp tác với các trường ở các quốc gia nói tiếng Anh. Những chương trình trao đổi sinh viên giống vầy là cơ hội để giáo sinh cải thiện kĩ năng ngôn ngữ ở nước nói tiếng Anh đồng thời các bạn cũng có thể học hỏi về văn hóa và đời sống xã hội ở đó nữa. cái này cũng rất cần thiết và có ích cho công việc giảng dạy của giáo sinh sau khi tốt nghiệp ra trường. 
(33) "For pronunciation skills in particular, I think EFL teacher training programmes in Vietnam should have three separate courses including pronunciation training, phonetics and phonology, and pronunciation pedagogy. Also, more time needs to be allocated to these courses. The pronunciation training course is for ELT students to learn and practice their pronunciation skills. Phonetics and phonology provides them with more specialised knowledge useful for their teaching pronunciation later. Meanwhile, the pronunciation pedagogy course is very important in providing ELT students with knowledge about pronunciation teaching methodology which they can apply in their future classes. These courses better assist ELT students to teach the language in general and pronunciation in particular. Also, testing and assessment criteria need to be strict to ensure the outcome quality." (P2, Teacher InI, Q7, Quynh)

(34) “(...) At the same time, [universities] need to design a separate pronunciation course in EFL teacher training programme. ELT students need to learn and practice a lot because pronunciation requires time to be bettered. For this to be done, credits for this course must be increased and divided into several semesters. Besides, requirements in testing and assessment must also be strict to avoid ELT students
Đối với kĩ năng phát âm nói riêng thì theo tui các chương trình đào tạo giáo viên tiếng Anh ở Việt Nam nên có ba khóa học riêng biệt là luyện âm, ngữ âm âm vị và phương pháp giảng dạy phát âm. Đồng thời là thời gian dành cho các môn học này cần phải được tăng lên. Mục đích của môn luyện âm là để giáo sinh học và luyện phát âm, môn ngữ âm âm vị sẽ cung cấp kiến thức chuyên ngành mà cái này thực sự rất hữu ích để các em dạy phát âm sau này. Học phần phương pháp giảng dạy phát âm lại rất quan trọng, giúp giáo sinh nắm bắt về phương pháp giảng dạy để các em áp dụng sau khi tốt nghiệp ra trường. Các khóa học này sẽ hỗ trợ giáo sinh tốt hơn trong việc dạy tiếng nói chung và phát âm nói riêng. Đồng thời các tiêu chí kiểm tra đánh giá cũng cần phải được thắt chặt để đảm bảo chất lượng đầu ra.

Đồng thời cần có khóa phát âm riêng trong chương trình đào tạo giáo viên. Giáo sinh cần học và luyện tập nhiều vì pronunciation đòi hỏi một thời gian dài luyện tập thì mới giỏi được. Để làm được điều này thì số tín chỉ cho môn này cần phải tăng lên và chia ra nhiều học phần. Với lại trong quá trình đào tạo thì các quy định về kiểm tra đánh 
being lazy in the training process. More

time is also needed for pronunciation

pedagogy in the teaching methodology

course so ELT students can learn more

about pronunciation teaching methodology

and they can also have more opportunities

for teaching practice. In addition, the

course of phonetics and phonology also

needs to be emphasised. This is the

theoretical basis ELT students should

master in order to know how to teach

[pronunciation] after graduation." (P2,

Teacher InI, Q7, Na)

(35) "For the pronunciation training course, if possible, I think universities should invite

native-speaker teachers to teach

pronunciation to ELT students. This

provides them with more exposure to

native pronunciation in real-life situations.

It's also an opportunity for them to learn,

practice, and refine their pronunciation

skills with native speakers and so they'll be

more confident in teaching after

graduation." (P2, Teacher InI, Q7,

Nguyen) giá cũng phải nghiêm ngặt để tránh

tình trạng giáo sinh lười biếng. Thời lượng dành cho môn giảng dạy phát âm trong học phần ELT cũng phải được tăng lên để giáo sinh có thêm thời gian nghiên cứu học hỏi các phương pháp giảng dạy phát âm cũng như là có thêm cơ hội để tập giảng. Đồng thời môn ngữ âm âm vị cũng cần được chú trọng vì đây là nền tảng lí thuyết giáo sinh cần phải nắm để biết đường mà dạy phát âm sau khi ra trường.

Với khóa luyện âm nếu có thể thì anh nghĩ nhà trừơng nên mời giáo viên bản xứ đảm nhiệm việc dạy phát âm cho giáo sinh để giúp các em được tiếp xúc với phát âm của người bản ngữ nhiều hơn, được học và luyện tập với người nước ngoài nhằm trau chuốt kĩ năng phát âm và như vậy sau khi tốt nghiệp ra trường các em sẽ tự tin hơn khi đứng lớp.
(36) "I remember my teacher mostly asked us to listen and repeat after her. Normally, when we made pronunciation errors in our speaking, she wrote the words down on the board. Then she asked us how to read those words. When we got it wrong, she smiled, then read the words and asked us to repeat after her. That's it." (P1, FGI1, Q1, S1)
Em nhớ là hầu như cô chỉ kêu tụi em lặp lại theo cô. Thông thường khi mà tụi em nói sai thì cô viết mấy từ đó lên bảng rồi hỏi tụi em đọc mấy từ đó như nào. Khi tụi em đọc sai thì cô cười, xong đọc mẫu rồi kêu tụi em lặp lại theo cô. Vậy thôi à. 
(37)

“As I recall, my teacher seldom taught pronunciation. Usually, he corrected our errors when we got it wrong. With the words we made pronunciation errors when speaking, he usually transcribed them on the board. Then he read [the words] and asked the whole class to repeat after him." (P1, FGI4, Q1, S3)

(38) "I remember my teacher corrected the way we stressed in words. When we spoke with some words that we stressed wrong, she pointed out where the mistakes were and asked us to listen and repeat after her. But usually, she only corrected the words we spoke with pronunciation errors through repetition. Normally, she gave model pronunciations and then asked us to repeat after her. She didn't even transcribe the words." (P1, FGI6, Q1, S1)

(39) "I think this approach to pronunciation teaching is not very effective. It's okay but just like 'a drop in the ocean'. So, I think there should be classes for pronunciation like other skills so that we can have a clearer understanding about pronunciation and have opportunities for practice and so the effects will be long lasting." (P1, FGI1, Q2, S4)

(40) 'I think it's effective but not much. The effect doesn't last long because we don't have a chance for practice but only repeat after the teacher. Because we aren't taught
Theo em nhớ thì rất hiếm khi thầy em dạy phát âm. Thường thì thầy chỉ sửa lỗi cho tụi em thôi. Khi tụi em nói mà phát âm sai thì thường thầy sẽ phiên âm mấy từ đó lên bảng xong thầy đọc và biểu cả lớp đọc theo thầy.

Em nhớ là cô sửa dấu nhấn cho tụi em. Khi mà tụi em nói có mấy từ tụi em nhấn sai thì cô sẽ chỉ ra chỗ sai sau đó biểu tụi em lặp lại theo cô. Nhưng mà thường thường cô chỉ sửa phát âm bằng cách cho tụi em đọc đi đọc lại những từ mà tụi em đọc sai trong khi nói thôi. Thường là cô đọc mẫu rồi bắt tụi em lặp lại theo cô. Cô cũng chẳng phiên âm mấy từ đó luôn.

Theo em nghĩ thì cách dạy phát âm kiểu này không hiệu quả lắm. Dạy như vậy cũng được nhưng chỉ là một phần rất nhỏ trong một cái quá lớn. Cho nên em nghĩ nên có một số giờ học phát âm riêng giống như các kĩ năng khác vậy đó thì tụi em mới hiểu rõ và có cơ hội thực hành thì hiệu quả mới lâu dài được.

Theo em cũng có hiệu quả nhưng không nhiều lắm. Hiệu quả không lâu dài vì tụi em chẳng có cơ hội được thực hành gì cả. Do tụi em 
pronunciation explicitly and systematically, we don't know how to pronounce a new word we encounter even when we look it up in the dictionary." (P1, FGI3, Q2, S2) không được học phát âm đàng hoàng nên khi gặp từ mới, tra từ điển cũng không biết đọc như nào.
(41) 'I think this way of teaching doesn't help me much. In my opinion, the sole purpose of the teacher's transcribing words is to have the transcriptions on the board. What we only do is to listen and repeat after the teacher like a machine. Later on, we'll forget all about it because we aren't taught pronunciation theory and don't have opportunities for communication practice either." (P1, FGI5, Q2, S3)

(42) 'I think it's completely ineffective. The teacher correcting our errors through repetition is too mechanical. I think pronunciation requires time but I realise that not only the teacher teaching this semester but also those in previous terms don't care about it and so they don't spend time teaching pronunciation explicitly and systematically in class." (P1, FGI2, Q2, S3)
Theo em thấy cách dạy này không hiệu quả lắm. Theo em thì việc cô dạy phát âm kiểu chỉ phiên âm giống như là cứ phiên âm lên bảng cho có vậy thôi. Tụi em cứ nghe và lặp lại theo cô như một cái máy rồi sau đó cũng sẽ quên vì đâu có nắm được lý thuyết mà cũng chả được thực hành giao tiếp gì cả.
Theo em thì hoàn toàn không hiệu quả vì việc sửa lỗi bằng cách lặp đi lặp lại như này rất là máy móc. Theo em thấy thì không chỉ riêng giảng viên học kì này mà cả những giảng viên của mấy kì trước cũng không xem trọng phát âm nên không dành thời gian để dạy phát âm bài bản trong lớp. Mà cái này thì em nghĩ cần có thời gian.

Hoàn toàn không có hiệu quả. Cách dạy của cô không lưu lại ấn tượng gì trong đầu em cả. Cách bắt chước như này rất máy móc và khó nhớ. Kĩ năng phát âm cũng không cải thiện.

Em thấy không hiệu quả chút nào. Kiểu cô cho nghe và lặp lại thì 
looks just like the way we teach a parrot

how to speak. Even when she transcribed

words on the board, we can only read

[pronounce] the words that she has taught.

When encountering a new word, we don't

know how to say it correctly." (P1, FGI6,

Q2, S1)
"Pronunciation is one of the most

important skills that helps improve

language learners' listening and speaking

skills. When students fail in oral

communication due to their pronunciation

errors, they'll certainly be disheartened

and so will be demotivated in learning the

language. However, if they have more

chances for pronunciation learning and

practising and realise that other people

such as teachers and their peers

understand what they say, they will feel

more confident in speaking English.

Accordingly, their motivation in English

learning will be promoted." (P1, Teacher

InI, Q8, Quynh) cũng giống như một con vẹt học

nói. Nay cả khi cô phiên âm lên bảng thì tụi em cũng chỉ biết đọc những từ được cô dạy. Còn khi gặp từ mới thì không biết đọc sao cho đúng.

Pronunciation là một trong những kĩ năng quan trọng nhất vì nó giúp cải thiện kĩ năng nghe nói của người học tiếng. Khi các em nói tiếng Anh mà người khác nghe không hiểu thì chắc chắn sẽ khiến các em nản lòng và sẽ mất hết động lực học tiếng. Tuy nhiên, nếu các em có cơ hội học và luyện phát âm và nhận thấy à người khác hiểu được các em muốn nói gì thì các em sẽ cảm thấy tự tin hơn khi nói tiếng Anh. Thậm chí những người hiểu được các em nói tiếng Anh chỉ cần là thầy cô hoặc bạn bè trong lớp thôi cũng đủ tạo động lực cho các em trong việc học tiếng Anh rồi.

Phát âm là một kĩ năng bắt buộc.

Điều đó không cần bàn cãi vì nó giúp phát triển kĩ năng ngôn ngữ của người học, đặc biệt là nghe nói. Học ngoại ngữ thì phát âm cực kì quan trọng. Khi mà người nghe hiểu được những gì sinh viên nói thì các em sẽ cảm thấy vui hơn và có thêm động lực để học tiếng. Dần dà các em sẽ 
be more confident in speaking English."

(P1, Teacher InI, Q8, Phuong)

(47)

"Pronunciation is a very important skill.

First, it helps improve listening and

speaking skills. Second, many

pronunciation features such as sentence

stress, intonation or linking play an

essential role in oral communication.

These features not only help speakers

succeed in exchanging information but also

give a good impression on interlocutors.

They'll consider the speaker as being

proficient in using English." (P1, Teacher

InI, Q8, Diep)

(48) "Pronunciation is a very important skill in

English learning because it helps improve

learners' listening and speaking skills. So,

I usually raise my students' awareness of

this and encourage them to practice

[pronunciation]. When teachers and other

students in class understand what they say,

they'll feel more confident in speaking

English. Listening test scores can be

improved too if students are good at

pronunciation and vocabulary." (P1,

Teacher InI, Q8, Khoa) cảm thấy tự tin hơn khi giao tiếp

bằng tiếng Anh.

Pronunciation là kĩ năng rất quan

trọng. Trước hết là nó giúp cải thiện

kĩ năng nghe nói. Thứ 2 là có nhiều

yếu tố ngữ âm như nhấn câu, ngữ

điệu hoặc là nối âm đóng vai trò vô

cùng quan trọng trong giao tiếp.

Những yếu tố này không chỉ giúp

người nói đạt được mục đích giao

tiếp mà còn góp phần xây dựng hình

ảnh của một người không chỉ biết

mà còn sử dụng tiếng Anh thành

thạo trong mắt người nghe.

Pronunciation là kĩ năng rất quan trọng trong quá trình học tiếng Anh bởi nó giúp cải thiện kĩ năng nghe nói của học viên. Vì vậy, em thường nhắc nhở sinh viên về vấn đề này và khuyến khích các em tập luyện. Khi mà thầy cô hoặc bạn cùng lớp nghe và hiểu được các em muốn nói gì thì các em sẽ tự tin hơn trong việc nói tiếng Anh. Điểm thi nghe cũng sẽ tốt hơn nếu người học giỏi phát âm và chuẩn bị tốt về từ vựng.

(49) "Of course, it would be better if we include Dĩ nhiên sẽ tốt hơn nếu mình có communicative practice activities in teaching pronunciation. This is also what our students expect because they can apply what they have learned in real hoạt động giao trong quá trình dạy phát âm. Điều này cũng là mong muốn của sinh viên vì các em có 


\begin{tabular}{|c|c|c|}
\hline & $\begin{array}{l}\text { communication practice.” (P1, Teacher InI, } \\
\text { Q9, Phuong) }\end{array}$ & $\begin{array}{l}\text { thể áp dụng những gì vừa học vào } \\
\text { các tình huống giao tiếp thực tế. }\end{array}$ \\
\hline \multirow[t]{7}{*}{$(\mathbf{5 0 )}$} & $\begin{array}{l}\text { "The aim of teaching pronunciation is } \\
\text { certainly to improve learners' }\end{array}$ & $\begin{array}{l}\text { Chắc chắn học phát âm là phục vụ } \\
\text { cho định hướng giao tiếp, cải thiện }\end{array}$ \\
\hline & communication skills and this is what they & kĩ năng giao tiếp cho học viên. Đây \\
\hline & need. So, we can give students more & cũng là mong đợi của đa số học \\
\hline & opportunities for practice by creating & viên. Do đó, ta có thể đưa vào các \\
\hline & different communication situations so that & đoạn đối thoại hoặc các tình huống \\
\hline & they can apply what they have learned." & giao tiếp cụ thể để học viên áp dụng \\
\hline & (P1, Teacher InI, Q9, Diep) & những gì vừa học thì rất tốt. \\
\hline \multirow[t]{8}{*}{$(\mathbf{5 1})$} & "I think it would be much better if we teach & Theo em nghĩ sẽ tốt hơn nhiều nếu \\
\hline & pronunciation explicitly including the & mình dạy phát âm một cách bài bản \\
\hline & communicative practice stage. Today, & và có cả bước communicative \\
\hline & students are more demanding. They need & practice. Sinh viên giờ cũng đòi hỏi \\
\hline & theory and practice at the same time. They & dữ lắm, muốn cả lý thuyết và thực \\
\hline & expect to get involved in real & hành cùng lúc và luôn mong muốn \\
\hline & communication situations." (P1, Teacher & được tham gia thực hành giao tiếp \\
\hline & InI, Q9, Na) & qua các tình huống thực tế. \\
\hline \multirow[t]{6}{*}{ (52) } & "I think it's extremely important, the most & Em nghĩ là cực kì quan trọng, quan \\
\hline & important. It's the basis for listening and & trọng nhất. Nó giống như nền \\
\hline & speaking skills. Good pronunciation makes & móng của kĩ năng nghe nói á thầy. \\
\hline & it easier for messages to get through in oral & Khi phát âm chuẩn thì việc giao \\
\hline & communication with foreigners." (P1, FGI2, & tiếp với người nước ngoài sẽ dễ \\
\hline & $\mathrm{Q} 3, \mathrm{~S} 2)$ & dàng hơn. \\
\hline \multirow[t]{7}{*}{ (53) } & "Pronunciation is a very important skill. In & Phát âm là kĩ năng rất quan trọng. \\
\hline & my opinion, it lays the foundation for other & Theo em thì nó là nền tảng để phát \\
\hline & language skills to develop, especially & triển những kĩ năng ngôn ngữ khác \\
\hline & listening and speaking. I think good & nhất là nghe nói. Em nghĩ khi mà \\
\hline & pronunciation helps the speaker and the & phát âm đúng sẽ giúp người nói và \\
\hline & listener understand each other more easily. & người nghe hiểu nhau dễ hơn. Chỉ \\
\hline & Only when we understand what the speaker & khi nào mình nghe hiểu người ta \\
\hline
\end{tabular}


is talking about can we respond properly." $\quad$ nói gì thì mình mới trả lời đúng (P1, FGI6, Q3, S4) được.

(54) "Pronunciation is the most important skill. Phát âm là kĩ năng quan trọng I think it's the basis of other language skills, especially listening and speaking, because good pronunciation promotes mutual understandings between the speaker and the listener. Only when we understand the problem a speaker is talking about can we solve it. Besides, English has intonation. When we're good at pronunciation, we'll 'appreciate the beauty' of intonation and so we'll try our best to practice." (P1, FGI4, Q3, S3) nhất. Theo em nó là nền móng của các kĩ năng ngôn ngữ khác, nhất là kĩ năng nghe nói vì khi mình phát âm đúng thì người nói và người nghe mới hiểu được nhau. Khi mình hiểu vấn đề người ta đang đề cập thì mới có thể giải quyết vấn đề được. Bên cạnh đó trong tiếng Anh có ngữ điệu, khi mình phát âm tốt thì sẽ cảm nhận được cái hay cuả ngữ điệu và sẽ cố gắng nói tốt hơn.

(55) "I think pronunciation is very important. Em nghĩ phát âm rất quan trọng. Good pronunciation helps improve listening Phát âm tốt giúp cải thiện kĩ năng and speaking skills. When I spoke English with native speakers, they seemed not to understand what I was saying although I'm sure I used correct grammar structures." (P1, FGI1, Q3, S1) nghe nói. Khi em nói tiếng Anh với người bản xứ thì hình như họ không hiểu em nói gì mặc dù em chắc chắn mình dùng đúng cấu trúc ngữ pháp.

(56) "I think pronunciation is an important skill Em nghĩ phát âm là một kĩ năng because it helps me speak better, making oral interactions successful. It also quan trọng vì nó giúp em nói hay improves my listening skills." (P1, FGI3, hơn, giúp cho việc giao tiếp bằng lời Q3, S3) nói thành công. Nó còn giúp cải thiện kĩ năng nghe nữa.

(57) “Important, I think. It improves my Theo em là quan trọng. Nó giúp listening and speaking skills. Good cải thiện kĩ năng nghe nói. Phát âm pronunciation skills make it easier for me tốt giúp mình giao tiếp được với to communicate with foreigners. It serves người nước ngoài, phục vụ các 


\begin{tabular}{|c|c|c|}
\hline & $\begin{array}{l}\text { the communicative purposes in daily life." } \\
(\mathrm{P} 1, \mathrm{FGI} 5, \mathrm{Q} 3, \mathrm{~S} 2)\end{array}$ & $\begin{array}{l}\text { mục đích giao tiếp trong cuộc sống } \\
\text { hàng ngày. }\end{array}$ \\
\hline (58) & $\begin{array}{l}\text { "Pronunciation is very important. It helps } \\
\text { improve my listening and speaking skills. } \\
\text { Good pronunciation also makes me speak } \\
\text { better and more confidently. So, foreigners } \\
\text { can understand what I say more easily." } \\
\text { (P1, FGI1, Q3, S3) }\end{array}$ & $\begin{array}{l}\text { Phát âm rất quan trọng. Nó giúp cải } \\
\text { thiện kĩ năng nghe nói. Nó giúp } \\
\text { mình nói hay hơn, tự tin hơn. Và } \\
\text { như vậy người nước ngoài nghe } \\
\text { mới dễ hiểu mình. }\end{array}$ \\
\hline (59) & $\begin{array}{l}\text { “I think it's very important. It improves } \\
\text { listening and speaking skills. It's better if } \\
\text { my pronunciation is good because I can } \\
\text { understand what other people say and vice } \\
\text { versa. Also, I can improve my scores in } \\
\text { tests." (P1, FGI2, Q3, S4) }\end{array}$ & $\begin{array}{l}\text { Em nghĩ rất quan trọng. Nó giúp cải } \\
\text { thiện kĩ năng nghe nói. Phát âm tốt } \\
\text { sẽ tốt cho em hơn vì lúc đó em nghe } \\
\text { người ta nói em sẽ hiểu họ muốn nói } \\
\text { gì và người ta nghe em nói cũng sẽ } \\
\text { hiểu em muốn nói gì. Đi thi điểm } \\
\text { cũng sẽ cao hơn. }\end{array}$ \\
\hline (60) & $\begin{array}{l}\text { "I think it's very important. It improves my } \\
\text { listening and speaking skills. Other people } \\
\text { can understand us only when we pronounce } \\
\text { correctly. If we pronounce some words } \\
\text { incorrectly, the listener may interpret our } \\
\text { message in a wrong way. Moreover, good } \\
\text { pronunciation also makes me feel more } \\
\text { confident and helps me score better in tests." } \\
\text { (P1, FGI5, Q3, S1) }\end{array}$ & $\begin{array}{l}\text { Em thấy nó rất quan trọng. Nó giúp } \\
\text { cải thiện kĩ năng nghe nói. Nói rõ, } \\
\text { phát âm đúng thì người nghe mới } \\
\text { hiểu. Nếu phát âm sai thì người ta } \\
\text { sẽ hiểu sai ý mình muốn nói. Hơn } \\
\text { nữa phát âm tốt sẽ giúp em tự tin } \\
\text { hơn và thi điểm cao hơn. }\end{array}$ \\
\hline (61) & $\begin{array}{l}\text { "Yes. I'd like to attend pronunciation } \\
\text { classes but teachers should teach it } \\
\text { communicatively. This approach is more } \\
\text { practical because we can apply what we've } \\
\text { learned in communication. And when we } \\
\text { have more opportunities for practice, our } \\
\text { listening and speaking skills will improve." } \\
\text { (P1, FGI2, Q4, S1) }\end{array}$ & $\begin{array}{l}\text { Dạ có. Em muốn học phát âm } \\
\text { nhưng thầy cô nên dạy theo kiểu } \\
\text { giao tiếp vì học kiểu này rõ ràng là } \\
\text { thực tế hơn, tụi em có thể ứng dụng } \\
\text { những cái vừa học vào việc giao } \\
\text { tiếp. Và khi tụi em có cơ hội thực } \\
\text { hành nhiều hơn thì kĩ năng nghe } \\
\text { nói sẽ được cải thiện. }\end{array}$ \\
\hline
\end{tabular}


(62)

'Yes. I'd love it and I'd prefer teachers to teach pronunciation communicatively because it's practical and more interesting. Learning through listen-and-repeat activities is very boring, and we'll forget everything after repeating. If teachers teach [pronunciation] communicatively, we can improve not only my pronunciation but also listening and speaking skills. Then, it'll be better when I communicate with others outside the class." (P1, FGI4, Q4, S3)
Dạ có. Em thích lắm và em mong thầy cô sẽ dạy phát âm theo định hướng giao tiếp vì nó thực dụng và gây hứng thú hơn. Vì kiểu listen and repeat rất nhàm chán, đọc xong rồi quên à. Nếu thầy cô dạy theo kiểu giao tiếp thì tụi em không những có thể cải thiện phát âm mà còn cả kĩ năng nói nữa. Ra ngoài giao tiếp với mọi người sẽ tốt hơn.

(63) 'Yes. It's better to have pronunciation Dạ có. Có giờ học phát âm sẽ tốt classes. For a teaching approach, I don't know how to say but I would prefer that teachers taught it in ways that can help me improve both pronunciation and communication skills. If we can practice what we've learned from the theory, then the outcomes will be much better. Our listening and speaking skills can be improved much more." (P1, FGI6, Q4, S2)

(64) 'I think it would be good. I'd love to attend pronunciation classes. I hope teachers teach pronunciation communicatively because students will have more opportunities for practice in communicative situations. Also, the classroom atmosphere will be more interesting, making students more motivated to come to class." (P1, FGI2, Q4, S4)

(65) "Yes. I love it. There should be that part Dạ có. Em thích lắm. Khi học tiếng [pronunciation] in English learning to help learners master pronunciation and improve hơn. Phương pháp dạy thì em không biết nói như nào nhưng em thích thầy cô dạy theo kiểu có thể giúp tụi em cải thiện cả phát âm lẫn kĩ năng giao tiếp. Nếu mà mình thực hành lý thuyết vừa học thì hiệu quả sẽ cao hơn, có thể cải thiện kĩ năng nghe nói nhiều hơn Em nghĩ sẽ rất tốt đó thầy. Em rất muốn học lớp phát âm. Em cũng mong thầy cô dạy theo kiểu giao tiếp sẽ cho tụi em có cơ hội áp dụng vào tình huống giao tiếp thực tế. Với lại không khí lớp học sẽ sôi động hơn, sinh viên có động lực đến lớp. Anh là phải có phần đó để giúp người học nắm vững phát âm, cải 
their communication skills, so they'll be more confident in speaking English. I'd prefer teachers to teach [pronunciation] communicatively because it's practical and makes me more interested in learning.

Learning through listen-and-repeat activities is boring, so the outcomes won't be that great." (P1, FGI4, Q4, S1) thiện kĩ năng giao tiếp và khi đó sẽ tự tin hơn trong giao tiếp. Em thích thầy cô dạy theo kiểu giao tiếp hơn vì nó thực dụng và gây hứng thú cho em. Học theo kiểu listen and repeat rất nhàm chán buồn tẻ nên hiệu quả tiếp thu sẽ không cao.
(66) "I think pronunciation is an integral part in English learning. And I would prefer teachers to teach it communicatively. Learning through listen-and-repeat activities is very boring and mechanical. If teachers teach [pronunciation] communicatively, then it'll help us develop our listening and speaking skills because we have more opportunities for communication practice. It also makes students more motivated and active and so their 'brains' will work harder. They can learn more." (P1, FGI6, Q4, S4)

(67) "Yes. The reason is that I want to improve my communication skills. When I communicate with foreigners, I can understand them easily and they can understand what I say in return. I'd prefer that pronunciation was taught communicatively because it makes me more interested in learning. The lessons will be more comprehensible and I can absorb the knowledge transferred by my teacher
Em nghĩ phát âm là một phần không thể thiếu trong việc học tiếng Anh. Em thích học theo cách giao tiếp hơn. Nếu chỉ có listen and repeat thì sẽ rất nhàm chán, rời rạc và máy móc. Còn dạy theo kiểu giao tiếp em sẽ có cơ hội phát triển kĩ năng nghe nói vì tụi em có cơ hội thực hành giao tiếp. Với lại sẽ giúp sinh viên năng động hơn, khiến não hoạt động nhiều hơn và học được nhiều hơn.

Dạ có. Lý do là em muốn cải thiện kĩ năng giao tiếp. Khi em giao tiếp với người nước ngoài thì nghe hiểu được và họ nghe hiểu được em. Em thích học theo kiểu giao tiếp hơn vì như vậy sẽ giúp tụi em hứng thú hơn, lớp học bớt chán. Bài giảng sẽ dễ hiểu hơn, tụi em tiếp thu kiến thức thầy cô truyền đạt sẽ nhanh hơn nên kết quả sẽ tốt hơn. 
faster. So, the results will be much better."

(P1, FGI3, Q4, S1)

(68) "I think pronunciation needs to be

integrated in our English programme so that our pronunciation and communication skills can be improved. I think teachers should teach pronunciation communicatively because it's more practical. We can understand teachers' instruction faster and more easily, so the results will be better.” (P1, FGI5, Q4, S1)

(69) "Yes. I want to improve my pronunciation and communication skills. It's better if teachers teach [pronunciation] communicatively, giving us more opportunities to improve listening and speaking skills. Then I think students will have more chances for interactions and we can help each other correct our pronunciation errors too." (P1, FGI1, Q4, S4)

(70) "I think pronunciation needs to be included in our English programme and it should be taught effectively. Learning through listenand-repeat activities is very boring, mechanical, and not practical. Teaching [pronunciation] communicatively can help improve our listening and speaking skills a lot more. Also, there'll be more interactions between teachers and students through teacher correction of students' errors. We can also help each other correct ourselves.
Em nghĩ nên lồng ghép dạy phát âm vào trong chương trình tiếng Anh của trường để giúp tụi em cải thiện phát âm và kĩ năng giao tiếp. Em nghĩ thầy cô nên dạy phát âm theo ứng dụng giao tiếp vì như vậy sẽ thực tế hơn, tụi em sẽ nhớ bài giảng nhanh và dễ hơn. Như vậy sẽ hiệu quả hơn.

Dạ có. Em muốn cải thiện phát âm và kĩ năng giao tiếp. Thầy cô dạy theo kiểu giao tiếp sẽ tốt hơn vì tụi em có nhiều cơ hội hơn để cải thiện kĩ năng nghe nói. Em nghĩ lúc đó sinh viên sẽ có cơ hội giao tiếp nhiều hơn, đồng thời cũng có thể giúp nhau sửa lỗi phát âm nữa.

Em nghĩ nên đưa vào chương trình tiếng Anh của trường và phải dạy cho hiệu quả. Chứ nghe rồi lặp lại hoài thì sẽ gây nhàm chán. Rồi cảm giác nó máy móc và không thực tế. Dạy theo kiểu giao tiếp có thể giúp tụi em cải thiện kĩ năng nói nhiều hơn. Với lại giáo viên và sinh viên tương tác nhiều hơn thông qua việc thầy cô sửa lỗi cho sinh viên và tụi em giúp nhau sửa lỗi, giúp sinh 
This helps students become more confident viên tự tin hơn như vậy sẽ hiệu quả and so the results will be better." (P1, FGI3, hơn.

Q4, S2) 
Appendix 9

Appendix 9.1

Lesson plan:

Planned by:

Approach:

Teaching aids:

Procedures:

\section{Lesson plans}

Lesson plan used for the workshop demonstration

\section{LESSON PLAN}

/s/ as in sing and / $/$ / as in shoes

Loc Tan Nguyen

Communicative Pronunciation Teaching

textbook, CD, software, projector, flashcards, pictures, etc.

\begin{tabular}{|c|c|c|}
\hline Lesson stages & Teacher's activities & $\begin{array}{l}\text { Students' } \\
\text { activities }\end{array}$ \\
\hline $\begin{array}{l}\text { Description } \\
\text { and analysis }\end{array}$ & $\begin{array}{l}\text { - Getting started: Has students write the conversation in } \\
\text { pairs, using the cues given. Then invites some pairs to } \\
\text { read the conversation aloud. } \\
\text { A: What / you / do / last weekend? } \\
\text { B. I / go / show / some friends / Saturday. } \\
\text { A: Nice. How / it / be? } \\
\text { B: It / be / fantastic. } \\
\text { A: How / Sunday? } \\
\text { B: I / do / washing. } \\
\text { - Uses Pronunciation Power } 2 \text { to present and explain } \\
\text { how /s/ and /S/ are articulated. } \\
\text { - Gives demonstrations of where /s/ and /J/ occur (initial, } \\
\text { medial, final position) through oral illustrations followed } \\
\text { by written forms. }\end{array}$ & $\begin{array}{l}\text { - Work in } \\
\text { pairs to } \\
\text { build and } \\
\text { practice the } \\
\text { conversation }\end{array}$ \\
\hline & $\begin{array}{l}\text { Act 1: Divides the class into three groups (students have } \\
\text { two minutes working in pairs within their bigger group). } \\
\text { One group will make a list of words in which /s/ and / } / \\
\text { occur in initial position, the second group - medial, and }\end{array}$ & $\begin{array}{l}\text { - Discuss } \\
\text { and list } \\
\text { words as } \\
\text { directed, go }\end{array}$ \\
\hline
\end{tabular}




\begin{tabular}{|c|c|c|}
\hline & $\begin{array}{l}\text { the last group - final position. The letters symbolise the } \\
\text { sounds must be underlined and transcribed. } \\
\text { - Calls for the answers and gives feedback. } \\
\text { Act 2: Elicits from students by having them name the } \\
\text { clothes that contain either sound in any position. For } \\
\text { example, asks "Which clothes can you name containing } \\
\text { a /s/ or / } / \text { ??" }\end{array}$ & $\begin{array}{l}\text { to the board } \\
\text { when asked. }\end{array}$ \\
\hline $\begin{array}{l}\text { Listening } \\
\text { discrimination }\end{array}$ & $\begin{array}{l}\text { Act 1: Gets students to listen and circle the word they } \\
\text { hear. } \\
\text { 1. It's a ship / sheep. } \\
\text { 2. That's my sheet / seat. } \\
\text { 3. He's saving / shaving. } \\
\text { 4. She's sewing / showing. } \\
\text { 5. It's a saw / shore. } \\
\text { Optional act: Has students in pairs produce the above } \\
\text { sentences and monitor each other's production. } \\
\text { Act } 2 \text { : Has students listen and circle the correct picture. } \\
\text { Have Ss listen and circle the word they hear. The one } \\
\text { who has four down, cross or diagonal words will say } \\
\text { "Bingo". }\end{array}$ & $\begin{array}{l}\text { - Practice in } \\
\text { pairs. } \\
\text { - Listen and } \\
\text { circle the } \\
\text { correct } \\
\text { picture. }\end{array}$ \\
\hline
\end{tabular}




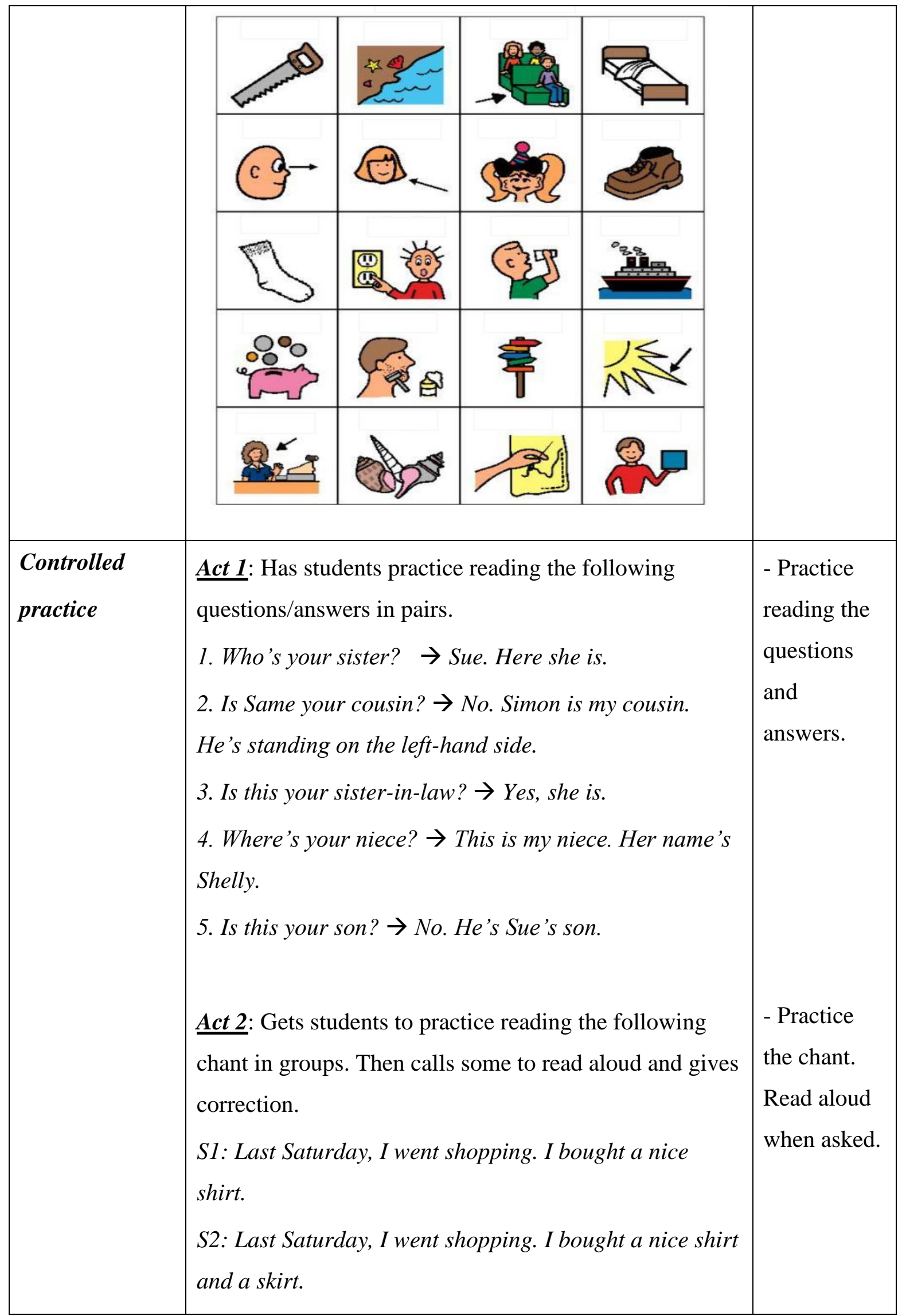




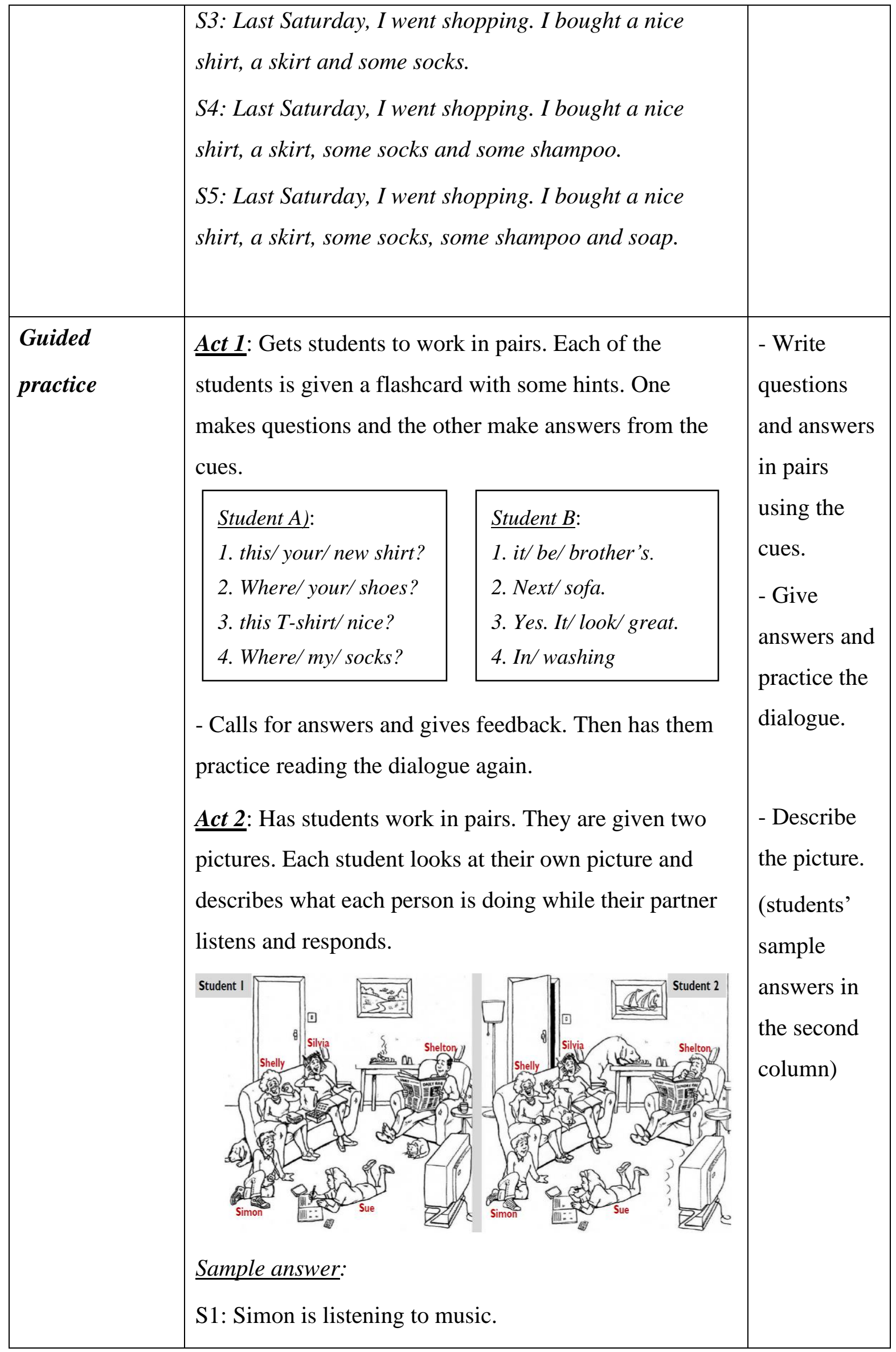




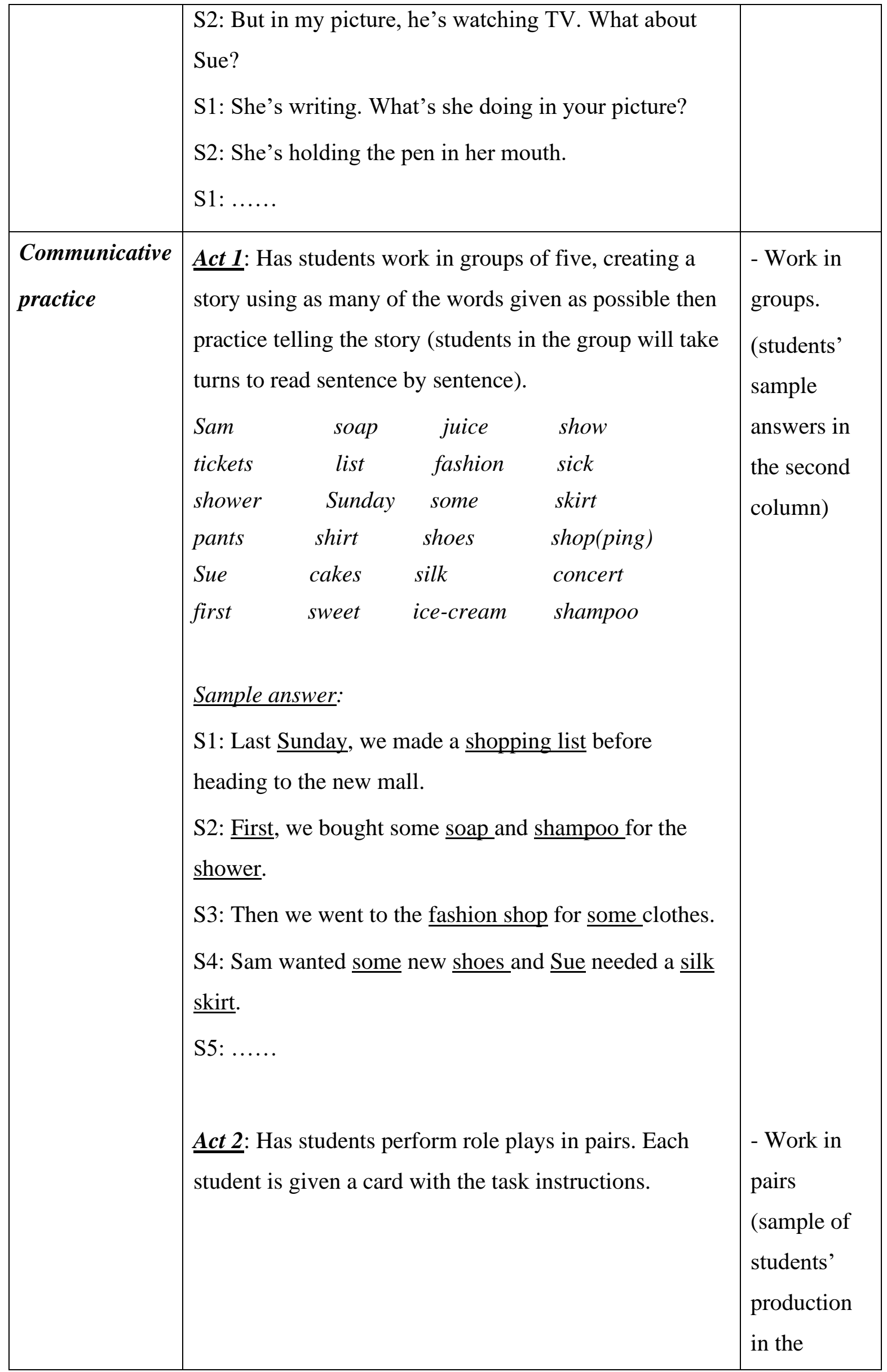




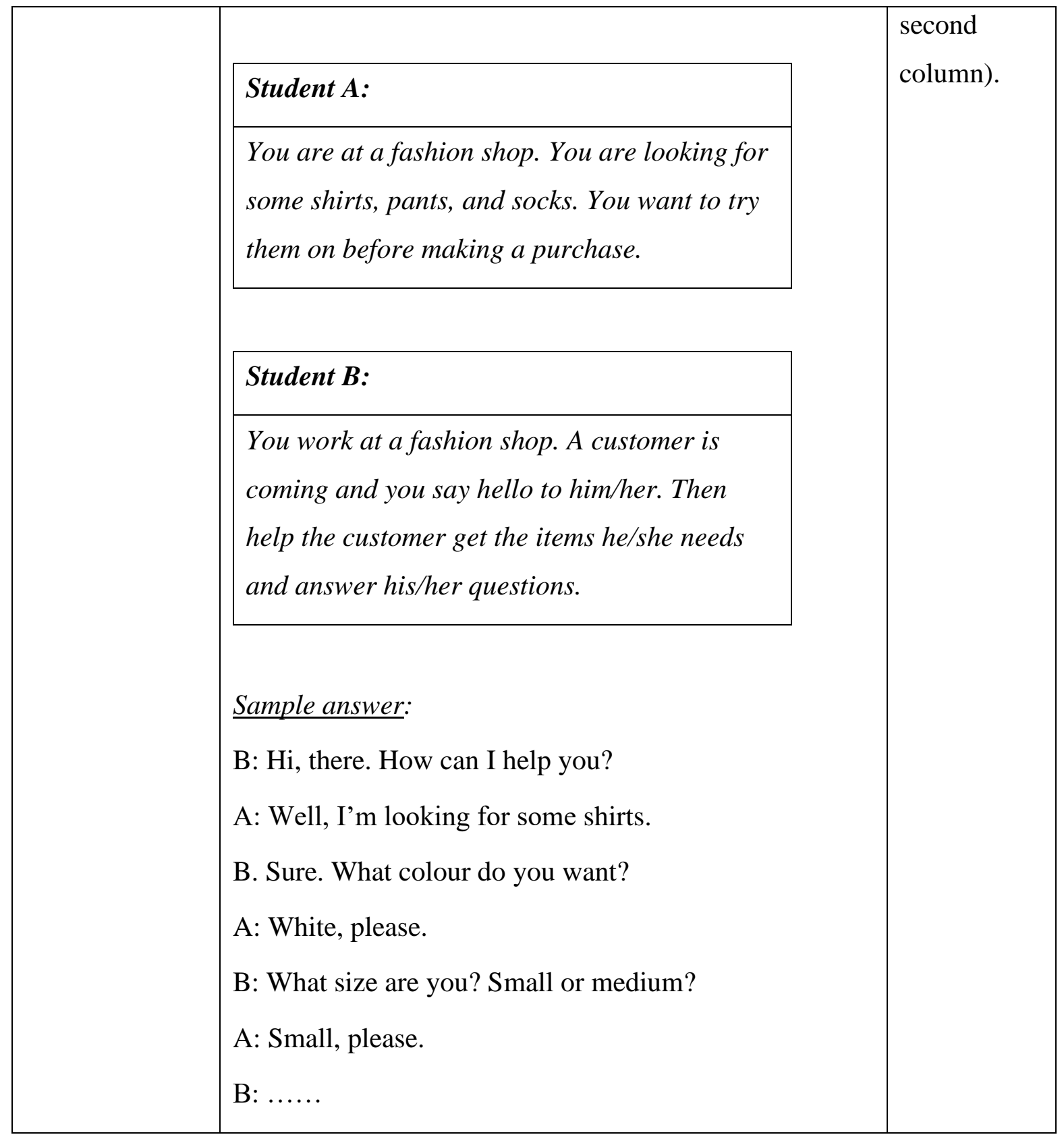


Lesson plan 1: $\quad$ Long and short vowels (/i:/ and /I/)

Planned by: $\quad$ Teacher Quynh

\section{Procedures:}

\begin{tabular}{|c|c|c|c|c|}
\hline \multirow{2}{*}{$\begin{array}{l}\text { Description } \\
\text { and analysis }\end{array}$} & \multicolumn{4}{|c|}{ - Present the productions of long /i:/ and short/I/ using pictures (p.7) } \\
\hline & $\begin{array}{l}\text { - Present the occuren } \\
\text { have students listen a } \\
\text { Spellings for /i:/ } \\
\text { Common } \\
\text { ee feet, succeed, ss } \\
\text { ie } \quad \text { believe, piece, } r \\
\text { ei } \quad \text { receive, perceiv } \\
\text { ea east, eat, mean } \\
\text { Other } \\
\text { e } \quad \text { key, medium, } p\end{array}$ & 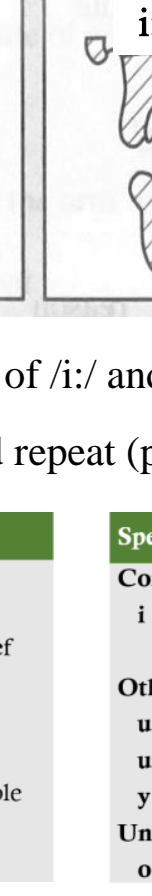 & $\begin{array}{l}\text { I/ in both W } \\
\text { ggs for /I/ } \\
\text { en } \\
\text { etween consonant } \\
\text { give, sit, listen } \\
\text { busy, business } \\
\text { build, guilty } \\
\text { gym } \\
\text { al } \\
\text { women }\end{array}$ & ten and oral fo \\
\hline Listening & \multicolumn{4}{|c|}{ - Activity 1A: Listen and repeat the words. (Exercise 2, p.8) } \\
\hline \multirow[t]{5}{*}{ Discrimination } & $\begin{array}{l}\text { 1. a. eat } \\
\text { b. it } \\
\text { 2. a. steal } \\
\text { b. still } \\
\text { - Activity 1B: Listen } \\
\text { - Activity 2: Bingo ge }\end{array}$ & $\begin{array}{l}\text { heel } \\
\text { hill } \\
\text { sheep } \\
\text { ship } \\
\text { ain and c } \\
\text { e (Exerci }\end{array}$ & $\begin{array}{l}\text { 5. a. reason } \\
\text { b. risen } \\
\text { 6. a. leave } \\
\text { b. live } \\
\text { cle the word } \\
\text { 3B, p.8) }\end{array}$ & $\begin{array}{l}\text { 7. a. deed } \\
\text { b. did } \\
\text { 8. a. each } \\
\text { b. itch } \\
\text { you hear. }\end{array}$ \\
\hline & 1. reason & 5. ship & 9. live & 13. heal \\
\hline & 2. it & 6. each & 10. fit & 14. sheep \\
\hline & 3. hill & 7. risen & 11. rich & 15. leave \\
\hline & 4. itch & 8. feet & 12. reach & 16. eat \\
\hline
\end{tabular}




\begin{tabular}{|c|c|c|c|c|c|c|c|}
\hline \multirow{13}{*}{$\begin{array}{l}\text { Controlled } \\
\text { practice }\end{array}$} & \multicolumn{7}{|c|}{ - Activity 1: Definition Game (Exercise 4, p.9) } \\
\hline & \multicolumn{3}{|c|}{ Words } & \multicolumn{4}{|c|}{ Definitions } \\
\hline & \multicolumn{3}{|c|}{ 1. a. leave } & \multicolumn{4}{|c|}{ the opposite of stay } \\
\hline & \multicolumn{3}{|c|}{ b. live } & \multicolumn{4}{|c|}{ the opposite of die } \\
\hline & \multicolumn{3}{|c|}{ 2. a. rich } & \multicolumn{4}{|l|}{ wealthy } \\
\hline & \multicolumn{3}{|c|}{ b. reach } & \multicolumn{4}{|c|}{ to extend the arm to get something } \\
\hline & \multicolumn{3}{|c|}{ 3. a. ship } & \multicolumn{4}{|c|}{ a large boat } \\
\hline & \multicolumn{3}{|c|}{ b. sheep } & \multicolumn{4}{|c|}{ a woolly animal } \\
\hline & \multicolumn{3}{|c|}{ 4. a. fill } & \multicolumn{4}{|c|}{ to put things in a container } \\
\hline & \multicolumn{3}{|c|}{ b. feel } & \multicolumn{4}{|c|}{ to touch something } \\
\hline & \multicolumn{7}{|c|}{$\begin{array}{l}\text { B: Leave means "the opposite of stay." } \\
\text { - Activity 2: Pair work (print flash cards + make copies for students) }\end{array}$} \\
\hline & \multicolumn{4}{|c|}{ Student A } & \multicolumn{3}{|l|}{ Student B } \\
\hline & \multicolumn{4}{|c|}{$\begin{array}{l}\text { I. Read sentences 1-3 to your partner } \\
\text { 1. It's been seen. } \\
\text { 2. Hand me the pin, please. } \\
\text { 3. Go on. Sick him! } \\
\text { II. Circle the word that your partner reads } \\
\text { 4. I'd like to see that cheek / chick. } \\
\text { 5. It's sipping / seeping. } \\
\text { 6. Give him a lick / leek. }\end{array}$} & \multicolumn{3}{|c|}{$\begin{array}{l}\text { I. Circle the word that your partner reads } \\
\text { 1. It's been sin / seen. } \\
\text { 2. Hand me the pin / peen, please. } \\
\text { 3. Come on. Sick / Seek him! } \\
\text { II. Read sentences 4-6 to your partner } \\
\text { 4. I'd like to see that chick. } \\
\text { 5. It's sipping. } \\
\text { 6. Give him a lick. }\end{array}$} \\
\hline \multirow[t]{7}{*}{$\begin{array}{l}\text { Guided } \\
\text { practice }\end{array}$} & \multirow{2}{*}{\multicolumn{4}{|c|}{$\begin{array}{l}\text { - Activity 1: Information gap ( } p r \\
\text { students) } \\
\text { Fill the blank boxes by asking your } \\
\text { partner: What word is in box_? Or What } \\
\text { is the word in box_?. In turn, your } \\
\text { partner will ask you for your six words. }\end{array}$}} & \multicolumn{3}{|c|}{ int flash cards + make copies $f$} \\
\hline & & & & & $\begin{array}{l}\text { Fill the blank } \\
\text { partner: Wha } \\
\text { is the word in } 1 \\
\text { partner will a }\end{array}$ & $\begin{array}{l}\text { res by asl } \\
\text { rd is in } b \\
\text { ?. In tu } \\
\text { ou for } y\end{array}$ & $\begin{array}{l}\text { our } \\
\text { Or What } \\
\text { ur } \\
\text { Y words. }\end{array}$ \\
\hline & & 1 & 2 & 3 & 1 & 2 & 3 \\
\hline & A & ship & & bean & A & knit & \\
\hline & B & & meeting & & trip & & keen \\
\hline & & trimming & & chit & $\mathrm{C}$ & cheap & \\
\hline & $\mathrm{D}$ & & feel & & D sheep & & dip \\
\hline
\end{tabular}




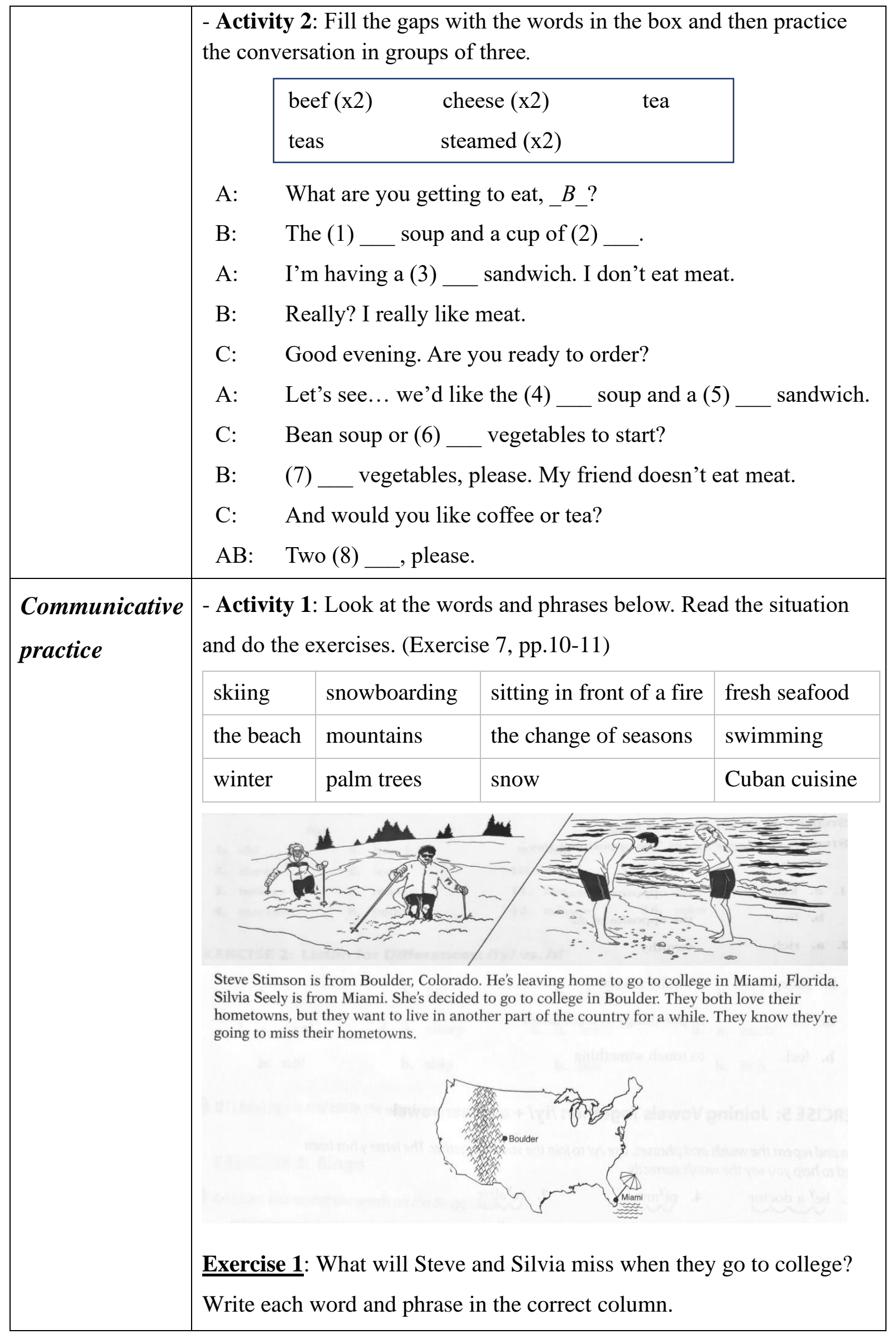




\begin{tabular}{|l|c|} 
Steve will miss ... Silvia will miss ... \\
$\begin{array}{l}\text { Exercise 2: Discuss your answers with a partner. Then use the words } \\
\text { and phrases to make sentences about Steve and Silvia. Follow the } \\
\text { examples. } \\
\text { Example: Steve's from Boulder. He'll miss the change of season. } \\
\text { Silvia's from Miami. She'll miss the beach. } \\
\text { - Activity 2: What do you miss about your hometown when studying in }\end{array}$
\end{tabular}


Lesson plan 2: $\quad$ Long and short vowels (/u:/ and / $/$ /)

\section{Planned by: $\quad$ Teacher Phuong}

Procedures:

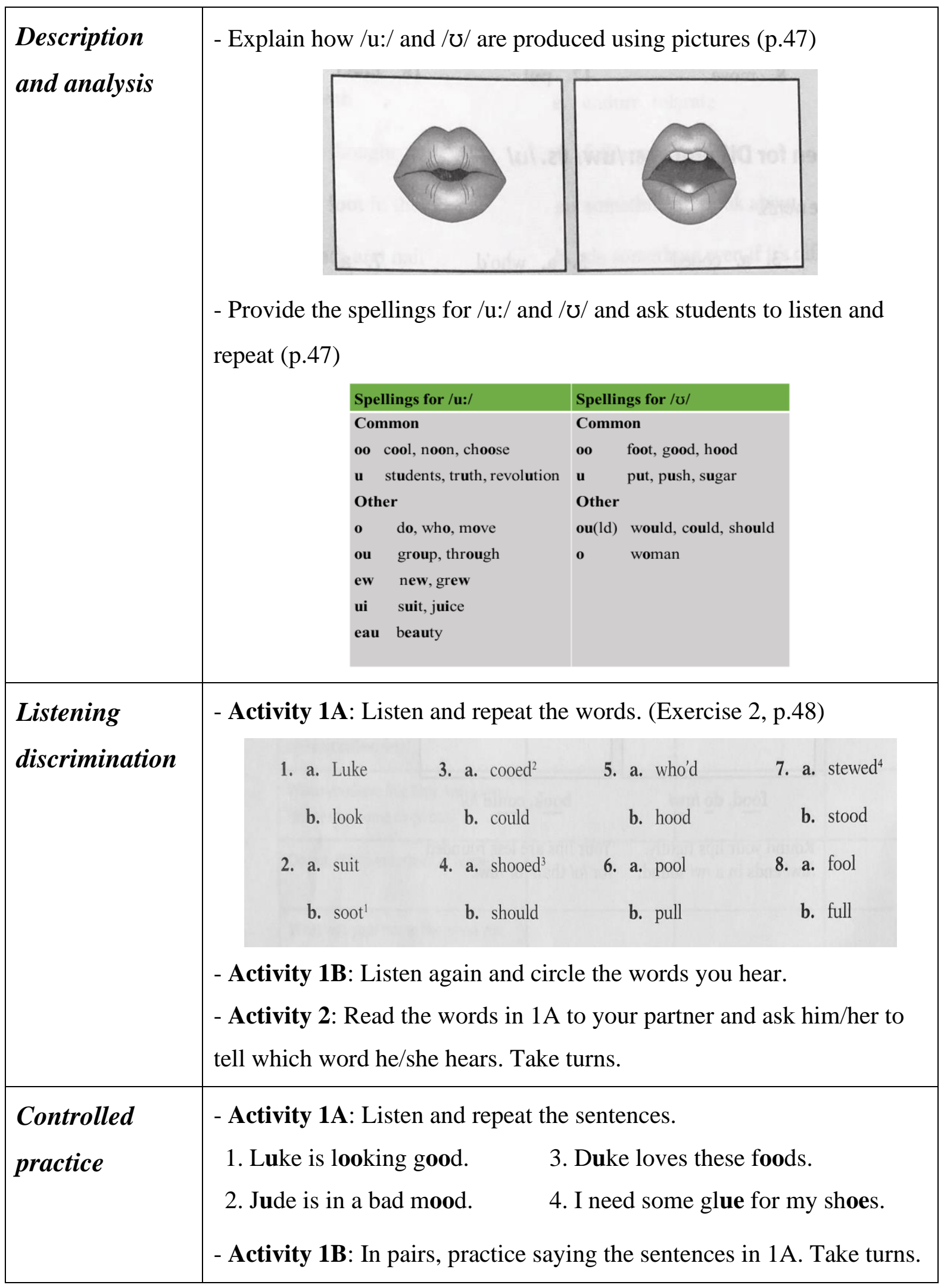




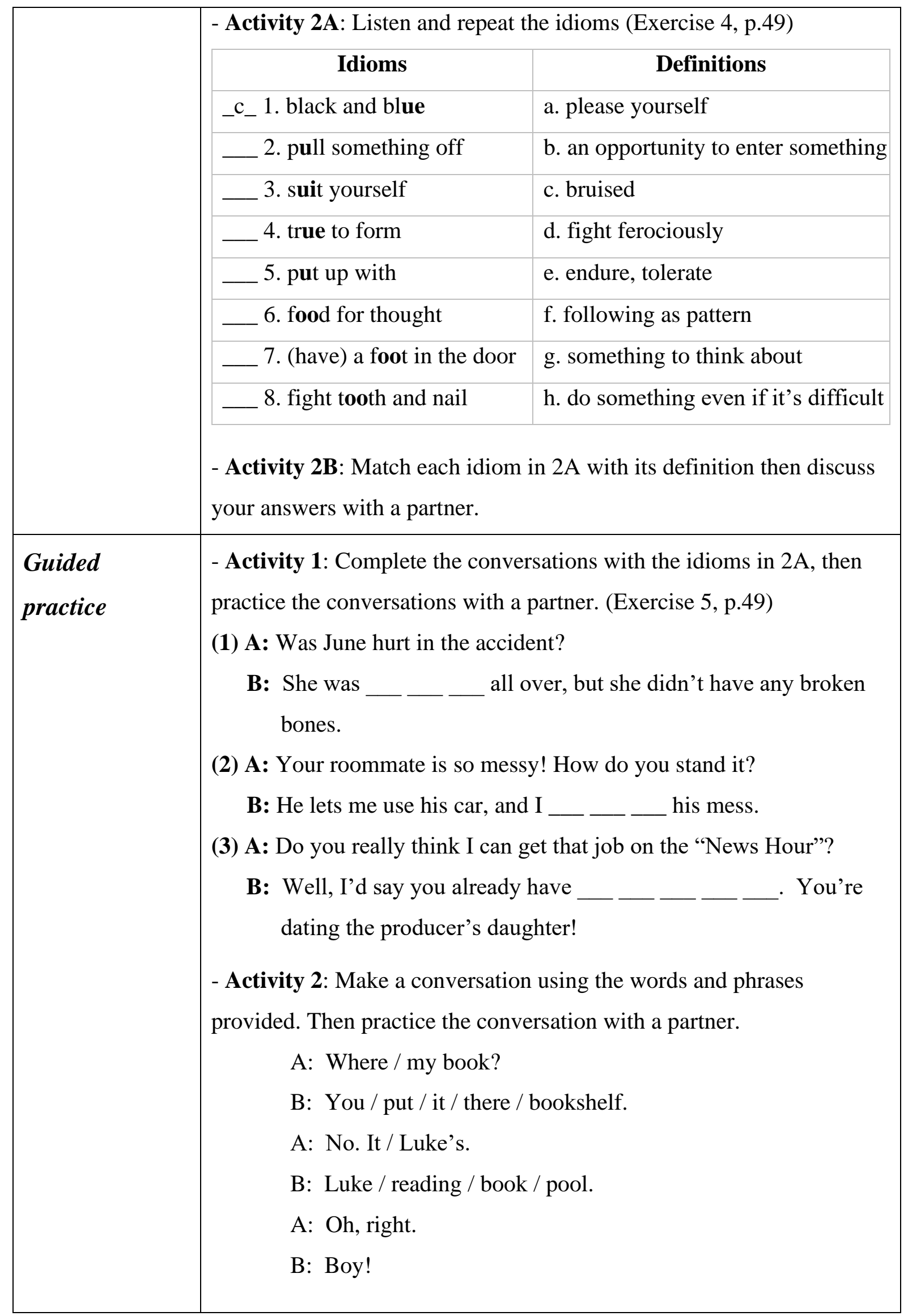




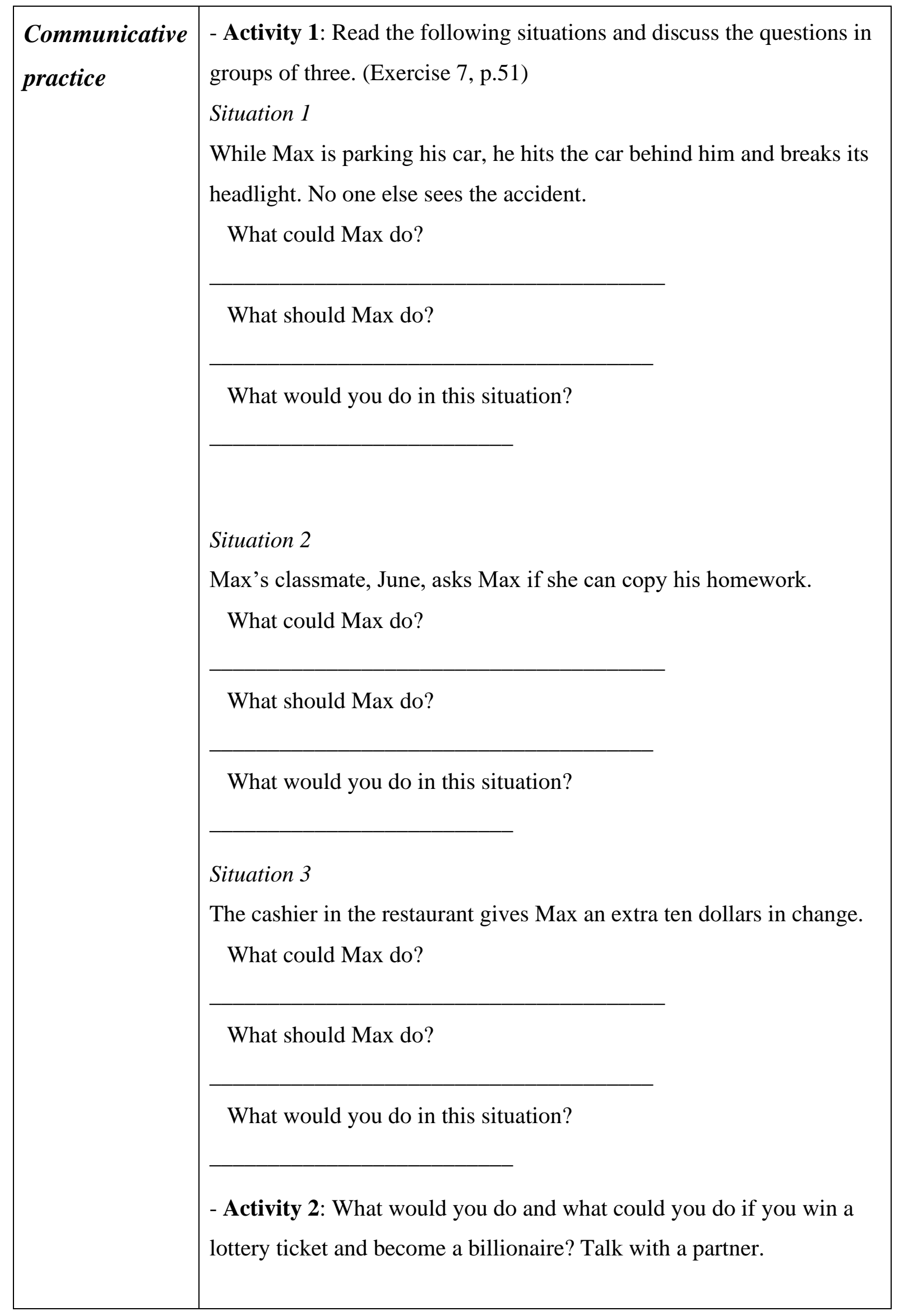


Lesson plan 3: $\quad$ Consonants $/ \mathrm{J} /$ and $/ 3 /$

Planned by: Teacher Nguyen

Procedures:

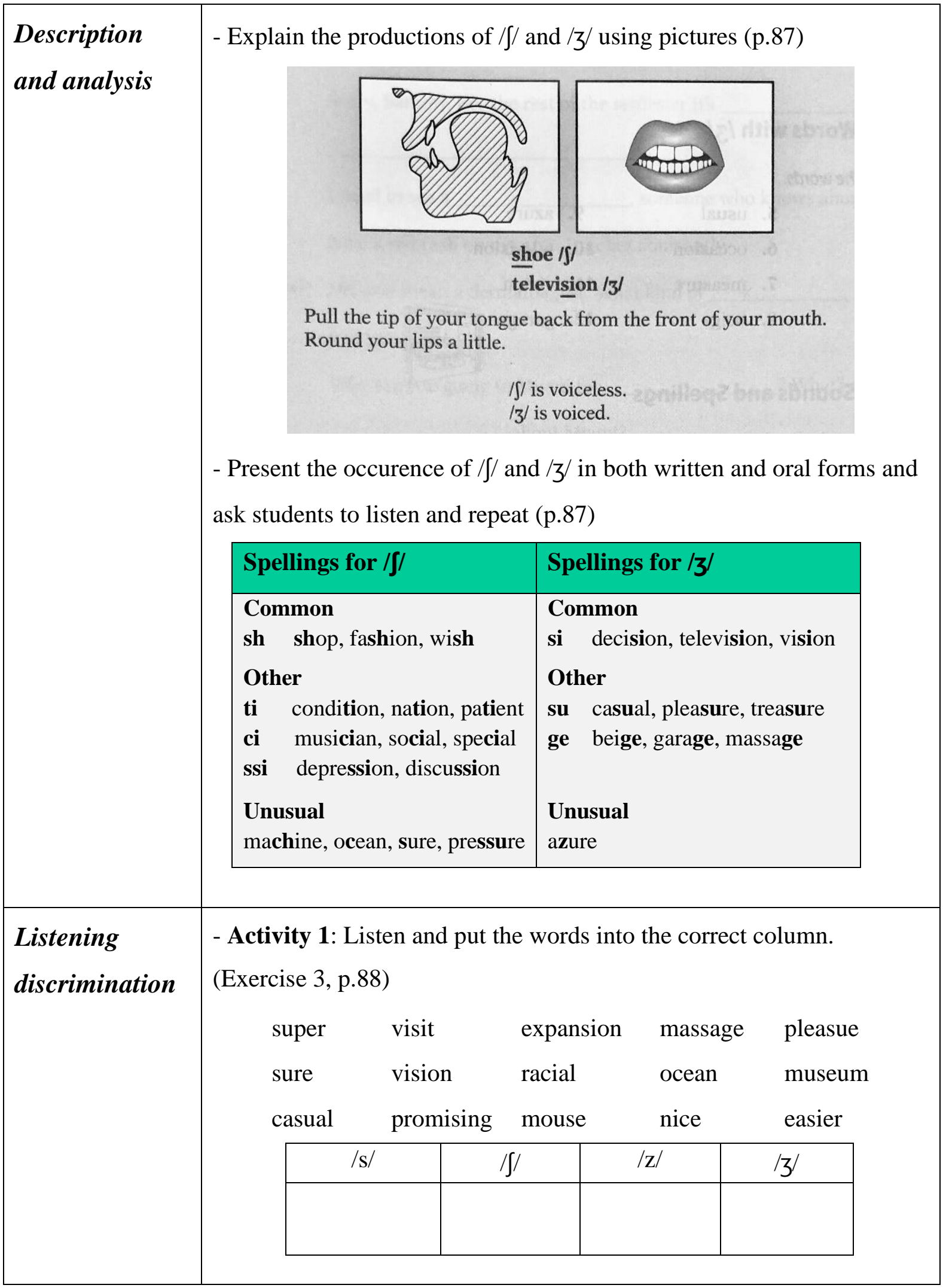




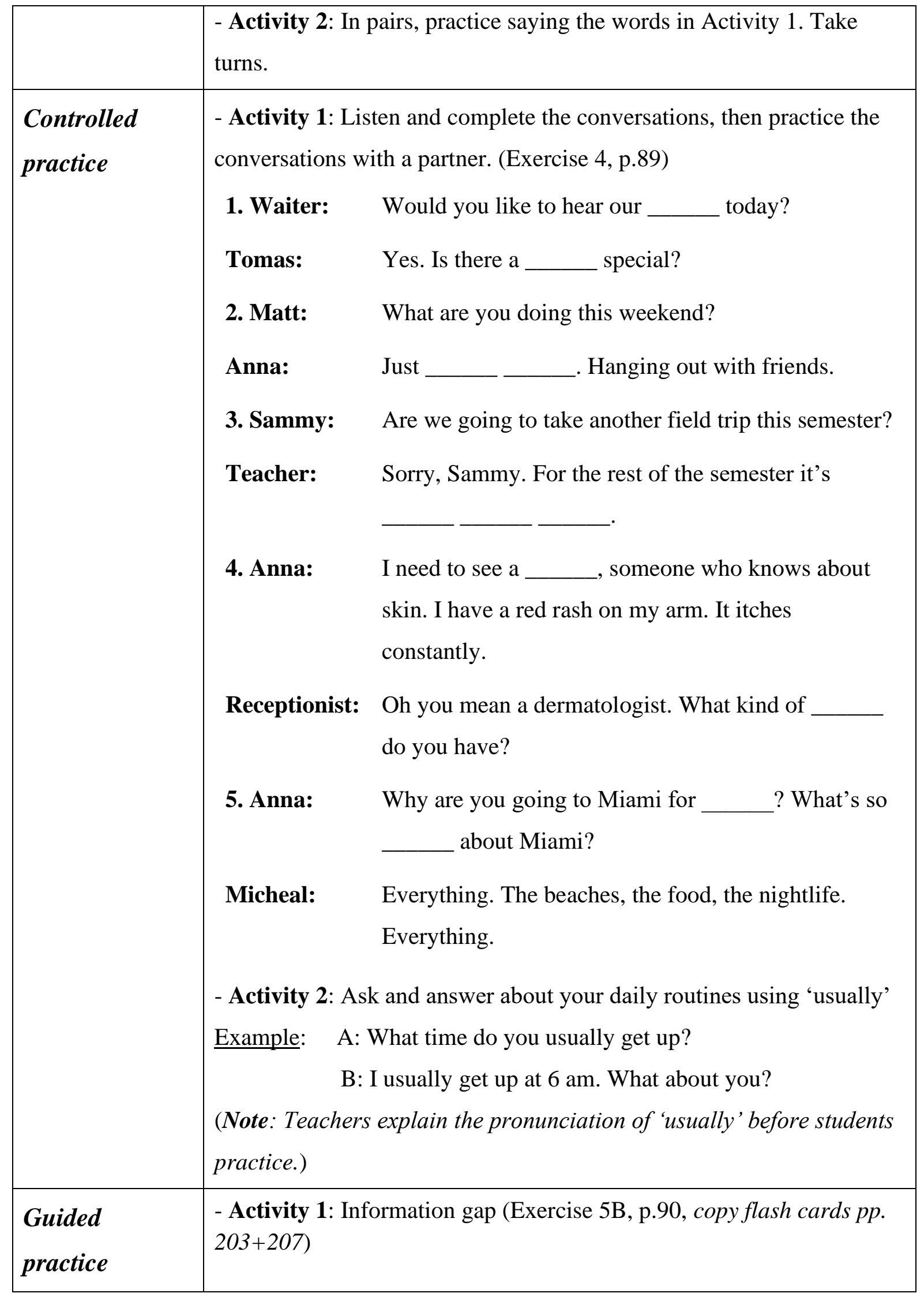




\begin{tabular}{|l|l|l|}
\hline Student A & $\begin{array}{l}\text { Minimum paid } \\
\text { vacation days }\end{array}$ & $\begin{array}{l}\text { Paid public } \\
\text { holidays }\end{array}$ \\
\hline France & 10 \\
\hline Hungary & $\begin{array}{l}23 \text { (if over } 31 \\
\text { years old) }\end{array}$ & \\
\hline India & & 19 \\
\hline Italy & 20 & 15 \\
\hline Japan & & 18 \\
\hline Latvia & 20 & \\
\hline Lebanon & & 12 \\
\hline Philippines & 5 & 13 \\
\hline South Africa & & \\
\hline South Korea & 19 & \\
\hline Thailand & & 30 \\
\hline $\begin{array}{l}\text { United Arab } \\
\text { Emirates }\end{array}$ & 30 & \\
\hline
\end{tabular}

\begin{tabular}{|l|l|l|}
\hline Student B & $\begin{array}{l}\text { Minimum paid } \\
\text { vacation days }\end{array}$ & $\begin{array}{l}\text { Paid public } \\
\text { holidays }\end{array}$ \\
\hline France & 30 & 10 \\
\hline Hungary & 12 & \\
\hline India & & 11 \\
\hline Italy & 20 & 11 \\
\hline Japan & & 14 \\
\hline Latvia & 15 & \\
\hline Lebanon & & 11 \\
\hline Philippines & & \\
\hline South Africa & 21 & 9 \\
\hline South Korea & & \\
\hline Thailand & 6 & \\
\hline $\begin{array}{l}\text { United Arab } \\
\text { Emirates }\end{array}$ & & \\
\hline
\end{tabular}

- Activity 2: Read the words listed below. Which words describe each vacation? In groups of three, discuss and put the words on the correct lines. (Exercise 6B, p.91)

$\begin{array}{llll}\text { glaciers } & \text { massage } & \text { international food } & \text { azure water } \\ \text { fashionable people } & \text { relaxing } & \text { nutritious food } & \text { shopping } \\ \text { unusual people } & \text { adventure } & \text { champagne } & \text { shows } \\ \text { restful } & \text { sunshine } & \text { delicious food } & \text { expensive } \\ \text { inexpensive } & \text { museums } & \text { dangerous } & \text { boring }\end{array}$

1. salmon fishing in Alaska:

2. diving for buried treasure in the Caribean:

3. staying home, sleeping late, watching television:

4. a week in New York City:

5. two weeks at a health spa:

6. a week in Paris:

7. a week of race-car driving lessons: 


\begin{tabular}{|l|l|}
\hline Communicative & $\begin{array}{l}\text { - Activity 1: Look at the following vacations and discuss the questions } \\
\text { in groups of three. (Exercise 6C, p.91) } \\
\text { 1. salmon fishing in Alaska } \\
\text { 2. diving for buried treasure in the Caribean } \\
\text { 3. staying home, sleeping late, watching television } \\
\text { 4. a week in New York City } \\
\text { 5. two weeks at a health spa } \\
\text { 6. a week in Paris } \\
\text { 7. a week of race-car driving lessons } \\
\text { 1. Have you ever taken any of the vacations listed above? } \\
\text { 2. Which of these vacations would you like to take and why? } \\
\text { - Activity 2: In pairs, talk about your last vacation. }\end{array}$ \\
\hline
\end{tabular}




\section{Lesson plan 4: $\quad$ Consonants $/ \mathrm{t} / /$ and $/ \mathrm{d} 3 /$}

\section{Planned by: $\quad$ Teacher Khoa}

\section{Procedures:}

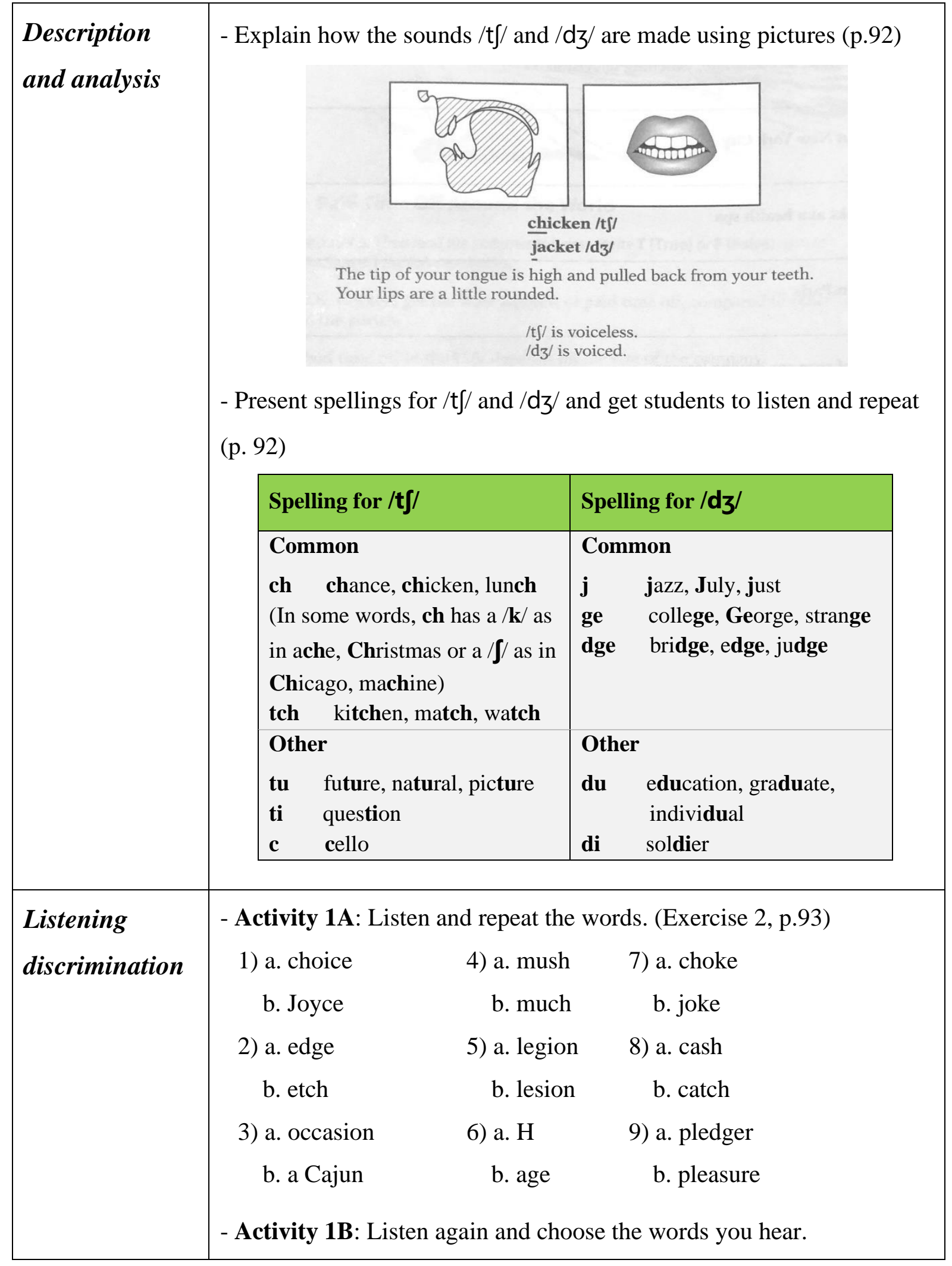




\begin{tabular}{|c|c|}
\hline & $\begin{array}{l}\text { - Activity 2: Work in pairs. Read the words in 1A to your friend. } \\
\text { He/She will tell you which word he/she hears. Take turns. }\end{array}$ \\
\hline $\begin{array}{l}\text { Controlled } \\
\text { practice }\end{array}$ & 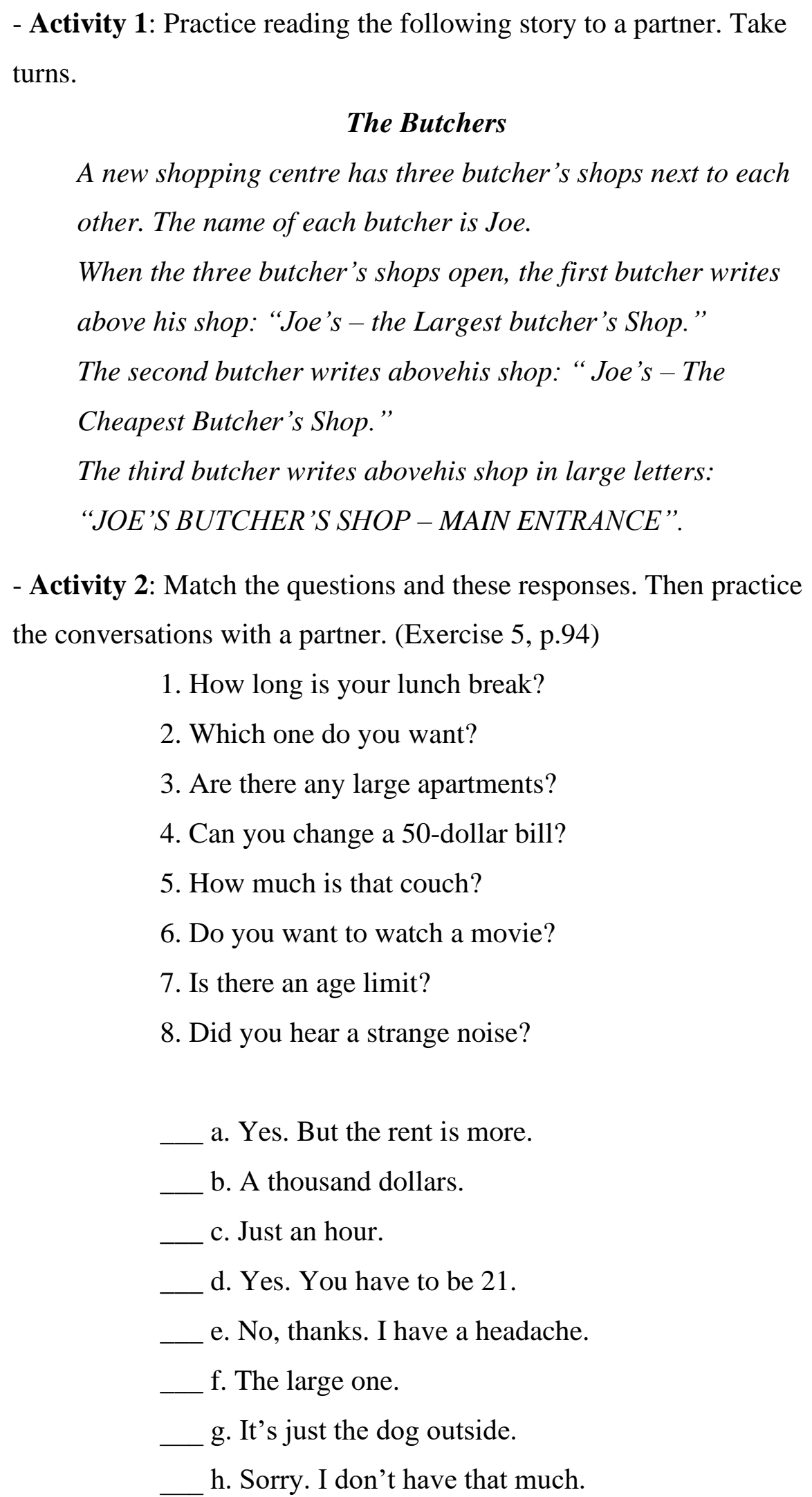 \\
\hline
\end{tabular}




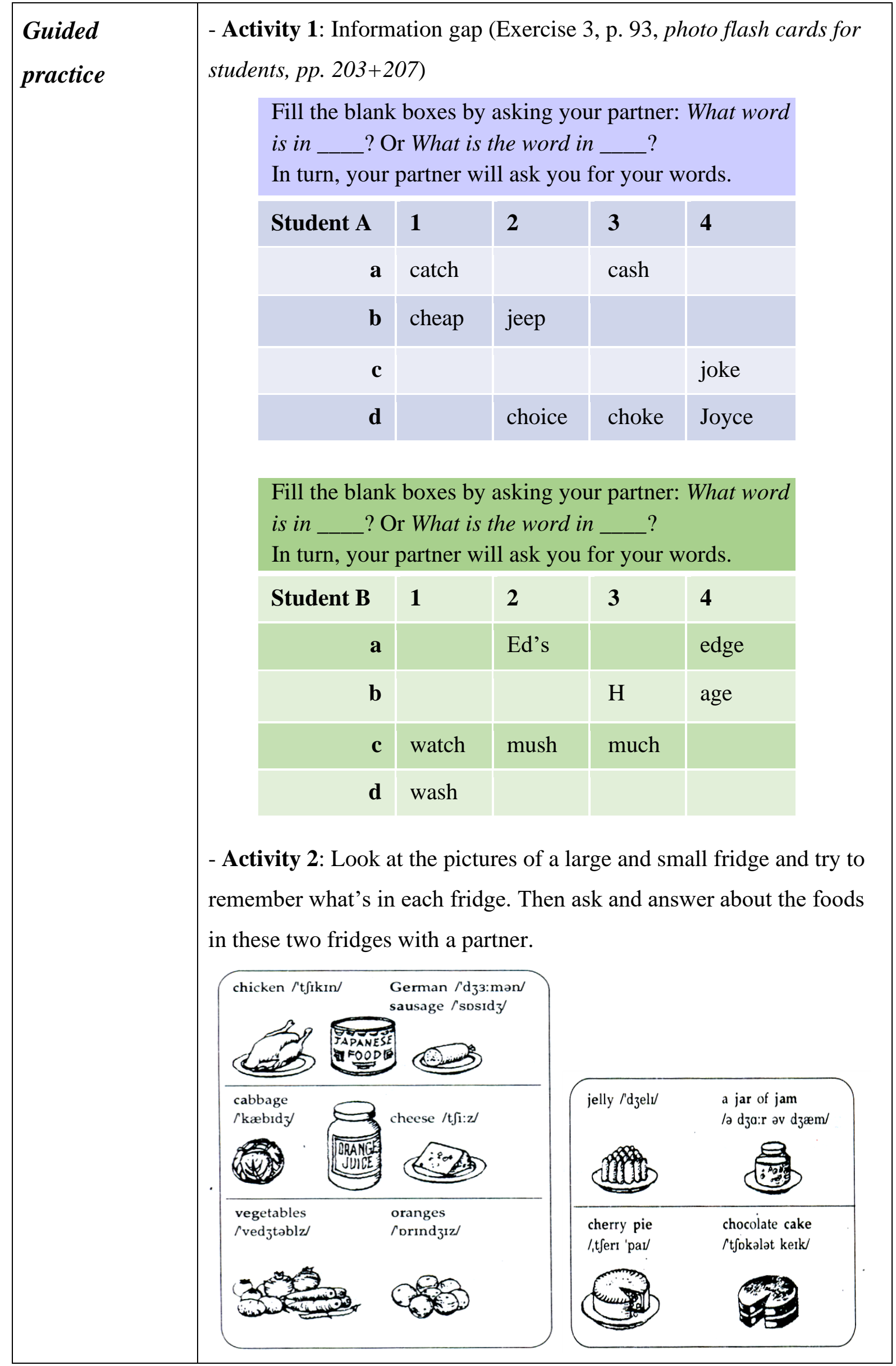




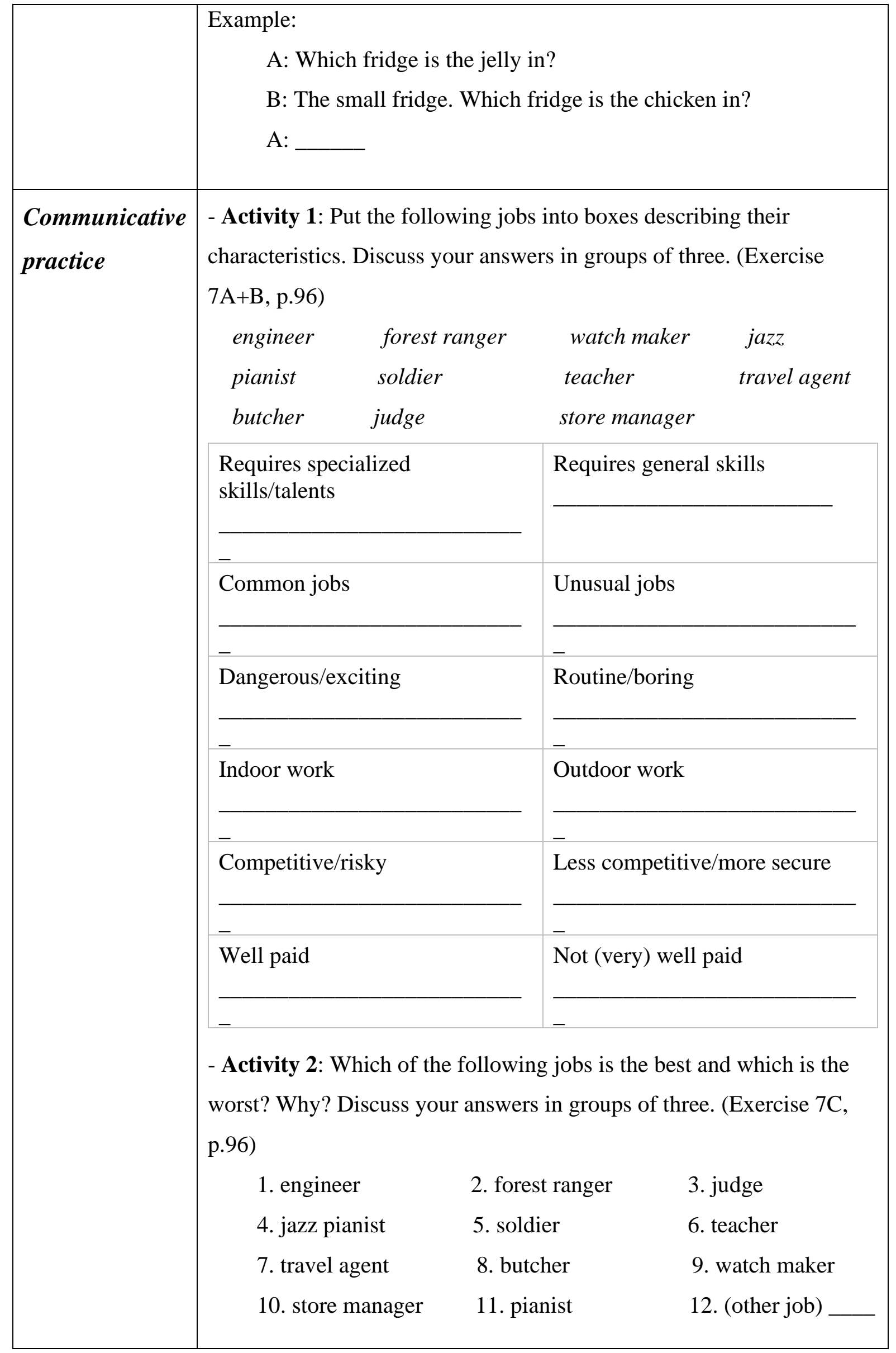


Lesson plan 5: $\quad$ Sentence stress

Planned by: $\quad$ Teacher Diep

Procedures:

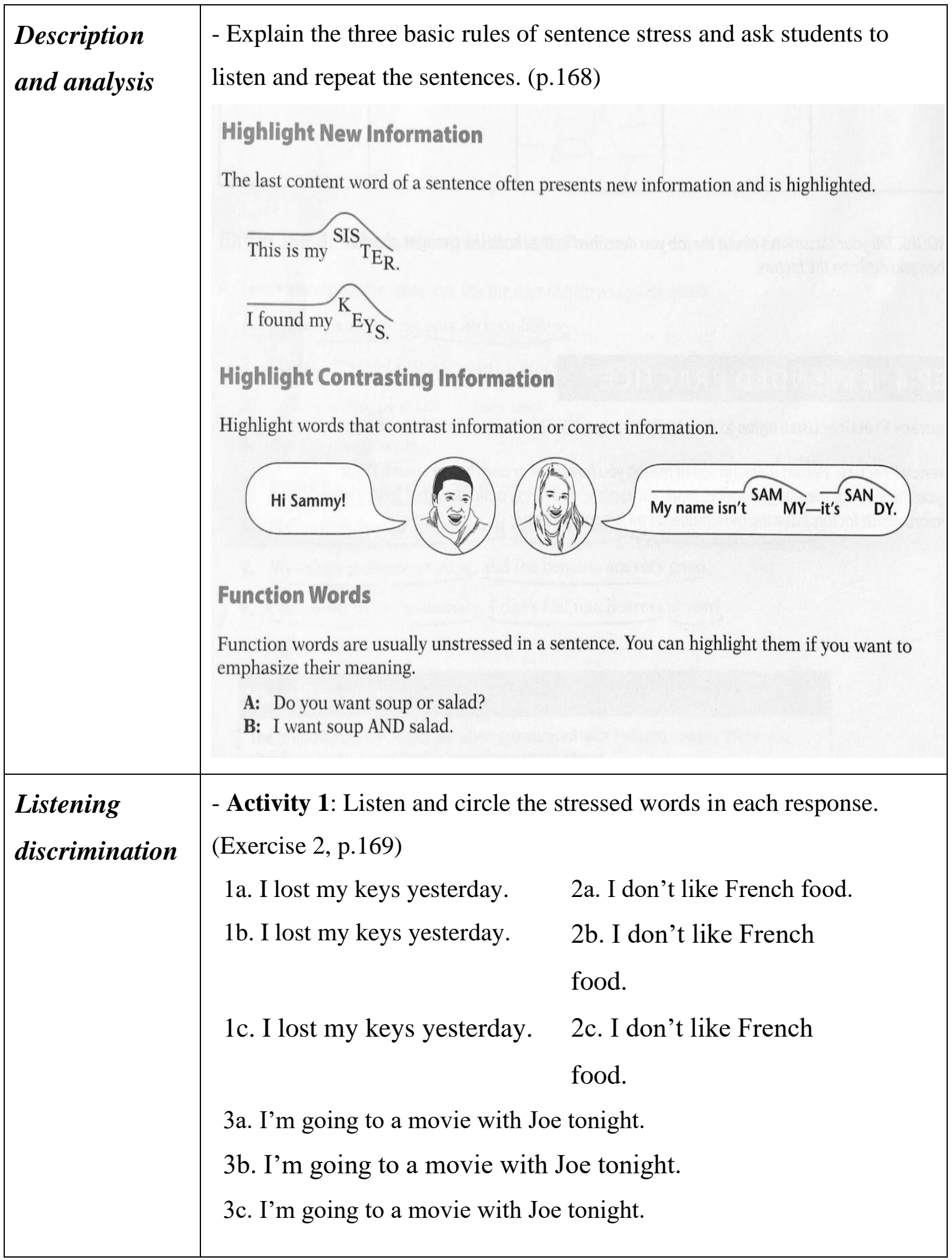




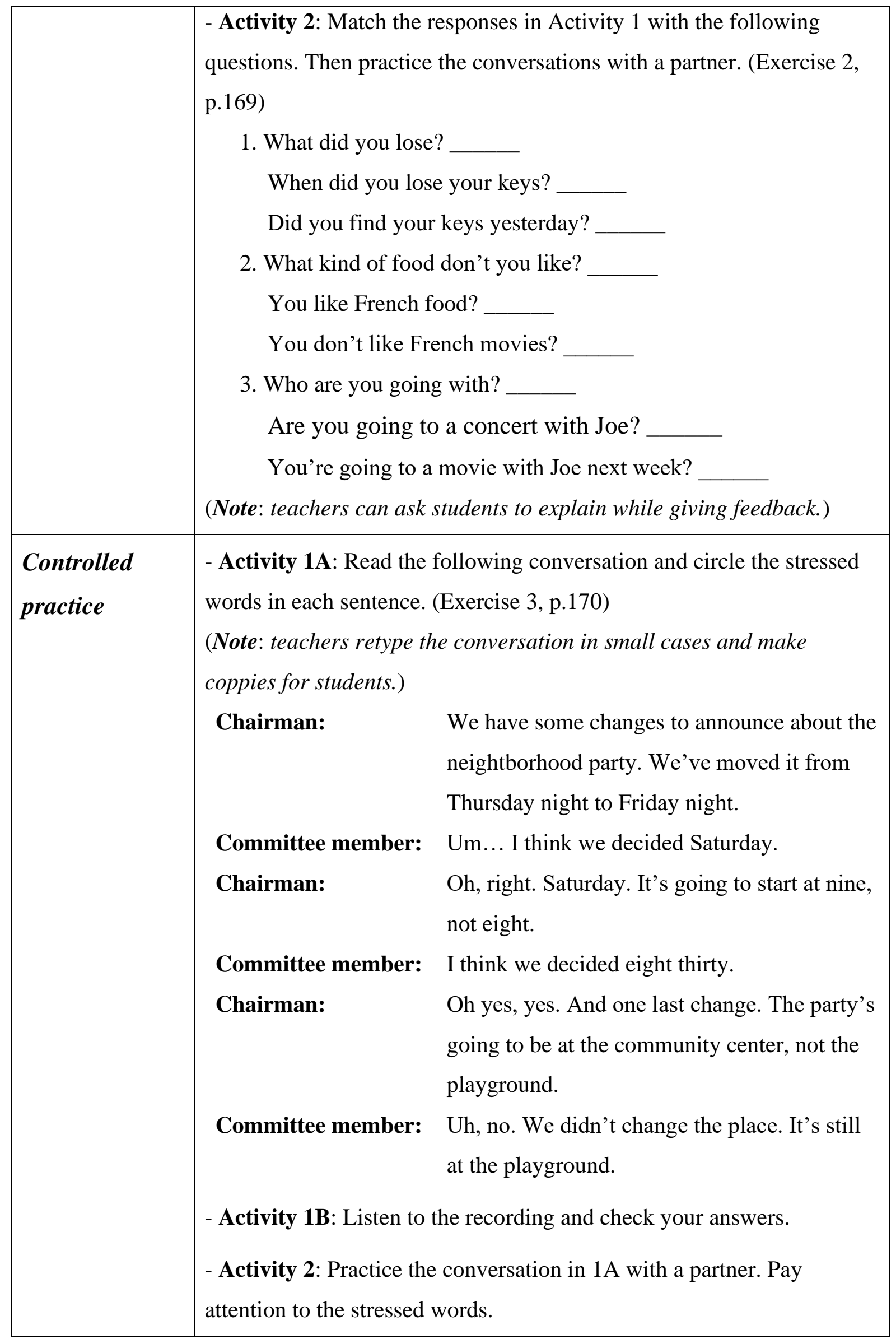




\begin{tabular}{|c|c|}
\hline $\begin{array}{l}\text { Guided } \\
\text { practice }\end{array}$ & 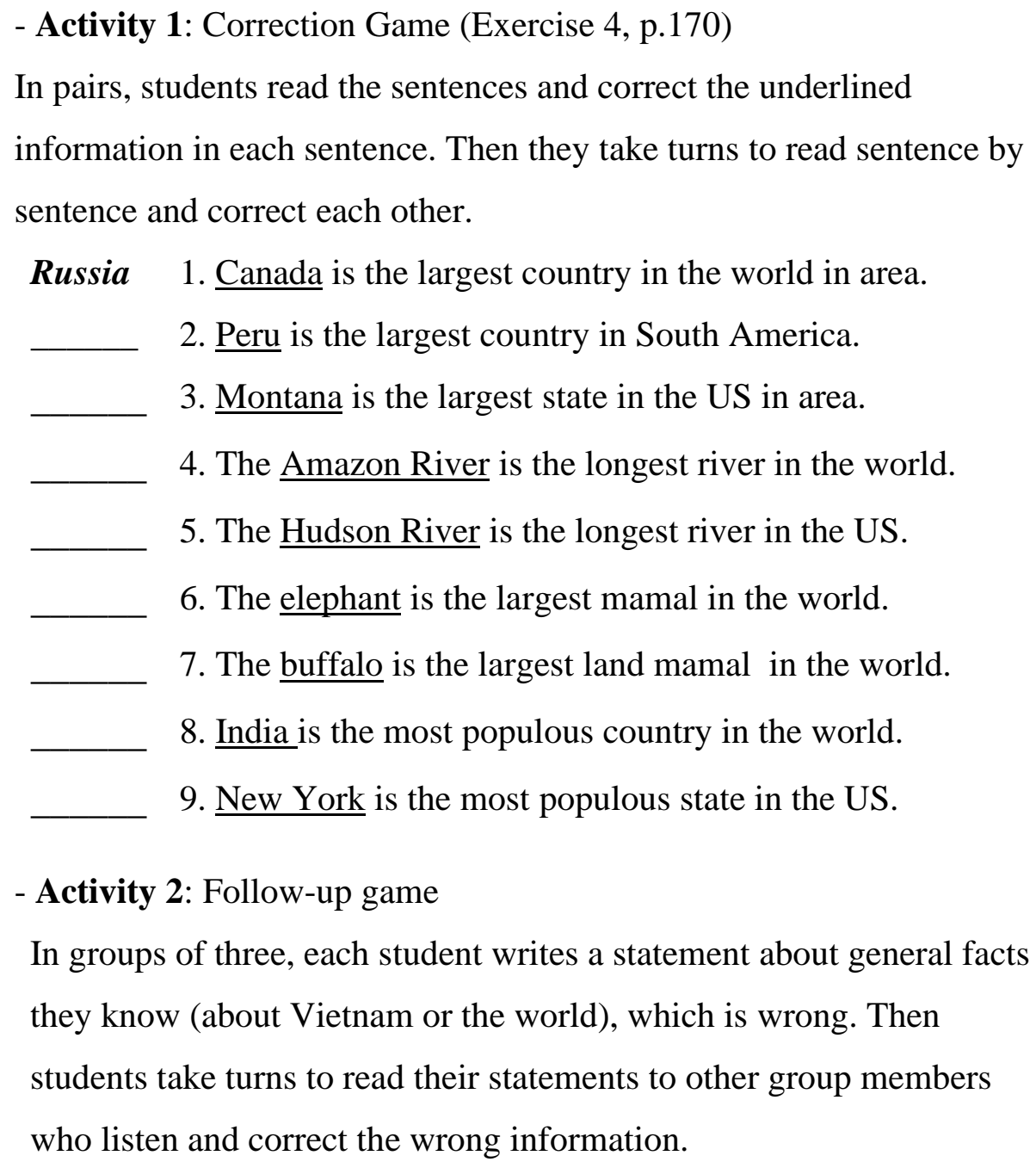 \\
\hline $\begin{array}{l}\text { Communicative } \\
\text { practice }\end{array}$ & $\begin{array}{l}\text { - Activity 1: Listen to the conversation and discuss the following } \\
\text { questions. (Exercise } 5 \mathrm{~A}+\mathrm{B}, \mathrm{p} .171 \text { ) } \\
\text { 1. How well does Felix know his neighbour? } \\
\text { 2. Do you think Felix's neighbour will agree to take the keys? } \\
\text { 3. Would you take the keys from Felix? Why or why not? } \\
\text { - Activity 2: Discuss the following questions with a friend. } \\
\text { 1. How close are you to your neighbours? } \\
\text { 2. Would you give your neighbour your keys? Explain. }\end{array}$ \\
\hline
\end{tabular}


Lesson plan 6: $\quad$ Intonation

Planned by: $\quad$ Teacher Diep

Procedures:

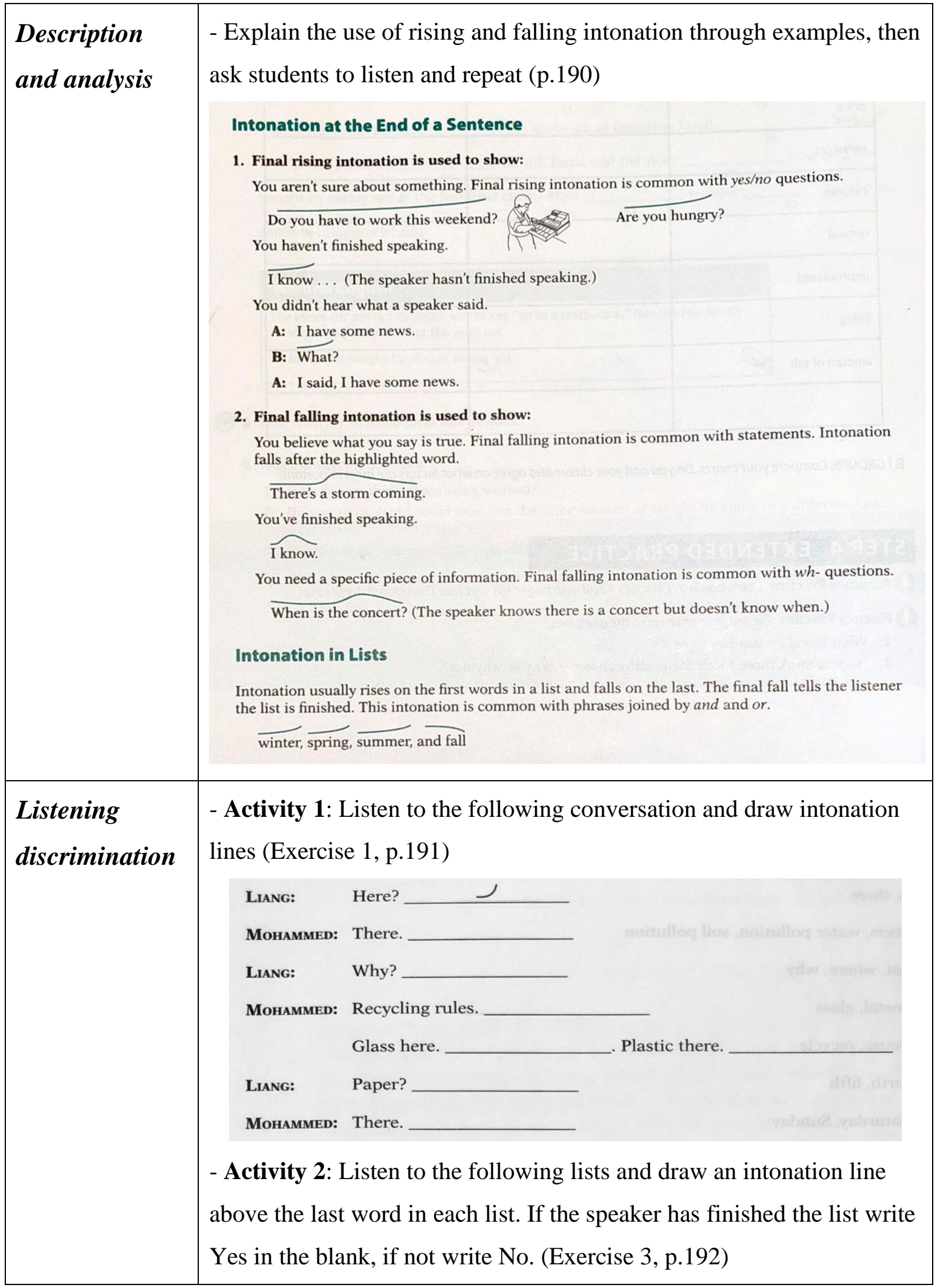




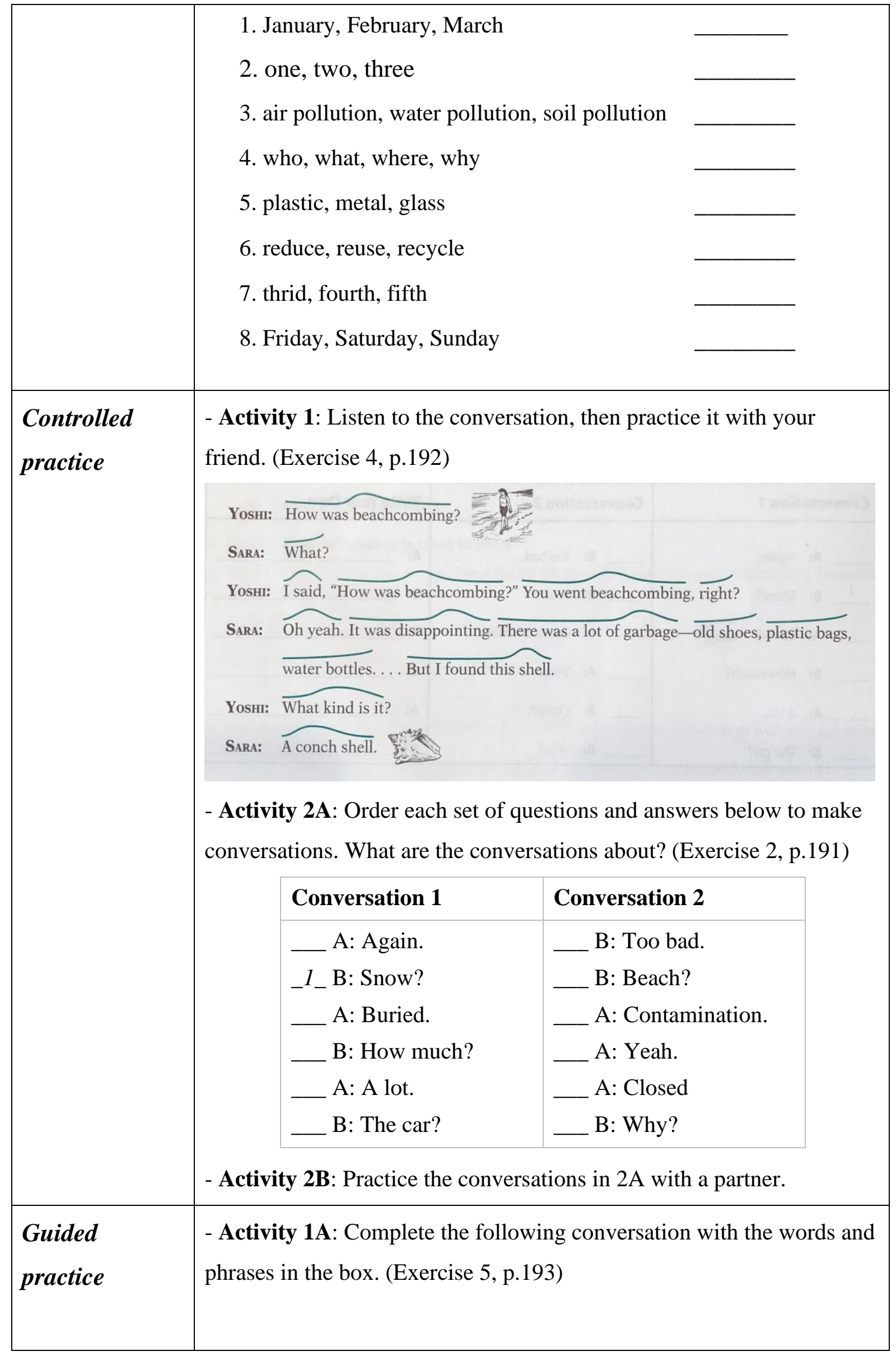




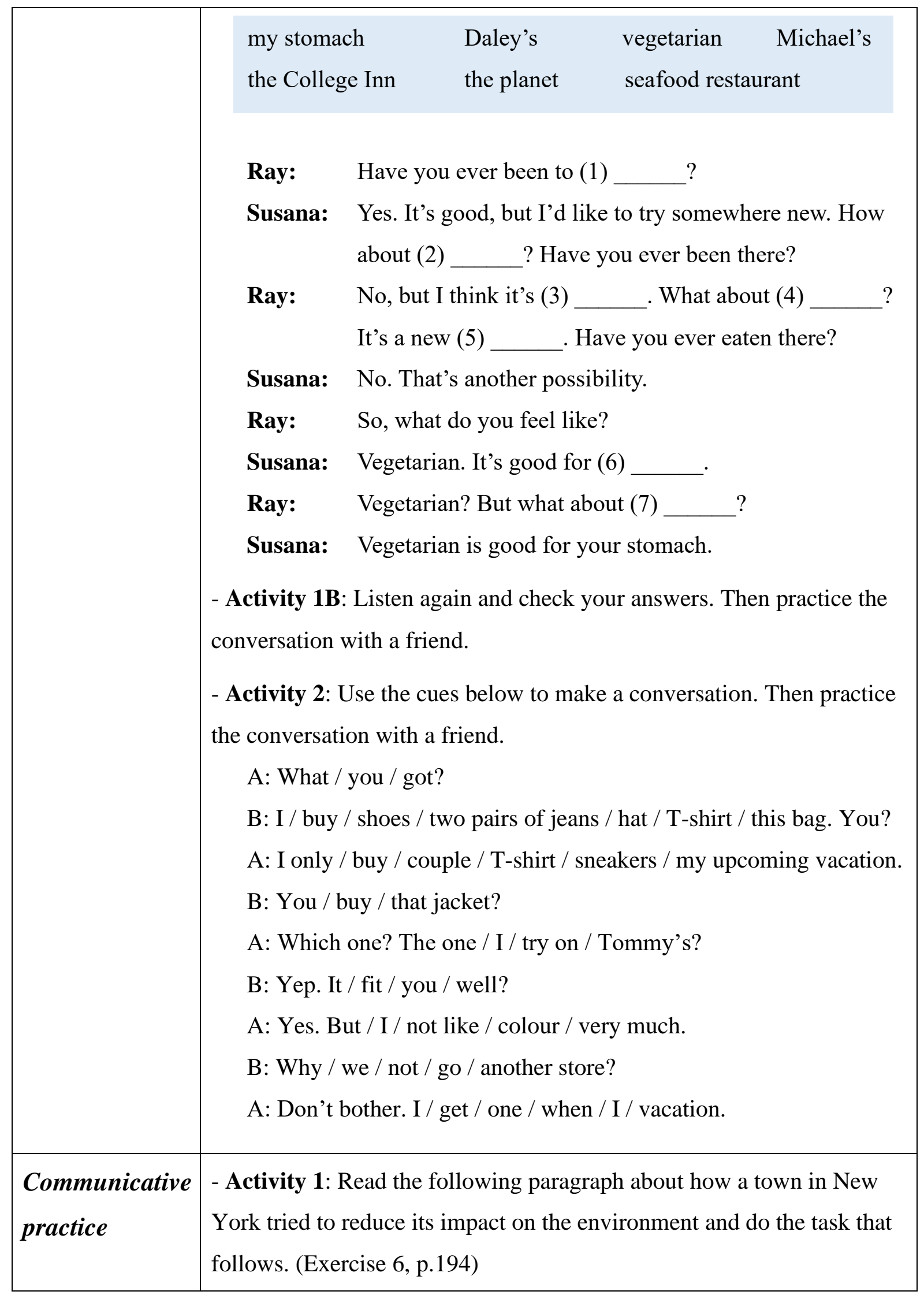




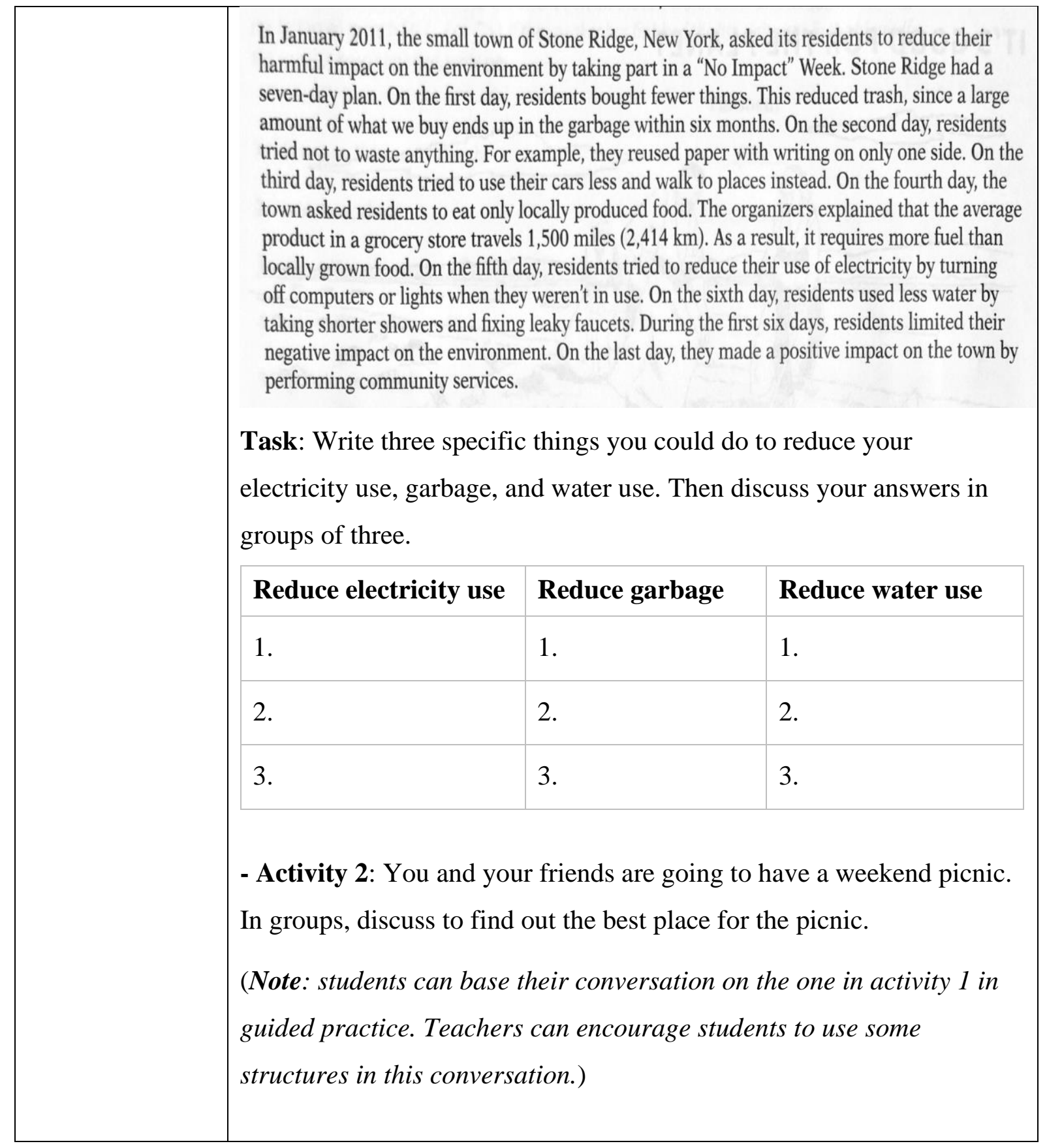




\section{Lesson plan 7: $\quad$ Final sounds and Linking}

Planned by: $\quad$ Teacher Na

Procedures:

\begin{tabular}{|c|c|c|c|c|}
\hline \multirow{3}{*}{$\begin{array}{l}\text { Description } \\
\text { and analysis }\end{array}$} & \multicolumn{4}{|c|}{ - Present three common cases of linking sounds using examples (p.127) } \\
\hline & \multicolumn{4}{|c|}{$\begin{array}{l}\text { 1. Final Consonant + Vowel } \\
\text { Join a final consonant to a following vowel clearly. } \\
\text { hold on leave early park entrance } \\
\text { 2. Final Consonant + Identical Consonant } \\
\text { Don't say the consonant twice. Make one long consonant. } \\
\text { bad day work quickly dress simply } \\
\text { 3. Final Consonant + Different Consonant } \\
\text { Pronounce the final consonant, but keep it short ('). Say the next word immediately. Don't } \\
\text { separate the consonants with a vowel sound. } \\
\text { book' bag rose' garden sharp') knife }\end{array}$} \\
\hline & \multicolumn{4}{|c|}{ - Ask students to listen and repeat the phrases. } \\
\hline Listening & \multicolumn{4}{|c|}{ - Activity 1A: Listen and repeat the words. (Exercise 1, p.128) } \\
\hline discrimination & 1) a. bell & b. belt & 5) a. hole & b. hold \\
\hline & 2) a. men & b. meant & 6) a. fell & b. felt \\
\hline & 3) a. car & b. card & 7) a. were & b. word \\
\hline & 4) a. stress & b. stressed & 8) a. lamb & b. lamp \\
\hline
\end{tabular}

- Activity 1B: Listen and choose the words you hear.

- Activity 2: Read the words in 1A to your friend and he/she will tell you which word he/she hears.

Controlled practice
- Activity 1A: Listen and repeat the phrases (Exercise 2, p.128)
Consonant + Vowel
1. correct answer
2. expert advice
3. finished early
4. piles of paper
5. picked it up

\section{Consonant +} Same Consonant

6. red door

7. half full

8. dark clouds

9. both thumbs

10. deep pool
Consonant + Different Consonant

11. junk' food

12. walked' fast

13. health' club

14. change) clothes

15. bird bath

- Activity 1B: Practice reading the phrases in 1A to a friends. Take turns. 


\begin{tabular}{|c|c|}
\hline & 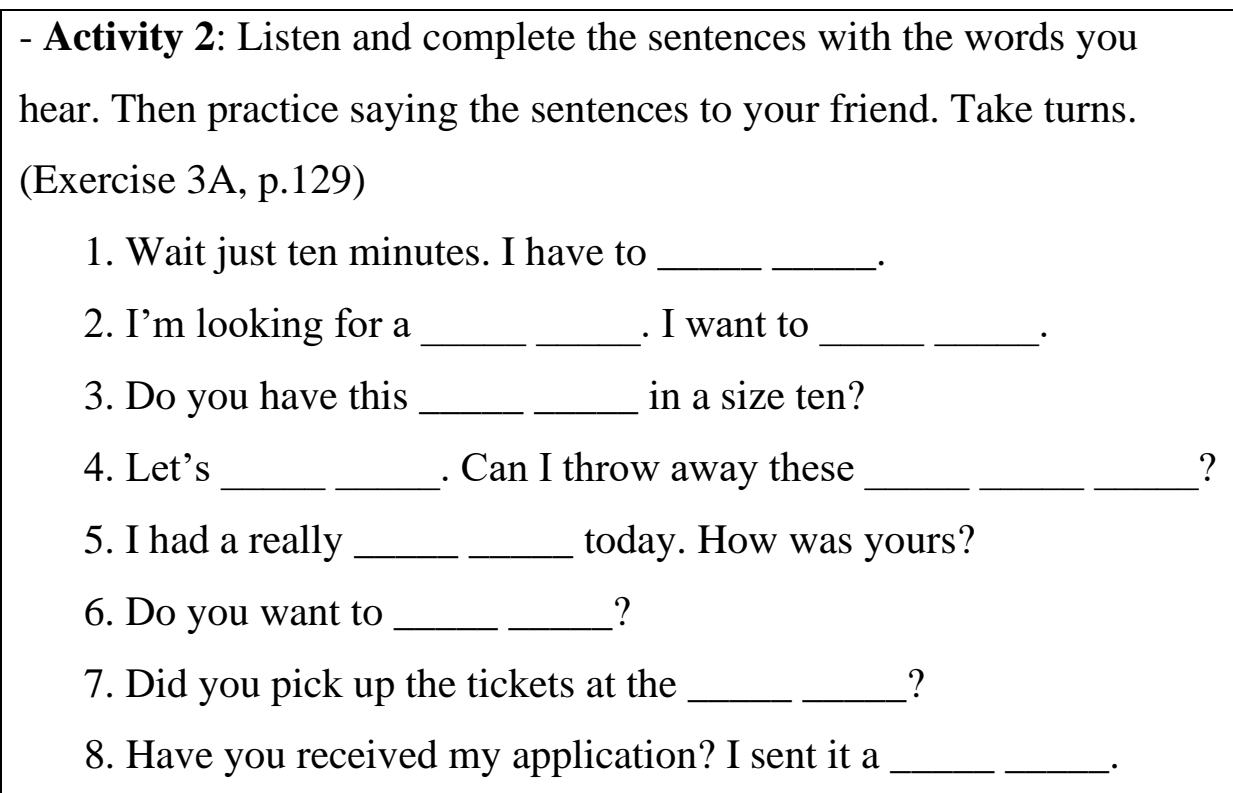 \\
\hline $\begin{array}{l}\text { Guided } \\
\text { practice }\end{array}$ & $\begin{array}{l}\text { - Activity 1: Match the sentences in Activity 2A (controlled practice } \\
\text { above) with the following responses. Then practice them with a partner. } \\
\text { Take turns. (Exercise 3B, p.129) } \\
\text { a. Sure. I don't need them any more. } \\
\text { b. Why don't you come with me to mine tonight? I'm taking a } \\
\text { kickboxing class. } \\
\text { c. Mine wasn't great either. Let's go shopping. I always feel } \\
\text { better when I spend money. } \\
\text { d. Sorry. Everything we have is on the rack. } \\
\text { e. Don't worry. What you're wearing looks great. } \\
\text { f. Hold on a moment. No, we haven't gotten it yet. } \\
\text { g. Yes. There's a great movie on channel } 5 . \\
\text { h. Yes. The show starts at } 8.30, \text { so we'd better leave now. } \\
\text { - Activity 2: Underline the phrases where sounds are linked. Then } \\
\text { practice the conversation with a friend. Take turns (Exercise 4, p. 130) } \\
\text { Luke: Today was a terrible day! Everything went wrong. } \\
\text { Sonia: What? }\end{array}$ \\
\hline
\end{tabular}




\begin{tabular}{|c|c|}
\hline $\begin{array}{l}\text { Communicative } \\
\text { practice }\end{array}$ & $\begin{array}{l}\text { - Activity 1: Read the sentences and check ( } \checkmark \text { ) the statements that } \\
\text { describe how you cope (or don't cope) with stress. Discuss your } \\
\text { answers with a friend. (Exercise 6A, p.131) } \\
\text { 1. I eat when I get upset. } \\
\text { 2. I avoid thinking about my problems. } \\
\text { 3. I get about } 5 \text { hours of sleep a night. } \\
\text { 4. At least twice a week, I exercise hard to make me sweat. } \\
\text { 5. I take a break when I'm stressed out. } \\
\text { 6. I I have a friend I can talk to about my problems. } \\
\text { - Activity 2: In groups of three, discuss which statements in Activity } 1 \\
\text { describe situations that can reduce stress? Increase stress? Explain. } \\
\text { (Exercise 6B, p.131) }\end{array}$ \\
\hline
\end{tabular}




\section{English translations}

Researcher: Thank you all for taking your time to come here today. Let's talk about your first experimental teaching session. How do you think your class went and which activities worked well? Respects to seniors, so please Teacher Phuong, you will talk first.

Phuong: [Laughed] Thank you. I saw students enjoyed most of my classroom activities, especially the communicative ones. Students engaged actively in practicing and especially liked speaking with their friends. But I felt many of them didn't like the controlled-practice activities very much.

Researcher:Uh huh. So, what do you think might be the problem?

Phuong: Uhm... Maybe because they found these activities boring. Usually students don't like mechanical tasks involving repetition. They prefer to practice speaking.

\section{Original Vietnamese}

Cảm ơn mọi người đã đến buổi thảo luận hôm nay. Giờ mình nói về buổi dạy thực nghiệm đầu tiên ha. Các thầy cô cảm nhận về buổi dạy đó như thế nào? Hoạt động nào thầy cô thấy hiệu quả và hoạt động nào không? Kính lão đắc thọ nha. Mời cô Phương nói trước ạ.

(Cười) Cảm ơn à! Cô thấy hầu hết sinh viên thích các hoạt động trong bài giảng, nhất là các hoạt động giao tiếp. Sinh viên tham gia luyện tập rất tích cực và đặt biệt các em thích tập nói với các bạn trong lớp. Tuy nhiên, có điều cô cảm thấy nhiều em có vẻ như không thích các hoạt động ở giai đoạn controlled-practice lắm.

Dạ. Vậy theo cô thì vấn đề nằm ở chỗ nào ạ?

Uhm... Có lẽ là do các em cảm thấy các hoạt động này chán hay sao đó. Thường thì các em không thích các bài tập mang tính mechanical cho lắm. Các em thích luyện nói hơn. 
Nguyen: Ifelt that too. I think another reason may be because my students are quite good at English, they found activities that only need repetition not very interesting. For students of a lower level, I think these activities would work.

Researcher:Uh huh. What do you think, Teacher Quynh?

Quynh: Ifelt the same. Students were really interested in speaking activities but seemed unresponsive to listen-andrepeat activities.

(...)
Anh cũng thấy vậy. Theo anh thì một nguyên nhân nữa đó là do sinh viên lớp anh cũng khá tiếng Anh. Cho nên đối với những bài tập chỉ yêu cầu các em nghe và lặp lại thì các em không thấy hứng thú cho lắm. Theo anh thì bài tập dạng này chắc hiệu quả hơn đối với các lớp trình độ thấp hơn.

À, dạ. Còn cô Quỳnh? Cô thấy buổi dạy đầu tiên của mình như nào?

Tui cũng vậy. Sinh viên rất hào hứng trong các hoạt động luyện speaking nhưng lại có vẻ thờ ơ đối với các bài tập chỉ yêu cầu các em nghe và lặp lại.

$(\ldots)$ 


\section{Extract English translations}

(71) "I think the first point is I have fostered my knowledge about pronunciation.

Clearly, if we don't apply previously learned knowledge in our teaching, it's certain that we'll gradually forget it. So, when I taught pronunciation communicatively in this semester, I had a chance to review pronunciation knowledge such as how English sounds are articulated, named and classified, etc. Understandings derived from this revision have helped me give clearer and precise explanations about places and manners of articulation of different sounds to my students." (P2, Teacher InI, Q2, Quynh)

(72) "As I told you in the previous interview session, I haven't taught pronunciation explicitly and systematically for a long time and so I think my professional knowledge has more or less faded. But when I did the experimental teaching, I had a chance to foster my pronunciation knowledge (...) For example, I know how a certain sound is produced but almost forgot what it's exactly called in English. Only when I planned experimental lessons did I recall how sounds are classified and named based on places

\section{Original Vietnamese}

Tui nghĩ cái lợi đầu tiên là tui đã củng cố lại kiến thức về phát âm. Rõ ràng nếu mình không áp dụng kiến thức đã học vào việc giảng dạy thì chắc chắn sẽ dần dần quên hết. Cho nên khi mà tui dạy phát âm theo định hướng giao tiếp ở học kì này tui có cơ hội ôn lại những kiến thức về phát âm ví dụ như âm trong tiếng Anh được phát như nào, đặt tên và phân loại ra làm sao, vân vân. Việc review như này giúp mình giải thích cho sinh viên rõ ràng và cụ thể hơn về vị trí cấu âm cũng như phương thức cấu âm.

Như anh nói ở lần phỏng vấn trước thì lâu rồi anh không có dạy phát âm một cách bài bản cho nên kiến thức chuyên môn về nó cũng ít nhiều mai một. Nhưng qua việc dạy thực nghiệm thì anh có cơ hội ôn lại và củng cố kiến thức phát âm của mình (...) Ví dụ như mình biết phát âm âm đó như nào nhưng mà không nhớ chính xác cái thuật ngữ dành cho nó. Tuy nhiên khi mà anh soạn bài giảng thực nghiệm thì anh nhớ lại mấy cái như là âm được 
and manners of articulation and I can

explain this to my students in a clearer

way. I think lesson planning helps

teachers review their professional

knowledge about what they are going to

teach and this is the first benefit I

received from the workshop and

experimental teaching sessions." (P2,

Teacher InI, Q2, Nguyen)

(73) "Another benefit is that the workshop has given me an in-depth understanding about the communicative framework for teaching pronunciation. As I told you in the previous interview session, I didn't know about this teaching approach. But thanks to the workshop, I now know exactly what it is and how it works. For me, this teaching strategy is completely new and it's what I really need because no one taught me how to teach pronunciation when I did my BA and MA." (P2, Teacher InI, Q2, Diep) phân loại và gọi tên như nào dựa vào vị trí cũng như là cách thức cấu âm. Điều này giúp anh giải thích rõ ràng hơn khi dạy cho sinh viên. Anh nghĩ việc soạn giáo án giúp giáo viên ôn lại kiến thức chuyên môn về những gì mình sắp dạy. Đây là cái lợi đầu tiên từ workshop cũng như việc dạy thực nghiệm.

Một cái lợi nữa là workshop đã giúp em hiểu rõ hơn về communicative framework để dạy phát âm. Lần trước phỏng vấn anh có hỏi em về cái này thật sự là em chưa bao giờ nghe nói luôn. Nhưng mà bây giờ nhờ cái workshop thì em đã biết chính xác nó là cái gì và ứng dụng như nào rồi. Với em thì cách dạy này hoàn toàn mới. Đây thực sự là cái em đang cần bởi vì hồi học đại học cũng như cao học đâu có ai dạy em về phương pháp dạy phát âm đâu.

Một cái lợi nữa là workshop đã giúp em hiểu rõ hơn về communicative framework để dạy phát âm. Em có nghe qua về cái framework này đâu đó rồi nhưng mà như anh thấy đó không có thời gian để tìm hiểu xem có áp dụng được không luôn. Giờ thì em đã biết cách áp dụng cái framework này vào việc dạy phát âm rồi. Hóa 
several years ago but failed to give it a careful examination. So far, my so-called pronunciation teaching has consisted of correcting students' pronunciation errors. From now on, I can apply this framework in my teaching pronunciation, so it will be better." (P2, Teacher InI, Q2, Na) ra cái framework này có ích và đã được đề xuất mấy năm rồi. Tiếc là em chưa có thời gian để tìm hiểu thỏa đáng. Đó giờ em toàn chỉ có sửa lỗi cho sinh viên thôi để cho có cái gọi là mình cũng có dạy phát âm. Từ giờ em có thể áp dụng cái framework này nên tốt hơn rồi.

Em cũng đã nhận thức được nguyên tắc trong giảng dạy phát âm. Trước đây em thấy các hoạt động trong sách phát âm được sắp xếp cái này trước cái này sau nhưng không biết tại sao người ta lại làm như vậy. Nhưng mà khi em biết về năm bước dạy trong cái framework mà anh giới thiệu thì em mới hiểu là à thì ra họ sắp xếp như vậy đều có mục đích cả.

Sau khi tham dự workshop thì cô mới biết là à thì ra việc dạy phát âm không chỉ đơn thuần là sửa lỗi sai cho siên viên bằng cách bắt các $\mathrm{em}$ nghe rồi lặp lại mà là cho sinh viên luyện tập theo các tình huống giao tiếp khác nhau thì sẽ tốt hơn (...) Giờ thì cô đã có cái nhìn chi tiết hơn về communicative framework, áp dụng nó như nào và thiết kế các hoạt động ra làm sao để phù hợp với mỗi giai đoạn trong quá trình giảng. Nói thật là buổi workshop đã mang đến cho cô một luồng gió mới trong việc 
make my pronunciation teaching more interesting and more effective." (P2, Teacher InI, Q2, Phuong) dạy phát âm. Từ giờ có thể cô sẽ áp dụng cách dạy này. Như vậy việc dạy phát âm của cô sẽ thú vị hơn và hiệu quả hơn.

Theo em thấy thì workshop này rất có ích đối với việc dạy phát âm của em. Đó giờ em toàn chỉ có sửa lỗi cho sinh viên bằng cách cho các em nghe và lặp lại thôi. Giờ thì em thấy cách dạy áp dụng cái communicative framework tốt hơn nhiều. Em đã biết trình tự các bước giảng. Khi em soạn giáo án thì các nguyên tắc của từng bước dạy giúp em thiết kế hoạt động phù hợp với tiêu chí và mục tiêu của từng bước. Nhờ đó bài giảng của em sẽ sinh động hơn, giúp sinh viên hứng thú hơn trong học tập. Thực ra em luôn muốn tự làm mới bản than trong công tác giảng dạy cho nên đây thực sự là một cách hay.

Tui cảm thấy tự tin hơn. Bữa tui có nói là tui tự tin khi dạy phát âm đúng không? Lúc đó đơn giản là vì tui tự tin về kĩ năng phát âm và năng lực giảng dạy của mình nên mới nói như vậy. Nhưng mà thực sự sau khi dự workshop và sau khi dạy thực nghiệm thì tui mới hoàn toàn tự tin. Hồi trước tui chỉ sửa lỗi phát âm sai của sinh viên để giúp các em nhận ra problem của mình 


\begin{tabular}{|c|c|c|}
\hline & $\begin{array}{l}\text { their problems in oral communication. } \\
\text { But now I have the 'basis' to confidently } \\
\text { diversify pronunciation activities in my } \\
\text { class based on this theory [CPT] to help } \\
\text { my students practice and improve their } \\
\text { pronunciation." (P2, Teacher InI, Q2, } \\
\text { Quynh) }\end{array}$ & $\begin{array}{l}\text { khi nói thôi. Bây giờ thì tui đã có } \\
\text { cơ sở để tự tin mở rộng các hoạt } \\
\text { động dạy phát âm trong lớp rồi. } \\
\text { Dựa vào lí thuyết này thì tui có thể } \\
\text { giúp sinh viên thực hành và cải } \\
\text { thiện phát âm của các em. }\end{array}$ \\
\hline (79) & $\begin{array}{l}\text { “Ah, there's one more thing. After } \\
\text { attending the workshop, I felt more } \\
\text { confident in teaching pronunciation. } \\
\text { Before, I didn't teach pronunciation } \\
\text { explicitly and systematically because I } \\
\text { was not really sure about how to teach it } \\
\text { well. I feel much better now and I'm sure } \\
\text { that I can do it well from now on. I } \\
\text { especially like the communicative } \\
\text { practice stage of the framework because } \\
\text { I've so far only corrected my students' } \\
\text { pronunciation errors through repetition. } \\
\text { But with this step, I now can give my } \\
\text { students more communication situations } \\
\text { to practice their pronunciation and at the } \\
\text { same time develop their communication } \\
\text { skills." (P2, Teacher InI, Q2, Diep) }\end{array}$ & $\begin{array}{l}\text { À, còn cái nữa. Sau khi tham dự } \\
\text { workshop thì em cảm thấy tự tin } \\
\text { hơn để dạy phát âm rồi. Trước đây } \\
\text { em đâu có dạy phát âm bài bản đâu } \\
\text { vì sợ không biết nên dạy như nào } \\
\text { cho hay. Giờ thì em cảm giác tốt } \\
\text { hơn nhiều và chắc chắn là em có } \\
\text { thể dạy tốt. Đặc biệt là em thích cái } \\
\text { bước thực hành giao tiếp trong cái } \\
\text { framework đó anh. Đó giờ em toàn } \\
\text { chỉ có sửa lỗi cho sinh viên bằng } \\
\text { cách cho các em nghe và lặp lại } \\
\text { thôi. Nhưng giờ với bước này thì } \\
\text { em có thể tạo ra nhiều tình huống } \\
\text { giao tiếp hơn để cho sinh viên thực } \\
\text { hành kĩ năng phát âm do đó đồng } \\
\text { thời các em có thể phát triển kĩ } \\
\text { năng nghe nói nữa anh. }\end{array}$ \\
\hline (80) & $\begin{array}{l}\text { "Clearly, attending PL programmes helps } \\
\text { teachers widen their professional } \\
\text { knowledge, update new teaching } \\
\text { methodology that helps them teach better } \\
\text { and students can learn the language } \\
\text { better." (P2, Teacher InI, Q3, Nguyen) }\end{array}$ & $\begin{array}{l}\text { Đương nhiên tham gia các chương } \\
\text { trình bồi dưỡng sẽ giúp giáo viên } \\
\text { mở rộng kiến thức chuyên môn, } \\
\text { cập nhật phương pháp giảng dạy } \\
\text { mới hỗ trợ giáo viên dạy tốt hơn và } \\
\text { giúp sinh viên học tiếng tốt hơn. }\end{array}$ \\
\hline
\end{tabular}


(81) "I think PL programmes are very

necessary because this is an opportunity

for teachers to update new teaching

theory to serve their teaching job. And of

course, modern teaching methodology

helps students learn the language better."

(P2, Teacher InI, Q3, Khoa)

(82) "Second, if teachers keep doing the same thing every day, then both teachers and students will get bored. Routineness makes teachers lose their interest in teaching and students become demotivated in learning. So, it's much better if teachers update new teaching theory and skills to serve their daily teaching job.” (P2, Teacher InI, Q3, Quynh)

(83) "In my opinion, it's very good if we have workshops twice a year. But if that's not possible, then there should be at least a big annual workshop with native speaker experts as keynote speakers. This is not only for teachers to update new knowledge and teaching methodology but it's also an opportunity for teachers to share their teaching experience." (P2, Teacher InI, Q4, Quynh)
Em nghĩ các chương trình bồi dưỡng là rất cần thiết vì đó là cơ hội để giáo viên cập nhật lí thuyết dạy mới phục vụ công tác giảng dạy. Và đương nhiên là phương pháp dạy hiện đại sẽ giúp sinh viên học tiếng tốt hơn.

Thứ hai, nếu giáo viên cứ mãi dạy y chang từ ngày này qua ngày khác thì sẽ khiến cả giáo viên lẫn sinh viên ngán. Công việc cứ đơn điệu hàng ngày như vậy sẽ làm cho giáo viên không còn hứng thú trong giảng dạy mà sinh viên cũng nản hết muốn học. Vậy nên nếu giáo viên cập nhật lí thuyết và kĩ năng dạy mới sẽ tốt hơn cho công việc giảng dạy hằng ngày.

Theo tui nếu mình tổ chức workshop mỗi năm hai lần thì quá tốt. Nhưng nếu không được thì ít nhất cũng nên có một workshop lớn mỗi năm có mời diễn giả là chuyên gia người bản xứ. cái này không chỉ để giáo viên cập nhật kiến thức và phương pháp dạy mới mà đó còn là cơ hội để giáo viên chia sẻ kinh nghiệm giảng dạy với nhau nữa.

Trước hết workshop có diễn giả là chuyên gia người bản xứ theo anh là rất tốt vì có thể giúp giáo viên 
to widen their professional knowledge and to learn new teaching skills. This is also it's an opportunity for teachers to share their teaching experience and learn from each other." (P2, Teacher InI, Q4, Nguyen)

(85) "I think the first thing our school should do is to have a workshop once a year for teachers to share their teaching experience and learn from each other. If we can invite native speaker experts to be keynote speakers, it'll be excellent because teachers can update on new knowledge and recent teaching trends in the world." (P2, Teacher InI, Q4, Khoa)

(86) "Second, learning courses in Englishspeaking countries are very good and very necessary for teachers ' professional growth. But these courses must be at least three months in length. Before, I attended a three-week course in the US and did learn something but not much because it was too short. But the three-month course in New Zealand was amazing. I studied in a modern education environment with advanced teaching methodology. I learnt a lot from the teaching staff there, from the knowledge they transferred in class to their teaching styles. I must say they were very professional." (P2, Teacher InI, Q4, Phuong) mở rộng kiến thức chuyên môn và học thêm kĩ năng giảng dạy mới. Đó không chỉ là cơ hội chia sẻ kinh nghiệm mà còn để giáo viên học hỏi lẫn nhau.

Theo em việc đầu tiên khoa cần làm là tổ chức workshop mỗi năm một lần để giáo viên chia sẻ kinh nghiệm và học hỏi lẫn nhau. Nếu có thể mời diễn giả là chuyên gia người bản xứ thì quá tuyệt vời vì giáo viên có thể cập nhật kiến thức mới và $x u$ hướng giảng dạy mới trên thế giới.

Thứ hai, các khóa học ngắn hạn ở các nước nói tiếng Anh là rất tốt và hết sức cần thiết để giáo viên phát triển chuyên môn. Tuy nhiên khóa học như này phải ít nhất là ba tháng, hồi trước cô đi học ba tuần ở Mỹ cũng học được một số thứ nhưng không nhiều lắm vì quá ngắn. Nhưng khóa ba tháng ở New Zealand thì tuyệt vời. Cô được học trong môi trường giáo dục hiện đại với phương pháp giảng dạy tiên tiến. Cô học được rất nhiều từ đội ngũ giảng viên ở đó, từ kiến thức mà họ truyền đạt trên lớp cho tới phong cách giảng dạy của người ta. Phải nói là rất chuyên nghiệp. 
(87) "Short-term learning courses are also very important for teachers ' professional growth. A majority of our teachers were trained in Vietnam, so if they can attend a three-or-six-month course in an Englishspeaking country such as England,

America or Australia, then they can not only develop their professional ability but they can also improve their language skills.” (P2, Teacher InI, Q4, Diep)

(88) "Short-term learning courses are also necessary for both teachers' professional growth and language skills development. A majority of teachers studied English through their teachers and textbooks in Vietnam, so if we have more opportunities for our teachers to study in Englishspeaking countries for about three months, I think they can not only improve their professional knowledge but also develop their language skills. Then they'll teach better and can help students learn the language better." (P2, Teacher InI, Q4, Na)

(89) "I think another long-term strategy is sending teachers to English-speaking countries to do a PhD. The university should have annual plans to encourage and support teachers in this. As I've just said, teachers will benefit a lot from studying in developed countries where there are modern educational environments and advanced teaching
Các khóa học ngắn hạn cũng rất quan trọng để giáo viên phát triển chuyên môn. Phần lớn giáo viên mình được đào tạo ở Việt Nam nên là nếu được tham gia khóa học ba hoặc sáu tháng ở nước nói tiếng Anh như Anh, Mỹ, Úc thì không chỉ có thể phát triển năng lực chuyên môn mà còn cải thiện được kĩ năng ngôn ngữ nữa.

Các khóa học ngắn hạn cũng rất cần thiết để giáo viên phát triển chuyên môn và kĩ năng ngôn ngữ. Đa phần giáo viên mình học tiếng Anh qua sách vở và giáo viên người Việt. Cho nên nếu có nhiều cơ hội hơn để học tập ở các nước nói tiếng Anh khoảng ba tháng thì em nghĩ giáo viên có thể cải thiện kiến thức chuyên môn và phát triển cả kĩ năng ngôn ngữ nữa đó anh. Như vậy giáo viên sẽ dạy tốt hơn, giúp sinh viên học tiếng tốt hơn. Một chiến lược về lâu dài nữa theo tui là đưa giảng viên sang các nước nói tiếng Anh để làm nghiên cứu sinh. Nhà trường nên có kế hoạch cụ thể hằng năm để khuyến khích và hỗ trợ giảng viên trong vấn đề này. Như tui mới nói thì giảng viên sẽ hưởng lợi rất là nhiều từ việc học tập ở các nước phát triển. Người ta có môi 
methodology. If short-term courses can

be so effective, then spending four to five

years studying and doing research will

bring about a lot more benefits. After

finishing, they're back with new things

that can better facilitate students'

language learning. They can also share

what they've learnt in foreign countries

with teachers who are unable to do so."

(P2, Teacher InI, Q4, Quynh) trường giáo dục hiện đại, phương pháp giảng dạy tiên tiến. Khóa học ngắn hạn đã hiệu quả như vậy rồi nên việc giảng việc được học tập và nghiên cứu bốn năm sẽ mang lại nhiều cái lợi hơn nữa. Sau khi học xong về nước với những cái mới thì giảng viên sẽ giúp sinh viên học tiếng tốt hơn. Giảng viên cũng có thể chia sẻ những gì mình học được ở nước ngoài với những đồng nghiệp không có cơ hội để đi học.

Tui nghĩ là sinh viên đã ý thức hơn về tầm quan trọng của phát âm đối với kĩ năng nghe nói của các em rồi. Bữa tui nói á, sinh viên nhìu đứa chỉ chăm chăm vào fluency và lơ đi việc luyện phát âm. Qua các buổi dạy thực nghiệm thì tui tin chắc các em đã nhận thức được là việc phát âm sai cản trở giao tiếp bằng lời nói như nào rồi. Khi mà tui giải thích điểm này cho các em thì tui tin là các em đã hiểu ra được là phát âm đúng và rõ để người khác nghe hiểu được cũng quan trọng y chang như nói trôi chảy vây.

(91) "Through the new teaching approach in this semester, I had time to analyse students' pronunciation problems, explain and illustrate how important pronunciation is in listening and
Thông qua phương pháp dạy mới ở học kì này thì anh có thời gian để phân tích lỗi phát âm của sinh viên, giải thích và minh họa để các em thấy phát âm quan trọng đối với kĩ 
speaking. I think students have realised

that they have so far ignored this in

English learning. From examples of

communication misunderstandings due to

pronunciation errors I showed in class,

I'm sure students have become more

attentive to pronunciation practice." ( $\mathrm{P} 2$,

Teacher InI, Q5, Nguyen) năng nghe nói như nào. Anh nghĩ

sinh viên đã nhận ra là các em trước đây đã không quan tâm đến điều này trong quá trình học tiếng Anh. Qua những ví dụ về hiểu lầm trong giao tiếp do phát âm sai mà anh cho các em xem trong lớp thì anh tin chắc sinh viên đã chú ý hơn đến việc luyện phát âm.

Với em, cái lợi đầu tiên là em đã giúp các em ý thức hơn về tầm quan trọng của phát âm trong việc học tiếng Anh. Trong quá trình dạy thực nghiệm ở học kì này, sau khi sinh viên nói thì em phân tích để các em thấy lỗi phát âm trong khi nói tiếng Anh nó nghiêm trọng như thế nào. Khi giải thích như vậy thì em nghĩ sinh viên đã nhận thức được phát âm quan trọng như nào và từ bây giờ chắc chắn các em sẽ chú ý luyện phát âm nhiều hơn. pronunciation.” (P2, Teacher InI, Q5, Khoa)

(93) "The second benefit is pronunciation Cái lợi thứ hai là kiến thức về phát knowledge. The experimental teaching sessions of sounds have provided students with basic knowledge about places of âm. Các tiết giảng về âm cung cấp cho sinh viên những kiến thức cơ bản nhất về vị trí cấu âm, phương articulation, manners of articulation as thức cấu âm cũng như là đặc điểm well as characteristics of the target của các âm mình dạy. Các em cũng sounds. They were also more conscious of final sounds and linking in their speaking. When I taught them sentence stress and intonation, students understood them more đã ý thức hơn trong việc phát âm âm cuối và nối âm trong khi nói. Khi cô dạy cho về nhấn câu và ngữ điệu thì sinh viên hiểu rõ hơn và cụ 


\begin{tabular}{|c|c|c|}
\hline & $\begin{array}{l}\text { deeply and clearly and basically could } \\
\text { apply them in speaking English. Before, } \\
\text { students didn't learn about these and so } \\
\text { they didn't know how to use rising and } \\
\text { falling intonation in their speaking or they } \\
\text { didn't know which word to stress in a } \\
\text { sentence." (P2, Teacher InI, Q5, Phuong) }\end{array}$ & $\begin{array}{l}\text { thể hơn và cơ bản có thể áp dụng } \\
\text { được trong khi nói. Trước đây các } \\
\text { em không được học những cái này } \\
\text { cho nên khi nói các em không biết } \\
\text { sử dụng ngữ điệu lên xuống như } \\
\text { nào hết cũng như không biết nhấn } \\
\text { từ nào trong câu luôn. }\end{array}$ \\
\hline (94) & $\begin{array}{l}\text { "Basically, students have understood more } \\
\text { clearly about places and manners of } \\
\text { articulation of the target sounds, sentence } \\
\text { stress, intonation and especially linking. } \\
\text { They've known how and when to raise and } \\
\text { lower their voice in speaking and which } \\
\text { word needs to be stressed in sentences. } \\
\text { What pleased me the most was that } \\
\text { students were more conscious of final } \\
\text { consonants and linking although they still } \\
\text { sometimes forgot to apply linking but I } \\
\text { think this requires them to do more } \\
\text { practice." (P2, Teacher InI, Q5, Diep) }\end{array}$ & $\begin{array}{l}\text { Cơ bản thì sinh viên hiểu rõ hơn về } \\
\text { vị trí và phương thức cấu âm của } \\
\text { những âm em dạy, về nhấn câu và } \\
\text { ngữ điệu, đặc biệt là nối âm. Các } \\
\text { em đã biết dùng ngữ điệu lên } \\
\text { xuống và nhấn từ nào trong câu khi } \\
\text { nói. Cái mà em hài lòng nhất là } \\
\text { sinh viên đã ý thức hơn trong việc } \\
\text { phát âm âm cuối và nối âm. Mặc dù } \\
\text { trong lúc nói các em đôi khi vẫn } \\
\text { quên nối âm nhưng em nghĩ cái này } \\
\text { đòi hỏi thời gian để luyện tập nhiều } \\
\text { hơn. }\end{array}$ \\
\hline (95) & $\begin{array}{l}\text { "Second, students have had a more } \\
\text { specific understanding about places of } \\
\text { articulation, manners of articulation and } \\
\text { the essence of those sounds I taught them. } \\
\text { Students have also basically understood } \\
\text { more clearly about sentence stress and } \\
\text { intonation and could apply this in } \\
\text { communication. Especially, students were } \\
\text { more aware of linking sounds in their } \\
\text { speaking. Before, they usually dropped the } \\
\text { final consonant in their speaking and } \\
\text { didn't link it with vowel that follows." (P2, } \\
\text { Teacher InI, Q5, Na) }\end{array}$ & $\begin{array}{l}\text { Thứ hai là sinh viên đã hiểu cụ thể } \\
\text { hơn về vị trí cấu âm, phương thức } \\
\text { cấu âm và bản chất của những âm } \\
\text { em dạy. Sinh viên cơ bản cũng nắm } \\
\text { được nhấn câu, ngữ điệu và có thể } \\
\text { áp dụng vào giao tiếp. Đặc biệt là } \\
\text { sinh viên đã ý thức hơn trong việc } \\
\text { nối âm khi nói. Trước đây khi nói } \\
\text { các em chuyên gia bỏ phụ âm cuối } \\
\text { và cũng không nối phụ âm cuối với } \\
\text { nguyên âm đầu của từ theo sau. }\end{array}$ \\
\hline
\end{tabular}


(96) "When I gave students communication situations for practice, I felt they were really eager to talk. They worked harder and engaged more actively in classroom activities. So, I think the results will be much better if we teach [pronunciation] during the whole semester. Then I'm sure that students' pronunciation in particular and listening and speaking skills in general will be remarkably improved and so they'll be more confident in speaking English.” (P2, Teacher InI, Q5, Phuong)
Cô thấy sinh viên nói rất hăng say khi cô cho các em luyện tập theo tình huống giao tiếp. Các em làm việc chăm chỉ hơn và tích cực tham gia vào các hoạt động trong lớp. Nên cô nghĩ là nếu mình dạy suốt cả học kì luôn thì kết quả sẽ tốt hơn nhiều. Nếu được như vậy thì cô chắc là phát âm của sinh viên nói riêng cũng như kĩ năng nghe nói nói chung sẽ cải thiện đáng kể. Từ đó các em sẽ tự tin hơn để nói tiếng Anh.

(97) "The last stage in the framework provides Bước cuối cùng trong cái framework students with communicative practice in real-life situations. I like this because it involves students more actively in classroom activities. Students practice not only pronunciation but also listening and speaking. I'm sure if we have more classes like these, students' pronunciation, listening and speaking skills will improve. So, students will be more confident in using English for oral communication. Some students asked me the other day for the book title so that they can go to the bookstore to buy one for their self-study." (P2, Teacher InI, Q5, Diep)

(98) "I saw that students were actively involved in most classroom activities, especially those communication tasks at cho sinh viên được thực hành giao trong cuộc sống. Em thích cái này vì nó làm cho sinh viên tích cực tham gia vào các hoạt động trong lớp. Các em không chỉ tập phát âm mà còn luyện được kĩ năng nghe nói nữa. nghe nói của các em sẽ được cải thiện nếu mình dạy nhiều buổi hơn theo cách này. Nhờ đó sinh viên sẽ tự tin hơn để nói tiếng Anh. Bữa trước có mấy đứa còn hỏi em tên sách để ra nhà sách mua về tự học nữa đó anh.

Em thấy sinh viên tham gia tích cực vào hầu hết các hoạt động trong lớp, nhất là các bài tập luyện giao tiếp tiếp theo những tình huống thực tế Em tin chắc kĩ năng phát âm và 
the end of the lesson. In my opinion, if we teach [pronunciation] communicatively like this, then students' pronunciation skill will definitely be improved. And this helps develop their listening and speaking skills as well. Gradually, they'll be more active and confident in speaking English. But the outcomes didn't come up to my expectation because the experimental teaching was too limited. If we teach more, then I'm sure it'll be much better." (P2, Teacher InI, Q5, Na) cuối buổi. Theo em nếu mình dạy theo định hướng giao tiếp giống như này thì kĩ năng phát âm của sinh viên nhất định sẽ được cải thiện mà kĩ năng nghe nói của các em đồng thời cũng phát triển theo. Lâu dần các em sẽ chủ động và tự tin hơn trong việc giao tiếp bằng tiếng Anh. Nhưng mà do dạy thực nghiệm quá ít nên hiệu quả không như em mong đợi. Em chắc chắn kết quả sẽ tốt hơn nhiều nếu mình dạy nhiều hơn như này.

(99) "Clearly, when I taught students theory about places and manners of articulation Rõ ràng một điều là khi anh giảng cho sinh viên lí thuyết về vị trí và of the target sounds and explained to them about special features of these sounds, they found it very interesting and realised that they didn't know about these before. They engaged actively in communication situations in class and this made the classroom atmosphere more lively." (P2, Teacher InI, Q5, Nguyen)

(100) "Through this teaching approach, I realised that students were more interested and more actively involved in classroom activities. They like speaking very much and so practiced more eagerly, which made the classroom atmosphere more interesting and lively." (P2, Teacher InI, Q5, Diep) phương thức cấu âm và giải thích về những điểm đặc biệt của những âm anh dạy thì sinh viên cảm thấy rất hứng thú vì nhận ra rằng trước giờ các em chẳng biết gì về những kiến thức này. Các em hoạt động tích cực khi luyện tập các tình huống giao tiếp trong lớp làm cho không khí lớp học sôi động hơn.

Qua phương pháp dạy này thì em nhận thấy là sinh viên rất hứng thú và tích cực tham gia vào các hoạt động trong lớp. Các em thích nói lắm luôn cho nên luyện tập rất là hăng khiến cho không khí lớp học vui nhộn và sôi động hơn. 
(101) "Teaching and learning is a reciprocal process, I believe. Whether students are interested in learning partly depends on the way teachers teach. Similarly, students' attitudes towards learning in class greatly affect teachers' teaching. The students' eagerness in learning and practicing pronunciation itself has given me an incentive for teaching pronunciation. Now I feel I more like teaching pronunciation." ( $\mathrm{P} 2$, Teacher InI, Q5, Quynh)
Dạy và học có mối quan hệ tương hỗ, tui tin là như vậy. Sinh viên có hứng thú học tập hay không một phần phụ thuộc vào cách giảng viên đứng lớp. Ngược lại thái độ học tập của sinh viên trong lớp cũng ảnh hưởng rất lớn đối với việc giảng bài của giảng viên. Chính sự hăng say học tập cũng như chịu khó luyện phát âm của sinh viên đã truyền lửa cho tui trong việc dạy phát âm. Giờ thì tui thất thích dạy phát âm hơn rồi.

Mặc dù thời lượng dạy hạn chế nhưng sinh viên đã có cơ hội học và luyện phát âm trên lớp đồng thời cũng có thể tự luyện tập them ở nhà. Cái này tùy vào phương pháp mà giảng viên chọn. Nếu sinh viên thấy hứng thú thì các em sẽ học chăm chỉ và hăng say hơn. Khi thấy sinh viên tham gia tích cực vào các hoạt động trong lớp khiến em cảm thấy rất vui và có nhiều động lực hơn để giúp các em luyện tập cải thiện phát âm.

Nếu nói về khó khăn thì cô nghĩ vấn đề duy nhất chính là thời gian. Thực tế thì thời gian trên lớp quá hạn chế cho nên rất khó để giảng viên dạy theo ý mình muốn dù biết cái gì mới tốt cho sinh viên. Khi 
teaching, some sections in the textbook

had to be assigned as students'

homework. Apart from pronunciation, students have to learn many other things.

Thus, if we actually want to teach

pronunciation to students

communicatively, then I think teaching

time for the English subject needs to be

increased so that we can help students

practice pronunciation in communication

situations." (P2, Teacher InI, Q6,

Phuong)

(104) "Difficulty? Uhm... maybe time

constraints. As you see, time allotted to

the English subject is too limited. Before

students studied [English] for six

semesters and each semester was 60

periods. Now it's been shortened to only

four semesters and each semester is only

45 periods. This, as I told you, has made

the curriculum overloaded and it's hard

for teachers to teach as much as they

want because they don't have enough

time. So, I think if we want to apply this

approach in teaching pronunciation, then

the first and foremost important thing is

to increase the number of periods for the

English subject. Otherwise, teachers can

only help students correct their

pronunciation errors as we usually do."

(P2, Teacher InI, Q6, Nguyen) dạy thực nghiệm thì cô đã phải giao

một số phần trong giáo trình để

sinh viên làm homework. Ngoài

phát âm ra thì sinh viên còn phái

học rất nhiều thứ. Cho nên nếu

mình thật sự muốn dạy phát âm cho

sinh viên theo định hứơng giao tiếp

thì theo cô thời lượng dành cho

môn tiếng Anh phải được tăng lên.

Có như vậy mình mới có thể giúp

sinh viên thực hành luyện phát âm

qua các tình huống giao tiếp được.

Khó khăn hả? Uhm...có lẽ là hạn

chế về mặt thời gian. Như em thấy

đó, thời lượng dành cho môn tiếng

Anh quá ít. Trước đây sinh viên

được học sáu học kì mỗi kì 60 tiết.

Giờ rút ngắn còn có bốn học kì mà

mỗi kì cũng chỉ còn có 45 tiết thôi.

Cái này như anh nói với em rồi là nó làm cho chương trình trở nên quá tải nên rất là khó để giảng viên dạy được nhiều như mong muốn bởi có muốn cũng không có thời gian. Do đó anh nghĩ điều quan trọng trên hết cần phải làm nếu muốn dạy phát âm theo cách này là phải tăng số tiếng dành cho môn tiếng Anh lên. Bằng không thì cách duy nhất mà giảng viên có thể làm là giúp sinh viên sữa lỗi như cách mình thường làm thôi à. 
(105) "I really enjoyed it. This way of teaching is Em rất là thích. Cách dạy này thú more interesting than the old one, listenvị hơn cách cũ là chỉ cho nghe và and-repeat, and of course more effective. It makes classroom atmosphere more lively and students work harder. I felt more interested in learning pronunciation this semester." (P2, FGI1, Q1, S4) lặp lại cho nên em thấy nó hiệu quả hơn. Giúp không khí lớp học sôi động hơn, sinh viên làm việc chăm chỉ hơn. Em cảm thấy hứng thú hơn trong việc học phát âm ở học kì này.

(106) "I liked it a lot. I find it more interesting Em thích lắm. Em thấy nó hay hơn than teachers simply ask us to listen and repeat as they usually do. This teaching approach makes me feel more interested in learning pronunciation than before." cách cho nghe và lặp lại như thầy cô thường làm. Dạy theo cách này khiến em cảm thấy hứng thú hơn khi học phát âm so với trước đây. (P2, FGI3, Q1, S3)

(107) “Oh, I really liked it. Classroom atmosphere is more lively than teachers having us listen and repeat like a machine. I saw my friends were more actively involved in activities. This way of teaching helps me understand more clearly about pronunciation, so I really like it." (P2, FGI5, Q1, S2)

(108) "I see this way of teaching is very interesting. The atmosphere was lively and students engaged actively in activities in class. I liked it a lot but it was too short, only four classes. I think it'll be better for our pronunciation skills if there are more classes like these." (P2, FGI2, Q1, S3)
Ôi! Em rất là thích luôn á thầy. Không khí lớp học sôi động hơn kiểu thầy cô chỉ cho nghe và lặp lại y như một cái máy. Em thấy các bạn cũng tích cực tham gia vào các hoạt động trong lớp. Cách dạy này giúp em hiểu rõ hơn về phát âm cho nên em rất là thích.

Em thấy cách dạy này rất thú vị. Không khí lớp học rất sinh động và các bạn sinh viên tham gian tích cực vào các hoạt động trong lớp. Em thích lắm nhưng mà ngắn quá thầy, có bốn buổi à. Em nghĩ nếu thầy cô dạy nhiều hơn giống như này thì sẽ tốt hơn đối với kĩ năng phát âm của tụi em đó thầy. 
(109) "I liked it very much. After those

pronunciation classes in this semester,

I've become more interested in learning

pronunciation. This way of teaching is

more useful than to listen and repeat

after the teacher when I make

pronunciation errors. But why was it so

short, teacher? I think it'll be more

helpful for us if teachers spend more time

teaching pronunciation this way." ( $\mathrm{P} 2$,

FGI6, Q1, S2)
Em thích lắm thầy. Sau các buổi

học phát âm ở học kì này thì em cảm thấy hứng thú hơn ttrong việc học phát âm. Cách dạy này có ích hơn cách thầy cô cho nghe và lặp lại theo thầy cô khi em phát âm sai. Nhưng sao ngắn quá vậy thầy? Em nghĩ nếu thầy cô dành thời gian để dạy phát âm cho tụi em theo cách này thì sẽ có lợi cho tụi em hơn đó thầy.

Nhờ các buổi học phát âm này mà tụi em có cơ hội để cải thiện kĩ năng nghe nói mặc dù không nhiều lắm. Những cái tình huống giao tiếp mà cô cho trong lớp giúp tụi em không những được luyện phát âm mà còn có thể tập nghe nói nữa. Theo em cái lợi đầu tiên là tụi em có cơ hội để cải thiện kĩ năng nghe nói bên cạnh kĩ năng phát âm. Em thích cách dạy này hơn so với cách cũ là thầy cô chỉ sữa lỗi bằng cách cho nghe và lặp lại. Dạy theo cách này cô cho tụi em cơ hội thực hành phát âm theo các tình huống giao tiếp em thấy rất hay.

Mặc dù cô dạy phát âm nhưng mà cô dạy theo hướng giao tiếp nên em nghĩ là tụi em có them cơ hội để cải thiện kĩ năng nghe nói thông qua việc thực hành dựa vào các tình 
practice in class. This is very good because

listening and speaking skills are very

important for our future job.” (P2, FGI6, Q S4)

(113) “After these classes, I've known where to put my tongue when pronouncing and how to pronounce those sounds properly. Also, my teacher taught us where to stress in sentences, how to raise and lower my voice in speaking and I've also been more aware of linking between words. I didn't know about these before." (P2, FGI, Q2, S1) huống giao tiếp mà cô cho trong lớp. Cái này rất là hay bởi vì kĩ năng nghe nói rất là quan trọng khi tụi em sau này đi làm đó thầy.

Sau khi học xong các lớp phát âm thì em biết phải đặt lưỡi chỗ nào khi phát âm và phải đọc mấy âm đó như nào cho đúng. Với lại cô cũng dạy tụi em nên nhấn chỗ nào trong câu, khi nói thì lên giọng xuống giọng như nào. Em cũng chú ý hơn việc nối âm giữa các từ với nhau. Mấy cái này đó giờ em không biết.

Theo em thic cách dạy này giúp em hiểu rõ hơn về phát âm. Thầy chỉ cho tụi em phân biệt sự khác nhau giữa các âm, chỉ cho tụi em nên đặt môi răng lưỡi ở đâu khi đọc các âm khác nhau. Bây giờ thì em biết them về nhấn câu, nói lên giọng xuống giọng như nào. Em cũng chú ý đọc âm cuối và nối âm giữa hai từ nhiều hơn. Đó giờ chưa ai dạy em mấy cái này.

two words. No one taught me these

before." (P2, FGI3, Q2, S3)

(115) “I’ve learnt basically about pronunciation theory through my teacher's classes. I've learnt how to pronounce sounds, what parts to use, and how to put my lips and tongue, etc. When my teacher showed us the difference between this and that sound or taught us
Qua mấy buổi cô dạy thì cơ bản em nắm được lí thuyết phát âm. Em biết đọc âm như nào, dung bộ phận nào, đặt môi lưỡi ra sao, vân vân. Khi mà cô chỉ cho tụi em sự khác biệt giữa âm này với âm kia hoặc là khi cô dạy nhấn câu thì em thấy rất 
how to stress in sentences, I found it very interesting because I didn't know about these before. My teacher also taught us how to speak with rising and falling intonation that helped us speak more naturally.” (P2, FGI5, Q2, S2)

(116) "I feel that my pronunciation and communication skills are improving. This is what I feel but I'm not sure how they are in reality because there were only four classes. But if we're taught more classes, then I'm sure my pronunciation and listening and speaking skills will be better.” (P2, FGI2, Q2, S2) là hay bởi vì trứơc giờ em chưa được học mấy cái đó. Cô cũng dạy tụi em ngữ điệu lên xuống khi nói phải sử dụng như nào. Cái này giúp tụi em nói nghe tự nhiên hơn á thầy.

Em cảm giác phát âm và kĩ năng giao tiếp của em có vẻ được cải thiện. Đó chỉ là cảm giác thôi còn thực tế thế nào, có cải thiện hay không thì em không chắc vì chỉ học có bốn buổi à. Nếu mà cô dạy nhiều hơn thì em chắc chắn phát âm cũng như kĩ năng nghe nói của em sẽ tốt hơn ạ.

Trước đây em rất là tự ti về trình tiếng Anh của mình nhất là kĩ năng nghe nói. Học mấy năm trời mà chả có tiến bộ gì hết thầy ơi. Hồi đó chủ yếu em học ngữ pháp thôi thầy. Đến khi cô dạy phát âm và cho tụi em thực hành dựa vào các tình huống giao tiếp giống học kì này thì em cảm thấy lạc quan hơn vì phát âm và kĩ năng nghe nói của em đang được cải thiện. Em nghĩ nếu mà thầy cô dạy phát âm theo cách này nhiều hơn nữa thì kết quả sẽ tốt hơn á thầy. the result will be much better." ( $\mathrm{P} 2$, FGI4, Q2, S3)

(118) "I saw that learning pronunciation this way helps students progress not only in
Em thấy học phát âm theo cách này giúp sinh viên tụi em không chỉ cải 
pronunciation but also in communication

skills. When I understand what people

say and they also get what I mean, the

communication is more likely to be

successful. In fact, because there were

only four classes, effectiveness is not that

much as expected. But if teachers teach

more, then I'm sure our improvement will

be much better." (P2, FGI6, Q2, S2)

(119) "And one more important thing in my opinion is that when pronunciation and listening and speaking skills have improved, I can understand correctly what people say in English and in turn they understand me. This naturally makes me feel more confident in communication and so more motivated in learning English.” (P2, FGI1, Q2, S4) thiện phát âm mà còn cả kĩ năng giao tiếp nữa. Khi em hiểu người ta nói gì và người ta cũng hiểu ý em thì giao tiếp mới thành công. Thực ra hiệu quả không như em mong đợi do tụi em được học có bốn buổi à thầy. Nhưng mà nếu thầy cô dạy nhiều hơn giống như này thì em chắc chắn tụi em sẽ tiến bộ rõ rệt.

Và một điều quan trọng nữa theo em đó là khi phát âm và kĩ năng nghe nói cải thiện thì em có thể hiểu chính xác khi người ta nói tiếng Anh mà ngược lại người ta cũng hiểu em. Tự nhiên nó làm em cảm thấy tự tin hơn khi giao tiếp và cảm giác thích học tiếng Anh hơn.

Theo em thì khi mình phát âm đúng, kĩ năng nghe nói tiến bộ sẽ giúp em hiểu người ta nói gì một cách dễ dàng mà người ta cũng hiểu những gì em muốn diễn tả. Lúc đó khi giao tiếp cảm giác rất tự tin cho nên em có nhiều động lực hơn để học tiếng Anh á thầy. motivation in learning English will increase." (P2, FGI6, Q2, S4)

(121) "Moreover, this way of teaching also helps me realise my pronunciation errors. When we practiced communicating or when we spoke up, my teacher pointed out where our pronunciation problems
Hơn nữa cách dạy này cũng giúp em nhận ra lỗi phát âm của em. Khi mà tụi em thực hành giao tiếp hoặc khi cô kêu tụi em đứng lên nói thì cô chỉ ra tụi em phát âm sai chỗ 
were and helped us correct them. I

remember we had to read [pronounce

words] by ourselves at secondary

schools. No one taught us, so we made a

lot of mistakes and gradually these have

become a habit [of pronouncing

incorrectly]." (P2, FGI1, Q2, S2)

(122)

"In my opinion, pronunciation should be taught immediately when students start to learn English at secondary levels. If secondary teachers teach pronunciation explicitly and systematically and students practice [pronunciation] during their seven years learning English at secondary schools, then it's not a burden for tertiary teachers any more. But the fact is that pronunciation in particular and listening and speaking skills in general were neglected at lower levels, so students need to learn these skills again at tertiary level. I think this is really important because we need to move forward but can't ignore it. So, pronunciation must be included in university English programmes and certain credits must be assigned to it." (P2, Teacher InI, Q7, Phuong)

(123) "In my opinion, it would be better if pronunciation was taught properly at lower levels and communication skills were taken good care of immediately when students started learning English. But the fact is that secondary teachers only nào rồi giúp tụi em chỉnh sửa. Em nhớ hồi cấp 3 tụi em toàn tự đọc không à không có ai chỉ hết á thầy. Do đó nên là tụi em mắc rất nhiều lỗi riết rồi thành thói quen luôn.
Theo cô thì phát âm nên dạy ngay khi sinh viên bắt đầu học tiếng Anh ở bậc phổ thông. Nếu giáo viên phổ thông dạy phát âm bài bản và sinh viên được luyện tập suốt bảy năm dưới phổ thông thì sẽ không còn là gánh nặng cho giảng viên khi các em vô đại học. Tuy nhiên thực tế là phát âm nói riêng và kĩ năng nghe nói nói chung không được chú ý ở dưới chính vì vậy mà sinh viên cần phải học lại những kĩ năng này ở bậc đại học. Cô nghĩ điều này là hết sức cần thiết vì mình cần đi tiếp nhưng cũng không thể ignore phần này ... Cho nên phát âm cần được đưa vào chương trình tiếng Anh ở bậc đại học và phải có số tín chỉ nhất định dành cho nó.
Theo anh tốt hơn là dạy phát âm bài bản ở cấp dưới và kĩ năng giao tiếp cần được chú trọng ngay khi sinh viên bắt đầu học tiếng Anh. Tuy nhiên thực tế là giáo viên phổ thông chỉ có tập trung dạy ngữ 
focused on grammar and vocabulary for

the sake of students passing the secondary

school graduation and university entrance

exams. As a result, they entered

universities with poor listening and

speaking skills, especially pronunciation.

So, I think this [pronunciation instruction

at the tertiary level] is very important if we

want students to use English for oral

communication effectively. And so, certain

credits must be assigned to pronunciation

in university English programmes." (P2,

Teacher InI, Q7, Nguyen) pháp và từ vựng để phục vụ kì thi tốt nghiệp và tuyển sinh đại học thôi. Kết quả là kĩ năng nghe nói của các em rất kém khi vô đại học, đặc biệt là các em phát âm rất tệ. Do đó anh nghĩ cái này rất là quan trọng nếu mình muốn sinh viên giao tiếp tốt bằng tiếng Anh. Do đó, phải có số tín chỉ nhất định dành riêng cho phát âm trong chương trình tiếng Anh ở bậc đại học.

Phát âm là kĩ năng rất quan trọng vì nó thực sự rất cần thiết cho sinh viên phát triển kĩ năng nghe nói. Tuy nhiên khi mà sinh viên bắt đầu học tiếng Anh từ năm Lớp 6 thì lại không được chú trọng. Ở bậc đại học thì dễ dàng nhận thấy hầu hết các em yếu kĩ năng giao tiếp, nhất là phát âm. Lí do chính theo em là ở phổ thông các em không được học và cũng không được chỉnh sửa. Giờ vô đại học thì các em rất cần được hỗ trợ để cải thiện phát âm nói riêng và kĩ năng nghe nói nói chung. Nên là phát âm cần phải đưa vào dạy chính thức trong chương trình tiếng Anh bậc đại học.

Tui nghĩ một hoặc hai tiết mỗi tuần là đủ rồi. Theo tui nghĩ nếu mà 
much on pronunciation, I'm afraid

students may get bored. Moreover,

they're adults and so mature enough to

be good at English. At university level,

they must be more conscious of self-

study, not only study what teachers teach

in class.” (P2, Teacher InI, Q8, Quynh) know what they have to do if they want to

mình tập trung vào phát âm nhiều

quá sợ là sinh viên sẽ ngán. Với lại các em lớn rồi nên là đủ trưởng thành để biết mình cần phải làm gì nếu các em muốn khá tiếng Anh. Ở bậc đại học thì các em cần phải ý thức trong vấn đề tự học chứ không phải thầy cô dạy gì thì chỉ học cái đó thôi thì chưa đủ.

\section{(126)}

"In my opinion, one to two periods per Theo em thì từ một đến hai tiết mỗi week would be okay. This is just enough, not too much that can make students bored. Teachers present theory and basically instruct students to practice in class. Basing on this, students then can practice more at home. Also, being good at pronunciation requires a long time to practice, not only a couple of days, so students' self-study is also very important." (P2, Teacher InI, Q8, Na) tuần là ô kê. Như này là vừa đủ, không nhiều quá làm sinh viên ngán. Trên lớp giảng viên chỉ cần cung cấp lí thuyết và hướng dẫn sinh viên thực hành căn bản thôi. Rồi dựa vào đó các em có thể tự luyện tập thêm ở nhà. Với lại để giỏi phát âm thì không thể một sớm một chiều được mà cần thời gian dài để luyện. Cho nên việc tự học của sinh viên cũng rất quan trọng.

(127) "They're adult learners and must be responsible for their self-study. So, I think we only need to focus on features that commonly cause pronunciation problems to Vietnamese learners. At university level, students are mature and conscious enough to acquire these and if they want to be better, they can do more practice at home independently." (P2, Teacher InI, Q9, Các em lớn rồi nên phải tự chịu trách nhiệm đối với việc tự học của mình. Cho nên cô nghĩ là chỉ cần tập trung vào các lỗi mà học viên người Việt thường mắc phải thôi. ở bậc đại học thì sinh viên đã đủ trưởng thành và đủ ý thức để tiếp thu mấy cái này. Và nếu như các em muốn giỏi hơn thì có thể tự luyện tập thêm ở nhà. Phuong) 
(128) “At university level, students can't only study what teachers teach in class as they used to do at secondary schools. If they want to be good, then they're obliged to do more self-study and self-practice at home. So, I think it's enough to focus on features that commonly cause pronunciation problems to Vietnamese learners only. Later on, they can base on what teachers have taught to do more self-study and self-practice without relying on teachers." (P2, Teacher InI, Q9, Khoa)

(129) "About what to teach, I think we should teach all features from sounds to intonation, etc. The first reason is, as I've told you, students basically don't know anything about pronunciation as they weren't taught [pronunciation] at secondary schools. So, I think we should teach them basic knowledge about pronunciation and from there they can practice more if they want to be better. That's right that self-study is really important for tertiary students but without basic instruction, how can they practice by themselves? Second, if we cover only particular sounds from time to time, I'm sure our lessons will become repetitive and this will make students bored and lose all their interest in learning. And we also need to make our lessons diverse because not every student
Lên đại học thì sinh viên không thể nào chỉ học những gì mà thầy cô dạy trên lớp như hồi dưới phổ thông được. Nếu muốn giỏi thì buộc các em phải tự học tự rèn thêm ở nhà. Cho nên theo em mình chỉ cần tập trung dạy các lỗi hay gặp ở sinh viên Việt Nam thôi. Sau đó dựa vào những gì thầy cô đã giảng trên lớp thì các em có thể tự học thêm tự luyện thêm mà không cần phụ thuộc vô thầy cô nữa.

Về việc nên dạy những gì thì theo anh là nên dạy hết tất cả các yếu tố từ âm cho đến ngữ điệu vân vân. Trước tiên theo như anh nói là do sinh viên cơ bản không biết gì về phát âm hết do các em không được học ở phổ thông. Do đó anh nghĩ mình nên dạy kiến thức cơ bản về phát âm từ đó các em có thể tự thực hành thêm nếu các em muốn giỏi hơn. Đúng là tự học là cực kì quan trọng đối với sinh viên bậc đại học nhưng mà nếu mình không giảng cơ bản thì làm sao mà các em tự thực hành được? Thứ hai là nếu mình cứ dạy đi dạy lại một số âm nào đó thì chắc chắn bài giảng sẽ lặp đi lặp lại khiến sinh viên ngán và sẽ không còn hứng để học nữa. Thêm nữa là mình cũng cần phải đa dạng hóa nội 
in one class has the same pronunciation problems. Some have difficulty with this sound but others with different sounds, for example." (P2, Teacher InI, Q9, Nguyen)

(130)

“(...) but we should teach all features to avoid repetition. For example, if we teach a certain sound from time to time, then students may think 'oh, that's all he/she can teach' and at that time they'll find it boring. So, I think teaching a variety of features makes a difference from lesson to lesson and so arouses students' interest [in learning]. I agree that Vietnamese learners share common pronunciation problems, but not all students in one class have the same problems. For example, student A can't produce this consonant properly but student B can do it. Conversely, student B has difficulty with this vowel but student A doesn't. Right? So, I think teaching all features is necessary. Of course, at university level self-study is very important but let's suppose students want to practice everything to improve their pronunciation but teachers only give instruction on some particular features, then how can they practice properly features that have not been taught? So, teaching all features will make every student aware of their own pronunciation problems and with teachers' basic dung bài giảng vì không phải sinh viên nào trong lớp cũng mắc cùng lỗi phát âm. Một số em mắc lỗi với âm này nhưng số khác thì với âm khác chẳng hạn.

(...) nhưng mình nên dạy tất cả các yếu tố để tránh lặp đi lặp lại. Ví dụ như nếu mình cứ dạy đi dạy lại một âm nào đó thì sinh viên có thể sẽ nghĩ à 'thầy/cô chỉ có thể dạy nhiêu đó thôi’ và lúc đó các em sẽ cảm giác chán. Cho nên em nghĩ là dạy đa dạng các yếu tố sẽ giúp bài giảng đa dạng và thu hút được sinh viên. Đồng ý là học viên người Việt mình thường mắc những lỗi phát âm giống nhau nhưng mà không phải tất cả sinh viên trong một lớp đều mắc cùng một lỗi. Ví dụ như bạn $\mathrm{A}$ không phát âm đúng được phụ âm này nhưng bạn $\mathrm{B}$ làm được. Ngược lại bạn B không đọc được nguyên âm này nhưng bạn $\mathrm{A}$ thì không. Ví dụ như thế chẳng hạn. Đúng không anh? Vậy nên theo em dạy đa dạng các yếu tố là cần thiết. Đương nhiên ở bậc đại học thì tự học rất là quan trọng. Nhưng mà giả sử sinh viên muốn thực hành tất cả mọi thứ để cải thiện phát âm trong khi giảng viên chỉ dạy số ít thôi thì làm sao các em luyện tập những âm không được học cho đúng? Do đó dạy tất 
guidance they can do more self-practice at home." (P2, Teacher InI, Q9, Diep) cả các yếu tố sẽ giúp tất cả sinh viên trong lớp ý thức về lỗi phát âm của bản thân. Rồi dựa vào hướng dẫn cơ bản của giảng viên các em mới có thể thực hành thêm ở nhà.

Đương nhiên nếu mình muốn giúp sinh viên cải thiện phát âm cũng như kĩ năng nghe nói thì theo cô phương pháp giảng dạy của giáo viên là vô cùng quan trọng. Để làm được điều này thì theo cô thấy dạy phát âm theo định hướng giao tiếp là phù hợp nhất. Sinh viên không chỉ được thực hành phát âm mà còn cả kĩ năng nghe nói dựa vào các tình huống giao tiếp. Những kĩ năng này hết sức quan trọng đối với sinh viên khi các em tốt nghiệp ra trường và bắt đầu đi làm. Phần lớn sinh viên trường mình đều nhắm tới các công ty nước ngoài vì lương cao và nhiều phúc lợi khác. Nhưng để đạt được mục tiêu này thì trước hết các em cần luyện tập những kĩ năng này trong thòi gian học tiếng Anh tại trường. Đây chính là lí do vì sao cô cho rằng cần phải dạy phát âm để thỏa mãn nhu cầu của sinh viên.

Dạy phát âm không chỉ giúp sinh viên cải thiện phát âm mà còn giúp các em phát triển kĩ năng nghe nói nữa nếu mình dạy theo định hướng giao tiếp giống như học kì này. 
communication situations students can

practice the target sounds and at the

same time practice speaking. If we carry

on like this, then I believe that students'

pronunciation and listening and speaking

skills will be remarkably improved. This

is very important because students after

graduation have to use English at their

workplace but before that they will have

to pass interviews in English. During an

interview [in English], if the interviewer

can't understand what they say, then the

opportunity for them to be employed is

rare." (P2, Teacher InI, Q10, Diep)
Thông qua các tình huống giao tiếp

thì sinh viên được thực hành các âm mình dạy cùng lúc với việc luyện nói. Nếu duy trì như này thì em tin là phát âm của sinh viên cũng như là kĩ năng nghe nói của các em sẽ được cải thiện rõ nét. Cái này rất quan trọng bởi vì sau khi ra trường sinh viên sẽ phải nói tiếng Anh ở cơ quan mà trước tiên là các em phải vượt qua các cuộc phỏng vấn bằng tiếng Anh. Trong khi phỏng vấn mà người ta không hiểu các em muốn nói gì thì cơ hội để được nhận vào làm là rất thấp.

Do yêu cầu công việc sau khi ra trường nên sinh viên cần phải nói tiếng Anh khá do đó kĩ năng phát âm tốt là ưu tiên hàng đầu. Trong khi phỏng vấn nấu mà phát âm cũng như kĩ năng nghe nói của các em yếu thì cơ hội được tuyển dụng sẽ rất thấp. Cho nên dạy phát âm và giúp sinh viên cải thiện kĩ năng nghe nói là rất quan trọng. Các em không chỉ được thực hành phát âm mà còn cả kĩ năng nghe nói trên lớp nếu giáo viên dùng phương pháp này để dạy.

pronunciation but also listening and speaking skills if teachers apply this teaching approach [CPT]." (P2, Teacher InI, Q10, Khoa) 
(134) “Also, I've noticed that most university students' pronunciation is very poor. Moreover, they're also weak at listening and speaking skills. Of course, there are also many students who are good at English, but this is only about fluency. They still make pronunciation errors in speaking but aren't aware that they need to practice to improve [pronunciation].

They're completely wrong when assuming that in communication their messages only need to get through and that's enough. This really is what makes them ignore pronunciation practice. So, I think English programmes at Vietnamese universities can't exclude this part [pronunciation instruction] but need to have certain credits for it. When teaching pronunciation communicatively, we can make students more aware of how pronunciation enhances their listening and speaking skills. So, they'll realise that pronunciation learning is as important as other language skills." (P2, Teacher InI, Q10, Quynh)

(135) "In my opinion, pronunciation must be taught immediately when we started learning English (...) Unfortunately, secondary teachers in Vietnam almost disregarded it, so I think reteaching pronunciation at university is very important. If university teachers teach pronunciation explicitly and
Theo tui nhận thấy thì kĩ năng phát âm của hầu hết sinh viên đại học rất là kém mà kĩ năng nghe nói của các em cũng yếu luôn. Đương nhiên là cũng có nhiều em khá tiếng Anh nhưng đó chỉ là về mặt fluency thôi. Các em vẫn còn mắc lỗi phát âm khi nói nhưng lại không ý thức được là các em cần phải luyện tập để cải thiện. Các em hoàn toàn sai lầm khi cho rằng trong giao tiếp chỉ cần message của các em get through là đủ. Đây chính là nguyên nhân khiến các em phớt lờ việc luyện phát âm. Vì vậy tui nghĩ chương trình tiếng Anh bậc đại học ở Việt Nam không thể thiếu phần này mà cần có số tín chỉ nhất định dành cho nó. Mục đích đầu tiên là để giúp sinh viên ý thức hơn về vai trò của phát âm trong việc học ngoại ngữ để các em thấy là à học phát âm cũng quan trọng như học những kĩ năng khác vậy.

Theo em thì phát âm phải được dạy ngay khi tụi em bắt đầu học tiếng Anh kìa (...) Tiếc là thầy cô phổ thông ở Việt Nam mình hầu như bỏ luôn phần này nên em nghĩ là dạy lại phát âm ở đại học là rất quan trọng. Nếu thầy cô đại học dạy phát âm bài bản giống như cô em ở học 
systematically like this semester, then

we'll have more chances to develop

listening and speaking skills. This is very

necessary because if we're good at

pronunciation, listening, and speaking

skills, the opportunity to be employed by

foreign companies is very high." ( $\mathrm{P} 2$,

FGI2, Q3, S2)
(136) 'I think it's very important and needs to be taught officially like other language skills. If teachers teach pronunciation like this semester, we'll have more chances to improve listening and speaking skills. After graduation, we'll have more job opportunities at foreign companies because they usually require applicants to be fluent in listening and speaking. And if we want to be good at listening and speaking, then we have to practice pronunciation more." (P2, FGI4, Q3, S4) kì này thì tụi em sẽ có cơ hội để phát triển kĩ năng nghe nói nhiều hơn. Cái này rất là cần thiết vì nếu như tụi em giỏi phát âm cũng như nghe nói tốt thì cơ hội được làm việc cho các công ty nước ngoài sẽ rất cao đó thầy.

Em nghĩ nó rất quan trọng và cần phải được dạy chính thức như mấy kĩ năng ngôn ngữ khác đó thầy. Nếu thầy cô dạy phát âm giống học kì này thì tụi em sẽ có nhiều cơ hội hơn để cải thiện kĩ năng nghe nói. Sau khi tốt nghiệp ra trường tụi em sẽ có nhiều cơ hội làm việc cho các công ty nước ngoài hơn bởi vì họ thường yêu cầu ứng viên nghe nói tiếng Anh tốt á thầy. Và như vậy nếu tụi em muốn nghe nói tốt thì luyện phát âm là rất cần thiết.

Em nghĩ nó rất quan trọng. Đối với sinh viên đại học thì việc học tiếng Anh không chỉ đơn giản là điểm số mà còn là công cụ để tụi em xin việc sau khi tốt nghiệp ra trường nữa. Thầy cô ở phổ thông không dạy phát âm cho tụi em nên là nếu tụi em được dạy lại ngay từ đầu thì sẽ tốt hơn. Khi dạy phát âm bài bản thì tụi em được tiếp thu kiến cơ bản về phát âm rồi có nhiều cơ hội để thực hành kĩ năng nghe nói nữa. Cái này 
graduation we all expect to be employed by foreign companies where we have to use English for daily communication. So, I think if we're good at pronunciation, listening and speaking skills, the opportunity to get a job is higher." (P2, FGI6, Q3, S4) thật sự rất cần thiết bởi vì sau khi tốt nghiệp ra trường thì tất cả tụi em đều mong muốn được làm việc cho các công ty nước ngoài mà mấy công ty này họ yêu cầu nói tiếng Anh hằng ngày. Nên em nghĩ là nếu tụi em phát âm tốt cũng như nghe nói trôi chảy thì cơ hội được vào làm sẽ cao hơn.

(138) “According to my own feelings, many Vietnamese students' pronunciation is poor, so they're too shy to speak English. Usually, they're afraid that people will laugh at them when they pronounce incorrectly (...) So, I think if we're good at pronunciation, we'll be more confident in communicating in English." (P2, FGI3, Q3, S1)

(139) “Although we've been studying English for more than seven years, secondary teachers almost taught vocabulary and grammar. This is why when we enter university, many of us can't speak English. I see that many students are scared of speaking English because they're afraid their pronouncing incorrectly makes people laugh at them. So, I think if teachers help us improve pronunciation, then we'll be gradually more confident in speaking English." (P2, FGI5, Q3, S4)
Theo cảm nhận của riêng em thì sinh viên Việt Nam nhiều bạn phát âm rất tệ cho nên thường các bạn rất ngại nói tiếng Anh. Các bạn sợ khi các bạn phát âm sai sẽ bị người ta cười (...) Nên theo em phát âm tốt giúp tụi em tự tin hơn khi giao tiếp bằng tiếng Anh.

Dù học tiếng Anh hơn bảy năm rồi nhưng thầy cô cấp 3 hầu như chỉ dạy ngữ pháp với từ vựng không à thầy. Nên là khi tụi em vô đại học thì nhiều đứa không biết nói tiếng Anh. Em thấy nhiều bạn ngại nói tiếng Anh vì sợ nếu phát âm sai sẽ bị người ta chọc quê. Nên là nếu thầy cô có thể giúp tụi em cải thiện phát âm thì em nghĩ dần dà tụi em sẽ tự tin hơn khi nói tiếng Anh á thầy. 
(140) "Moreover, it [being good at pronunciation] also helps me in learning vocabulary a lot. If I'm good at pronunciation, it's easier for me to learn new words by heart and remember them longer." (P2, FGI1, Q3, S2)
Với lại nó còn giúp em rất nhiều khi học từ vựng nữa đó thầy. Nếu phát âm tốt thì mình học thuộc lòng từ mới dễ hơn và nhớ từ lâu hơn.
(141) “(...) At university level, teachers only need to teach basic knowledge and instruct students to practice in class. Then, students have to do further practice at home if they want to be better. Selfstudy at university is very important, so I think one to two periods per week is enough." (P2, FGI2, Q4, S3)

(142) "I think teachers only need to spend one or two periods per week teaching basic theory and instructing us to practice in class. Then, students have to do further practice because at university level students are required to self-study rather than only studying what teachers teach in class.” (P2, FGI3, Q4, S4)

(143) "In my opinion, teachers only need to provide basic pronunciation theory. We're not English majors so don't need to understand it as deeply as English majors. Then, teachers instruct us to practice in class as a foundation for us to further practice at home (...)" (P2, FGI6, Q4, S1)

(144)
(...) Ở bậc đại học thì giảng viên chỉ cần dạy kiến thức căn bản thôi rồi hướng dẫn sinh viên thực hành trên lớp. Sau đó sinh viên sẽ tự thực hành thêm ở nhà nếu muốn giỏi. Việc tự học ở bậc đại học rất là quan trọng nên em nghĩ mỗi tuần một đến hai tiết là đủ rồi thầy.

Em nghĩ thầy cô chỉ cần dành ra một hoặc hai tiết mỗi tuần để dạy kiến thức cơ bản trên lớp và hướng dẫn tụi em thực hành thôi. Sau đó sinh viên sẽ phải tự thực hành thêm vì sinh viên đại học bắt buộc tự học thêm chứ không phải chỉ học những gì thầy cô giảng trên lớp.

Tụi em không phải dân chuyên Anh nên không cần phải tìm hiểu sâu như mấy bạn chuyên. Nên theo em thì thầy cô dạy phát âm chỉ cần dạy lí thuyết cơ bản thôi. Sau đó hướng dẫn tụi em thực hành qua trên lớp để có cơ sở tụi em tự luyện thêm ở nhà $(. .$.

Em nghĩ một hoặc hai tiết mỗi tuần là đủ rồi thầy. Dạy nhiều quá có khi 


\begin{tabular}{|c|c|c|}
\hline & $\begin{array}{l}\text { teaching [of pronunciation] can be } \\
\text { boring and students will feel stressed out } \\
\text { in learning. Maybe, it's counter- } \\
\text { productive." (P2, FGI3, Q4, S1) }\end{array}$ & $\begin{array}{l}\text { cũng chán mà sinh viên tụi em } \\
\text { cũng sẽ cảm thấy áp lực trong việc } \\
\text { học nữa. Có khi lại phản tác dụng á } \\
\text { thầy. }\end{array}$ \\
\hline (145) & $\begin{array}{l}\text { "I don't know how many is enough but } \\
\text { the more, the better, teacher. If there are } \\
\text { more periods for pronunciation, we'll } \\
\text { have more chances to practice listening } \\
\text { and speaking. Classes are crowded, so if } \\
\text { there's only one or two periods, it's } \\
\text { unlikely that everyone in class has a } \\
\text { chance to speak up and so teachers can't } \\
\text { help correct pronunciation of each } \\
\text { student." (P2, FGI1, Q4, S2) }\end{array}$ & $\begin{array}{l}\text { Em không biết bao nhiêu là đủ } \\
\text { nhưng mà càng nhiều càng tốt á } \\
\text { thầy. Nếu có thêm nhiều tiết học } \\
\text { phát âm thì tụi em càng có nhiều cơ } \\
\text { hội để luyện nghe nói. Lớp thì quá } \\
\text { đông nên là nếu chỉ có một hoặc hai } \\
\text { tiết thì không đủ cho tất cả các bạn } \\
\text { trong lớp đứng lên nói. Như vậy thì } \\
\text { thầy cô không thể giúp hết tụi em } \\
\text { sửa lỗi phát âm được. }\end{array}$ \\
\hline (146) & $\begin{array}{l}\text { "I want as many as possible (...) When I } \\
\text { studied at an English centre, a teacher } \\
\text { told me that good pronunciation requires } \\
\text { a long time for practice. So, if we're } \\
\text { taught more, we'll have more chances to } \\
\text { practice pronunciation and also develop } \\
\text { communication skills. Also, classes are } \\
\text { crowded, usually } 40 \text { to } 50 \text { students, so if } \\
\text { there's more time for teaching } \\
\text { pronunciation, teachers can help correct } \\
\text { our pronunciation." (P2, FGI4, Q4, S3) }\end{array}$ & $\begin{array}{l}\text { Em muốn càng nhiều càng tốt (...) } \\
\text { Khi em học ở trung tâm Anh ngữ } \\
\text { có một thầy nói với em là để phát } \\
\text { âm tốt thì cần một thời gian rất dài. } \\
\text { Nên là nếu tụi em được học nhiều } \\
\text { thì dĩ nhiên sẽ có nhiều cơ hội hơn } \\
\text { để luyện phát âm đồng thời phát } \\
\text { triển kĩ năng giao tiếp nữa. Với lại } \\
\text { lớp thì đông, thường là } 40,50 \text { sinh } \\
\text { viên một lớp nên nếu có nhiều thời } \\
\text { gian thì thầy cô có thể dạy và giúp } \\
\text { tụi em sửa phát âm. }\end{array}$ \\
\hline (147) & $\begin{array}{l}\text { "If comparing with my previous teachers, } \\
\text { I realise that the way my teacher taught } \\
\text { pronunciation in this semester is much } \\
\text { more effective. Before, teachers only } \\
\text { sometimes corrected errors by having us } \\
\text { listen and repeat when we pronounced }\end{array}$ & $\begin{array}{l}\text { Nếu so với các thầy cô trước đây } \\
\text { thì em thấy cách cô em dạy phát } \\
\text { âm học kì này hiệu quả hơn nhiều. } \\
\text { Hồi trước thầy cô chỉ thi thoảng } \\
\text { sửa lỗi sai bằng cách cho tụi em } \\
\text { nghe và lặp lại theo thầy cô thôi à. }\end{array}$ \\
\hline
\end{tabular}


incorrectly. This semester, we had more

chances to practice what my teacher

taught right away in communication

situations. I saw this very interesting

because it can help foster our listening

and speaking a lot." (P2, FGI1, Q5, S1)
Học kì này thì tụi em có nhiều cơ

hội hơn để thực hành những gì cô

vừa dạy dựa vào các tình huống giao tiếp cô cho. Em thấy cách dạy này rất thú vị vì nó có thể giúp em cải thiện kĩ năng nghe nói rất nhiều.

Em đề nghị nên đưa phát âm vào chương trình tiếng Anh của trường mình và thầy cô dạy theo phương pháp giao tiếp á thầy. Khi tụi em được học theo phương pháp giao tiếp thì tụi em có nhiều cơ hội hơn để thực hành. Mấy cái tình huống mà cô cho trong lớp ở học kì này em thấy rất bổ ích vì nó gắn liền với cuộc sống hàng ngày. Nên theo em thì dạy theo kiểu giao tiếp hiệu quả hơn chỉ cho tụi em nghe rồi lặp lại. teaching [pronunciation] communicatively is more effective than simply having us listen and repeat." (P2, FGI3, Q5, S3)

(149) "I suggest pronunciation to be included Em đề xuất nên đưa phát âm vào and taught like this semester. I expect that teachers provide us with more chances for communication practice in specific situations. I don't know how to say but I see that teaching [pronunciation] communicatively as my teacher did in this semester is more effective than teachers only correcting errors by getting us to listen and repeat." dạy và dạy y như học kì này á thầy. Em mong thầy cô cho tụi em nhiều cơ hội luyện tập giao tiếp nhiều hơn theo các tình huống cụ thể. Em không biết nói sao cho đúng nhưng em thấy cách dạy theo kiểu giao tiếp của cô em học kì này hiệu quả hơn việc sửa lỗi bằng cách chỉ cho tụi em nghe rồi lặp lại.

(P2, FGI5, Q5, S1) 
(150)

“(...) Moreover, this way of teaching

makes the classroom atmosphere more relaxing. Uhm ... when we feel the

practical applicability of these communication situations, we'll be more interested in learning. So, I prefer this way of teaching because it's more effective." (P2, FGI1, Q5, S4)
(...) Hơn nữa cách dạy này làm cho không khí lớp học dễ chịu và thoải mái hơn. Uhm ... khi mà tụi em cảm nhận được tính ứng dụng thực tế của những tình huống thực hành giao tiếp cô cho thì tụi em sẽ hứng thú hơn trong học tập. Vậy nên là em thích cách dạy này hơn vì nó hiệu quả hơn.

(...) Em thấy cách cô dạy phát âm học kì này thú vị hơn và có ích hơn việc thầy cô chỉ thình thoảng sửa lỗi ở những học kì trước. Với cách dạy này thì tụi em được thực hành những âm cô vừa dạy theo các tình huống giao tiếp nên em cảm giác việc học như vậy có ý nghĩa hơn.

FGI2, Q5, S3)

(152) “(...) If teachers teach [pronunciation] communicatively like this semester, I'm sure students will be more interested in learning pronunciation. Classroom activities are diversified, so we'll be more excited and enjoy learning more. And once students feel they like learning pronunciation, I think they'll spend more time on practice." (P2, FGI6, Q5, S4)
Nếu mà thầy cô dạy theo kiểu giao tiếp giống như học kì này thì em chắc chắn các bạn sinh viên sẽ hứng thú hơn trong việc học phát âm á thầy. Các hoạt động trong lớp rất là đa dạng nên tụi em cảm thấy hưng phấn hơn và thích học hơn. Và khi mà sinh viên cảm thấy thích học phát âm rồi thì em nghĩ các bạn sẽ dành nhiều thời gian để luyện tập thôi.

Theo em nếu thầy cô dạy phát âm theo kiểu giao tiếp như học kì này thì tụi em sẽ biết thêm về lí thuyết 
pronunciation theory. For example,

teachers explain how to pronounce a sound or tell us when to use rising or falling intonation in speaking. This is very necessary because we need to know the basis so that we can do self-practice properly." (P2, FGI2, Q5, S2)

(154)

“(...) Before, teachers only transcribed words on the board and asked us to listen and repeat. And that's it. This way of teaching is old-fashioned, boring and not as effective as the communicative teaching my teacher used in this semester. Teaching [pronunciation] communicatively allows us, although basically, to know more about pronunciation theory. For example, my teacher showed us how a sound is pronounced and how to recognise its spellings. She also taught us sentence stress and intonation. These are the basis for our further practice at home." (P2, FGI4, Q5, S1) phát âm. Ví dụ như khi thầy cô giải thích cách đọc một âm nào đó hoặc là khi nói phải lên giọng xuống giọng chỗ nào. Cái này rất là cần thiết bởi vì tụi em cần phải biết những cái căn bản thì mới tự luyện tập đúng được.

\section{(...) Trước đây thầy cô chỉ phiên} âm lên bảng rồi cho tụi em nghe và lặp lại. Chỉ vậy thôi. Cách dạy này vừa cũ vừa chán mà lại không hiệu quả bằng kiểu giao tiếp cô em dung ở học kì này. Dạy kiểu giao tiếp giúp tụi em biết thêm về lí thuyết phát âm dù chỉ là căn bản thôi. Ví dụ như lúc cô chỉ cho tụi em cách đọc một âm như nào rồi nhận dạng nó theo chữ viết ra sao. Cô còn dạy tụi em cách nhấn câu và ngữ điệu nữa. Mấy cái này là nền tảng giúp tụi em tự luyện tập thêm ở nhà.
(155) “(...) I see teaching [pronunciation] communicatively as my teacher did in this semester is very effective, so I prefer this approach. We're provided with basic knowledge about pronunciation theory, and my teacher's explanations were very clear and easy to understand. She had both sounds and pictures for illustrations. We don't need to understand [pronunciation theory] as deeply as
(...) Em thấy cách dạy giao tiếp giống như cô làm học kì này rất là hiệu quả nên là em thích cách dạy này. Cô dạy tụi em lí thuyết cơ bản rồi giải thích rất rõ ràng và dễ hiểu. Cô còn dùng cả âm thanh và hình ảnh để minh họa nữa. Tuy là tụi em không cần tìm hiểu sâu như mấy bạn chuyên ngữ nhưng cũng cần 
English majors but need to know

basically so that we can do more self-

practice at home." (P2, FGI6, Q5, S3) hiểu một cách cơ bản để có thể tự

thực hành thêm ở nhà. 
Appendix 12

Quantifications of students' responses

Appendix 12.1

Students' beliefs about their teachers' pronunciation teaching efficacy

\begin{tabular}{|c|c|c|c|c|c|c|c|}
\hline Scale of effectiveness & $\begin{array}{l}\text { FG1 } \\
(n=4)\end{array}$ & $\begin{array}{c}\text { FG2 } \\
(\mathrm{n}=4)\end{array}$ & $\begin{array}{l}\text { FG3 } \\
(n=4)\end{array}$ & $\begin{array}{c}\begin{array}{l}\text { FG4 } \\
(n=4)\end{array}\end{array}$ & $\begin{array}{c}\begin{array}{l}\text { FG5 } \\
(\mathrm{n}=4)\end{array}\end{array}$ & $\begin{array}{c}\text { FG6 } \\
(\mathrm{n}=4)\end{array}$ & $\begin{array}{l}\text { Total } \\
(\mathrm{n}=24)\end{array}$ \\
\hline Not very effective & 1 & 1 & 3 & 1 & 1 & 1 & 8 \\
\hline Not effective at all & 3 & 3 & 1 & 3 & 3 & 3 & 16 \\
\hline
\end{tabular}

Appendix 12.2 Students' beliefs about pronunciation in EFL learning

\begin{tabular}{lccccccc}
\hline Pronunciation in EFL learning & $\begin{array}{c}\text { FG1 } \\
(\mathrm{n}=4)\end{array}$ & $\begin{array}{c}\text { FG2 } \\
(\mathrm{n}=4)\end{array}$ & $\begin{array}{c}\text { FG3 } \\
(\mathrm{n}=4)\end{array}$ & $\begin{array}{c}\text { FG4 } \\
(\mathrm{n}=4)\end{array}$ & $\begin{array}{c}\text { FG5 } \\
(\mathrm{n}=4)\end{array}$ & $\begin{array}{c}\text { FG6 } \\
(\mathrm{n}=4)\end{array}$ & $\begin{array}{r}\text { Total } \\
(\mathrm{n}=24)\end{array}$ \\
\hline $\begin{array}{l}\text { Improve listening/speaking } \\
\text { skills }\end{array}$ & 4 & 4 & 4 & 4 & 4 & 4 & 24 \\
\hline Promote learner confidence & 1 & 0 & 0 & 0 & 1 & 0 & 2 \\
\hline Better test scores & 0 & 1 & 1 & 0 & 1 & 0 & 2 \\
\hline
\end{tabular}

Appendix 12.3 Students' beliefs about the pronunciation teaching approach they preferred (Phase 1)

\begin{tabular}{lccccccc}
\hline $\begin{array}{l}\text { Communicative pronunciation } \\
\text { teaching can }\end{array}$ & $\begin{array}{l}\text { FG1 } \\
(\mathrm{n}=4)\end{array}$ & $\begin{array}{l}\text { FG2 } \\
(\mathrm{n}=4)\end{array}$ & $\begin{array}{l}\text { FG3 } \\
(\mathrm{n}=4)\end{array}$ & $\begin{array}{l}\text { FG4 } \\
(\mathrm{n}=4)\end{array}$ & $\begin{array}{l}\text { FG5 } \\
(\mathrm{n}=4)\end{array}$ & $\begin{array}{l}\text { FG6 } \\
(\mathrm{n}=4)\end{array}$ & $\begin{array}{l}\text { Total } \\
(\mathrm{n}=24)\end{array}$ \\
\hline $\begin{array}{l}\text { Improve listening/speaking } \\
\text { skills }\end{array}$ & 2 & 3 & 3 & 3 & 4 & 3 & 18 \\
\hline $\begin{array}{l}\text { Reduce classroom tension and } \\
\text { increase learner motivation }\end{array}$ & 1 & 3 & 2 & 2 & 0 & 4 & 12 \\
\hline $\begin{array}{l}\text { Speed up learner } \\
\text { comprehension of teacher }\end{array}$ & 1 & 0 & 2 & 1 & 2 & 1 & 7 \\
$\begin{array}{l}\text { instruction } \\
\text { Promote interactions through }\end{array}$ & 2 & 0 & 1 & 0 & 1 & 0 & 4 \\
error corrections & & & & & & & \\
\hline
\end{tabular}




\begin{tabular}{lccccccc}
\hline $\begin{array}{l}\text { Pronunciation teaching in } \\
\text { tertiary EFL classes can }\end{array}$ & $\begin{array}{c}\text { FG1 } \\
(\mathrm{n}=4)\end{array}$ & $\begin{array}{c}\text { FG2 } \\
(\mathrm{n}=4)\end{array}$ & $\begin{array}{c}\text { FG3 } \\
(\mathrm{n}=4)\end{array}$ & $\begin{array}{c}\text { FG4 } \\
(\mathrm{n}=4)\end{array}$ & $\begin{array}{c}\text { FG5 } \\
(\mathrm{n}=4)\end{array}$ & $\begin{array}{c}\text { FG6 } \\
(\mathrm{n}=4)\end{array}$ & $\begin{array}{c}\text { Total } \\
(\mathrm{n}=24)\end{array}$ \\
\hline $\begin{array}{l}\text { 1. Develop listening and } \\
\text { speaking skills }\end{array}$ & 4 & 4 & 4 & 4 & 4 & 4 & 24 \\
$\begin{array}{l}\rightarrow \text { good for future jobs } \\
\text { 2. Increase confidence in }\end{array}$ & 1 & 0 & 1 & 1 & 2 & 1 & 6 \\
speaking English & & & & & & & \\
\hline $\begin{array}{l}\text { 3. Facilitate vocabulary } \\
\text { learning }\end{array}$ & 1 & 0 & 0 & 1 & 0 & 1 & 3 \\
\hline
\end{tabular}

Appendix 12.5 Students' beliefs about the pronunciation teaching approach they preferred (Phase 2)

\begin{tabular}{lccccccc}
\hline $\begin{array}{l}\text { Communicative } \\
\text { pronunciation teaching can }\end{array}$ & $\begin{array}{c}\text { FG1 } \\
(\mathrm{n}=4)\end{array}$ & $\begin{array}{c}\text { FG2 } \\
(\mathrm{n}=4)\end{array}$ & $\begin{array}{c}\text { FG3 } \\
(\mathrm{n}=4)\end{array}$ & $\begin{array}{c}\text { FG4 } \\
(\mathrm{n}=4)\end{array}$ & $\begin{array}{c}\text { FG5 } \\
(\mathrm{n}=4)\end{array}$ & $\begin{array}{c}\text { FG6 } \\
(\mathrm{n}=4)\end{array}$ & $\begin{array}{c}\text { Total } \\
(\mathrm{n}=24)\end{array}$ \\
\hline $\begin{array}{l}\text { 1. provide opportunities for } \\
\text { oral interaction }\end{array}$ & 4 & 4 & 4 & 4 & 4 & 4 & 24 \\
\hline $\begin{array}{l}\text { 2. arouse student interest in } \\
\text { learning }\end{array}$ & 3 & 4 & 3 & 4 & 4 & 4 & 22 \\
\hline $\begin{array}{l}\text { 3. provide basic theory about } \\
\text { pronunciation }\end{array}$ & 3 & 2 & 2 & 2 & 2 & 3 & 14 \\
\hline
\end{tabular}

